MODERATE-TEMPERATURE GEOTHERMAL WATERS IN

CALISTOGA, NAPA COUNTY, CALIFORNIA

Report of the Second Year, 1979-80 of the

U.S. Department of Energy-California State-Coupled Program

for

Reservoir Assessment and Confirmation

By

LES G. YOUNGS $2 /$

C. FORREST BACON $1 /$

RODGER H. CHAPMAN $2 /$.

GORDON $W$. CHASE 2 /
CHRIS T. HIGGINS 1 /

HASMUKHRAI H. MAJMUNDAR 3 /

GARY C. TAYLOR 1

November 10, 1980

This work was performed under Grant No. DE-FG03-79ET37035

for the U.S. Department of Energy, Division of Geothermal Energy, by the California Department of Conservation, Division of Mines and Geology

1/ Geologist, California Division of Mines and Geology

2/ Geophysicist, California Division of Mines and Geology

3/ Geochemist, California Division of Mines and Geology 


\section{DISCLAIMER}

This report was prepared as an account of work sponsored by an agency of the United States Government. Neither the United States Government nor any agency Thereof, nor any of their employees, makes any warranty, express or implied, or assumes any legal liability or responsibility for the accuracy, completeness, or usefulness of any information, apparatus, product, or process disclosed, or represents that its use would not infringe privately owned rights. Reference herein to any specific commercial product, process, or service by trade name, trademark, manufacturer, or otherwise does not necessarily constitute or imply its endorsement, recommendation, or favoring by the United States Government or any agency thereof. The views and opinions of authors expressed herein do not necessarily state or reflect those of the United States Government or any agency thereof. 


\section{DISCLAIMER}

Portions of this document may be illegible in electronic image products. Images are produced from the best available original document. 
PHASE I STUDIES

SUMMARY OF PHASE ONE ACTIVITIES (FY 1979-80).................... 6

Update of the GEOTHERM File............................. 6

Public Geothermal Map...................................

PHASE II STUDIES, CALISTOGA AREA

PHASE II STUdies, CALISTOGA AREA - METHODOLOGY.................... 9

Areal Extent........................................... 10

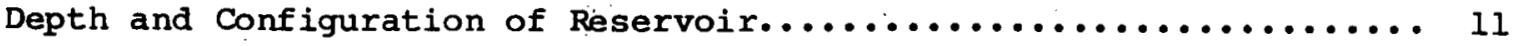

Flow Rates and Reservoir Capacity.......................... 12

Locations and Depths of Hottest Waters....................... 13

Quality of Thermal waters - Problems......................... 14

HISTORICAL USE OF THE MODERATE-TEMPERATURE RESOURCE............... . 16

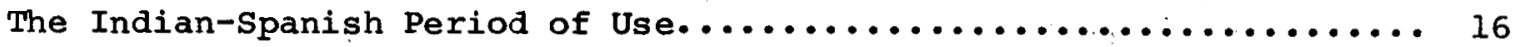

Arrival of the American settlers........................... 18

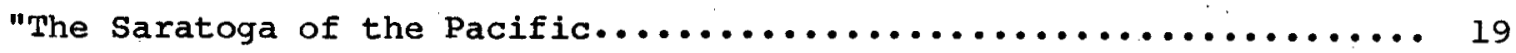


Decay and Revival of Calistoga as a Resort.................. 21

History of Well-drilling and Geyser Wells................. 23

"Old Faithful Geyser of California"..................... 27

Disappearance of the springs......................... 28

Bottled Mineral water.............................. 29

Recent Use of the Geothermal Resource.................... 30

The Resource Development's Effect on the "Hot Water" Table........ 32

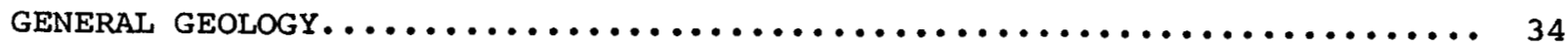

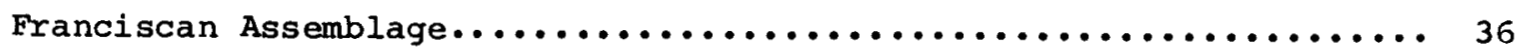

Great Valley sequence.....................................40

Sonoma Volcanics....................................... 41

Alluvium. ............................................. 43

Geologic structure.......................................46

Iocal Folding..........................................48

Local Faulting............................................ 49

GEOPHYSICAL INVESTIGATIONS...............................

Magnetic surveys...................................... 50

Purpose........................................... 5.... 50

Aeromagnetic Data.................................. 51

Equipment and Field Procedure......................... 54

Ground Magnetic Data.................................. 54

Conclusions....................................... 59 
Gravity Survey $\ldots \ldots \ldots \ldots \ldots \ldots \ldots \ldots \ldots \ldots \ldots \ldots \ldots \ldots \ldots \ldots \ldots \ldots$

Equipment and Field Procedure...................... 60

Gravity Data................................... 61

Interpretation of Data........................... 62

Regional Anomalies........................... 62

Local Anomalies............................ 65

Conclusions.................................. 66

Seismic Refraction Survey.......................... 67

Purpose.......................................... 67

Equipment and field Procedure...................... 67

Interpretation of Data.......................... 68

Seismic velocities......................... 68

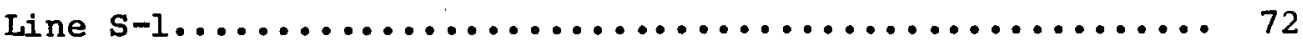

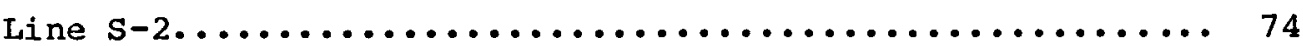

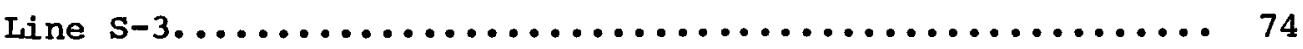

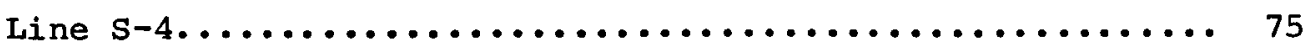

Conclusions.................................. 76

Electrical Resistivity Survey........................ 77

Purpose........................................ 77

Equipment and Field Procedure...................... 77

Resistivity Data............................... 79

Interpretation of Dipole-Dipole Data................. 80

Models of tines $-R-8$ and $R-3 \ldots \ldots \ldots \ldots \ldots \ldots \ldots \ldots \ldots \ldots \ldots$

Interpretation of VES Data....................... 88

Conclusions................................... 90 
Compaxison of Geophysical Traverses on Greenwood Avenue

and Tubbs Lane............................................ 91

Composite Geophysical Anomaly Map.......................... 93

Conclusions........................................ 95

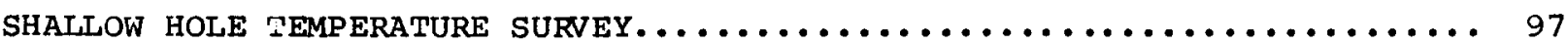

HYDROLOGY AND GROUNDWATER QUALITY RELATED TO GEOLOGY STRUCTURES

AND FORMATIONS AND TO RESOURCE ASSESSMENT...................... 1. .

Location and Extent of Study Area........................... 102

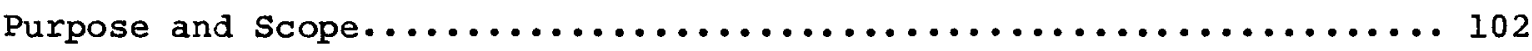

Previous work............................................. 104

Ultramafic Rocks, Franciscan Formation and Sedimentary

Rocks of Cretaceous Age.................................. 105

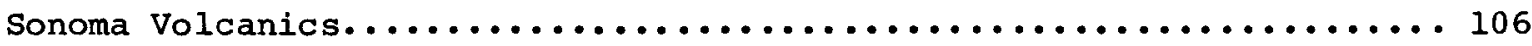

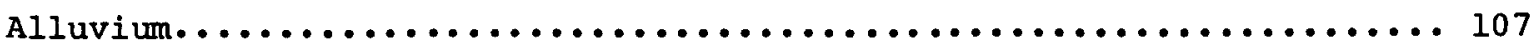

Relationship of water Chemistry to structure.................. 108

Preliminary Interpretation of water Well Chemistry Data..........110

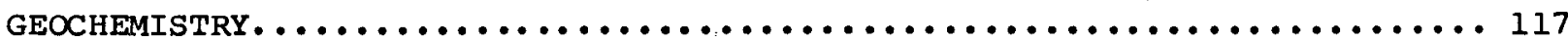

Introduction. ........................................ $\ldots 17$

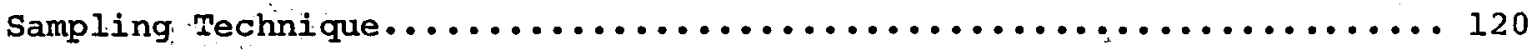

Field Analysis......................................... $\ldots \ldots$

Laboratory Analysis. .....................................124

CALISTOGA 15 MINUTE QUADRANGLE SEISMICITY (with tabulated data)........ 128 
INTERPRETATION-INTEGRATION AND RESOURCE ASSESSMENT................ 132

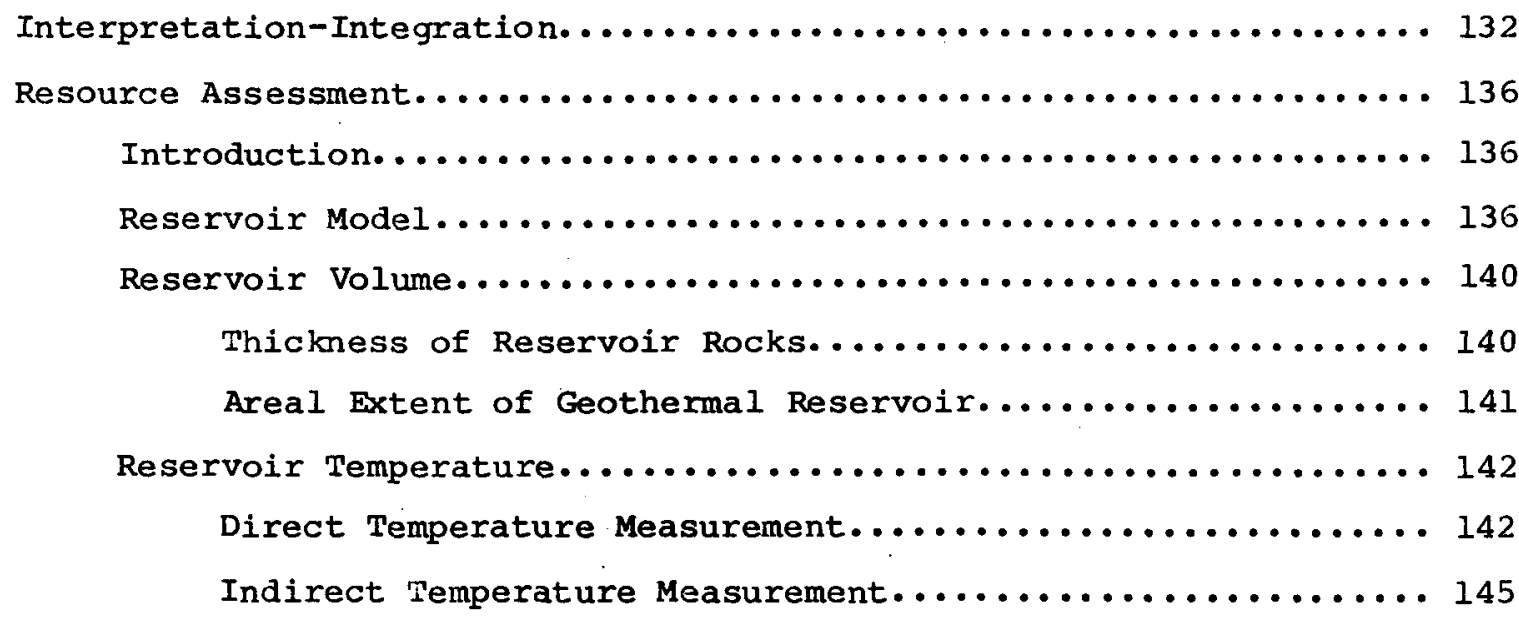

EXPLORATORY DRILLING PROGRAM AT CALISTOGA...................... 152

Background.......................................... 152

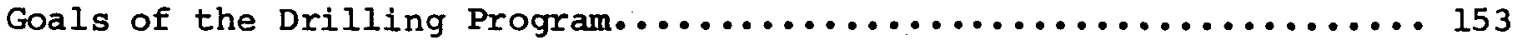

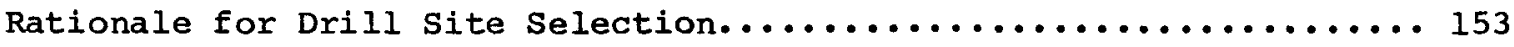

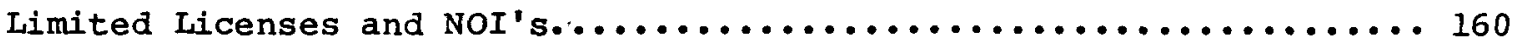

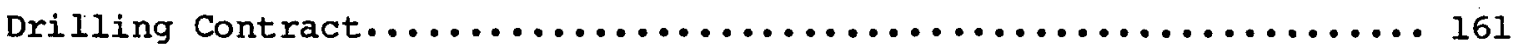

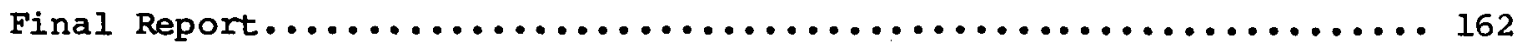

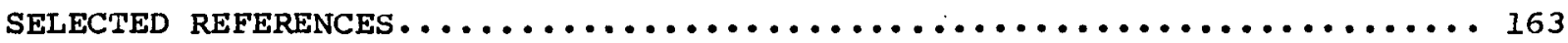

PHASE II STUDIES, PASO ROBLES - under separate cover

Appendix A Geochemical Data

Appendix B Down-Hole Temperature Logs (included with Plates and Figures) 
Table 1. Magnetic susceptibility, density, data and lithology of rock from Calistoga................ 52

Table 2. Tabulated data of earthquakes that have occurred within the Calistoga 15 minute quadrangle....... 129

Table 3. Order from "hottest to coldest" wells in Calistoga........ 143

Table 4. Geothermometric temperatures for well water samples above $24 \mathrm{C}$ (surface) at Calistoga............ 148 
Figure 1. Regional Geology.............................. 35

Figure 2. Ground magnetic profile CMl4..................... 57

Figure 3. Ground magnetic profile cMl5...................... 58

Figure 4. Two-dimensional gravity interpretation, section $\mathrm{A}-\mathrm{A}:$ Calistoga area................... 64

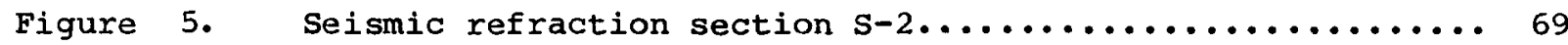

Figure 6. Seismic refraction section $5-3 \ldots \ldots \ldots \ldots$

Figure 7. Seismic refraction section $5-4 \ldots \ldots \ldots \ldots \ldots$

Figure 8. Resistivity pseudo section line R-4................ 81

Figure 9. Resistivity pseudo section line $\mathrm{R}-4 \ldots \ldots \ldots \ldots$

Figure 10. Resistivity pseudo section line $\mathrm{R}-5 \ldots \ldots \ldots \ldots \ldots$

Figure 11. Resistivity pseudo section line . $6 \ldots \ldots \ldots \ldots$

Figure 12. Resistivity pseudo section line R-7................ 85

Figure 13. Resistivity pseudo section line .

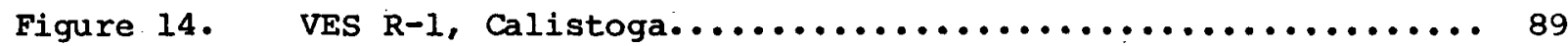

Figure 15. Shallow Temperature Thermistor Readings Compared

to Resistivity Results........................ 100

Figure 16. Groundwater magnesium content map.................. 113

Figure 17. Hypothetical diagrammatic cross-section of a portion of the geothermal reservoir at Calistoga..... 138

Figure 18. Location map of proposed geothermal exploratory drill sites at Calistoga....................... 155 


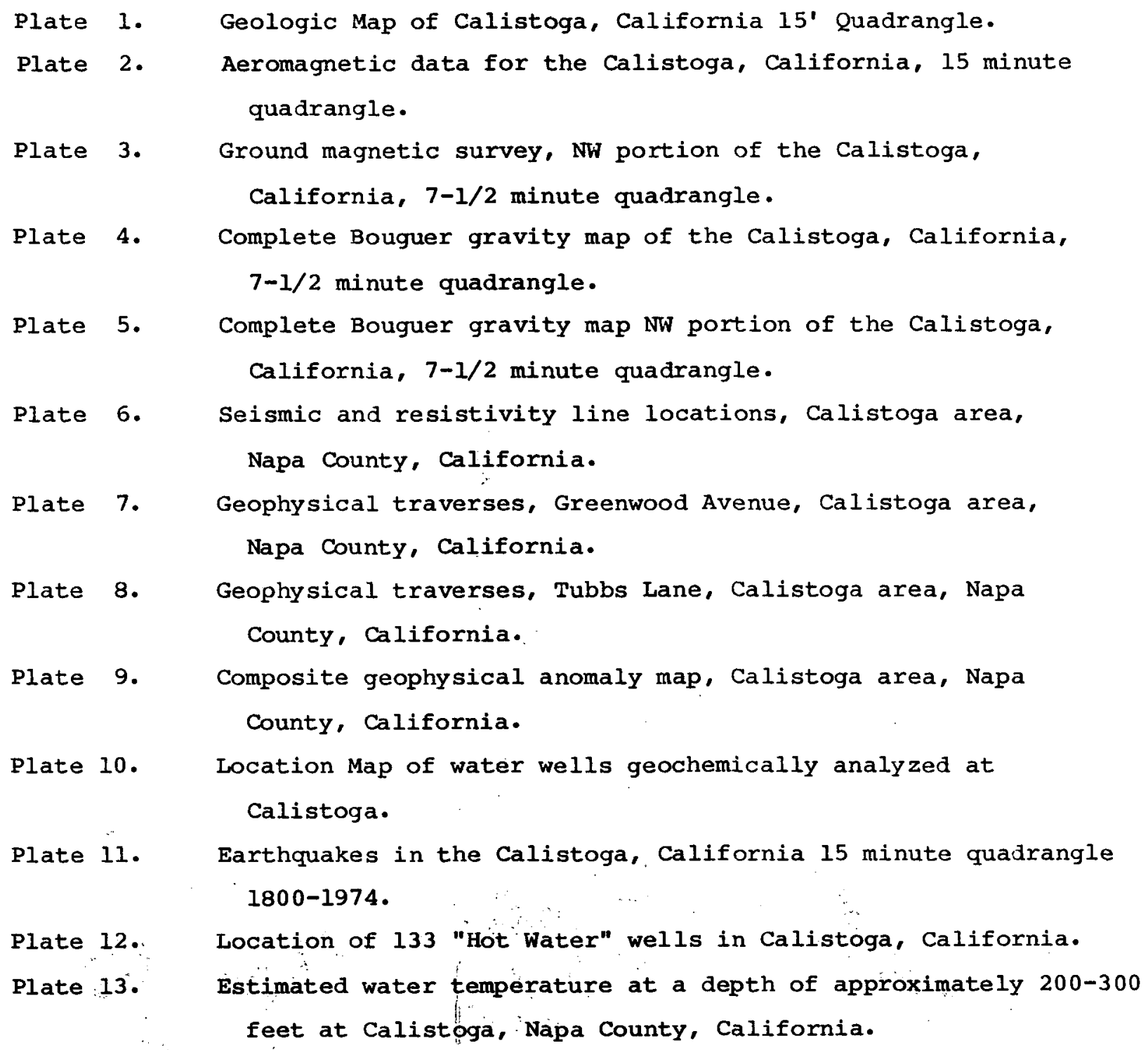




\section{ABSTRACT}

The California Division of Mines and Geology (CDMG), under contract to the U.S. Department of Energy (DOE), has performed, under its second year geothermal contract (1979-80), Phase I statewide assessment studies and Phase II site specific assessment studies. Phase I studies included updating and completing the USGS GEOTHERM File for California and compiling all data needed for a California Geothermal Resources Map. Phase II studies included a program to assess the geothermal resource at Calistoga, Napa County, California. The Calistoga effort was comprised of a series of studies involving different disciplines, including geologic, hydrologic, geochemical and geophysical studies.

The Calistoga geothermal, area is relatively large and contains a considerable shallow, moderate temperature geothermal resource with the extent not known until now. Additionally, CDMG's findings indicate that the area along the southwest side of the main geothermal area is either a deep seated source of heat or a deep seated hydrogeothermal resource and thus the geothermal area may be much larger than was previously believed. The area containing near surface geothermal resources, determined by CDMG, is 5.79 square miles and the vertical section of sediments containing geothermal fluids above $25^{\circ} \mathrm{C}$, and serving as the major part of the reservoir, averages 280 feet deep. The maximum recorded temperature is $135^{\circ} \mathrm{C}$ and the maximum estimated temperature is $140^{\circ} \mathrm{C}$. A drilling program, still to be completed, has been designed by CDMG to confirm what has been done and to provide information as to the volume, quality, mix, and thermal energy of the geothermal fluids available for use. 
This report presents the results of the investigations performed under the terms of the second year contract (1979-80) between the U.S. Department of Energy (DOE) and the California Division of Mines and Geology (CDMG) under the State Coupled Program. As explained in the report for the first year of this program (Martin and others, 1980, p. 2), there are two operationally distinct technical phases in the program. Phase I involves the compilation, verification, and dissemination of existing data, as well as use of this data to produce state geothermal maps and related publications and to assess regional and local geothermal areas. Phase II involves site specific studies in which new data are generated by geophysical surveys and drilling operations. The data are used to quantitatively assess the resource potential of a given geothermal reservoir.

The main efforts in the second year were divided between Phase I and Phase II studies. Phase I studies included updating the USGS GEOTHERM file and compilation and submittal of the data for the low and moderate temperature geothermal resources map of California. Phase II studies included an intensive study of the low and moderate temperature geothermal resources of the Calistoga area in Napa County, California.

Phase I work for the GEOTHERM file was concerned mainly with adding data to, and deleting data from, and making corrections on each of the original 966 records in the file, as well as inserting newly found data on previously 
unrecorded wells and springs. Deletions for elemination of duplicate entries were approximately equal to new entries. Complete data were developed and sent to National Oceanic and Atmospheric Administration (NOAA) for publication of a 1:750,000 scale Geothermal Resources Map of California showing the distribution of the known low and moderate temperature geothermal resources within the State. A lithographer's proof of the final map was reviewed and returned with corrections to NOAA in late June 1980. Copies of this map will abe available to the public from the Division of Mines and Geology in early 1981.

For Phase II studies of low and moderate temperature geothermal resources, under the second year contract, the Calistoga area in the upper Napa Valley was chosen. The Calistoga groundwater and geothermal area is unique in having (a) a long history of development and use as a geothermal resource (first by Indians and then by early settlers, for domistic use, space heating, and spas); (b) high and sometimes artesian groundwater, and (c), surprisingly, a shortage of potable ground water for domestic use. This last factor, and a proposal to remedy the situation by using geothermal heat to remove deleterious salts from poor quality water obtained from a local aquifer, was partly instrumental in focusing CDMG's attention on the area. Subsequently, it was decided by the local electorate that the water from the state water project should be imported to satisfy the domestic water need. However, the extensiveness of the geothermal resource in the area, the many potentials for its use, its ease of access and a good local source of manpower continues to make the resource attractive for a priority Phase II study by CDMG. 
The purpose of this study is to provide new insight into the extent of the geothermal resource--its areal extent has never been determined--and its quality, and to gain an understanding of the geologic factors that control its occurrence. This report outlines the steps taken to accomplish this end and presents the results obtained to date. Included are studies of the history of the resource, the geology of the area, geophysical studies, geochemical sampling and temperature testing for 206 wells in the area, and a map showing the seismicity of the nearby region.

Still to be completed as part of the 1979-80 project are the drilling, sampling, and testing of up to six geothermal test holes ranging in depth from 400 to 990 feet. Upon completion of the drilling and testing program, a final supplement will be prepared to present interpretation of all the data obtained. Results from a separately funded study, based on geochemical sampling, not only for the newly completed test holes, but also for wells tested throughout the area, will be released in a separate report (Majmundar, work in progress). Maps, together with the other interpretive data, are expected to provide a new and concise picture, not only of the extent and potential of the hot and cold water aquifers, but also of the subsurface geologic stratigraphy and structure--the controlling elements for the aquifers and their contained waters.

The present report presents a wealth of new geophysical information developed by CDMG in its Calistoga studies. Studies using resistivity, seismic refraction, gravity, magnetic and chemical methods are described, as 
are the good correlations obtained by comparing the resistivity results with those from a shallow hole temperature study made in the area northwest of the center of Calistoga. The best overall results obtained, by far, are those from use of the resistivity method and, in fact, it has been possible to determine the subsurface higher temperature areas directly using resistivity. It should be pointed out that one of the studies included, the geochemical analyses, is not called for under terms of the 1979-80 contract but is presented only as a complimentary study to those funded by DOE.

Because geologic and hydrologic data from drilling operations are not yet available, the conclusions presented in this report are necessarily identified as being preliminary in nature. In addition, some types of data, as mentioned above, cannot be finalized until the drilling and testing operations are complete. The final supplementary report will contain all of the data from drilling, complete with interpretations, and is expected to be available during the first quarter of 1981 . 
PHASE I STUDIES 
SUMMARY OF PHASE I ACTIVITIES (FY 1979-80)

Phase I work during Fiscal Year 1979-80 consisted of two major projects: (1) the updating of the California records in the U.S. Geological Survey's GEOTHERM file (a computer data bank listing data for all known thermal springs and wells in California) and (2) the compilation of a map that shows the distribution of known geothermal resources in california. The former task is ongoing whereas the latter was completed during 1979-80.

$$
\text { Updating of the GEOTHERM File }
$$

The U.S. Geological Survey's computer file GEOTHERM was substantially updated during Fiscal Year 1979-80. At the beginning of the year, the file contained 966 records of thermal wells and thermal springs. Initially, these records were compared with the CDMG Jenning's file of thermal wells and springs for mutual completeness. Many of the GEOTHERM records lacked chemical analyses; project staff abstracted chemical data from the literature for as many of these records as possible. The literature search mainly included various USGS and California Department of Water Resources reports as well as the chemical records at the Ios Angeles office of the Department of Water Resources. This search also revealed dozens of new thermal wells and thermal springs. 
At the end of June 1980, the first complete updating of the file was nearly finished. Emphasis was made on adding data to, deleting data from, and making corrections on each of the original 966 records, and on inserting records for the newly found wells and springs. Many of the 966 records were deleted from the file because of duplications or because they were not considered truly thermal. The number of deletions was approximately equal to the number of new records added to the file.

Another purpose of updating the file was to ensure that the file contained records of all the thermal wells and thermal springs shown on the public geothermal map, described below. People who desire more detailed information on particular wells or springs than is given on this map (for example, a chemical analysis) will, in most cases, find it in the GEOTHERM file. The file will also be used as a basic source of data for the technical geothermal map, that is to be compiled in FY 1980-81.

\section{Public Geothermal Map}

The major accomplishment in Phase I activities during 1979-80 was the compilation of a map (scale 1:750,000) that shows the distribution of known geothermal resources in California. The map is intended.for use by both the general public and technical community. A proof of the map was reviewed in late June, 1980, was approved with minor changes to be made by NOAA, and is expected to go to the printer in late 1980. Printed copies will probably be available to the public in January 1981. 
Specifically, the map shows the locations of thermal springs and thermal wells, areas underlain or possibly underlain by thermal water $\left(>20^{\circ} \mathrm{C}\right)$ suitable for direct-heat applications, KGRA's, points of measured heat flow, and cultural and geographic data. A table lists the location, and, where available, the temperature, rate of flow, total dissolved solids, and well depth for each well and spring. Notes on the map highlight geothermal phenomena and applications at many localities throughout the state. The data for the wells and springs were drawn exclusively from the three sources discussed above: the Jenning's file (a part of CDMG Bulletin 201, in press), the GEOTHERM file, and our literature search during the fiscal year. 
PHASE II STUDIES, CALISTOGA AREA

$$
-9-
$$




\begin{abstract}
At the outset of CDMG's Calistoga geothermal investigation, it was decided that, in order to provide a resource assessment for the area, information would have to be gathered on the following: (a) the areal extent of the hot water reservoir; (b) the depth and configuration of the reservoir, including the configuration of geologic boundaries and barriers; (c) flow rates and yield for the geothermal fluids within the reservoir and, if possible, for individual aquifers within the area; (d) locations and depths where the hottest water is to be found; and (e) quality of the thermal waters and problems to be expected from use of those waters.
\end{abstract}

As with any complex research project, a logical first step is to perform a search of the literature. Although much information was available concerning thermal waters in the area, no delineation of the resource could be made without developing abundant new data.

\title{
Areal Extent
}

One of the best ways to determine the areal extent of the hot water in a geothermal area that contains a multitude of wells is to canvass the well owners and to measure, temperatures and sample waters from the wells. Geothermal gradients and total depth temperatures obtained from certain of the wells can also provide some of the needed information to help determine 
vertical as well as lateral reservoir configuration, and where the hottest water can be found. Chemistry of the water can provide information on maximum temperatures of mixed water. For these reasons, a program was established early to systematically sample and run temperature tests on the wells throughout the Calistoga area. This work was performed with the cooperation of the California Division of Oil and Gas. Chemical analyses of the water samples were performed by CDMG and by University of Utah Research Institute (UURI). The intensive use of the electrical resistivity technique was originally planned to help delineate the boundaries of the reservoir, however, delays in delivery of the new resistivity equipment that had been ordered, precluded part of the intended use of this technique for this purpose.

Depth and Configuration of Reservoir

\begin{abstract}
Several techniques were planned for use in the program to develop a picture of the subsurface configuration. These included detailed geologic mapping to supplement existing maps, gravity studies, resistivity studies, seismic studies, and to a lesser extent, magnetic studies. Information from these methods was used, in addition to information about the subsurface gained from the survey of existing water wells, to develop profiles to show depths to basement and to different horizons within the reservoir. Pertinent information from water wells was necessarily sketchy because of a lack of good drill logs and other data relative to the wells.
\end{abstract}


The CDMG drilling program was designed, in part, to develop substantiating information for the reservoir configuration developed through the methods outlined above. Two sets of proposed drill hole locations, those in the Tubbs Lane-Bennett Lane vicinity, and those along Greenwood Avenue, were chosen to provide checks on the geophysical profile alignments and to provide correlative alignments of the wells themselves that would substantiate basement configuraton. In addition, these drill holes are expected to provide detailed information on the stratigraphy within the reservoir and on the basement rock itself.

\section{Flow Rates and Reservoir Capacity}

At the beginning of CDMG's Calistoga studies, it was expected that documentation on flow rates and draw down in the geothermal reservoir, information essential to development of a quantitative estimate of reservoir capacity, would become available from two sources. These included (1) testing of one or more existing wells in cooperation with the owner/operator and (2) drilling and testing by CDMG of a series of test holes at strategic locations within the reservoir area. As of the date of this report, it has not been possible for CDMG to gain the cooperation of an owner of an appropriate existing well to procede with the necessary testing. The primary reason has been that such testing would severely interfere with the owner's normal operation of the wells. The result is that CDMG will have to depend 
very heavily on its own still-to-be-completed drilling program for data on flow rates, draw downs, and specific yield to provide data with which to estimate quantitative reservoir capacity. Another aspect of this problem lies with the presence (or absence) of water barriers within the reservoir proper. A separately funded geochemical study of the Calistoga area is being carried on by CDMG concurrently with this study and preliminary results so far show the probable presence of one or more major fault controlled water barriers within the alluviated part of the valley. The feasibility of using geochemical techniques to show fault controlled partitioning of different water types was recognized early in CDMG's study and plans were made for its use. Significant results are expected to be available in time for use in making the final assessment of this area.

Locations and Depths of Hottest Waters

One of the main objectives of the program to visit and systematically sample the existing wells throughout the Calistoga area, was to obtain temperature information, including a temperature profile for each well wherever possible. These temperature data, together with geothermometry based on geochemical techniques, were two of the main methods planned to provide the temperature picture, including maximum temperatures for the reservoir area in and around Calistoga. The other technique that was planned to provide a major contribution to temperature information was resistivity. An extremely strong correlation between the measured occurrence of hot water 
and areas interpreted as being hot based upon resistivity has proven the use of the resistivity technique. Contouring of the temperatures to be found at different depths in the reservoir area and in outlining the periphery of the hot water zone provide two of the major elements needed in reservoir as sessment.

Quality of Thermal Waters-Problems

At the outset of CDMG's studies in the Calistoga area, it was recognized that deleterious chemical constituents were present in harmful quantities in at least part of the hot waters to be found within the reservoir. These constituents, when present in quantity, can result in a host of problems ranging from scaling of pipes and water handling equipment, to detrimental effects on agricultural plant growth. Chemical analysis of the samples collected from wells of various depths throughout the reservoir area was seen as a most logical and useful method to obtain the needed data; however, because mixing of water from different levels in an existing well is an ever-present problem, it was planned to carefully sample water from each interval as encountered during the drilling of CDMG's test wells. The sites of the proposed wells are strategically located to provide a cross section of the valley and also to provide samples from special locations known to have waters with unique characteristics. The samples taken from CDMG's test wells during drilling are thus expected to provide, by far, the most exact data 
available on water quality and to pinpoint the location of sources of problem waters, both vertically and horizontally within the reservoir area.

In summary, the Division of Mines and Geology program for resource assessment at Calistoga was planned using a variety of techniques. One that was considered essential was to collect and study data gathered from a survey of the existing water and thermal wells. The purpose was to provide information on the areal extent and vertical distribution of hot waters and to provide chemical data for geothermometry, water quality, and related problems, and also to provide information on partitioning and source areas for different types of subsurface water--a potential key to reservoir limits and to fault controlled barriers within the reservoir. Geophysical and geological techniques planned and used included: the resistivity technique to locate and delimit hot and chemically variable waters and also geologic structure; seismic, magnetic, and mapping techniques to delineate geologic unit occurrence and subsurface structure, and microacoustics to attempt to locate areas of high subsurface thermal activity. To complete the assessment, it was considered essential to obtain first hand flow data and accurate information on the temperature, stratigraphy, and water chemistry at specific depths. To accomplish this, the CDMG drilling program was planned. All but the drilling program and attendant studies have now been completed and so far results have proven the success of the resource assessment program as planned. An addendum to this report will be submitted to present the results of the drilling program. 
HISTORICAL USE OF THE MODERATE-TEMPERATURE GEOTHERMAL RESOURCE

In this day of awakening interest in alternate energy sources, moderate-temperature geothermal resource areas are coming under scrutiny. One technique helpful in evaluating a potential resource area is to study the historical use of the "hot water: in the area. Fairly good historical documentation is available for Calistoga, California. Researching the literature and interviewing local residents of Calistoga has brought to light the use of the moderate-temperature geothermal resource there.

The Indian-Spanish Period of Use

\begin{abstract}
According to all historical sources and local lore, the Indians residing in the Upper Napa Valley were the first to utilize the hot springs and steaming mud at the present site at Calistoga. In a fanciful drawing, labeled "Calistoga in primitive times", found in the 1871 "Handbook of the Calistoga Springs", several Indians are shown relaxing about the hot springs. Two or three are apparently partaking of a natural steam bath.
\end{abstract}

How long the Indians had been coming to the springs to "bathe away aches and pains" is not clear. Beard (1979, p. 12) reports that the Napa Valley has been continuously inhabited by man for 4,000 years and probably longer. 
Studies of two nearby Lake county archaeological sites have placed ancient man there approximately 10,000 - 12,000 years ago (Beard, 1979, p. 9).

When Spanish explorers and friars pushed into the Upper Napa Valley in 1823 looking to extend their line of missions up California, probably several thousand Indians were encamped throughout the valley and foothills, mostly along streams and rivers. The Spanish termed the Indians "Guapos", later anglicized to "Wappo" by immigrating Americans. The Wappo lands encompassed the lower Napa River Valley to lower Clear Lake and to the area now known as "The Geysers".

A permanent wappo village had one or two sweat houses. A daily bath in the sweat house was common practice for the Wappo men. The sweat house served as a combination health spa, men's club, and ceremonial center (Beard, 1979, p. 46). It has long been assumed that the wappo practiced their daily sweat bath ritural utilizing the natural resources available at the hot springs.

The Spanish "discovered" a number of hot springs and probably some small geysers grouped several hundred feet to the south and east of a small, isolated volcanic tuff knoll. They called the place "Aqua Caliente". In a succession of names, the surrounding area was called the Aqua Caliente District, Hot Springs, Calistoga Springs and eventually, Calistoga. The meadow containing the hot springs was often called the Springs Ground. 
The Spanish friars chose to establish their twenty-first and last mission approximately 30 miles south of Aqua Caliente. Nothing seems to be recorded about the springs at Calistoga until the date 1857.

Arrival of the American Settlers

The American, George C. Yount, settled in the upper Napa Valley in 1831 and was endowed with a Spanish grant of land in 1836 from General Mariano Guadalupe Vallejo at Petaluma-Sonoma. Dr. Edward Turner Bale was awarded a land grant from General Vallejo in 1841. Dr. Bale's grant included present day st. Helena and extended northwestward to encompass the present day Calistoga City limits and all the valley lands out to the foothills that enclose the upper Napa Valley.

The American owmership of two large tracts of land in this area attracted early American immigrants who wanted their own small farms, and Yount and Bale were glad to sell portions of their grants to the immigrants for profit. As a result, in the late 1830's and early 1840's the Upper Napa Valley began to acquire new settlers. 
"The Saratoga of the Pacific"

In 1857, Samuel Brannan, reportedly California's first millionaire, began buying up portions of the springs Ground. By 1859, he had acquired nearly 2,000 acres of upper valley property including all the Springs Ground. He set out to build a health resort to rival the famed Saratoga Hot Springs of New York State.

A popular story of the times relates how the resort became known as Calistoga. According to the story, Sam Brannan, while slightly "under the influence", meant to say that he was going to build the saratoga of California, But instead said, "Calistoga of Sarafornia". The Name "Calistoga" had appeal and was adopted.

In the fall of 1862, Brannan declared his fabulous resort open at a gala party of some 3,000 people. The grounds included a large hotel, stables, racetrack, 25 neat little cottages for guests, dance pavilion, store, bath houses, steam rooms, mud baths, laundry, swimming pool, an observatory placed atop the volcanic tuff knoll (dubbed Mount Lincoln, by Brannan), and even an aviary. A grand place it was by any standards.

I.C. Adams, in a passage (1946, p. 6) explaining how the bath houses were built at the hot springs, makes a very interesting observation about the consequences of drilling wells at a later date in the area: 
Before there were any geysers here, there were many individual springs and streams of hot water from which on cool days, steam could be seen rising; but since the drilling of the geysers this is practically a thing of the past as it seems the surface pressure has been taken off and this has done away with the smaller emanations. Over some of the little individual springs lattice houses were built which were approximately eight by ten feet in size, with seats running lengthwise on the inside upon which patrons could sit while partaking of the water if they so desired.

One house was about a hundred feet from the entrance gate and another was at the upper end of the grounds and was known as the "Chicken-Broth Spring". It was so named because the water tasted like weak chicken broth, especially if a pinch of salt and a dash of pepper were added.

Writing in 1881, the anonymous author of "History of Napa and Lake

Counties" (1881, p. 347) records some temperatures at the famed Calistoga

Springs :

Several years ago a well was bored directly in front of the hotel, and at the depth of seventy feet rock was struck which prevented further progress, and water stood in this well at the uniform temperature of one hundred and eighty-five degrees. There was a Russian steam bath formed by having the bath-room erected immediately over a spring which had a temperature of one hundred and ninety-five degrees, with apparatus for letting steam come up into the room. There are a host of springs there, each differing from the others in some peculiarity.

From the "Handbook of Calistoga and the Geysers" (1871, p. 11) comes this

quantitative record of temperatures at the Calistoga Springs:

There are baths of all temperatures, dozens of them, from cold to scalding hot, by which last, eggs are boiled and combining medicinal virtues applicable to every ill that flesh is heir to.

And still another record of early temperatures at the springs comes from

Waring (1915, p. 108):

The observed temperatures of the principal springs range from 126 to 173 and their flows from about one-fourth gallon to 5 gallons per minute. The hottest spring which yields about 1 gallon a minute, appears to be the most strongly mineralized, though its mineralization is only slightly perceptible to the taste. 
At Brannan's resort, one could spend the day strolling the grounds, partaking of mud or steam baths, and preparing lunch in special cooking houses utilizing the natural steaming waters from the springs. It has been reported that bathing towels were also sterilized in the waters of the hottest springs, thus providing a "natural boiling laundry".

It appears that at least one of the small cottages built for guests was at one time heated by piped hot water from the springs. It seems more than likely that this was attempted some years after Sam Brannan lost ownership of the resort.

Brannan lavishly landscaped his resort with palms, hardwoods, flowers, cactii, etc. Some of these plants and trees still are growing today in Calistoga. However, Brannan reportedly had to bring in "fresh" soil for some of his gardens because of the high concentrations of "toxic minerals" in the soil around the springs. This may be the earliest record of the high concentrations of boron evident in some of the geothermal waters at Calistoga today.

The Decay and Revival of Calistoga as a Resort

Sam Brannan was going broke by 187.3. Resorts closer to the San Francisco area were, becoming more popular. He leased the once magnificent resort to George Schonewald, but the economic situation worsened. In 1875, the 
Sacramento Savings Bank ordered all of Brannan's property in Calistoga sold. Leland Stanford, who once considered siting his university at Calistoga, but instead chose Palo Alto because it was closer to the Bay Area, retained the main resort and several of the guest cottages. Then began a long succession of managers of the resort and a gradual decline and decay of the facilities hastened by several fires that destroyed some of the buildings.

Mr. A.C. Tichenor became proprietor of the property in 1880 ("History of Napa and Lake Counties", 1881, p. 349). He erected a steam whistle and had "some machinery in motion, operated by the steam of one of the springs". He also placed some sort of gas collecting device over one of the springs and attached a lighted burner. The burning gas was called "carburetted hydrogen" (methane?). Mr. Tichenor also claimed the waters of the springs were laden with gold. Through a "secret process" he added some gold to the water and was supposed to be able to recover six times the original amount of gold.

In 1911, Jacques Pacheteau became proprietor of the resort and bought all of Leland Stanford's interest in 1919. The Pacheteau family built up the grounds and improved the resort. Although no longer owned by the Pacheteau family, the resort thrives today as Pacheteau's Original Hot Springs, Inc.

In approximately 1922, Charley Nance bought a lot on the southern edge of the original Springs Ground and started the second mud bath spa in Calistoga (Adams, 1946, p. 19). The operation still thrives today as Nance's Hot Springs, located on Lincoln Avenue. 
Other motels/spas have been built through the years in Calistoga. Some are still operating today; some closed and became low-income apartment complexes. There are presently four mud-bath spas in Calistoga (Buck, 1980). There are approximately four or five more establishments that offer hot mineral water baths, jacuzzi baths, heated swimming pools, and massages. Today, Calistoga offers more types of hot mineral water "treatments" and more facilities than any other "hot springs" resort area in California.

History of Well-Drilling and Geyser Wells

The first geysering hot water well at Calistoga was drilled on Sam Brannan's resort ground (now Pacheteau's Original Hot Springs) probably in the late 1860's. Bancroft's "Tourists' Guide" (1871) provides the following account of the drilling:

A well was bored at this place preparatory to the erection of a bath-house, to the depth of sixty-five feet, when the boring instruments were blown out with tremendous force high into the air, as if some unseen power beneath was resenting intrusion of mortals upon his domain. The workmen ran for their lives and could not be induced to resume operations on any terms. An attempt was made to pump water from this well, and after a few strokes a violent stream was blown out of the well ten or fifteen feet high. If the pumping were stopped the blowing would stop also, but was renewed afresh as often as the pumping was resumed. The water being cold at the top, seemed to hold in abeyance the steam and intensely hot water below; the action of the pump relieved the superincumbent pressure when the hot water below rushed out. 
Adams (1946, p. 30) surmises that "this well was left to its own devices as it were, as nothing was ever done with it. The probabilities are that it was filled with debris at the time and forgotten."

The date when the second geysering well was drilled is uncertain, but it was in existence before 1916. A local resident of Calistoga relates that, when she moved to Calistoga as a young lady of eight years in 1916, there were two geysering wells, one at the Ephriam Light winery and one out on Tubbs Lane owned by Mr. Bhegnasco. She recalls having the impression that the Light well was drilled about two years prior to her arrival and that the Bhegnasco well was drilled perhaps only one year or less before her move to Calistoga.

Ephriam Light bought the stable building from Sam Brannan's decayed resort and turned it into a neat winery. Adams (1946, p. 30) relates the happenstances of drilling a well on the property:

Mr. Ephriam Light, knowing that his property was situated on the edge of the hot-water land, thought that by boring a well he could get hot water which would be available at all times and with which he could wash the barrels and tanks as they needed it without having to build a fire each time, so he hired a local well-driller--Mr. Strubel--to drill a well for him.

At a depth of one hundred fifty feet hot water was struck and the drilling was stopped. Shortly after this his son Edward who lived close by, heard a loud swishing noise one night and running out saw hot water and steam being shot high into the air. It would seem that the drilling had been stopped just before the area of hot water was struck and that the plug between where the drilling stopped and where the lake of boiling 
water is had been blown out which allowed the hot water and steam to shoot out. For a time one could set one's watch by the intervals at which the spouting occurred but it changed quite frequently. at first it would shoot every day or so and finally got down to about an hour or so.

The geyser caused a terrific stir about the area. Benches were set up for the people who came to sit and wait for the eruption. A few years later the well was capped.

The stable-converted-to-winery still stands in Calistoga today on Grant Street, but it is no longer used as a winery. The present occupant is the Napa Valley Springs Mineral Water Company. The company commercially bottles mineral water from a "hot water" well on the property (not the original geysering well).

Allen and Day (1927, p. 98-99) write that by 1924 thirteen geyser wells had been drilled in Calistoga and all but three were capped so that the water could be utilized. Other wells that didn't geyser have been drilled into the geothermal zone, also. An unpublished map (Koenig and Anderson, 1970) shows the location of 76 "hot water" wells in Calistoga.

Many of the "hot water" wells drilled in Calistoga were flowing or artesian wells. Today approximately ten wells are openly discharging at the surface. Many of the artesian wells have been capped. Three spectacular flowing wells are on the Pacheteau's Original Hot Springs property. These wells flow at a pressure of $80 \mathrm{psi}$, and it is reported that two of them flowing together can discharge 250,000 gallons of $100^{\circ} \mathrm{C}$ water in 
approximately 8 hours. These wells are approximately 160-180 feet deep and were drilled around 1920. Apparently these wells have flowed at the same volume since they were drilled.

The three wells are controlled by gate valves at the well heads. The water is directed into holding tanks for cooling before it is used in the swimming pool, mineral baths, mud baths, etc. In addition, the resort has put their geothermal resource to a clever practical use: to dry bath towels and linens after washing, two large commercial clothes dryers are employed. The heat is supplied by geothermal well water circulating about the large drying drums.

The geothermal wells at "Pacheteau's" have provided some "hair-raising" moments throughout the years. Adams (1946, p. 30) provides the following account:

In 1928 the boiling water geyser on the Springs Ground next to the Pacheteaus Bath-house ran amuck and was finally brought under control by the Calistoga Fire Department after it had "shot" for several days continuously. It not only damaged the nearby bath-house but drained other wells in the vicinity. This incident had its start when A.H. Word, a local well-driller reached a depth of one hundred fifty feet while boring a well for Mrs. Pacheteau. Suddenly tools and equipment went hurtling through the air propelled by a force which was estimated to be about one thousand pounds to the square foot. For days the frantic efforts of the people failed, as they attempted to "cap" the geyser. After much publicity in bay-area papers, the springs Ground was the goal of thousands of motorists for several days. Finally it was the Fire Department that solved the problem. They pumped cold water into the well fast enough to cool it off thus allowing workmen to cap the pipe and to put a concrete packing around it. 
Approximately eight years ago, a similar incident occurred. There was an old abandoned open well in the driveway in front of the bath house at "Pacheteau's". Some of the waste water from the mineral baths had been allowed to drain into this well for years. Apparently over the years some debris had been dropped down the well, also. One night, this well erupted with a vengeance belching forth cans, bottles, and sundry debris. The local Fire Department was prevailed upon again to quench the eruption, and the well was capped and buried.

"Old Faithful Geyser of California"

There remains only one uncapped geysering water well in Calistoga today • That one is the old Bhegnasco well at the corner of Tubbs Lane and Myrtledale Road which apparently has always remained open since it was drilled circa 1915(3). The well erupts on a somewhat regular basis on the average of every 40 minutes (Rinehart, 1972) and has long been both a point of interest and a tourist attraction. It is now called the "Old Faithful Geyser of California". The grounds around the geyser have been moderately well maintained, the result of which is a small park-like setting for tourists awaiting the eruption. The eruption lasts sometimes as long as three minutes. It has been reported that the discharge during the eruption is 4,000 gal/min, sometimes shooting to a height of sixty feet or higher. 
A local resident related how he had been baptized at the geyser in 1942 . Apparently others had been baptized there also. He remembered that in the 1940's weddings were occasionally performed at the geyser site.

Disappearance of the springs

In the "Handbook of Calistoga and the Geysers" (1871, p. 4), the author describes the abundance of hot springs on the old Springs Ground:

There are upwards of a hundred within an area of about sixty acres...in winter when a slight frost tips the glades with silver, the boiling springs send up clouds of vapor as from a hundred steam engines...

Waring in 1915 (p. 108) writes:

Four main springs rise at the base of a knoll of buff-colored tuffaceous material at the northern border of the meadow land, and a few pools and seepages of hot water appear in the meadow itself...about 400 yards west from the springs, a dug well supplies warm water for tub baths...warm water is also obtained in several other wells near by and there is one strongly flowing artesian well.

If both authors are to be believed, the old springs ground was beginning to dry up by 1915. The meadow lands are apparently completely dry at the surface today, except for some discharge flowing from the artesian wells at "Pacheteau's". A large mobile hame park and a glider airport are situated on a large portion of the original hot spring-laden meadow land. 
Bottled Mineral Water

\begin{abstract}
Guests at Sam Brannan's Calistoga Hot Springs would not only bathe and steam themselves, but also drink the spring waters in hopes of curing a malady or simply improving their constitutions. Today, bottling the mineral water at Calistoga is a thriving business; there are three commercial mineral water bottling companies operating in town. It is reported that a fourth bottling company, with its works located in Santa Rosa, obtains some of its water from the "Pacheteau's" wells.
\end{abstract}

The largest in sales volume and the longest in business is the Calistoga Mineral Water Company on First Street. A well was put down on this site in 1920, and the temperature of the water was reported to be $212^{\circ} \mathrm{F}$. In 1924 , the first bottles of mineral water were produced, and the company has remained in business ever since.

Prior to 1975, the Napa Valley Springs Mineral Water Company was only a small weekend business. After that date, the company stepped up to full production and now puts out its product in gallon plastic jugs. Their production well was probably drilled about 1920, also.

The Crystal Geyser Water Company, located on Washington Avenue, drilled their production well in 1978. After testing the water and ensuring the presence of a large enough supply, a bottling plant was erected at the site. According to the company, they now rank third in total mineral water sales in 
California. First in sales in California is the French import "Perrier". Second is the California Mineral Water Company •

The volume of water pumped from the moderate-temperature geothermal resource for mineral water bottling purposes is unknown. Because of the competitive nature of the mineral water business, the bottling companies guard their production figures. However, it may be assumed, since the popularity of Calistoga's mineral waters is great, that a relative large volume of "hot water" is removed from the resource annually.

Recent Use of the Geothermal Resource

Through the years, a few enterprising individuals attempted to utilize the geothermal resource at Calistoga for home heating. According to a long-time Calistogan, these heating systems generally had to be abandoned when, in a few years, the water pipes would be choked full of mineral deposits. There have been successes in recent years.

There are at least two private residences totally heated by utilizing hot water from a well. One house, built in the late 1950's to early 1960's, simply has copper pipes built into the concrete foundation through which the geothermal waters circulate, heating the whole house from the floor up. The other house has an elaborate custom-made heat exchanger system whereby the heat from mineral laden waters is transferred to a system containing fresh 
water. This eliminates the mineral deposit problem that plagued early heating systems.

There is one motel/spa in Calistoga that heats its entire complex from a geothermal well. The hot waters circulate through a space-heating system in each of the units.

There may be as many as 20-25 residences that are using water from a "hot well" directly as a domestic hot water supply in Calistoga. Approximately 10-12 residences are utilizing their "hot wells" for heating swimming pools, private mineral water baths, jacuzzi-type spas, etc.

In the mid $1950^{\prime} s$, a moderate size greenhouse was built and heated with two geothermal wells. This business is still operating today on Tubbs Iane. Another greenhouse complex, which used two geothermal wells as a heat source, was started in the early 1960's in the same general area, but the economics of the plant business apparently forced the abandonment of this operation in the late $1960^{\prime} \mathrm{s}$.

Very recently, there has been a renewed interest on the part of some Calistogans to utilize the geothermal resource as an alternate energy source. A few new homes have been built with a geothermal well designed into their system as a potential auxiliary heating supply for some domestic needs. There is much interest in converting some older residences to geothermal heating, also. An estimated two to five wells are currently 
drilled annually in Calistoga with the explicit goal of tapping the geothermal resource.

The Resource Development's Effect on the "Hot Water" Table

It is obvious that the "hot water" table has lowered about the original Springs Ground since the development of the geothermal resource there. The history suggests that the springs dried up sometime between 1910-1920, probably at least in part due to the drilling of the first deeper (150-190 feet) water wells in Calistoga. It is now generally believed by townspeople and local well drillers that a well must abe drilled over 100 feet to reach the resource in this area.

Even though the "hot water" table has deepened around Pacheteau's, it may not have lowered very much in nearby areas. It was reported that shallow excavations (dug in the early 1960's to 8-10 feet deep) in the vicinity of Tubbs Lane and Bennett Lane became so hot that the soil was nearly "too hot to touch", even when no water flowed into the excavations.

Despite moderately heavy commercial and domestic development of the resource over the years, some geysering and flowing wells drilled around 1920 are still producing at what appears to be nearly their original volume. 
Although geothermal wells have been drilled elsewhere in Calistoga, none seem to have been able to produce as much hot water as the wells at Pacheteau's. Therefore, the largest volume of the resource may be in this area, although exploratory drilling may prove this conclusion wrong.

The literature suggests that the temperature of the resource may not have changed much in at least the last 120 years (that is, boiling water is still available from the resource). 
The geologic formations within or near the Calistoga Geothermal Project Area have been studied and mapped by Johnson (1940), Carter (1943), Weaver (1949), Taliaferro (1951), Kunkel and Upson (1960), Koenig (1961, 1963), Blake and others (1971), and lastly by fox and others (1973). Regional studies were limited to providing insight into structural and lithologic controls of geothermal waters. Thus, the brief description of the geologic formations, history, and water bearing properties contained within this report has, for the most part, been abstracted from published works.

The Calistoga area lies within the southern end of the Mayacmas Mountains. The geologic framework for the Mayacmas Mountains is characterized by a series of northwest-trending folded and faulted blocks and thrust plates (Figure 1). The mountains are typically broken into a corresponding series of northwest-trending ridges and valleys.

In the Mayacmas Mountains, the Great Valley sequence of Jurassic to Cretaceous marine miogeosynclinal sedimentary rocks and underlying igneous rocks are in thrust fault contact with, and overlie the rocks of, the eugeosynclinal Franciscan assemblage of similar age. Also present in this zone are: Marine sedimentary rocks of Tertiary age, southeast of Clear Lake; the Sonoma Volcanics, of Pliocene age, near and south of Mount St. Helena; and numerous scattered exposures of non-marine sedimentary rocks of Pliocene to Holocene age. 

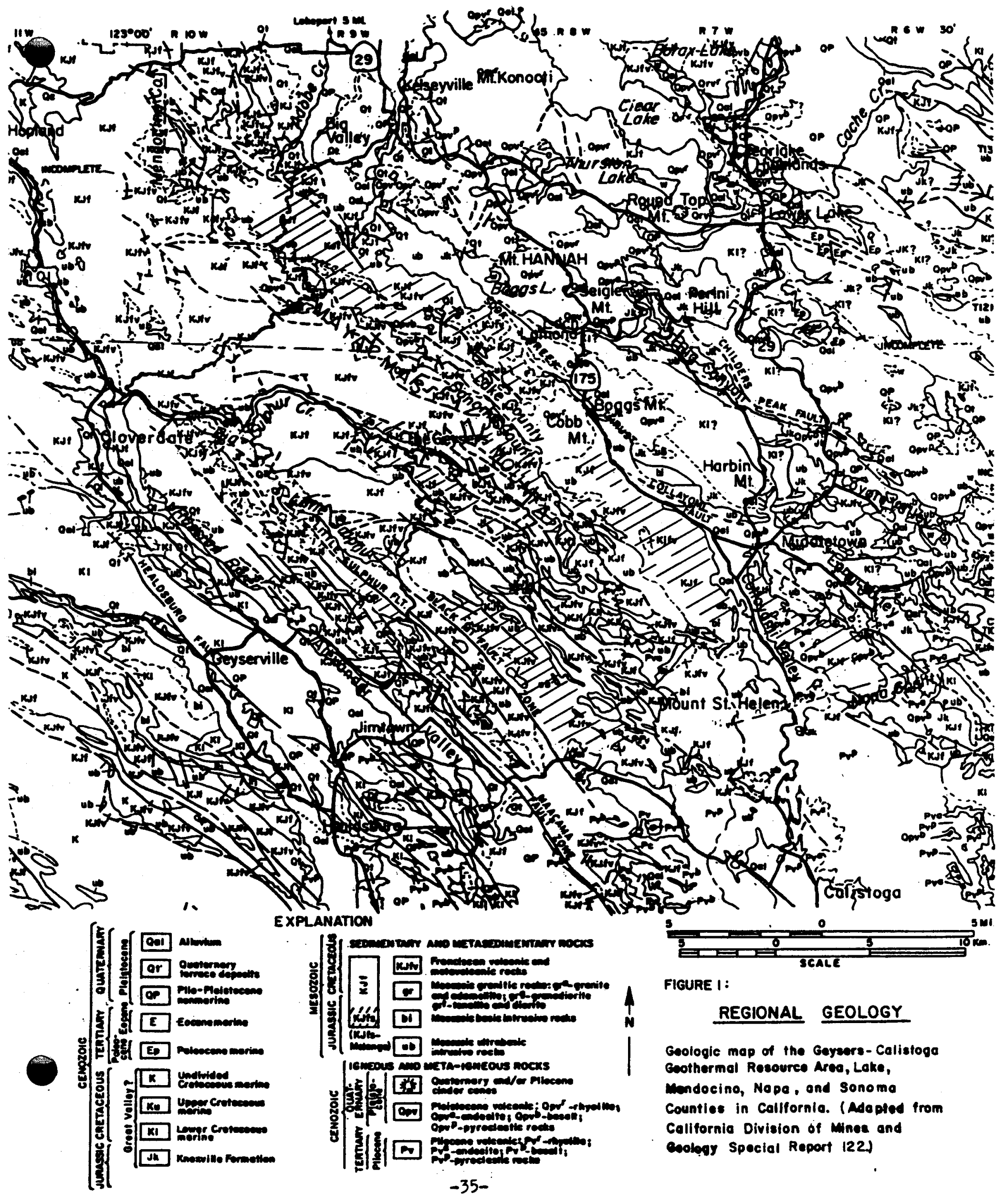

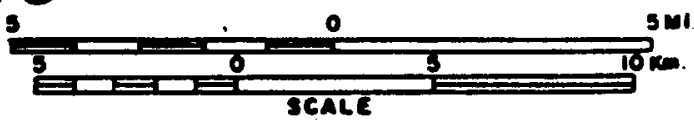

FIGURE 1 :

\section{REGIONAL GEOLOGY}

Geologic map of the Geyears-Calistoga

Eeothermal Resoures Areo, Lake,

mendocino, Nope, and Sonoma

Countles in Callfornla. (Adepted from

California Division of Mines and

Cooleay Special Report I22) 


\section{Franciscan Assemblage}

Rock units, assigned to the Franciscan assemblage by Blake and others (1971), occur in major portions of the Mayacmas Mountains. The Franciscan assemblage contains an abundance of sheared rock characterized by high clay content and low permeability. Areas where these rocks are exposed in the Mayacmas Mountains have large numbers of landslides. The entire assemblage can be divided into three major rock units that are separated by faulting into three thrust plates. The unit that is most unstable and that apparently extends beneath the Sonoma Volcanic rocks and other younger rocks in the Calistoga area, is exposed over major parts of the area to the northwest. This unit is the sheared shale and sandstone (KJfs) of Blake and others (1971) which contains resistant masses of hard rocks of several lithologic types. Most of the sheared rock in the Franciscan assemblage, together with masses of shattered sandstone, is assigned to this unit. The term "melange" has been applied to Franciscan rocks of similar characteristics by Hsu (1969).

A melange unit generally consists of a highly sheared lustrous gray to black shale matrix containing abundant hard, resistant blocks of metagraywacke sandstone, chert, greenstone, serpentinite, and metamorphic 
rock. The blocks range in size from less than 1 foot $(30 \mathrm{~cm})$ to greater than 5 miles $(8 \mathrm{~km}$ ) in length. They make up a highly variable proportion of the entire unit.

The second of the three subdivisions of the Franciscan rocks, and the most stable for engineering purposes, consists principally of metagraywacke sandstone with lesser amounts of other metamorphic constituents, including metagreenstone and metachert. This unit is characterized by blueschist minerals, such as glaucophane, lawsonite, and jadeitic pyroxene. The main outcrop area lies to the northwest of Calistoga near Geyserville and Jimtown.

The third Franciscan unit has widespread outcrops in the Mayacmas Mountains, particularly west and north of the present study area. it consists predominantly of graywacke-type sandstone and shale with minor greenstone, limestone, and chert and some lenses of conglomerate. The sandstone ranges from massive to thin bedded, but the rock is frequently shattered and commonly veined with laumontite and is subject to landslide activity.

The base of the Franciscan assemblage has not been recognized and no older formations are exposed. It is probable that the Franciscan rocks were deposited upon a thin oceanic crust and were tectonically emplaced in their present position as the Pacific plate slid beneath, the North American continental plate. 
Several rock types occur as discrete masses within the Frnaciscan units, and their presence can often serve as an indication of the melange-like character of the unit within which they occur. They include high grade metamorphic rocks such as glaucophane schist, eclogite, and amphibolite; blocks of graywacke and metagraywacke sandstone; chert and metachert; greenstone, serpentinite, and silica-carbonate rock. Many of the high-grade metamorphic rock inclusions occur in blocks less than 100 feet $(30 \mathrm{~m})$ long. The three most important rock types are greenstone, serpentinite, and silica-carbonate rock.

Greenstone: These altered mafic submarine volcanic rocks include gray to greenish-gray spilitic basalts in the form of pillow lavas, massive flow rock, tuffs, and breccias. In many parts of the area, they occur as discrete masses no more than a few hundred feet thick, but McNitt (1968) has estimated a thickness of 7,000 feet for the massive pile that trends northwestward for several miles from the vicinity of the Geysers Resort. In some places, these rocks contain minor amounts of fossiliferous limestone; in others, the greenstone contains incipient blueschist minerals or is reconstituted to blueschist. Landslide activity, although not as prevalent as in some other rock units, does occur in the larger greenstone outcrop areas.

Serpentinite, including relatively fresh ultramafic masses "intrudes" the lower or melange unit of the Franciscan assemblage and occurs as sheets, lenses, andi irregular shaped masses, both within and along the boundaries of the unit. Depending on the degree of internal shearing and alteration, 
serpentinite can present foundation problems for well drilling and for other engineered structures.

Silica-carbonate rock, a product of the hydrothermal alteration of serpentinite, can be relatively hard and strong. It most often occurs in blocks and masses associated with serpentinite and is often associated with the occurrence of mercury deposits.

Although the Franciscan assemblage comprises the bedrock within the Calistoga study area, actual outcrops of Franciscan rocks occur as small isolated exposures, confined to the north and northeastern margins of the valley. Typically, these outcrops are comprised of graywacke or greenstone, although an extensive body of serpentinite is exposed northwest of Kimball Reservoir.

Chemical analyses of the serpentinized intrusions (Bailey, Irwin, and Jones, 1964) indicate that the rock is composed of almost equal parts of silica and magnesium but also contains residual amounts of other rock-forming minerals. Analyses of the sandstones and shales of the Franciscan assemblage (Bailey, Irwin, and Jones, 1964) indicate that silica and aluminum are the dominant constituents, followed by iron, magnesium, and calcium, respectively. Except where fractured or deeply weathered, the ultramafic rocks and the Franciscan rocks are poorly permeable and yield water of poor quality. 
Great Valley Sequence

the Jurassic and Cretaceous Great Valley sequence consists mainly of well-bedded sandstone and shale, massive shale and siltstone or mudstone with minor sandstone, and conglomerate lenses and beds. Swe and Dickinson (1970), in their studies centered in the Lower Lake quadrangle have described 35,000 feet of clastic sedimentary strata, ranging in age from Late Jurassic to Late Cretaceous, as belonging to the Great Valley sequence. They have divided the entire sequence stratigraphically into four main segments, three of which, although broken by faults, are apparently conformable successions of strata. The fourth consists of several segments of similar age each bounded entirely by faults. None of these rocks crop out in the immediate Calistoga vicinity.

Ultramafic rocks, largely pyroxenite and serpentinite, basaltic pillow lavas and breccias, quartz diorite, diorite, gabbro, and diabase are present locally at the base of the Great Valley sequence. These rocks are in $f$ ault contact with the Franciscan rocks.

Iogs of wells and pump-test information supplied by drillers, pump companies, and land owners indicate that the consolidated sedimentary rocks of Cretaceous age, rocks of the Franciscan assemblage and the ultramafic rocks generally yield small quantities of water to wells. However, significantly larger quantities of water may be obtained from highly fractured or deeply weathered zones. Well-test information from 36 wells 
drilled into these rocks show an average yield of $19 \mathrm{gpm}$ (gallons per minute) with most wells yielding $10 \mathrm{gpm}$ or less. Most of the well tests for which both yield and drawdown information are available, show a specific capacity less than or equal to 0.1 galion per minute per foot of drawdown (Faye, 1973, p. 14).

Sonoma Volcanics

Tertiary volcanic rocks are exposed on the surface over all of the marginal area of the Napa Valley. These rocks are composed almost entirely of material of volcanic origin, and are considered to constitute a part of the Sonoma Volcanics of upper Pliocene age.

The Sonoma volcanics constitute a thick and highly variable series of volcanic rocks including andesite, basalt, and minor rhyolite flows with interbedded and discontinuous layers of tuff, tuff breccia, agglomerate and scoria.

Tuff, by far the most common and widely distributed rock in the Sonoma Volcanics, is a fragmental rock made up entirely of volcanic material. Enormous quantities of volcanic ash were showered on the area and accumulated under various conditions. Most of these tuffs appear to be massive and were deposited on the irregular surface of the land. Locally, however, some of them are definitely waterworked, apparently shallow lake deposits. Tuffs formed this way are often soft and usually fine grained and light both in 
color and weight, but coarse varieties are common and, in some places, these appear to be more a kind of agglomerate, containing angular particles of lava, mostly andesite and basalt. Ordinarily, the massive tuff contains numerous pumice fragments, which vary in size from very small grains to fragments up to an inch or more in length. The majority of the tuff is white in color, but gray and buff colored varieties are common, and in some localities the gray and white tuffs occur interbedded (Johnston, 1948).

the tuffs are separated at a number of horizons by lava flows, which are either basaltic or andesitic in composition. These lavas usually occur as dense, heavy, very fine-grained rocks, but are commonly scoriaceous, have vesicles which may or may not be filled, and may be porphyritic in nature. Flow banding is commonly present and columnar jointing occurs locally. The lava flows are much more resistant to weathering and erosion than the tuffs, and they commonly crop out in steep cliffs and form caps on many of the ridges.

A number of lenses of sediments, composed almost entirely of volcanic material, none of which are either thick or extensive, are found locally. These sediments are composed of loosely consolidated sands, gravels, and conglomerates, most of which were probably deposited in streams or shallow lakes, while others represent erosion intervals between periods of volcanism.

Redeposited, water-laid pyroclastic materials, diatomite, silt, sand and gravel are exposed in roadcuts along the Silverado Trail east and southeast 
of St. Helena. In the vicinity of Calistoga, prominent bodies of rhyolite and rhyolitic tuff have been altered by hydrothermal processes to a hard, dense, fine-grained rock. Thin-section and $x$-ray diffraction analyses indicate that the altered rhyolitic rocks now consist primarily of quartz and kaolinitic and montmorillonitic clays.

Well-test information from 140 wells tapping the Sonoma Volcanics show an average yield of $32 \mathrm{gpm}$ and an average specific capacity of 0.6 gallon per minute per foot of drawdown (Faye, 1973).

\section{Alluvium}

In this report, deposits described as alluvium include the older alluvium, terrace deposits, older alluvial-fan deposits, and younger alluvium as mapped and described by Kunkel and Upson (1960) and Fox and others (1973).

The older alluvium of Napa Valley is composed of lenticular deposits of unconsolidated and poorly sorted clay, silt, sand, and gravel. Where exposed at the surface, it is predominantly a reddish-brown color and exhibits cross-bedding. The material is unconsolidated but somewhat compacted, and some lenses of gravel are cemented. The sand and gravel fragments are composed mainly of andesitic debris, but they include chert. 
Terrace deposits include numerous isolated bodies of unconsolidated clay, sand, gravel, and cobbles that cap hilltops and benches or border the base of steep hills and mountain slopes. All these bodies are thin and of small extent. Locally, they conceal the older formations on which they lie unconformably. Some are remnants of former river-channel or flood-plain deposits, some may be marine terrace deposits, and some are older alluvial fan deposits. They occur at several altitudes above present sea level and present stream grades. They range in thickness form 0 to 15 feet, except for the older alluvial fan deposits which may be considerably thicker. No fossils have been found in these deposits, but their stratigraphic positon indicates an age from late Pleistocene to Holocene. They may be equivalent in part to the older alluvium. These deposits are unconsolidated. Although in most places they contain a large proportion of sand and gravel, they are mainly non-waterbearing, because generally they are thin and occur above the water table. Where these deposits overlie either the Huichica or the Glen Ellen formation, the coarse gravel of the terrace deposits may easily be mistaken for gravel interbedded with the underlying formations, and a false impression of the water-bearing character of the underlying formations may be inferred. Because these deposits are mainly non-water-bearing, they have been mapped only where they are relatively thick or where they obscure the nature of the underlying formations (Kunkel and Upson, 1960).

The younger alluvium consists of interbedded unconsolidated gravel, sand, silt, clay, and peat in beds comprising channel, flood-plain, and alluvial fan deposits. These deposits overlie or overlap all other formations in the 
Napa Valley. They were deposited by the streams, much as we see them today, in valleys cut by streams graded to a lower position of sea level thought to correspond with a late Pleistocene glacial stage (Upson, 1949, Louderback, 1951). Hence, the younger alluvium may be in part late Pleistocene, but for the most part it is considered to be recent (Holocene) because deposition is continuing (Kunkel and Upson, 1960).

The floor of the Napa Valley consists of channel deposits and flood-plain deposits composed predominantly of well-sorted gravels and sand interbedded with silts. This material is not well exposed in section; and for the most part is indistinguishable from the older alluvium. However, typically, these deposits are less than 30 feet thick.

The yield of wells tapping the alluvium ranges from about $50 \mathrm{gpm}$ to about 3,000 gpm depending on the number and thickness of gravel and sand lenses penetrated at the particular well. Well-test information supplied by drillers, pump companies, and land owners for 100 wells perforated in the alluvium indicate that this unit is by far the best aquifer in the project area. The average yield of these 100 wells, is about $220 \mathrm{gpm}$, and the average specific capacity is about 10 gallons per minute per foot of drawdown (Faye, 1973). 
Geologic Structure

The geologic structure for much of the Mayacmas Mountains area is characterized by the northwest trends of the outcrop patterns of the Jurassic and Cretaceous rocks and of the fault zones that separate them into tilted and folded blocks or plates of strata. The area north of Calistoga is essentially bisected by a major thrust fault zone called the Soda Creek thrust by Swe and Dickinson (1970). This zone, which apparently follows a line of serpentinite outcrops trending northwestward, marks the line of separation between the outcrop areas of the Great Valley sequence on the northeast and the Franciscan assemblage on the southwest.

Swe and Dickinson (1970) postulated that, together with overthrust Eocene and Paleocene strata, the Great Valley sequence forms a thrust complex that rests structurally upon the Franciscan assemblage along the soda Creek thrust, and is overlain unconformably by late Cenozoic strata. A number of subsidiary thrusts, that are discordant to the bedding, divide both the Great Valley sequence and the Franciscan assemblage into three or more successive thrust plates or slices.

Emplacement by regional thrust faulting of the Great Valley sequence and early Tertiary rocks above the Franciscan assemblage was probably complete by Oligocene time, after which the entire complex, including the thrust faults themselves, were folded and cut by faults during later Cenozoic deformations. The late Tertiary-early Quaternary oregeny, which probably 
produced most of this folding and faulting, also brought with it the volcanism that produced the Sonoma Volcanics and the Clear Lake lavas. Mount St. Helena itself is built up of a series of folded flows and beds and is not a former major volcanic vent. The fact that the maximum dip of beds in the vicinity does not usually exceed 20 degrees indicates that oregenic activity in that area was relatively mild in post-Sonoma Volcanics time.

Folding and erosion have exposed the Soda Creek thrust and underlying Franciscan rocks along the Soda Creek anticline outside the Calistoga area on the north. Of the several subsidiary thrusts or other faults known to have sizable displacements within the Great Valley sequence, most prominent is the Collayomi fault. This fault may be associated with the soda creek thrust which separates the Great Valley and Franciscan rocks.

The more important fault zones associated with the Franciscan assemblage outcrop area include (1) the complex fault zone along Big Sulphur Creek to the northwest; (2) the Little Sulphur fault and Black Mountain fault zone that bound the Little sulphur graben along Little sulphur Creek; and (3) the Maacama and Chianti fault zones. Gealey (1951) estimates that the Sonoma volcanic rocks have been downdropped by nearly 2,100 feet $(700 \mathrm{~m})$ by the combined action along the Maacama and adjacent Chianti fault zones that border the Mayacmas Mountains on the southwest. These facts would tend to agree, at least in part, with the concept expressed by McNitt (1968) that the Mayacmas Mountains are a large complex horst bounded by faults. 
Local Folding

As mentioned above, the folding that has affected the Franciscan rocks is difficult to document in the Calistoga area due to lack of outcrops and reliable attitudes. That folding and faulting have occurred in the Franciscan rocks is evidenced by sharp attitude changes within short distances and near vertical to vertical bedding.

The rocks of the Sonoma Volcanics that cover most of the Franciscan rocks south of Mt. St. Helena were gently folded and faulted by compressional forces from the northeast or southwest after their deposition. Broad, parallel synclines and anticlines transgress across the area in a northwest-southeast direction and, in general, the topography follows these folds. Thus, Napa Valley is a broad, asymmetric syncline plunging to the southeast and the large mass of overthrust Franciscan rocks exposed to the southwest of Napa Valley comprises the crest of an anticline. Gentle dips in the range of 10 to 30 degrees are the most common within the Sonoma Volcanics, although steep dips and tight folds have been documented (Johnston, 1948, p. 32)., 
Local Faulting

\begin{abstract}
The pre-Pliocene (pre-Sonoma Volcanics) faults that occur within the Franciscan Formation, although contemporaneous with major folding, are poorly exposed within the study area. Major northwest trending fault zones in Franciscan rocks have been mapped to the northwest of Napa Valley (Fox and others, 1973), but the overlying Tertiary volcanic rocks and Quaternary alluvium mask any pre-Sonoma faulting that may be present within the Napa Valley •
\end{abstract}

The Sonoma Volcanics show some evidence of Pliocene and post Pliocene faulting. Mapping by Fox and others (1973) has shown the occurrence of two short length faults north of the town of Calistoga, as well as some relatively large, both in length and possible displacement, faults occurring 3 to 5 miles south and southeast of Calistoga. The faults all appear to be of normal displacement.

A major structural feature with a strong local effect is the large northwest trending thrust; along which Franciscan rocks have been overthrust upon Sonoma Volcanic rocks at a relatively shallow angle of 20 to 30 degrees. This thrust is the major feature of the western limb of the Napa Valley syncline. The eastern terminus of this thrust, in all probability, is coincident with the current axial plane of the Napa Valley and may result in a major structural discontinuity underlying the Napa Valley. 
GEOPHYSICAL INVESTIGATIONS

Geophysical surveys were undertaken by the Division of Mines and Geology in the Calistoga area in order to provide additional information concerning the geology as related to the hot water resource. Parts of two aeromagnetic surveys and a reconnaissance gravity survey were already available in the area. Therefore, the Divison's geophysical work consisted for the most part of relatively detailed ground magnetic, gravity, electrical resistivity, and seismic refraction surveys. A discussion of each of these surveys and their interpretation follows.

Magnetic Surveys

Purpose

\begin{abstract}
Measurements of the earth's magnetic field are often useful for determining structural trends and details of the geology including the location of possible faults in geothermal areas. Magnetic "lows" in some geothermal areas have been attributed to the alteration of magnetite in rocks by hydrothermal fluids (Studt, 1963); magnetic data have also been used to help locate possible geothermal heat sources (Goldstein and others, 1978, p. 32).
\end{abstract}


U.S. Geological Survey aeromagnetic maps are available in the Calistoga area (U.S. Geological Survey, 1973, 1974). These maps are most useful for studying the regional geology. For more local detail, however, ground magnetometer data were obtained in the area. The ground data also served to aid in interpretation of the airborne magnetic anomalies.

Aeromagnetic Data

Plate 2 is an aeromagnetic map of the Calistoga 15 minute quadrangle compiled from U.S. Geological Survey open-file maps (1973, 1974). Overall, the map is characterized by northwest aeromagnetic anomaly trends in the Calistoga area. The largest magnetic anomalies (up to 200-300 gammas in amplitude) are associated with exposures of serpentinite in the Franciscan basement rocks located south and east of Mt. St. Helena, and in the southeastern corner of the map area. The rocks of the Sonoma Volcanics, in general, evidently have only a minor effect on the aeromagnetic map in the Calistoga area. The reason for this is evident in Table 1, which shows that the Tertiary volcanic rocks generally have low values of magnetic susceptibility in comparison with serpentinite. A possible exception to this is andesite flow rocks that often exhibit reverse magnetic polarity and cause prominent magnetic anomalies in the southwestern part of the map sheet (Chapman and Chase, 1977). 
Table 1. Magnetic susceptibility, density, data, and lithology of rock samples from Calistoga, Napa County, California. Measurements by Paul V. Anderson.

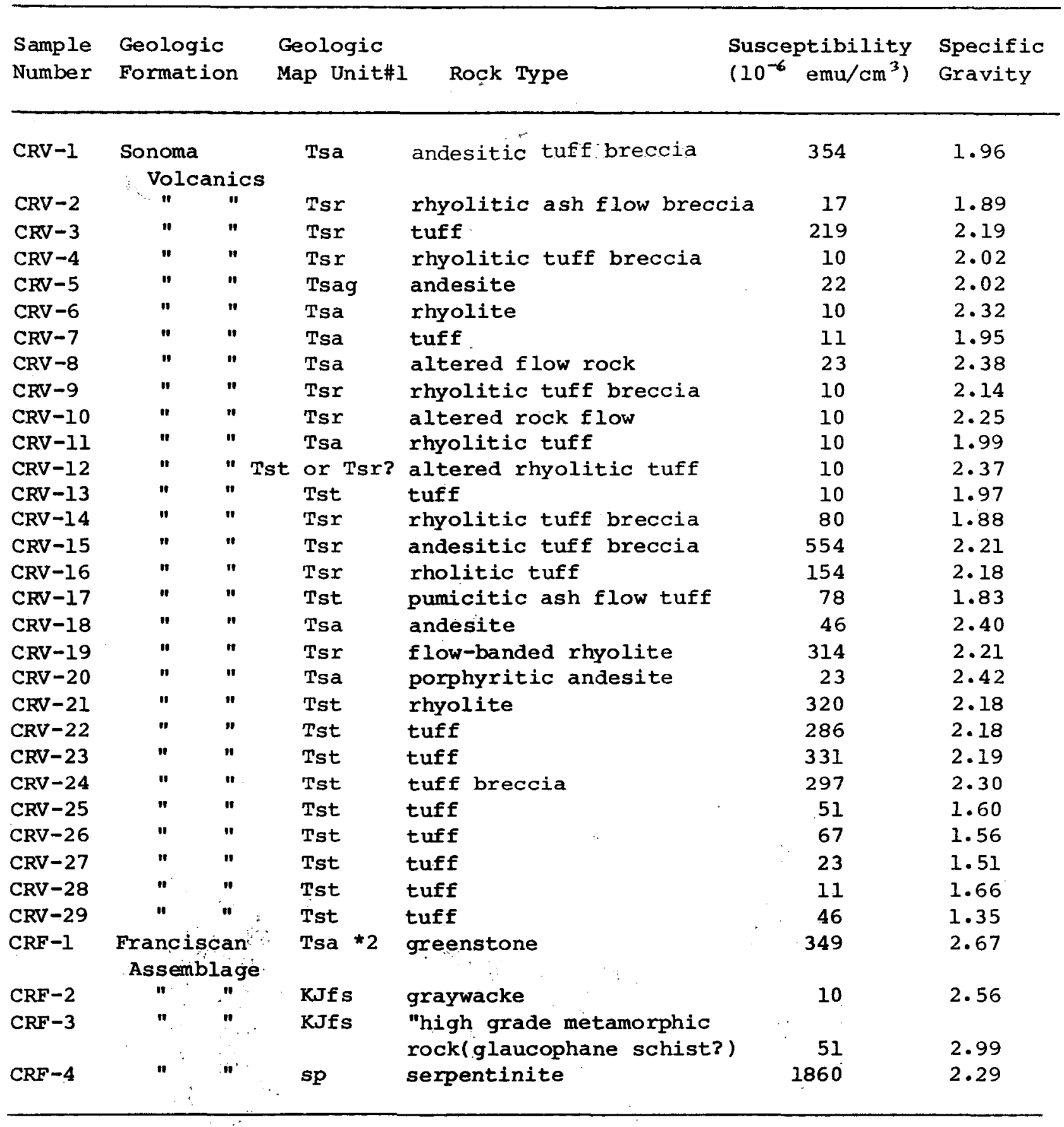

*1. The geologic map units are from Fox and others (1973).

*2. Sample CRF-1 was from a small greenstone outcrop characteristic of the Franciscan Assemblage. The outcrop was not shown on the geologic map by Fox and others (1973) probably because the outcrop was too small for adequate mapping. 
Near Calistoga, the general aeromagnetic pattern consists of several subparallel, northwest-trending, positive and negative anomalies including: (1) a positive anomaly approximately parallel to Napa Valley but located at a distance of about $11 / 2$ miles to the southwest; (2) a negative anomaly, the axis of which is located near the southwestern side of Napa Valley; this anomaly extends to the northwest through Knight's Valley; and (3) a small (in amplitude) positive anomaly that extends southeastward along the northeastern side of the valley from the large magnetic "high" just south of Mt. st. Helena.

The positive anomaly located southwest of Napa Valley near Calistoga decreases in amplitude toward the northwest. Near the latitude of Calistoga, the trend of this anomaly apparently turns westward. Near the southeastern corner of the map, this anomaly is associated with outcrops of serpentinite. Thus, the northwestern continuation of this anomaly suggests the possible presence of some serpentinite in the subsurface in this direction. Similarly, the small positive magnetic anomaly on the northeastern side of the valley may represent a small amount of serpentinite in the subsurface in this area as well. Alternatively, the latter anomaly could represent Franciscan greenstone which crops out in this area in several places, although this rock usually does not have a very high magnetic susceptibility (Table 1). 
Equipment and Field Procedure for Ground Survey

Ground magnetometer traverses were obtained in the Calistoga area by means of an EGG - Geometrics proton-precession magnetometer, model 816, that has a sensitivity of one gamma. A total of 15 ground lines were run (Plates 2 and 3). Most stations were spaced at intervals of 100 feet, usually estimated by pacing, but the station spacings on some lines were from 200 to 500 feet. Plate 3 shows the location of 13 of the 15 magnetometer lines. The location of two additional reconnaissance lines are shown on Plate 2 . The ground magnetometer lines total about 18.5 miles in length.

Ground Magnetic Data

Ground magnetic data were plotted both in profile and plan map form (Plate 3). On Plate 3, the data are contoured at intervals of 50 and 100 gammas. The regional magnetic gradient, which is about 10 gammas per mile, increasing to the northeast, has not been removed from these data. In general, on magnetic profiles that cross Napa Valley (CM4, CM5, CM7, CMl2, and $C M 13)$, except for line $\mathrm{CM} 13$, the magnetic values tend to rise gradually toward the northeast at a much faster rate than the normal gradient. This is shown on Plate 3 and is in general agreement with the aeromagnetic map (Plate 2). 
Near the southwest end of profiles CM4 and CM7, there is also a slight rise in the magnetic levels, resulting in a small magnetic "low" centered near Myrtledale Road on both of these lines. This magnetic "low" is near the Old Faithful (California) geyser on profile CM4, and could be related to the geothermal field, but it may actually represent a regional low between positive anomalies located to the southwest and the northeast as shown on the aeromagnetic map (Plate 2). Alternatively, the small magnetic gradients on the southwestern sides of the negative anomalies on profiles CM4 and CM7 (values increasing toward the southwest) could represent changes in rock types in the valley. Within the valley area, the profiles usually show only relatively small magnetic anomalies. Some of the very local, high frequency, magnetic anomalies are probably caused by man-made sources, such as pipes and culverts. Others of these smaller anomalies could be caused by relatively magnetic volcanic rocks or by small masses of serpentinite or possibly greenstone in the underlying basement rocks.

The magnetic "highs" located near the northeastern ends of lines CM2 and CM5 evidently represent the flanks of the large positive anomaly shown on the aeromagnetic map south of Mt. St. Helena, which evidently is caused by serpentinite. The relatively large local dipole anomaly (about 1500 gammas peak to peak) near the middle of line' CM2 may be caused by a magnetic volcanic rock or by serpentinite in the basement rocks. The small southeastward trending positive anomaly (300 gamma contour) that crosses lines CM7, CMll, and CMI2, evidently corresponds to the small positive 
aeromagnetic anomaly located along the northeastern side of the Napa Valley in this area.

Line CMl4 (Figure 2) was run along a trail up Ritchie Creek and line CMl5 (Figure 3) traversed the Diamond Mountain Road in order to investigate the positive aeromagnetic anomaly shown on Plate 2 in this area. These lines show somewhat erratic magnetic values, with small to moderate local anomalies. The sharpness of these anomalies suggests near-surface sources for the most part. These sources could be within the Sonoma Volcanics or within the Franciscan basement rocks if they are not deeply buried. The local anomalies on both of these profiles are evidently superimposed on very broad positive magnetic anomalies with amplitudes of about 200 to 300 gammas that appear to correspond to the positive aeromagnetic anomaly - These broad positive anomalies could originate in the basement rocks, and might represent the cumulative effect of a number of small masses of serpentinite. The small amplitude of the anomalies appears to preclude the presence of only one or a few large masses of serpentinite, however. Alternatively, the anomalies could represent the cumulative effect of a number of andesite flows within the Sonoma Volcanics, or possibly a buried igneous intrusive rock mass within the basement rocks in this area. 


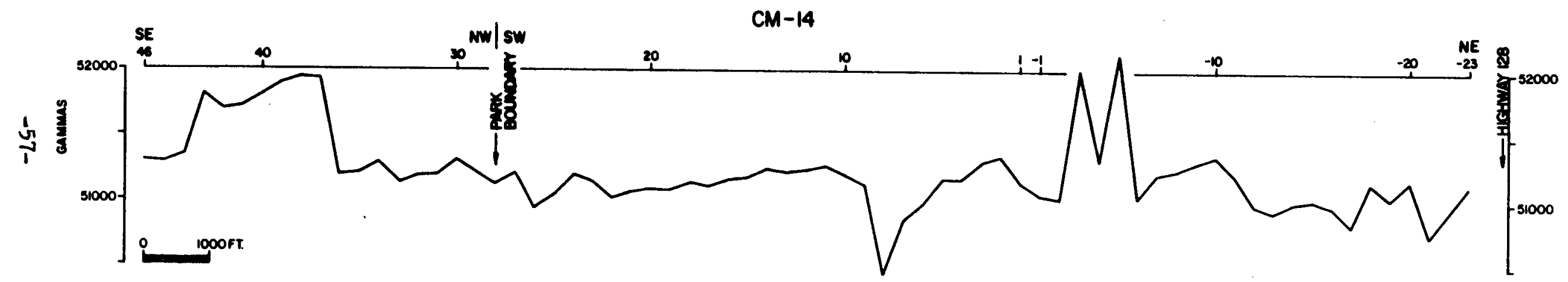

GROUND MAGNETIC PROFILE CM-14

CALISTOGA AREA

MAPA COUNTY, CALIFORNIA

BY

LES YOUNGS

FIGURE 2 


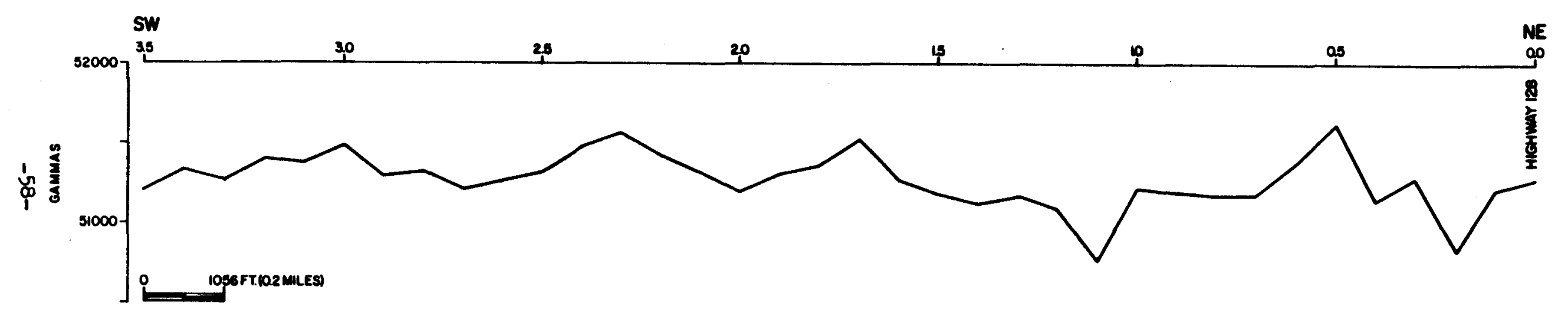

GROUND MAGNETIC PROFILE CM-15

CALISTOGA AREA

NAPA COUNTY; CALIFORNIA

L.G. YOUNGS

FIGURE 3 
Conclusions

The largest magnetic anomalies in the Calistoga area are evidently caused primarily by serpentinite, although smaller magnetic anomalies may be caused by relatively magnetic units within the Sonoma Volcanics or by greenstone in the Franciscan rocks. Anomalies within the Napa Valley are almost all small and indicate that there is little serpentinite in the basement rocks in this area. There is little evidence in the magnetic data to indicate faults within or near the geothermal area. This may mean that magnetic units are not offset in the valley, but it does not mean that faults are not present.

A low amplitude negative anomaly near the geothermal area in the northwestern end of the valley could be related to the geothermal zone, and could reflect a zone of hydrothermally altered rocks, but it is more likely that this apparent negative anomaly is a part of a regional magnetic low.

The broad positive magnetic anomaly that appears to correspond in part to the large negative gravity anomaly south of Calistoga may have in part the same cause as the gravity anomaly. However, serpentinite is probably not the cause of either of the anomalies. An igneous intrusive mass could be the cause of both anomalies, but there are other equally plausible possible causes. 
Gravity Survey

Purpose

Gravity measurements are often used to supplement other geophysical data in geothermal areas both to aid the study of the regional geology and to provide information on local structure that may be related to geothermal reservoirs. In some areas, such as at The Geysers in northern California, gravity measurements have also revealed the presence of the possible heat source for the geothermal phenomenon (Chapman, 1975).

Regional gravity measurements and a Bouguer anomaly map were available in the area (Chapman and Bishop, 1974). Additional gravity measurements were made during this study both to provide more regional information and to investigate the geothermal area near Calistoga in greater detail.

Equipment and Field Procedure

Gravity measurements were made in the Calsitoga area using La Coste and Romberg geodetic gravity meter G-129. For the regional survey, readings were made at elevation points from U.S. Geological Survey $71 / 2$ minute maps. A few station elevations were also obtained by interpolation of the 40-foot topographic map contours. For the detailed lines in Napa Valley, elevation points were obtained by surveying. All readings were referenced to a gravity 
base station in Calistoga (Chapman, 1966, p. 43). A total of about 190 new gravity stations were obtained during the survey.

Gravity data

All the gravity data were reduced to complete Bouguer anomalies using a reduction density of $2.67 \mathrm{~g} / \mathrm{cm}^{3}$. Terrain corrections were made out to a radius of $166.7 \mathrm{~km}$. Plate 4 is a regional map at a scale of 1:62,500 showing gravity data contoured at an interval of 2 milligals (mgal). Plate 5 is a local map showing gravity data near calistoga contoured at an interval of 0.5 mgal where possible.

One of the major features on Plate 4 is a prominent northwest-trending negative gravity anomaly, the axis of which is located about 1 to $11 / 2 \mathrm{miles}$ southwest of the southwest edge of the valley near Calistoga. In this area, the anomaly is located principally over exposures of the Sonoma Volcanics. South of Calistoga, this anomaly has a maximum amplitude of about 15 mgal. To the southeast (off the map), the anomaly may continue down Napa Valley at a reduced amplitude (Chapman and Bishop, 1974). This part of the anomaly at least may be associated with sedimentary and volcanic deposits within the valley.

\footnotetext{
Because of the prominent negative anomaly discussed above, Napa Valley near Calistoga is characterized in general by a moderately-steep gravity
} 
gradient, with gravity values increasing toward the northeast. Northeast of Napa Valley, an irregular pattern of negative and positive anomalies is present over the Sonoma Volcanic rocks and Franciscan basement rocks exposed in this area.

Inte rpretation of Data

Regional Anomalies. Overall, gravity values decrease generally throughout the Calistoga area toward the northeast, reflecting the regional gravity gradient in this part of the Coast Ranges. This regional gradient has not been removed from the gravity data in Plates 4 and 5, but this has only a minor effect on the interpretation of the local anomalies. Locally, however, the gravity data in the Calistoga area apparently are strongly affected by the thicknesses of the younger, less dense Sonoma Volcanics and sediments that overlie the Franciscan basement rocks and by other density variations as well.

Plate 4 shows that the large negative gravity anomaly, centered south of Calistoga, tends to dominate the gravity field in the Calistoga area. Residual anomalies from trend surface analyses of the gravity data (not shown) suggest that the main anomalous mass is located chiefly in a northwest-trending zone about one mile wide, approximately between the Mark West Springs Road on the northwest and the Diamond Mountain Road on the southeast. The cause of this anomaly is puzzling. The anomaly could be 
caused by a relatively deep basin or a structure such as a graben or caldera filled with Sonoma Volcanics. The average measured density of 29 samples of Sonoma Volcanics is $2.04 \mathrm{~g} / \mathrm{cm}^{3}$ (Table 1 ). This value yields a density contrast of about $0.6 \mathrm{~g} / \mathrm{cm}^{3}$ with Franciscan basement rocks (average density of about $\left.2.65 \mathrm{~g} / \mathrm{cm}^{3}\right)$. Assuming this density contrast, a two-dimensional analysis (A-A, Plate 4 and Figure 4) indicates that a graben or syncline with thickness of about 5000 feet of these rocks would be required to satisfy the anomaly. This thickness of volcanic rocks seems to be unreasonably large considering the geology of the area. Even if the average density of the volcanic rocks is less than $2.0 \mathrm{~g} / \mathrm{cm}^{3}$, any reasonable value of the density requires what appears to be an excessive thickness of these rocks.

Other possible causes for the negative anomaly include: (1) a thick mass of serpentinite in the Franciscan basement rocks, (2) an extensive zone of extremely altered rocks in the basement, (3) a underlying intrusive mass within the basement consisting of either glassy or partially molten rocks, or (4) some combination of the above. Serpentinite has a relatively low density (Table 1), but if this is the cause of the anomaly, a large magnetic anomaly should also characterize this area. In fact, there is a positive magnetic anomaly of a few tens of gammas shown on the aeromagnetic map (Plate 2) in part of this area. However, ground magnetometer lines CMl4 and CMI5 (Figures 2 and 3 ) that cross this aeromagnetic anomaly show a very broad anomaly with a possible maximum amplitude of only 200-300 gammas. Therefore, serpentinite probably is not the cause of the gravity anomaly. If altered basement rocks 
are the cause of the anomaly, the volume of these rocks required is so large that the hypothesis also appears to be unlikely.

It is possible that an elongate intrusive mass ( 3 above) could be the cause of the negative gravity anomaly, or at least that part of it south of Calistoga. This mass could possibly explain the small associated magnetic anomaly as well, and might serve as the source of heat for the geothermal phenomena in Napa Valley near Calistoga. However, our analysis of the anomaly indicates that the top of such an intrusive mass probably would be no deeper than two or three thousand feet. Any such hot intrusive mass at this shallow depth probably would result in extensive geothermal activity in the area immediately over the anomaly, but these effects evidently are lacking here, although we have no subsurface temperature measurements or thermal gradient measurements for evidence. Thus, the cause of the anomaly is puzzling. None of the possible alternative hypotheses seems to fit perfectly with other observed data.

Local Anomalies. Plate 5 is a detailed contour map of Bouguer gravity anomalies in the vicinity of Calistoga. The southern half of this map is dominated by the negative gravity anomaly south of Calistoga and the southward decreasing values of gravity related to this feature. Relatively local features include two positive anomalies, one centered on the northeastern side of the valley north of Calistoga ( -16.5 contour) and one in the northwestern end of the valley ( -16 contour). These anomalies are 
probably caused by near-surface Franciscan rocks that include greenstone, at least in the area north and northwest of Calistoga. Two small negative anomaly closures with an overall northwest trend are present near the central part of the valley. These small negative anomalies may reflect the thickness of alluvium or some other relatively low density rock unit in the valley.

The gravity profiles on Greenwood Avenue and Tubbs Lane are shown on Plates 7 and 8 and discussed briefly in the section entitled "Comparison of geophysical traverses on Greenwood Avenue and on Tubbs Lane".

Conclusions

The results of the gravity study in the Calistoga area have revealed a possible structure or low-density mass southwest of Calistoga. Although the cause of the anomaly is uncertain, if a graben or caldera is present, this structure could include reservoirs that might serve as sources of additional hot water. Alternatively, if a heat source is present, the area that may be underlain by the geothermal resource might also be of substantially larger size than known at the present time.

\footnotetext{
Gravity data within Napa Valley reflect the thicknesses of sedimentary
and volcanic rock units above Franciscan basement rocks and indicate the presence of some dipping contacts, some of which could be faults. For example, see Plates 7, 8, and 9. Small negative anomalies near and southeast
} 
of the old Faithful geyser could be associated with the geothermal field, or they could represent the thickness of valley fill in this area.

\section{Seismic Refraction Survey}

Purpose

Seismic refraction lines were run in the Calistoga area for the following reasons: (1) to determine, if possible, the depth of Franciscan "basement" rock in the valley, (2) to investigate rock types and structure in the area, and (3) to determine, if possible, whether some of the apparent resistivity anomaly boundaries or zones of low resistivity might represent fault zones.

Equipment and Field Procedure

A 12 channel EGG-Nimbus enhancement seismograph, model 1210, was used for the seismic refraction survey. The source of energy was a 400 pound free-falling weight that was dropped a distance of about 4 feet onto a steel plate on the ground. Two cable lengths were used, 550 feet and 1100 feet, with geophone spacing of 50 feet and 100 feet, respectively. The weight was dropped at each end of the geophone cable, and frequently also at an offset distance of about 550 feet from each end in order to obtain data from greater depths. 
The locations of the four seismic refraction lines are given in Plate 6. The total length of seismic refraction lines surveyed is approximately 11,350 feet. The locations and lengths of the four refraction lines are Iisted below:

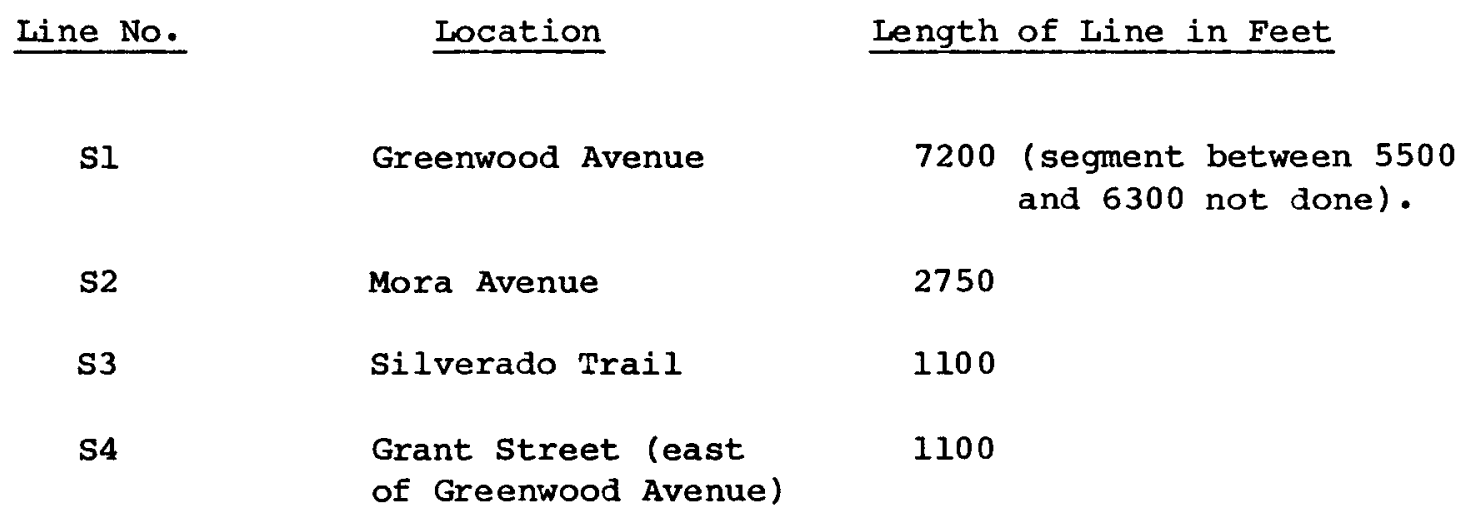

Interpretation of Data

Seismic velocities. The seismic refraction lines (Figures 5-7 and Plate 7) show four basic ranges in velocity that probably represent different rock units.: The layers representing these velocity ranges are listed below:

$\begin{array}{ccc}\text { Layer } & \frac{\text { Velocity Range }}{\text { in feet per second (fps) }} & \frac{\text { Thickness }}{\text { in feet }} \\ 1 & 1000-1500 & 5-20 \\ 3 & 6000-6500 & 50-250 \\ 4 & 8000-9500 & 0-450\end{array}$


SEISMIC SECTION S-2 (MORA AVENUE)

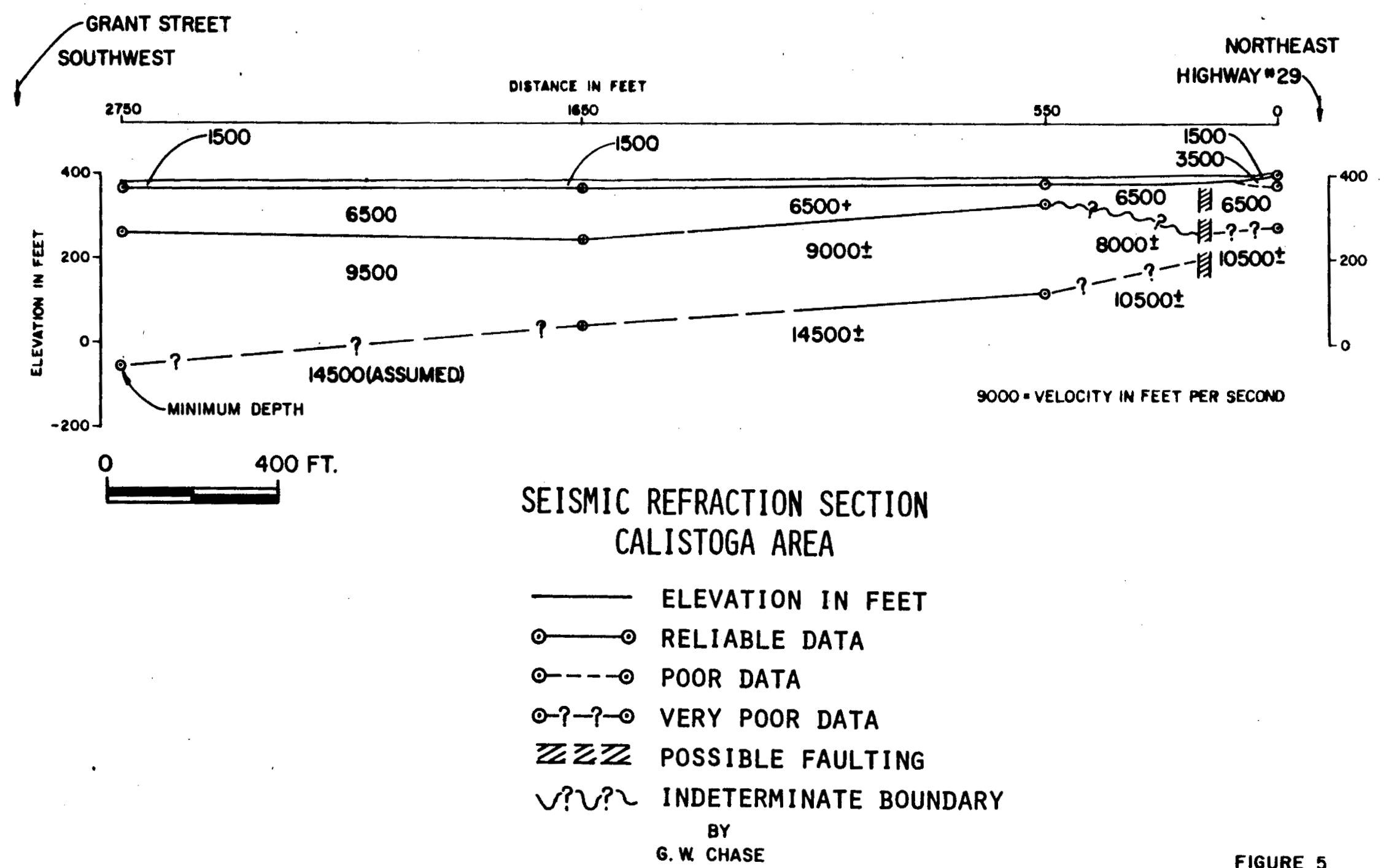




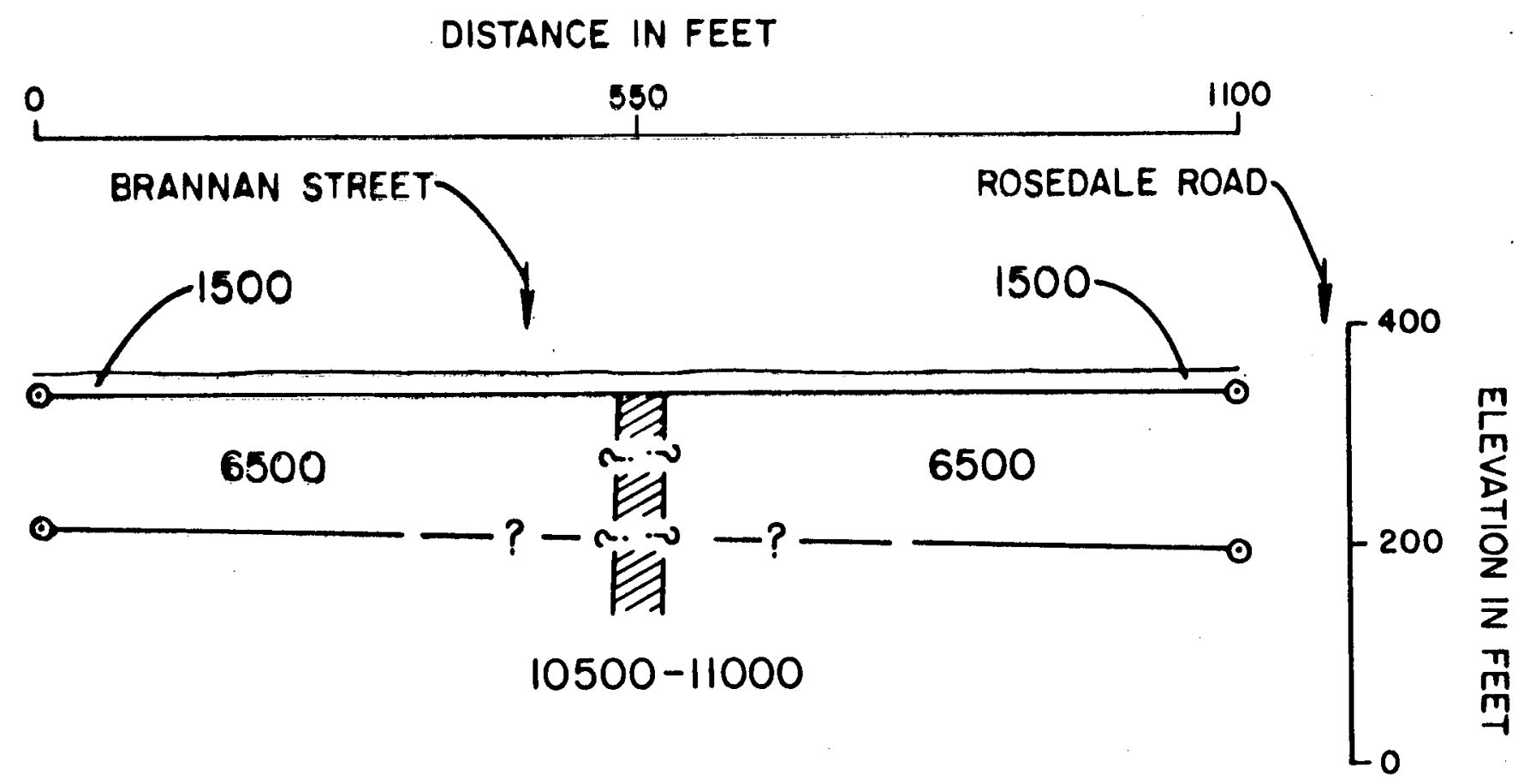

$$
\begin{gathered}
\text { 6500 - VELOCITY IN FEET } \\
\text { PER SECOND }
\end{gathered}
$$

SEISMIC REFRACTION SECTION CALISTOGA AREA

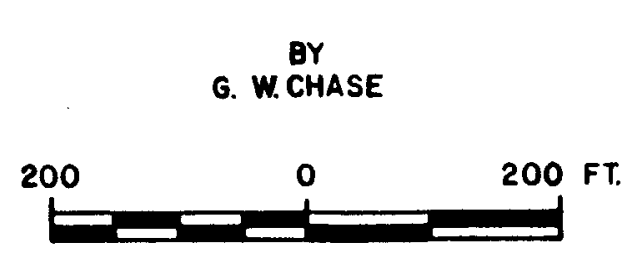

$$
\begin{aligned}
& \text { - ELEVATION IN FEET } \\
& \multimap \text { RELIABLE DATA } \\
& \text { 0- - } \odot \text { POOR DATA } \\
& \text { ๑-?--?-० VERY POOR DATA } \\
& \text { T? } ? \text { ? } ? \text { ? }
\end{aligned}
$$




\section{SEISMIC SECTION S-4 (GRANT STREET)}

GREENWOOD AVENUE

(LINE S-I, STATION 40)

NORTHWEST

SOUTHEAST

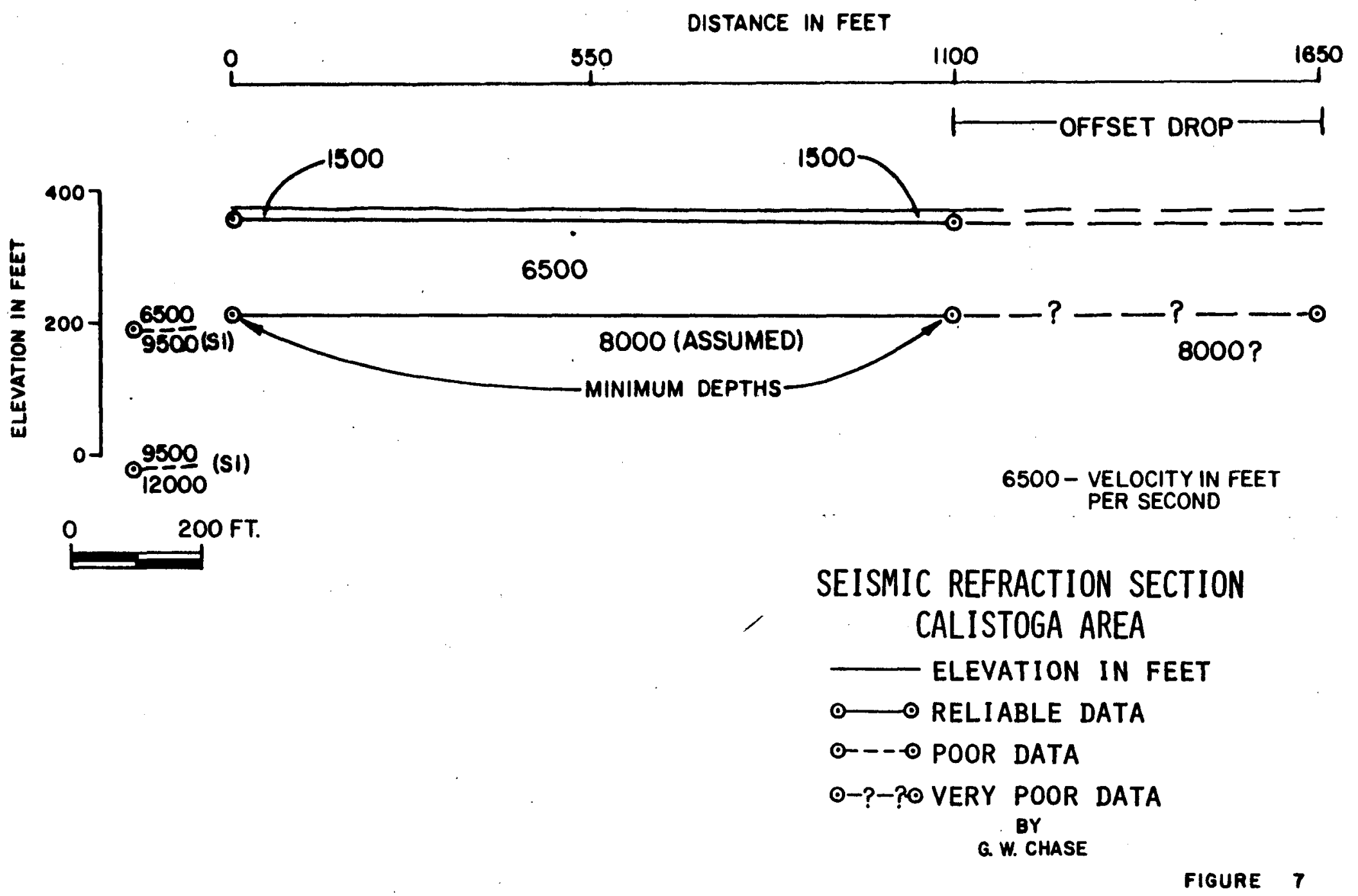


The 1000-1500 fps and 6000-6500 fps layers are found consistently in the upper part of the sections on all the lines. The 8000-9500 fps layer is found on most, but not all of the lines. The 12,000-14,500 fps layer is found on some of the lines, especially near the northeastern edge of the valley where the unit is apparently at a relatively shallow depth.

At this time, we have insufficient information to identify the rock types associated with all of the characteristic velocities. Layer 1 (1000-1500 fps) is probably near-surface overburden, above the water table. Layers 2 (6000-6500 fps) and 3 (8000-9500 fps) have not been identified. However, Layer 2 could be associated with the water table, although the velocity is somewhat high for this. Iayer 3 could be highly fractured Franciscan rocks (greenstone or graywacke) or possibly Tertiary volcanic rocks. Layer $4(12,000-14,500 \mathrm{fps})$ probably represents relatively dense Franciscan basement rock, probably greenstone or metagraywacke or both. Plate 7 shows the interpretive section for seismic line Sl, Figures 5-7 show the sections for seismic lines 2,3 , and 4 .

Iine Sl. Seismic line Sl (Plate 7) trends northeast along Greenwood Avenue and consists of a number of 550 and 1100 feet seismic spreads. Near the northeastern end of the line, layer 4 velocities (probable Franciscan basement rocks) were determined to be at depth of about 60 feet. The seismic interface marking the top of this velocity layer dips toward the southwest; beyond a distance of about 2200 feet (Plate 7), the interface becomes 
increasingly difficult to map accurately. On the south end of the line, south of Blossom Creek, the highest seismic velocity observed $(10,500 \mathrm{fps})$ is intermediate between velocity layers 3 and 4 , and it is possible that this represents a rock type not encountered in the rest of the area surveyed. Layer 2 (6000-6500 fps) is present all along the section, including the area south of Blossom Creek, but this unit is irregular in thickness. Layer 3 (8000-9500 fps) is found in the section south of the 2200 feet mark, and this layer also varies in thickness irregularly. This unit may not be present south of Blossom Creek unless it is represented by the 7300 fps unit mapped here.

In the vicinity of Blossom Creek, there is apparently a discontinuity in the seismic section near the gap in the seismic line in this area. The correlation of the seismic units across the discontinuity is not clear; it is possible that this discontinuity represents a fault zone. Additional evidence for this possible fault zone is shown by an abrupt change in the magnesium $(\mathrm{Mg})$ and bicarbonate $\left(\mathrm{HCO}_{3}\right)$ concentrations measured in water from wells in the area (Figure 16). These concentrations are both much higher southwest of a northwest-trending zone that passes near the seismic discontinuity.

On the northeastern end of the section, between the 800 and 1400 foot marks (Plate 7), a low-velocity zone (about 9000 fps) is present in seismic layer 4. There is also a fairly steep southward slope of the velocity discontinuity on the top of layer 4 in this area that is near a steep gravity 
gradient. It is possible that this low velocity zone represents a fault zone, but this is uncertain.

Line S2. Seismic line 2 (Figure 5) trends northeast along Mora Avenue. This line consists of one 550 foot and two 1100 foot seismic spreads. On this line, in general, the interfaces between layers 2 and 3 and between layers 3 and 4 show southwestward components of dip. Between points 0 and 550, on the northeastern end of the line, there is a possible fault zone, judging from the offset shown in the 10,500 fps layer and the apparent disappearance of layer 3 (8000 fps) at the northeastern end of the 1 ine. In this area, the 10,500 fps layer is believed to be layer 4, although this velocity is unusually low. Layer 4 was not detected at the southwestern end of this line. The queried interface shown at this end of the line actually represents the minimum depth to this unit based on seismic data.

Line S3. Seismic line S3 (Figure 6) trends southeastward along the Silverado Trail from northwest of Brannan Street to near the intersection with Rosedale Road. This line consists of one 1100 foot long seismic spread that crosses an anomalously low resistivity zone near Brannan street (Line R-6, Figure 11). On this line, seismic layers 1 and 2 were found to have velocities within the normal range (1500 fps and 6500 fps respectively). However, the third layer detected on this line (at a depth of about 150 feet) has a velocity of between 10,500 and 11,000 fps, which is intermediate in value between velocities normally found for layers 3 and 4 . 
Thus, either layer 3 was not found on this line, or layer 3 has a higher than normal velocity.

Just east of the Brannan street intersection, there is some indication in the data to suggest possible faulting, although there is no detectable offset in the layers at this point. This possible fault zone corresponds approximately to a change in apparent resistivity from about 15 ohm feet on the northwest, to approximately 40-60 ohm-feet on the southeast (Line R-6, Figure 11).

Line s4. Seismic line S4 (Figure 7) trends southeastward along Grant Street from the intersection with Greenwood Avenue. This line consists of one 1100 foot long seismic spread that crosses an anomalously low-resistivity zone (line R-7, Figure 12). On this line, layers 1 and 2 were found to have velocities within the normal range (1500 fps and 6500 fps, respectively). However, the only evidence for the interface between layers 2 and 3 (8000 fps velocity) was found in the data from an offset drop taken southeast of the end of the line. Thus, the interface immediately above the 8000 fps layer shown in Figure 7 represents only a minimum depth for this layer. No evidence for velocity layer 4 was observed on this line. Just northwest of the end of this line, data points representing the interfaces between layers 2 and 3 , and 3 and 4, as determined on seismic line sl, are shown on the S4 section (Figure 7). The interface between layers 2 and 3 from seismic line 51 (elevation 190 feet) shows good agreement with the minimum depth interface between these layers on line $\mathbf{5 4}$ (elevation $210 \mathrm{feet}$ ). 


\begin{abstract}
Seismic line S4 shows no evidence for a fault or other structures associated with the apparent resistivity anomaly on line R-7 (Figure 12, stations $32-34$ )
\end{abstract}

Conclusions

The seismic lines in the Calistoga area show that the interface that may represent Franciscan basement rocks underneath the valley generally dips toward the southwest, at least in the northeastern part of the valley. The deepest point at which the interface was detected was in excess of 500 feet (on line sl). Generally, this interface could not be mapped beyond approximately the center of the valley. On the line that crosses the entire valley (Sl), this interface was not detected on the southwest side of the valley.

Seismic evidence for faulting was indicated at a few places on the lines. The best example of this is a possible fault near the north end of line s2 that indicates basement rocks are offset down to the south in this area. In some cases, possible zones of hot water interpreted from the resistivity data may be associated with faults indicated on the seismic data such as on lines Sl and s3. If drill holes are completed in the future near some of these seismic lines, it should be possible to correlate the seismic layers described here with rock units. 
Electrical Resistivity Survey

Purpose

Because hot, mineralized water is known to be relatively electrically conductive, geothermal fields are often characterized by anomalously low values of electrical resistivity. The purpose of the resistivity survey at Calistoga was to map electrical properties of the rocks in the vicinity of the known hot water field and attempt to determine both the possible continuity of the resource in the area, and to map possible extensions horizontally and at depth.

Equipment and Field Procedure

The equipment used for this survey consists of a Geotronics Model FT-4 transmitter with an output rated at 4 amps, and 800 volts (3.2 KVA). The power supply, also supplied by Geotronics, is a Model B-2 engine generator with an output of $5 \mathrm{KVA}$ at $400 \mathrm{~Hz}$. The receiver used is the Bison model 2390. This is a digital signal enhancement receiver that provides an average reading every 10 cycles. Because it is necessary to synchronize the precision time base of the transmitter and receiver, the Geotronics transmitter was modified to supply a synchronization pulse that is compatible 
with the Bison receiver system. Thus, the two units can be operated independently for as long as one day while both units remain on and at the same frequency. In this system, the practical operating time is limited to about 3 hours by the fuel capacity on the the motor generator set.

The resistivity survey in the Calistoga area consists chiefly of a number of lines along which resistivity was measured using the polar dipole-dipole electrode system (Keller, 1966). The dipole interval used was 200-feet and the receiver was usually moved out from a transmitter dipole-receiver dipole distance $(\mathrm{N})$ of $\mathrm{N}=1$ (200 feet) to $\mathrm{N}=10$. The transmitter dipole usually consisted of two electrodes about 3 feet apart at each end. All electrodes were thoroughly wet with salt water. It was found necessary to add water to the transmitter electrodes periodically to prevent them from drying out. After the completion of one series of measurements along the line from distance of $\mathrm{N}=1$ to $\mathrm{N}=10$, the transmitter was moved along the line either 400 or 600 feet, and a new series began. In addition to the dipole-dipole survey, one Schlumberger vertical electrical sounding (VES) was also done in the area.

All resistivity measurements were made at a frequency of one $\mathrm{Hz}$ and two measurements were generally made using different values of transmitter current. This yields, at each station, two independent measurements of resistivity which were generally found to be in good agreement. When not in good agreement, these measurements were repeated. Resistivity values were 
collected in the field, and a resistivity pseudo-section was plotted as the work progressed.

Resistivity Data

Plate 6 shows the locations of 7 dipole-dipole lines, R3-R9, and one VES sounding $R l$, in the Calistoga area. The total length of the lines surveyed is approximately $71 / 2$ miles. A listing of the lines, showing street and road locations and lengths, is given below.

DIPOLE-DIPOLE RESISTIVITY LINES

Line No.

$\mathbf{R 3}$

R4 \& R4 Ext.

R5

R6

R7

R8

R9
Location

Greenwood Avenue

Pickett Road, Dunaweal Lane

Bennett Iane

Silverado Trail

Myrtledale-Grant street

Tubbs Iane

Brannan Street
Length in feet

$$
\begin{array}{r}
7,200 \\
10,800 \\
3,600 \\
4,200 \\
5,600 \\
5,600 \\
2,800 \\
\hline
\end{array}
$$

TOTAL 
The results of the dipole-dipole resistivity measurements were plotted and contoured in the standard manner (Parasnis, 1975, p. 219-222), which results in resistivity pseudo-sections. The individual sections are shown in Figures 8-13 and Plates 7 and 8. These sections, which show apparent resistivity values, are not true scale two-dimensional representations. The one vertical electrical sounding is shown in Figure 14.

Interpretation of Dipole-Dipole Data

All of the dipole-dipole pseudo-sections, with the exception of section R9, which was only recently completed, were sent to the University of Utah Research Institute (UURI) for analysis. The following comments on these data were provided by Bill sill (Duncan Foley, personal communication, 1980):

of the six lines of dipole-dipole data, the four in the vicinity of the geyser ( $R 3, \mathrm{R} 5, \mathrm{R} 7, \mathrm{R} 8$ ) show low resistivity zones (3-10 ohm-feet) that may be of interest. Line R5 shows a limited low resistivity zone (10 ohm-feet) at intermediate $\mathrm{N}$ spacings. Near the intersection with line R8, line R7 may also show this zone, although it appears at larger $\mathrm{N}$ spacings and has a smaller apparent resistivity (3-6 ohm-feet). On line R7 this conductive zone continues almost to line R3. At this point in the pseudo-section there are some highly suspect values (i.e., 100's of ohm-feet values next to $10^{\prime} \mathrm{s}$ of ohm-feet). These sorts of changes in $p$ for a unit change in $\mathbf{N}$ or a horizontal change of one dipole are generally impossible to model, at least with 2 dimensional models. Beyond this region there is again a suggestion of a low resistivity zone, at moderate $\mathbf{N}$ values.

Lines $\mathrm{R} 3$ and $\mathrm{R} 8$, which are roughly parallel and cross the above lines, show similar conductive zones at intermediate depths. The nature and extent of the zones in the intersecting pseudo-sections indicate that the region is not very two dimensional. However, the extent of the conductive zone in lines R5 and R7 suggests that the best choice for two-dimensional modeling would be the perpendicular lines R3 and R8. The modeling of these two lines is discussed in more detail below. 


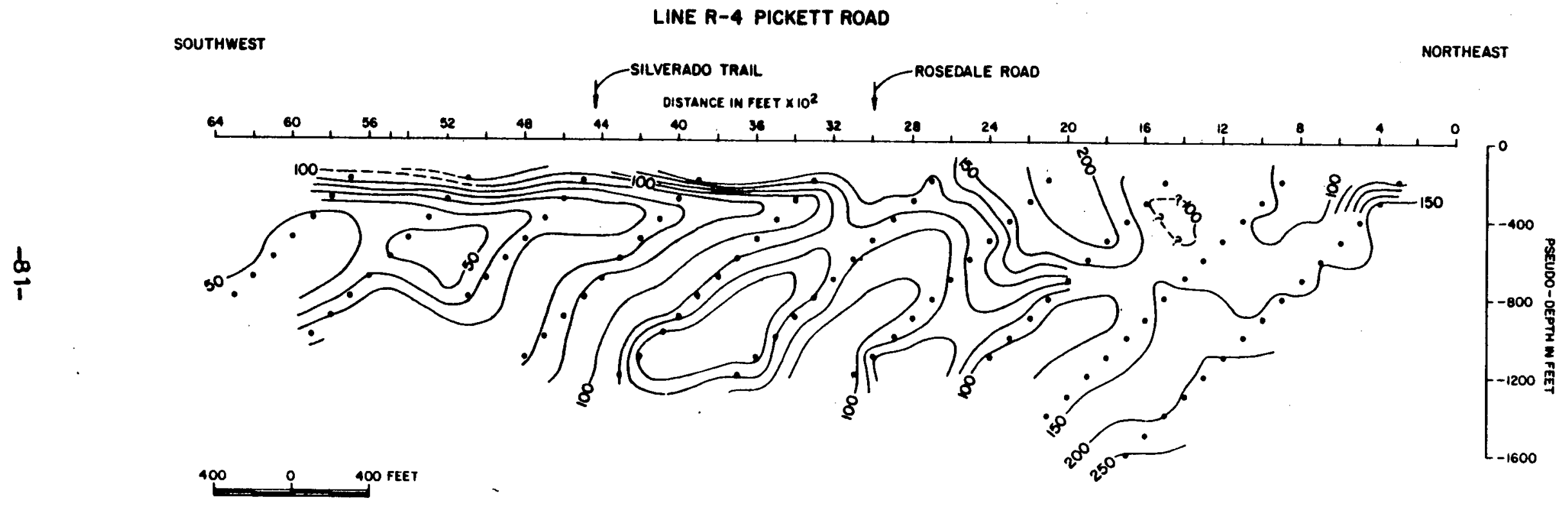

\author{
RESISTIVITY PSEUDO SECTION \\ CALISTOGA AREA \\ CONTOUR INTERVAL - 10 OHM FEET \\ - 50 OHM FEET \\ G. W. CHASE
}


LINE R-4 (EXTENSION) DUNAWEAL ROAD

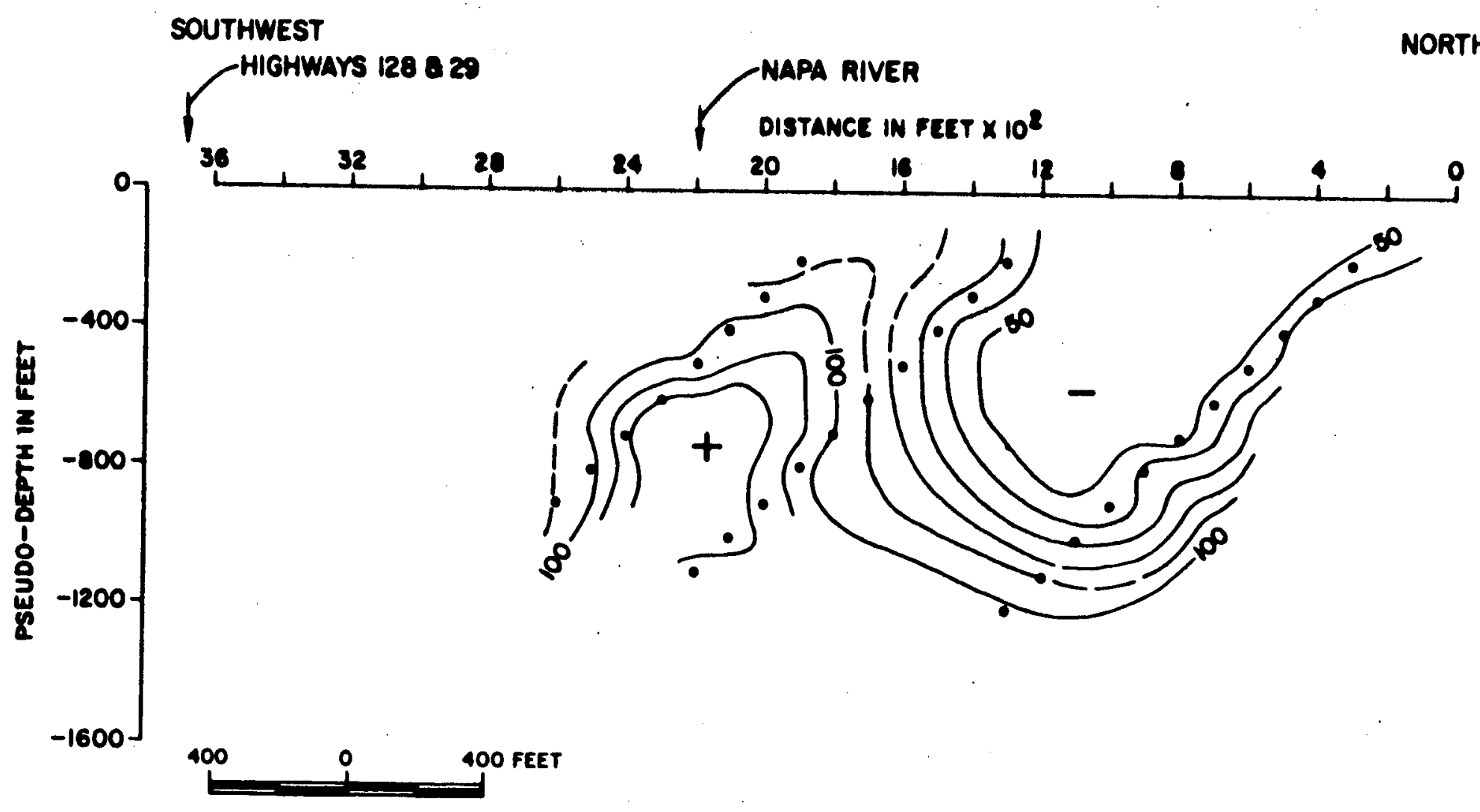

$$
\begin{aligned}
& \text { RESISTIVITY PSEUDO SECTION } \\
& \text { CALISTOGA AREA } \\
& \text { CONTOUR INTERVAL - } 10 \text { OHM FEET } \\
& \text { G. W. CHASE }
\end{aligned}
$$


NORTHWEST

SOUTHEAST

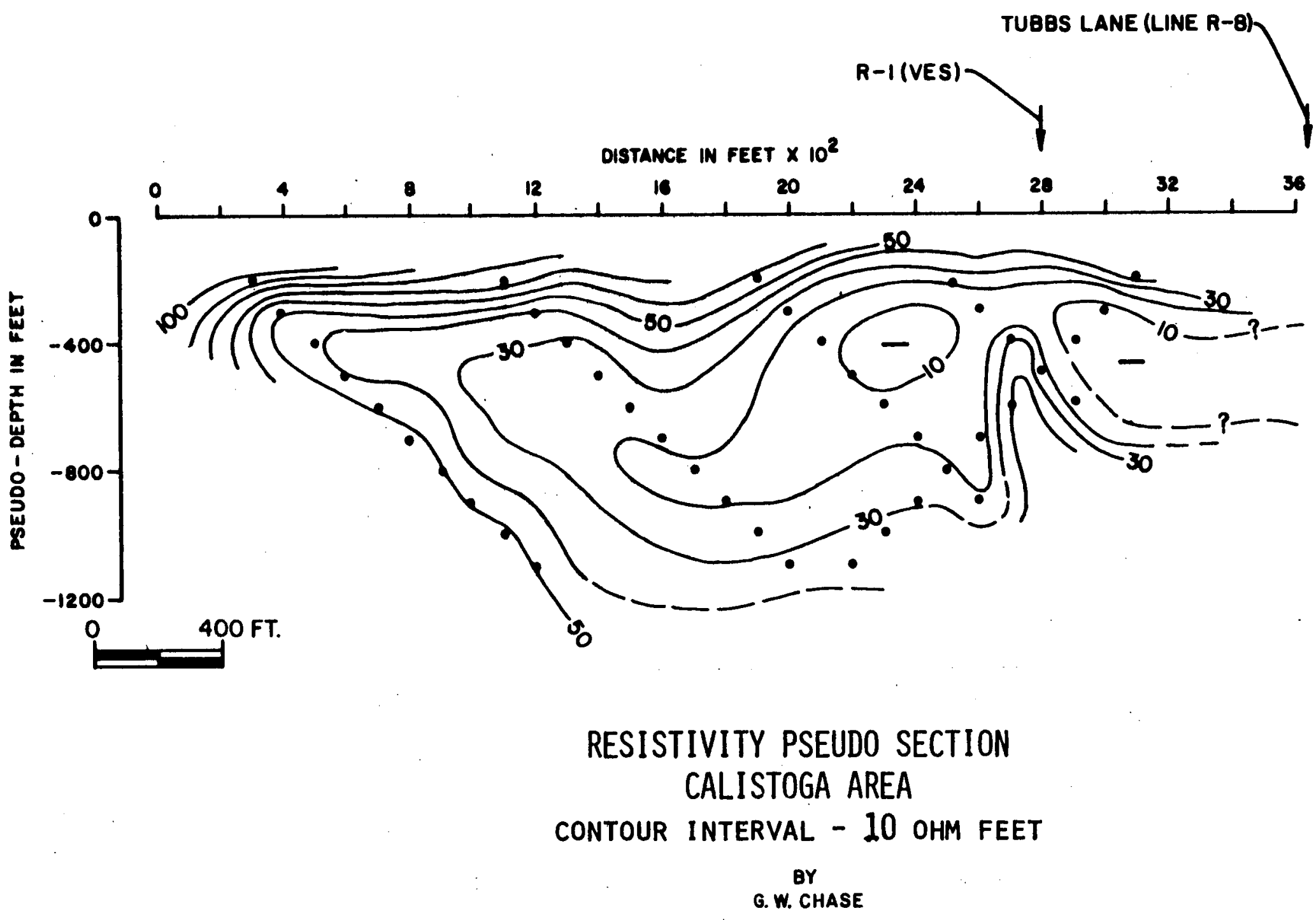




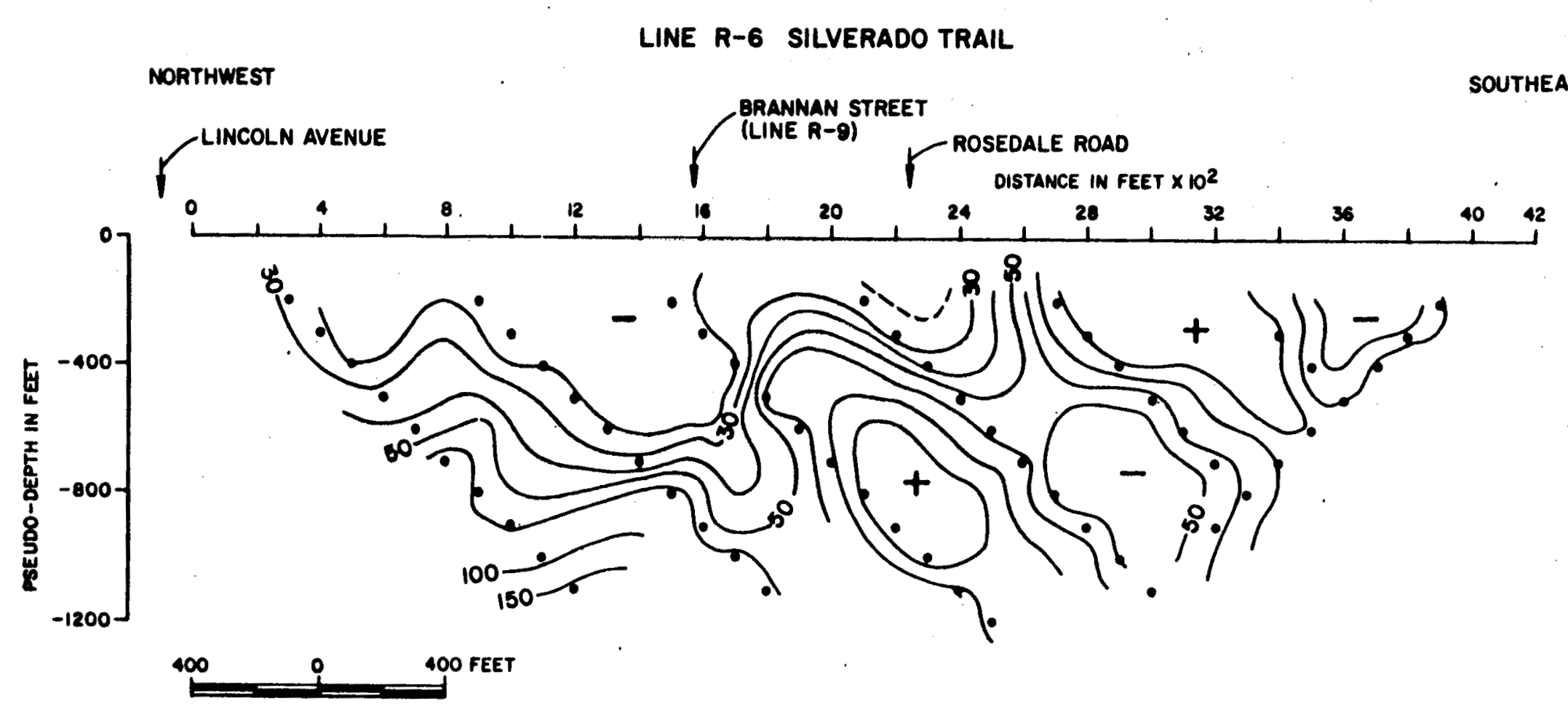

$$
\begin{gathered}
\text { RESISTIVITY PSEUDO SECTION } \\
\text { CALISTOGA AREA } \\
\text { CONTOUR INTERVAL }-10 \text { OHM FEET } \\
-50 \text { OHM FEET } \\
\text { G. W. CHASE }
\end{gathered}
$$


LINE R-7

WEST

MYRTLEOALE STREET

EAST

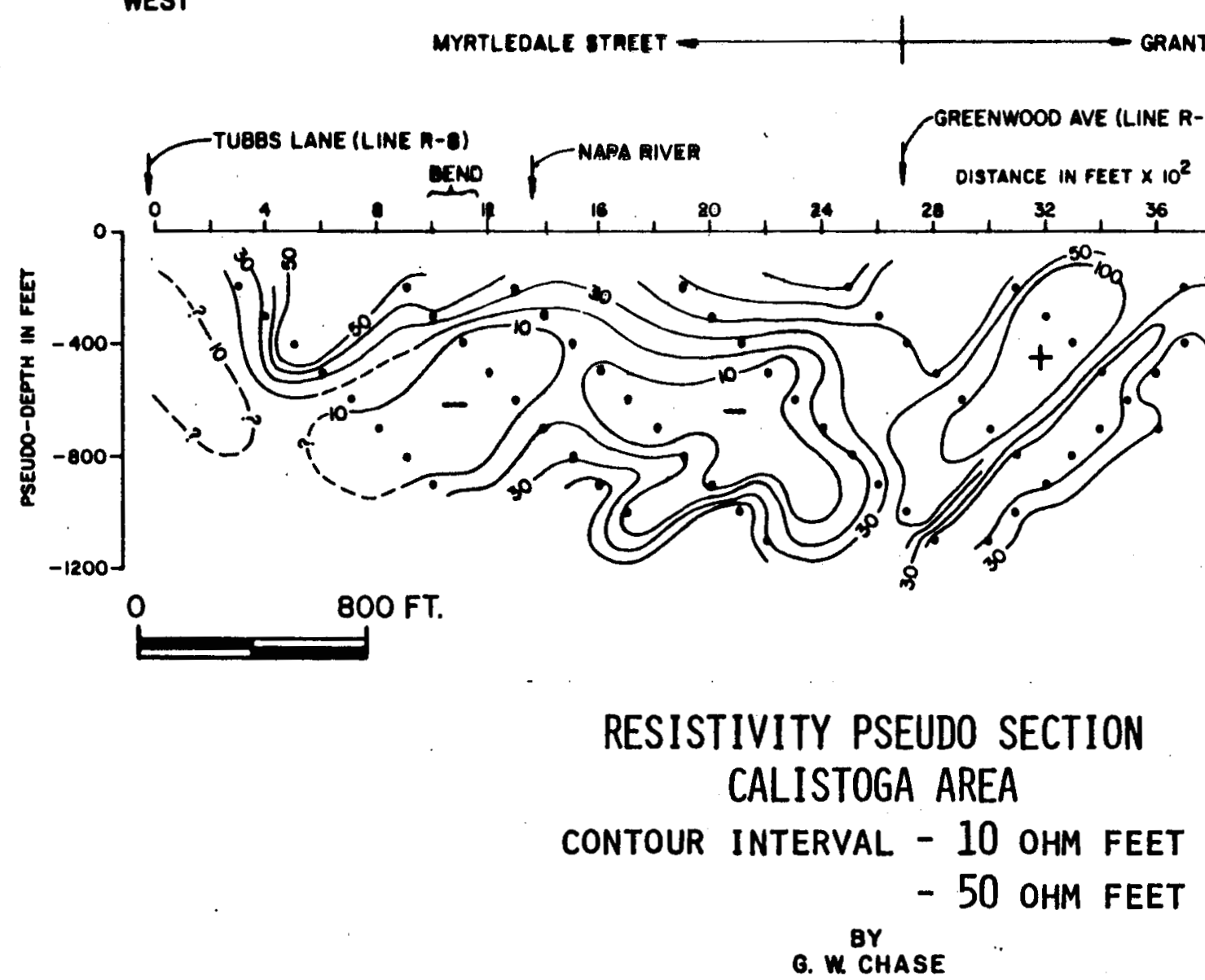



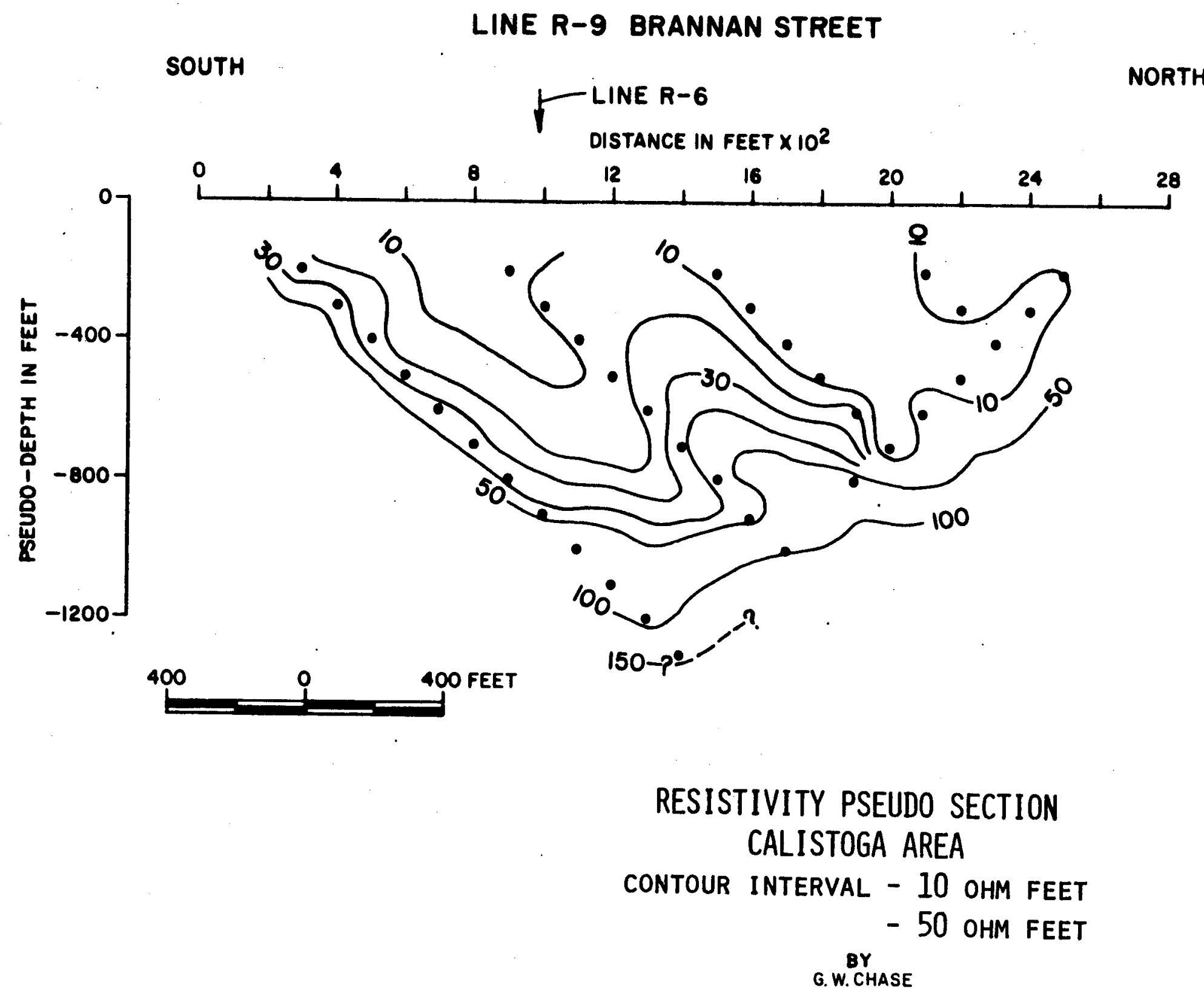

FIGURE 13 
Line R4 shows moderately high resistivity and a general trend of increasing resistivity to the NE. The contours and values suggest the possibility of a contact near $3200^{\prime} \mathrm{SW}$. Line R6 shows mainly a shallow more conductive zone to the west.

Models of lines $R 8$ and $R 3$

The model for line R8 and the calculated results and the observed data (contours) are shown in Figure 1 (See Plate 8 in this report). The diagonals show the locations of the lines of observed data. There is generally good agreement between the model results and the observed data except for the region below $3200^{\prime} \mathrm{sW}$. Here again, there are some suspicious observed data, with very low values next to very large ones.

The model shows a very broad conductive region ( $20 \mathrm{ohm}$-feet) centered roughly on the geyser. The most conductive region (5 ohm-feet) is at the surface right at the geyser and seems to be shifted to the NE at depth. Looking at the model-observed comparison below 2200'SW (the model has larger apparent resistivity) suggests that we might get somewhat better fit by expanding the width of the $5 \mathrm{ohm}-\mathrm{foot}$ zone at depth. The data used in the modeling (N 6 ) does not really limit the depth extent of this zone.

Figure 2 [see plate 7 in this report] shows a similar display of model and observed data for line R3 . Here the data quality seems to be better and the agreement is quite good. Line R3 shows a conductive zone (10-20 ohm-feet) similar to line R8 but the conductive zone does not extend to the surface. Also, R3 shows a moderately conductive zone (20-30 ohm-feet) extending much further to the SW than is seen in the model R8. Here again, the depth extent of the lower layers in the model are not restricted by the data.

In addition to the resistivity lines discussed above, another line R9 was recently completed along Brannan Street in Calistoga (Figure 13), and additional data were obtained on the southeastern end of line-R7 on Grant Street (Figure 12). Line R9 shows two areas of shallow low resistivity of less than $10 \mathrm{ohm}-\mathrm{feet}$ that may be of possible interest. One of these is located just south of Silverado Trail near stations 8-10 and the other, near station 22 , on the north end of the line. 
The additional data on the southeastern end of line R7 (Figure 12) shows some puzzling zones of high and low values that are difficult to interpret and may be suspect as mentioned in the comments on this line mentioned above.

In regard to the interpretation of line $\mathrm{R4}$ (Figure 8), an extension of this line to the southwest might reveal resistivity values low enough to be of interest. The values of resistivity decrease in this direction, and at the present end of the line (stations 60-64) are in the range of 40-50 ohm-feet.

Interpretation of VES Data

One Schlumberger vertical electrical sounding (VES) (Figure 14) was completed on dipole-dipole line $\mathrm{R} 5$ at station 2800 . This is a relatively shallow sounding, as the maximum current electrode distance (a-b) obtained was 1500 feet. An interpretation of this sounding was made by means of the theoretical curves by Orellana and Mooney (1966). This analysis (Figure 14) indicates near surface layers with resistivities of about 41 ohm-feet and 140 ohm-feet, respectively. At a depth of about 40 feet, however, a layer with a resistivity of about 8 ohm-feet was encountered that may indicate hot water.

Comparison of dipole-dipole line R5 (Figure 10) and the VEs sounding shows that the low resistivity layer of less than 10 ohm-feet is found on 
CALISTOGA AREA (VES R-I)

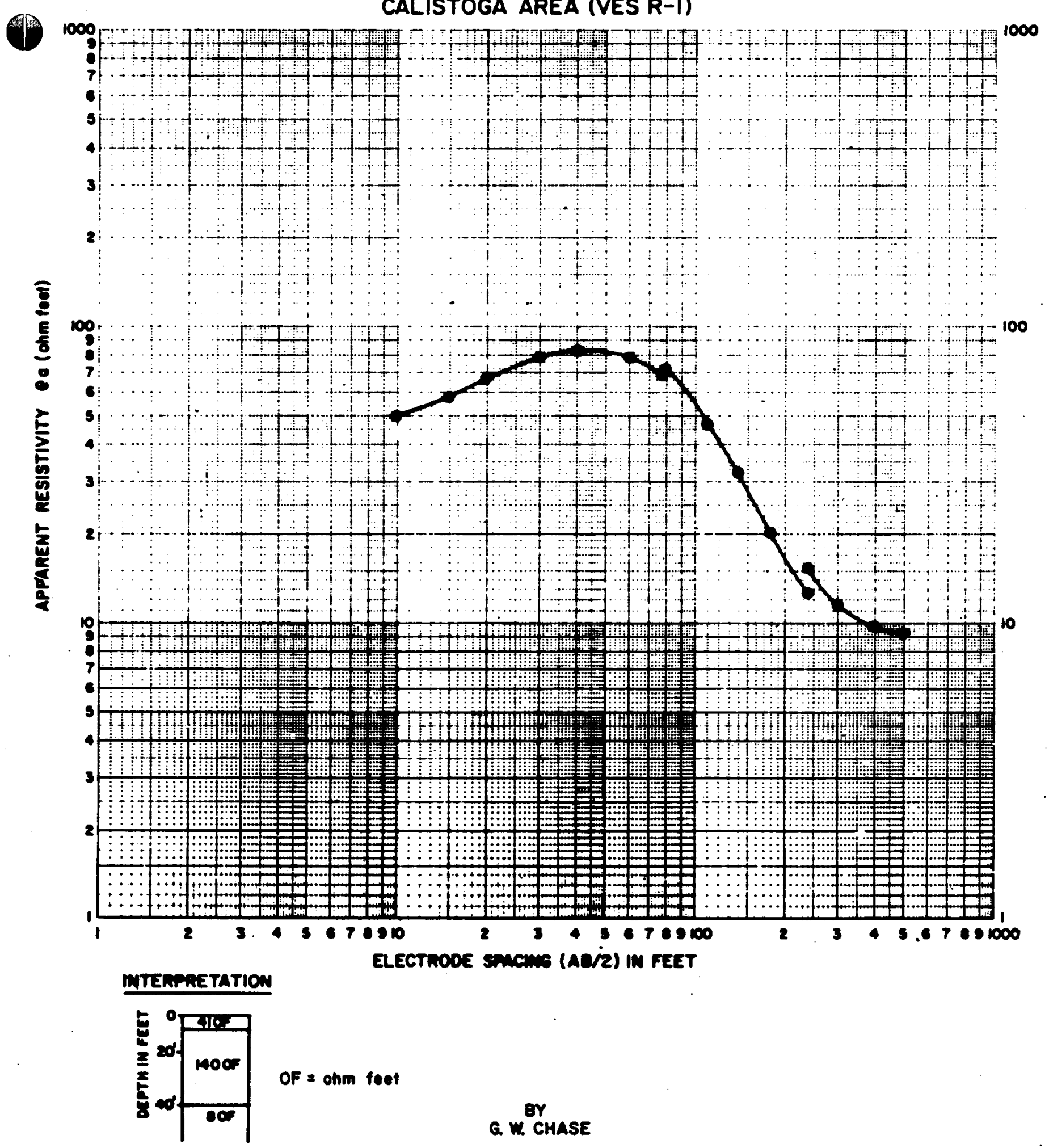

FIGURE 14 
both the pseudo-section and the schlumberger sounding. However, on the pseudo-section, this layer appears at a depth of about 300 feet in comparison with a depth of about 40 feet on the sounding. At least a part of this apparent discrepancy might be resolved if a model could be developed for the dipole-dipole section.

Conclusions

The limited number of dipole-dipole resistivity lines completed for this project in the Calistoga area indicate fairly shallow conductive zones in the vicinity of the geyser on Tubbs Lane (lines R5, R7 and R8). This conductive zone or zones extends southeastward at least as far as Greenwood Avenue where it is deeper (Line R3). No lines were run west of the geyser, however. Unfortunately, it was not possible to conduct these surveys within the City of Calistoga where hot water is also known and is used at a number of resorts. However, conductive zones were also located on lines just north of town (lines R6 and R9).

Limited work, located about a mile southeast of Calistoga, revealed lower it.

conductivity values, at least on the lines run (R4 and R4 extension). The lowest resistivity values of 40-50 ohm-feet in this area are not favorable for hot water. Nevertheless, warm water may be present in this area also. 
In general, the resistivity pseudo-sections indicate an irregular distribution of the conductive zones and, therefore, the hot water resource. Some of the lines, notably R3, do not show any lower depth limits for the resource. In order to determine this, a larger electrode spacing would have to be used.

\author{
Comparison of Geophysical Traverses \\ on Greenwood Avenue and on Tubbs Iane
}

Comparison of different types of geophysical data covering the same area is a necessary part of the interpretation process. If data for two or more techniques tend to corroborate each other, the interpretation is much more certain. In this study, a good comparison of different types of data can be made on two lines - Greenwood Avenue and Tubbs Lane.

Plate 7 shows a comparison of electical resistivity data (Sections $A$ and $B$ ), seismic refraction (section $C$ ), and gravity and ground magnetic lines (D and E, respectively) on Greenwood Avenue. Plate 8 is a similar set of sections and profiles for Tubbs Lane, except that there is no seismic section. The electrical resistivity data on both Plates 7 and 8 include the dipole-dipole pseudo-section (A) and a two-dimensional resistivity interpretation of this section (B) for a maximum dipole spacing of $N=6$ done by the University of Utah Research Institute (Duncan Foley, written communication $: 1980)$. 
A comparison of the sections and profiles on Greenwood Avenue indicates some possible correlations. For example, the zone of lowest electrical resistivity (10 ohm-feet) that represents possible hot water located below a depth of 200 feet between stations 18 and 34 (Plate 7, Part B) corresponds approximately with both a fairly steep gravity gradient (Part D) and a change in the seismic section (Part C) (layer 3, present on the south part of the section, terminates in this zone). Also, the resistivity low is bounded on the northeast by a possible steep contact with a zone of higher resistivity (75 ohm-feet). The contact is: somewhat northeast of the center of the steep gravity gradient and also near a low velocity zone in the basement rocks, and, therefore, could be interpreted as a fault. Both the magnetometer and the gravity profiles show small negative anomalies located near the intersection with Grant street (stations 32-42), but whether or not these anomalies have the same cause and whether or not they are related to the geothermal resource is uncertain.

The geophysical traverses on Tubbs Lane (Plate 8) are somewhat similar in appearance to those on Greenwood Avenue: On these traverses, however, the zones of lowest electrical resistivity $(5,10$, and 20 , ohm-feet) from the model (Plate 8, part B, between stations 12 and 40) correspond approximately to a small negative gravity anomaly (C) in the same area, but the small negative magnetic anomaly (D) is offset somewhat to the northeast on this line. In this comparison, also, the northeastern boundary of the resistivity 
low (20 ohm-feet) is near the center of the steep gravity gradient, which could represent a possible fault.

Composite Geophysical Anomaly Map

Plate 9 is a compilation of some of the more important observations from geophysical data in the vicinity of the known hot water zones near Calistoga. This plate shows anomalies in the geophysical data that might be related to the hot water resources directly or to geologic structures that control the location of the resource. Included on the plate are 1) partial contours of the lowest values of apparent resistivity, 2) contacts or discontinuities indicated by the resistivity data, 3) an alignment of relatively steep gravity gradients, 4) discontinuities in the seismic refraction data, and. 5) contours of maximum temperatures from wells at depths of from 200 to 300 feet.

The resistivity values shown on the contours of Plate 9 do not represent one particular electrode spacing, rather the contours are smoothed to approximate the lowest values disregarding depth. As discussed in the section of this report on electrical resistivity methods, low resistivity values probably represent relativly hot water. Northwest of Greenwood Avenue, the resistivity low, as marked by the $10 \mathrm{ohm}$-feet contour, correlates approximately with the known hot water, zone (see Plates 9 and 12 ). The resistivity anomaly: has been left open southeast of Greenwood Avenue because 
reliable data were not obtained in this area. A resistivity low also characterizes the hot water zone northeast of Calistoga (15 ohm-feet contour), but this anomaly is open on the south side because of a lack of data in this area.

Some of the anomalies and anomaly alignments suggested by the seismic, resistivity, and gravity data shown on Plate 9 may represent faults or other contacts as discussed in previous sections of this report. However, because the distribution of the data is inadequate in much of the area to provide corroborative evidence, no fault trends are indicated on the plate with the exception of one gravity anomaly alignment. This alignment is a relatively steep local gradient found on both the Tubbs Lane and Greenwood Avenue lines that could represent a fault or dipping contact. 
of the geophysical methods used in this study in the Calistoga area, the resistivity data apparently were found to be the most useful for delineating the geothermal resource. A positive correlation was found between zones of high electical conductivity where available and known areas of hot water from temperature measurements in wells. Possible extensions of the hot water zones, both in plan and at depth, were also found on some of the lines surveyed. Two such areas, located on Greenwood Avenue and Brannan street, respectively, are scheduled to be evaluated by drill holes.

Magnetic data are affected chiefly by serpentinite in the Franciscan basement rocks and possibly by andesite flows in the Sonoma Volcanics in some places, but Franciscan "greenstone" may also cause some of the smaller anomalies. A low-amplitude negative anomaly could be associated with that part of the geothermal field near the old Faithful (California) geyser, but this is uncertain.

Gravity data indicate a large low-density structure or mass located southwest of Calistoga. This structure or mass could include possible zones favorable for geothermal phenomena: Iocally, gravity data reflect the thicknesses of the Cenozoic rocks above the basement rocks and also suggest at least one possible fault zone. A small gravity low could be associated with the geothermal field near the geyser and to the southeast, as is the case with the magnetic anomaly mentioned previously, or it-could represent the thickness of valley fill in this area. 
The seismic refraction lines have mapped seismic velocity interfaces in the valley near calistoga. Some of the seismic layers detected can be identified ffor example alluvium above the water table and Franciscan basement rocks), but others will only be identified if the units can be recognized in future drill holes in the area. Judging from the seismic results, the basement rocks become deeper toward the southwest in the valley. There is also evidence for faults on some of the seismic sections. In some examples, these fault zones and those suggested by resistivity data, might be related to the apparent boundaries of the geothermal field.

The basic geophysical data used in this report are available on request from the California Division of Mines and Geology, 2815 "O" Street, Sacramento, California 95816. 
SHALLOW HOLE TEMPERATURE SURVEY

During the course of geothermal studies at Calistoga, it was decided that combined testing of the microacoustic and shallow temperature probe techniques should be carried out. Both techniques require that a probe hole, approximately six feet deep, be provided for each test site. Holes drilled were used alternately for temperature and then for acoustic probes. So far, the microacoustic method has not yielded conclusive results.

There are several accounts in the literature of the successful use of shallow temperature probes to better define the location of geothermal resource at depth (Chaturvedi, 1977; LeSchack and others, 1978). In theory and in favorable situations in practice, it is possible to take very precise temperature readings in a group of shallow (6 feet or 2 meter) holes, drilled on a grid pattern, to develop a shallow temperature variation pattern that will correspond very favorably with the temperature pattern at depth. Magnitude of the variations is greatly subdued near the surface and, for that reason, a precision temparature reading device, which permits the user to detect small incremental differences, is, required. A map, developed by drawing contours. on the shallow temperature measurement points, will often reflect areas of highest heat in the deeper subsurface and can be helpful in selecting a drill site to tap a potential geothermal resource. The big advantage in using this technique, as compared to many others, lies in its relatively low cosst. In most cașes, use is made of accurately calibrated thermistors that are placed in the earth, in drill họles, and allowed to 
stabilize for a period of time, sometimes over night, before the readings are taken. Corrections are applied for such variables as large differences in elevation, local topographic variation, diurnal variations, albedo, differences in soil moisture, roughness, etc. (see LeShack and others, 1978).

The northern part of Calistoga has provided a unique testing situation for the method because of the occurrence of very shallow groundwater (4-9 feet) under slight artesian pressure. Test holes augered to the water table first transmit a hissing sound, indicating gas escaping from the top of the water surface; this is followed by a quiet flow of water into the hole.

The heat probe used in these tests consists of a carefully calibrated thermistor that was fixed to protrude approximately 1 inch $(2.5 \mathrm{~cm})$ from the bottom of a 6.5 foot length of $1 / 2$ inch PVC pipe. The thermistor and the end of the pipe were covered with a thin rubber membrane (baloon) that provided a water-tight cover, but still provided maximum surface and heat contact with the surrounding medium by "collapsing" around the thermistor when the probe is immersed in water or loose soil. Thermistor leads were fed through the pipe to the surface where they could be attached to the read-out instrument, a Simpson 460D, series 3, meter. Readings were taken with the thermistor immersed in water or in loose soil at the bottom of the hole. The top of the probe pipe was plugged, with clay. For readings in dry holes, backfill made up of material removed from the hole during excavation and protected from heat or drying, was placed back in the hole around the outside of the probe near the sensor to provide good heat coupling. Time was then allowed for 
temperature stabilization. For this study, corrections for elevation, topography, albedo, etc. were not considered necessary because all sites were on flat ground with nearly identical characteristics.

Temperature probe stabilization was tested in the calistoga area both above and below the water table. Results show that stabilization is nearly complete, in a two meter hole above the water table, in approximately 35 minutes. Stabilization below the water table is much more rapid and is complete in only a few minutes. For purposes of the testing performed at Calistoga, readings were taken at several time intervals leading up to stabilization at 35 minutes which was considered a standard reading point. Final readings were taken for each station at double the required stabilization time, or about 70 minutes. No evidence of groundwater movement of the near surface waters was, noted with the possible exception of the easternmost station (6.60). In that one instance, a small fluctuation of temperature readings was noted toward the end of the testing period, after about two hours.

In general, the results obtained using the shallow temperature probe method agree extremely well with those obtained using the well-established resistivity technique. Figure 15 shows the preliminary contour map developed as a result of shallow temperature work performed by CDMG in the Bennett Lane area of calistoga: The cross section is a reduced version of the resistivity profile (described elsewhere in this report) developed by CDMG using new data from readings taken along Bennett Lane.. The zone of highest heat, as 


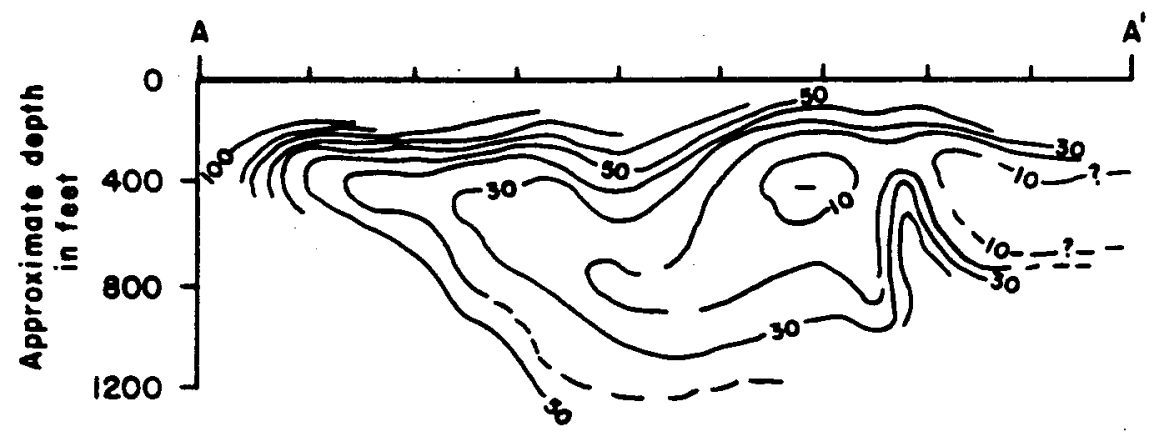

FIG. 15-A Resistivity section along Bennett Lane, Section A-A'. Contours are in ohm-feet.

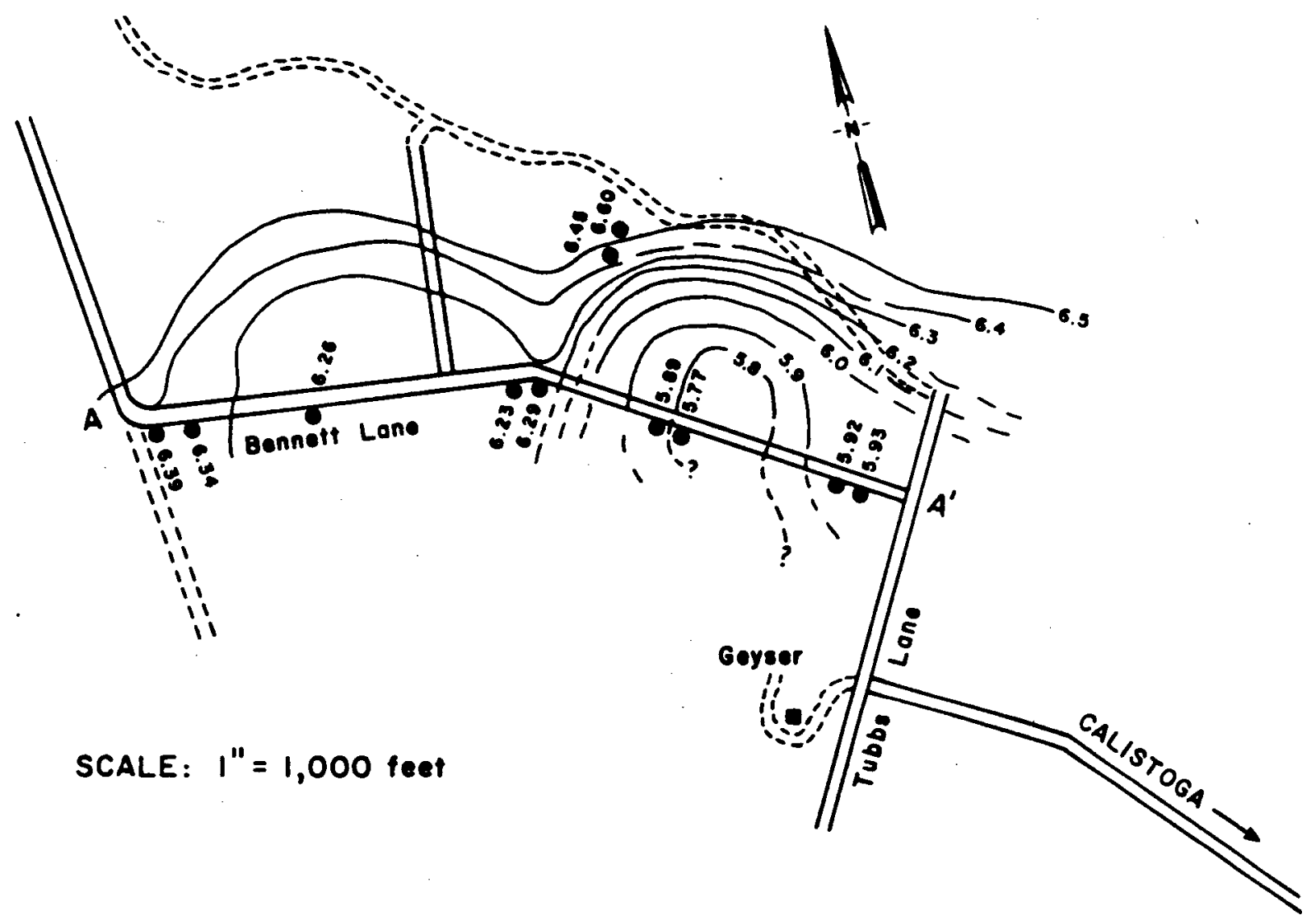

FIG. 15-B Shallow temperature thermistor reading contour map, Bennett Lane vicinity, Calistoga. Contour numbers represent thousands of ohms. $\left(162.5 \Omega=1{ }^{\circ} \mathrm{C}\right)$

FIGURE I5 SHALLOW TEMPERATURE THERMISTOR READINGS COMPARED TO RESISTIVITY RESULTS -- BENNETT LANE AREA Decreasing numbers in each figure are indicative of higher temperofures or the effects of higher temperatures.

BY: C. F BACON 
indicated in both the temperature map and the resistivity section, lies between the Bennett Lane midpoint curve and Tubbs Lane. A second area with high heat lies west of the curve. Notice that the higher heat zones outlined on the temperature probe map (indicated by lower probe resistance) coincide very well with the low resistivity areas depicted on the resistivity profile. Because the effects of heat are known to cause a lowering of resistivity of the rocks in a thermal area, these two methods provide corroborative results.

The study here described has been a test study to determine the usefulness of the shallow Eemperature probe method. Although the area studied has turned out to be a special case because of shallow ground water, testing done, both above and below the water table in the area, has shown that results in the two situations are comparable. The effect of a stable body of groundwater in the neär subsurface is believed to have a masking effect on the amount of variation in temperature that would be measurable near the surface due to deep subsurface temperature variations. Nevertheless, small lateral variations in temperature are measurable and are believed to be significant in reflecting deep seated temperature variation. The method is therefore planned:for extensive use in CDMG's further studies of low and moderate temperature geothermal resource areas. 
HYDROLOGY AND GROUNDWATER QUALITY AND ITS RELATION TO

GEOLOGIC STRUCTURE AND FORMATIONS AND TO RESOURCE ASSESSMENT

Locations and Extent of Study Area.

Two hundred and six water wells were sampled by CDMG in the upper part of Napa Valley surrounding the town of Calistoga. That part of the basin of interest to this study included an area bounded by Bennett Lane and its intersection with Highway 128 on the northwest to Larkmead Avenue on the southeast.

Purpose and Scope

The purpose of this study is to assess the occurrence and quality of ground water in the upper Napa Valley basin and relate the occurrence of waters of particular quality and temperature, to geologic formations and structure in the area. Both literature sources (Barnes, 1970; White, Barnes, and $O^{\prime N e i l, ~ 1973 ; ~ W h i t e, ~ 1957 a ~ a n d ~ 1957 b) ~ a n d ~ w a t e r-q u a l i t y ~ d a t a ~(F a y e, ~ 1973 ; ~}$ Bader and svitek, 1973) from the Napa Valley Area indicate that sodium-chloride and sodium-bicarbonate waters are associated with faulting. The association of faulting with ground waters of particular quality provides a mechanism for extrapolating faults into areas where the underlying geology is not readily apparent but where sufficient water-quality data are available. Similar hypothetical extensions can be made with respect to 
ground waters associated with particular formations whereby formational waters with differing chemical constituents can be used in defining structural boundaries and/or source area limits. In the Calistoga area, the occurrence of sodium-chloride and sodium-bicarbonate waters was used to detect faults in older rocks which underlie undisturbed alluvial deposits of Holocene age, and the existence of the magnesium-bicarbonate water was used to detect ultramafic rocks at depth.

Several investigators (Waring, 1915, Kunkel and Upson, 1960, and Faye, 1975) have suggested that the occurrence of hydrothermal waters in the Calistoga area has been associated with and/or controlled by faulting. Generally, all hot water wells in the Calistoga area have a high sodium chloride content. Barnes (1970) describes water containing high concentrations of sodium, chloride, bicarbonate, and boron ions that issues from springs along known or inferred fault zones in the western Coast Ranges of North America. In northern Napa Valley, a chemical analysis of water from Napa Soda Springs indicates the occurrence of sodium chloride water. The springs issue from orifices along the inferred strike of the soda Creek fault. Sterns, Sterns, and waring (1937) also implied an association between faults and the occurrence of hot springs in the Calistoga area.

As has been noted, flowing wells in the Calistoga area are with few exceptions, hydrothermal and yield sodium chloride water. Considering the relation of silica solubility to water temperature (Fournier and Rowe, 1966), it is possible that hot sodium chloride water, rising from depth, along 
faults mixes with downward-percolating cooler water causing the precipitation of silica and the subsequent cementation of material at the mixing interface. White, Muffler, and Truesdell (1971) indicate that such "self-sealing" phenomena are common in hot-water dominated hydrothermal systems with temperatures in excess of $150^{\circ} \mathrm{C}\left(302^{\circ} \mathrm{F}\right)$. Such activity, taking place over an area of several square miles, could produce a zone of relatively impermeable material that would confine sodium chloride water under a potentiometric head.

The scope of this study includes the tabulation (Appendix A) and preliminary geologic and ground-water quality data for the Calistoga area. A second separately funded study, currently in progress, will utilize water chemistry data in a concerted effort to help delineate subsurface geologic formations and structures. A preliminary map (Figure 16) and commentary on some of the findings from that study are presented here. A separate final report on the results of that study will be presented to DOE upon completion.

\section{Previous Work}

Waring (19.15) cataloged the various hot springs and "health resorts" located in the study area in the early 1900's. More comprehensive water-resources studies were completed by Bryan (1932), Kunkel and Upson (1960), Bader and Svitek (1973), and Berkstresser (1968). Regional investigations of ground-water quality, containing data and conclusions 
pertinent to the Napa Valley area, include Barnes (1970), Barnes and O'Neil (1970), Roberson and Whitehall (1961), White (1957a and 1957b), White, Hem and Waring (1963), White, Muffler and Truesdell (1971), White, Barnes and O'Neil (1973), and Garrison (1972).

Faye (1973) developed a digital computer model of ground-water flow through the alluvium in northern Napa Valley and investigated the quality of ground water relative to irrigaton and domestic supplies. Faye (1975, unpublished thesis) also attempted to correlate ground water quality to geologic formations and structure in the Napa Valley. Lack of an adequate water-well data base prevented the validation of Faye's study (Faye, 1980 pers. Communication) and this current geochemical study is an extension of Faye's work.

Ultramafic Rocks, Franciscan Formation, and Sedimentary Rocks of Cretaceous Age

\footnotetext{
The "ultramafic rocks, Franciscan Formation, and the sedimentary Cretaceous rocks are saturated below the water table, but yield very little water to wells. This restricted ability to yield water to wells results from a very low average hydraulic conductivity which, for these rocks, is probably in the order of $10^{-4}$ fpd (feet per day) or less (Faye, 1973). Ground water flow patterns in these units generally conform to the topographic slopes In the

except where interrupted by faults or other barriers that impede ground-water
} 
movement. The few well records available indicate that confined conditions occur locally within this group of rocks (Faye, 1973).

Sonoma Volcanics

The tuff breccia, scoriaceous material, and sedimentary deposits that compose a relatively small part of the Sonoma Volcanics generally are more permeable than the older ultramafic, Franciscan, and sedimentary Cretaceous Rocks and yield, on the average, greater quantities of water to wells. The hydraulic conductivity of the breccia, scoria, and sedimentary deposits is probably on the order of $10^{-2}$ to $10^{-3}$ fpd. Other units of the Sonoma Volcanics, most notably the andesitic, basaltic, and rhyolitic flow rocks and the hydrothermally altered material, yield little water to wells and probably have a hydraulic conductivity on the order of $10^{-4}$ fpd or less (Faye, 1973 ).

water in the Sonoma Volcanics commonly is confined, though few wells penetrating this unit actually flow at land surface. of the wells that do flow, most are located in the Calistoga area, and the majority of these discharge hydrothermal water. Density differences between the hydrothermal water and the cooler ground water are caused by high subsurface temperatures and pressures and probably contribute to the upward movement of hydrothermal water and to the potentiometric heads observed at flowing, hot water wells and "geyser" wells, in the Calistoga area. On the other hand, the relation of depth to the occurrence of confined hydrothermal water in wells in the 
Calistoga area suggests that the occurrence of hydrothermal water may be associated with a confining zone. The fact that flowing wells, discharging hydrothermal water, occur in the project area is probably due to the combined influence of a local confining zone and the geothermally induced density differences of ground water (Faye, 1973).

\section{Al luvium}

The alluvium is by far the best aquifer in the project area and is locally capable of providing water to wells at rates of more than 3,000 gpm. The average hydraulic conductivity of the alluvium, as determined from drillers' logs and from specific-capacity data ranges from 10 to more than $100 \mathrm{fpd}$, depending on the percentage of sand and gravel in the alluvial deposits. The distribution of sand and gravel is irregular and variable, but the average values of hydraulic conductivity follow a general pattern; hydraulic conductivity increases from north to south and from the peripheries of the valley toward the Napa River. Thus, along any section that crosses the valley, the average hydraulic conductivity near the Napa River is virtually always the highest, and ranges from approximately 40 fpd near Calistoga to more than 110 fpd near Oak Knoll Avenue (Faye, 1973).

Except for small localized areas of semiconfinement, water in the alluvium is unconfined and moves under a natural hydraulic gradient that conforms in a general way to the surface topography. 
The thickness of the alluvium increases progressively from north to south, and from the periphery of the valley toward the Napa River. Recharge to the alluvium occurs by infiltration of rain, percolation from streams, and subsurface inflow from older rocks. Discharge from the alluvium occurs by evapotranspiration, ground-water flow to the Napa River, pumping of wells, and subsurface outflow across the southern boundary of the project area.

Relationship of Water Chemistry to Structure

As mentioned previously, several studies have suggested that there is a relation between faulting and the occurrence of hydrothermal waters in the Calistoga area.

Faye (1973) suggests that sodium-chloride water may be associated with faults. Barnes (1970) indicates that similar waters in the Western Coast Ranges "are found issuing from known or inferred faults." White, Muffler, and Truesdell : (1971) state that hot-water systems dominated by sodium-chloride type waters "are usually found in permeable sedimentary volcanic rocks and in competent rocks such as granite that can maintain open channels along faults or fractures."

Faye, (1975) presented data to support the hypothesis that "Sodium-chloride, sodium-bicarbonate, and related type water were associated 
with faulting in the Napa Valley area and this relationship was further supported by the lack of association of both sodium-chloride and sodium-bicarbonate waters with any one particular geologic formation or unit. Faye (1975) concluded that his preliminary water chemistry data suggests the occurrence of a major fault down the topographic axis of the Napa Valley.

CDMG has undertaken to perform a detailed water sampling program in the Calistoga area in the upper Napa Valley. A major reason for conducting the program is to see if a correlation exists, as Faye and others have hypothesized, between water quality and structure. We are interested in learning the extent of the controls on the occurrence of hydrothermal fluids. The detailed water analysis will not be completed until the data from the CDMG Calistoga drilling program is available. By combining the information obtained from drilling and testing the series of strategically placed drill holes with information gleaned from the sampling of 206 water wells in the area, a series of maps will be prepared with contours drawn on chemical constitujents in the waters. It is expected that water barriers between different water types, such as those created by faults in the subsurface, will become apparent from these maps. These. maps will be completed and presented in the final adendum to this report on the work in the Calistoga area, expected to be completed in early 1981. 
Preliminary Interpretation of Water Well Chemistry Data

The information presented in this subsection represents some preliminary results obtained from a separately funded ongoing study of the geochemistry of water samples taken from wells in the Calistoga area. A more complete account of the results of the geochemical study is planned for the addendum to this report to be submitted upon completion of CDMG's drilling program.

The 206 water wells sampled in Calistoga were plotted on an enlarged 7 1/2' base of the area. Overlays of various chemical constituents were made; of particular interest were calcium, magnesium, sodium, and bicarbonate. These individual overlays were plotted in parts per million and contoured using 10 to $25 \mathrm{ppm}$ contour intervals dependant upon the range of values for each chemical constituent.

Calcium - Values ranged from a low of 1 ppm to 234 ppm and were contoured on a $10 \mathrm{ppm}$ interval. Data show a broad linear trend parallel with the axis of the valley with higher values associated with the Northeast side of the valley versus the Southwest side. Higher values are associated with known hot water, which is to be expected, but data do tend to indicate a split coincident with the valley axis.

Sodium - Values ranged from 0 to $282 \mathrm{ppm}$ and were contoured on a $50 \mathrm{ppm}$ interval. "Data" show linear highs associated with the northeastern side of Napa valley. Again, sodium values are related to water temperature but an 
interpretaion of a ground water barrier is warranted, coincident with the axial trend of the valley. Sodium highs are concentrated around known hot water wells, but the sharp falloff of sodium values toward the valley margins could be indicative of a relatively linear source for the hot water, such as upwelling along a fault, with little outward migration.

Magnesium - Bicarbonate - These two chemical constituents were individually contoured, but are combined in this discussion because typically Mg-HCO are not temperature dependant but probably are indicative of water source. The Mg overlay (Figure 16) shows a very sharp linear high associated with the southwest side of the valley and a sharp abrupt break in values approximately coincident with a geophysical anomally discovered in a SW-NE traverse along Tubbs Lane.

\footnotetext{
Barnes \& O'Neil (1969) associated magnesium-bicarbonate water in the Coast Ranges with serpentine and ultramafic rocks. Thus, the Mg high depicted on Figure 16 probably represents water that has its source in or in contact with ultramafic rocks underlying the Sonoma Tuff. This high Mg water could indicate: (1) ultramafic rocks localized at a shallow depth along the north part of the southwestern side of the valley, (2) water has its source to the northwest and has picked up Mg content by downslope movement toward the valley. Either way, the localized Mg anomaly tends to support a groundwater bàrier, structural or lithologic, between the high Mg content waters and the aquifers lying along the central and northeastern side of the valley.
} 
Preliminary analysis of the water well geochemistry data seems to indicate several common trends between individual constituents. In particular, both calcium and sodium show a broad linear trend associated with the northeastern side of the valley and coincident with known wells producing hot water. This anomaly is to be expected, but interestingly both show a rapid decrease in concentration toward the northeastern margin of the valley coincident with a more general, but still significant, drop in concentration along the southwestern margin of the valley. The rapid decrease along the northeastern margin may help define the hot water resource boundary, as being indicative of a relatively narrowly confined source (that is, a fault). With a narrow linear conduit within the valley, one would not expect much migration upslope against a groundwater surface flowing from Northeast to Southwest toward the Napa River. .

Additionally, linear trends between water type $\left(\mathrm{Mg}-\mathrm{HCO}_{3}\right)$ and mineral assemblages (Na-Ca) contours show a common spatial discontinuity along the southwest side of the valley that may define the southwestern margin of a hot water resource basin.

In addition to the preliminary maps showing the plots of contours of chemical constituents in the waters, several preliminary overlay maps were made showing outlines of areas containing waters predominantly of one or another of four regimes. These include: sodium bicarbonate, sodium chloride, calcium bicarbonate, and magnesium calcium bicarbonate. Results 


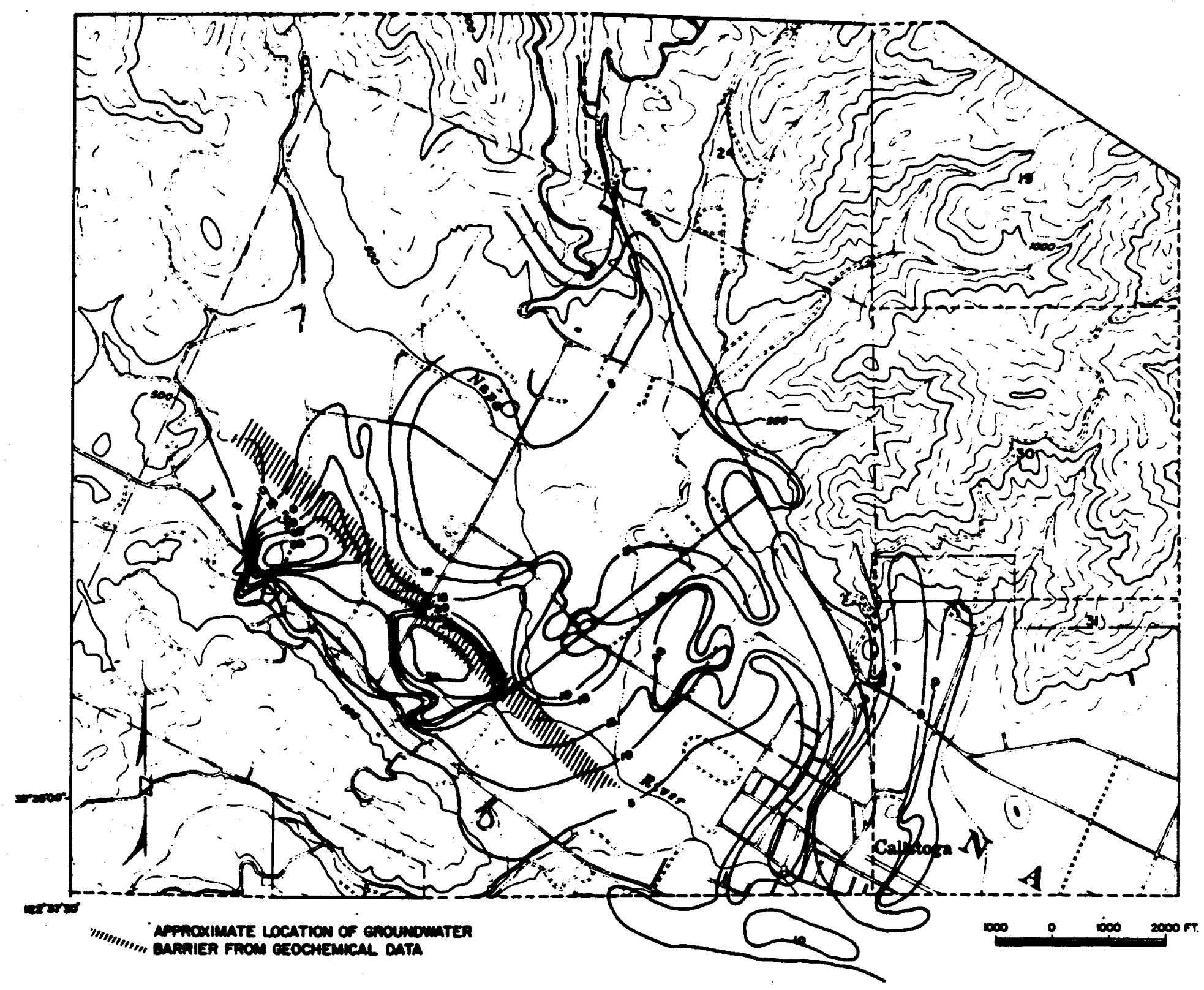

PRELIMINARY CONTOUR MAP SHOWING MAGNESIUM CONTENT IN GROUNDWATER FOR THE CALISTOGA STUOY AREA

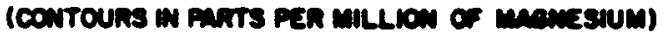

By G. G. Toylor

FIGURE 16 
from these plots again show strong linear trends--and linear boundaries between water types--that parallel the axis of the valley. This further supports the concept that subsurface water barriers are present within the valley and that they most likely are fault controlled. In addition to an anomally with a trend and location similar to the one shown in Figure 16, these preliminary plots also show a major boundary marking the break between waters of different chemical constituents that trends northwest-southeast approximately along the center of the valley.

Interestingly, the very pronounced breaks seem to occur in the deeper waters between the 150 and 200 feet depth levels. Plots attempted for waters at shallower depths, 50-100 feet, do not clearly show large, well defined zones, but rather smaller randomly located and oriented zones. This fact also tends to support the idea of major concentrations of waters of certain chemical types welling up along faults in the deeper subsurface where they are also separated by fault related barriers. The near surface waters are apparently diffused and may be intermixing so that no major well-defined zones are apparent.

Also present on some of the preliminary overlay maps are relatively sharp boundaries or sharp changes in contours that trend roughly normal to the axis of the valley. These are not as continuous or as prominent as are the trends that parallel the axis of the valley, but, they are strong enough and sharp enough to be interpreted as probably associated with cross cutting faults. Such a trend can be seen on the sample map of Figure 16 near the center of 
the map and beginning just southeast of the sharp drop off in magnesium content contours. The trend is northeastward from that area.

It appears from this study that the subsurface in the Calistoga valley area is "partitioned off" by a series of water barriers that trend both parallel to and approximately normal to the axis of the valley. These barriers, in at least some of the instances, are approximately coincident with breaks in geophysical lines, where these are intersected--which strongly suggests that the barriers may represent the locations of faults not readily recognized at the surface. This may help explain why wells in certain locations in the main Calistoga resource area fail to produce useful amounts of hot water, while others nearby flow artesian in large quantity.

It also appears that the chemical analyses can help provide information from which to delineate the mârgins of the thermal area. The rapid drop off of sodium and calcium that coincides well with the boundaries of the hot water reservoir have, in this preliminary study provided such corroborative information. Although these data are preliminary and from an ongoing separate study, results so far indicate that the geochemical techniques here described can be a powerful tool in the study of a geothermal area. A more complete analysis of the results of our study will be available for inclusion in the adendum to this report planned for submittal after completion of CDMG's drilling program. 
In summary, from our preliminary results, it appears that in geothermal areas such as Calistoga, where a strong water well data base is available, it is profitable to perform geochemical analyses similar to those described above to locate water barriers that can represent the locations of subsurface faults or structures, and to delineate the boundaries of the resource area. 
In the exploration for geothermal fields, geochemistry plays a most important role among the branches of the geological sciences. The primary consideration in the development of a geothermal system is the temperature, size, and type of thermal reservoir. The chemical composition of a thermal water provides the only indirect means of quantitatively estimating the temperature of the thermal reservoir and determining the type of thermal system. The concentrations of silicon, sodium, potassium, calcium, and magnesium (for correctional purposes) in thermal waters indicate the temperature at which the water was last in equilibrium with rock in the thermal reservoir.

Early in the investigaton of Calistoga's geothermal resource, California Division of Mines and Geology (CDMG) found that there were many "hot water" wells in an approximately 5-6 square mile area. It was estimated that as many as 100 hot water wells had been drilled there. Calistoga appeared to be a near ideal location to apply geochemical techniques to discover properties of the geothermal resource.

CDMG decided that a door-to-door canvassing of well owners would be the most efficient and productive way to discover and sample geothermal wells in 
the area. California Division of Oil and Gas (CDOG) also had an interest in a water well survey at Calistoga. A cooperative joint study was initiated. CDOG provided most of the field team for the project.

The field team began the well sampling survey at Calistoga in early March 1980. Sampling continued intermittently for the next three months. A set of goals for the water well sampling project was established:

1. Determine the mineralogical water quality of fresh and geothermal aquifers at Calistoga.

2. Establish the extent of the geothermal reservoir.

3. Determine temperatures of aquifers via direct measurement and geothermal analysis.

4. Determine reservoir relationship to subsurface geology and hydrology

Sufficient funds were not available in the Department of Energy (DOE) supported Low and Moderate : Têmperature Geothermal Resources of California project, therefore, the geochemical water well survey was proposed as a complement to the DOE supported project

In this report, the intention is to give an account of the number of wells sampled, the special sampling, filtering, and preservation techniques used, the temperature measuring methods employed at calistoga, and the details of th: analytical techniques used. Some of the detailed interpretations.. of the chemical analysis and the geothermometrical calculations are reported here; others will be reported at a later date. 
A total of 206 water wells were sampled in the Calistoga area. One hundred forty-two of the sampled wells had measured temperatures of less than $25^{\circ} \mathrm{C}, 40$ of the wells had temperature measurements between $25^{\circ}-50^{\circ} \mathrm{C}$, and $^{\circ} 24$ wells had measured temperatures over $50^{\circ} \mathrm{C}$. Plate 10 shows the location of the sampled wells. Wells and associated chemical analyses were assigned sequential reference numbers from G-001-80 to G-206-80. The reference numbers have no significance other than the sequence in which the wells were sampled. Note that only the central portion of each reference number appears on Plate 10 i.e. the numbers $001-206$.

Plate 12 is a compilation of locations of 133 "hot water" wells around Calistoga. Sources of well location information include the CDMG's water swell survey, published and unpublished literature, and a down hole temperature survey by Occidental Geothermal, Inc.

It is very difficult to define the term "hot" in low and moderate temperature geothermal resource areas. For the sake of simplification, $25^{\circ} \mathrm{C}$ was chosen as the temperature limit at Calistoga, above which a water well is labeled "warm" or "hot".*

*Note: For the purpose of preparing Geothermal Resources Map of California, CDMG has chosen $20^{\circ} \mathrm{C}$ as the starting temperature for warm water. But, in practice, at Calistoga, CDMG found that a $20^{\circ}-22^{\circ} \mathrm{C}$ temperature is easily reached by water in metal pressure tanks 
standing in the sun. Therefore, a starting "warm" temperature threshold of $20^{\circ} \mathrm{C}$ would be misleading. Hence, $25^{\circ} \mathrm{C}$ has arbitrarily been chosen as the cutoff point for a geothermal well for the purpose of this investigation only.

Sampling Technique

The purpose of sampling geothermal waters is to determine all the properties of the water in a natural state. Some of the constituents in these fluids are unstable and change with time. Unique problems are encountered because of this instability and/or high concentrations of some constituents. For example (a) silica may occur at concentrations up to several hundred ppm (parts per million). Therefore, silica may polymerize during sample storage and not react with molybdate color-forming reagents (while analyzing for silica) or precipitate with concurrent loss of coprecipitating elements; (b) $\mathrm{As}^{+3}, \mathrm{Fe}^{+2}$ and other variable valence ions may be rapidly oxidized upon aeration at elevated temperatures, in which case valence species determinations would be precluded; (c) sulfides may be oxidized rapidly by dissolved oxygen; (d) $\mathrm{H}_{2} \mathrm{~S}$ gas is unstable in the presence of moisture, oxygen, and to a lesser extent, ultraviolet light; (e) pH may rise rapidly (up to two orders of magnitude) due to exsolution of dissolved $\mathrm{CO}_{2}$, or decrease due to $\mathrm{CO}_{2}$ uptake or $\mathrm{H}_{2} \mathrm{~S}$ oxidation. 
Because of the instability of the dissolved constituents of geothermal fluids, immediate filtration of the hot water is necessary without allowing degassing of waters supersaturated with $\mathrm{CO}_{2}$.

$\mathrm{H}^{+}+\mathrm{HCO}_{3}^{-} \quad \mathrm{H}_{2} \mathrm{O}+\mathrm{CO}_{2}$

Thus, the main changes in the geothermal samples result from loss of carbon dioxide, oxidation of hydrogen sulfide and ammonia, oxidation and precipitation of arsenic, iron, and manganese, loss of calcium ion as calcium carbonate precipitates, and precipitation of silica. The danger is always with precipitation. Once precipitates are formed, there is no way to restore the initial composition of the sample.

Plastic bottles used for sampling are permeable to oxygen, which is evidenced by continuous oxidation of iron. from the ferrous to the ferric state. They are also permeable to hydrogen sulfide, which is evidenced by the smell in the storage cabinets. Some constituents like sodium, potassium, and chloride are stable but many more are unstable (pH, iron, manganese, arsenic, carbonate, bicarbonate, ammonia, hydrogen sulfide, calcium and sulfate) and therefore one or more preservation techniques are used. Plastic bottles are used in this study only because of convenience.

As Presser and Barnes (1974) suggest, the information needed for a particular study and the desired accuracy should be established first and then appropriate sampling techniques should be selected. 
Before using the plastic bottles for sampling, they were first soaked for a week in 108 nitric acid and then soaked for a week in deionized distilled water.

Special plastic plexiglass filters were manufactured after the design obtained from U.S. Geological Survey, Menlo Park. A 0.45 micrometer Gelman, $90 \mathrm{~mm}$ diameter membrane filter, was used to filter the samples in conjunction with air pressure from a bicycle pump. The filter was rinsed with distilled deionized water immediately prior to use. The plastic bottles were rinsed first with the filtered sample and then the filtered sample was collected.

The water sample collected at each site was sub-divided into four separate bottles: one $125 \mathrm{ml}$ filtered nonacidified for chloride and fluoride determination; one $250 \mathrm{ml}$ filtered nonacidified sample for carbonate, bicarbonate, and total dissolved solids (T.D.S.) deternination; and one $125 \mathrm{ml}$ filtered acidified ( $1 \mathrm{ml} \mathrm{HCl}$ in $125 \mathrm{ml}$ sample) for sulfate determination.

\title{
Fiela Analysis
}

\begin{abstract}
Temperature measurements were obtained with either a total immersion, maximum reading, mercury-in-glass thermometer or with a conventional mercury-in-glass thermometer. "In most of the cases, pipes coming out of wells were directly connected to pressure tanks next to the well-heads.
\end{abstract}


Because there is no other feasible way to sample, water was taken from these pressure tanks. Water was allowed to flow for considerable time after water pumps were started. When we were sure of sufficient water being allowed to flow freely, a clean one-gallon plastic sample bottle was filled after rinsing several times with the sample water. Then the temperature of water was measured at the mouth of the faucet while water was running out. In some cases, a temperature-probe, manufactured by Gisco-Keck Geophysical Instruments (\#DR-789 Digital Temperature Meter), was used for determining the down hole temperature measurements. In very few cases, where we could not sample the water, we took the owner's word for the temperature or relied on the published and unpublished literature.

An "Ionalyzer" specific ión meter model 407-A, manufactured by orion Research, was used to measure $\mathrm{pH}$ of the water samples. The meter was calibrated with pH buffers 7 and 4 . Batteries of the meter were charged every alternate day so that no fluctuations in reading could occur. $A$ combination $\mathrm{pH}$ electrode was used for $\mathrm{pH}$ measurement. It was cleaned with deionized distilled water before and after its use.

Salinity and conductivity were measured with the $\mathrm{S}-\mathrm{C}-\mathrm{T}$ (salinity-conductivity-temperature) meter, model 33, manufactured by Yellow springs Instrument Co. Salinity measurements are manually temperature compensated by direct dial. Conductivity measurements are not temperature compensated; however, a temperature function is provided on the instrument to aid with calculation of corrections. Salinity is expressed in percent ( 8 ) 
and conductivity as micromhos/centimeter (umhos/cm). Conductivity measurements are the electrical conductance the sample would show if measured between opposite faces of a $1 \mathrm{~cm}$ cube. Salinity is the number of grams of salt per kilogram of sample. Zero of the S-C-T meter is adjusted first and then the meter is calibrated before taking the reading by turning the Mode control to Redline and adjusting the Redline control so that the meter needle lines up with the red line on the meter dial. Readings are taken after plugging the probe into the probe jack on the side of the instrument and putting the probe in the sample to be measured.

Chloride concentration was determined semiquantitatively in the field with the help of "Quantab" chloride titrator tabs.

\section{Laboratory Analysis}

The results of field and laboratory analyses are presented in Appendix-A. All of the cation analyses were done by Inductively coupled Plasma Spectrometer at the Earth Science Laboratory of the University of Utah Research Institute (UURI) at Salt Lake City. UURI also analyzed two anions chloride $\left(\mathrm{Cl}^{-}\right)$and fluoride $\left(\mathrm{F}^{-}\right)$.

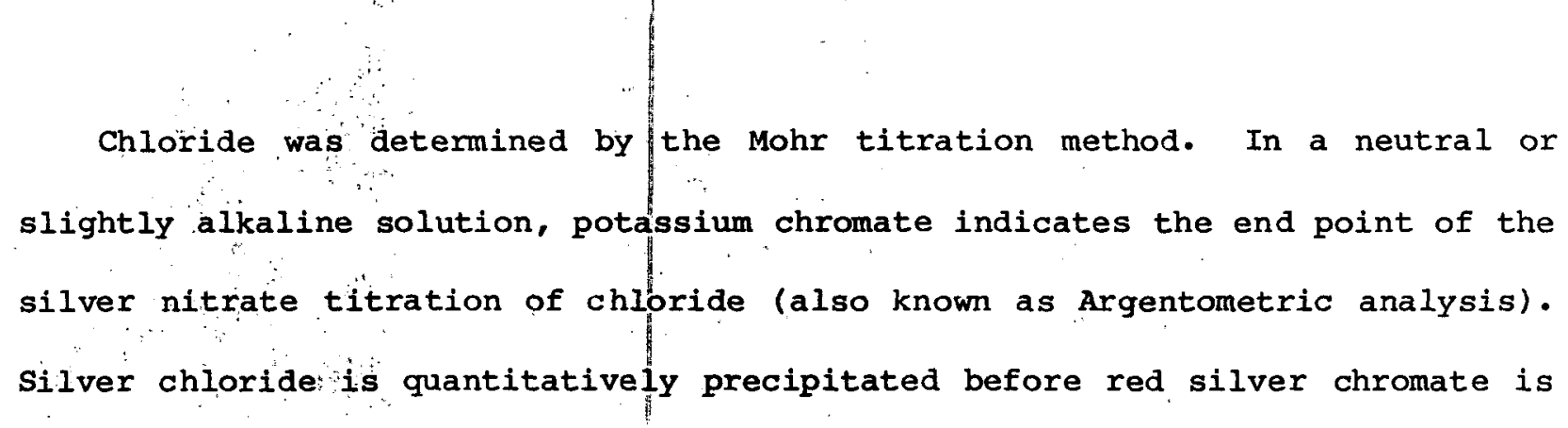


formed. Chloride was also determined in the field. The comparison of the results obtained by both methods is in progress and will be given in the second and final part of the report.

Fluoride was determined by a specific ion meter manufactured by orion Research, using the fluoride combination electrode by the method of addition using Total Ionic Strength Adjustor Base (TISAB).

Carbonate, bicarbonate, sulfate and total dissolved solids (TDS) were determined at the Geochemical Laboratory of the Division of Mines and Geology at San Francisco.

Carbonate and bicarbonate were determined by titration of an acid titrant using phenolphthalein as an indicator for carbonate and methyl orange for bicarbonate.

Sulfate is dissolved in water from most sedimentary rocks. Most chemists prefer to analyze sulfate in the field. Experience has shown that if the sample is preserved with hydrochloric acid and brought to the laboratory within a week's time and analyzed, accurate analysis for sulfate can be achieved. Five $\mathrm{ml}$ of acidified sample was pipeted in a test tube, in which 0-1 gm of bar̂ium chloride reagent was added. The test tube was shaken side to side until solution was complete. The reaction was allowed to proceed for 5 to 10 minutes (never more than 10 minutes) until barium chloride was in solution. If the sulfate ion is present, white precipitates form. The 
precipitates in suspension were transferred into a silica or quartz cell and absorbance was determined at $420 \mathrm{mu}$ wavelength in a spectrophotometer. A standard working curve was prepared by treating various sulfate standards with barium chloride and reading the absorbance of the white suspended precipitates and plotting concentration against absorbance. Using this working curve, the sample absorbance readings were converted to ppm (parts per million) values.

Theoretically, dissolved solids are anhydrous residuals of the dissolved substances in water. But in practice, the term "dissolved solids" is not an accurate measure of the weight of substances in solution. The total disolved solids were determined by calculations. Results obtained via calculation methods pose a problem, when compared with results obtained by the "residue-on-evaporation" method. In the "residue-on-evaporation" method, the bicarbonate is converted to carbonate in the evaporation and drying process and thus the amount of TDS determined by the "residue-on-evaporation" method is always less than those determined by "calculation" method. To check the accuracy of our calculation method, sixty samples were also analyzed by the "residue-on-evaporation" method. Results of TDS by both methods do not compare well unless recalculation for bicarbonate reconversion to carbonate is taken into consideration.

On the basis of the amount of bicarbonate present in the sample, corrections were made and the corrected values are given in Appendix A. 
(Specific Conductance) $\times(0,65+0.1)=$ TDS

From the above formula, constants were calculated for all water samples, but the result was different in all cases and was never a constant, 0.65+0.1. The total dissolved solids values were checked by two different methods and are correct. Therefore, it is concluded that the meter with which the specific conductance and salinity were determined, was not accurate.

The conclusions to be derived from the geochemistry are those given in the section on Interpretation and Integration, in Table 4 concerning geothermometric temperatures, and those given in the section on Hydrology and Groundwater concerning preliminary results in the use of geochemical overlay maps to determine the location of groundwater barriers and fault structure and to help delimit the boundaries of the hot water reservoir. The reader is referred to those sections for a complete discussion of the respective conclusions. 
It is widely recognized that seismic activity is often high in and around the major geothermal areas of the world and that, in some geothermal areas, there is a direct correlation between seismic activity and fluid withdrawal. The monitoring of seismic noise associated with geothermal areas has also been used as a tool for geothermal resource exploration.

To evaluate the regional pattern of seismic activity around Calistoga and to ascertain if the seismic activity bore any relationship to the moderate-temperature geothermal resource, all seismic events since 1800 were computer plotted for the Calistoga 15 minute quadrangle. Seismic data used for computer plotting were obtained from the California Division of Mines and Geology (CDMG) Earthquake Catalog system.

Sixty-eight events have been recorded for the Calistoga 15 minute quadrangle. Fifty events were computer plotted. The system does not allow "overprints". Therefore, only one of several events (the largest) occurring at the same coordinates, but at different times, is plotted.

Table 2 is a reproduction of the computer listing of all the earthquakes pertinent to the study. The table provides earthquake data on location, time, depth, magnitude, etc. A magnitude (MAG) of 9.99 means that no data were available to determine the actual magnitude of the event. 
TABULATED DATA OF THE EARTHQUAKES THAT HAVE OCCURRED WITHIN THE CALISTOGA 15 MINUTE QUADRANGLE (1800-1974),

CALIFOPNIA DIVISION OF MINES AND GEOLOGY EARTHUUAKE CATALOOG SYSTEM
PROGRAM RETRIEVE

VER. CONIOQH-123
DATE: $06 / 26 / 70$ REQUEST: $1-A$ PAGE:

DATA KETRISVAL REQUEST FOR: EARTHQUAKES CALISTOGA QUAD

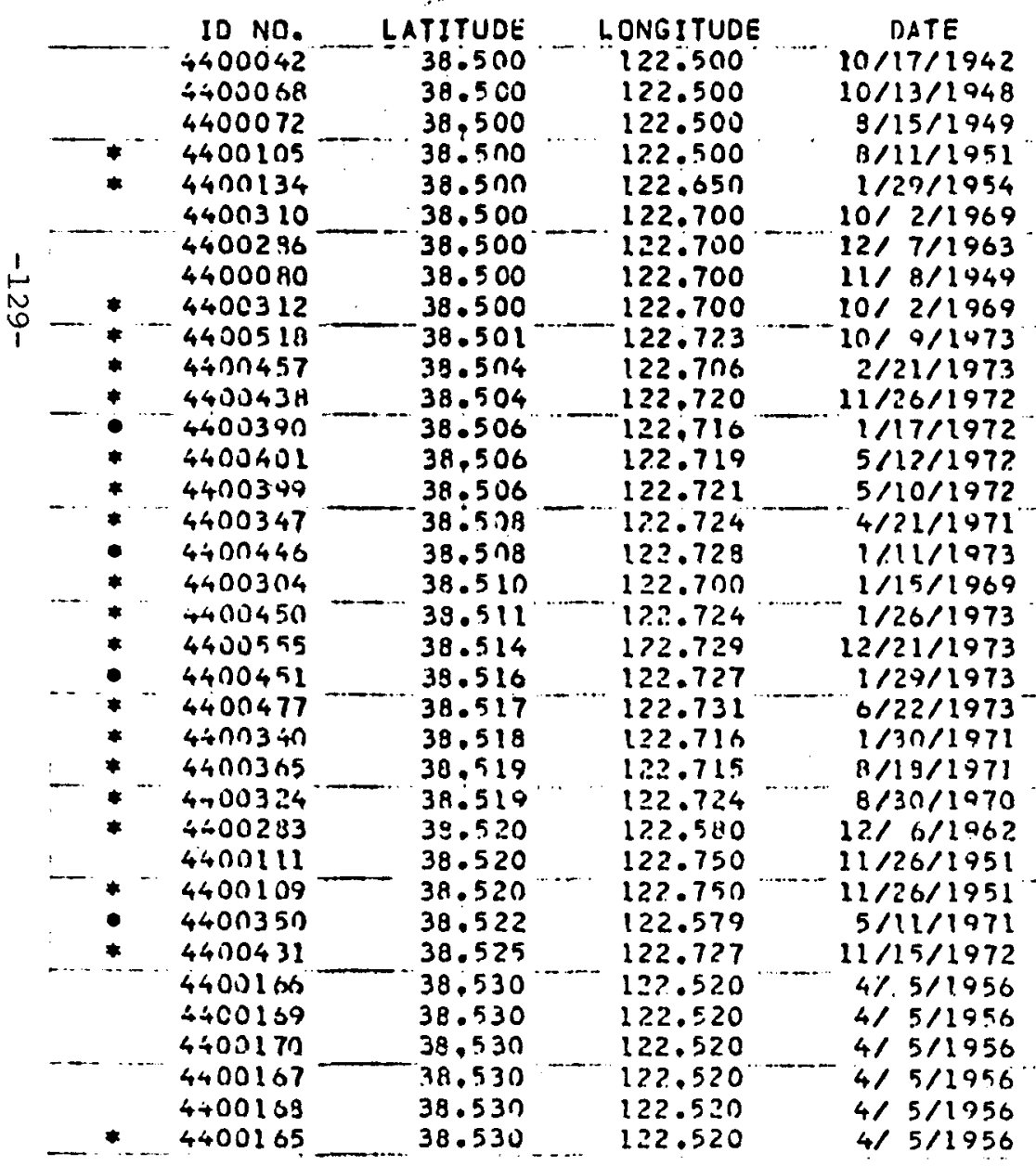

TIME

$\begin{array}{lll}6 & 10 & 0.0 \\ 0 & 23 & 0.0\end{array}$

235254.0

141554.0

$736 \$ 6.0$

51421.0

12411.6

124116.0

$710 \quad 9.0$

$\begin{array}{lll}20 & 7 & 43.7\end{array}$

652.30 .4

$\begin{array}{lll}19 & 20 & 35,7\end{array}$

111956,8

$18 \quad 4 \quad 59.1$

12812.4

54334.2

4289.0

$\begin{array}{lll}0 & 44 & 16.9\end{array}$

175434.8

$14 \quad 45 \quad 3.6$

122518.0

10124.0

124133.4

$\begin{array}{lll}1 & 41 & 0.1\end{array}$

132126.0

132420.6

203239.0

42932.0

43352.0

61749.0

43229.0

43328.0

42913.0

$O E P T H$
0.0
0.0
0.0
0.0
0.0
0
0.0
0.0
0.0
2.7
0.1
7
6
3.6
5
5.0
4
0
5.0
5.1
6
3.6
7
8.6
5.4
0
0
0
5.0
8
0.0
0.0
0.0
0.0
0.0
0

QUAL REF $\begin{array}{lllllll}0 & 1 & 9.99 & 1 & 0 A & 006 \\ D & 1 & 9.99 & 1 & 1 & 5 C & 001\end{array}$

$1,2.20 \ldots 1 \ldots . . .20$

c 12.80

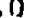

4.0

4.0
5.8

5.1

3.8

7.6

8.7

0.0

0.0

0.0

5.0

8.4

0

0.0

0.0
-...-

B $\cdots$

$B$

c

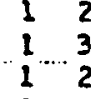

$\begin{array}{lll}3.104 \quad 001 & 0 \\ 2.70 & 1\end{array}$

$3.40 \mathrm{~A} 001$.

2.44

1.74

2.78

$9 \quad 2.52$

92.65

1.13

91.54

13.00

C

(3)

$B$

C

C

B
$C$

$\cdots$




\section{TABLE $\stackrel{2}{2}$ (CONTINUED)}

CALIFRRNIA DIVISION OF MIMES AND GEOLLOGY EARTHQUARE CATALOG SYSTEM
PROGRAM RETRIEVE

VER. CONIOSH-123
DATE: $06 / 26779$

$\begin{array}{rr}\text { PAGE: } & 5\end{array}$

\section{DATA RETRIEVAL REQUEST FOR: EARTHIUAKES CALISTOGA QUAD}

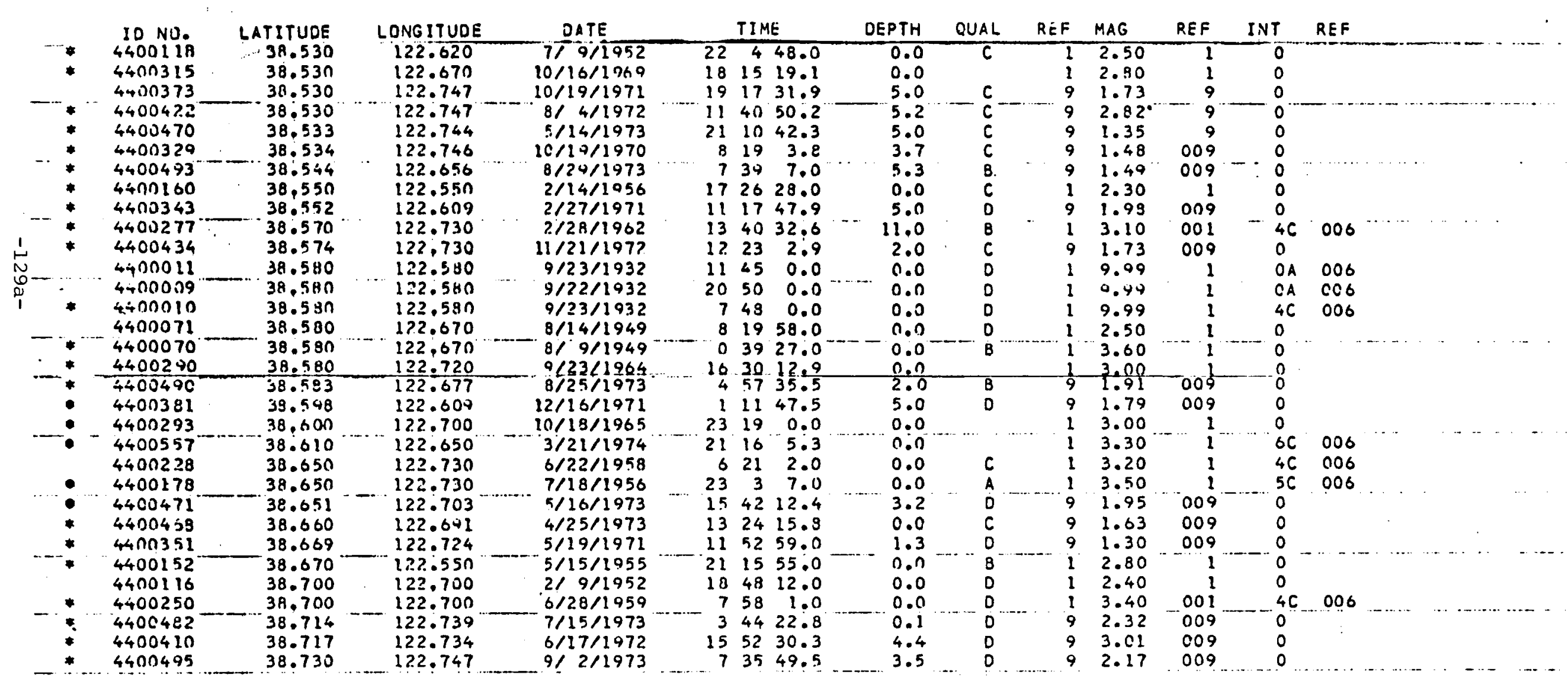


The CDMG Earthquake Catalog has been compiled from a great many sources of information. Data for the earthquakes recorded in Table 2 have been compiled from three of those sources.

Number

9

Reference

University of California, Berkeley (1976). Magnetic tape catalog of earthquakes in northern California, 1910-1974.

U.S. Department of Commerce, Coast and Geodetic Survey, United States Earthquakes, Annual publications, Washington, D.C.

U.S. Geological Survey (1976). Magnetic tape catalog of earthquakes in west-central California, 1969-1973.

Prior to about 1969, earthquake events in northern California were recorded primarily by the U.C. Berkeley seismograph network. Then the U.S. Geological survey sited several instruments in northern California counties. The higher seismograph station density provides better quality data. Hence, epicenter Iocations recorded post 1969 by the U.S. Geological Survey are of higher quality than events reported earlier.

The quality (QUAL)' ratings listed in the table are somewhat arbitrary and are not directly comparable from one soüre to another. The following key provides the criteria the institutions above use to assign quality judgements. Also, the codes accompanying the magnitude and intensity (INT) values are explained. 
I. Quality of Hypocenter (QUAL)

A. Source: U.C. Berkeley (REF 001)

Epicenter quality is subjective, ranging in quality from high to low as follows:

$$
\begin{aligned}
& \text { A - Excellent } \\
& \text { B - Good } \\
& \text { C - Fair } \\
& \text { D - Poor }
\end{aligned}
$$

B. Source: U.S. Geological Survey (REF 009)

$\begin{array}{lcc}\text { A - Excellent } & \frac{\text { Epicenter }}{1 . \mathrm{km}} & \frac{\text { Focal Depth }}{2 \mathrm{~km}} \\ \text { B - Good } & 2.5 & 5 \\ \text { C - Fair } & 5 & 5 \\ \text { D - Poor } & 5 & 5\end{array}$

II. Type of Magnitude (MAG)
A - Local Richter
B - Surface wave
C - Body wave
D - Local estimated from intensity
E - Local estimated from duration

III. Type if Intensity (INT)

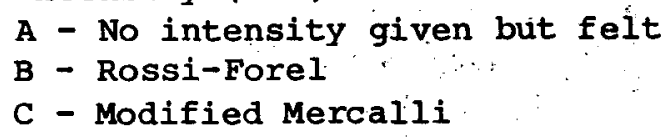

The epicenter locations were manually plotted over the Calistoga 15 minute topographic quadrangle (Plate 11). The data and map are presented with no discussion of analysis at this time. 
This report, as has been mentioned at appropriate points in the preceding sections, was written prior to completion of the California Division of Mines and Geology drilling investigations in the Calistoga area. of great importance is the data that CDMG expects to obtain from the drilling of up to six geothermal test wells in the upper Napa Valley area at strategic points in and around the City of Calistoga. Drilling of these wells is expected to begin in the Fall of 1980 and should be completed within a three month period. Upon completion of the drilling, the new data obtained, including water test data, pump data, temperature data, and well log information, will be integrated with the data already obtained in the Calistoga studies, and the results will be submitted in the form of a final addendum to this report. The addendum is expected to be available in early 1981.

\footnotetext{
Among the important results obtained from the studies so far are the conclusions reached about the relative success of the various instrumental techniques. The resistivity method, as shown in this study and in previous studies, is a most useful tool for delineating the geothermal resource. A positive correlation was found between zones of high electrical conductivity and known areas of hot water. In addition, a test using a shallow hole temperature survey over an area where resistivity lines were also run, has shown an excellent correlation of results from the two methods. This is
} 
particularly interesting because of the very shallow ground water encountered in' the area of the tests--a factor that can be detrimental, under adverse circumstances, to the use of the shallow hole temperature method.

\begin{abstract}
Also of particular importance was the finding that the gravity data indicate the presence of a large low-density structure or mass centered southwest of Calistoga. The discovery of this feature was a direct result of the geophysical exploration done for this project, and so far no other substantiating information has been developed. This structure or mass could include possible zones favorable for geothermal resources, or it could be a source of heat for the geothermal phenomena. If either of these hypotheses is correct, the most favorable zone for possible additional geothermal resource development is located within the negative gravity anomaly generally between the Mark West Springs road, on the northwest, and the Diamond Mountain road, on the southeast. Temperature and temperature gradient measurements in drill holes in this general area could be used to help evaluate these hypotheses.
\end{abstract}

Both gravity and magnetic data indicate a low or negative anomaly in the vicinity of the old Faithful (California) Geyser. At present, it is uncertain whether these anomalies are related to the geothermal field or are merely representative of the thickness of valley fill in the area. Drilling that is planned for the area should provide some answers for this problem. 


\begin{abstract}
Seismic refraction lines run by CDMG in the valley near Calistoga have indicated a velocity interface between seismic layers and also a general deepening of the basement rocks in the valley toward the southwest. Gravity and resistivity have also shown a general thickening of the sediments to the south. These facts, coupled with the linear and abrupt topographic change, tend to support the concept of a fault along the southwestern margin of the valley (shown dashed on the geologic map Plate 1). However, additional proof may depend on the outcome of the drilling program.
\end{abstract}

Faults are, in some cases, indicated in the geophysical sections but not on the maps of the valley area. Preliminary results have shown (see section on Hydrology and Groundwater Quality Related to Geologic Structures) that by drawing contours, on map overlays, based on water chemistry, it is possible to approximately delineate some of the faults indicated in the geophysical sections. In addition, it is expected that by drilling, logging, and testing water chemistry for certain selected drill holes it may be possible to further delineate some of these faults on maps. The outcome is partially dependent on the hypothesis presented by Faye (1973) that chemistry of the highly mineralized waters, given enough data points (wells), can be used to delineate the structural controls (faults) on the waters of the area. Additional information on the testing of this promising hypothesis will be presented in the final report addendum.

One of the problems brought on by the relatively high mineralization of the thermal waters in the Calistoga area is that of scaling and corrosion of 
pipes and other handling equipment. Another is that the deleterious substances in the themal waters can cause a severe impact on agriculture if allowed to get into irrigation water in the area. As was mentioned above, in another section of this report, a plan has been suggested to use geothermal heat to remove deleterious salts from poor quality water and thus make it satisfactory for domestic use. The local electorate, however, has voted to import fresh water to make up local shortages of good quality water. This means that geothermal heat could be used in a heat exchange system for hydroponics or other agricultural processing. Space heating has long been a use for geothermal energy at Calistoga and light industrial processing is also a potential use. The area has great potential for such utilization.

In general, the indications developed so far in this study of the geothermal resource at Calistoga point toward a significantly larger resource than was previously believed. Heat or hot water may extend to the southwest beneath the upland area. Additional testing not covered by current year funding, would be required to prove the quantity and quality of the geothermal resource in that area. 
Introduction

A geothermal resource assessment, by necessity, must be updated, refined, and reevaluated as more data on a particular resource area become available. Hence, some of the material presented below, about the low to moderate temperature geothermal resource at Calistoga, California, may be modified in the future. The pending CDMG exploratory drilling program at Calistoga, the pending CDMG interpretation of water well geochemical data from Calistoga, and private geothermal resource utilization in Calistoga will all add greatly to the refinement of the assessment of the geothermal resource.

Reservoir Model

The geothermal resource at Calistoga is a hydrothermal convection system or, probably more correctly, a combination of two or more hydrothermal convection systems. Such systems require a heat source, a fluid, and sufficient vertical permeability for hot, low-density fluids to rise and, in most systems, be recharged by descending cooler fluids. Convective circulation of hot fluids is the mechanism that transports energy from depth to reservoirs near the earth's surface. 
Hydrothermal convection systems are most likely to develop in areas where there is a residual heat supply related to relatively young volcanism. Fault zones are most generally the conduits for moving fluids in convection systems. Many known hydrothermal convection systems appear to be located at and controlled by intersecting geologic structures.

Waring (1915, p. 109) early suggested that faulting was responsible for the hot water seepage at the original hot springs at Calistoga. Faye (1975) inferred from his study the existence of a fault aligned with the topographic axis of the upper Napa Valley at Calistoga. Others have speculated, at various times, on the existence and location of faulting in the subsurface of the upper Napa Valley. The geophysical studies conducted by CDMG at Calistoga and reported herein indicate locations of possible faulting. Preliminary maps, from the forthcoming CDMG water well geochemical analyses of Calistoga, indicate locations of possible faulting around Calistoga.

Figure 17 depicts a model of an ascending portion of a hydrothermal convection system and two inferred fault locations near Tubbs Lane in Calistoga. The hypothetical model is based primarily on five temperature logs along section $A-A^{\prime}$ of Plate $B-1$ in Appendix $B$.

\footnotetext{
Temperature logs from wells numbered 6 and 9 show an abrupt decrease in temperature with depth (or change in sign of slope of temperature curve from positive to negative) at approximately 164 feet and 190 feet resepctively. Whereas temperature logs from wells numbered 7 and 8 (aligned between wells
} 


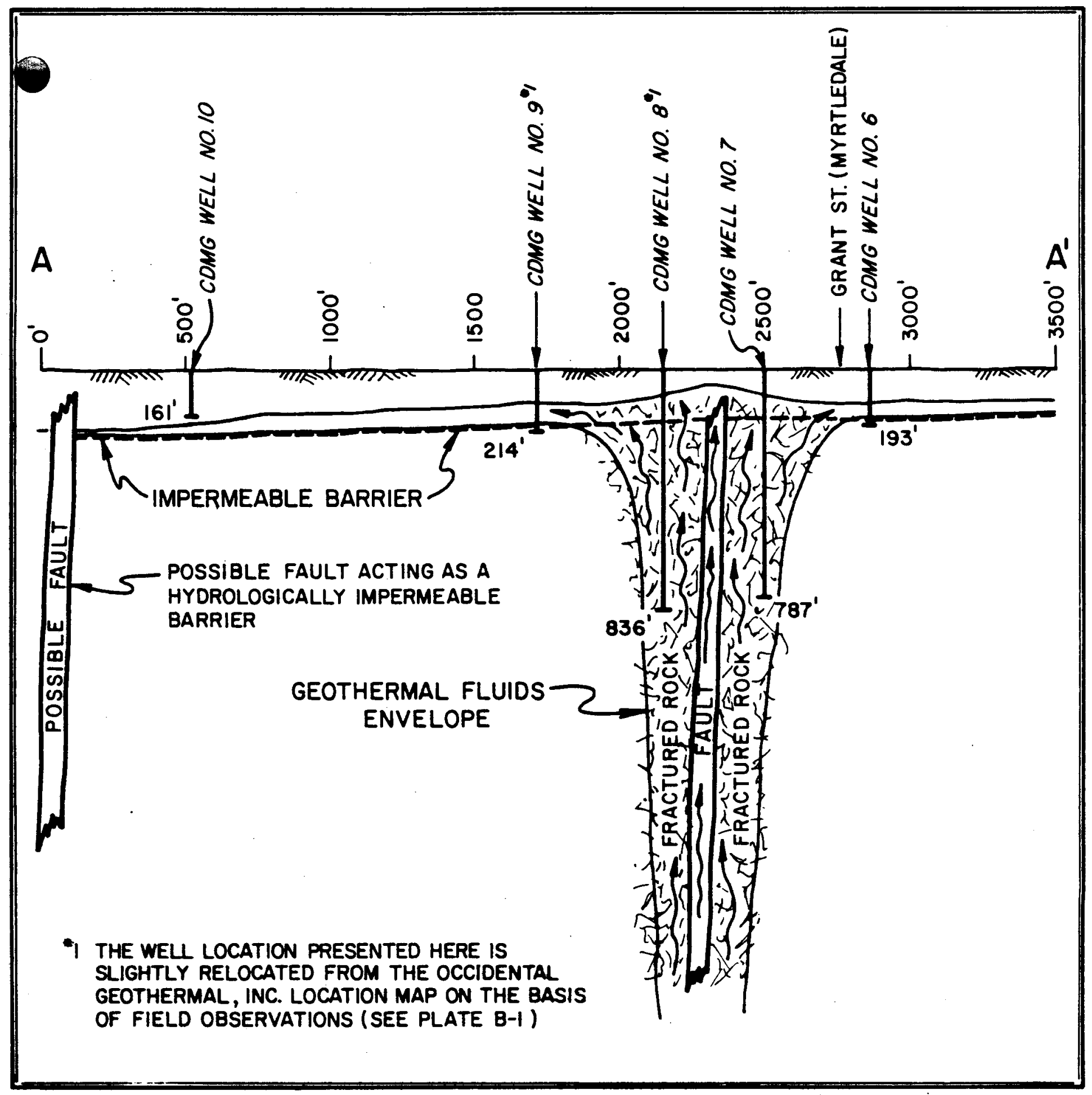

Figure 17. Diagramatic cross-section of a portion of the geothermal reservoir at Calistoga, California based primarily on temperature logs along section $A-A^{\prime}$ of Plate $B-1$, Appendix B. By L.G. Youngs, 1980, CDMG. 
numbered 6 and 9) show a continuous positive slope or increase in temperature with depth throughout their respective temperature curves.

The hypothetical cross-section in Figure 17 offers one possible explanation that satisfies these temperature log criteria. Wells numbered 6 and 9 have completely penetrated through the hot water table and into a cooler environment. Whereas wells 7 and 8 may be within a permeable fracture zone associated with faulting where deep seated hot water rises to near surface.

Well no. 10 (Figure 17) shows no change in the sign of the slope of the temperature curve; also, this well does not have nearly as "hot" a temperature as the other 4 wells mentioned above. Hence, this well probably does not intersect the main body of the "hot water" table.

The Tertiary Sonoma Volcanics draping the hills about Calistoga are evidence of relatively recent volcanic activity in the Upper Napa Valley. The heat source or "driving" mechanism for hydrothermal convection systems at Calistoga is probably the reminant heat from the magma chamber or chambers that were the source of the Tertiary volcanic rocks.

The remaining requirement for a hydrothermal convection system, a fluid, is probably primarily provided by meteoric waters ascending fault or fracture zones in the vicinity of Calistoga. Faults act like conduits bringing the meteoric water near the heat source and providing a passage way for the 
hotter, less lense geothermal fluids to rise toward the surface. Thus, Figure 17 shows geothermal fluids rising through fractured bedrock and migrating outward through the much more permeable and porous alluvial stratum.

Preliminary maps (not included in this report) from a forthcoming report on water well data from Calistoga, show at least three markedly different chemical types of geothermal fluids distributed around Calistoga. This may indicate the presence of several subsurface hydrothermal convection systems.

Reservoir Volume

Thickness of Reservoir Rocks: 'A geothermal reservoir is a complex, heterogeneous volume of rock and.water, but most of the thermal energy is contained in the rock. Most volumetric estimates consider the reservoir as a volume of rock and water regardless of permeability and porosity. That is, no attempt is made to distinguish those parts of a reservoir that are permeable and porous from those that are not. This often leads to choosing a somewhat arbitráry thickness or depth of a geothermal reservoir.

The intention in this report is simply to provide an approximate estimate of the volume of alluvium that probably contains geothermal waters at Calistoga. "This value does not include "hot" water available in basement rock fracture zones or fault zones. To this end, then, an average depth of 
valley alluvium of 400 feet is inferred from well data and geophysical surveys at Calistoga.

The average depth (derived from 13 temperature logs in Appendix $B$ ) of the top of the "hot" water aquifer is approximately 120 feet. This is the average depth at which those particular temperature curves exhibited a markedly high increase in temperature versus depth. Subtracting this figure from the figure for the average depth of valley alluvium yields an average thickness of 280 feet of possible "hot" water bearing alluvial aquifer.

Areal extent of geothermal Reservoir: Plate 12 is a compilation of 133 "hot" water wells located near Calistoga. It is assumed that all of these wells have temperatures greater than or equal to $25^{\circ} \mathrm{C}$. An approximate boundary line has been constructed enclosing the wells and has been modified to fit geophysical and other evidence as appropriate. This boundary serves as an estimate of the lateral extent of the geothermal aquifer pending revisions based on future drill holes. The enclosed area is approximately 5.79 square miles.

Therefore, there is an approximate volume of sediments 280 feet deep by 5.79 square miles in area $\left(3.07 \times 10^{-1} \mathrm{mi}^{3}\right)$ that probably contains intersticial waters with a temperature greater than $25^{\circ} \mathrm{C}$. Results from flow testing during the forthooming CDMG drilling program at Calistoga should further refine the potential volume of geothermal fluids available at 
Calistoga, and also help determine whether or not fluids contained in basement rock fracture zones can provide a significant part of the resource.

Reservoir Temperature

Direct Temperature Measurement: Appendix B of this report contains 26 down-hole temperature logs from the Calistoga area. Occidental Geothermal, Inc. provided 20 of the logs,; and 6 were measured during the CDMG, 1980, water well survey at Calistoga. The logs from Occidental Geothermal, Inc. have been redrafted and assigned new location numbers to economize space and to make it easier to locate the wells on the location map (Plate B-l, Appendix B). Occidental's well numbers also appear on the logs when appropriate.

The greatest directly recorded temperature on the logs is $275.1^{\circ} \mathrm{F} / 135^{\circ} \mathrm{C}$ at a depth of 192 feet (CDMG well no. 3).

Data from the temperature logs have been recorded in Table 3 . Temperatures were picked from each thermal curve at the 50 foot, 100 foot, and 200 foot depth. Temperature extrapolations were made if the well's depth was near, but less than, these selected depths. All 26 wells were ranked from "hottest to coldest", first, by their 50 foot temperatures, secondly, by their 100 foot temperatures, and, thirdiy, by their 200 foot temperatures. Then the three rank numbers for each well were averaged. Table 3 lists the 
TABLE 3

Approximate order from "hottest to coldest" of selected wolls in Calistoga, Callfornia based on temperature log data.

\begin{tabular}{|c|c|c|c|c|c|c|}
\hline $\begin{array}{l}\text { Approximate } \\
\text { Rank }\end{array}$ & $\begin{array}{c}\text { CDMG } \\
\text { Temperature } \\
\text { Log } \\
\text { Number } \\
\end{array}$ & $\begin{array}{c}\text { Temperature } \\
\text { at } \\
50^{\mathrm{Foot}} \\
\left.\text { Depth ( }{ }^{\circ} \mathrm{F}\right) \\
\end{array}$ & $\begin{array}{c}\text { Temperature } \\
\text { at } \\
100 \text { Foot } \\
\left.\text { Depth ( }{ }^{\circ} \mathrm{F}\right)\end{array}$ & $\begin{array}{c}\text { Temperature } \\
\text { at } \\
200 \mathrm{Foot} \\
\text { Depth } \mathrm{F}^{\circ} \mathrm{F} \text {. }\end{array}$ & $\begin{array}{l}\text { Temperature and } \\
\text { depth of deepest } \\
\text { probe penetration } \\
\text { (OF/Feet) }\end{array}$ & Remarks \\
\hline 1 & 3 & $254.5^{\circ}$ & $265^{\circ}$ & Extraplolated $\sim 277^{\circ}$ & $275.1^{\circ} / 192$ & $\because$ \\
\hline 2 & 18 & $213^{\circ}$ & $250^{\circ}$ & Extrapolated $\sim 252^{\circ}$ & $251.9^{\circ} / 190^{\prime}$ & \\
\hline 3 & 7 & $232.7^{\circ}$ & $241^{\circ}$ & $245^{\circ}$ & $255.5^{\circ} / 787^{\prime}$ & \\
\hline 4 & 6 & $217.2^{\circ}$ & $227^{\circ}$ & Extrapolated $\sim 237^{\circ}$ & $240.3^{\circ} / 193^{\prime}$ & . \\
\hline 5 & 2 & $195^{\circ}$ & $\begin{array}{l}\text { Extrapolated } \\
\sim 233^{\circ}\end{array}$ & NA & $223.3^{\circ} / 92^{\prime}$ & \\
\hline 6 & 17 & $199^{\circ}$ & $213^{\circ}$ & $236.2^{\circ}$ & $273.7^{\circ} / 1890^{\prime}$ & · \\
\hline 7 & 8 & $167^{\circ}$ & $190^{\circ} \mathrm{p}$ & $204.7^{\circ} \mathrm{P}$ & $243.6^{\circ} / 836^{\prime}$ & \\
\hline 8 & 12 & $93^{\circ}$ & $\begin{array}{l}\text { Extrapolated } \\
\sim 140^{\circ}\end{array}$ & NA & $135^{\circ} / 96^{\prime}$ & $\begin{array}{l}\text { "Could not get down to bottom. Put well on pro- } \\
\text {-duction, producing water temperature } 204^{\circ} \mathrm{F} . "\end{array}$ \\
\hline 9 & 9 & $154^{\circ}$ & $159^{\circ}$ & $178.4^{\circ}$ & $178^{\circ} / 214^{\prime}$ & \\
\hline 10 & $\mathbf{5}$ & $150.8^{\circ}$ & $157.7^{\circ}$ & Extrapolated $\sim 180^{\circ}$ & $178^{\circ} / 198^{\prime}$ & \\
\hline 11 & 16 & $139^{\circ}$ & $152^{\circ}$ & Extrapolated $\sim 208^{\circ}$ & $203.5^{\circ} / 192.5^{\prime}$ & · \\
\hline 12 & 13 & $98.2^{\circ}$ & $150^{\circ}$ & NA & $161.8^{\circ} / 137^{\prime}$ & \\
\hline 13 & 15 & $120.2^{\circ}$ & $135^{\circ}$ & NA & $142.5^{\circ} / 137$ & \\
\hline 14 & 4 & $\begin{array}{l}\text { Extrapolated } \\
\sim 108^{\circ}\end{array}$ & NA & NA & $106.5^{\circ} / 46^{\prime}$ & \\
\hline 15 & 26 & $91.3^{\circ}$ & $109.5^{\circ}$ & $154.3^{\circ}$ & $157.1^{\circ} / 207^{\prime}$ & \\
\hline 16 & 14 & $96^{\circ}$ & $111^{\circ}$ & $152.5^{\circ}$ & $152.5^{\circ} / 216^{\prime}$ & $\cdot$ \\
\hline 17 & 11 & $122.8^{\circ}$ & $124.8^{\circ}$ & $130^{\circ}$ & $132.4^{\circ} / 237^{\prime}$ & \\
\hline 18 & 22 & $67.7^{\circ}$ & $92^{\circ} \circ$ & $114^{\circ}$ & $137.5^{\circ} / 340^{\prime}$ & \\
\hline 19 & 19 & $76.5^{\circ}$ & $88.5^{\circ}$ & Extrapolated $\sim 108^{\circ}$ & $107.4 / 196^{\prime}$ & Wells are approximately ranked by \\
\hline 20 & 20 & $76^{\circ}$ & $78^{\circ}$ & NA & $85.2^{\circ} / 137$ & $\begin{array}{l}\text { temperature measured or anticipated } \\
\text { at } 200 \text { foot depth at each well }\end{array}$ \\
\hline 21 & 23 & $72^{\circ}$ & $76.7^{\circ}$ & $94^{\circ}$ & $103.5^{\circ} / 255^{\prime}$ & location. Weli locations aro \\
\hline 22 & 10 & $75.2^{\circ}$ & $74^{\circ}$ & Extrapolated $\sim 84^{\circ}$ & $81.8^{\circ} / 161^{\prime}$ & $\begin{array}{l}\text { presented on Plate } B-1 \text {, in } \\
\text { Appendix } B \text {. }\end{array}$ \\
\hline 23 & 24 & $72^{\circ}$ & NA & NA & $72.4^{\circ} / 55^{\prime}$ & \\
\hline 24 & 21 & $71^{\circ}$ & $\begin{array}{l}\text { Extrapolated } \\
\sim 77^{\circ}\end{array}$ & NA & $72^{\circ} / 87^{\prime}$ & \\
\hline 25 & 1 & $71^{\circ}$ & $74^{\circ}$ & $83^{\circ}$ & $88.8^{\circ} / 260^{\prime}$ & \\
\hline 26 & 25 & $69.3^{\circ}$ & $70.3^{\circ}$ & NA & $72.5^{\circ} / 117^{\prime}$ & \\
\hline
\end{tabular}


26 wells by their relative averaged rank., Given the data available, this method of ranking the wells--first by their different depth temperatures and then by their averaged ranks--provides the best possible quantitative temperature comparison of the 26 wells. Coincidentally, the ranking based on averaged ranks is almost exactly the same as the ranking based on the 200 foot temperature.

WeIl No. 3 (CDMG numbers) is relatively the "hottest" well of the 26 wells and well No. 25 is the least "hot".

Plate B-1, Appendix B shows the 26 thermally logged water wells approximately grouped in three areas; Tubbs Lane, around the City of Calistoga, and southeast of Calistoga along the Silverado Trail. Four of the first five "hottest" wells from Table 3 are near Tubbs Lane. The wells numbered 20-25 (Southeast of Calistoga) appear in the ranks of the nine "coldest" wells in Table 3. This apparent temperature distribution indicates that the geothermal resource is "hottest" around Tubbs Lane, slightly less "hot" around the city of Calistoga, and much "cooler" southeast of Calistoga.

Plate 12 displays the location of 133 "hot water" wells around Calistoga. Most locations are annotated with the well depth and a directly recorded temperature. The well locations have been compiled from three sources: (1) Koenig and Anderson, 1970, (2) Occidental Geothermal, Inc., 1977, and (3) the CDMG, 1980, water well survey at Calistoga. The recorded 
temperatures were derived from several methods as indicated in the explanation on Plate 12 .

Plate 13 is a contour map of the estimated water temperature at a depth of approximately 200-300 feet at Calistoga. There are 32 annotated well locations posted on the map. The posted temperature is that temperature recorded for the indicated depth at each well location. The contours have been approximately located utilizing the posted well data, inferences from empirical well data not shown (mainly from plate 12), local well driller's experiences, inferences from geophysical data (discussed elsewhere in this report) and topographic effects. Because the contour lines are approximately located, further refinement of the contour locations is expected with additional information from CDMG's forthcoming drilling program and information available from private geothermal resource utilization at Calistoga.

Indirect Temperature Measurement: Geothermometry (that is, the use of chemical geothermometers) is an indirect method of assessing the temperature of a geothermal reservoir. Geothermometry methods are based on temperature-dependent, water-rock reactions which determine the chemical and isotopic composition of thermal waters. The most common soluable chemical constituents of thermal waters are $\mathrm{SiO}_{2}, \mathrm{Na}, \mathrm{K}, \mathrm{Ca}, \mathrm{Mg}, \mathrm{Cl}, \mathrm{HCO}, \mathrm{and} \mathrm{CO}_{3}$. The silica, $\mathrm{Na}-\mathrm{K}-\mathrm{Ca}$, and sulfate-isotope geothermometers are those most 
generally used to estimate geothermal reservoir temperatures. The validity of these geothermometers is based on the following assumptions:

1. Temperature-dependent reactions at depth control the concentration of the geothermometer.

2. The reservoir contains an adequate supply of the reactants.

3. Water-rock equilibrium is established in the reservoir.

4. The constituents used in the geothermometer do not reequilibrate with the confining rock as the water flows to the surface.

5. Mixing of thermal and nonthermal groundwater does not occur.

Problems arise in using the geothermometers when one or more of these assumptions are violated. Hence, some of the calculated geothermometric temperatures presented below may be subject to considerable error.

Table 4 is a list of 64 , water wells from Calistoga (having surface temperatures of $24^{\circ} \mathrm{C} / 75^{\circ} \mathrm{F}$ or greater) that were geochemically analyzed. The geochemical sample numbers refer to the individual geochemical analyses in Appendix $A$ and to the water well locations on Plate 10. For each well, geothermal reservoir temperatures have been calculated using five geothermometers or geothermometric techniques.

Muffler (1979, p. 64), utilizing the Na-K-Ca geothermometric method, calculated a reservoir temperature of $141^{\circ} \mathrm{C} / 286^{\circ} \mathrm{F}$ for the geothermal reservoir at Calistoga. The average of the Na-K-Ca method of calculating temperature for all the wells from Table 4, except those footnoted, is $137^{\circ}$ $\mathrm{C} / 279^{\circ} \mathrm{F}$. Muffler's value and CDMG's calculated value compare favorably. 
Further analysis of the data in Table 4 is expected in a forthcoming CDMG report on the interpretation of the geochemical data collected at Calistoga. Preliminarily, however, the geothermal reservoir temperature at Calistoga is approximately $140^{\circ} \mathrm{C} / 284^{\circ} \mathrm{F}$. 
Table 4. Geothermometric temperatures for the well water samples above $24^{\circ} \mathrm{C}$ (surface temperature) at Calistoaga, California. BY H.H. Majmundar, 1980, CDMG.

\begin{tabular}{|c|c|c|c|c|c|c|}
\hline $\begin{array}{l}\text { Sample } \\
\text { Numbers }\end{array}$ & $\begin{array}{l}\text { Surface } \\
\text { Temp. } \\
\left({ }^{\circ} \mathrm{C}\right) * 1\end{array}$ & $\begin{array}{c}\mathrm{SiO}_{2} \\
\text { Temp. } \\
\text { adiabatic } \\
\left({ }^{\circ} \mathrm{C}\right)\end{array}$ & $\begin{array}{l}\mathrm{SiO}_{2} \\
\text { Temp. } \\
\text { conductive } \\
\left({ }^{\circ} \mathrm{C}\right)\end{array}$ & $\begin{array}{l}\text { Na/K Temp. } \\
\text { White \&Ellis } \\
\text { (cf.Trusdell } \\
1975)\left({ }^{\circ} \mathrm{C}\right)\end{array}$ & $\begin{array}{l}\text { Na/K Temp. } \\
\text { Fornier \& } \\
\text { Trusdell } \\
(1973)\left({ }^{\circ} \mathrm{C}\right)\end{array}$ & $\begin{array}{l}\text { NaKCa } \\
\text { Temp. } \\
\left({ }^{\circ} \mathrm{C}\right)\end{array}$ \\
\hline$G-001-80$ & 45 & 142 & 146 & 107 & 98 & 144 \\
\hline$G-003-80$ & 31 & 103 & 101 & 127 & 120 & 131 \\
\hline$G-008-80$ & 25 & 79 & 73 & 143 & 136 & 149 \\
\hline$G-009-80$ & 135 & 143 & 147 & 113 & 104 & 161 \\
\hline$G-010-80$ & 39.5 & 130 & 133 & 90 & 81 & 141 \\
\hline$G-012-80$ & 65 & 147 & 153 & 96 & 87 & 150 \\
\hline$G-016-80$ & 37 & 98 & 95 & 66 & 58 & 201 \\
\hline G-019-80 & 64 & 141 & 145 & 90 & 80 & 137 \\
\hline G-020-80 & 97.5 & 146 & 152 & 100 & 91 & 131 \\
\hline$G-021-80$ & 97.9 & 148 & 154 & 86 & 76 & 134 \\
\hline$G-022-80$ & 47 & 157 & 165 & 121 & 113 & 149 \\
\hline$G-025-80$ & 36 & 126 & 127 & 132 & 125 & 134 \\
\hline$G-027-80$ & 25 & 121 & 122 & 149 & 142 & 163 \\
\hline G-037-80 & 42 & 115 & 116 & 101 & 92 & 141 \\
\hline G-044-80 & 40 & 121 & 122 & 148 & 141 & 165 \\
\hline G-054-80 & $24 \vdots$ & 98 & 95 & 96 & 86 & 133 \\
\hline G-057-80 & 37.5 & 113 & 112 & 74 & 63 & 116 \\
\hline G-058-80 & 57 & 129 & 131 & 64 & $\quad 54$ & 115 \\
\hline$G-063-80$ & 28 & 91 & 88 & 111 & 102 & 129 \\
\hline$G-066-80$ & 35 & 101 & 99 & 119 & 1.11 & 117 \\
\hline$G-067-80$ & 36 & 98 & 95 & 149 & 143 & 135 \\
\hline G-068-80 & 34 & 105 & 103 & 78 & 68 & 119 \\
\hline$G-071-80^{* 2}$ & $30^{t}$ & 76 & 70 & 291 & 298 & 29 \\
\hline$G-084-80 * 3$ & 24 & 73 & 66 & 179 & 175 & 23 \\
\hline
\end{tabular}


Table 4 (Continued)

\begin{tabular}{|c|c|c|c|c|c|c|}
\hline $\begin{array}{l}\text { Sample } \\
\text { Numbers }\end{array}$ & $\begin{array}{l}\text { Surface } \\
\text { Temp. } \\
\left({ }^{\circ} \mathrm{C}\right)\end{array}$ & $\begin{array}{c}\mathrm{SiO}_{2} \\
\text { Temp. } \\
\text { adiabatic } \\
\left({ }^{\circ} \mathrm{C}\right)\end{array}$ & $\begin{array}{l}\mathrm{SiO}_{2} \\
\text { Temp. } \\
\text { conductive } \\
\left({ }^{\circ} \mathrm{C}\right)\end{array}$ & $\begin{array}{l}\text { Na/K Temp. } \\
\text { White \&Ellis } \\
\text { (cf.trusdell } \\
1975)\left({ }^{\circ} \mathrm{C}\right)\end{array}$ & $\begin{array}{l}\mathrm{Na} / \mathrm{K} \text { Temp. } \\
\text { Fornier \& } \\
\text { Trusdell } \\
(1973)\left({ }^{\circ} \mathrm{C}\right)\end{array}$ & $\begin{array}{l}\text { NaKCa } \\
\text { Temp. } \\
\left({ }^{\circ} \mathrm{C}\right)\end{array}$ \\
\hline$G-086-80$ & 24 & 51 & 42 & 166 & 160 & 141 \\
\hline$G-088-80$ & 26 & 87 & 82 & 109 & 100 & 116 \\
\hline$G-091-80^{* 4}$ & 28 & 94 & 90 & 233 & 234 & 28 \\
\hline$G-092-80$ & 41 & 137 & 141 & 121 & 113 & 159 \\
\hline G-093-80 & 93 & 141 & 145 & 111 & 102 & 157 \\
\hline G-095-80 & 52 & 122 & 123 & 81 & 71 & 129 \\
\hline$G-096-80$ & 85 & 128 & 130 & 89 & 79 & 91 \\
\hline G-097-80 & 95 & 143 & 147 & 115 & 107 & 158 \\
\hline G-098-80 & 96 & 140 & 144 & 110 & 102 & 145 \\
\hline G-099-80 & 94 & 138 & 142 & 113 & 104 & 150 \\
\hline$G-100-80$ & 86 & 138 & 142 & 106 & 97 & 96 \\
\hline$G-101-80^{* 4}$ & 25 & 69 & 62 & 271 & 276 & 172 \\
\hline G-102-80 & 65.5 & 126 & 127 & 59 & 48 & 119 \\
\hline G-103-80 & 34 & 111 & 111 & 74 & 64 & 120 \\
\hline G-104-80 & 45 & 135 & 139 & 83 & 73 & 134 \\
\hline G-105-80 & 44 & 145 & 151 & 97 & 87 & 131 \\
\hline G-106-80 & 55 & 147 & 153 & 96 & 87 & 142 \\
\hline G-107-80 & 25 & 87 & 82 & 57 & 46 & 110 \\
\hline G-108-80 & 57. & 111 & 111 & 95 & 86 & 126 \\
\hline G-109-80 & 51 & 107 & 105 & 68 & 57 & 113 \\
\hline G-110-80 & 28 & 98 & 95 & 98 & 89 & 115 \\
\hline$G-111-80$ & 104 & 141 & 145 & 113 & 105 & 152 \\
\hline$G-112-80$ & 30 & 124 & 126 & 85 & 75 & 132 \\
\hline
\end{tabular}


Table 4 (Continued)

\begin{tabular}{|c|c|c|c|c|c|c|}
\hline $\begin{array}{l}\text { Sample } \\
\text { Numbers }\end{array}$ & $\begin{array}{c}\text { Surface } \\
\text { Temp. } \\
\left({ }^{\circ} \mathrm{C}\right)\end{array}$ & $\begin{array}{c}\mathrm{SiO}_{2} \\
\text { Temp. } \\
\text { adiabatic } \\
\left({ }^{\circ} \mathrm{C}\right)\end{array}$ & $\begin{array}{c}\mathrm{SiO}_{2} \\
\text { Temp. } \\
\text { conductive } \\
\left({ }^{\circ} \mathrm{C}\right)\end{array}$ & $\begin{array}{l}\text { Na/K Temp. } \\
\text { White \&Ellis } \\
\text { cf.Trusdell } \\
1975)\left({ }^{\circ} \mathrm{C}\right)\end{array}$ & $\begin{array}{l}\mathrm{Na} / \mathrm{K} \text { Temp. } \\
\text { Fornier \& } \\
\text { Trusdell } \\
(1973)\left({ }^{\circ} \mathrm{C}\right)\end{array}$ & $\begin{array}{l}\text { NaKCa } \\
\text { Temp. } \\
\left.\text { ( }{ }^{\circ} \mathrm{C}\right)\end{array}$ \\
\hline$G-113-80$ & 57 & 117 & 117 & 73 & 62 & 124 \\
\hline G-114-80 & 41 & 111 & 111 & 90 & 80 & 131 \\
\hline G-115-80 & 35 & 119 & 120 & 152 & 146 & 164 \\
\hline G-116-80 & 30 & 123 & 125 & 85 & 75 & 126 \\
\hline G-117-80 & 24 & 103 & 101 & 93 & 84 & 112 \\
\hline$G-137-80$ & 27 & 107 & 105 & 140 & 133 & 130 \\
\hline$G-138-80$ & 25 & 100 & 97 & 159 & 154 & 139 \\
\hline G-156-80 & 30 & 89 & 85 & 125 & 117 & 127 \\
\hline$G-157-80 * 5$ & 28 & 69 & 62 & 332 & 345 & 193 \\
\hline G-161-80 & 35 & 130 & 133 & 327 & 339 & 223 \\
\hline G-169-80 & 40 & 101 & 99 & 117 & 110 & 126 \\
\hline G-178-80 & 30 & 103. & 101 & 147 & 140 & 129 \\
\hline$G-179-80$ & 55 & 123 & 125 & 95 & 85 & 130 \\
\hline$G-180-80$ & 55 & 113 & 112 & 112 & 103 & 142 \\
\hline$G-201-80$ & 33 & 117 & 117 & 143 & 137 & 161 \\
\hline$G-202-80$ & 27 & 110 & 109 & 147 & 140 & 162 \\
\hline G-206-80 & 55 & 117 & 117 & 102 & 93 & 132 \\
\hline
\end{tabular}

\section{Footnotes:}

1. Surface temperatures were usually measured at a convenient faucet closest to the well head. Water pumps were generally allowed to run for severai minutes to ensure that the water was as fresh as possible from the weli. Note that this temperature probably is not the hottest water temperature in the well.: 
Footnotes (Continued)

Note: Some calculated temperatures are anomalous. The following footnotes provide an explanation for the indicated abnormal temperatures.

2. Ca and $\mathrm{Mg}$ predominate over $\mathrm{Na}$ and $\mathrm{K}$, and $\mathrm{K}$ is minimum of all.

3. Ca predominates $\mathrm{Na}$ and Mg predominates $\mathrm{K} ; \mathrm{K}$ is less than 2.5 , yet 2.5 value has been taken for cal"culations which might have brought this abnormality in the calculated temperatures.

4. $\mathrm{Ca}$ and $\mathrm{Mg}$ are considerably higher than $\mathrm{Na}$ and $\mathrm{K}$. $\mathrm{K}$ is less than 2.5 , yet 2.5 value has been taken for calculations which might have brought this abnormality in the calculated temperatures.

5. Ca is considerably higher than $K$. $K$ is less than 2.5 , yet 2.5 value has been taken for calculations which might have brought this abnormality in the calculated temperatures. 
CDMG EXPLORATORY DRILIING PROGRAM AT CALISTOGA, CALIFORNIA

\begin{abstract}
Background
In the initial phase of the California Division of Mines and Geology (CDMG) investigations of the moderate temperature geothermal resource at Calistoga, California, over 200 water well driller's reports were obtained from the files of the California Department of Water Resources' (CDWR). It was hoped that correlation of these logs would reveal the subsurface geology of the Upper Napa Valley, yield temperature data, and allow correlation of aquifers. Several correlation attempts proved entirely futile, due to the un-technical nature of the driller's "geologic" logs, on most of which temperature data was omitted. Probably the unsuccessful correlation attempts were also partly due to the unexpected complexity of the subsurface geology.
\end{abstract}

Three deep geothermal wells (over 1500 feet) were drilled exploring for steam in Calistoga in the late 1950's and early 1960's. These were logged by a geologist, but unfortunately, the records cannot be located.

In view of the lack of usable drill hole data, it became evident that drilling some exploratory holes at Calistoga would add a great deal of scientific information to CDMG's investigation of the geothermal resource. 
Goals of the Drilling Program

While organizing the exploratory drilling program for the Calistoga investigation, careful consideration was given to the amount of funding set aside for drilling operations. It was essential to glean the greatest amount of scientific information from the smallest number of drill holes.

Depths to the hot water zone or zones were needed. Geologic columns were required to unravel the subsurface geology and augment geophysical surveys that CDMG performed at Calistoga. Down hole temperatures were required from temperature gradient surveys (to this end, approximately 25 temperature gradient surveys were obtained from Occidental Geothermal, Inc. of existing "hot water" wells around Calistoga). The areal extent of the geothermal resource might be determined by "wildcat" type drilling. Aquifer testing is required to determine the volumetric nature of the geothermal resource. Chemical analysis of the resource was required to ascertain geochemical and geothermometric properties. Keeping all of these goals in mind, a drilling and casing program was devised and drill site selection was begun.

Rationale for Drill Site Selection

It was determined that as many as six drill holes could be completed with the funding available. Site selection was done with the goals of the program in mind. The goals are to provide (1) base data for geophysical investigations and interpretations, (2) base data on the aquifers and the 
flow of the aquifers, and (3) geochemical information for use in better understanding aquifer limits and geologic structure and to aid in understanding the source and replenishment of water in the system. Along with these goals, the following considerations were weighed in choosing drill sites:

1. Noise pollution.

2. Ease of accessibility.

3. Visual pollution.

4. Nearness of structures.

5. Availability of existing wells at the site for possible reinjection of discharge from the test well.

6. Landowner acceptance.

Initially, six sites were chosen. Then, it was deemed prudent to select six more sites to be alternates if some of the original sites were disallowed due to environmental reasons or landowner rejection. Eventually, 13 drill hole sites were selected in and around Calistoga mostly in vacant fields. The Figure 18 map shows the locations.

Each site was assigned a number for reference purposes. The sites are numbered LES-1 through LES-13. (LES-5 does not appear on the map because it has already been withdrawn by the landowner). The sequence of site numbers has no significance other than the order in which property owners were contacted. It is assumed that at a later date, the drill sites will be re-numbered after completion of each hole. A preliminary sequence of drill sites in order of preference has been established: 


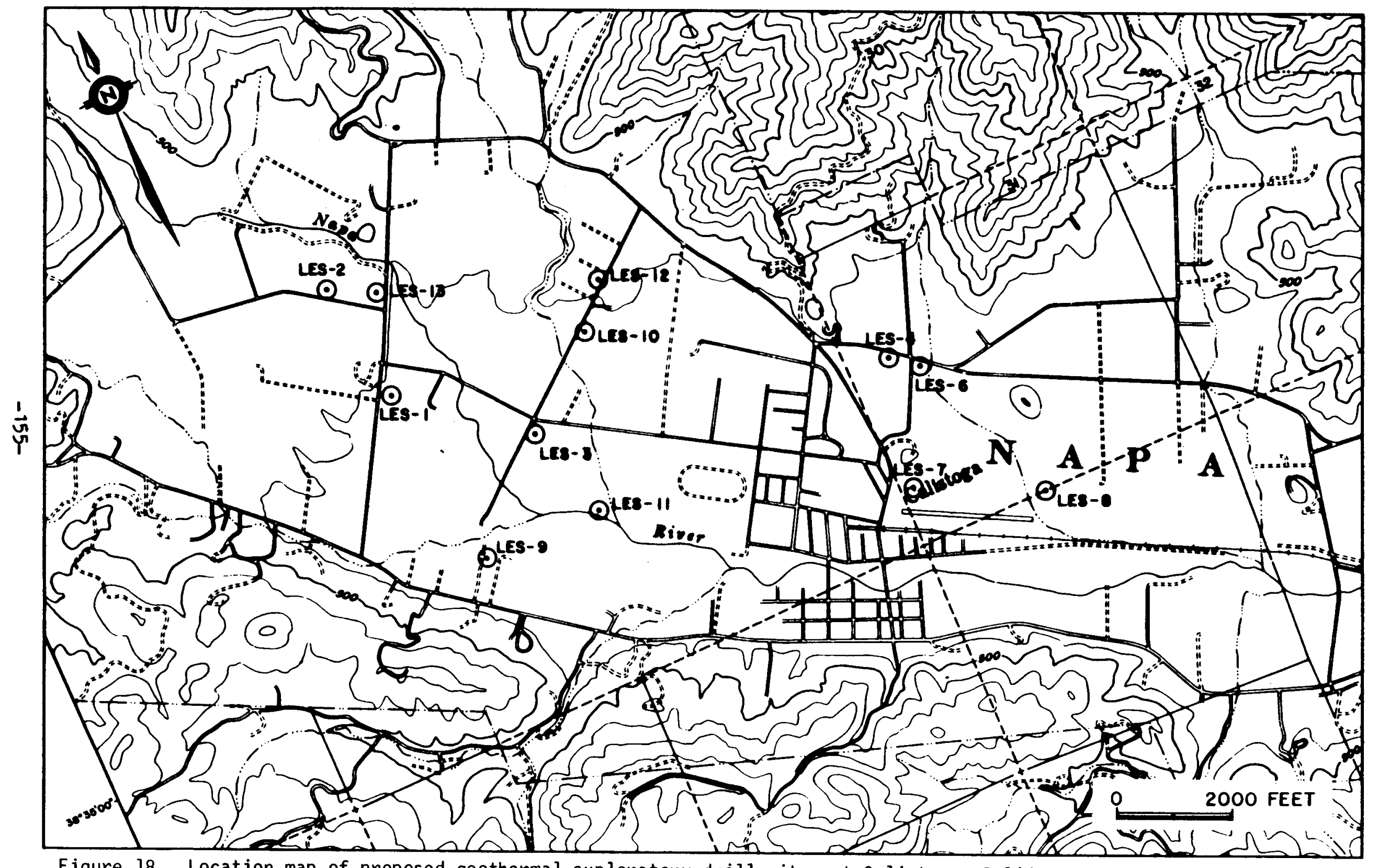

Figure 18. Location map of proposed geothermal exploratory drill sites at Calistoga, California. 
RANK OF PREFERENCE

1.

2 .

3.

4.

5.

6.

7.

8.

9.

10.

11.

12.

13.
DRIII SITE

LES- 1

LES-3

LES-9

LES -10

LES-2

LES-4

LES-7

LES- 11

LES-8

LES-13

LES-12

LES-6

LES-5 (withdrawn)

The following list details the significance of each drill hole site to the overall moderate temperature geothermal investigation at Calistoga:

IES-1 The site is along a traverse where three different geophysical surveys were performed by CDMG. The site has three abandoned wells (two over 1500 feet deep) which may be adequate for reinjection purposes if the exploratory well is across the street. Several of the wells on the property are flowing and there are some more nearby. It was reported that the Franciscan Formation (assumed to be the basement rock type under the valley is only about 200 feet from the surface at this site (Unexpectedly shallow). It is assured that the geothermal resource can be tapped at this site. 
LES-2 Four geophysical techniques have been employed along a traverse near this site, including a shallow hole temperature survey. Correlation of stratigraphy, depth to basement, and vertical position, thickness, and type of aquifers are among the geologic questions to be answered. Local residents and geophysical data indicate a very shallow "hot water" zone at this site (worthy of scientific investigation). The site is essentially close to the edge of an area that encloses the known "hot water" wells at Calistoga. It is expected that the resource can be tapped at this site.

LES-3 The site is near the center of a traverse across the valley where four geophysical surveys"were preformed. A geologic log from this site correlated with. logs from. LES-9 and LES-10 (or LES-12 as an alternate) could produce "an excellent geologic cross-section laterally across the valley. There is an estimated $85 \%$ chance of striking the resource at this site.

LES-4 The site is along a traverse where three geophysical techniques were performed. Some of the lowest electrical resistivity values were recorded at this site. This may indicate a very hot water zone, very mineralized water zone, a large volume of hot water, or a combination of any of the above. The site is near a possible N-S trending fault trace. 
LES-5 This site has been withdrawn from the list of proposed drill sites by the property owner.

LES-6 The site is proposed as an alternate for LES-4 if drilling is disallowed there. It is significant for the same reason as LES-4.

LES-7 No geophysical surveys were performed near this site. It is on the grounds of "Pacheteau's" spa where three wells (approximately 180 feet deep) are reported to bottom in serpentine. It is suspected that this is not the case. Several "hot water" wells are nearby lending themselves to possible piezometric head measurements if an exploratory well were flow tested here. This is the site of the original hot springs at Calistoga. The greatest volume of hot water appears to be available at "Pacheteau's".

LES-8 No geophysical surveys were performed very near this site. It is near the edge of the area of known geothermal wells at Calistoga. It is also on the ëdge of the old original hot springs grounds (now aried up)

LES-9 The site lies on the outer edge of a traverse where four different geophysical surveys were performed. The site, in conjunction with LES-3 and LES-10 (Les-12 as an alternate), would provide geologic data that may be correlated to produce a geologic cross-section across the valley. There may be a fault trace between IsES-3 and 
LES-9. The site is in an area long thought by local residents to be void of "hot water".

LES-10 Four geophysical techniques were employed along a traverse near this site. This site (or LES-12 as an alternate), in conjunction with LES-3 and LES-9, could provide geologic information that may be correlated to produce a geologic cross-section across the valley.

LES-11 There were no geophysical surveys near this site. The site is slightly remote from any known geothermal well. A temperature gradient survey here would fill in a blank area on the map.

LES-12 This site is an alternate to LES-10 if that site should be disallowed for environmental reasons or landowner disapproval. It has the same significance to the geothermal investigation of Calistoga as LES-10.

LES-13 The site was chosen as an alternate location if several other sites and their alternate were rejected due to environmental objections or landowner disapproval. Three different geophysical techniques were employed on a traverse near this site. The site is apparently on the edge of an area suspected of having a very "shallow "hot water" aquifer. Geologic questions to be answered are the same as for the LES-2 site. 


\section{Limited Licenses and NOI's}

In all, three drill sites are within Napa County jurisdiction, eight sites lie within the limits of the City of Calistoga, and one site (LES-13) is on California state owned property.

CDMG staff have drafted a "Limited License" form for landowners to grant permission for drilling the exploratory wells on their property. As of this writing, seven property owner's have responded favorably and one property owner has withdrawn from the program.

Notices of Intention to Drill a Geothermal Resources Well (NOI) have been drafted for each proposed drill site as required by the California Divison of Oil and Gas (CDOG). A copy of the proposed drilling and casing program described above was attached to each NOI.

The NOI's have recently been submitted to the proper agencies. For sites within the city limits of Calistoga, they have been submitted to the City of Calistoga, and for sites within the Napa County limits, but outside city limits, they have been submitted to the Napa County Planning Department.

The submitting of the NOI's initiates the processes involved under the California Environmental Quality Act (CEQA) as administered by the lead agency (city or county and/or CDOG). The CEQA program allows approval, 
conditional approval, or disapproval of a drill site. There are three progressively more stringent filing categories under CEQA regulations that allow approval of a particular drill site: 1) Notice of exemption, 2) Negative declaration, 3) Environmẹtal impact report (EIR). However, a site could be disallowed after preparing an EIR, the category that requires the most rigorous and complete assessment of the impact the proposed activity may have on the environment.

Napa County is currently deciding what category of the CEQA process the proposed drill sites should be regulated by, while the City of Calistoga has issued a notice of exemption. Also, each is responsible for issuing the Land Use Permits for arilling for the sites that come under their respective jurisdicitons.

Drilling Contract

CDMG has prepared and recently released for bid a drilling contract to perform all proposed drilling operations at Calistoga. The contract has been made available to 14 northern California well drilling companies, and bids were received from three of those companies. Award is pending. 
Final Report

Upon completion of the drilling tests, the data developed by all of the tasks of this project will be considered in developing a comprehensive interpretation of the geothermal resources of the area. A final report covering the Calistoga area will then be prepared and released to the public. 
SELECTED REFERENCES

Adams, I.C., 1946, Memoirs and anecdotes of early days in Calistoga, Unpublished, $51 \mathrm{p}$.

Allen, E.T. and Day, A.L., 1927, steam wells and other thermal activity at "The Geysers", California: Carnegie Institution of Washington, Publication No. 378 , p. $98-100$.

Anderson, D.N., 1970, Untitled collection of water well survey forms of geothermal wells in Calistoga, California: California Division of oil and Gas, unpublished, $137 \mathrm{p}$.

Anonymous, 1871, Bancroft's tourists' guide, around the Bay, (North) Geysers, A.L. Bancroft, San Francisco, California, 306 p.

Anonymous, 1871, Handbook of the Calistoga Springs: Alta California Book and Job Printing House, San Francisco, California, approximately 30 p.

Anonymous, 1881, History of Napa and Lake Counties: California, Slocum, Bowen and Company, San Francisco, California, p. 345-350.

Archuleta, Kay, 1977, The Brannan saga - early day Calistoga: Smith McKay Printing Company, San Jose, California, 114 p.

Arnold, H.H., 1948, My Iife in the Valley of the Moon: National Geographic Magazine, v. 94, no. 6, p. 693.

Bader, J.S. and Svitek, J.F., 1973, Data for selected wells - Napa

Quadrangle, Yountville Quadrangle, Rutherford Quadrangle, St. Helena Quadrangle, and Calistoga Quadrangle (5 reports): U.S. Geological Survey Open-file reports.

Bailey, E.E., Irwin; W.P., and Jones; D.L., 1964, Franciscan and related rocks and their significance in the geology of western California: California Division of Mines and Geology Bulletin 183, 165 p.

Barnes, Ivan, 1970, Metamorphic waters from the Pacific Tectonic belt of the west coast of the United States: Science, v. 168, May 22, p. 973-975.

Barnes, Ivan and O'Neil, J.R., 1969, The relationship between fluids in some fresh alpine-type ultramafics and possible modern serpentinization, western United States: Geological Society of America Bulletin, v. 80, p. 1947-1960.

Beard, Yolande S. 1979, The wiapo - a report, Makli Museum Press, Morongo Indian Reservation, Banning, California, 88 p. 
Berkstresser, C.F., Jx., 1968, Data for springs in the northern Coast Ranges and Klamath Mountains of California: U.S. Geological Survey Open-File Report, $49 \mathrm{p}$.

Blake, M.C., Jr., Smith, J.T., Wentworth, C.M., and Wright, R.H., 1971, Preliminary geologic map of western Sonoma County and northernmost Marin County, California: U.S. Geological Survey-Department of Housing and Urban Development Basic Data Contribution 12.

Brown, E. and others, 1970, Methods for collection and analysis of water samples for dissolved minerals and gases, Book 5, Chapter Al of Techniques of Water Resources Investigations of the United States Geological Survey.

Bryan, E.N., 1932, Report of Napa Valley investigation: California Department of Public Works, $71 \mathrm{p}$.

Buck, Claudia, 1980, Mud - back to primodial ooze and loving it: The Sacramento Bee, Thursday, April 24, 1980, p. D-1 and D-11.

Burch, S.H., Grannel, R.B., and Hanna, W.F., 1971, Bouguer gravity map of California, San Luis Obispo: sheet: California Division of Mines and Geology, scale 1:250,000, 4 p. text.

Byerly, P.E., 1966, Interpretations of gravity data from the central Coast Ranges and San Joaquin Valley,: California: Geological Society of America Bulletin, v. 77,..p. 83-94.

Carter, William H., 1948, Geology of the northeast corner of the Calistoga quadrangle, scale 1:62,500, University of California, Berkeley, unpublished M.A. thesis.

Chapman, R.H., 1966, The California Divison of Mines and Geology gravity base station network: California Division of Mines and Geology Special Report 90, 49 p.

Chapman, R.H., 1975, Geophysical study of the Clear Lake region, California: California Division of Mines and Geology Special Report 116, 23 p.

Chapman, R.H., and Bishop, C.C., 1974, Bouguer gravity map of California, Santa Rosa Sheet: California Divison of Mines and Geology, map and 7 p. text, scale, 1:250,000.

Chapman, R.H., and Chase, G.W. 1977, Geophysical survey däta,Appendix B, in Armstrong, C.F.; Environmental geologic analysis of the Porter Creek study area, Sonoma County, California: California Divison of Mines and Geology Open-File Report 77-13SF, 40 p.

Chaturvedi, I. ; 1977, Shallow thermal surỵey as a tool for geothermal site selection: in Abstracts for 1977 Annual Meeting, Association of Engineering Geologists, p. 22.: 
Crutchfield, W.H., Jr., 1953, The geology and silver mineralization of the Calistoga district, Napa County, California: University of California Berkeley, unpublished M.S..thesis, 71 p.

Dibblee, T.W. Jr., 1976, The Rinconada and related faults in the southern Coast Ranges, California, and their tectonic significance: U.S. Geological Survey Professional Paper 981, 55 p.

Dickerson, R.E., 1922, Tertiary and Quaternary history of the Petaluma, Point Reyes, and Santa Rosa Quadrangles: California Academy Science Proceedings 4 th series, v. 11, no. 19. p. 527-601.

Durham, D. L., 1974, Geology of the southern Salinas Valley area, California: U.S. Geological Survey Professional Paper 819, 111 p.

Faye, R.E., 1973, Ground-water hydrology of northern Napa Valley, California: U.S. Geological Survey Water-Resources Investigation 13-73, $64 \mathrm{p}$.

Faye, 1975, Groundwater quality and its relation to geologic structure and formations in the Napa Valley area, California: unpublished thesis

Fluke, Lloyd, editor, 1959, Calistoga centennial book, Don Crawford Association, Napa, California, $100 \mathrm{p}$.

Fournier, R.O., and Rowe, J.J., 1966, Estimation of underground temperatures from the silica content of water from hot springs and wet-steam wells: America Journal Science, v. 264, p. 685-697.

Fox, K.F., Jr., Sims, J.D., Bartow, J.A., and Helley, E.J.,1973, Preliminary geologic map of eastern Sonoma County and Western Napa County, California: U.S. Geological Survey Miscellaneous Field Studies map MF-483 (also Basic Data Contribution (56), scale 1:62,500.

Garrison, L.W., 1972, Geothermal steam in The Geysers-Clear Lake region, California: Geological Society of America Bulletin, v. 83, no. 5, p. 1449-68.

Gealey, W.K., 1951, Geology of the Healdsburg quadrangle, California: California Division of Mines Bulletin, $161,75 \mathrm{p}$.

Goldstein, N.E., Norris, R.A., and Wilt, M.J., 1978, Assessment of surface geophysical methols in geothermal exploration and recommendations for future research: Lawrence Berkeley Laboratory, University of California, Report No. LBL $-6815,166$ p.

Hanna, W.F. 1970, Aeromagnetic and gravity features of the western and Salinas basement terranes between Cape San Martin and San Luis Obispo, California: U.S. Geological Survey Professional Paper 700-B, p. 66-77. 
Horwitz, W., 1970, Official methods of analysis of the Association of Official Analytical Chemists, [llth edition]: A.O.A.C., Washington, D.C.

Hsu, K.J., 1969, Preliminàry report and geologic guide to Franciscan melanges, Morro Bay-San Simeon Area, California: California Division of Mines and Geology Special Publication 35, 46 p.

Johnson, F.A., 1943, Petaluma Region: California Division of Mines Bulletin 118, p. $622-627$.

Johnston, Stedwell, 1948, The geology of a portion of the Calistoga quadrangle: University of California, Berkeley, M.A. thesis, 41 p.

Keller, G.V., 1966, Dipole method for deep resistivity studies: Geophysics, v. 21 , no. 6 , p. 1088-1104.

Koenig, James B., 1961, Reconnaissance geologic map of part of the Calistoga quadrangle, California, scale 1:24,000, California Division of Mines and Geology, reconnaissance mapping for the State Geologic Map.

Koenig, J.в., 1963, Geologic map of California, Olaf P. Jenkins edition, Santa Rosa sheet: California Division of Mines and Geology, scale $1: 250,000$.

Koenig, J.B. and Anderson, D.N., 1970, Map of Calistoga Geothermal Area, Napa County, California: California Division of Oil and Gas, Unpublished.

Kunke1, Fred and Upson, J.E., 1960, Geology and ground water in Napa and Sonoma Valleys, Napa and Sonoma Counties, California: U.S. Geological Survey Water Supply Paper 1498, 252 p.

LeShack, L.A., J.E. Lewis, N.W. O'Hara, and Chang, D.C., 1978, Shallowtemperature suxveys-- A rapid reconnaissance technique for geothermal prospects: Preprint for Annual Meeting Society of Exploration Geophysicists, pp. 1-36.

Martin, Roger C., Higgins, Christ., and Olmstead, Dennis, 1980, Resource assessment of low- and moderate-temperature geothermal waters in California; Report of the first year, $1978-79$ of the U.S. Department of Energy-California State-coupled program: California Division of Mines and Geology interim report for the U.S. Department of Energy: Division 3-16 of Geothermal Energy, 188 p, 9 plates.

McNitt, J.R., 1968, Geology of the Kelseyville quadrangle, Sonoma, Lake, and Mendocino Counties, California: California Division of Mines and Geology Map sheet 9, scale 1:62,500.

Muffler, L.J.P., editor, 1979, Assessment of geothermal resources of the United States - 1978: U.S. Geological Survey Circular 790, 163 p. 
Nettleton, L.L., 1940, Geophysical prospecting for oil: McGraw Hill Book Company, New York, $444 \mathrm{p}$.

Occidental Geothermal, Inc., 1977, Downhole temperature log survey in Calistoga, California: unpublished.

Orellana, Ernesto, and Mooney, H.M., 1966, Master tables and curves for vertical electrical soundings over layered structures: Interciencia, Madrid.

Osmont, V.C., 1905, A geologic section of the Coast Ranges north of the Bay of San Francisco: University of California Department of Geology Science Bulletin, v. 4, p.39-87.

Parasnis, D.S., 1975, Mining geophysics: Methods in geochemistry and geophysics, v. 3, Elsevier, New York, 395 p.

Ploff, Donald, 1977, Preliminary documentation for a FORTRAN program to compute gravity terrain corrections based on topography digitized on a geographic grid: U.S. Geological Survey Open-File Report 77-535, 45 p.

Presser, T.S. and Barnes, I., 1974, Special Techniques for determining chemical properties of geothermal water: U.S. Geological Survey, Water Resources Investigations Paper 22-74.

Rainwater, F.H. and Thatcher, L.L., 1960, Methods for collection and analysis of water samples: U.S. Geological Survey Water Supply Paper 1454.

Real, C.R., Toppozada, T.P., and Parke, D.L., 1978, Earthquake catalog of California, January.1, 1900 - December 31, 1974, California Division of Mines and Geology, Special Publication 52, 15 p.

Rinehart, J.S., 1972, Fluctuations in Geyser Activity caused by variations in earth tidal forces, barometric pressure, and tectonic stresses: Journal of Geophysical Research, v. 77, no: 2, p. 342-350.

Roberson, C.E., and Whitehall, H.C., 1961, Ammoniated thermal waters of Lake and Colusa Counties, California: U.S. Geological Survey Water-Supply Paper No. 1535-A, p. 11 .

Stearns, N.D., Stearns, H.T., and Waring, G.A., 1937, Thermal springs in the United States: U.S. Geological Survey, water Supply Paper No. 679-B, P. 123

Studt, F.E., 1963, Geophysics of Waiotapu area, in Waiotapu geothermal field: New Zealand Department of Science and Industry Research Bulletin 155 , p. $35-41$. 
Swe, Win, and Dickinson, W.R., 1970, Sedimentation and thrusting of Late Mesozoic rocks in the Coast Ranges near Clear Lake, California: Geological Society of America, v. 81, no. 1, p. 165-188.

Swick, C.H., 1942, Pendulum gravity measurements and isostatic reductions: U.S. Coast and Geodetic Survey Special Publication no. 232, 82 p.

Taliaferro, N.L., 1951, Geology of the San Francisco Bay counties: California Division of Mines Bulletin 154, p. 117-150.

Taras, J.J. and others, 1971, standard methods for the examination of water and waste water: $13 \mathrm{th}$ edition, American Public Health Association, Washington, D.C.

Thompson, J.M., 1975, Selecting and collecting thermal springs for chemical analysis: A method for field personnel: U.S. Geological Survey Open-File Report 75-68.

U.S. Geological Survey, 1973, Aeromagnetic map of the Clear Lake area, Lake, Sonoma, Napa, and Mendocino Counties, California: U.S. Geological Survey Open-File Report 73-299, scale, 1:62,500.

U.S. Geological Survey, 1974, Aeromagnetic map of parts of the Santa Rosa and San Francisco 1 X 2 quadrangles, California: U.S. Geological Survey Open-File Report 74-81, scale, 1:125,000.

Waring, G.A., 1915, Springs of California: U.S. Geological Survey Water-Supply Paper 338, $410 \mathrm{p}$.

Weaver, C.E., 1949, Geology of the Coast Ranges immediately north of the San Francisco Bay region, California: Geological Society of America Memoir 35, 242 p.

White, D.E., 1957, Magmatic, connate, and metamorphic waters: Geological Society of America Bulletin, v. 68, p. 1659-1682. 1957, Thermal waters of volcanic origin: Geological society of America Bulletin, v. 68, p. 1637-1658.

White, D.E., Barnes, I., and O'Neil, J.R., 1973, Thermal and Mineral Waters of Nonmeteoric Origin, California Coast Ranges: Geological Society of America Bulletin, v. 84, p. 547-560.

White, D.E. . Hem, J.D., and Waring, G.A., 1963, Chemical composition of sub-surface waters: U.S. Geological Survey Professional Paper 440-F, 67 p.

White', D.E., Hem, J.D., and Waring, G.A., 1963, Chemical composition of sub-surface waters: U.S. Geological Survey Professional Paper 440-F, 67 p.

White, D.E., Muffler, L.J.P., and Truesdell, A.H., 1971, Vapor-dominated hydrothermal systems compared with hot-water systems: Economic Geology, v. 66, p. 75-97. 


\section{APPENDIX A}

The following are reproductions of annotated computer printouts of the geochemical analysis of water wells sampled by California Division of Mines and Geology (CDMG) at Calistoga, California. The analyses are numbered G-001-80 through G-206-80.

Correspondingly, the analyses' identification numbers relate to the water well location numbers 001-206 on Plate 10.

For a later report CDMG plans to present this data on microfiche. 
CALISTOGA SET 1

1 G-001-80

ELEMENT

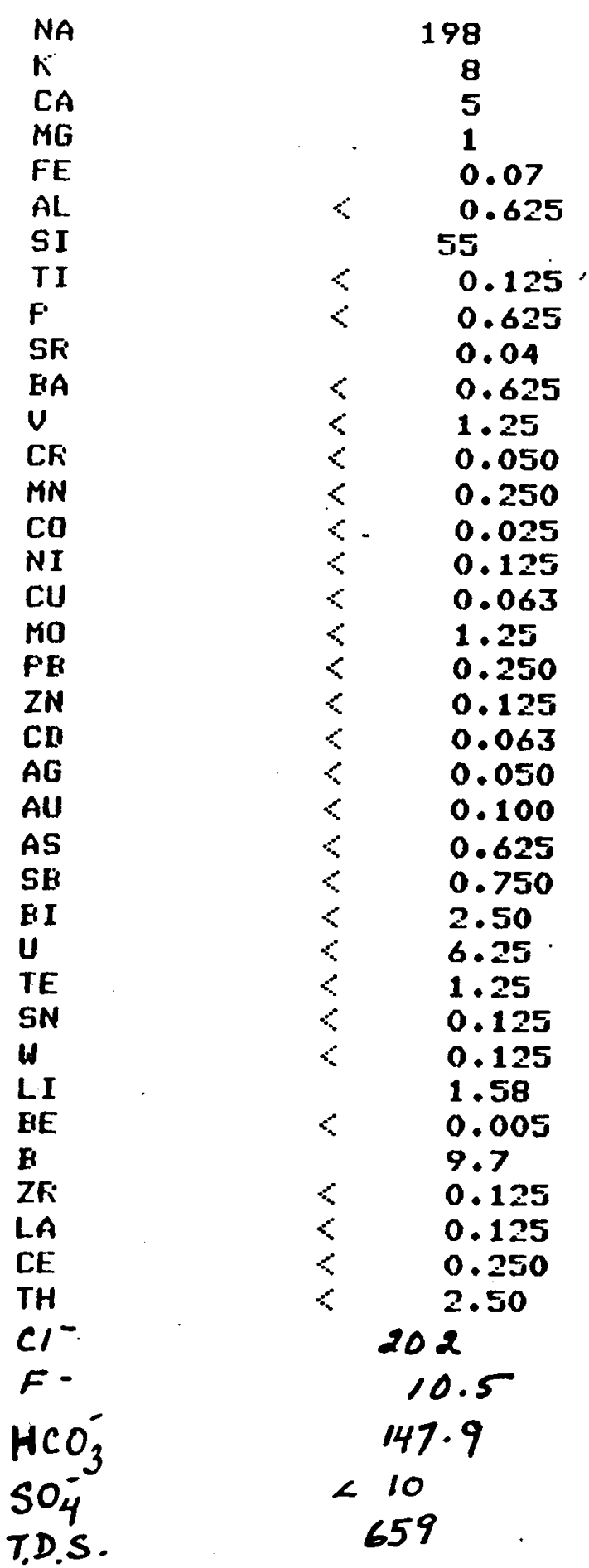

CONCENTFATION (PFM)

$\begin{array}{ll}\text { Tempuature } & 45^{\circ} \mathrm{C} \\ \text { pH } & 7.00 \\ \text { Salinity } & 0.05 \% \\ \text { Specifie Conductance } & 600 \mathrm{\mu moh} / \mathrm{cm}\end{array}$

CORPECTED T.0.5. 586 
CALISTOGA SET 1

$2 \quad$ G-002-80

ELEMENT

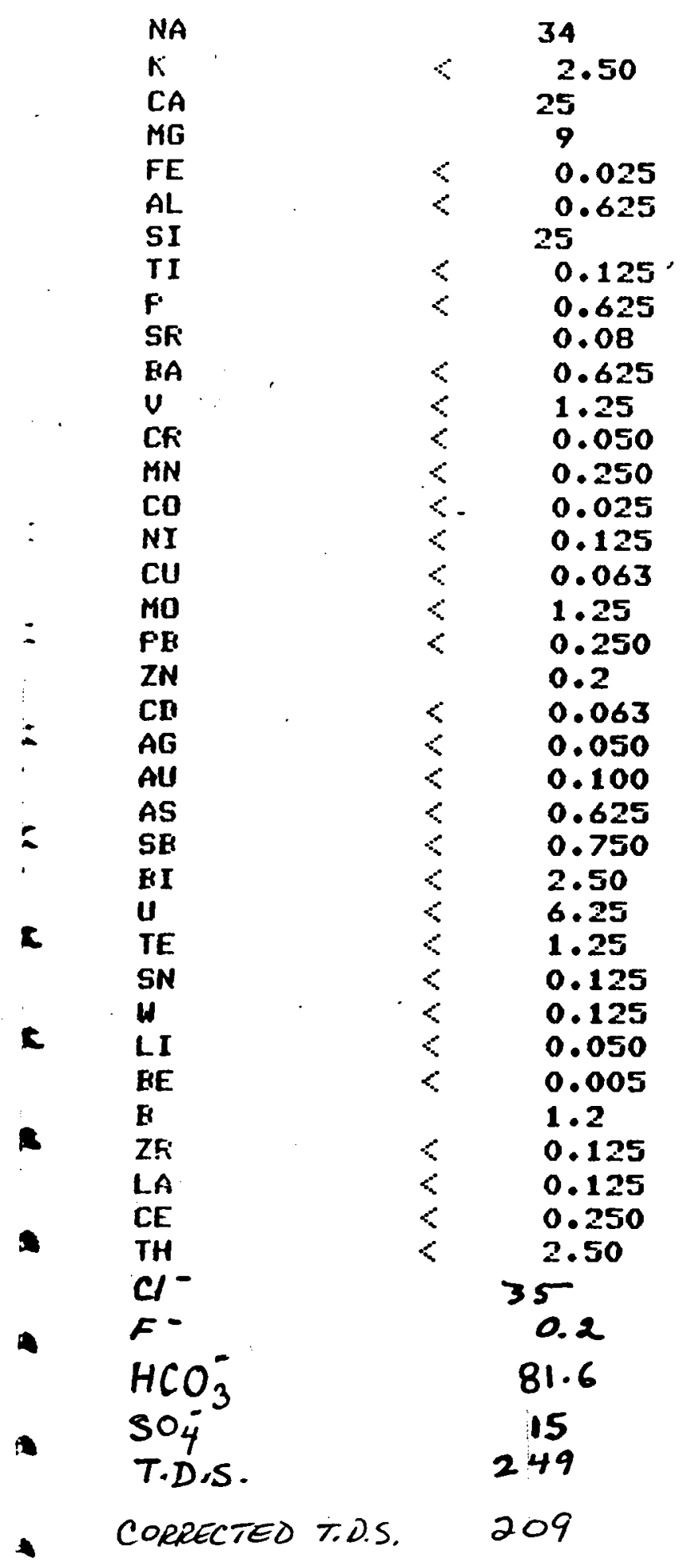

CONCENTKATION (FPM)

$\begin{array}{ll}\text { Tenferature } & 18.5^{\circ} \mathrm{C} \\ \text { pH } & 6.20 \\ \text { Salinity } & 0.00 \%\end{array}$

specifue Couductance $250 \mathrm{unosh} / \mathrm{cm}$ 
CALISTOGA SET 1

$3 \quad 6-003-80$

\section{ELEMENT}

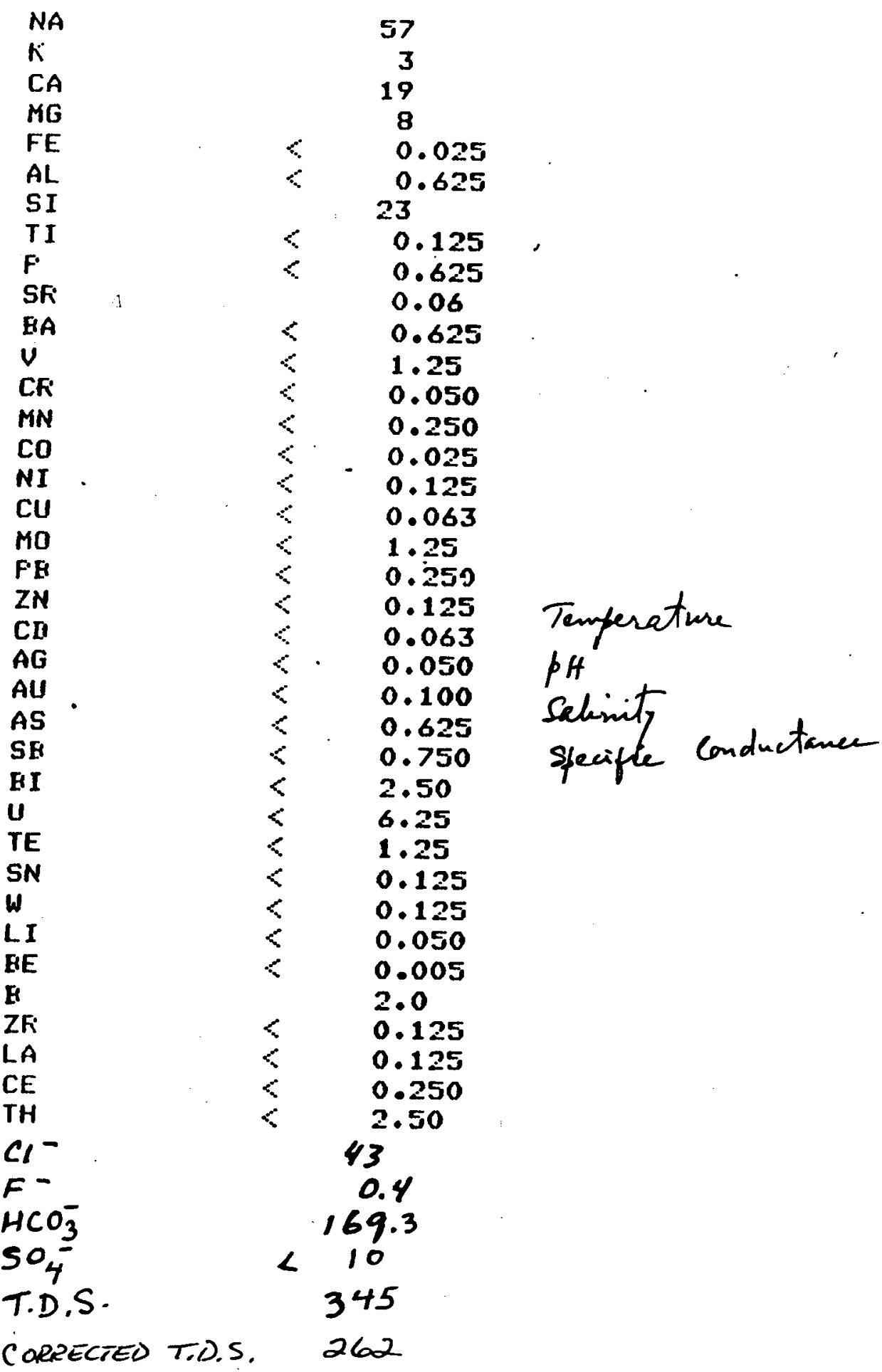

\section{CONCENTFATION (FFM)}

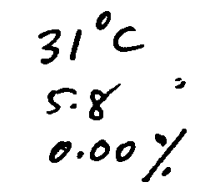

380 enertan 
CALISTOGA SET 1

4 G-004-80

ELEMENT

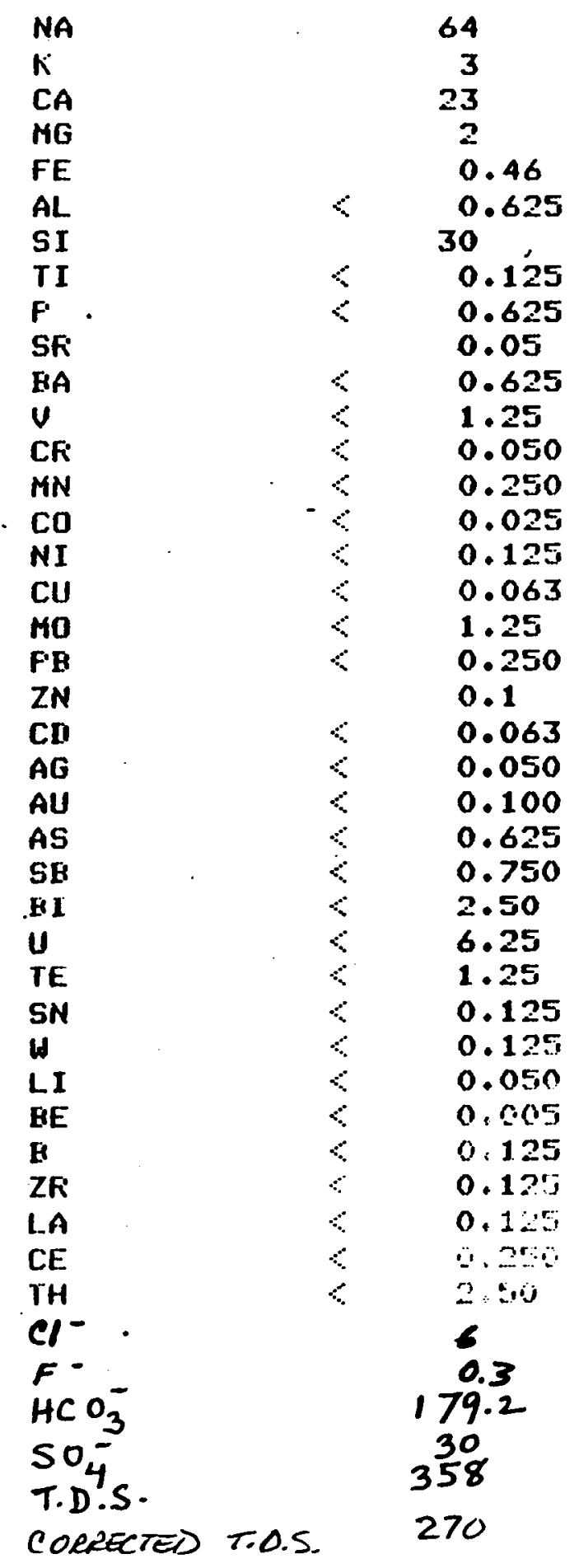

CONCENTRATION (FFM) 
CALISTOGA SET 1

$5 \quad 6-005-80$

EI...EMENT

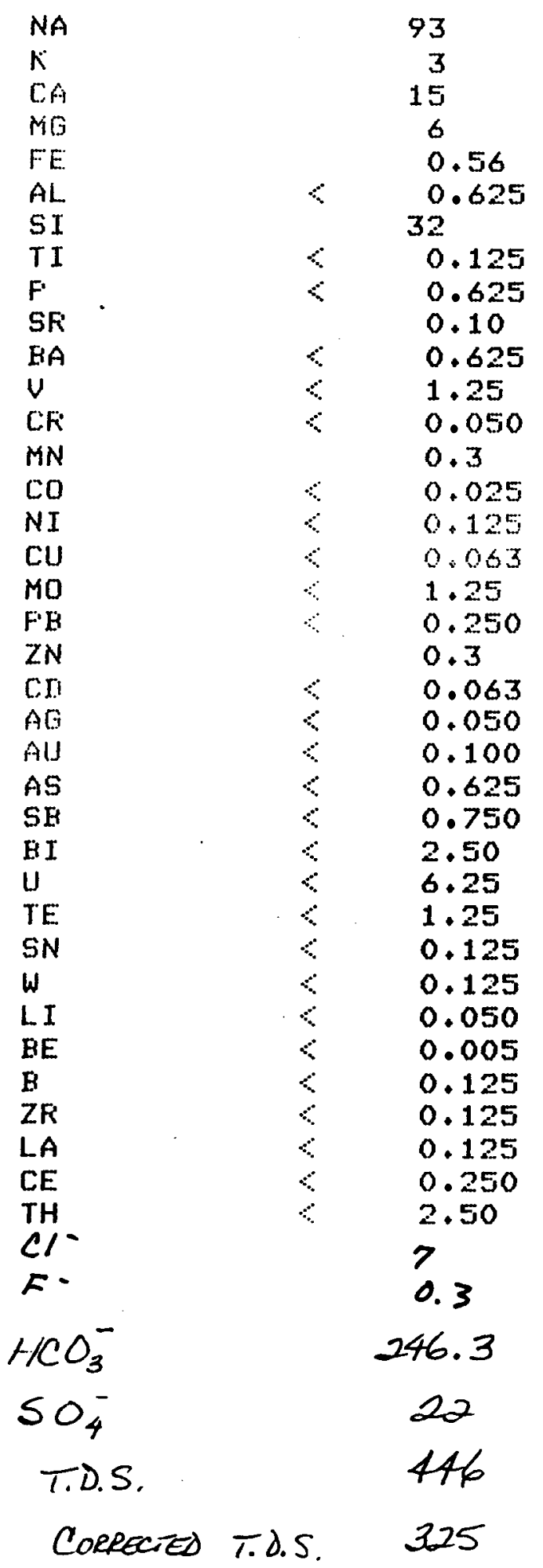

CONCENTFATION (FFM)

$\begin{array}{ll}\text { Temperature } & 19^{\circ} \mathrm{C} \\ \mathrm{pH} & 6.15 \\ \text { Salinity } & 0.02 \%\end{array}$

Spec. Conductance 300 umokf $\mathrm{cm}$ 
CALISTOGA SET 1

6

G-006-80

ELEMENT

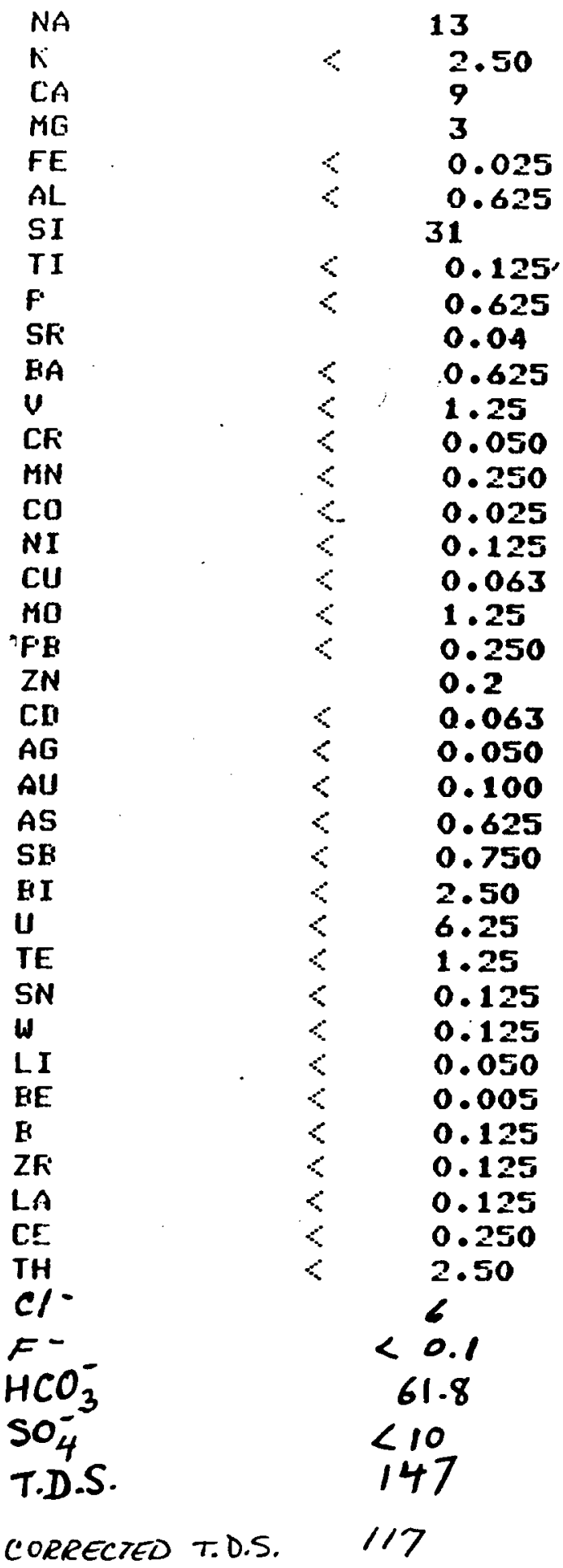

CONCENTFATION (FFM)

Temperature

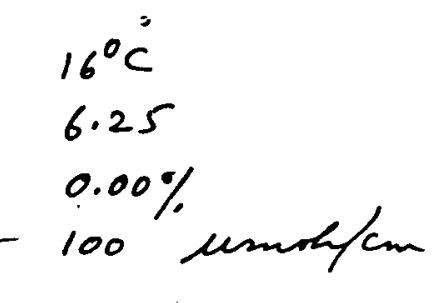

salinity

Specific Conductaner $100 \%$ unoticm

2 
CALISTOGA SET 1

7

G-007-80

ELEMENT

NA

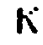

CA

MG

FE

AL

SI

TI

$F$

SR

HA

U

CF:

$M N$

$\therefore \mathbf{C O}$

NI

$\mathrm{CU}$

MO

FB

ZN

CD

AG

AU

AS

SE

BI

U

TE

SN

U

LI

IE

ZF

LA

CE

IH

$\mathrm{Cl}-$

$\mathrm{F}$ -

$\mathrm{HCO}_{3}^{-}$

$\mathrm{SO}_{4}^{-3}$

T.D.S.

CORRECTED T.D.S.
CONCENTFATION (FFM)

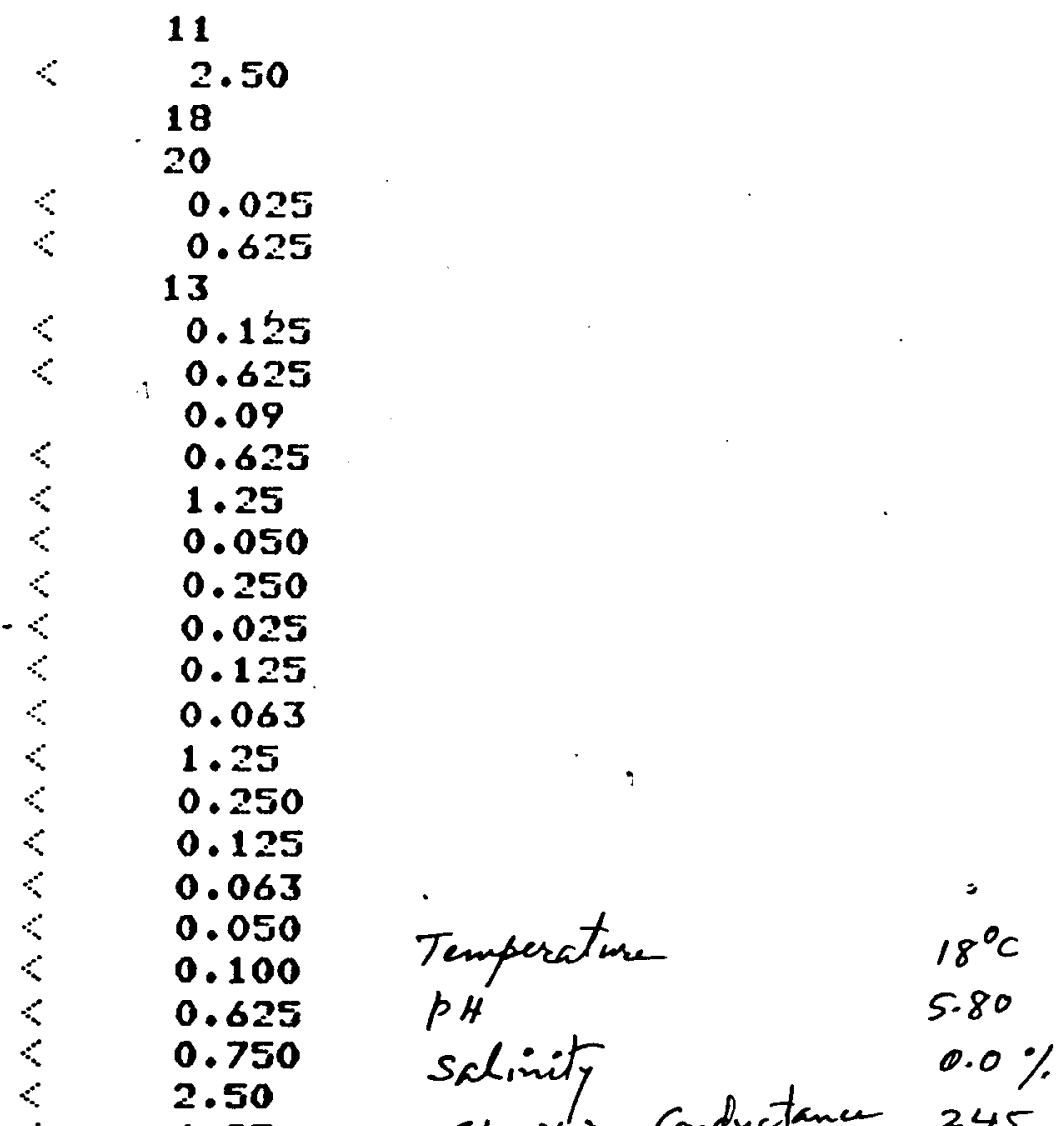

6.25

1.25

0.125

0.125

0.050

0.125

0.125

0.125

2.50

$<\quad 10.1$

125.8

$<\quad 10$

specific Conductance 245 unnoh/cm

) 
CALISTOGA SET 1

8

G-008-80

ELEMENT

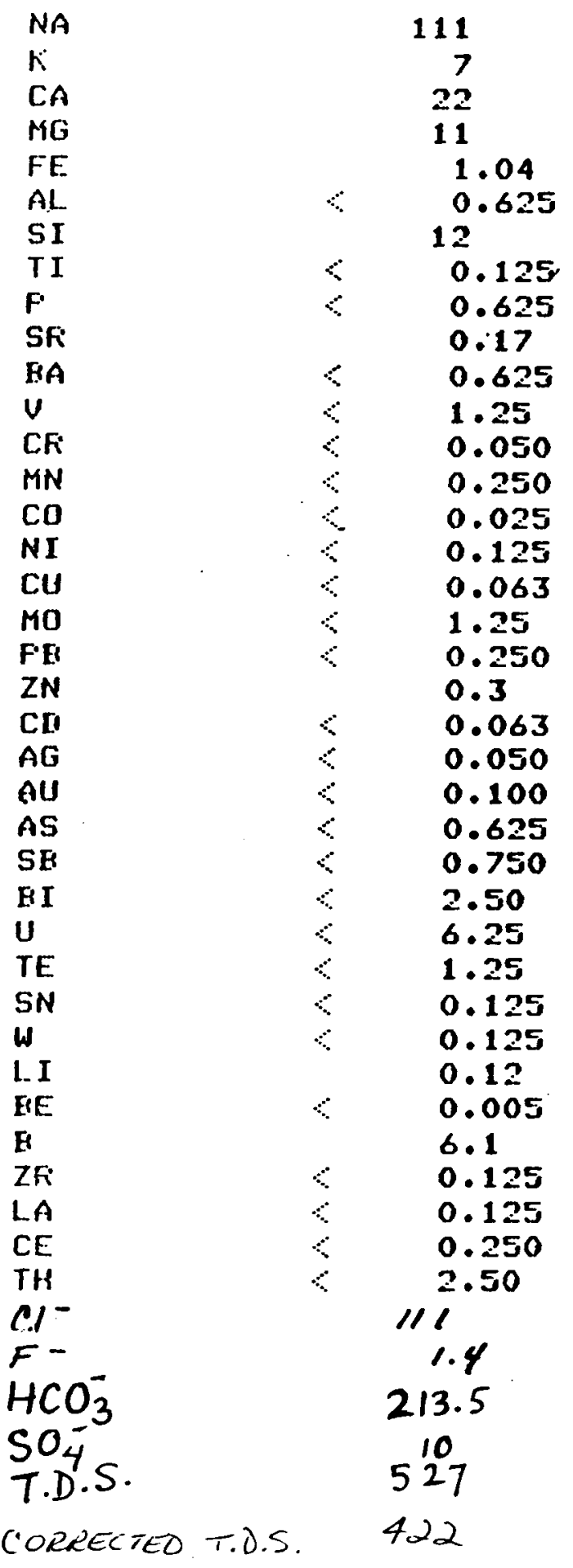

CONCENTFATION (FFM)

Temperature

$\begin{array}{ll}\mathrm{PH} & 6.20\end{array}$

Salinity
Specific Conductance $500 \%$ Mmok/cm 
CALISTOGA SET 1

9

G-009-80

ELEMENT

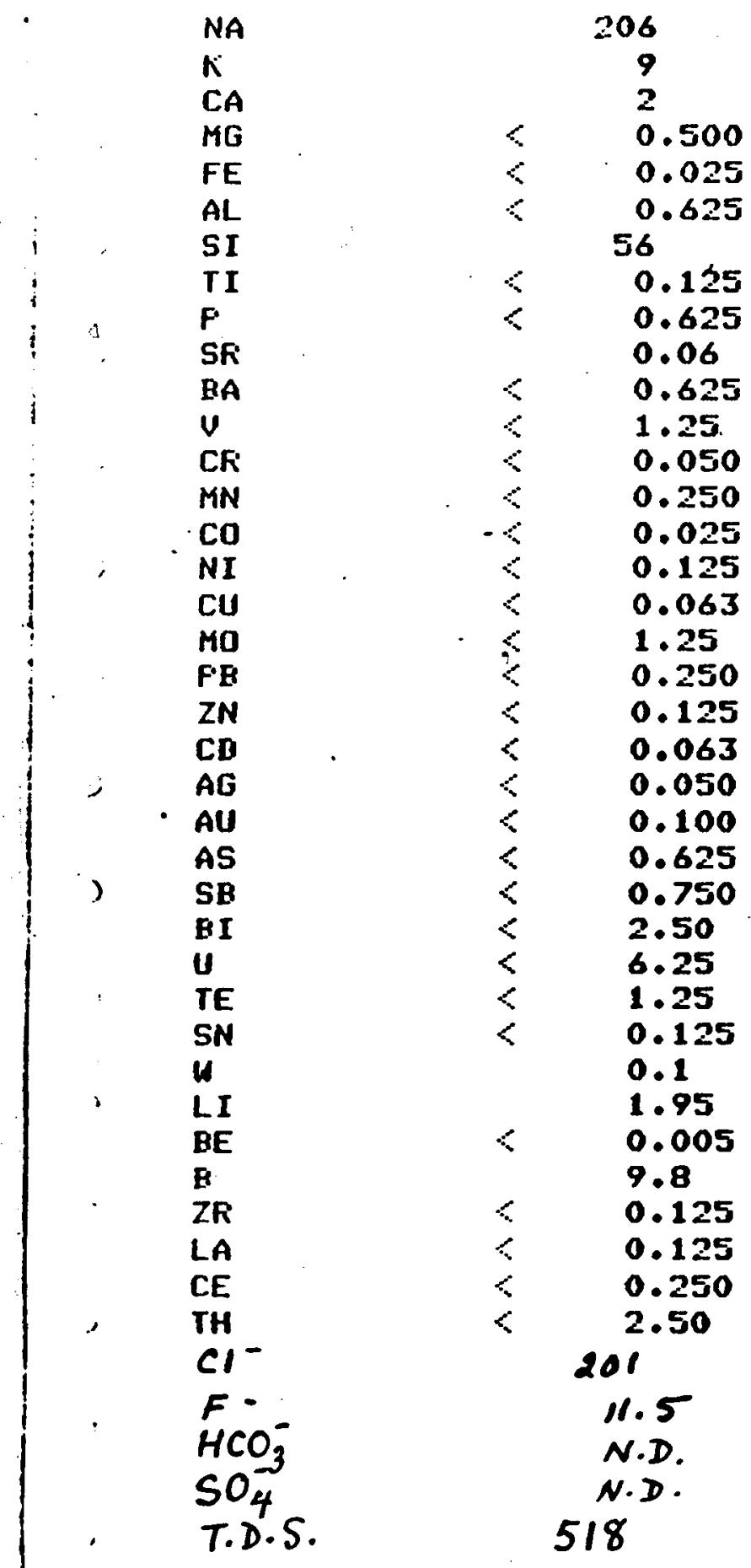

CONCENTFATION (FFM) 
CALISTOGA SET 1

$10 \quad$ G-010-80

ELEMENT

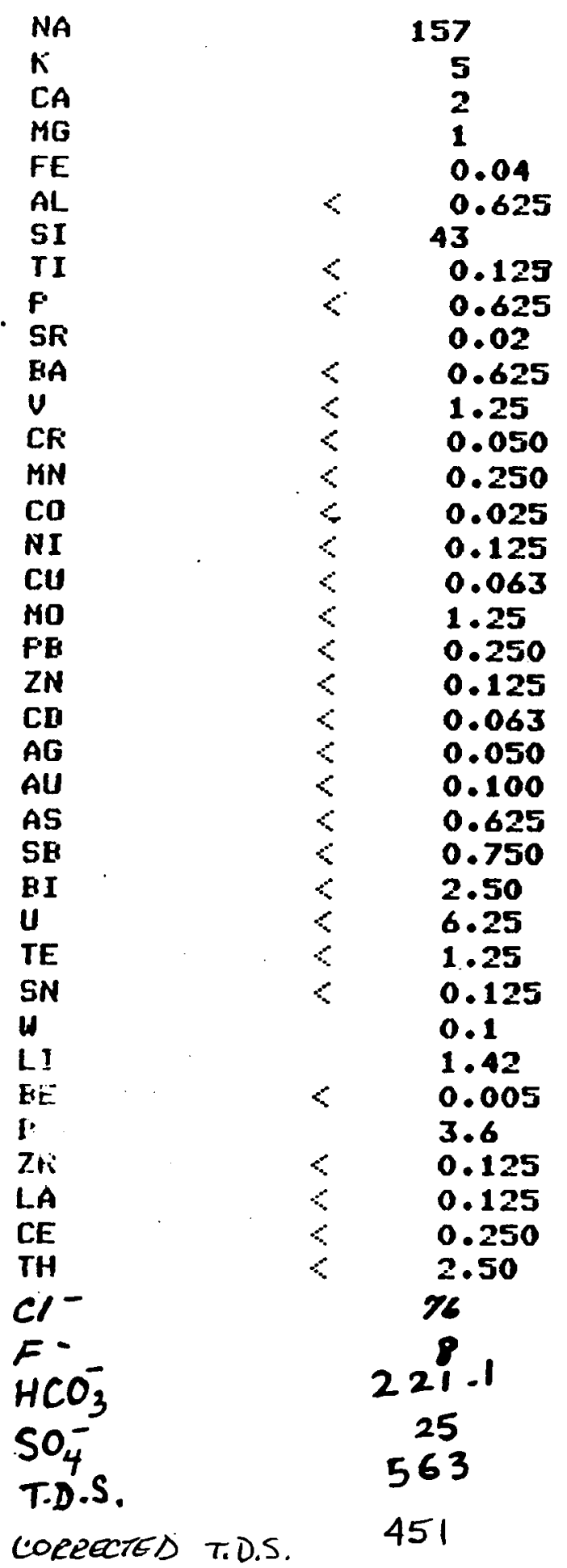

CONCENTRATION (F.PM)

$\begin{array}{ll}\text { Temperature } & 39.5^{\circ} \mathrm{C} \\ \text { pH } & 7.25 \\ \text { salinity } & 0.10 \% \\ \text { specifie Conductance } & 670 \text { umoh/an }\end{array}$ 
CALISTOGA SET 1

11

G-011-80

ELEMENT

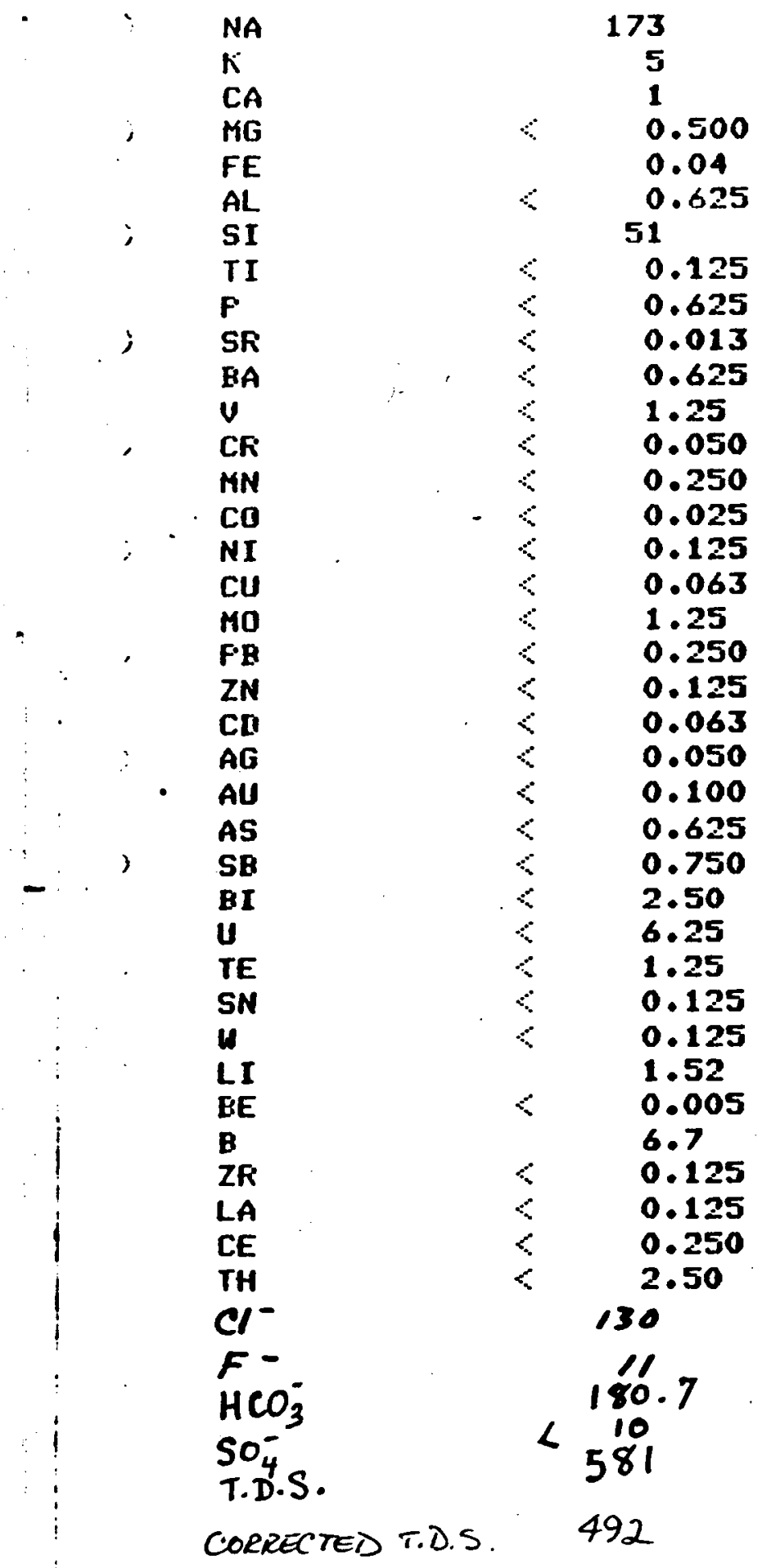

CONCENTFATION (FFM)

Tenperature $p H$ Salinity

specific Conductance 650 uno. $178^{\circ} \mathrm{F} @ 214^{\prime}$

$7 \cdot 4$

$0.01 \%$ 
CALISTOGA SET 1

12 G-012-80

ELEMENT - CONCENTRATION (FFM)

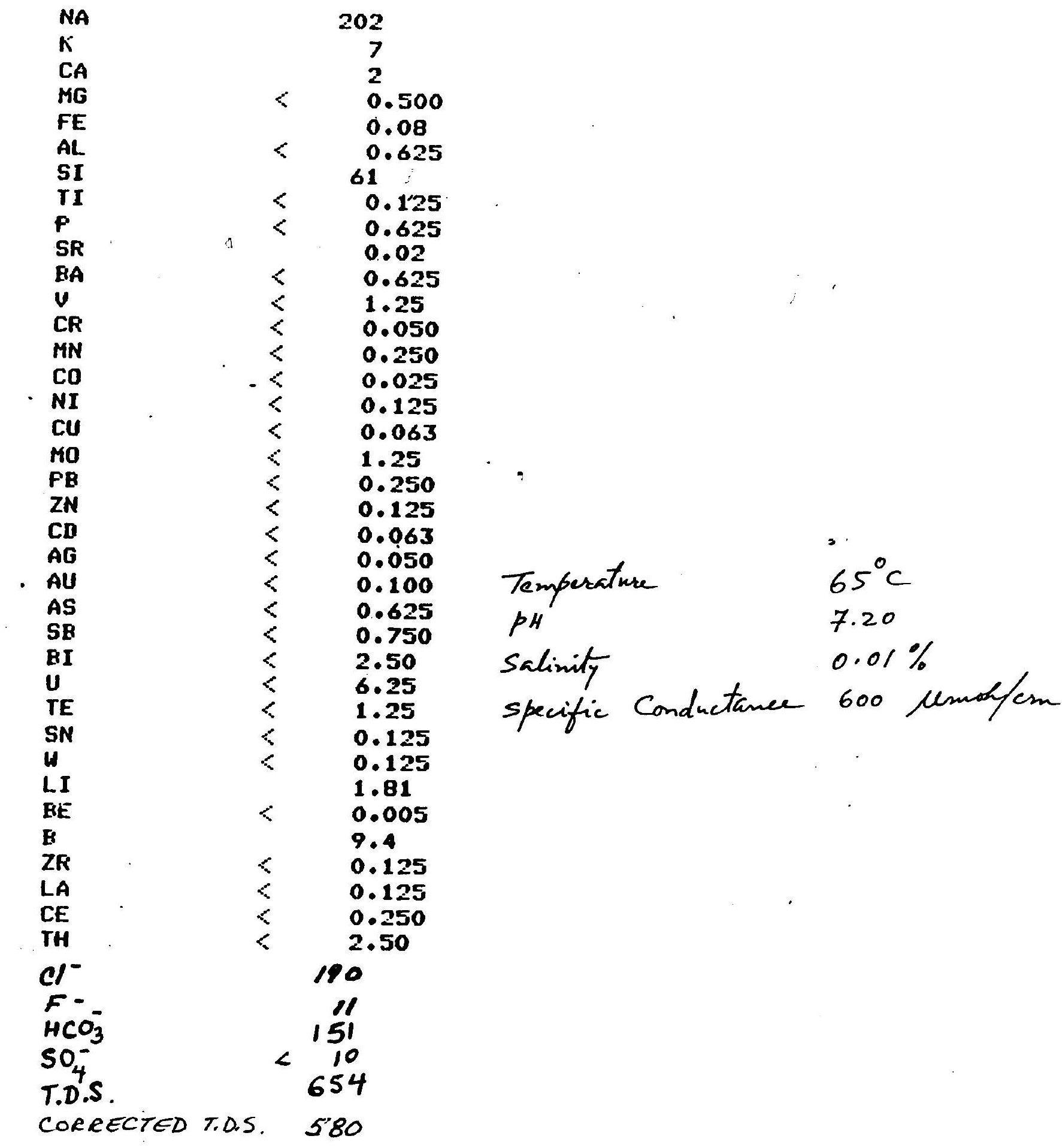


CALISTOGA SET 1

$13 \quad G-013-80$

ELEMENT

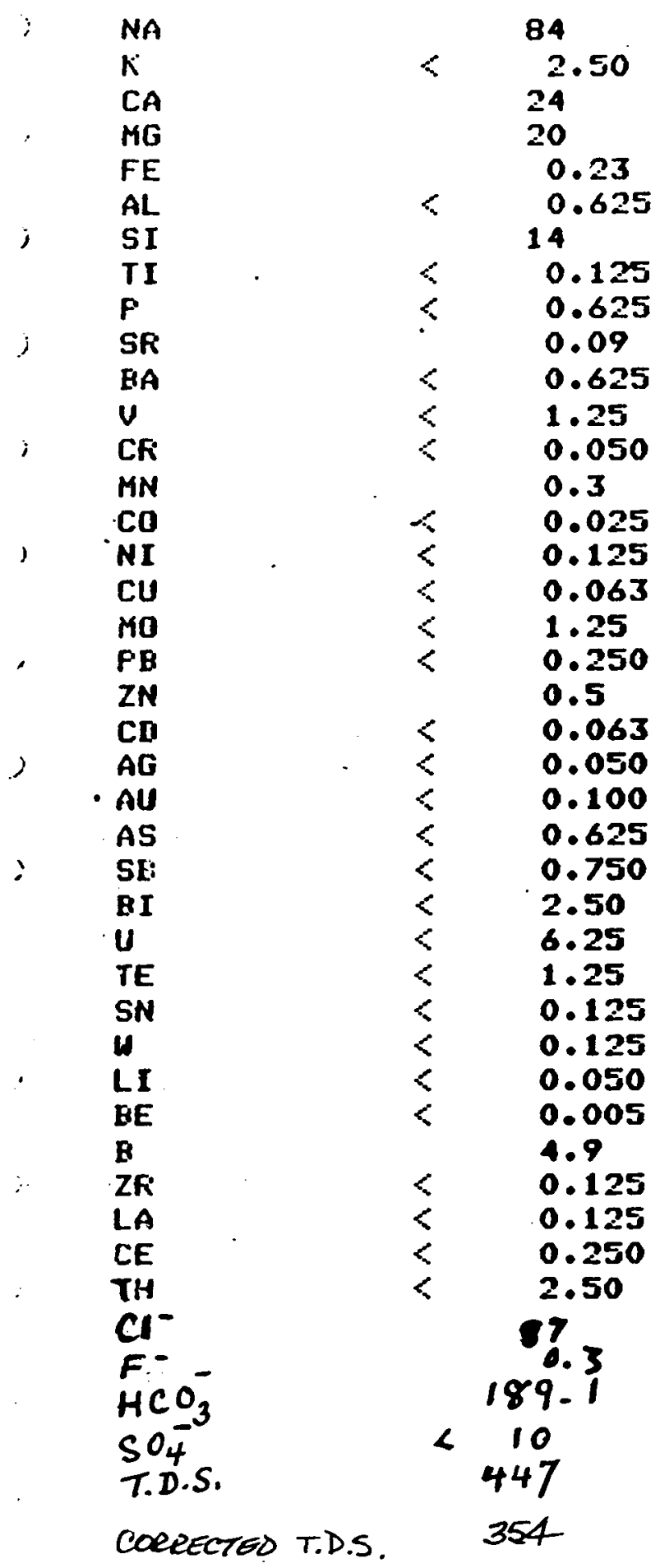

CONCENTRATION (PPM)

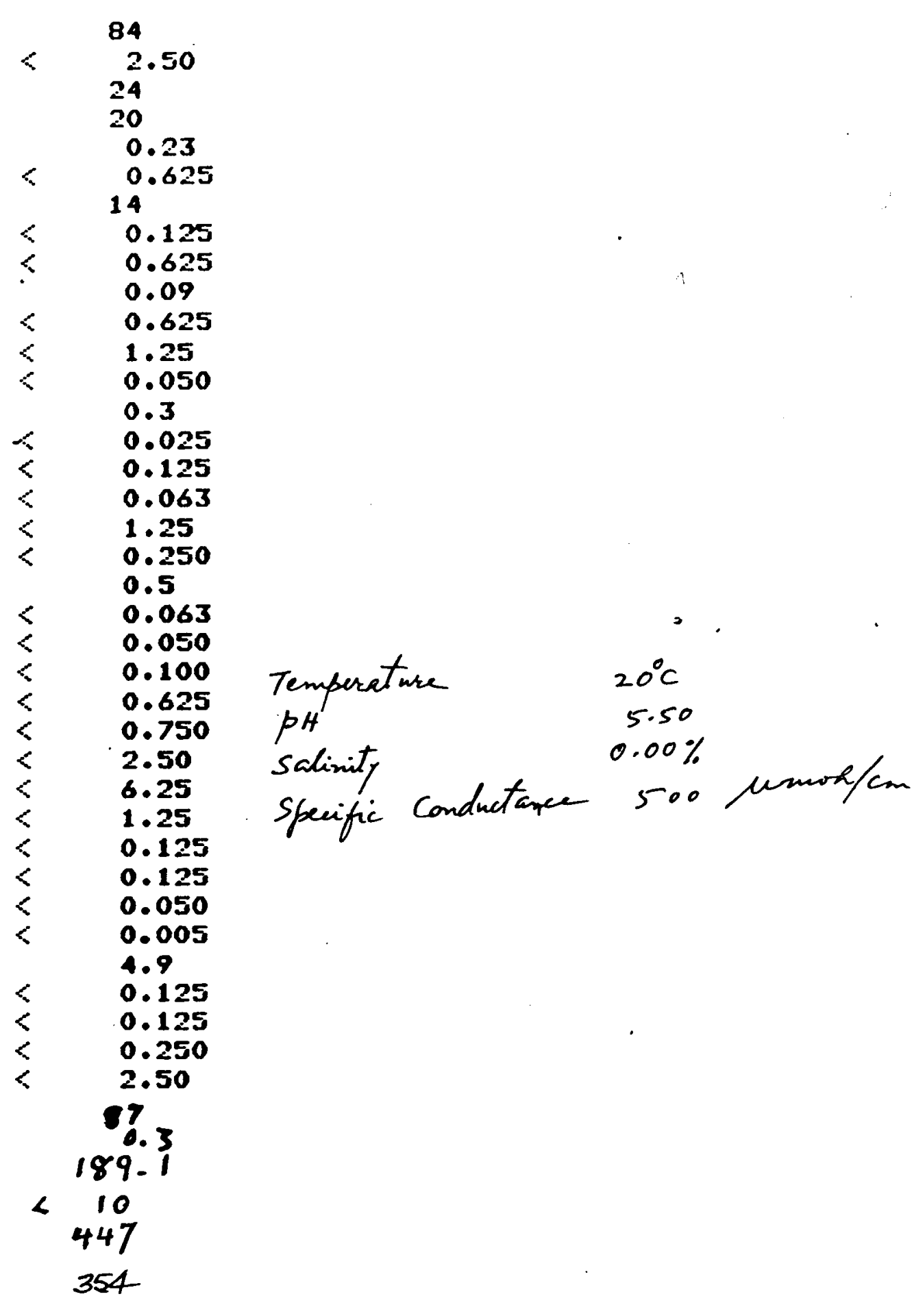


CALISTOGA SET 1

14 G-014-80

ELEMENT

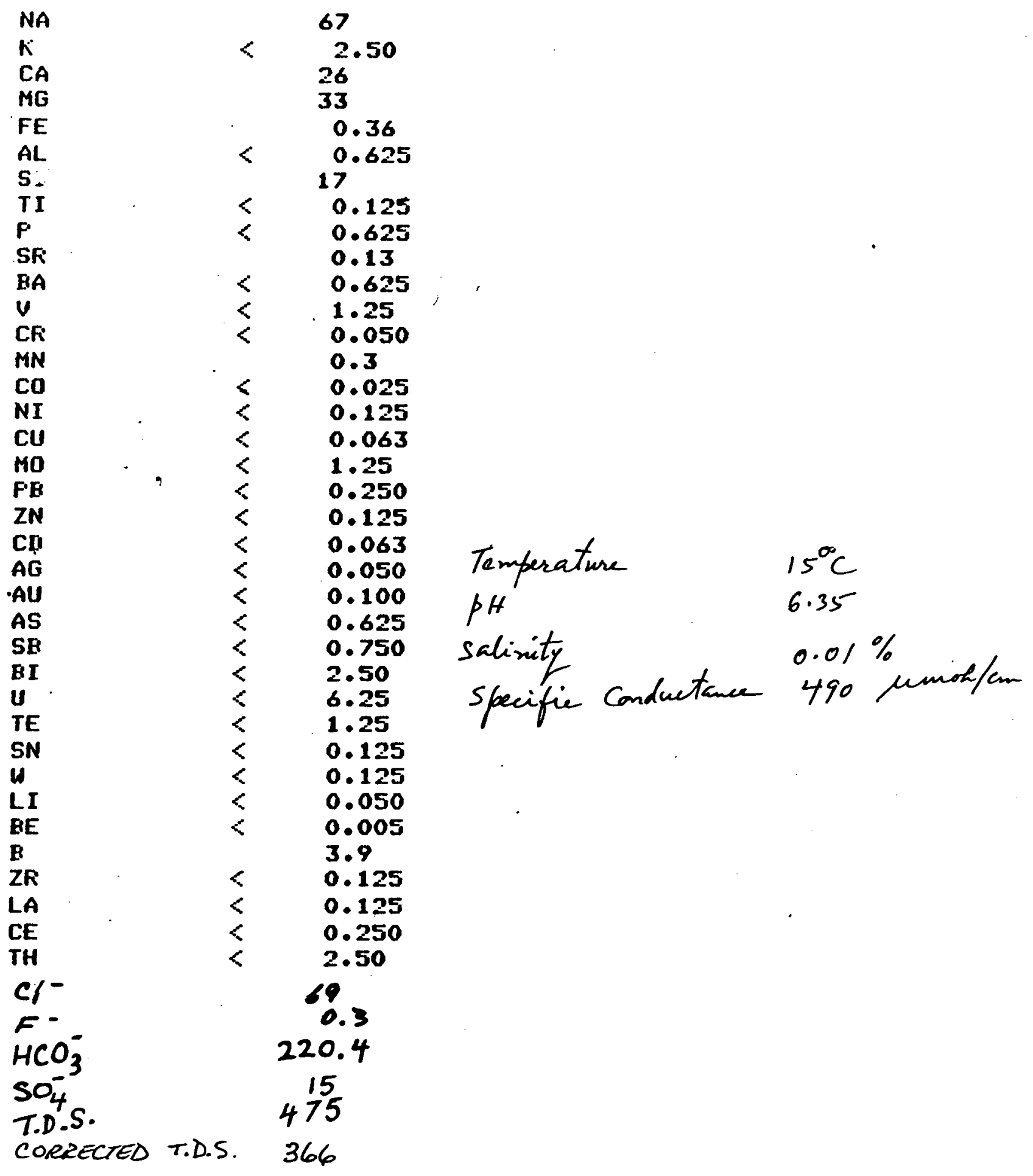


CALISTOGA SET' 1

15 G-015-80

ELEMENT

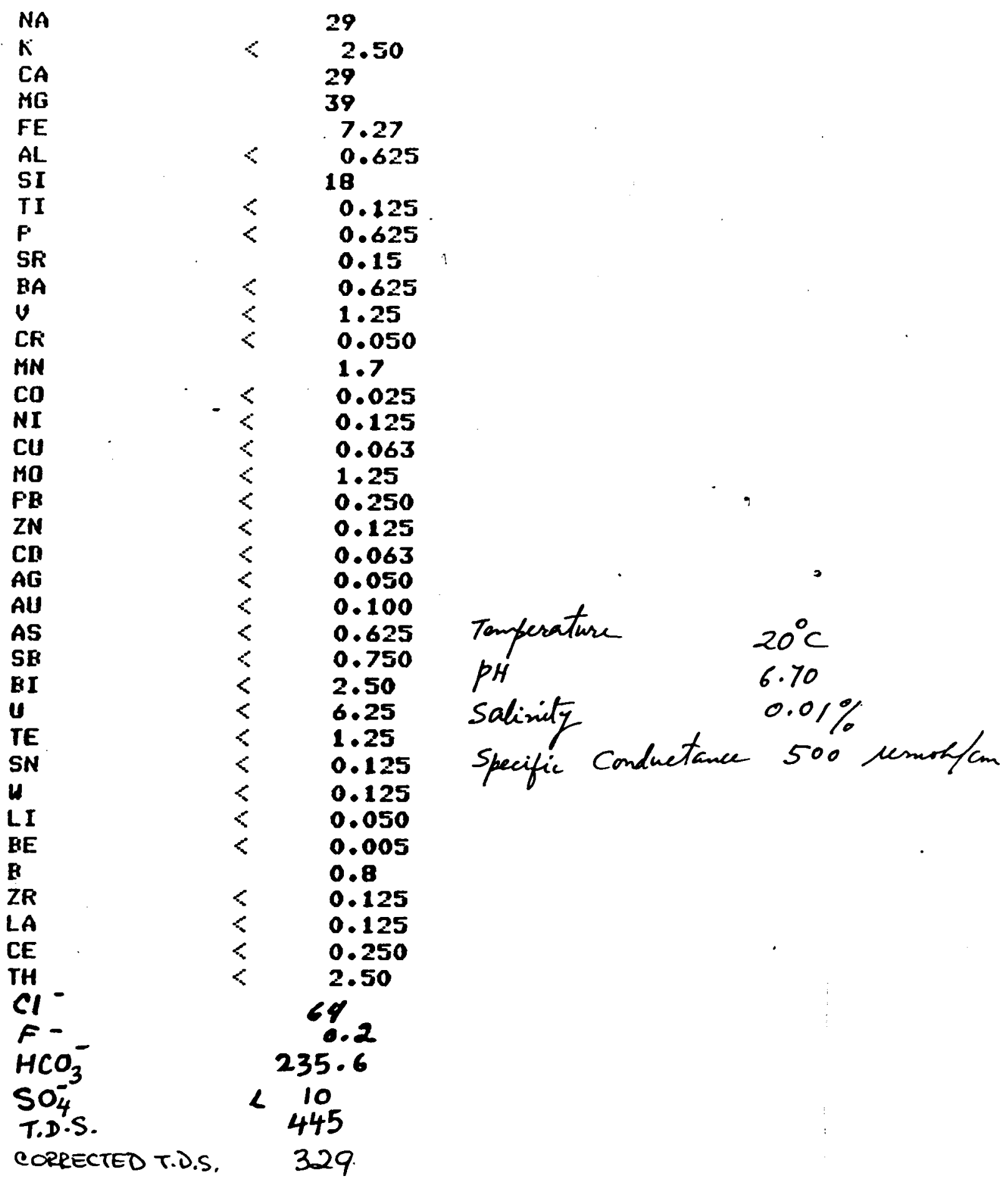


CALISTOGA SET 1

16 G-016-80

ELEMENT

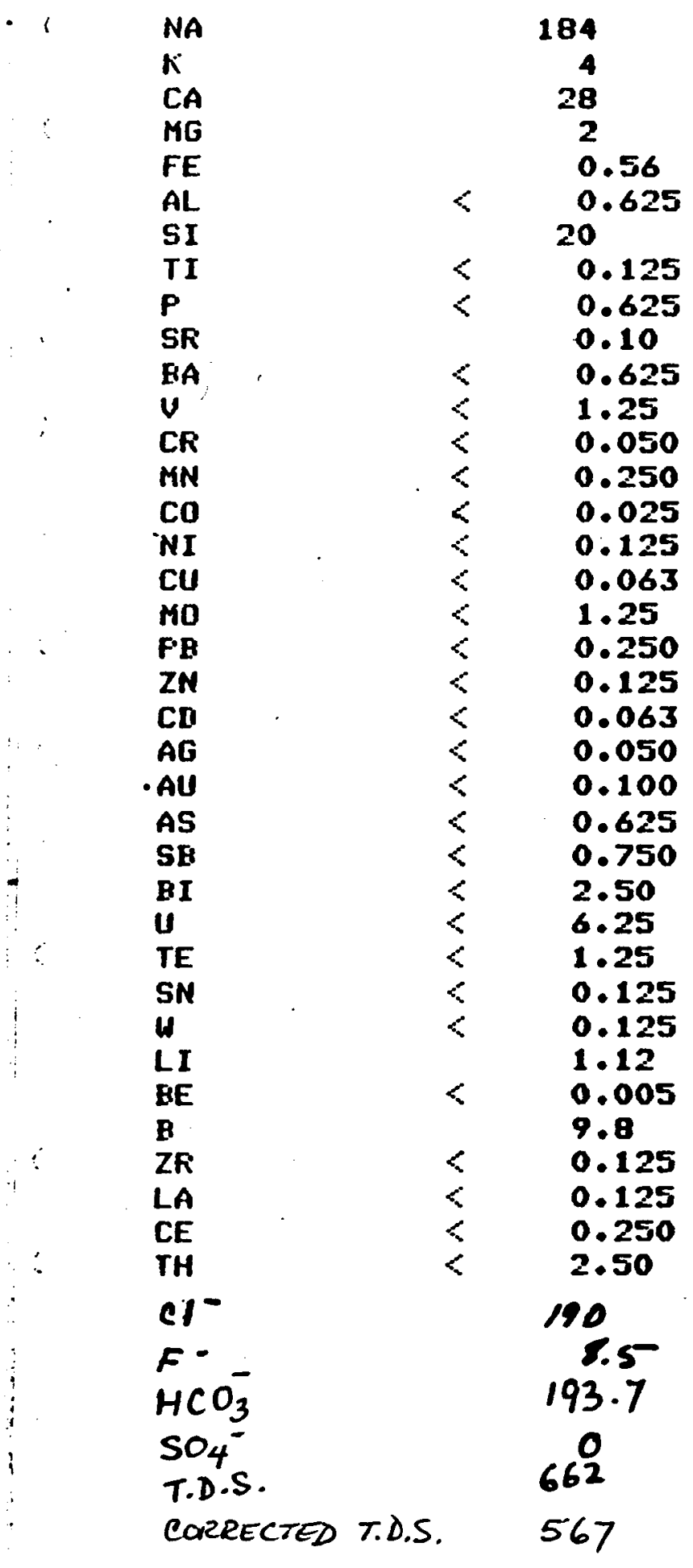

CONCENTRATION (PPM)

Temperature

salinity Conductance $0.03 \%$

A 
CALISTOGA SET 1

17 G-017-80

ELEMENT

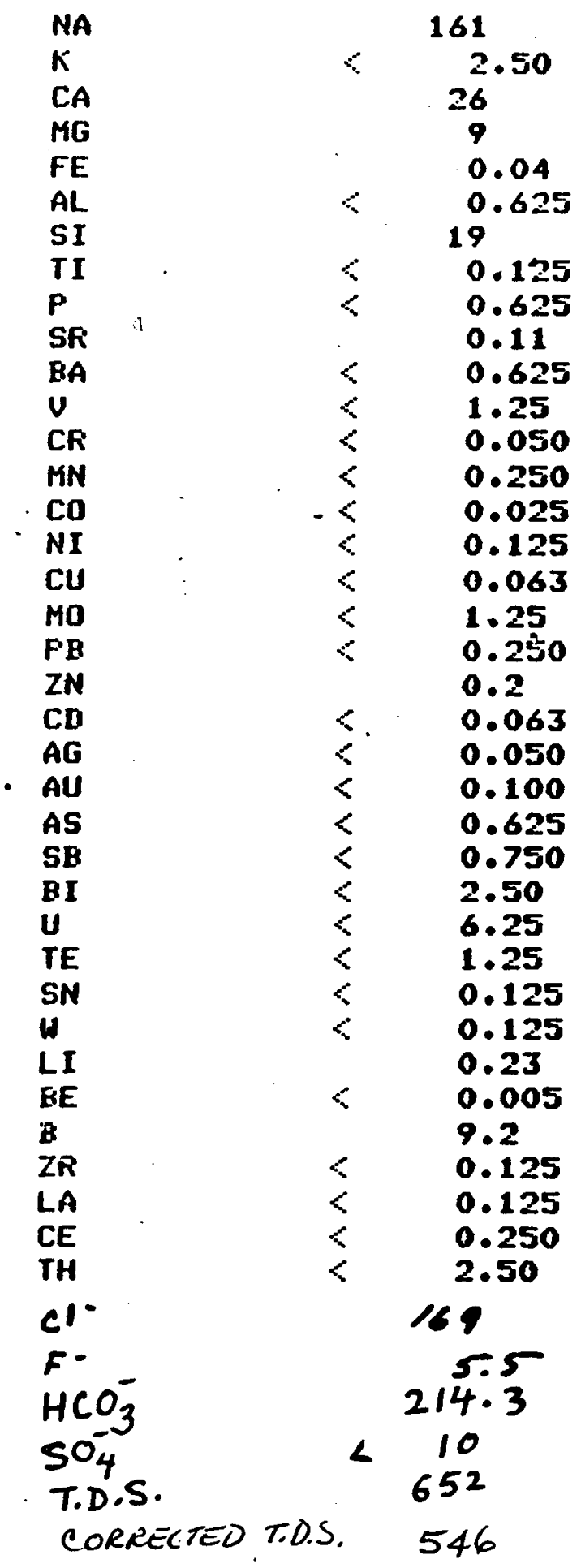


CALISTOGA SET 1

$18 \quad G-018-80$

ELEMENT

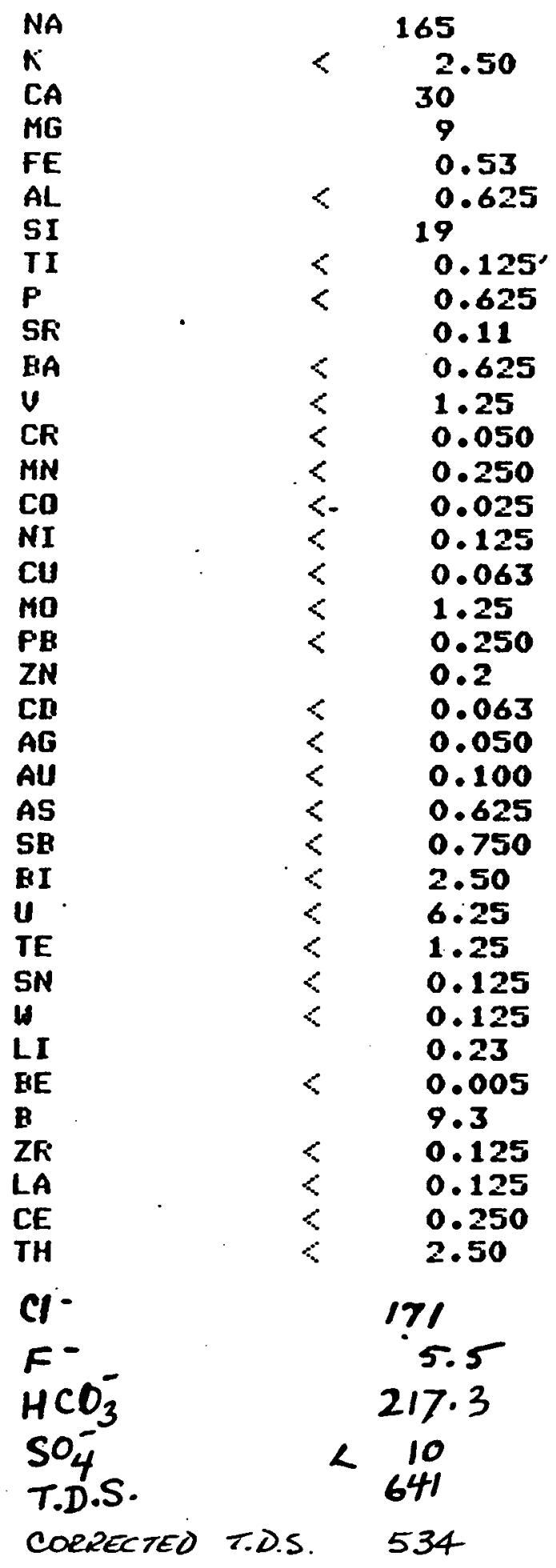

CONCENTFATION (FPM) 
CALISTOGA SET.2

19 G-019-80

ELEMENT

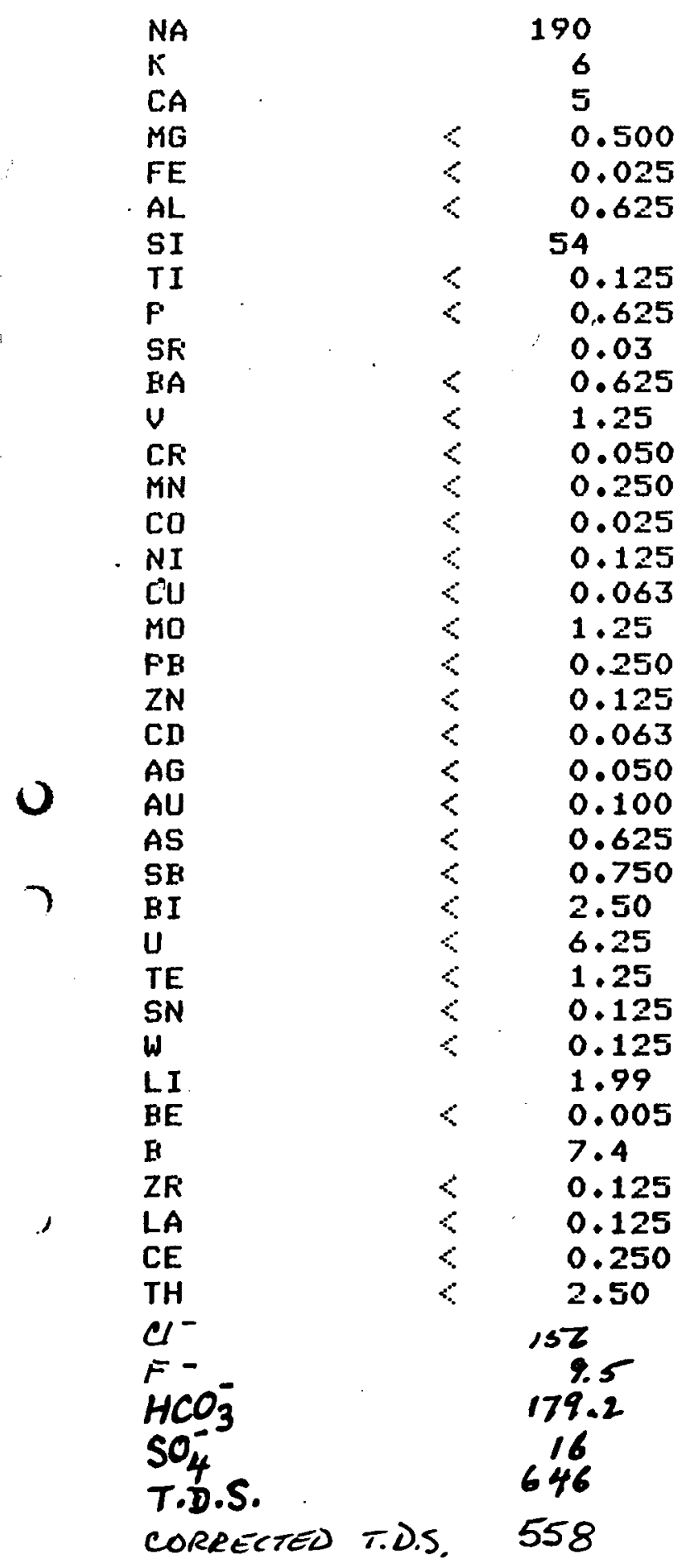

CONCENTKATION (F'F'M) 
CALISTOGA SET 2

20

G-020-80

ELEMENT

NA

$K$

$C A$

MG

FE

AL

SI

F

SR

BA

V

CF

MN

CO

$N I$

CU

MO

PE

ZN

CI

$A G$

AU

AS

SB

BI

$U$

TE

SN

W

LI

BE

B

ZR

LA

CE

TH

$\mathrm{Cl}^{-}$

$\mathrm{HCO}_{3}$

$\mathrm{SO}_{4}^{-3}$

T.D.S.

CORRECTED T.D.S. 599$$
154 \cdot 8
$$

10
$<\quad 675$
CONCENTRATION (PPM)

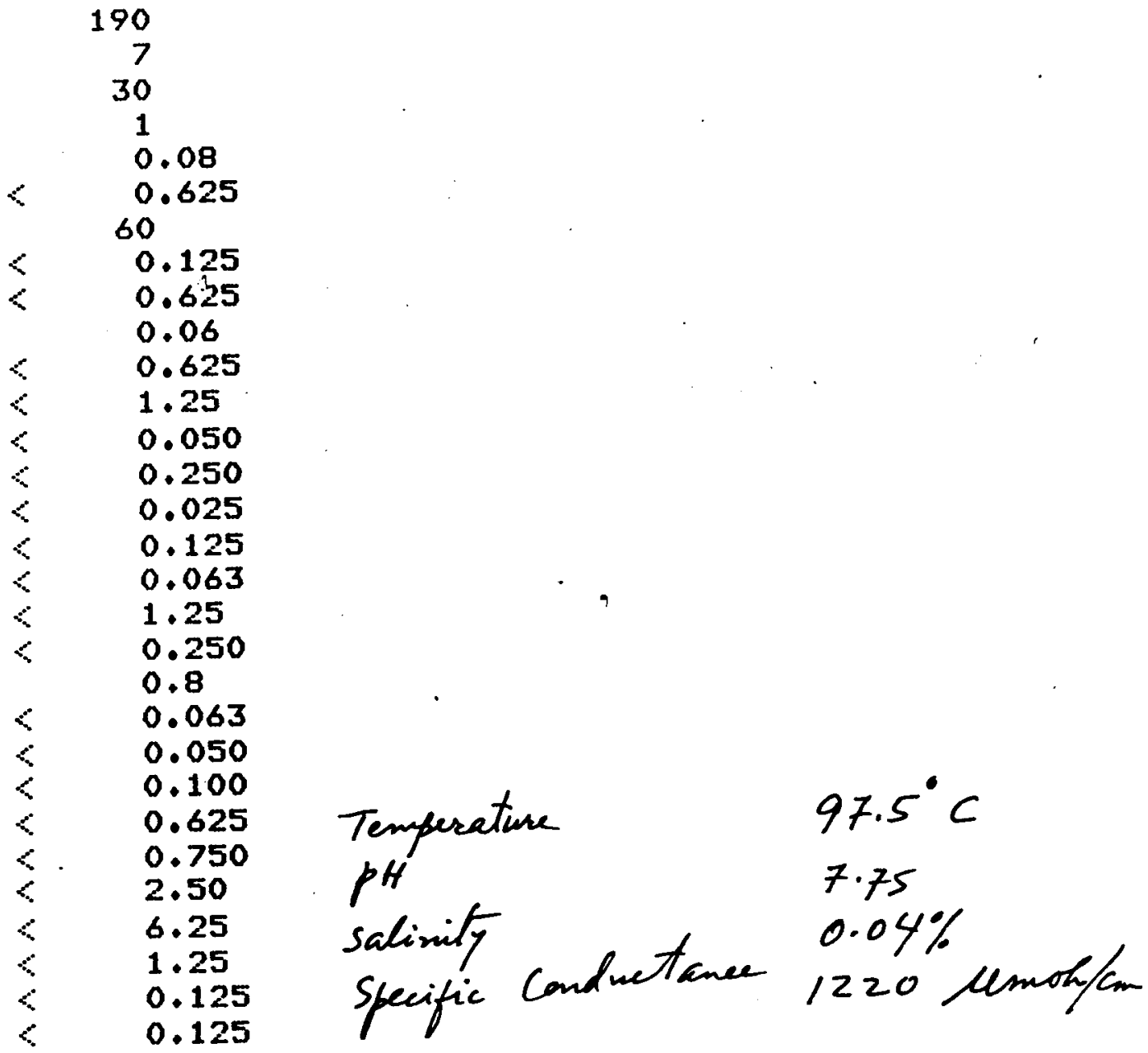

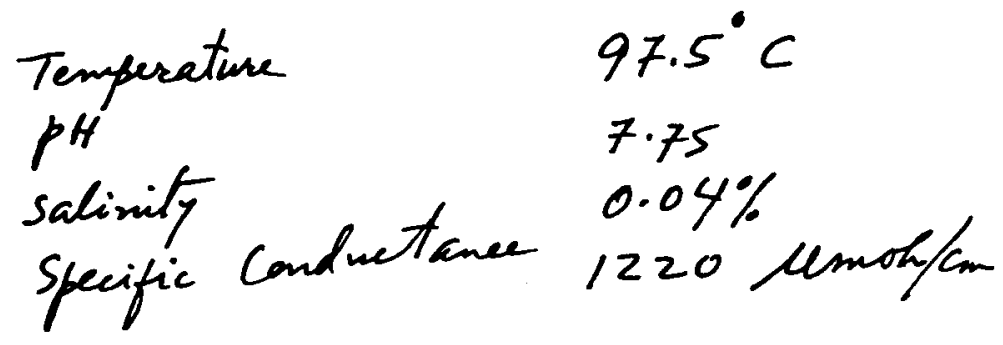

$6 \quad 0.005$

$<\quad 0.125$

$<\quad 0.125$

$\begin{array}{ll}< & 0.250 \\ < & 2.50\end{array}$$$
11.0
$$ 
CALISTOGA SET 2

$21 \quad G-021-80$

ELEMENT

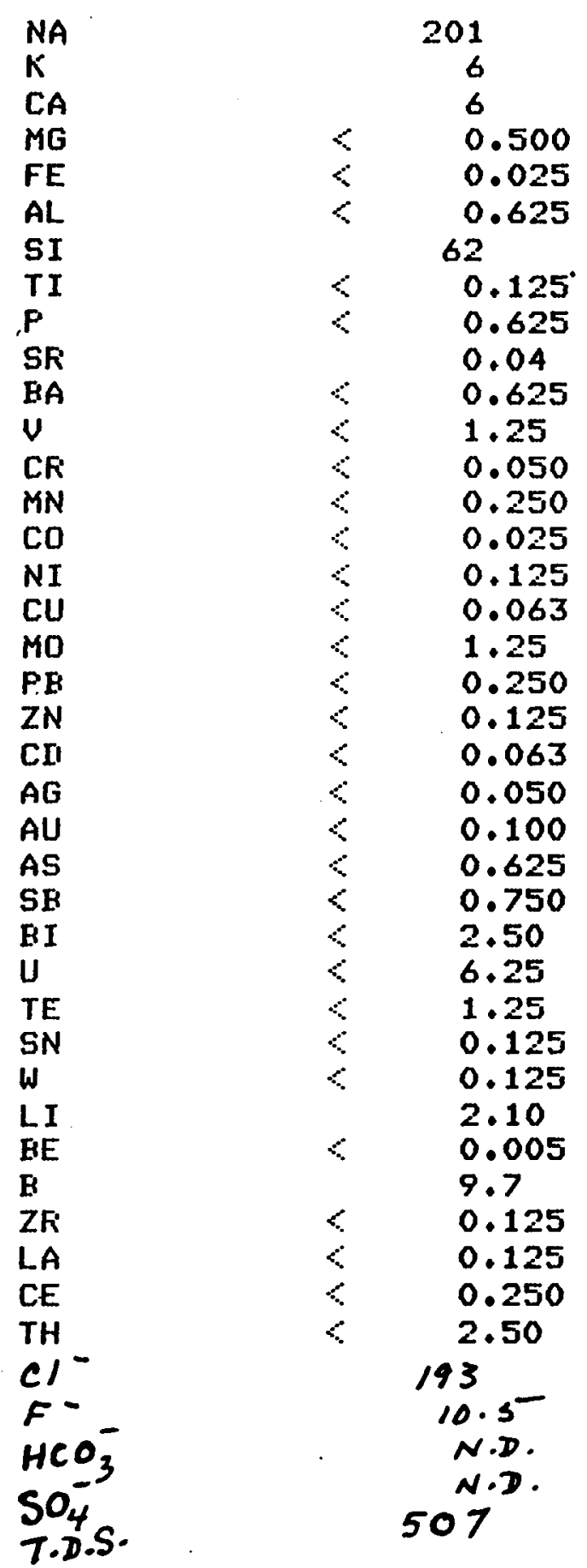

CONCENTFATION (FPM)

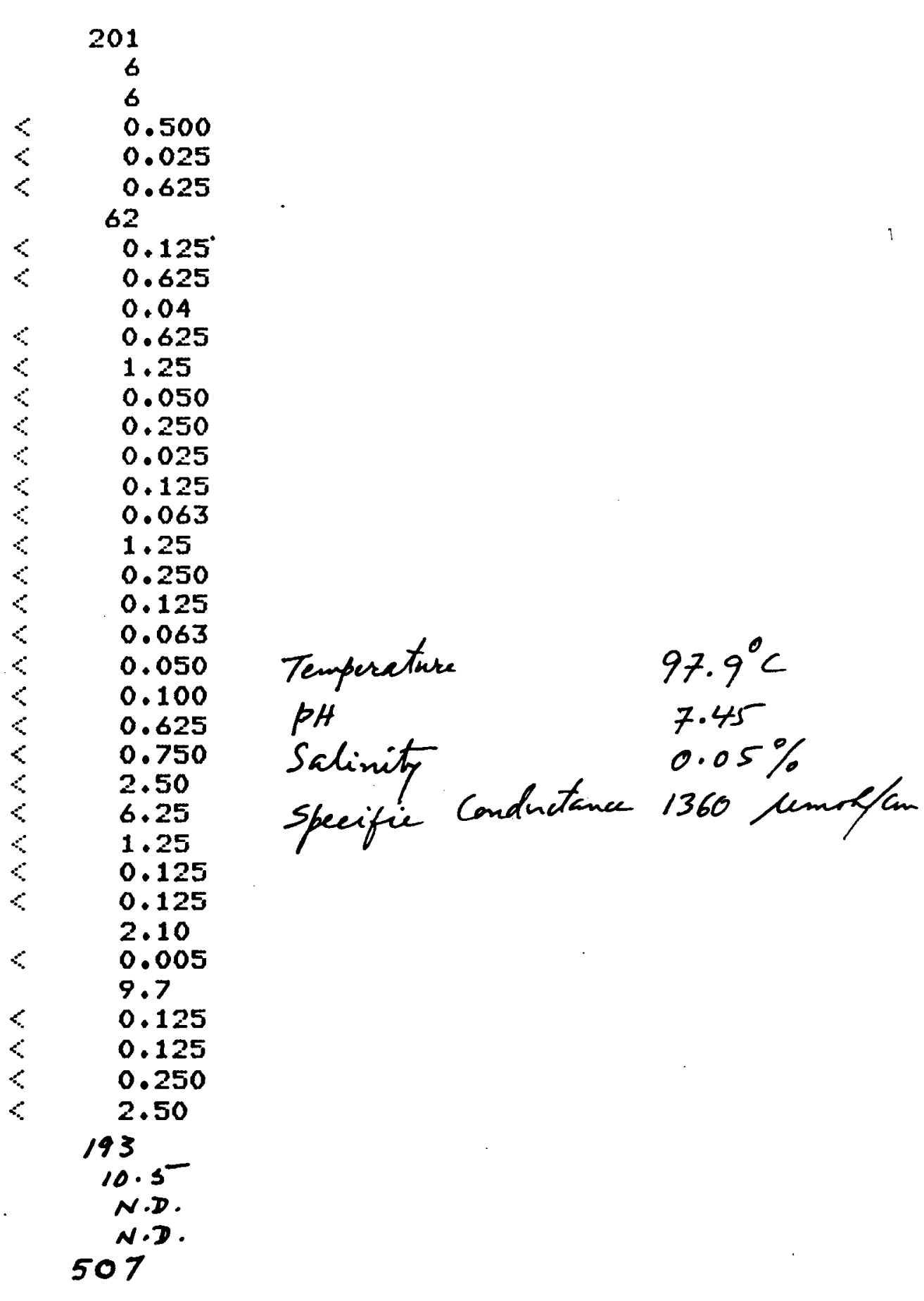


()

CALISTOGA SET 2

22 G-022-80

ELEMENT

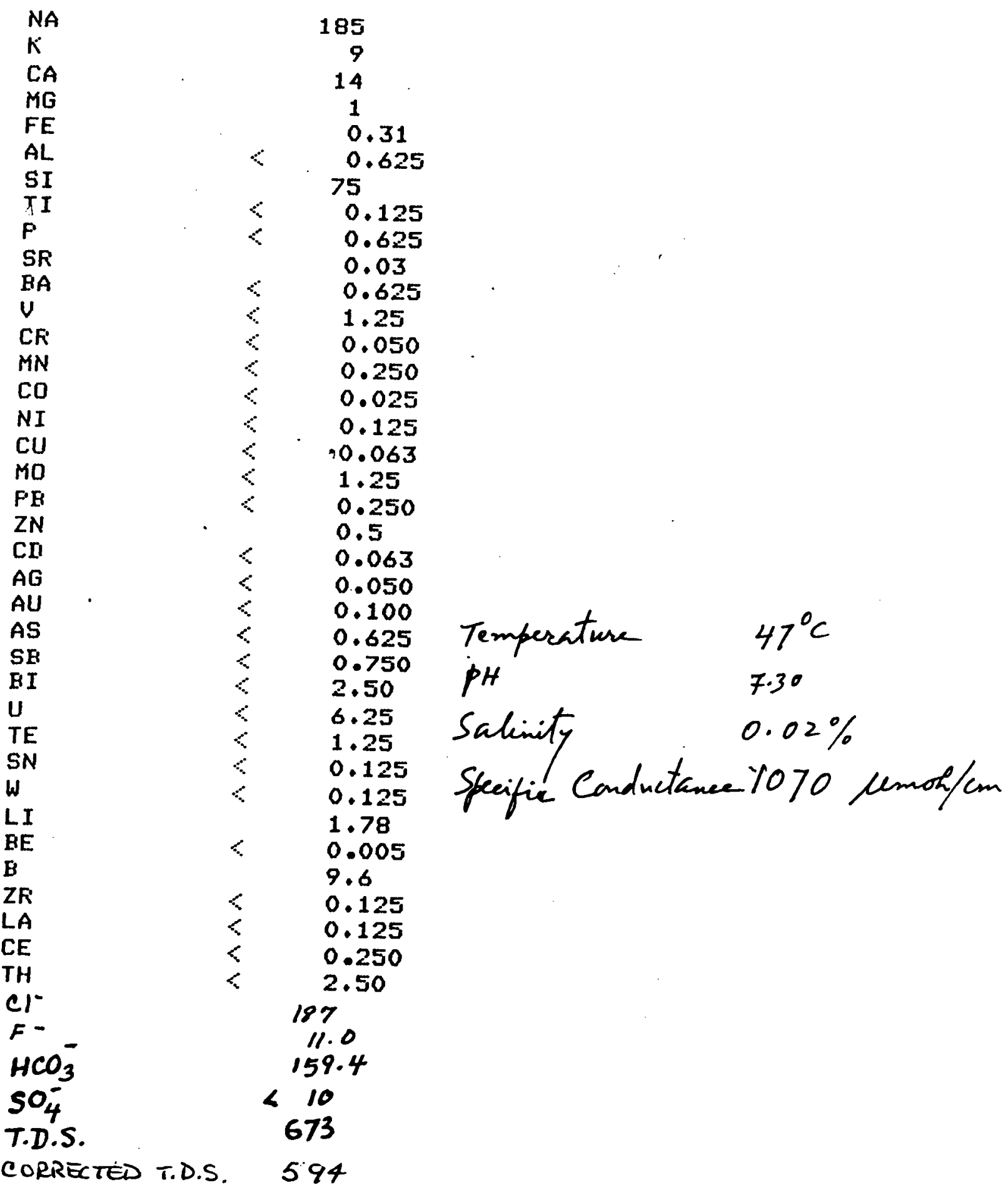

CONCENTRATION (PFM) 


\section{CALISTOGA SET 2}

23

G-023-80

ELEMENT

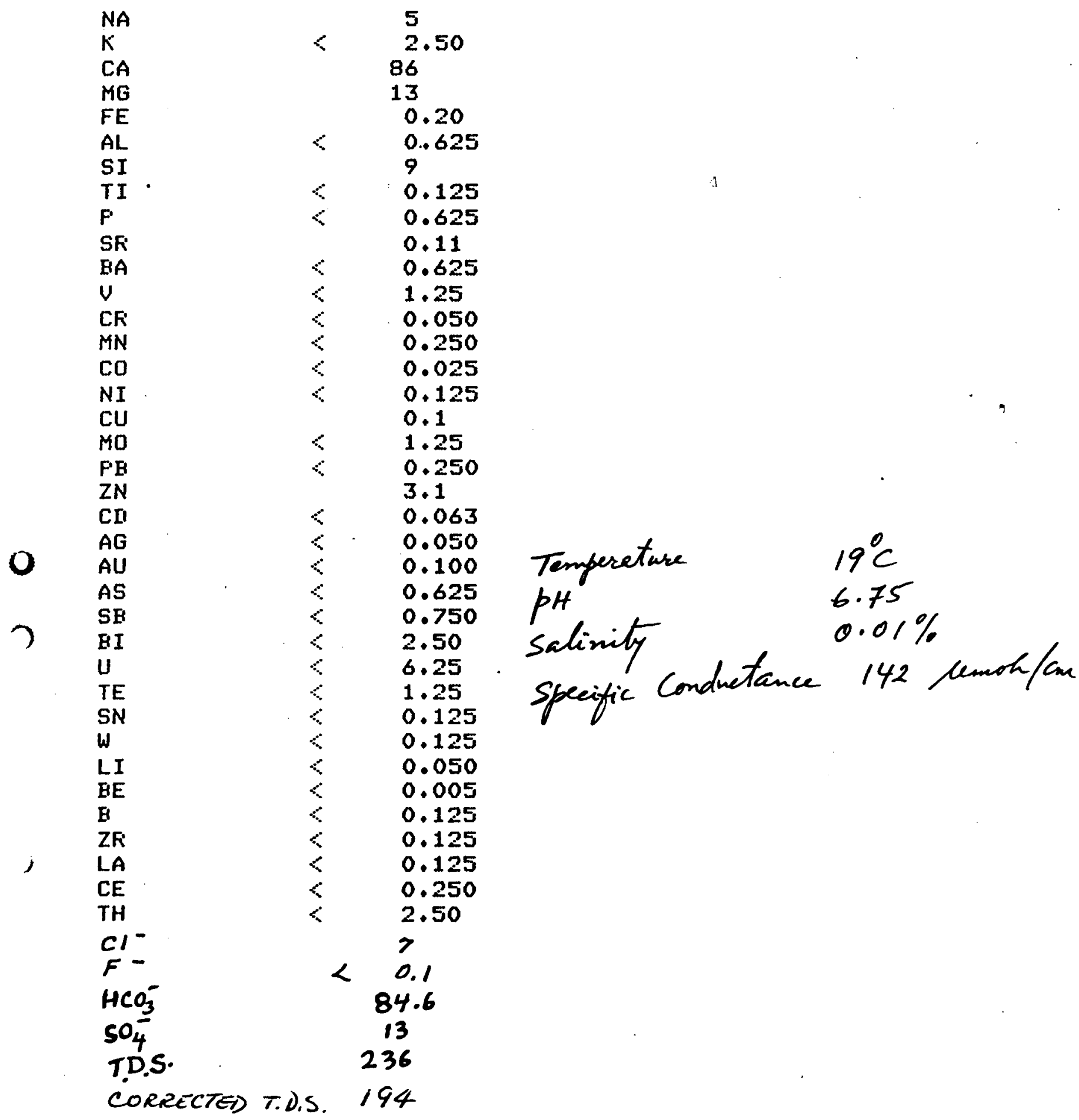

CONCENTRATION (FFM)

0.11

0.625

1.25

0.050

0.250

0.025

0.125

0.1

1.25

0.250

3.1

0.063

0.050

0.100

0.625

0.750

2.50

6.25

1.25

0.125

0.125

0.050

0.005

125

0.125

0.250

13

94 
CALISTOGA SET 2 .

24

G-024-80

ELEMENT

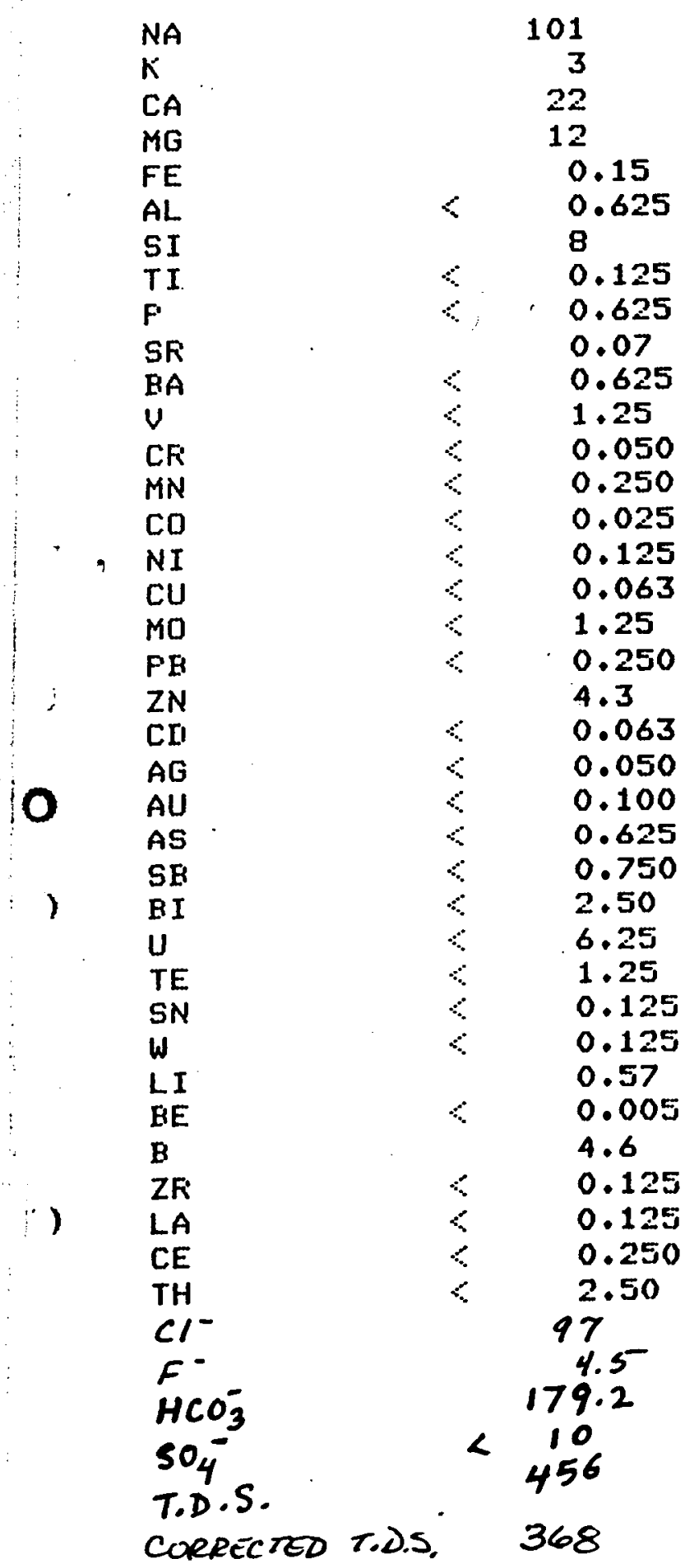

CONCENTRATION (FFM) 
CALISTOGA SET 2

$25 \quad G-025-80$

ELEMENT

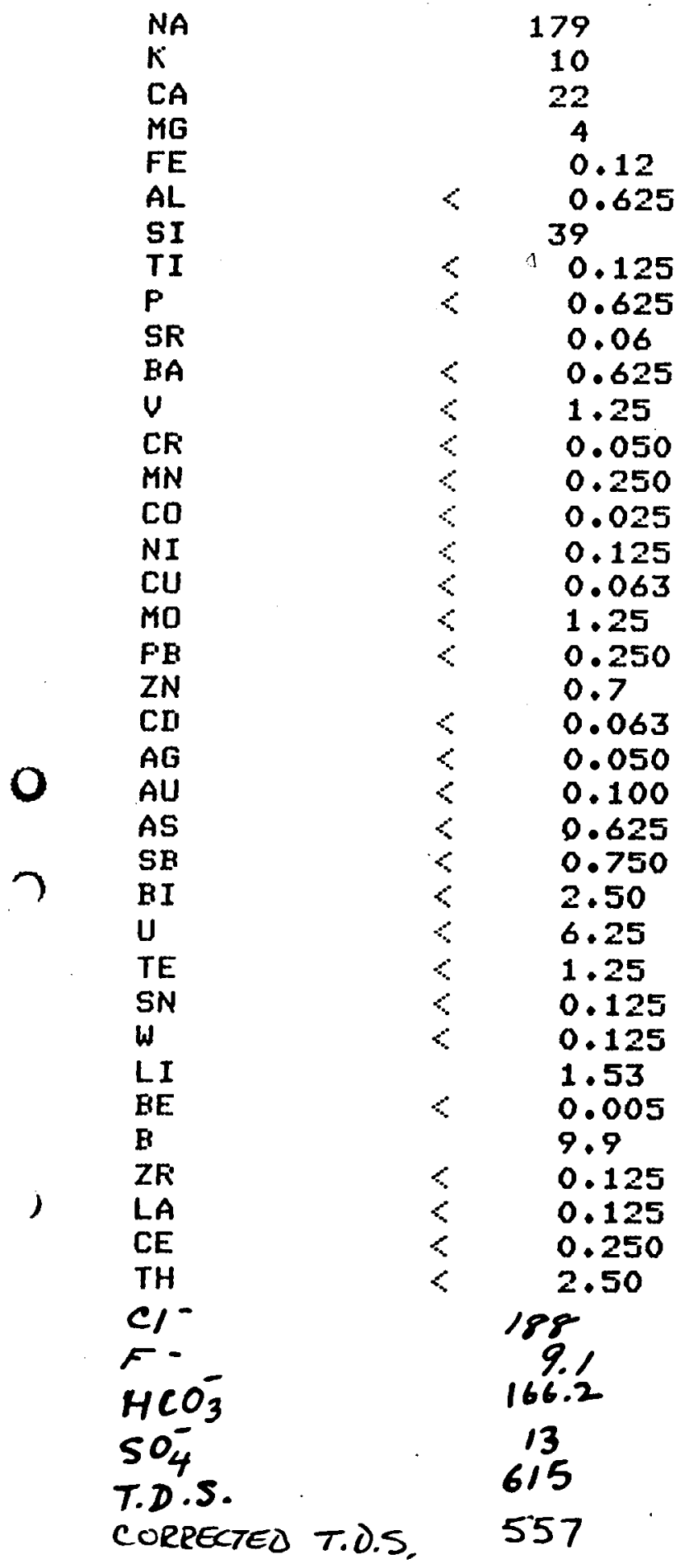


CALISTOGA SET 2

$26 \quad G-026-80$

ELEMENT

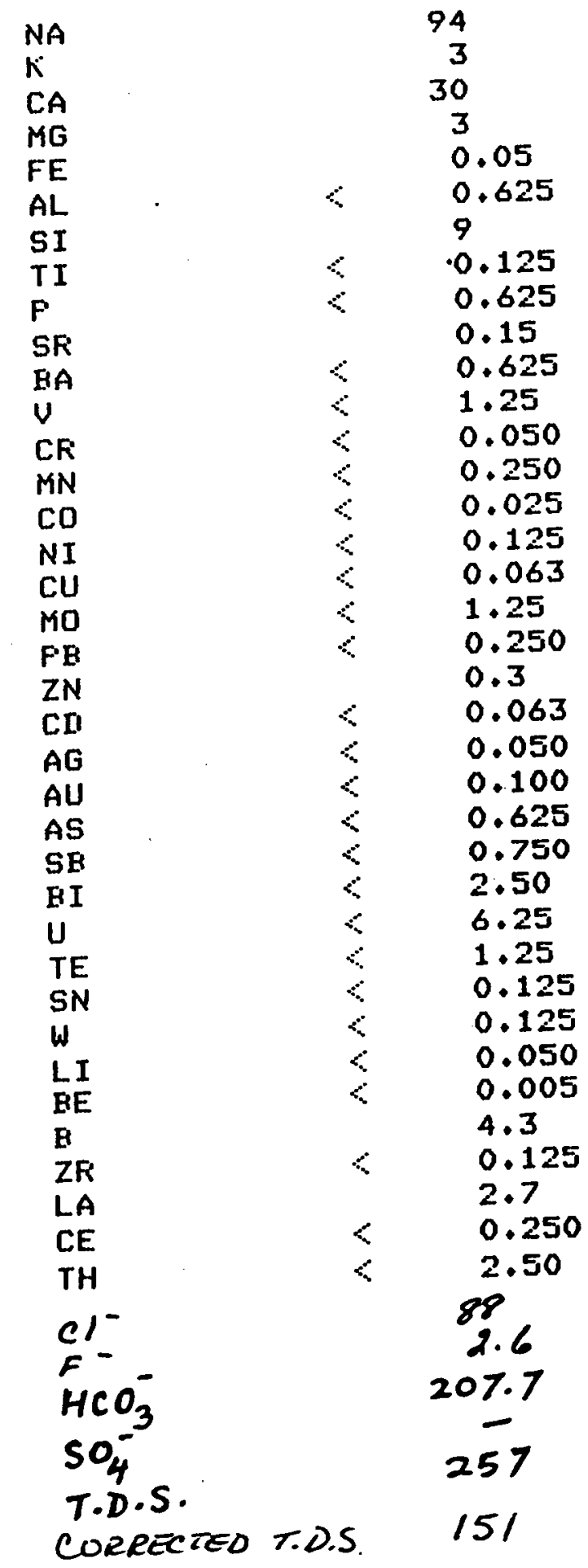

CONCENTFATION (FFM)

1 
CALISTOGA SET 2

$27 \quad$ G-027-80

ELEMENT

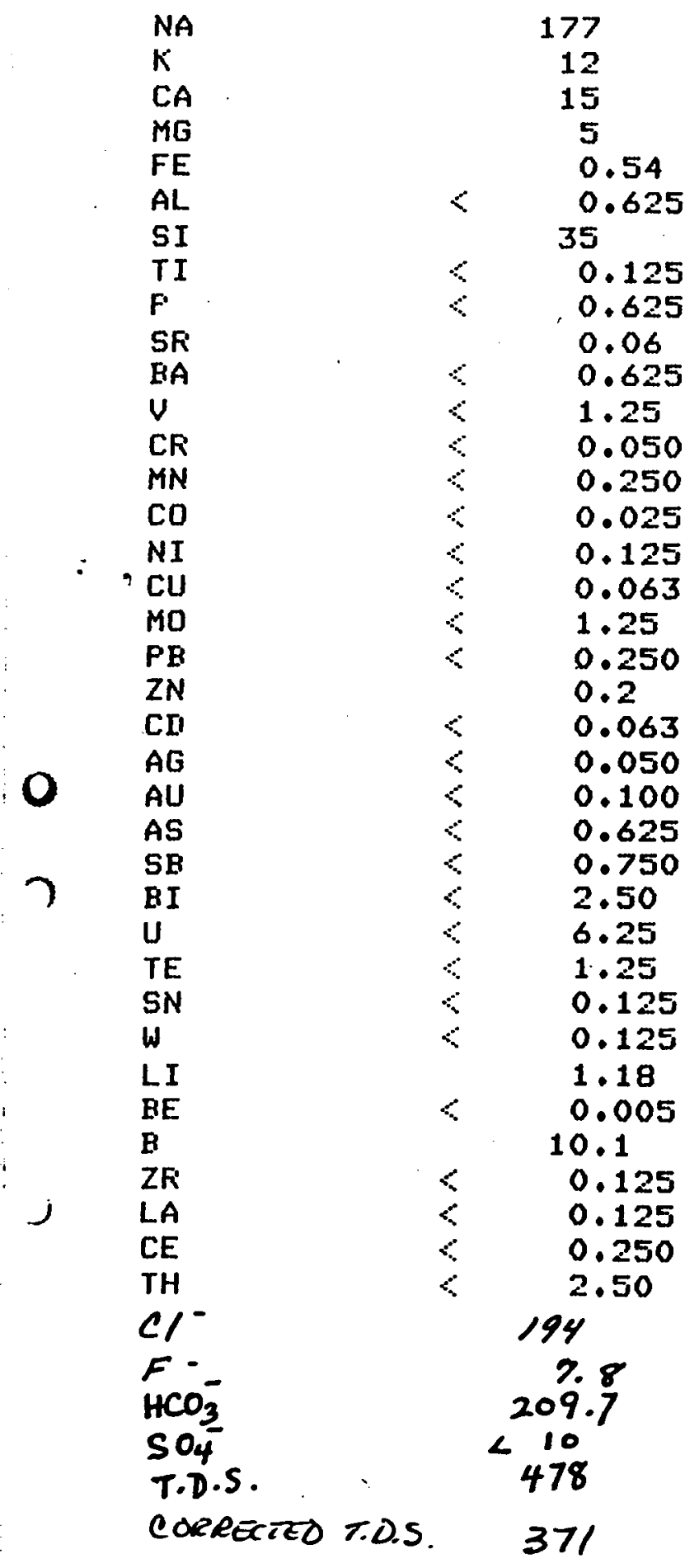


J

CALISTOGA SET 2

28 G-028-80

ELEMENT

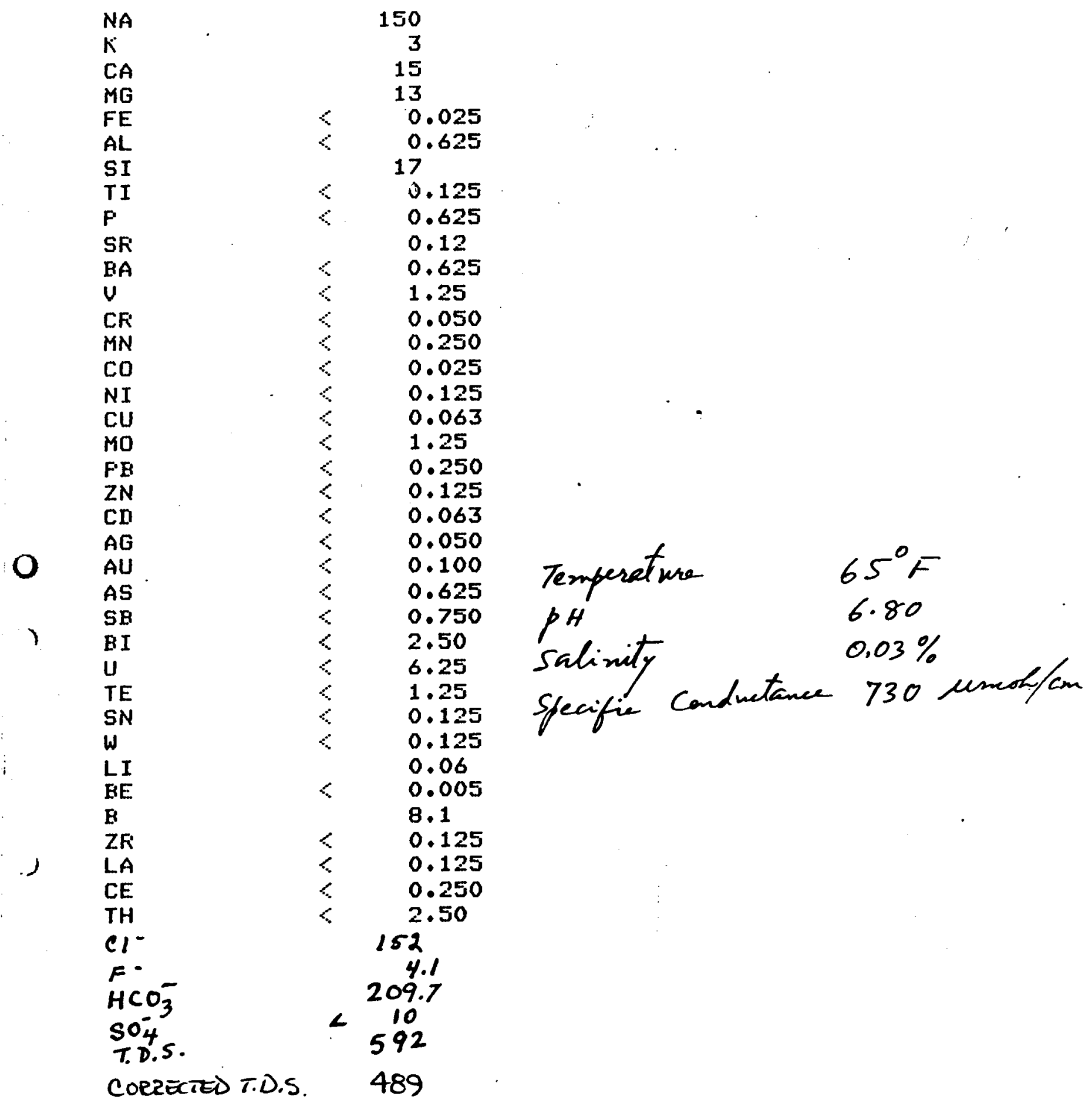




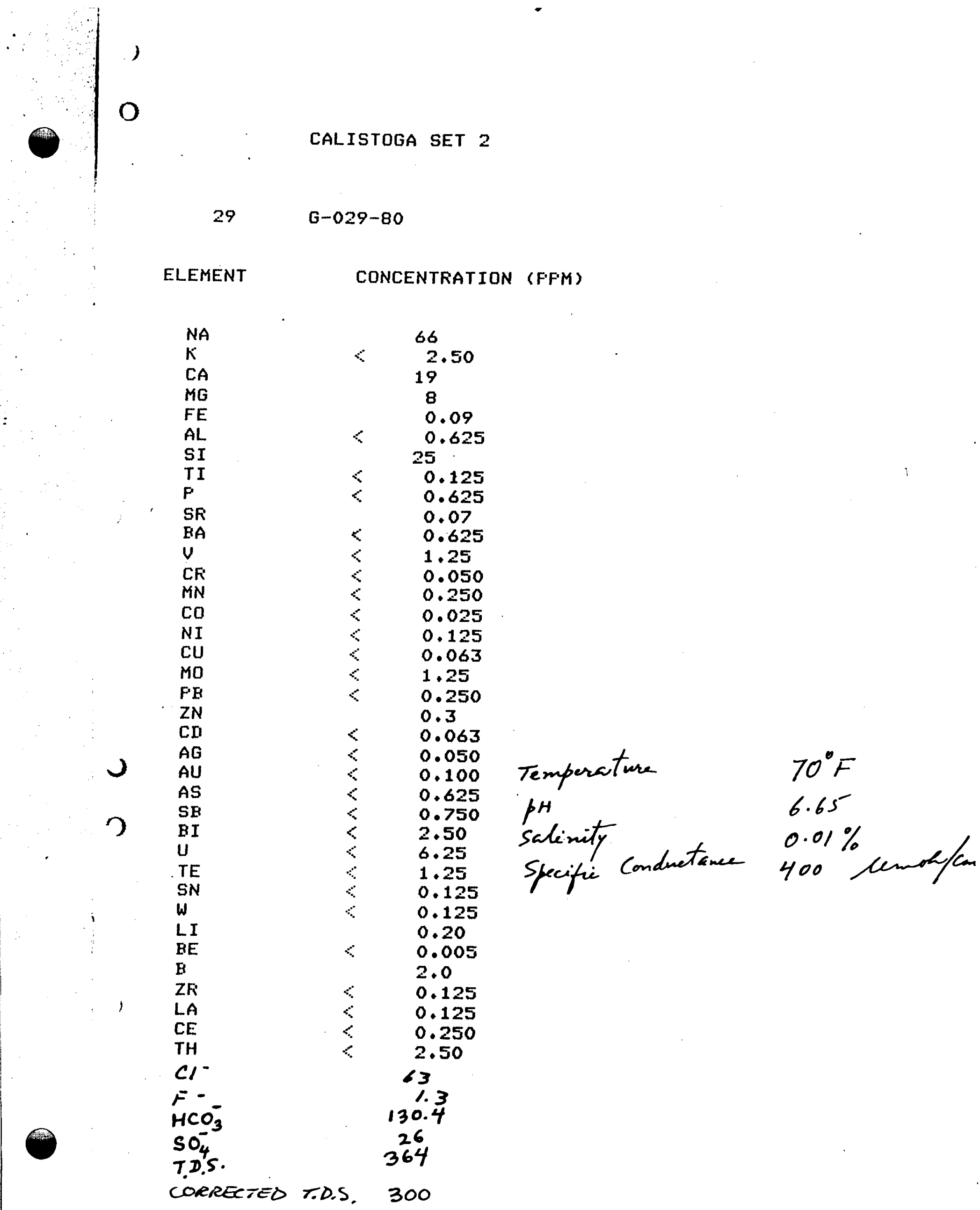


CALISTOGA SET 2

30

$G-030-80$

ELEMENT

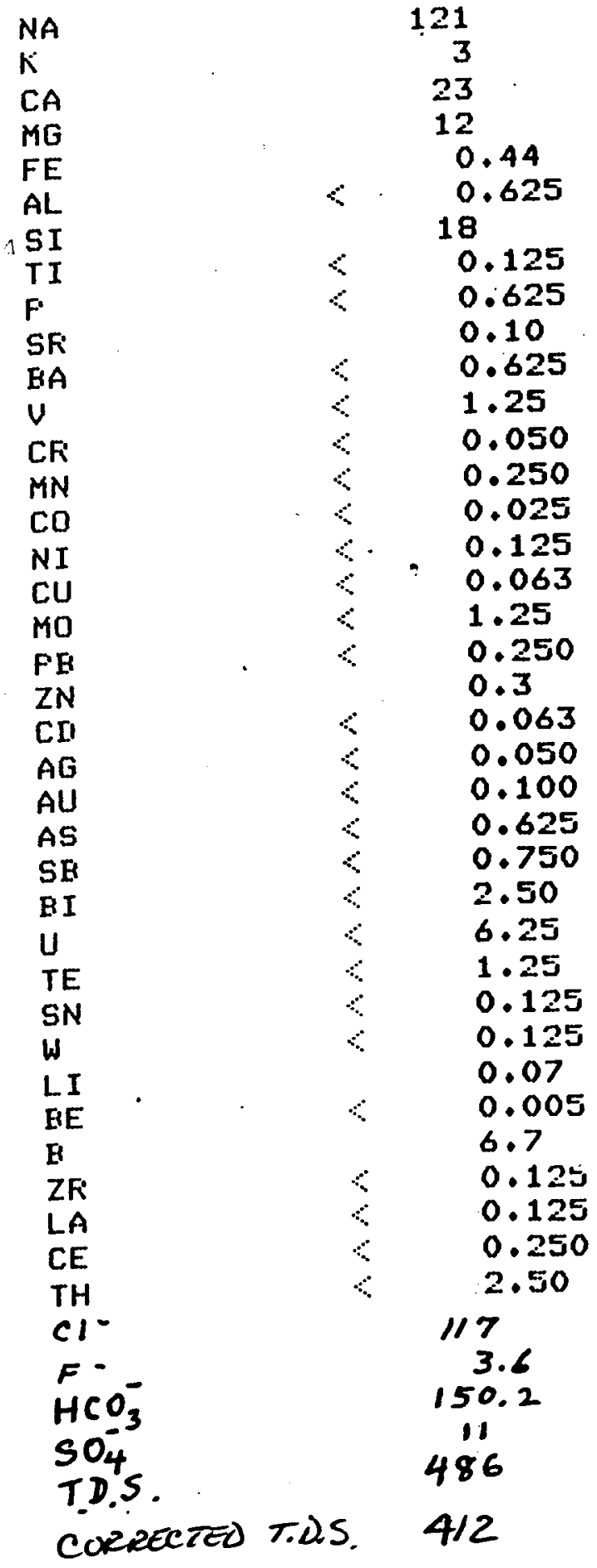

CONCENTFIATION (FPH)

$\begin{array}{lc}\text { Temperature } & 70^{\circ} \mathrm{F} \\ \text { pH } & 6.90 \\ \text { salimity } & 0.02 \%\end{array}$

specific conductance 580 Mmole/cen 


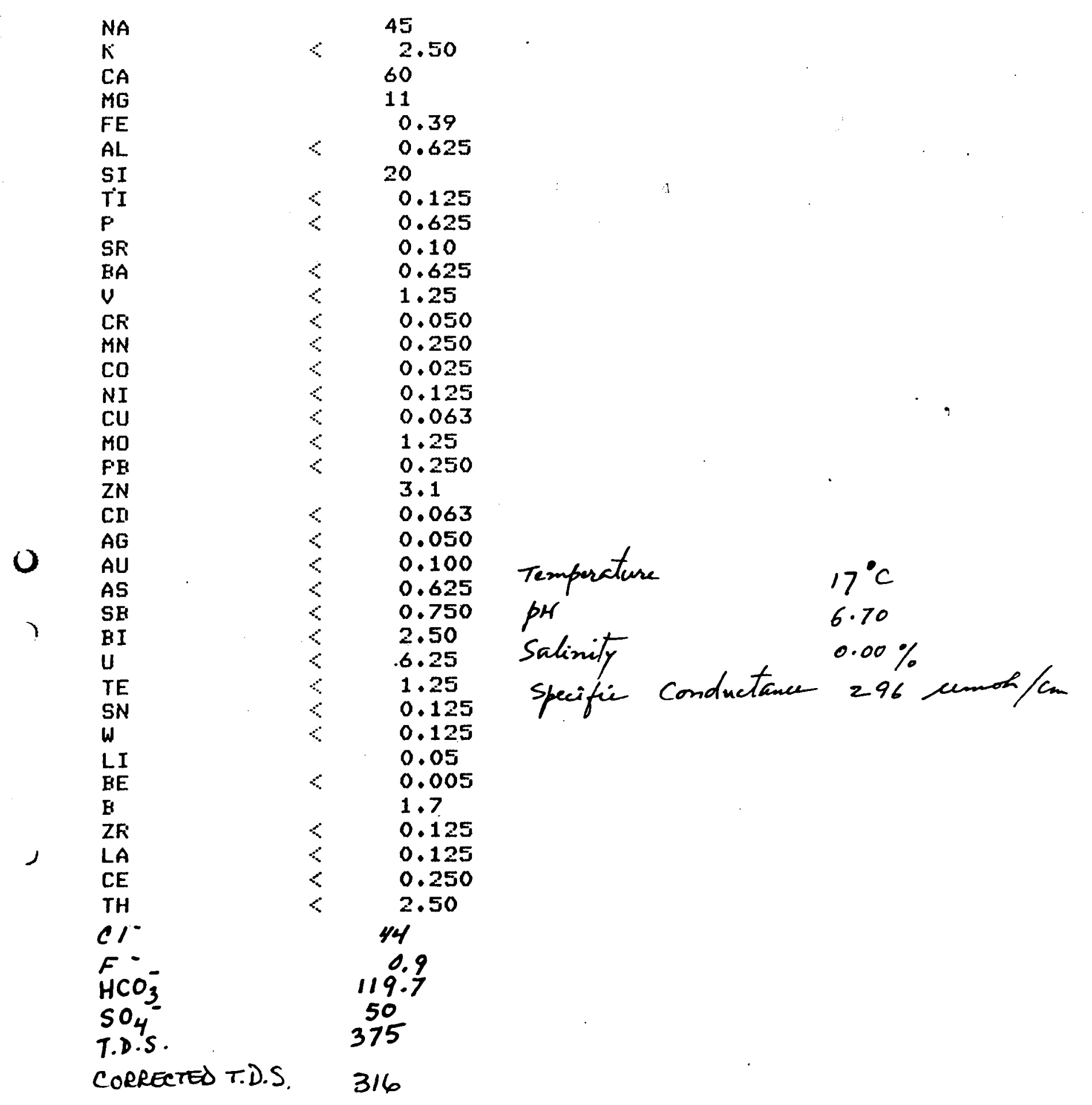


CALISTOGA SET 2

$32 \quad 6-032-80$

ELEMENT

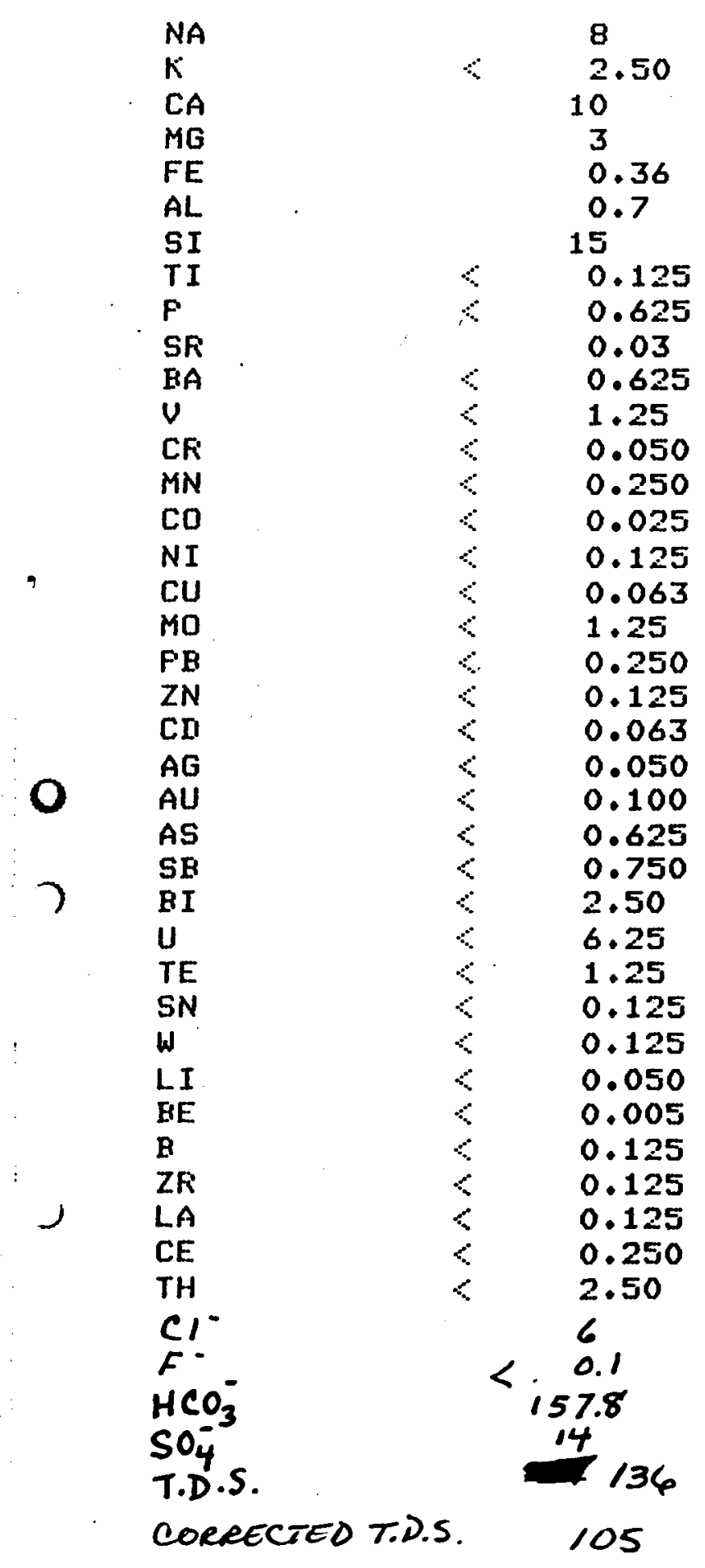




\title{
CALISTOGA SET 2
}

33

G-033-80

ELEMENT

\author{
CONCENTRATION (FFM)
}

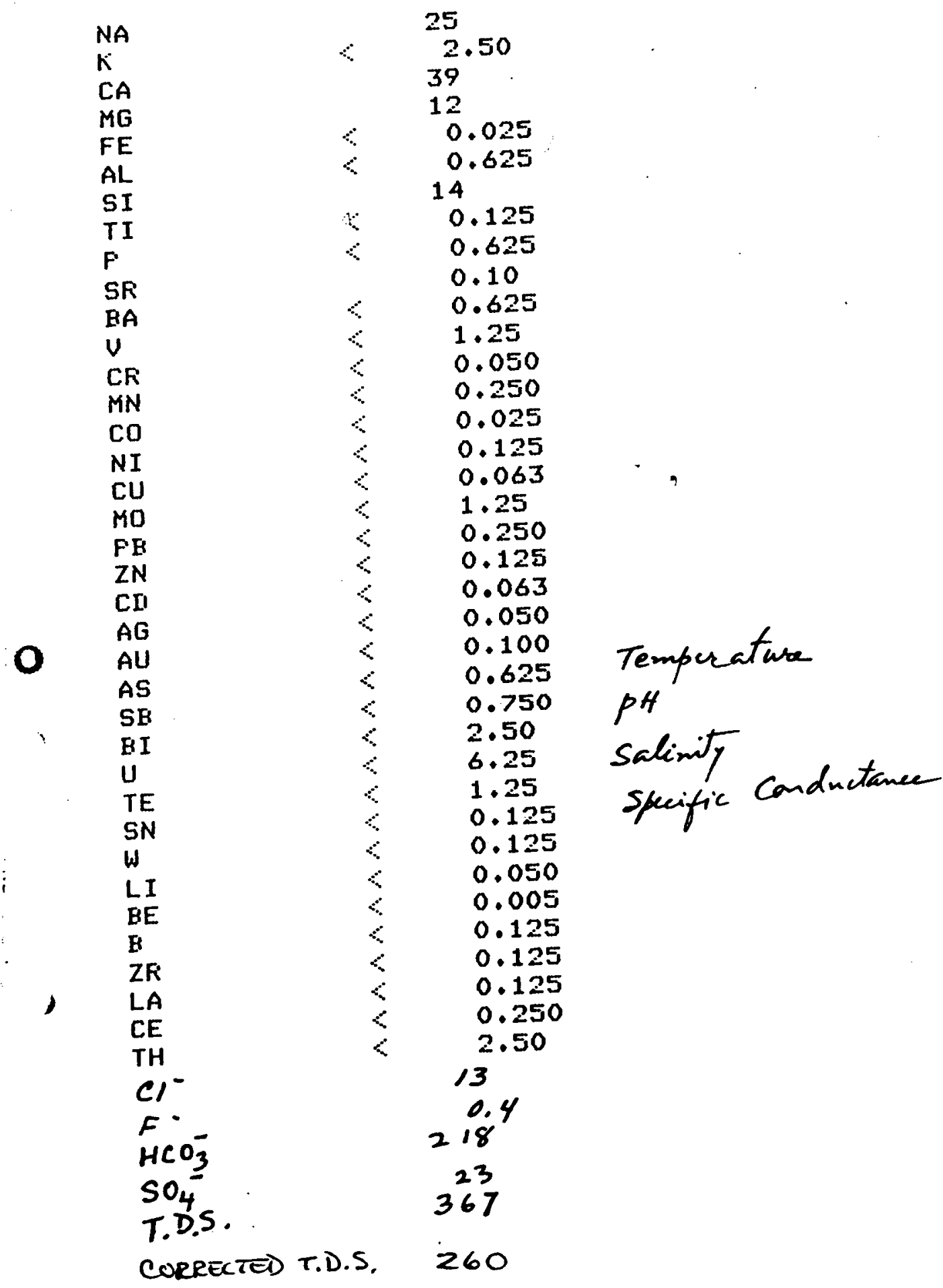

$21^{\circ} \mathrm{C}$

6.30

$0.04 \%$

390 umotifem 
CALISTOGA SET 2

34

G-034-80

ELEMENT

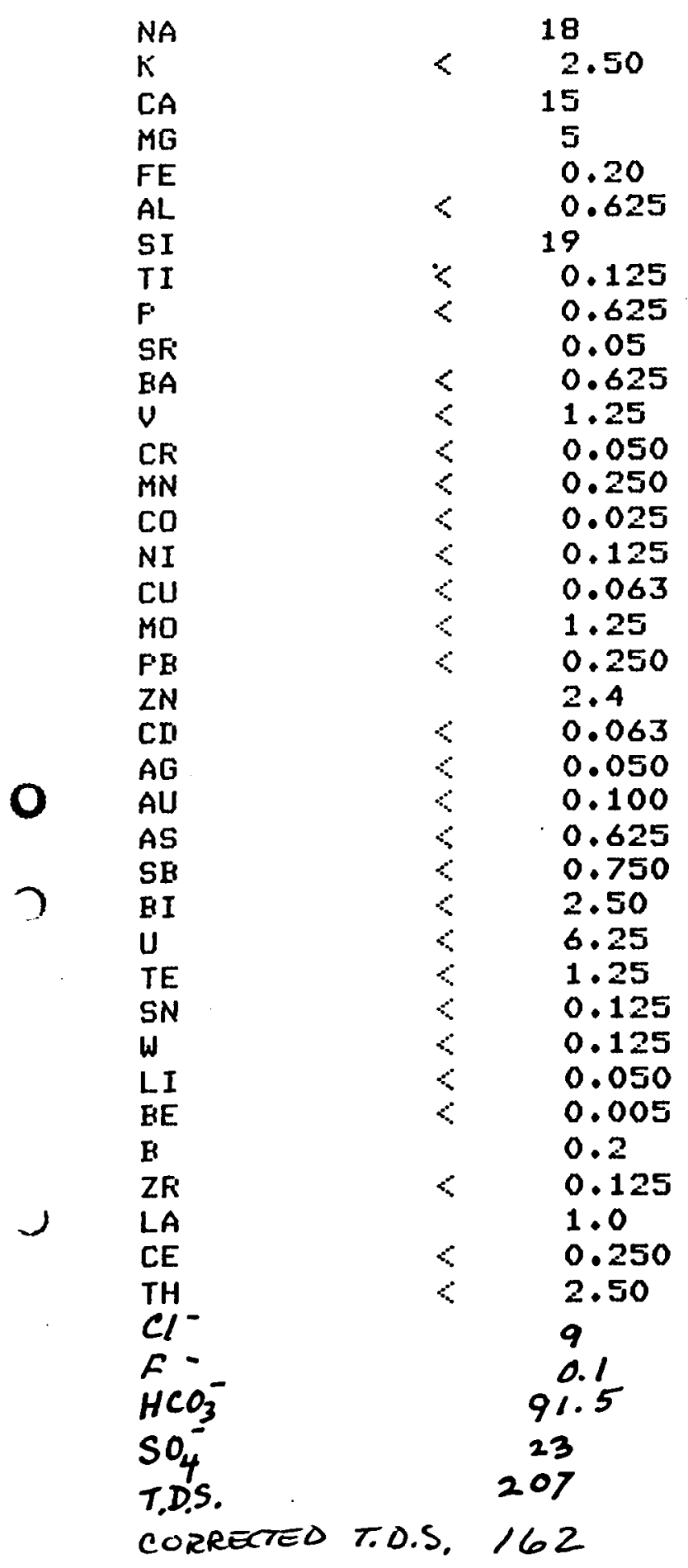

CONCENTFATION (FFM)

Temperature

pH $\quad 6.19$

Salinity $\quad 0.02 \%$

specifex conductance $185^{\circ}$ umerh/cm 
CALISTOGA SET. 2

$35 \quad$ G-035-80

ELEMENT

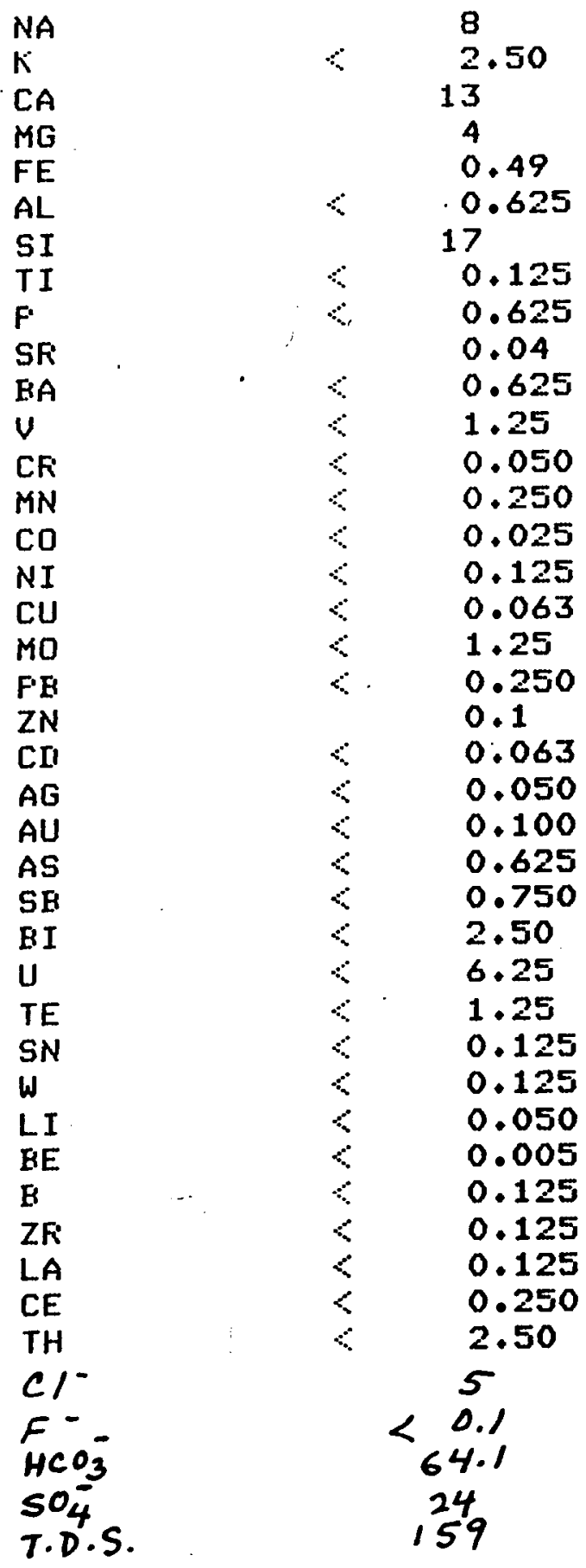

COCRETED T.D.S. 127 
0

CALISTOGA SET 2

$36 \quad G-036-80$

ELEMENT

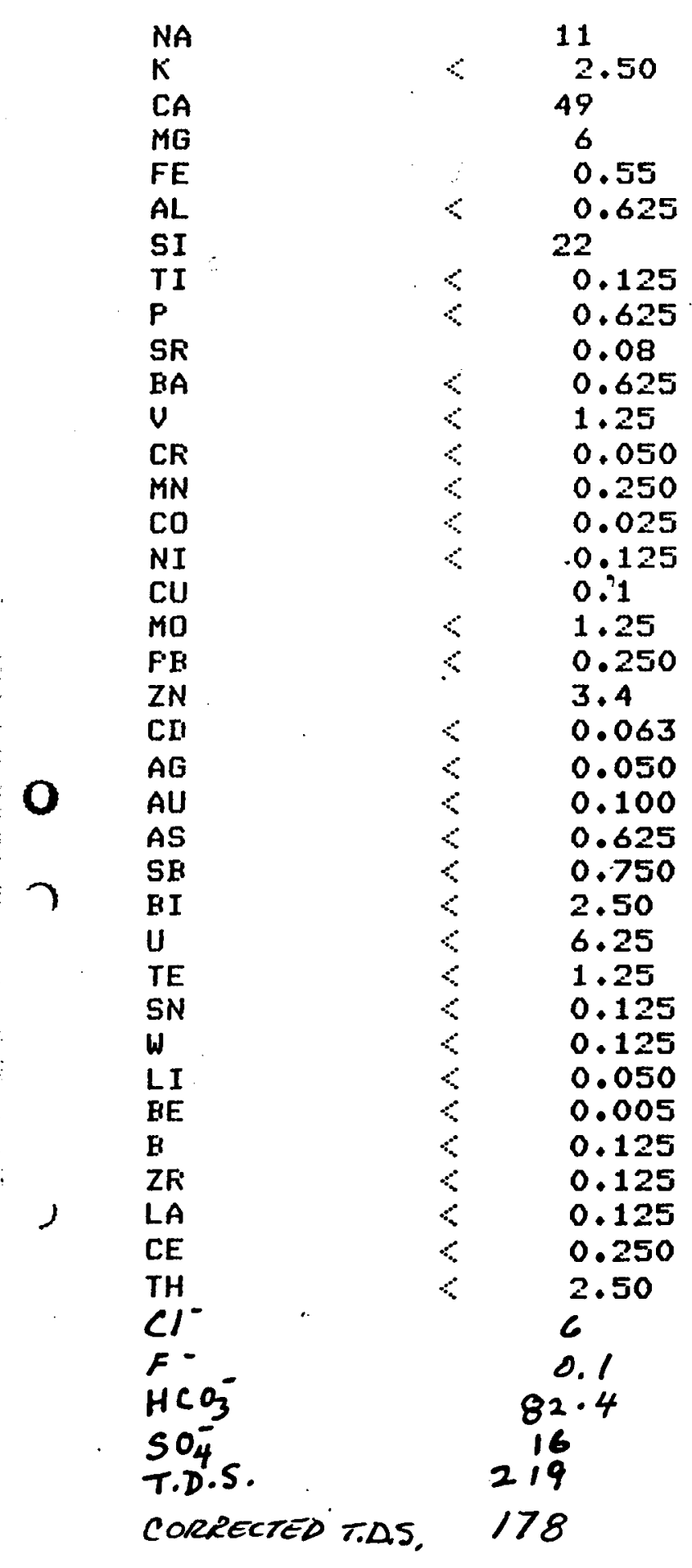

CONCENTFATION (FFM)

$\begin{array}{ll}\text { Temperature } & 13^{\circ} \mathrm{C} \\ \text { pHt } & 6.40 \\ \text { Salinity } & 0.002 \%\end{array}$

specuic Conducterce 159 umot/can 


\section{CALISTOGA SET 2}

37

G-037-80

ELEMENT

\section{CONCENTFATION (FFM)}

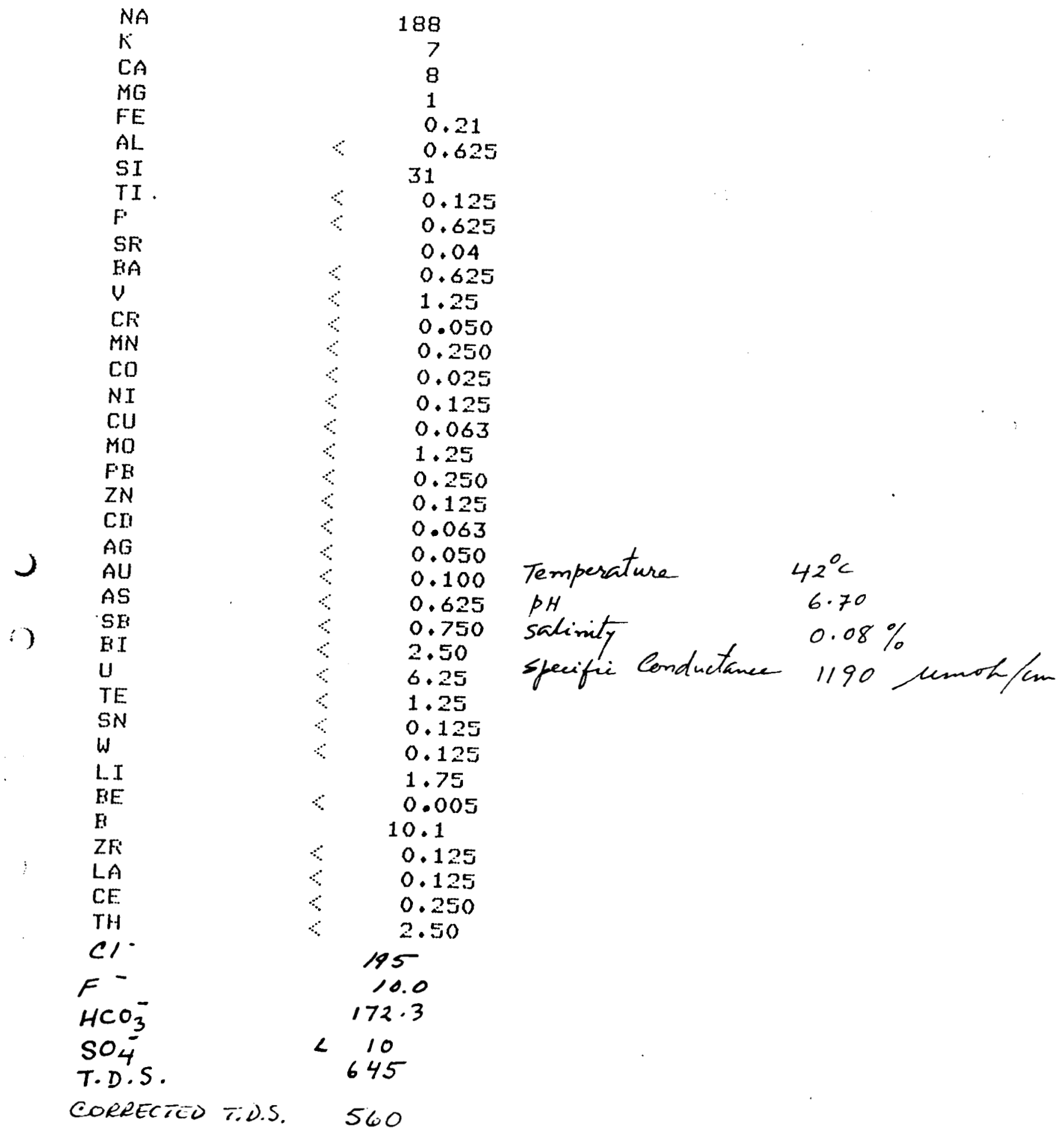


CALISTOGA SET 2

38

G-038-80

ELEMENT

CONCENTFATION (PFM)

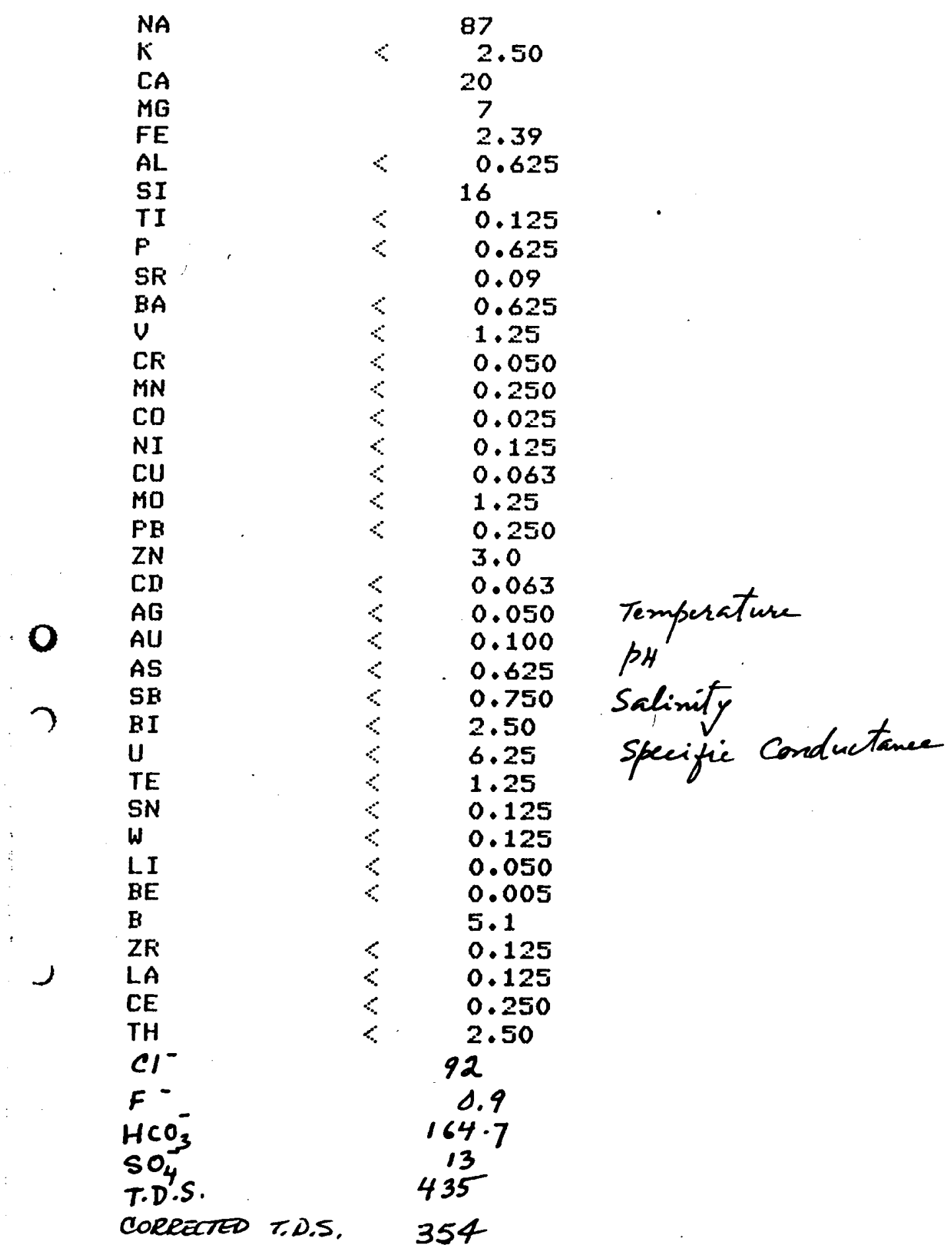

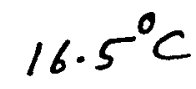

6.10

$0.05 \%$

590

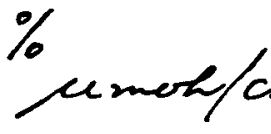


0

o

CALISTOGA SET 2

39

G-039-80

ELEMENT

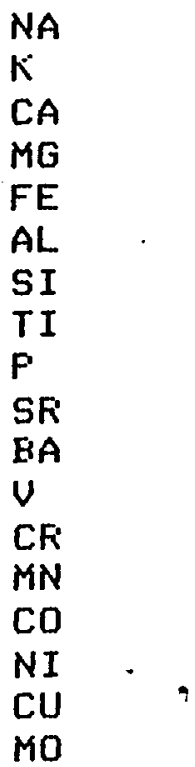

$F$

ZN

CII

Q AG

AU

AS

SE

B I

U

TE

SN

W

LI

BE

B

ZF

)
CONCENTRATION (FF'M)

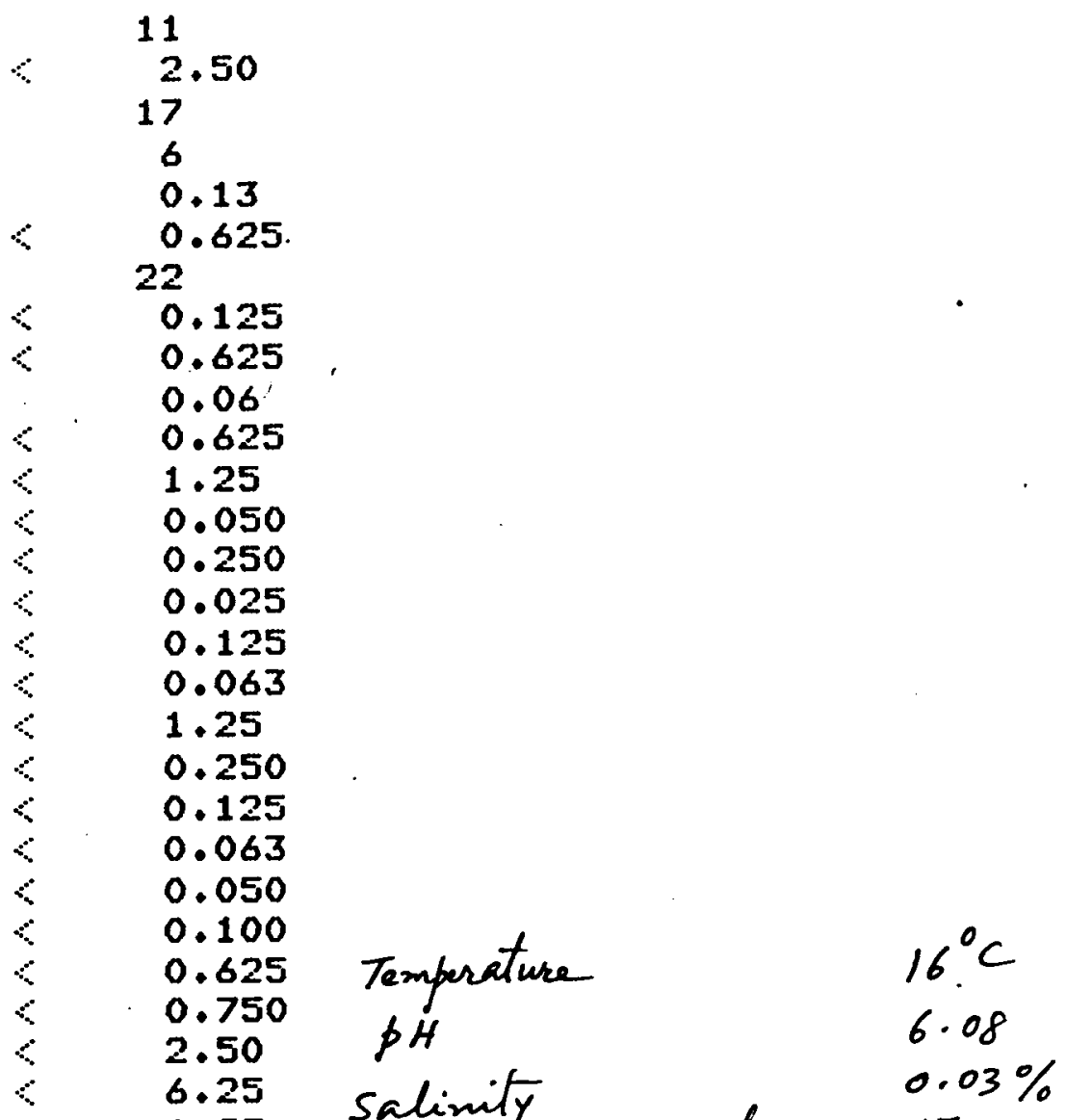

$5 \quad 1.25$ Salinity conductance $170 \mathrm{umot} / \mathrm{cm}$

0.125

0.050

0.005
$\therefore \quad 0.125$

0.125

0.125

$<\quad 0.250$

2.50

TH

Cl

$\mathrm{HCO}_{3}^{-}$

$\mathrm{SO}_{4}^{-}$

T.D.S.

CORRETED T.0.5.

$$
\begin{gathered}
5 \\
<.1 \\
80.8 \\
180 \\
140
\end{gathered}
$$


0

CALISTOGA SET ?

$40 . \quad G-040-80$

ELEMENT

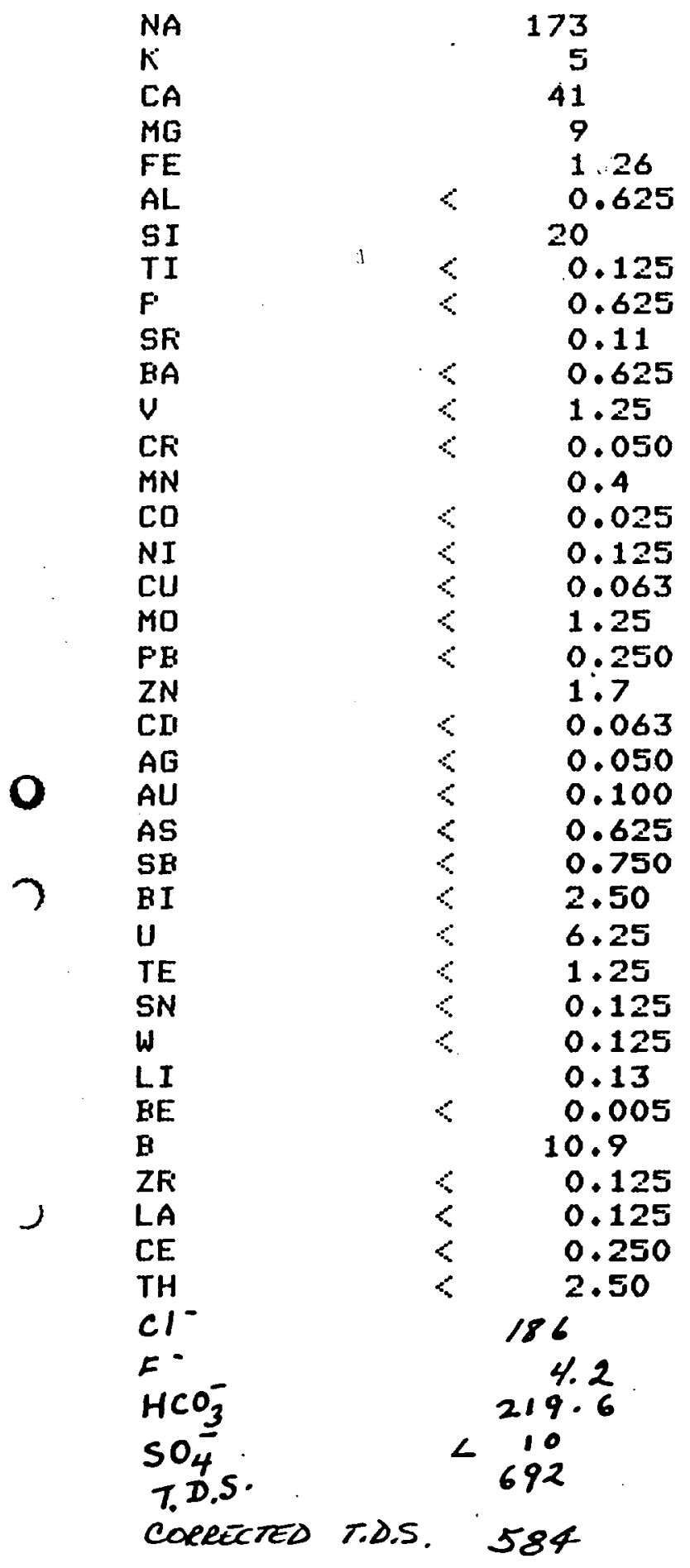

CONCENTRATION (PPM)

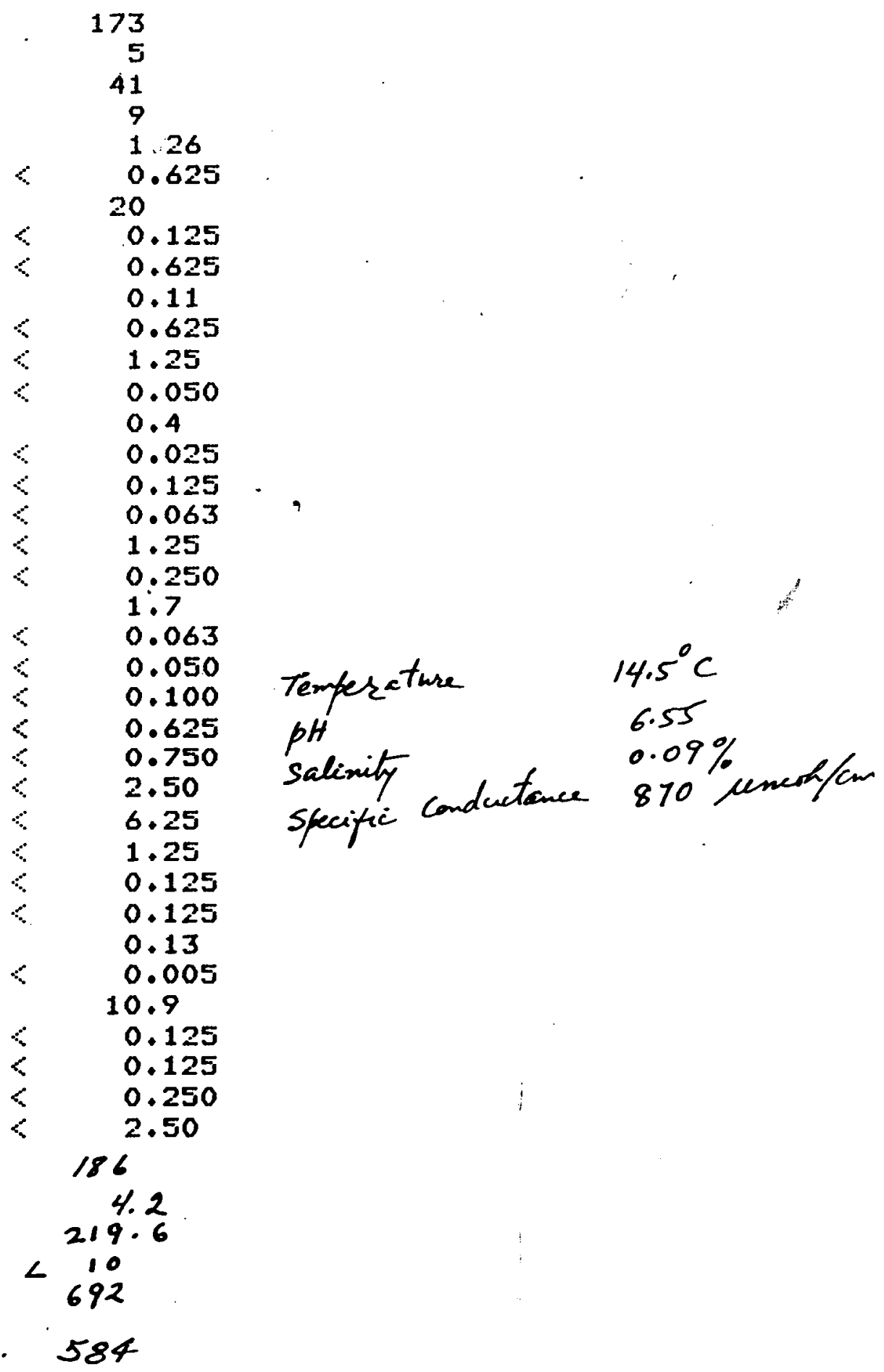


CALISTOGA SET ?

41

$G-041-80$

ELEMENT

CONCENTRATION (PPM)
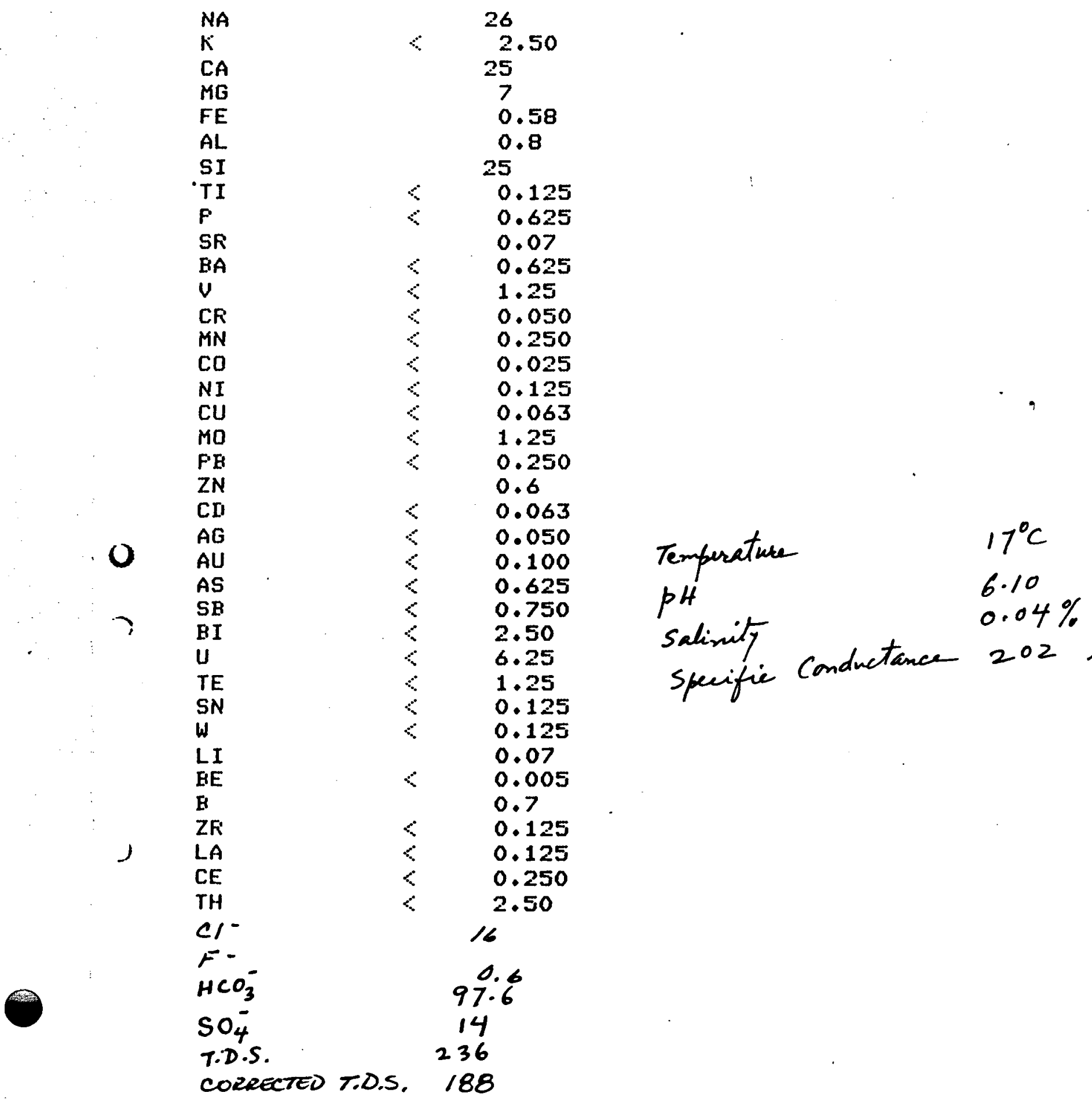
?

CALISTOGA SET 2

42

G-042-80

\section{ELEMENT}

$N A$

$\kappa$

$C A$

$M G$

FE

AL

SI

TI

$P$

SF

EA

V

CF

$M N$

CO

$\mathrm{NI}$

CU

MO

$\mathrm{FE}$

ZN

CII

O $A G$

Q AU

AS

) $\quad$ BI

U

TE

SN

W

LI

BE

E

ZF

) LA

CE

TH

$\mathrm{Cl}^{-}$

$F$

$\mathrm{HCO}_{3}^{-}$

$\mathrm{SO}_{4}^{-}$

TDS.

CONCENTFATION (FFM)

$$
\begin{aligned}
& 147 \\
& 5 \\
& 20 \\
& 12 \\
& <\quad \begin{array}{ll}
12 \\
<\quad 0.025 \\
& 0.625
\end{array}
\end{aligned}
$$

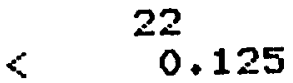

$$
\begin{aligned}
& <\quad 0.625 \\
& 0.12 \\
& \therefore \quad 0.625 \\
& <\quad 1.25 \\
& <\quad 0.050 \\
& \begin{array}{ll}
0.6 \\
<\quad 0.025
\end{array} \\
& <0.125 \\
& 0.1 \\
& 1.25 \\
& 0.250 \\
& 0.2 \\
& 0.063 \\
& 0.050 \\
& 0.100 \\
& 0.625 \\
& 0.750 \\
& 2.50 \\
& 6.25 \\
& 1.25 \\
& 0.125 \\
& 0.125 \\
& 0.26 \\
& \therefore \quad 0.005 \\
& 8.8 \\
& <\quad 0.125 \\
& <\quad 0.125 \\
& <\quad 0.250 \\
& <2.50 \\
& 156 \\
& 207.4 \\
& \begin{array}{r}
10 \\
603
\end{array} \\
& \text { pH } \\
& \text { salesity } \\
& \text { specific Conductance } \\
& \begin{array}{l}
15^{\circ} \mathrm{C} \\
6.30 \\
0.06 \%
\end{array} \\
& \begin{array}{l}
0.06 \% \\
750 \text { userot } / \mathrm{cm}
\end{array}
\end{aligned}
$$

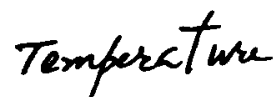

CUREETED T.D.S. 501 


\title{
CALISTOGA SET 2
}

43

$6-043-80$

ELEMENT

\author{
CONCENTRATION (FPM)
}

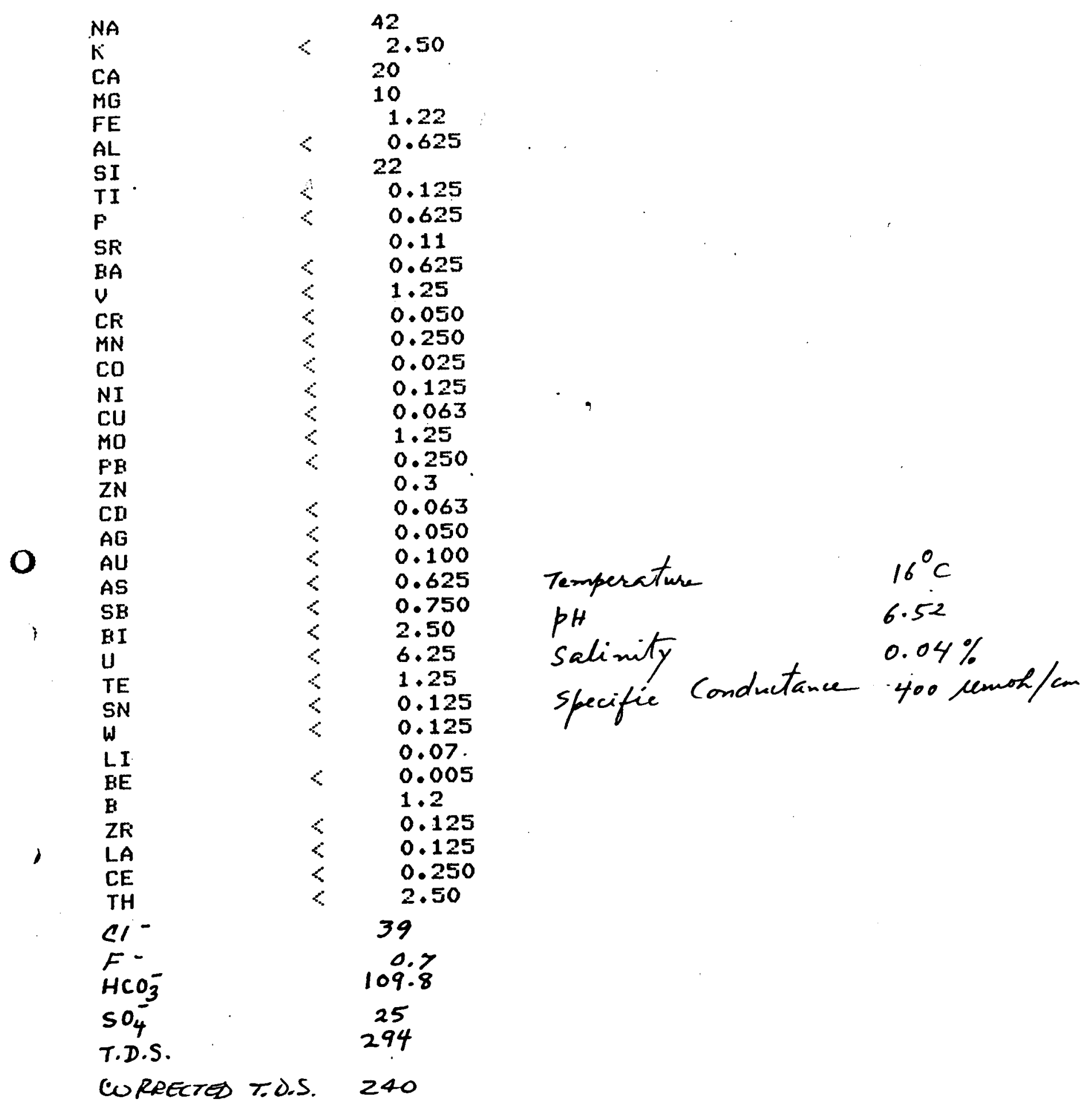


CALISTOGA SET 2

$44 \quad$ G-044-80

ELEMENT

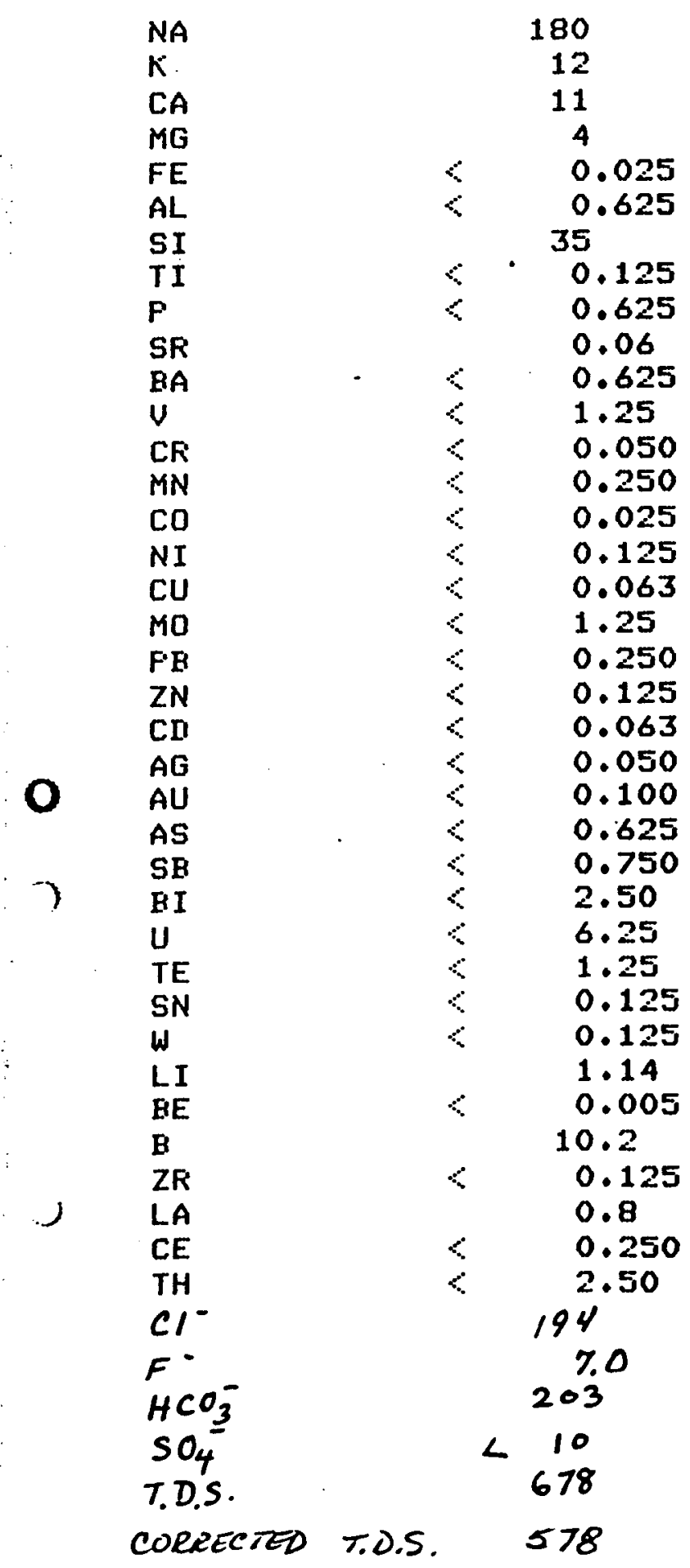


$J$
$?$

CALISTOGA SET 2

45

$G-045-80$

ELEMENT

CONCENTRATION (PPM)

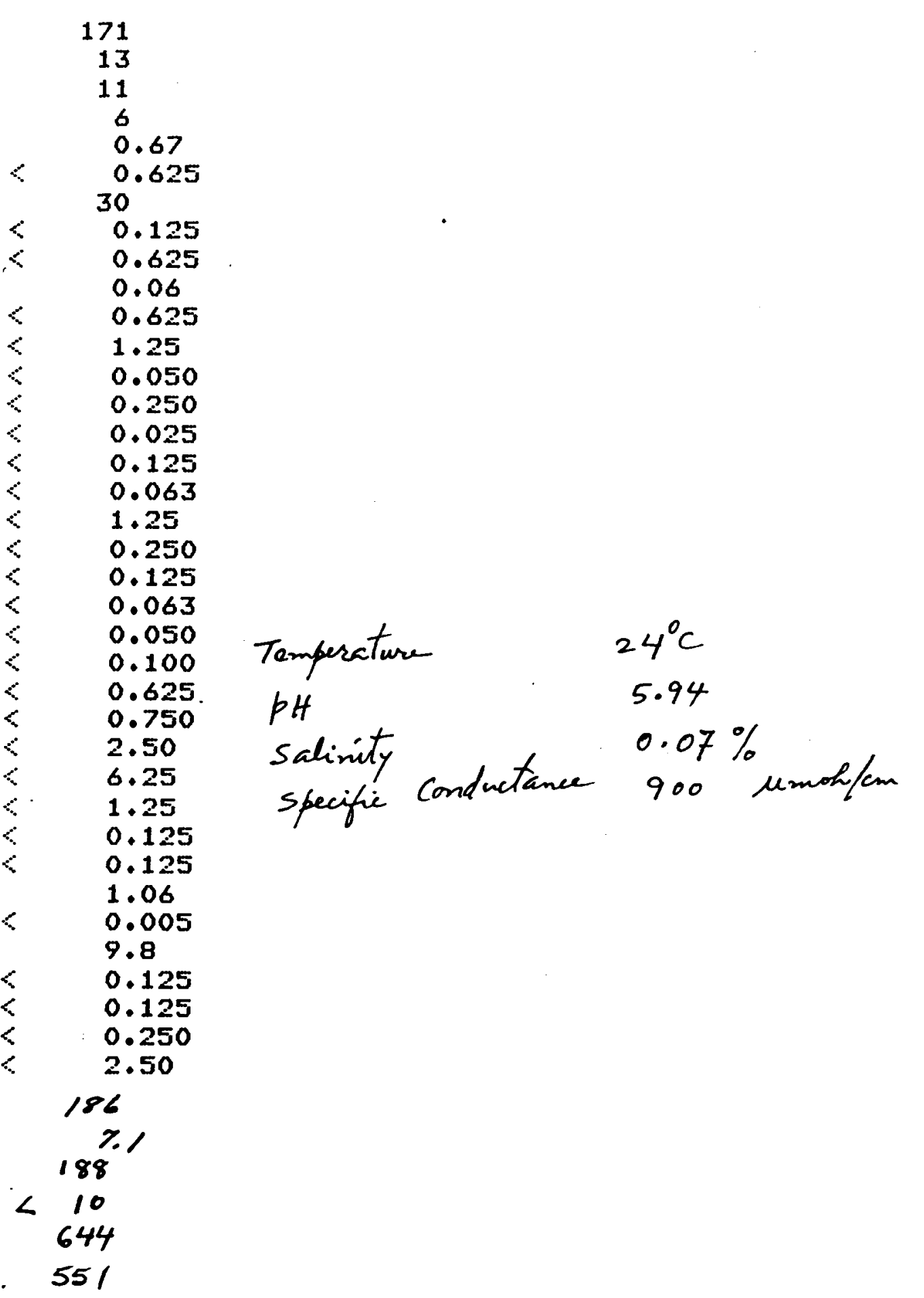


CALISTOGA SET 2

$46 \quad G-046-80$

ELEMENT

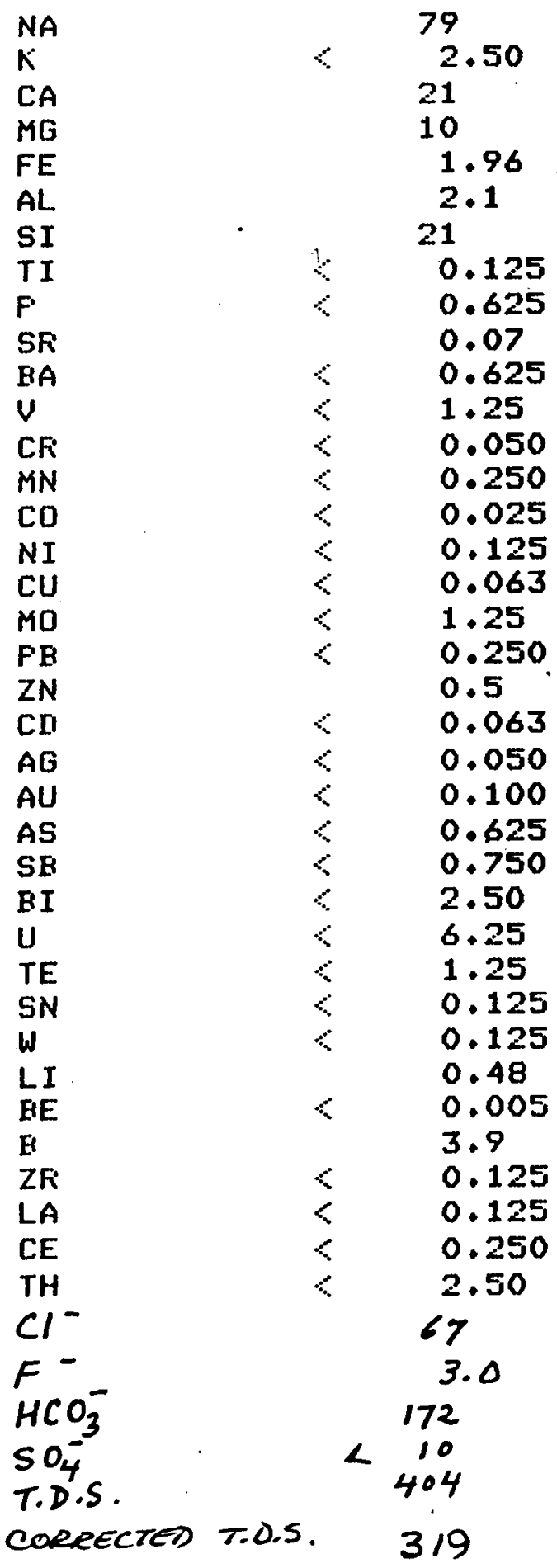

CONCENTRATION (F'F'M)

$\begin{array}{lc}\text { Temperature } & 22^{\circ} \mathrm{C} \\ \text { pH } & 5.90 \\ \text { Salinity } & 0.05 \%\end{array}$

specific conductance 410 unot/an 
CALISTOGA SET 2

$47 \quad$ G-047-80

ELEMENT

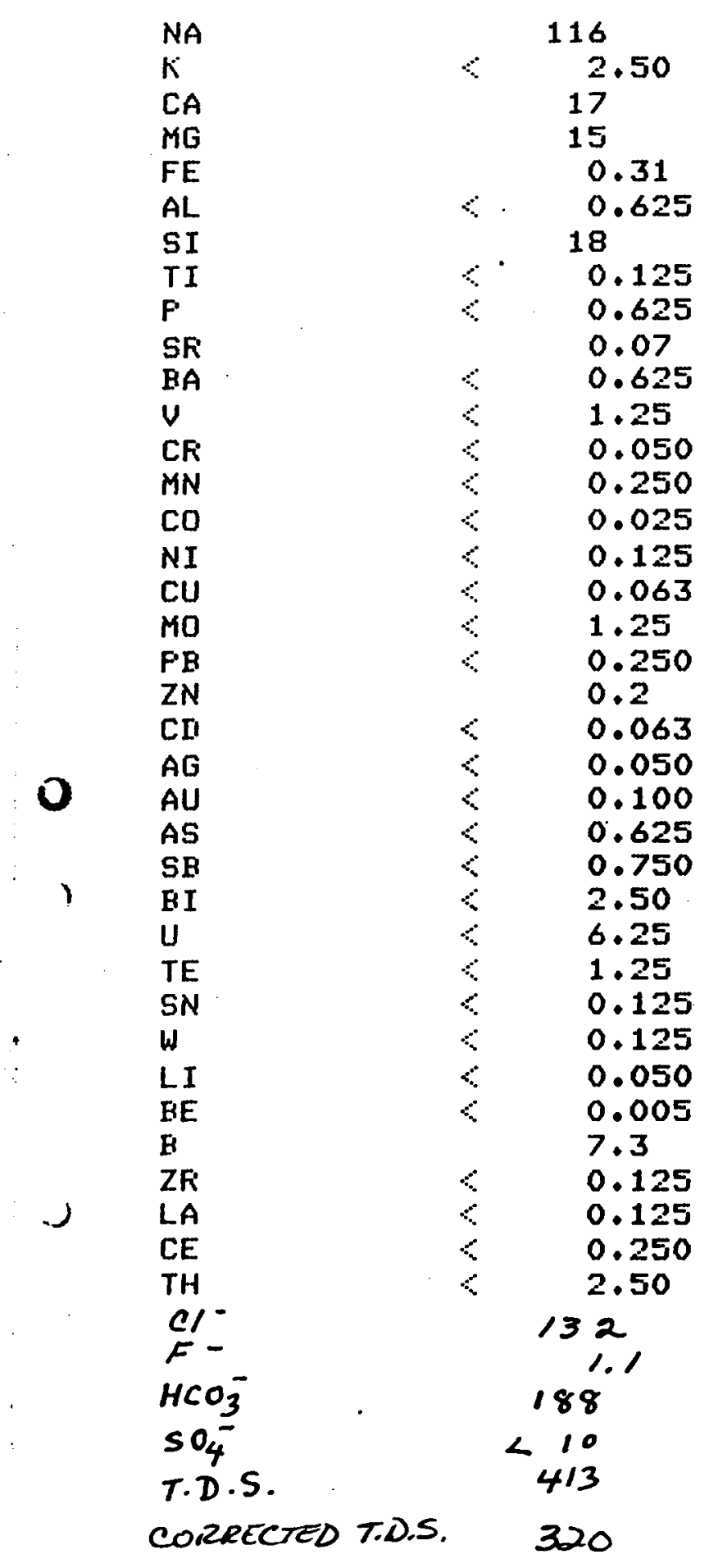


1)

CALISTOGA SET 2

$48 \quad$ G $-048-80$

ELEMENT<smiles>[AlH2]</smiles>

$C A$

$M G$

FE

AL

SI

TI

$F$

SR

BA

$\checkmark$

MN

CO

$N I$

CU

MO

$\mathrm{F} \cdot \mathrm{H}$

ZN

CII

AG

AU

AS

SE

)

BI

U

TE

SN

W

LI

EE

B

ZFi

LA

CE

TH

$\mathrm{Cl}^{\circ}$

$\mathrm{F}^{-}$

$\mathrm{HCO}_{3}^{-}$

$\mathrm{SO}_{4}^{-}$

T.D.S.

CORRECTEO T.0.5.
CONCENTRATION (FFM)

1.03
$\therefore \quad 2.50$

28

30

2.94

$\therefore \quad 0.625$

$<\quad 0.125$

0.625

0.13

0.625

1.25

0.050

1.1

0.025

$\therefore \quad 0.125$

$<\quad 0.063$
$\therefore \quad 1.25$

$\therefore \quad 0.250$

0.3

$<\quad 0.063$

$0 \quad 0.050$

0.100

0.625

0.750

2.50

6.25

1.25

0.125

0.125

0.050

0.005

8.1

$\therefore \quad 0.125$

0.125

$\therefore \quad 0.250$

$<2.50$

162

1.4
04.4

10
581

$\begin{array}{ll}\text { Temperature } & 18^{\circ} \mathrm{C} \\ \text { pH } & 5.79\end{array}$

salinity

specific Conductance 720 unurh/cm

480 


\section{CALISTOGA SET 2}

$49 \quad$ G-049-80

\section{ELEMENT}

CONCENTRATION (FF'M)

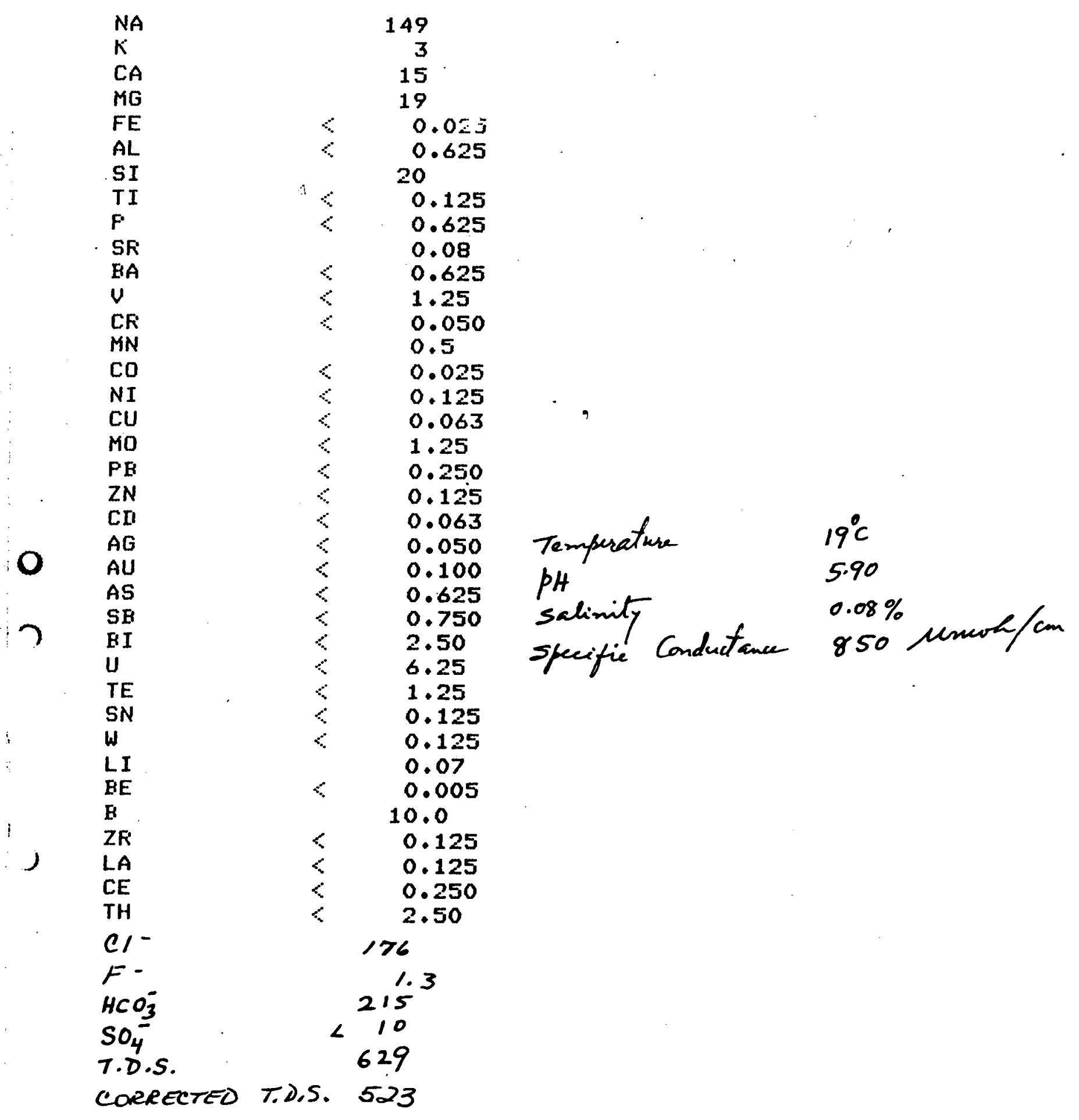


CALISTOGA SET 2

$50 \quad G-050-80$

ELEMENT

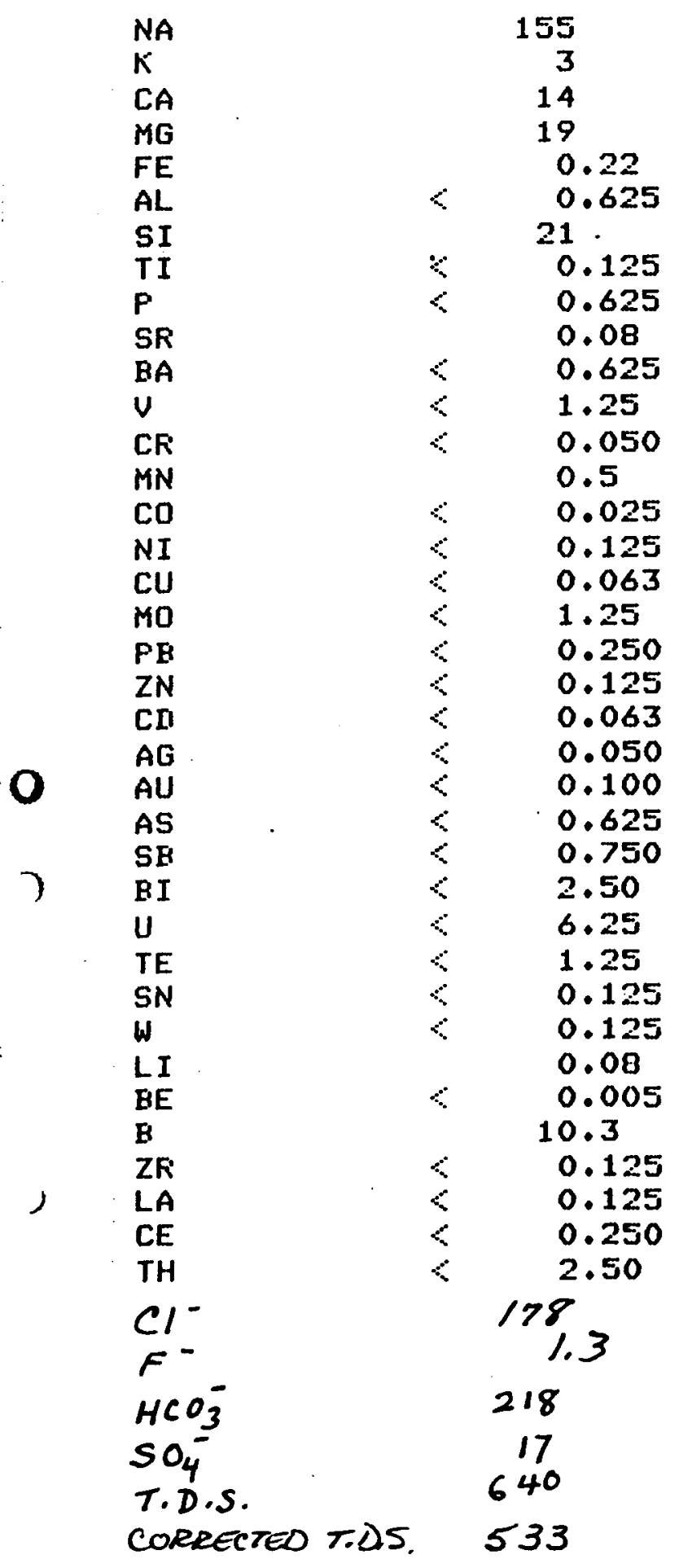


)

$\Omega$

CALISTOGA SET 2

51

G-051-80

ELEMENT

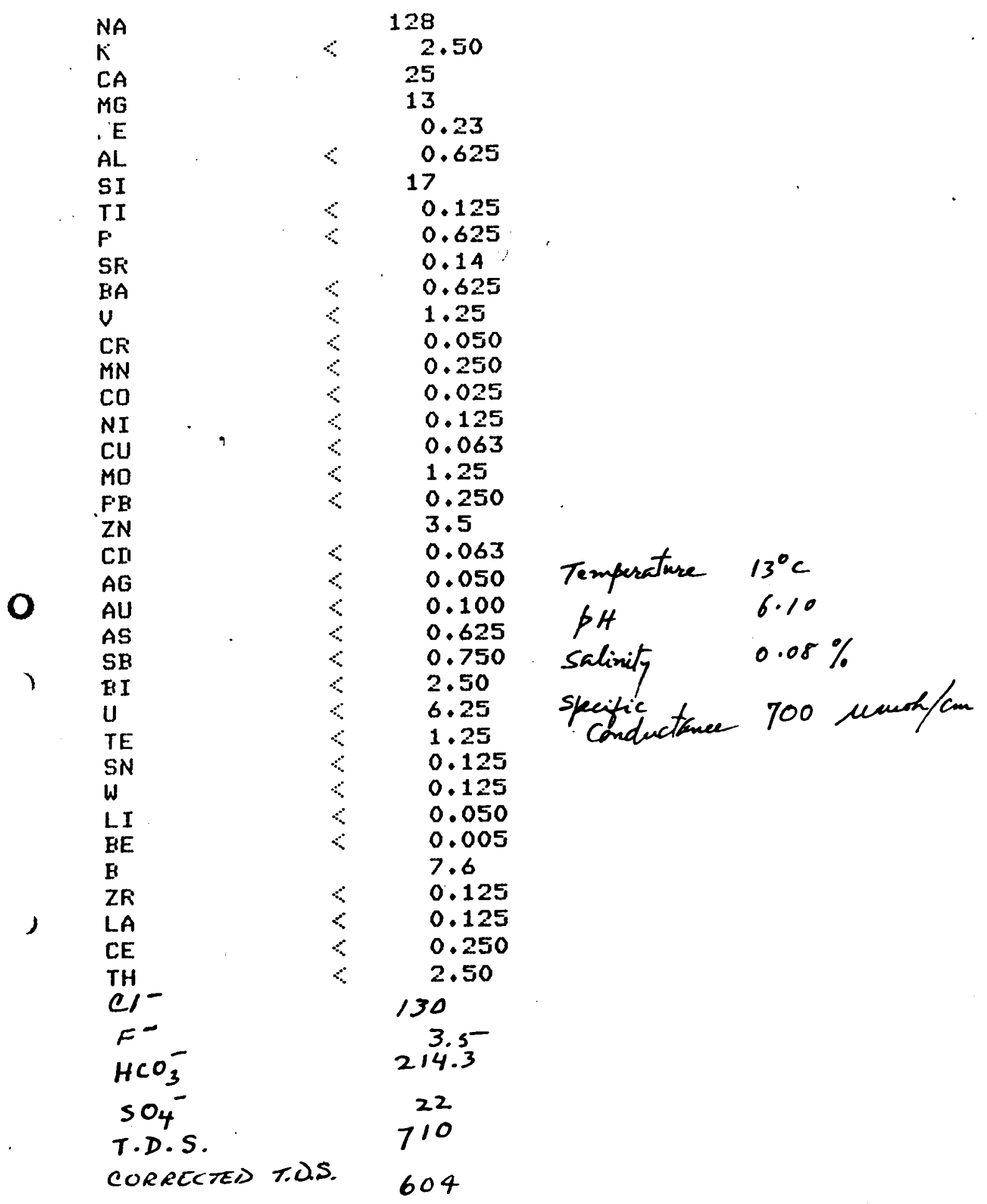


CALISTOGA SET 2

$52 \quad G-052-80$

ELEMENT

NA

K

$C A$

MG

FE

AL.

SI

TI

$\mathrm{F}$

SF

BA

U

CR

$M N$

CO

$N I$

$\mathrm{CU}$

$M O$

$F \cdot B$

ZN

CII

AG

o

AU

AS

SE

U

TE

SN

W

;

LI

BE

H

ZK

)
CONCENTRATION (F'F'M)

27
6.50
66

19
0.04
$<\quad 0.625$
24

$<\quad 0.125$
$<\quad 0.625$

$<0.625$

$<\quad 0.625$

$<\quad 1.25$

$\therefore \quad 0.050$

$\therefore \quad 0.250$

$\therefore \quad 0.125$

$\therefore \quad 0.063$

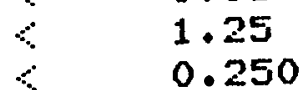

2.0

$\therefore \quad 0.063$

0.050
0.100

$\therefore \quad 0.625$

$\therefore \quad 0.750$

$\therefore \quad 2.50$

$6.25 \quad 6.25 \quad$ speific

$\begin{array}{ll}\therefore & 1.25 \\ & 0.125\end{array}$

$<\quad 0.125$

$\because \quad 0.050$

0.00
0.3

$\therefore \quad 0.125$

$\therefore \quad 0.125$

$\therefore \quad 0.250$

2.50

$\mathrm{TH}$

$\mathrm{Cl}^{-}$

$\mathrm{HCO}_{3}^{-}$

$\mathrm{SO}_{4}^{-}$

T. D.S.

2
38

$<\begin{gathered}0.1 \\ 142.6\end{gathered}$

49

389

Temperature
pH
Salinity
specific Conductence

$19^{\circ} \mathrm{C}$

6.25

$0.05 \%$

590 Mrnoth/an

CORRECTED T. D.S. $\quad 319$ 
)

CALISTOGA SET 2

$53 \quad$ G-053-80

EIEVENT

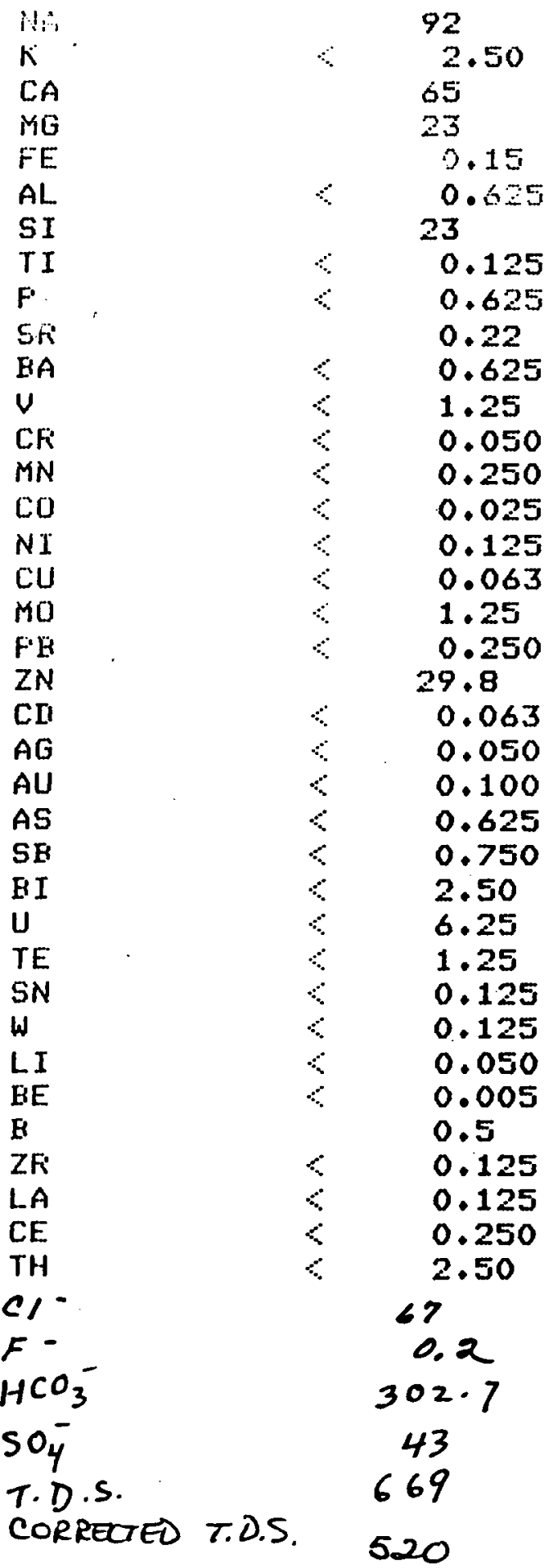

CONCENTRATION (FFPM)

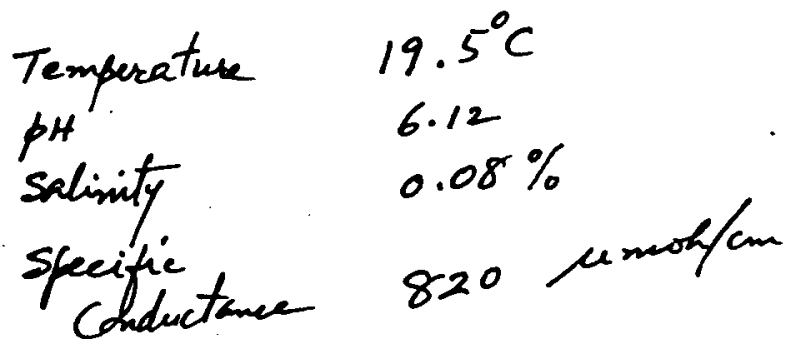


()

0

CALISTOGA SET 2

54

$G-054-80$

ELEMENT

NA

$K$

CA

MG

FE

$A L$

SI

TI

$F$

SF:

BA

U

CF

MN

CO

$N I$

$\mathrm{CU}$

MO

FB

ZN

CII

AG

AU

AS

SE

BI

U

TE

SN

W

LI

BE

E

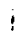

1

$Z F$

LA

CE

$\mathrm{TH}$

$\mathrm{Cl}^{-}$

$\mathrm{F}^{-}$

$\mathrm{HCO}_{3}^{-}$

$\mathrm{SO}_{4}$

T.D.S.

COERECTED T.D.S.
CONCENTRATION (FFM)

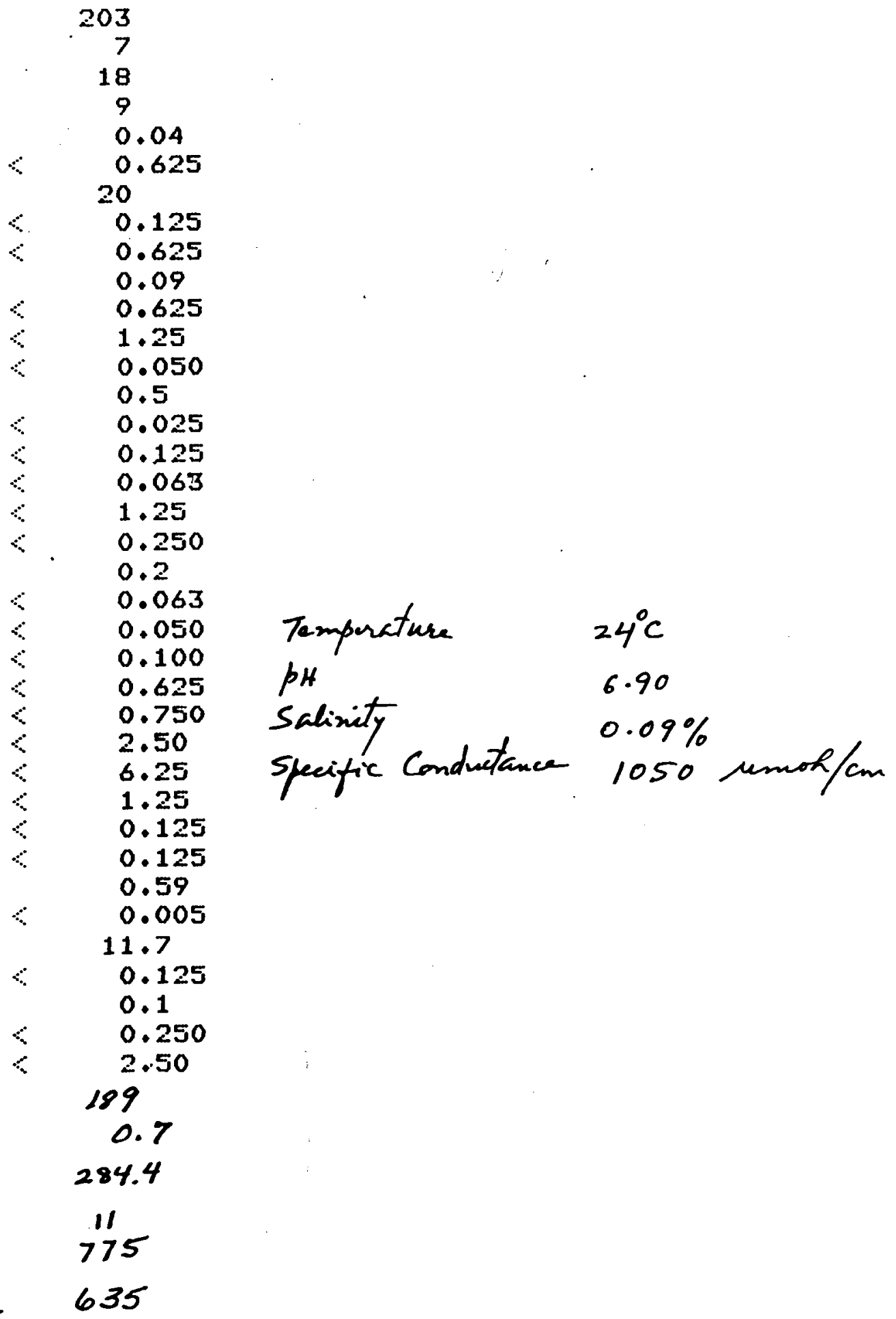


了

0

CALISTOGA SET 2

$55 \quad G-055-80$

ELEMENT

NA

$\kappa$

$C A$

$M G$

FE

AL

SI

TI

$F$

SR

BA

$\checkmark$

CF

$M N$

CO

$N I$

$\mathrm{CU}$

MO

PE

ZN

CI

AG

AU

AS

SB

BI

U

TE

SN

W

LI

BE

E

J LF

CE

TH

$\mathrm{Cl}^{-}$

$\mathrm{HCO}_{3}^{-}$

$\mathrm{SO}_{4}^{-}$

T.D.S.

CORRECTED T.D.S.
CONCENTRATION (FFM)

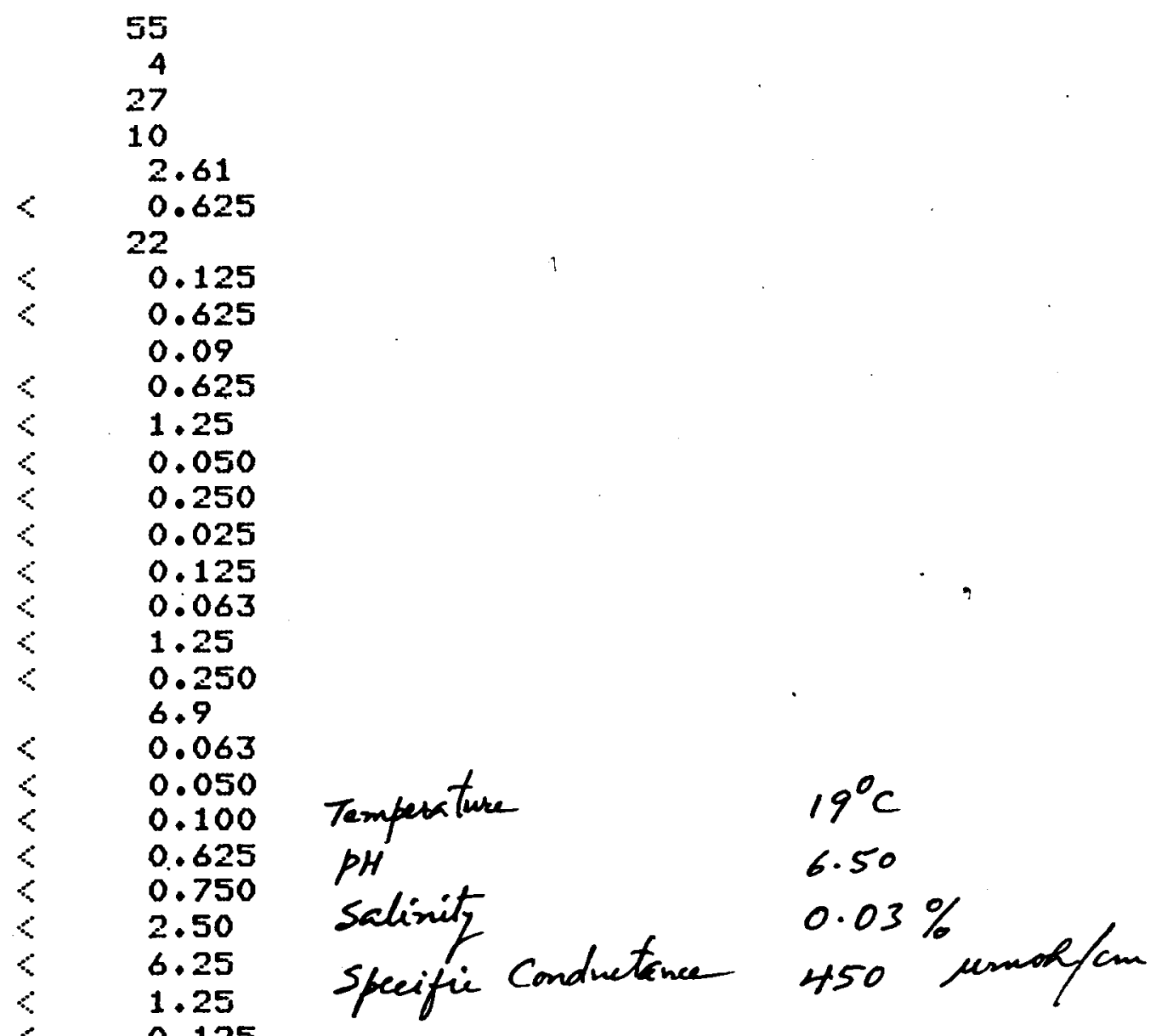


i)

CALISTOGA SET 3

$56 \quad G-056-80$

ELEMENT

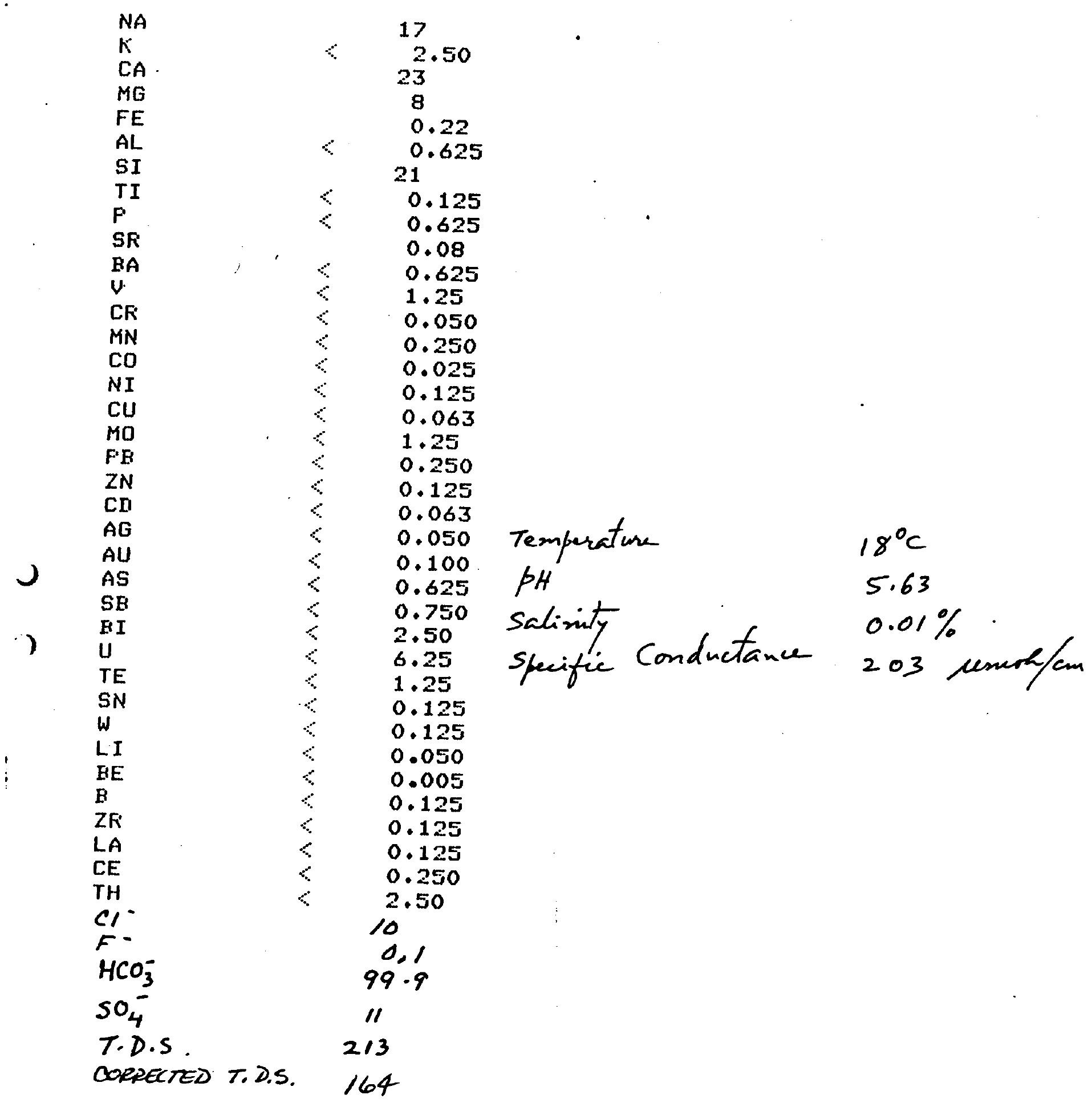

CONCENTRATION (PPM) 
o

0

CALISTOGA SET 3

57

G-057-80

ELEMENT

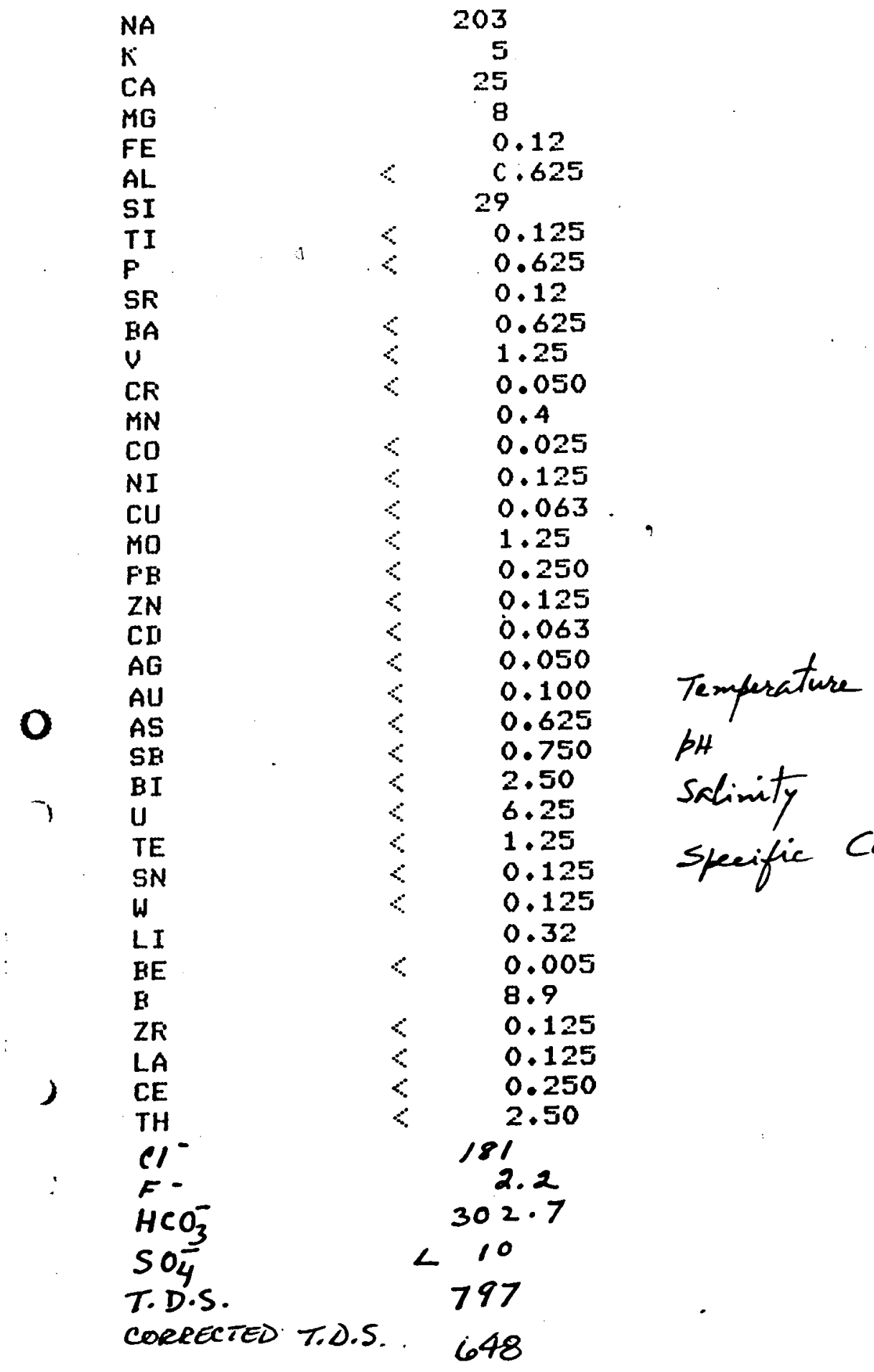

CONCENTRATION (FFM)

$$
\begin{aligned}
& 37.5^{\circ} \mathrm{C} \\
& 6.50 \\
& 0.08 \%
\end{aligned}
$$

1180 unishy 
0

CALISTOGA SET 3

$58 \quad G-058-80$

ELEMENT

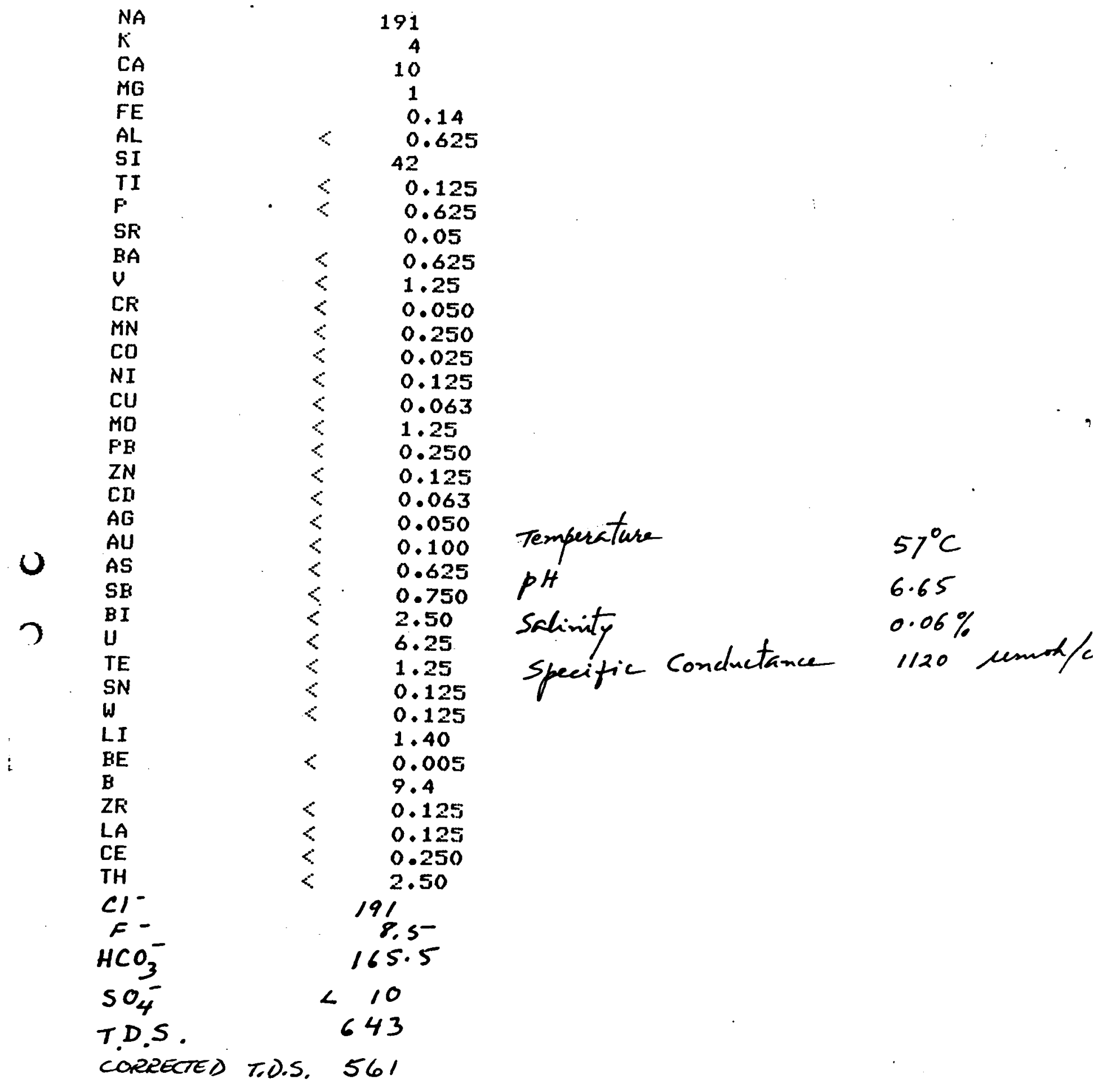


0

CALISTOGA SET 3

$59 \quad G-059-80$

ELEMENT

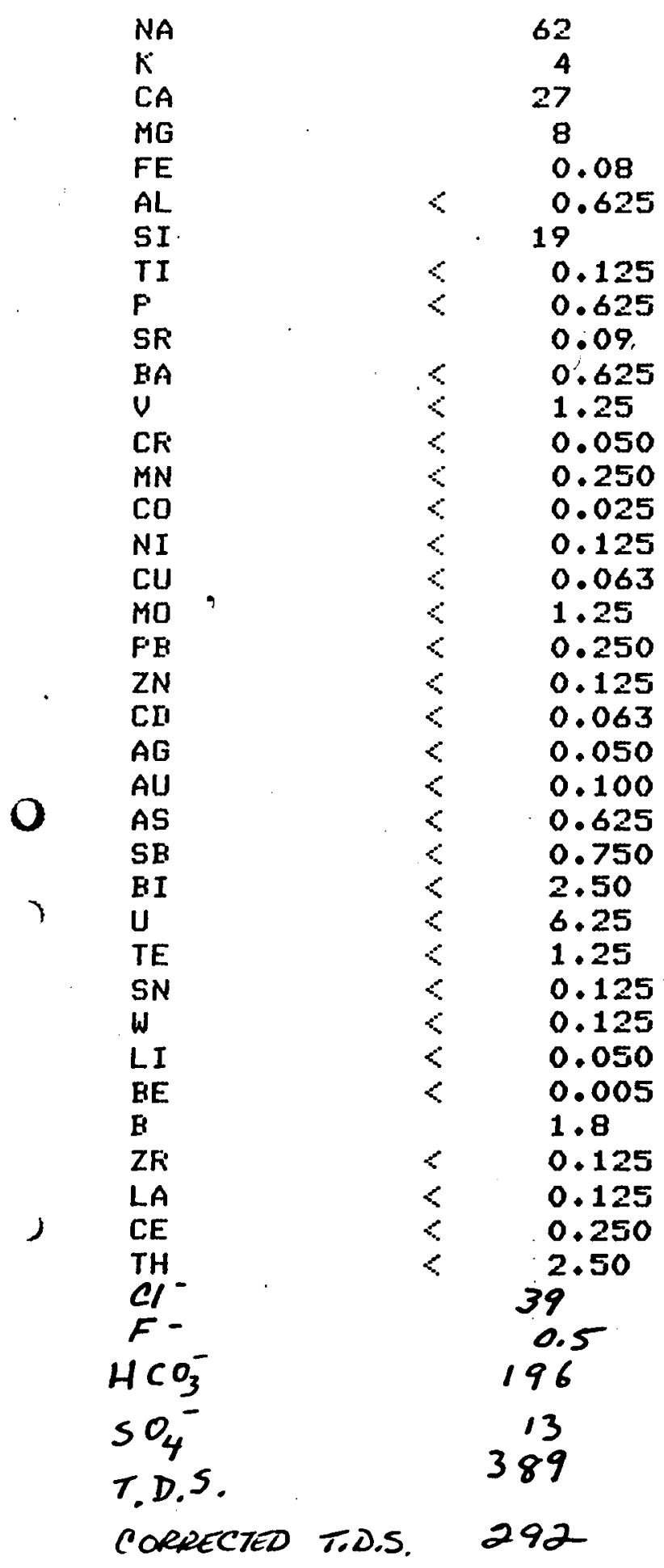

CONCENTRATION (PPM)

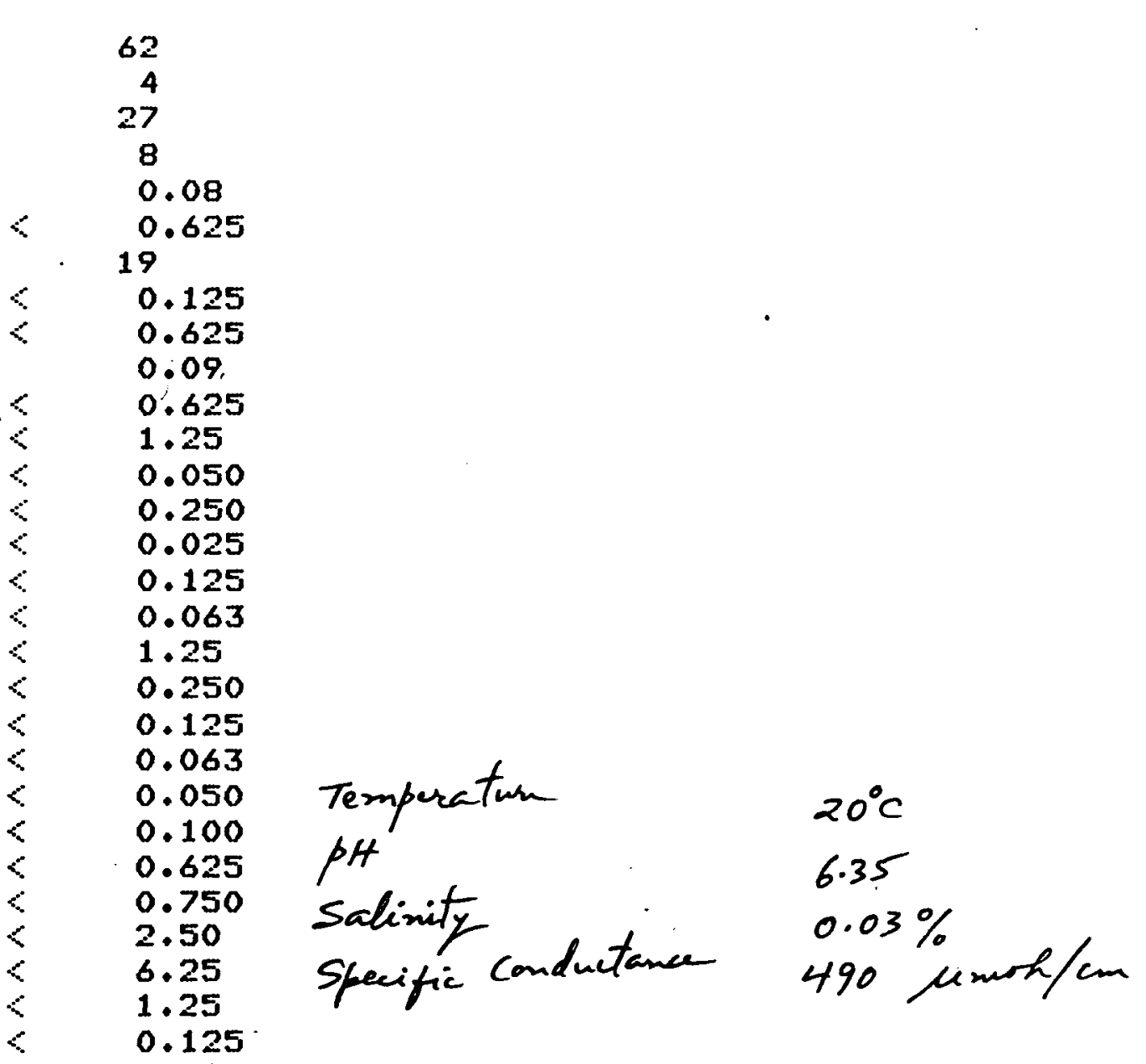


)

0

CALISTOGA SET 3

60

G-060-80

ELEMENT

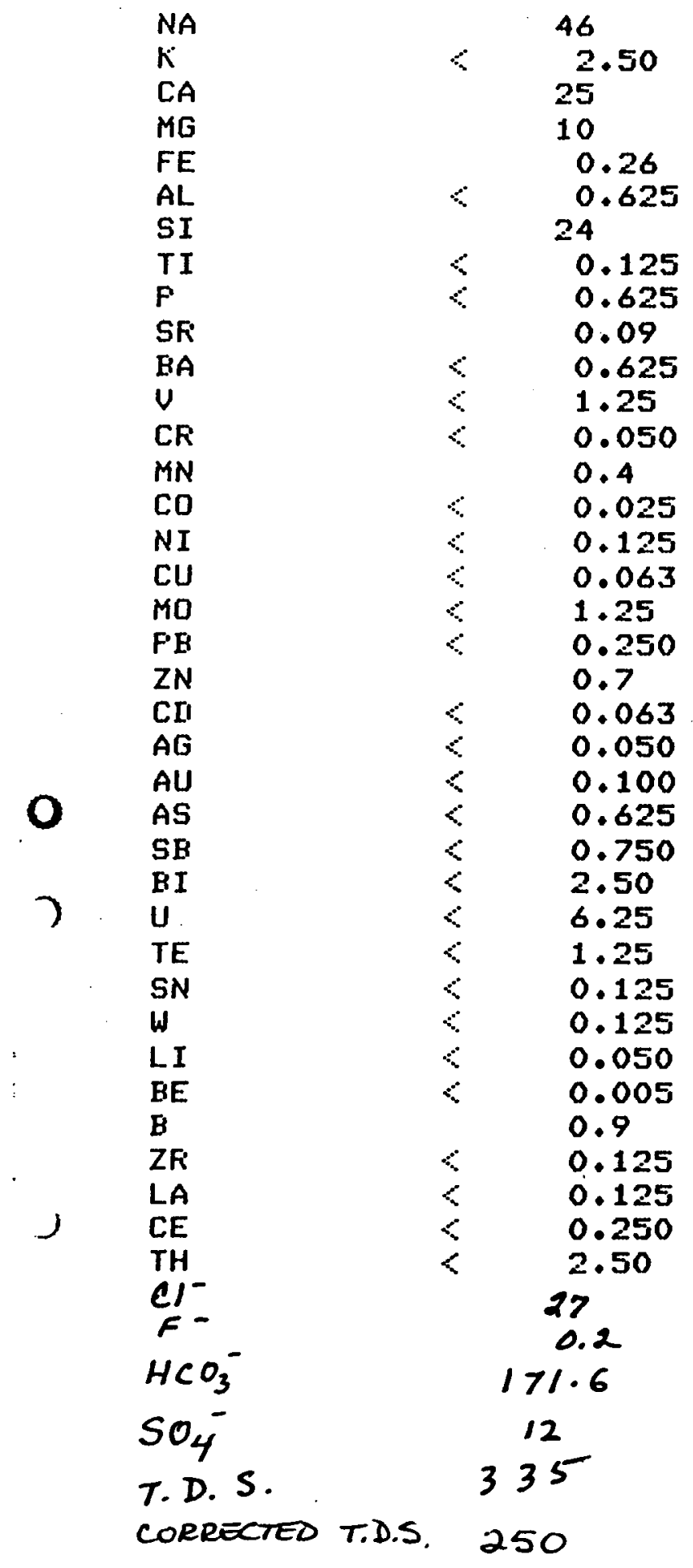

CONCENTRATION (PFM)

$\begin{array}{ll}\text { Temperature } & 10^{\circ} \mathrm{C} \\ \text { PH } & 6.64 \\ \text { Sodvity } & 0.03 \% \\ \text { specific Conductance } & 390 \mu \text { undef am }\end{array}$ 
)

O

CALISTOGA SET 3

61

G-061-80

ELEMENT

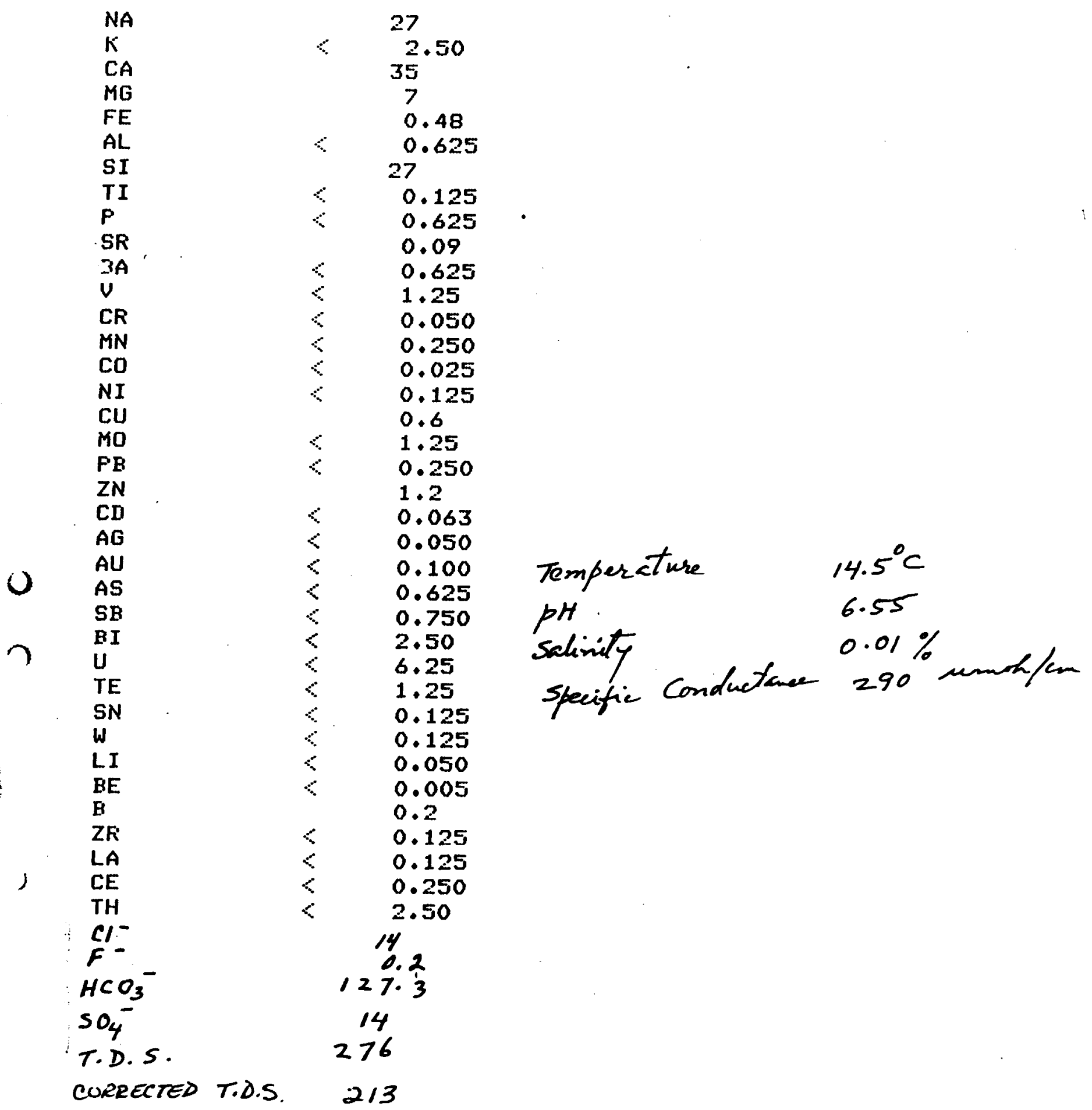


)

62
CALISTOGA SET 3

$$
\text { G-062-80 }
$$

ELEMENT

CONCENTRATION (FFM)

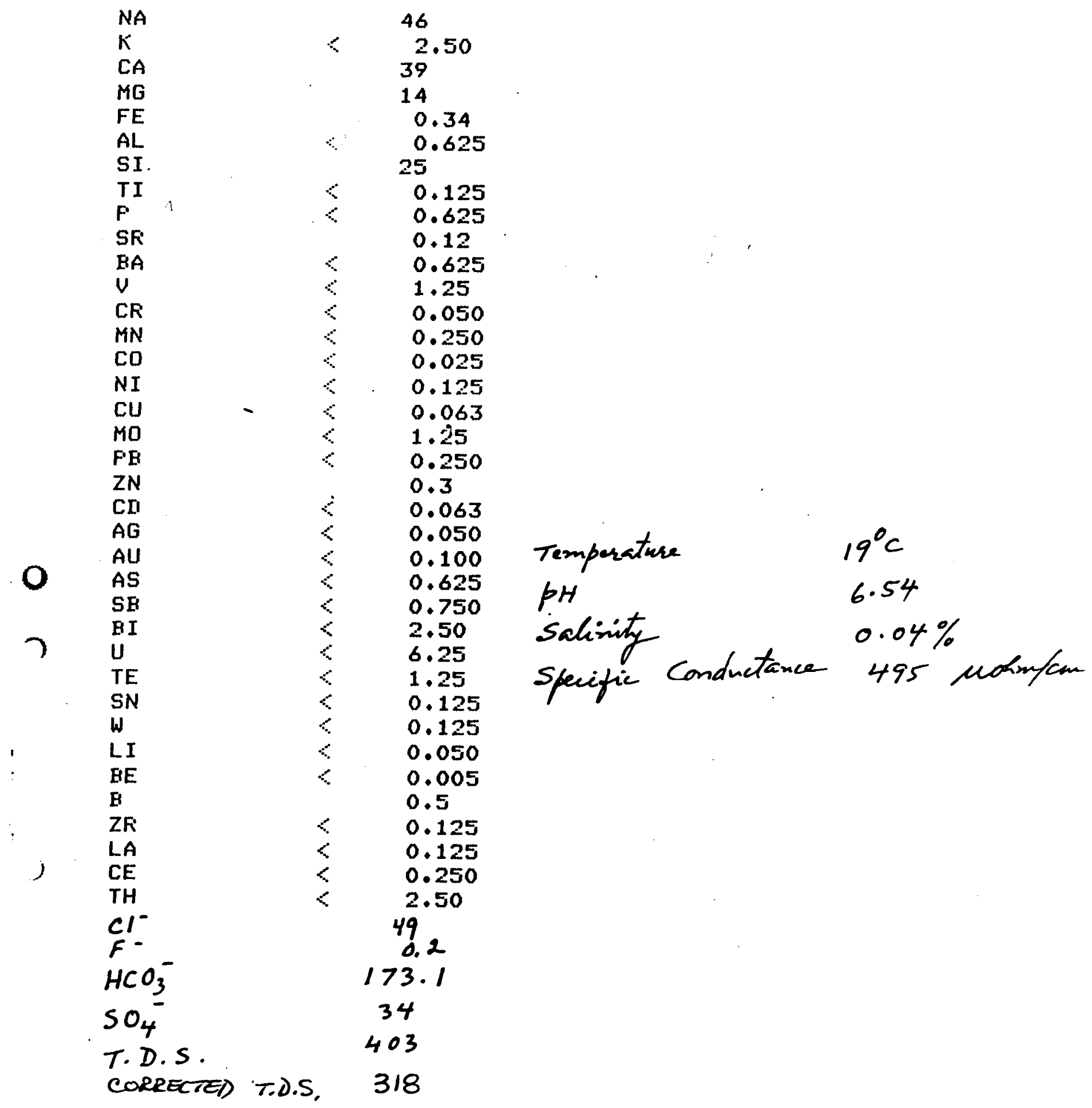


- 3

CALISTOGA SET 3

63

G-063-80

ELEMENT

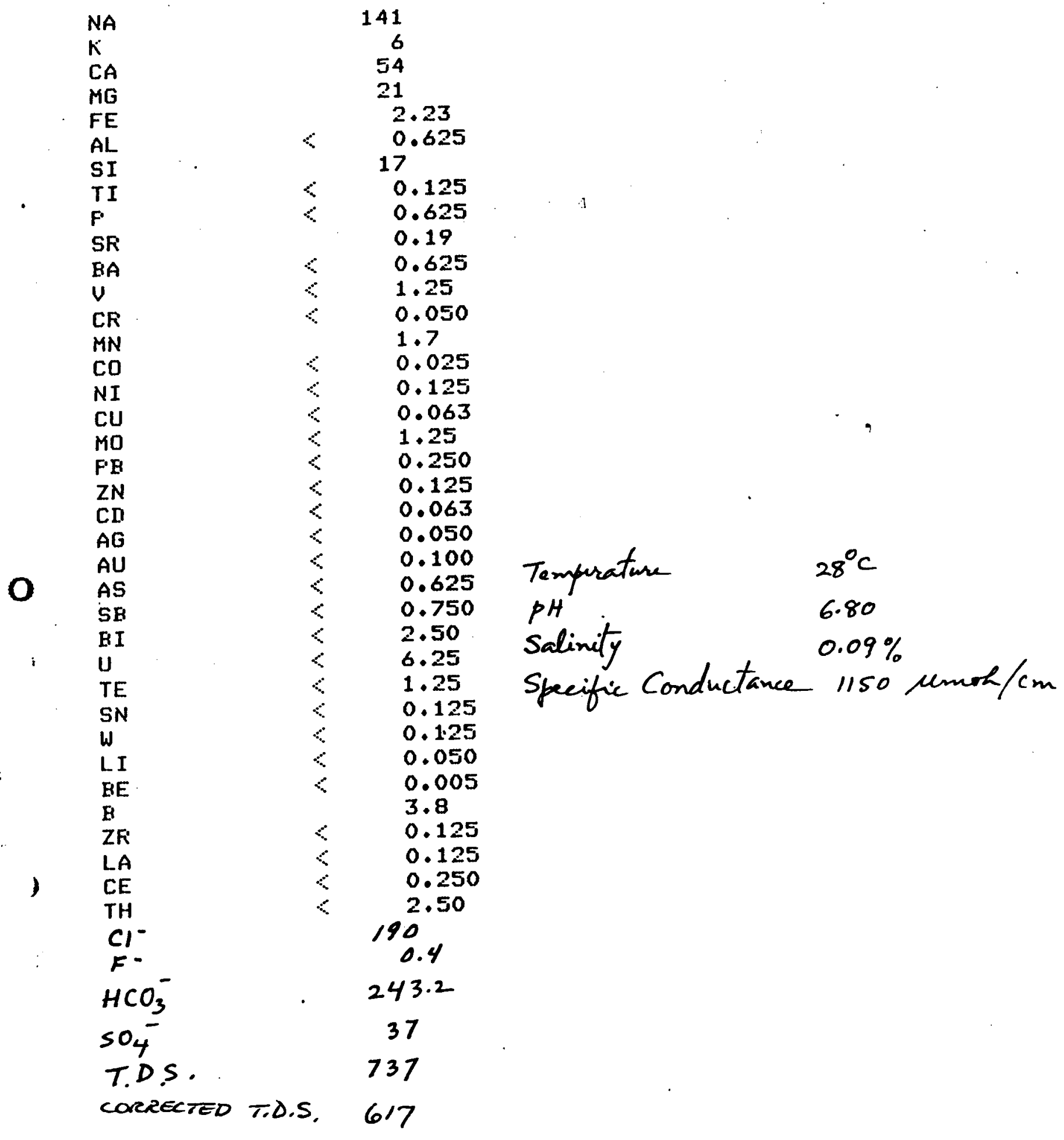


1

?

CALISTOGA SET 3

64

G-064-80

ELEMENT

NA
$K$
$C A$
$M G$
$F E$

AL

SI

TI

P

SF

BA

U

CR

$M N$

CO

NI

CU

MO

$F \cdot B$

ZN

CD

$A G$

AU

AS

SB

EI

U

TE

SN

W

LI

BE

E

ZF

LA

CE

TH

$\mathrm{Cl}^{-}$

$\mathrm{F}-$

$\mathrm{HCO}_{3}^{-}$

$\mathrm{SO}_{4}^{-}$

T.D.S.
CONCENTRATION (FFM)

56
2.50
34
11
2.00
0.625
23

$<\quad 0.125$
$<\quad 0.625$

0.10

$<\quad 0.625$

$<\quad 1.25$

$<\quad 0.250$

$\because \quad 0.025$

$<\quad 0.125$

$\begin{array}{ll}< & 1.25 \\ < & 0.250\end{array}$

0.5

$<\quad 0.063$

$8 \quad 0.050$

$\therefore \quad 0.100$

0.625

$\begin{array}{lll}0.750 & \text { Salinity } & 0.03 \% \\ 2.50 & 0.25 \\ 1.25 & \text { specific Conductance } & 450\end{array}$

$\because \quad 0.125$

0.125

0.050

0.005

1.1

$<\quad 0.125$

$<\quad 0.125$

$<\quad 0.250$
$<\quad 2.50$

38

0.3

$162 \cdot 4$

29

380 $21^{\circ} \mathrm{C}$

6.80

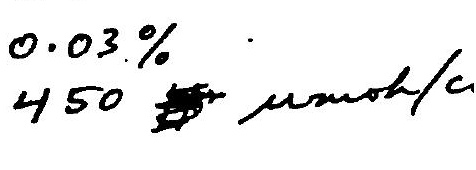

CORECTES T.D.S. 300 
.

o

CALISTOGA SET 3

$65 \quad$ G-065-80

ELEMENT

$N A$

Ki

$C A$

MG

FE

AL

SI

${ }^{\mathrm{TI}}$

SF

BA

U

CF

MN

CO

$N I$

$\mathrm{CU}$

MO

F'B

ZN

CII

$A G$

AU

AS

SB

EI

$U$

TE

SN

$W$

LI

$\mathrm{BE}$

B

ZLF

J

CE

CONCENTRATION (FPM)

54
$\therefore \quad 57$

14

0.72

$\therefore \quad 0.625$

$<\quad 0.125$
$\therefore \quad 0.625$

0.15

$\therefore \quad 0.625$

$1 \quad 1.25$

$<\quad 0.050$

$<\quad 0.250$

$\therefore \quad 0.025$

$\therefore \quad 0.125$

$\because, \quad 0.063$

$\checkmark \quad 0.250$

0.8

$<\quad 0.063$

$\because \quad 0.050$

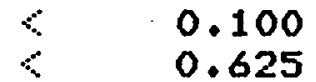

0.625
$<\quad 0.750$

2.50

$\therefore \quad 6.25$

Temperattere

ptt

salinity

specific Conductance

$<\quad 0.125$

$\because \quad 0.050$

0.005
1.2

$<\quad 0.125$

$\mathrm{TH}$

$\mathrm{Cl}^{-}$

\begin{tabular}{ll}
$<$ & 0.250 \\
\hdashline & 2.50
\end{tabular}

$\mathrm{HCO}_{3}^{-}$

83
0.1
160.9

$\mathrm{SO}_{4}^{-}$

T.D.S.

26
318

CORRECTED T.0.5. 239 
)

?

CALISTOGA SET 3

$66 \quad G-066-80$

ELEMENT

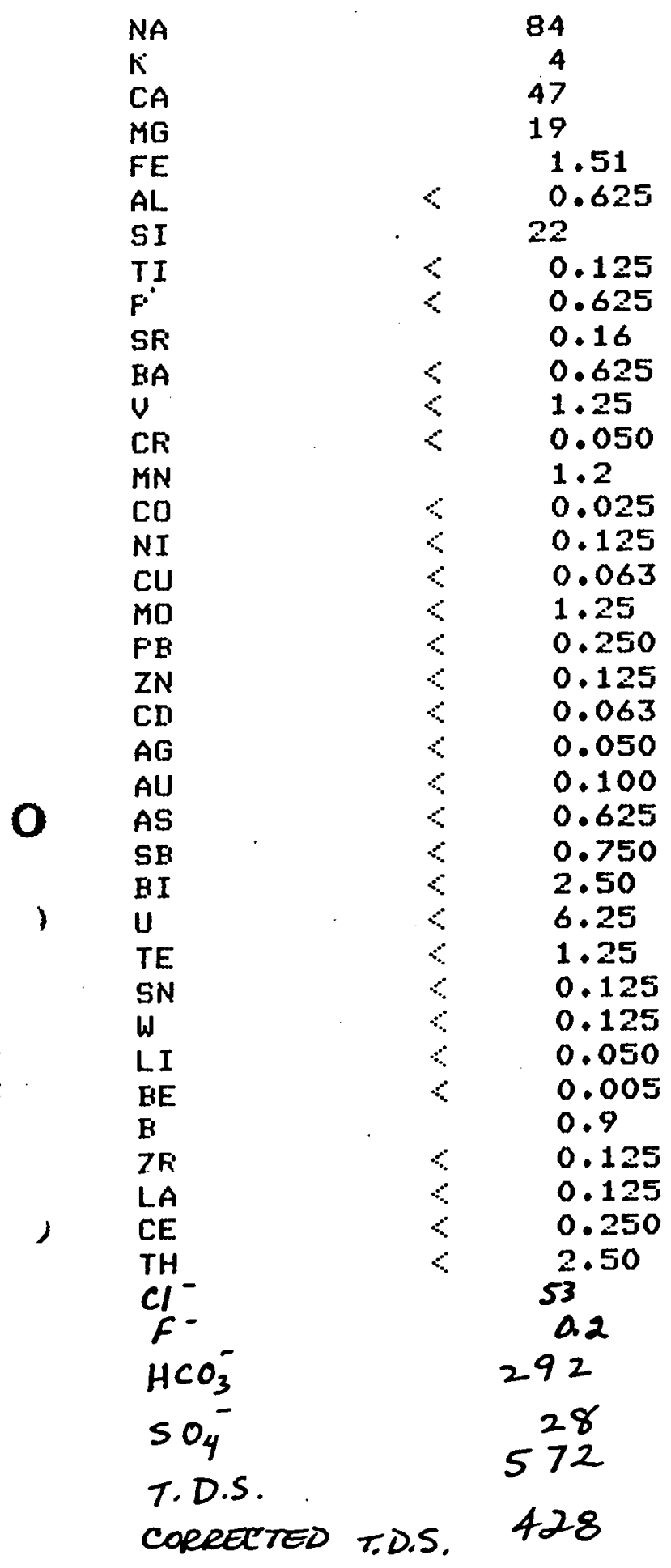

CONCENTRATION (FEM)

Temperature

PH

salinity

specific conductance

840 unoth/cm 
)

67

CALISTOGA SET 3

ELEMENT<smiles>c1c[nH]cn1</smiles>

$C A$

$M G$

FE

AL

SI

TI

F

SR

BA

U

CR

MN

CO

$N I$

CU

MO

$F B$

ZN

CII

AG

AU

0

7

SB

E I

U

TE

SN

W

LI

BE

B

ZF:

LA

CE

TH

Cl-

$\mathrm{HCO}_{3}^{-}$

$\mathrm{SO}_{4}^{-}$

T.D.S.

COREECTED T.D.S.
CONCENTKATION (F'F'M)

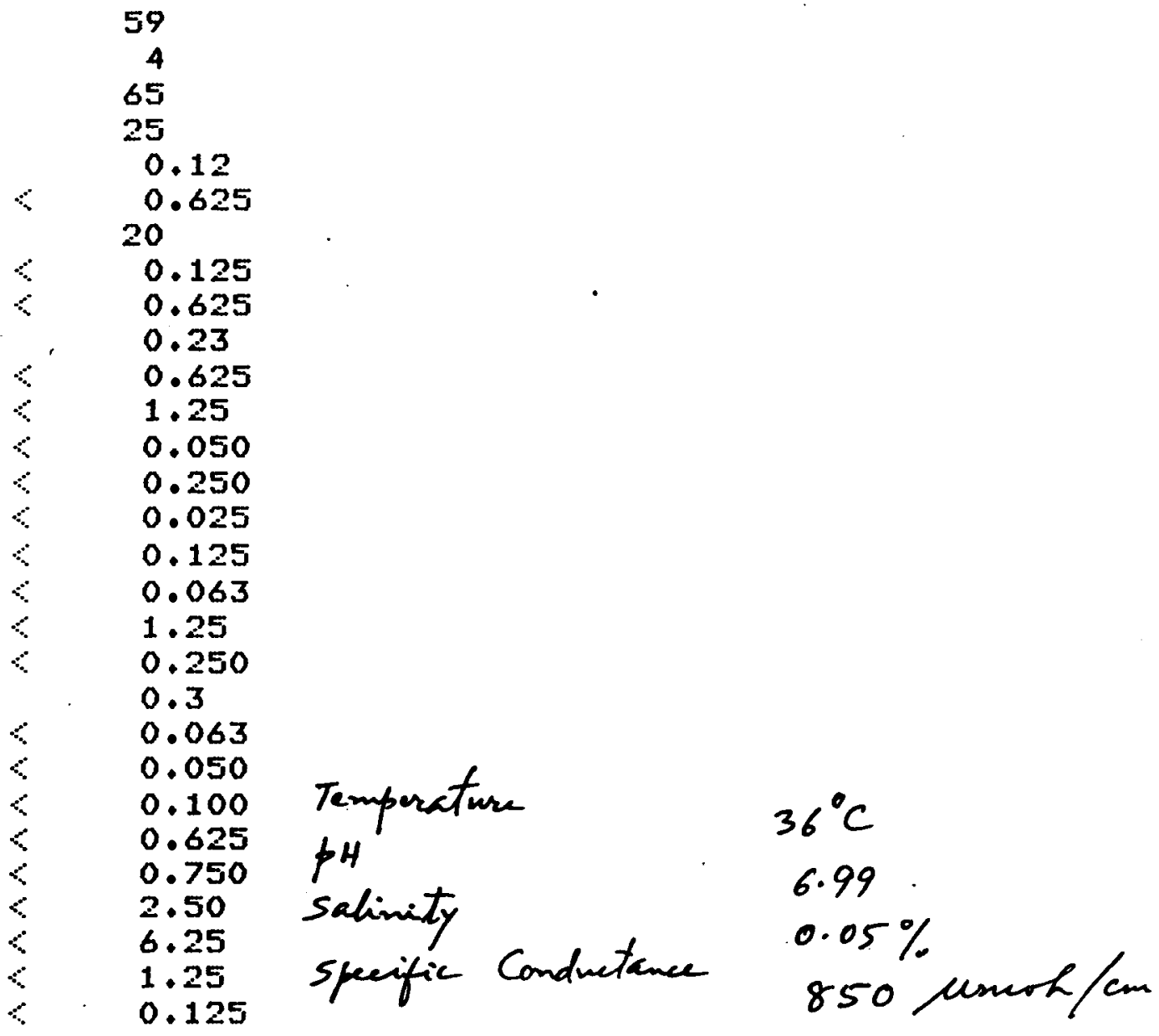

$\because \quad 0.125$

$<\quad 0.050$

$\begin{array}{ll}< & 0.5 \\ < & 0.125 \\ < & 0.125 \\ < & 0.250 \\ & 2.50\end{array}$

43

0.2

163.9

50

454

372 
$68 \quad G-068-80$

ELEMENT

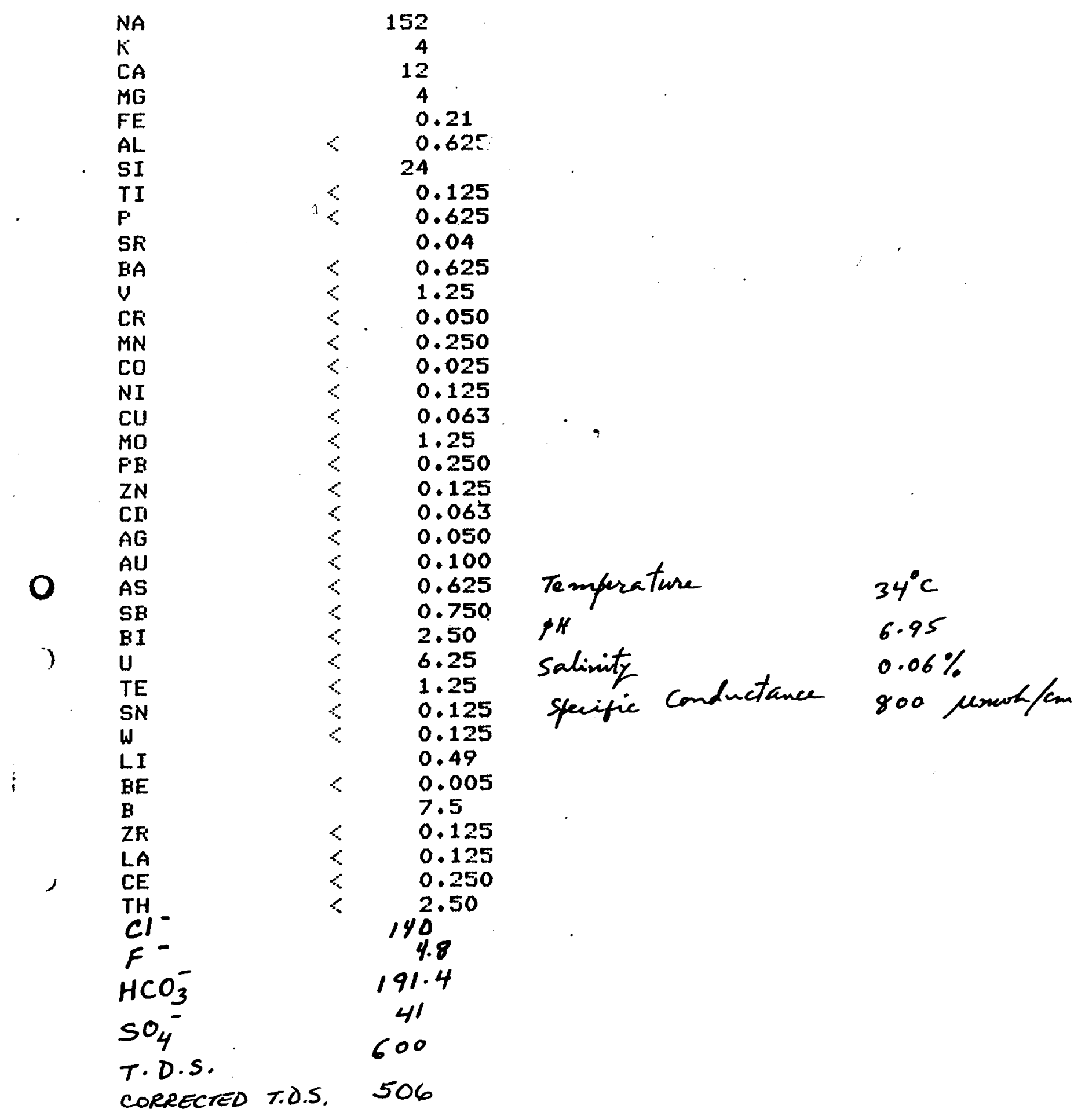


)

CALISTOGA SET 3

69

G-069-80

ELEMENT

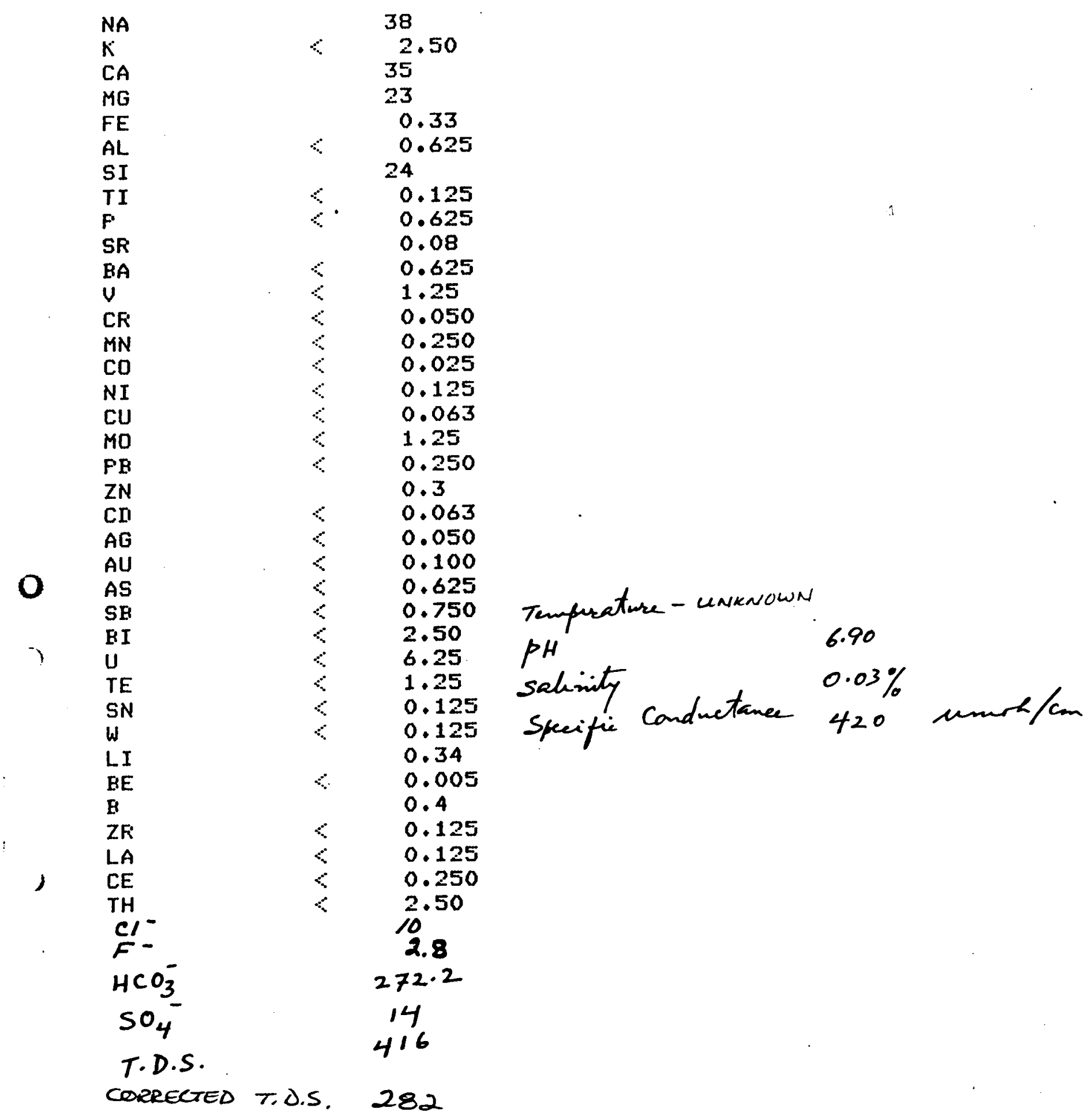


)

o

CALISTOGA SET 3

70

G-070-80

ELEMENT

NA

$K$

$\mathrm{CA}$

$M G$

FE

AL

SI

TI

$P$

- $S F$

BA

U

CR

$M N$

CO

NI

CU

MO

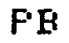

ZN

Cn

$A G$

AU

O AS

SE

$\mathrm{BI}$

U

TE

SN

W

LI

BE

B

ZF

LA

CE

$\mathrm{TH}$

$\mathrm{Cl}^{-}$

$\mathrm{HCO}_{3}^{-}$

$\mathrm{SO}_{4}{ }^{-}$

T.D.S.
CONCENTFATION (FPM)

14
35
6

0.33
0.625
10

$\because \quad 0.125$

0.11

0.625

1.25

0.050

0.250

0.025

0.125

0.063

1.25

0.250

0.8

0.063

0.050

0.100

0.625

0.750

2.50

6.25

1.25

PH

$\begin{array}{ll}\text { Salinity } & 0.01 \% \\ \text { specific conductaner } & 260 \mu \mathrm{mar} / \mathrm{cm}\end{array}$

$15^{\circ} \mathrm{C}$
6.90
$0.01 \%$
260 umatam

0.125

0.050

0.005

0.125

0.125

0.125

0.250

2.50

5.2

145.6

16

219

CORRECTED T.D.S.

147 
)

CALISTOGA SET 3

71

G-071-80

ELEMENT

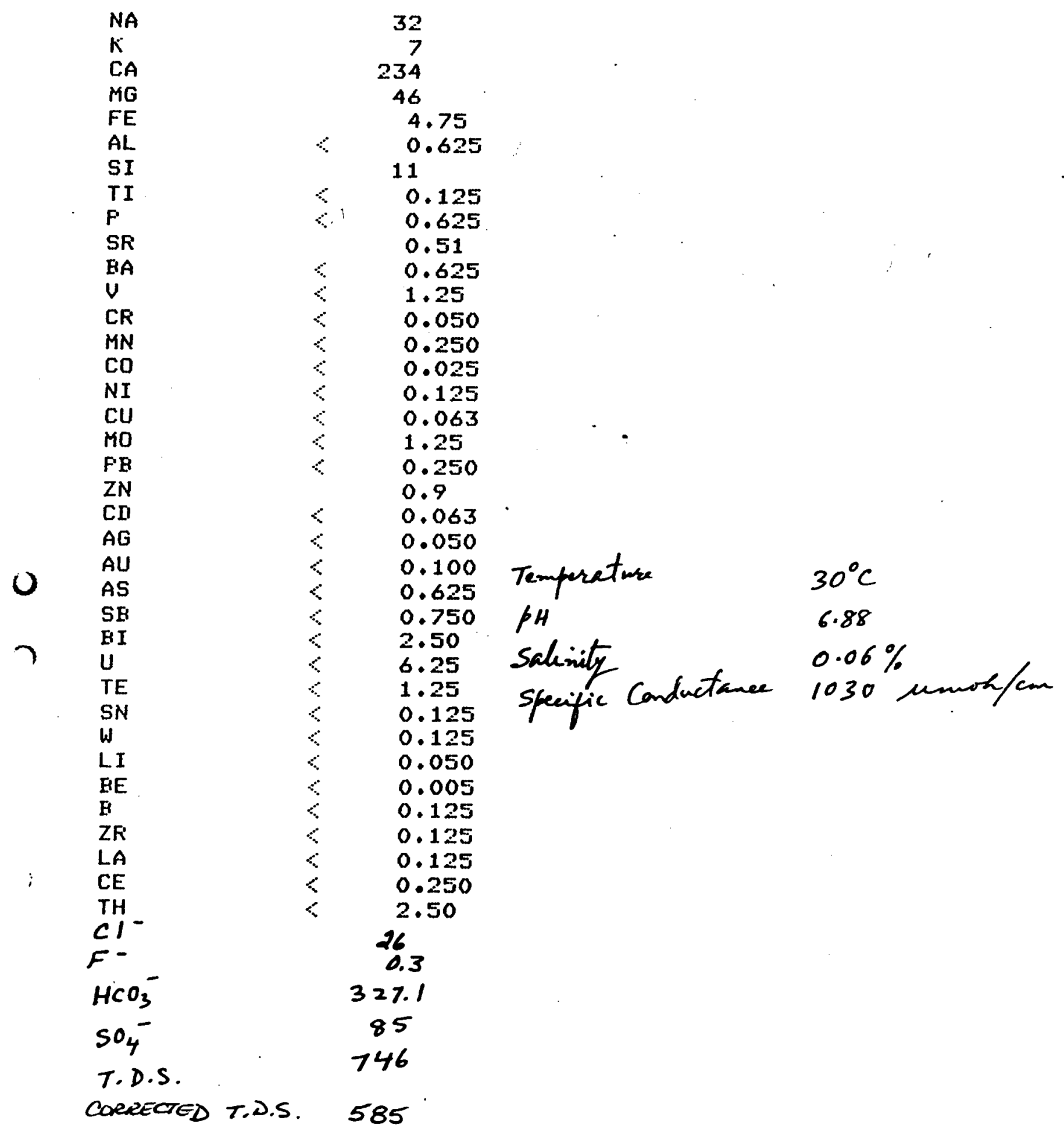

CONCENTFATION (PFM)

585 
CALISTOGA SET 3

72 G-072-80

ELEMENT

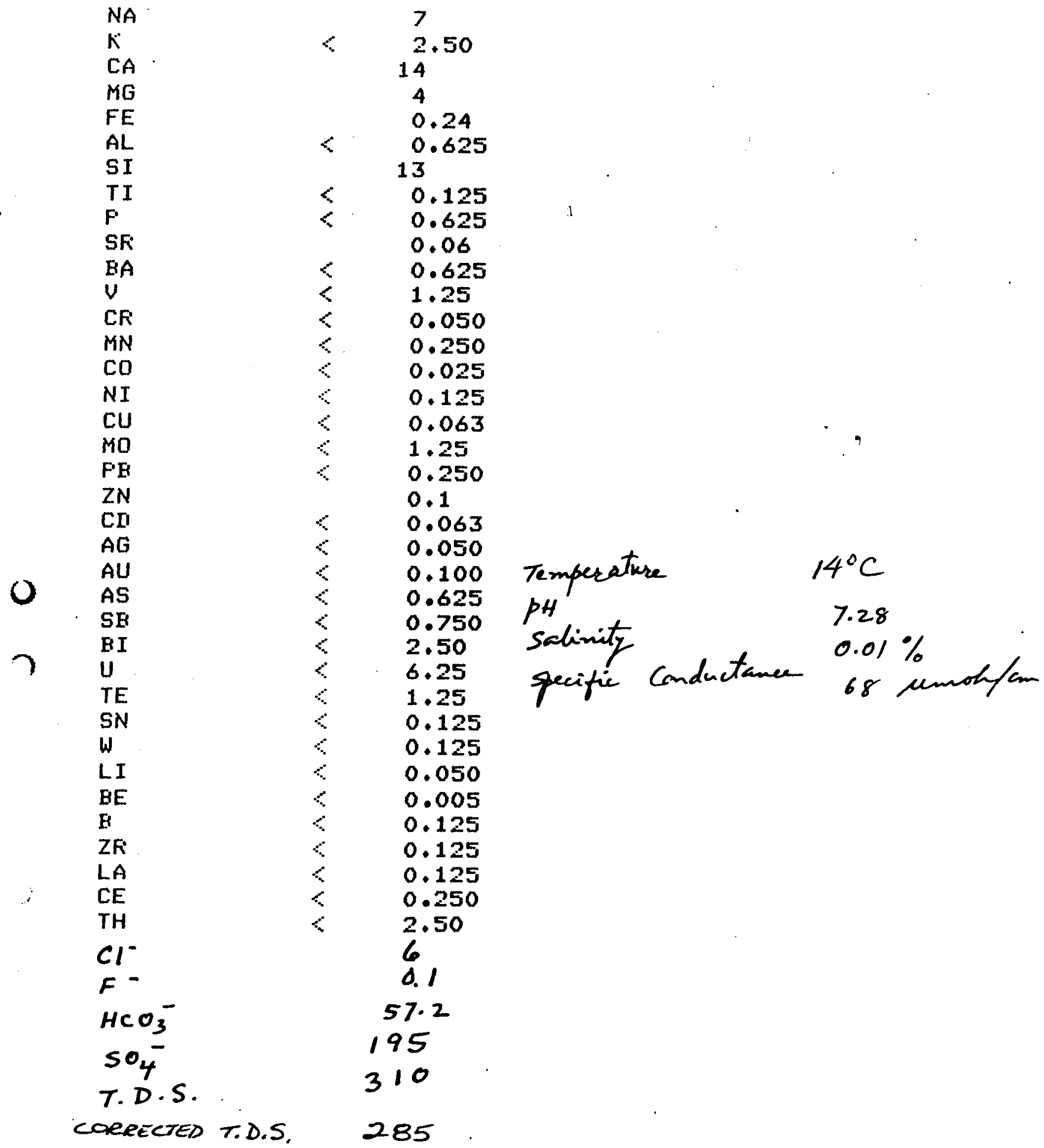


)

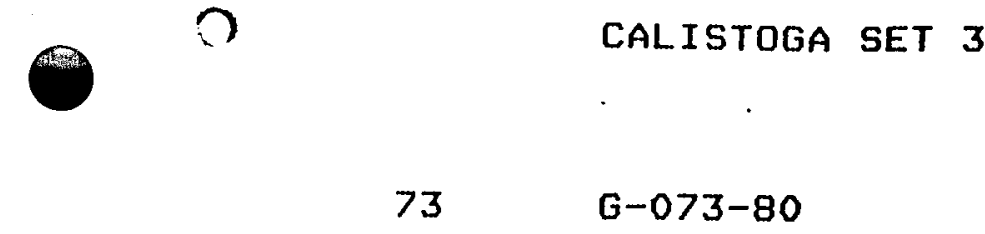

ELEMENT

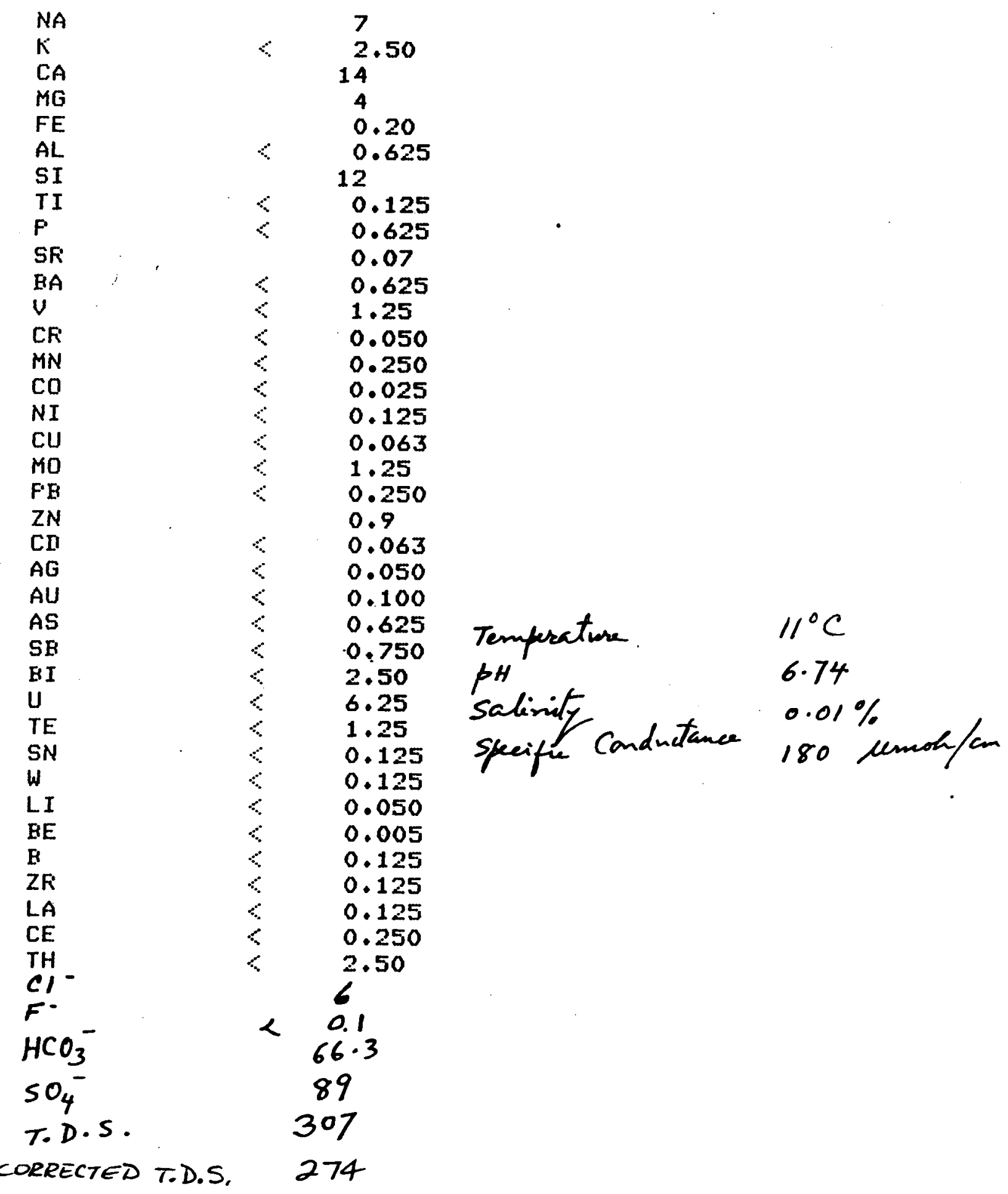


CALISTOGA SET 3

74

G-074-80

ELEMENT

CONCENTFATION (FPM)

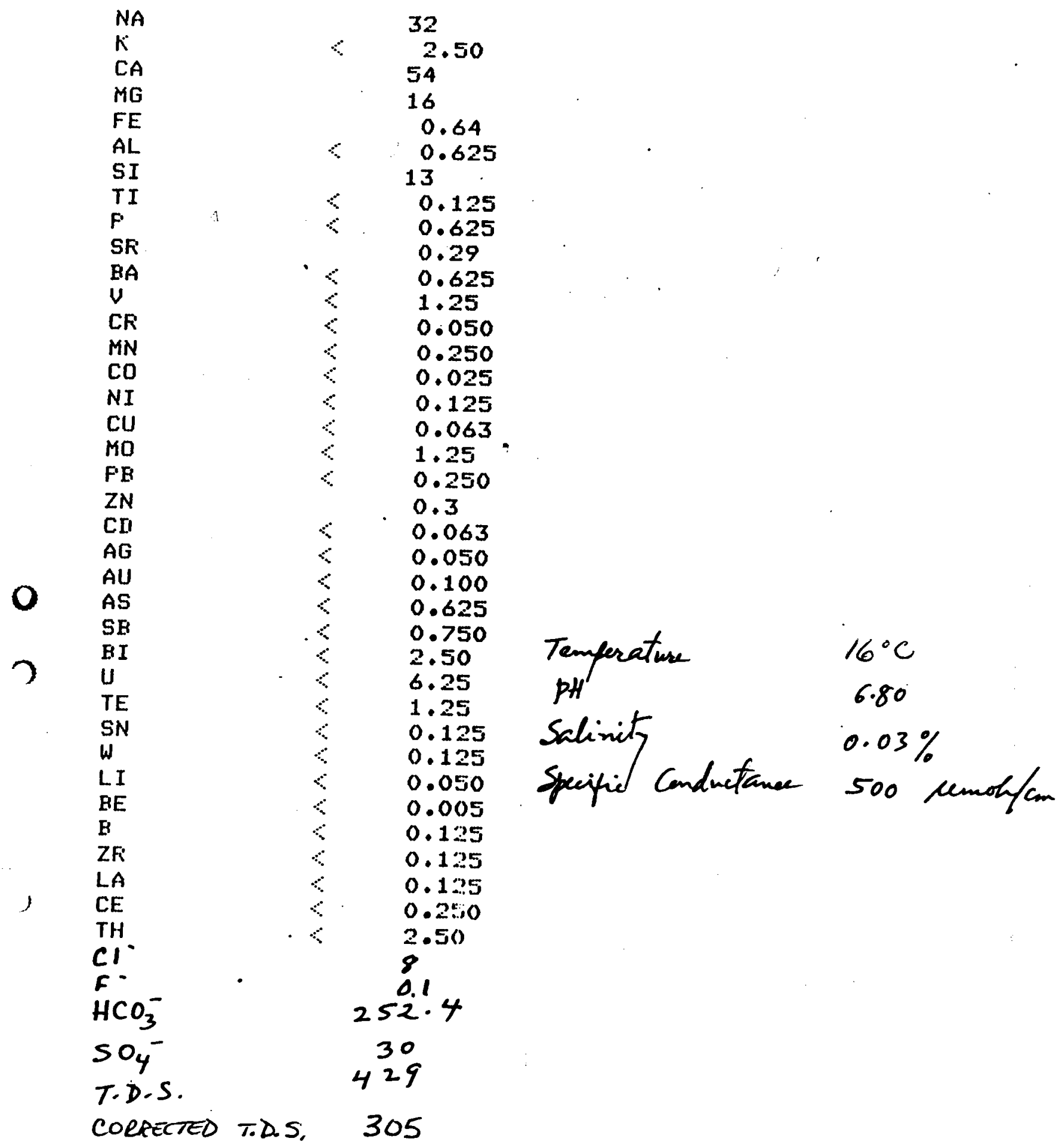




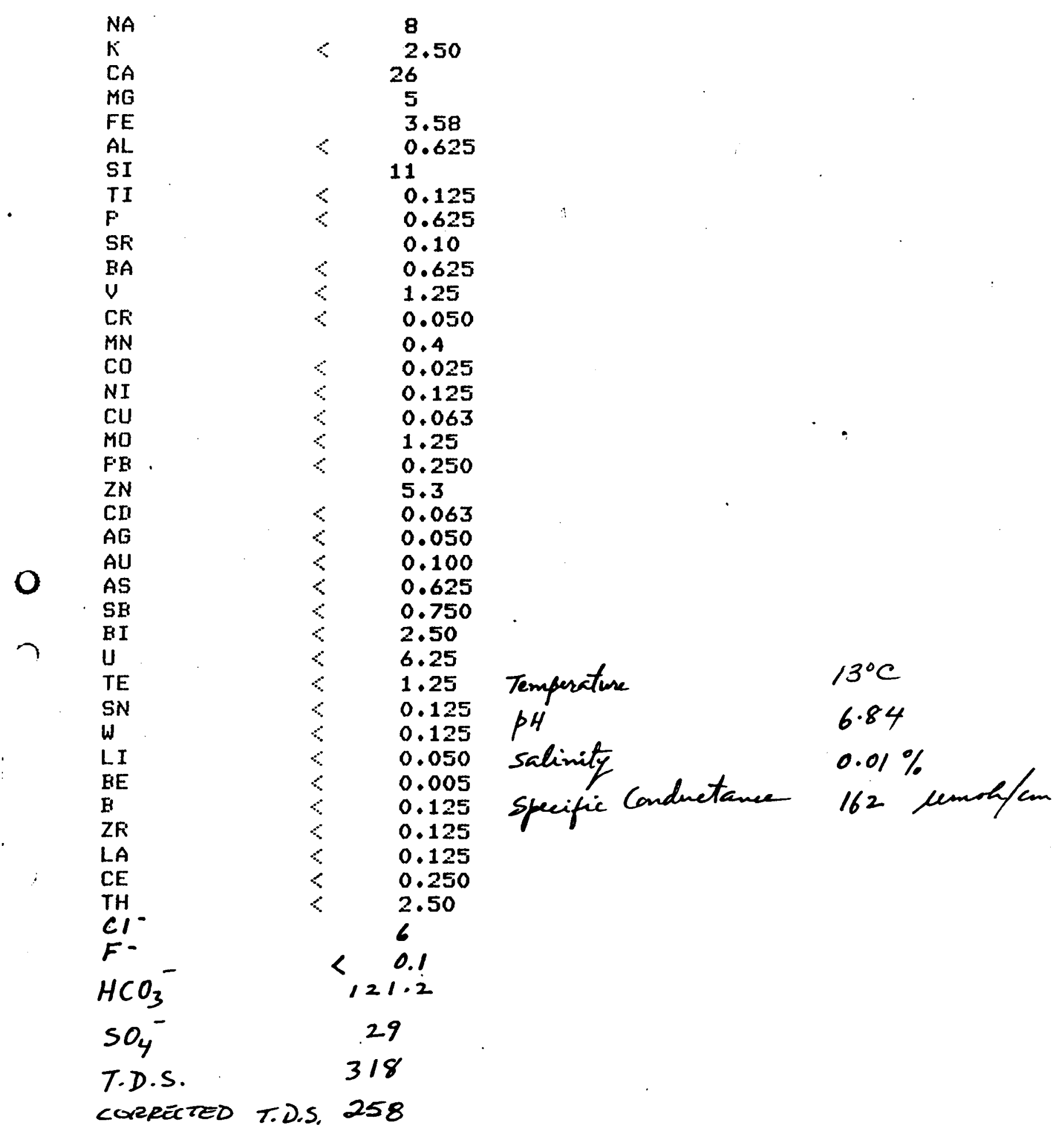


1)

CALISTOGA SET 3

76

G-076-80

ELEMENT

CONCENTRATION (FPM)

NA

$K$

$C A$

$M G$

FE

AL

SI

TI

$F$

SR

HA

CF

MN

$\mathrm{CO}$

NI

CU

MO

F'B

ZN

CII

AG

AU

AS

$S B$

) $\mathrm{BI}$

$U$

TE

SN

W

LI

$\vdots \quad$ HE

B

ZF

LA

CE

TH

$\mathrm{Cl}^{-}$

$\mathrm{HCO}_{3}^{-}$

$\mathrm{SO}_{4}^{-}$

T.D.S.

CORRECTED T.0.5. 235

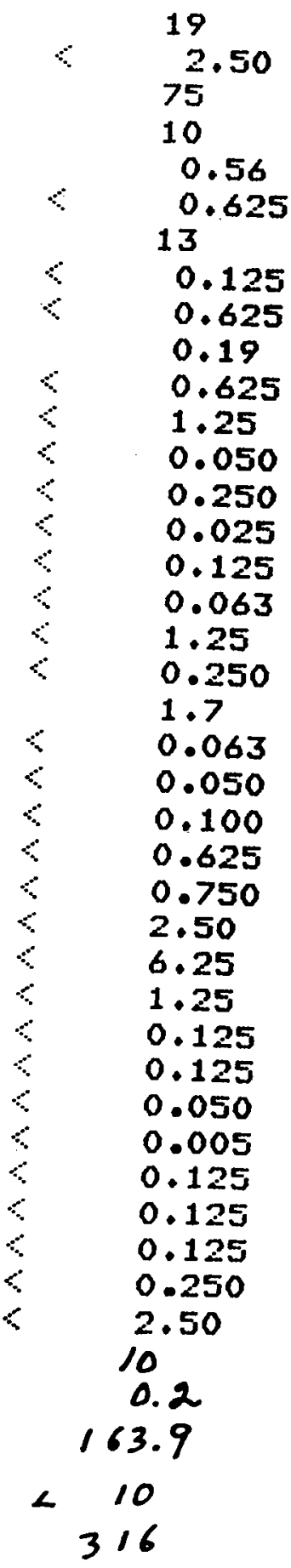

$\begin{array}{ll}\text { Temperature } & 16^{\circ} \mathrm{C} \\ P H & 6.70\end{array}$

Salinity

$0.02 \%$

Specific Conductance 300 umok/an 
)

$\infty 7$

CALISTOGA SET 3

77

G-077-80

ELEMENT

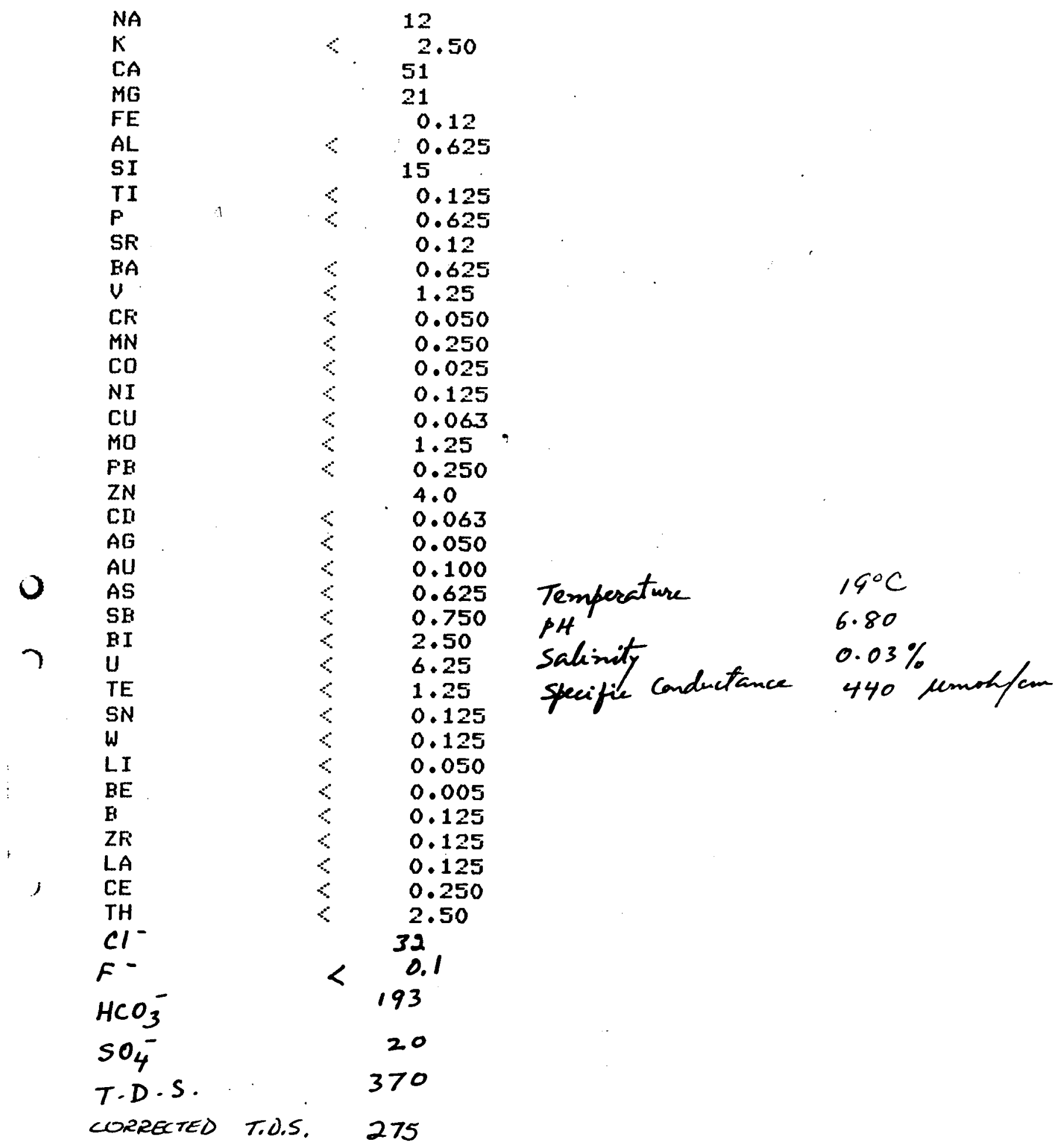


78 G-078-80

\section{ELEMENT}

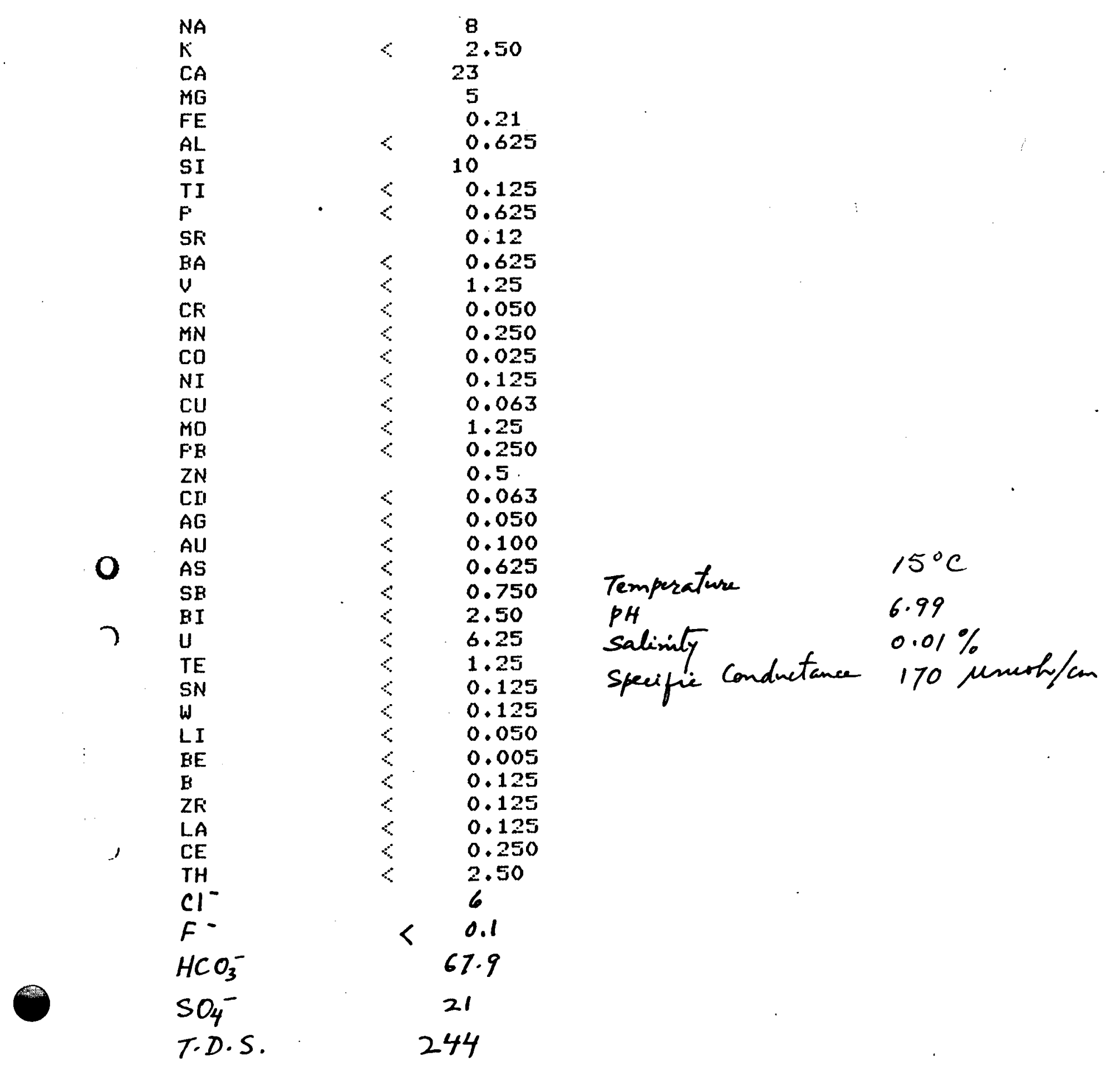

\title{
CONCENTRATION (FFM)
}

\author{
(PPM)
}

CURRETES T.D.S. 211 
) 1

79
CALISTOGA SET 3

$G-079-80$
ELEMENT

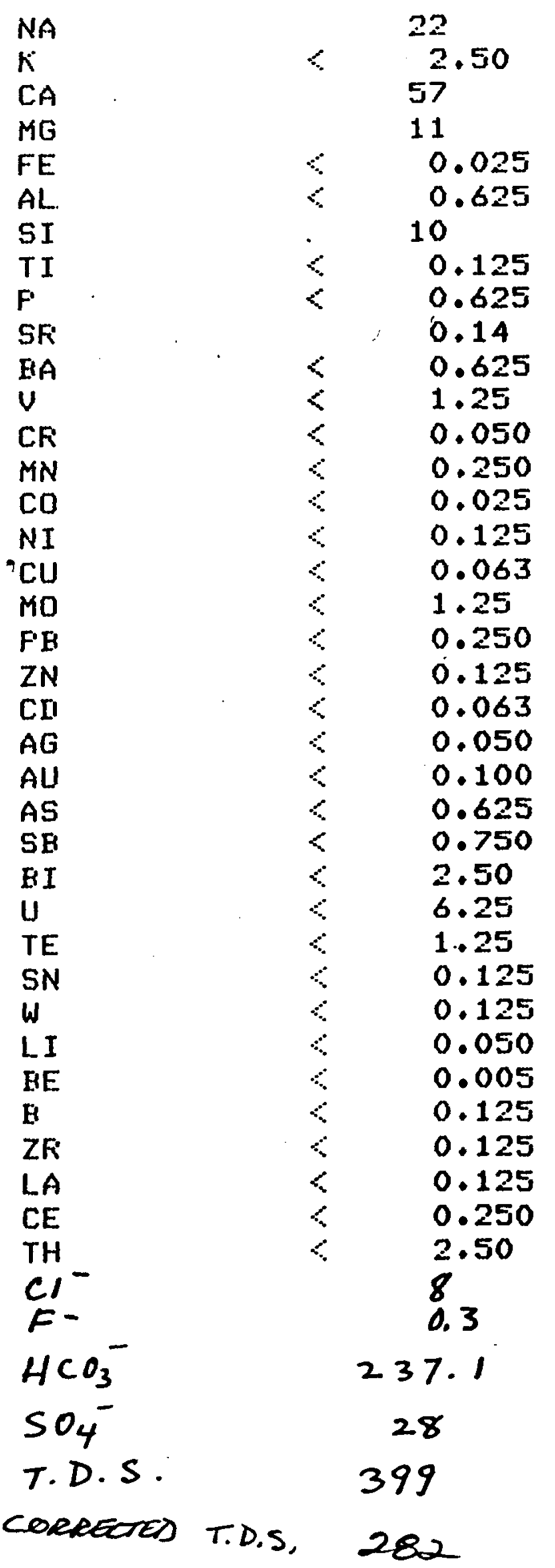

CONCENTRATION (FEM)

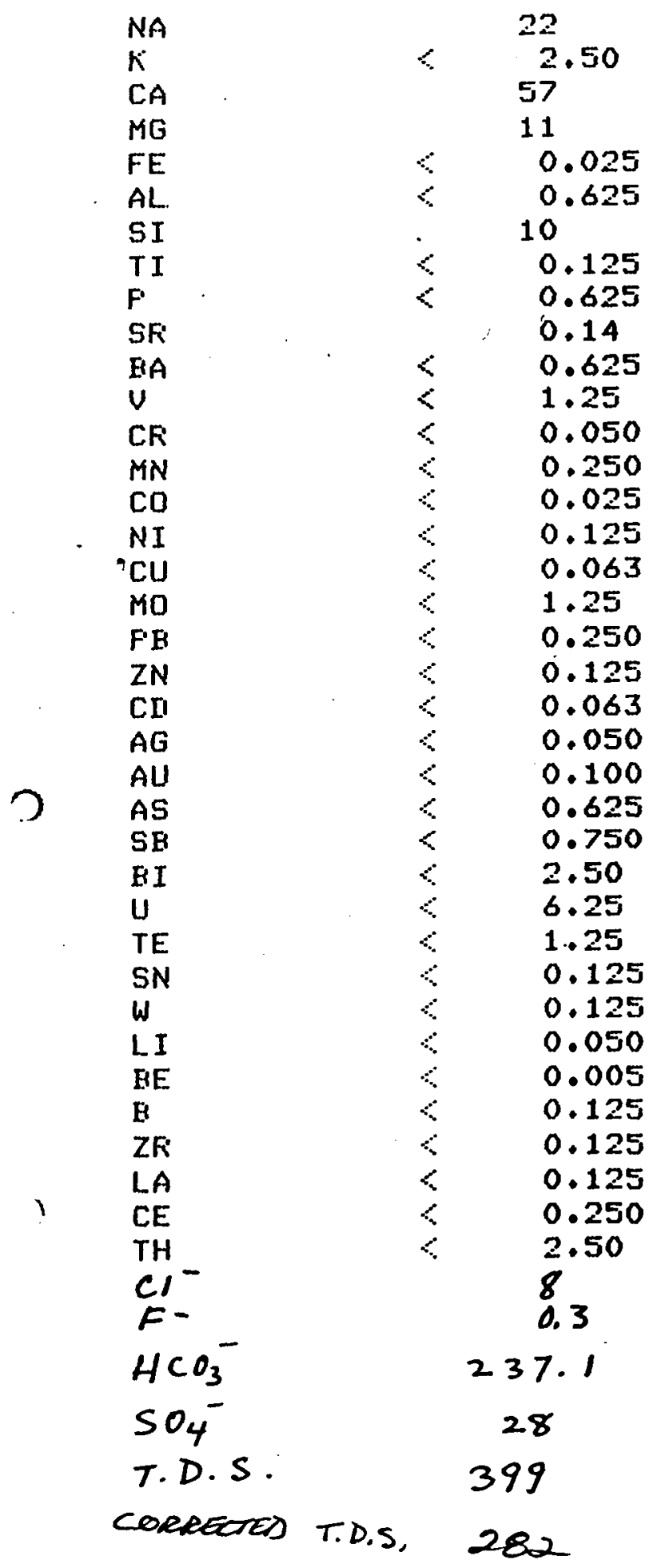


CALISTOGA SET 3

80

$\mathbf{G}-080-80$

ELEMENT

NA

K

$\mathrm{CA}$

$M G$

FE

AL

SI

TI

F.

SR

BA

U

CF

MN

CO

$N I$

CU

MO

FE

ZN

Cn

$A G$

AU

AS

SB

BI

U

TE

SN

W

LI

BE

E

ZFi
LA

CE

TH

$\mathrm{CI}^{-}$

$\mathrm{F}^{-}$

$\mathrm{HCO}_{3}^{-}$

$\mathrm{SO}_{4}^{-}$

T. D.S.

CORRECTEO T.D.S. $\quad 155$

17

23

198
CONCENTRATION (FPM)

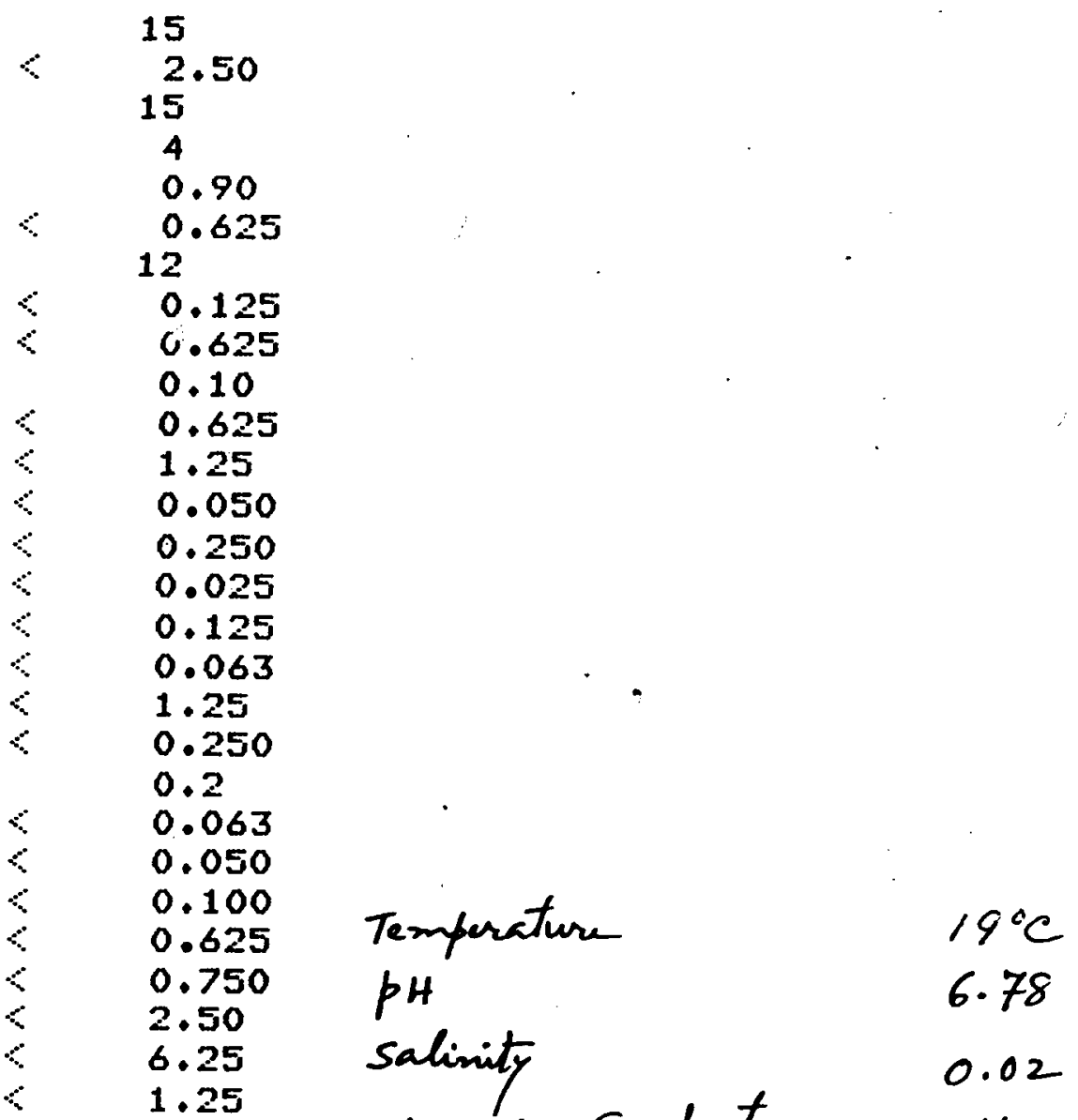

0.125
0.125 specific Conductance 148 umert/com

0.050

0.005

0.125

0.125

0.125

0.250

2.50

0.1

87.7 
!

CALISTOGA SET 3

$81 \quad$ G $-081-80$

ELEMENT

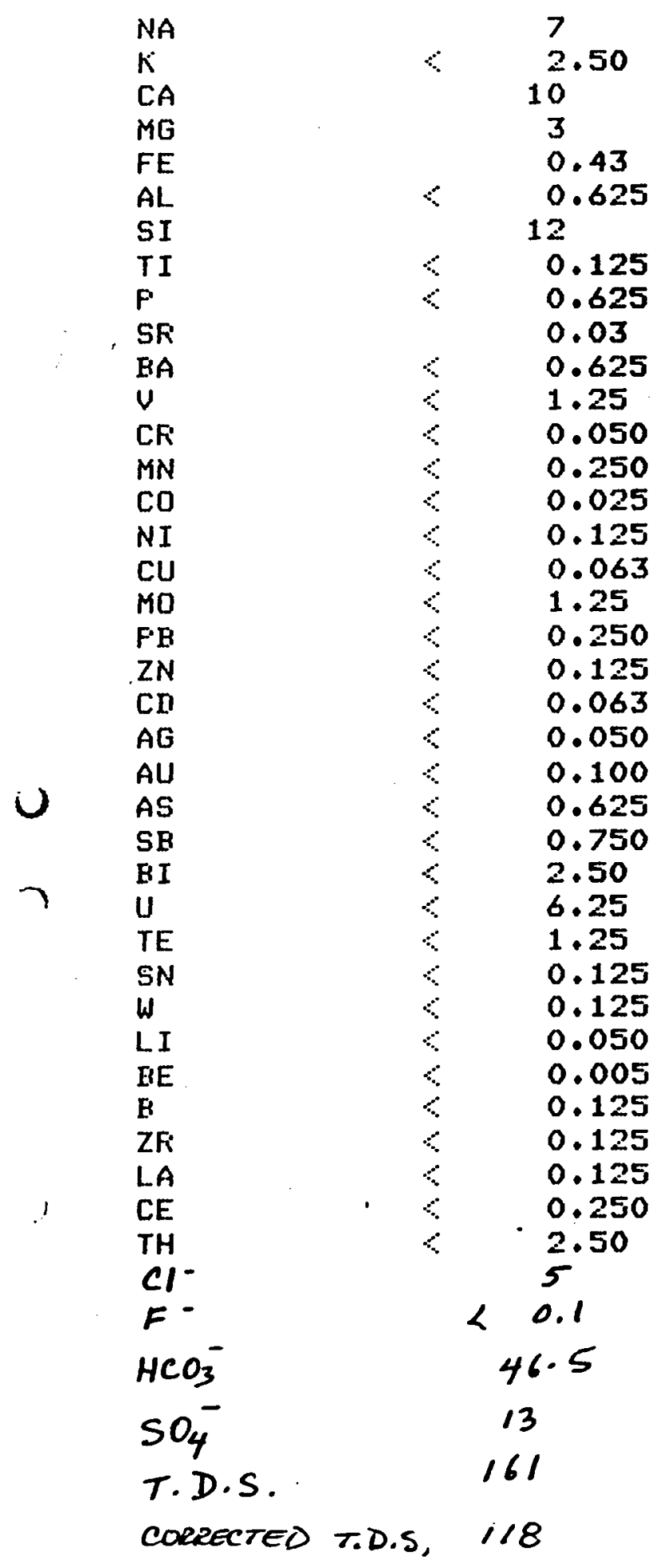


82 G-082-80

ELEMENT

CONCENTRATION (FFM)

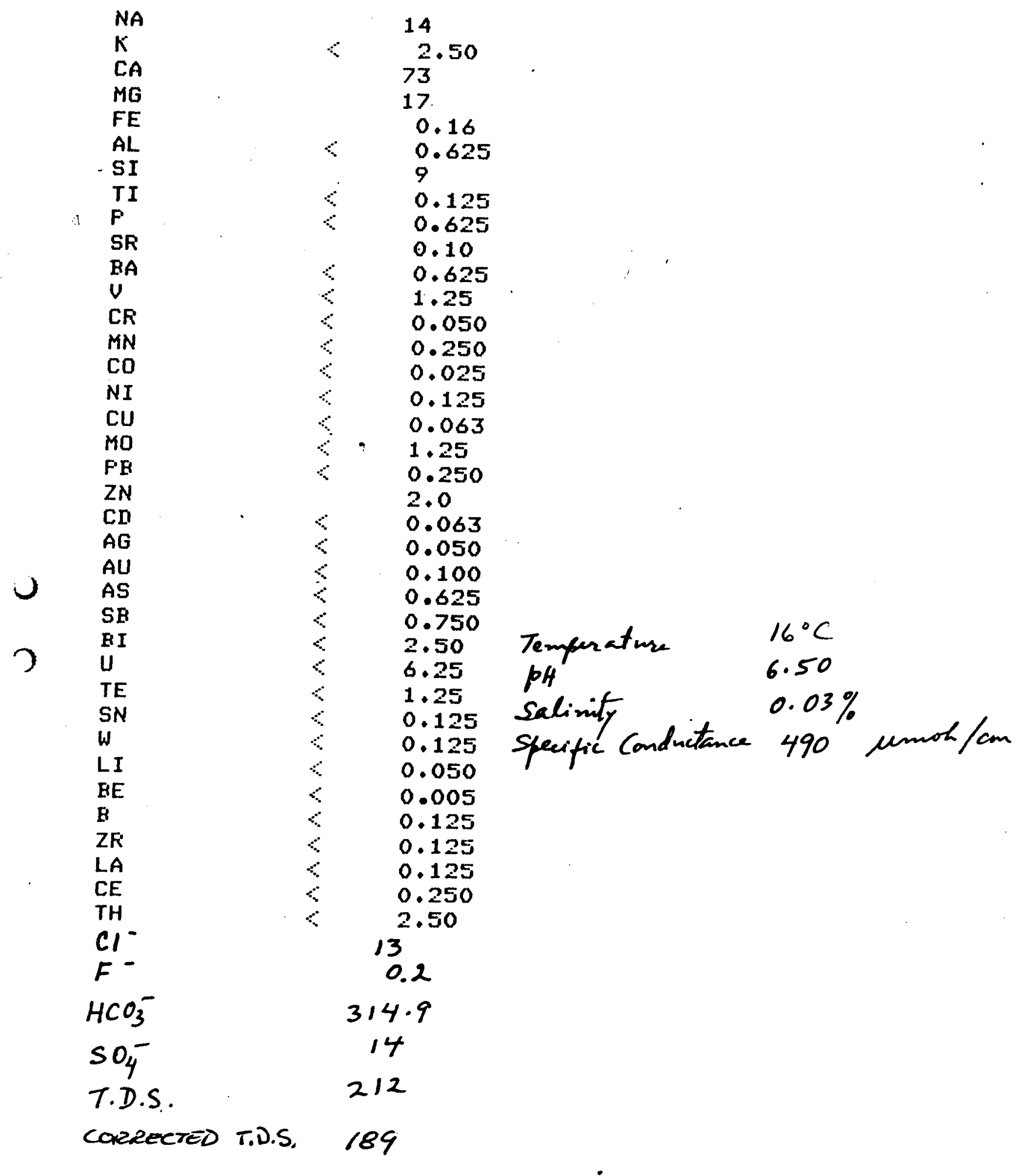


)

CALISTOGA SET 3

83 G-083-80

ELEMENT

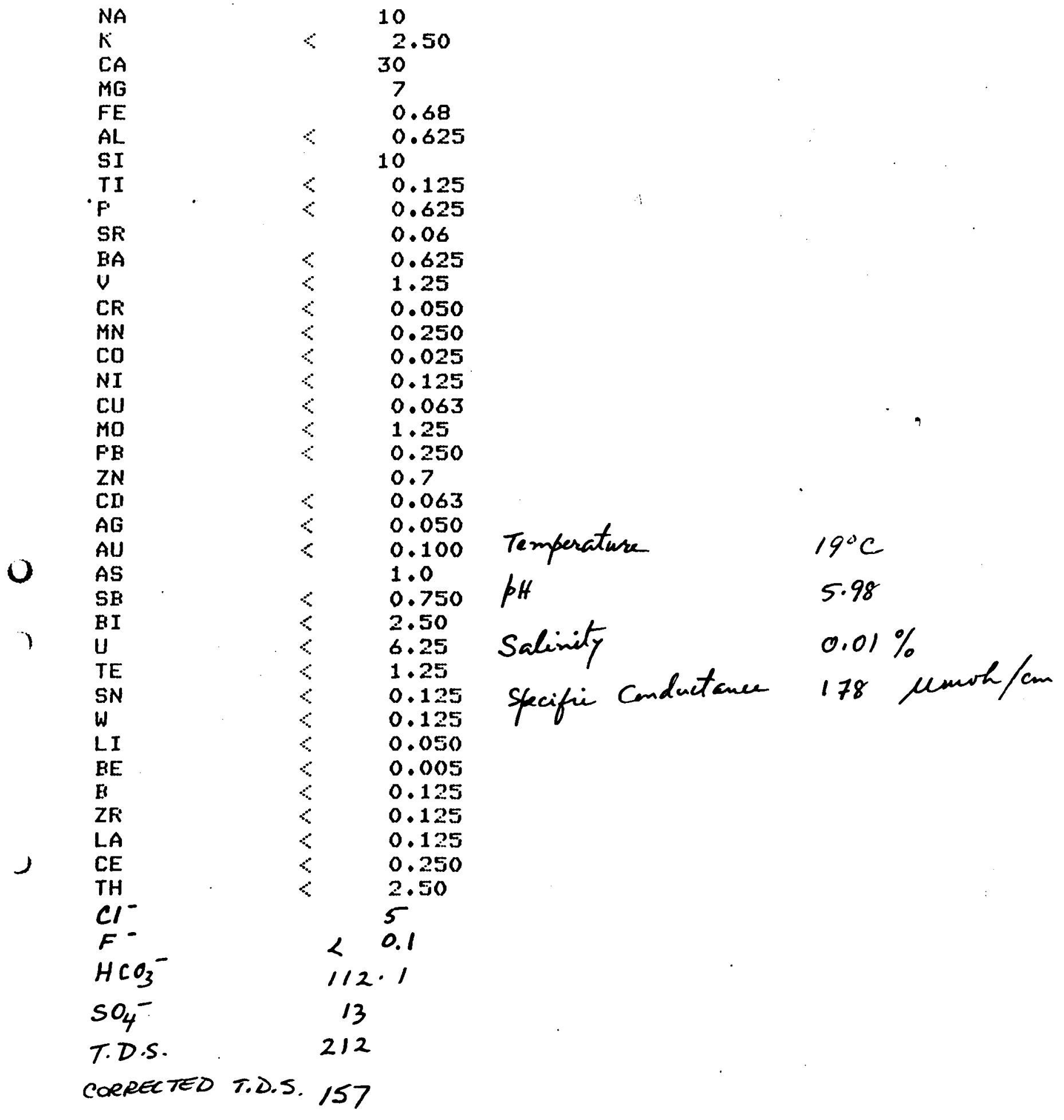




\section{CALISTOGA SET 3}

84

$$
\text { G-084-80 }
$$

\section{ELEMENT}

\section{CONCENTFATION (FFM)}

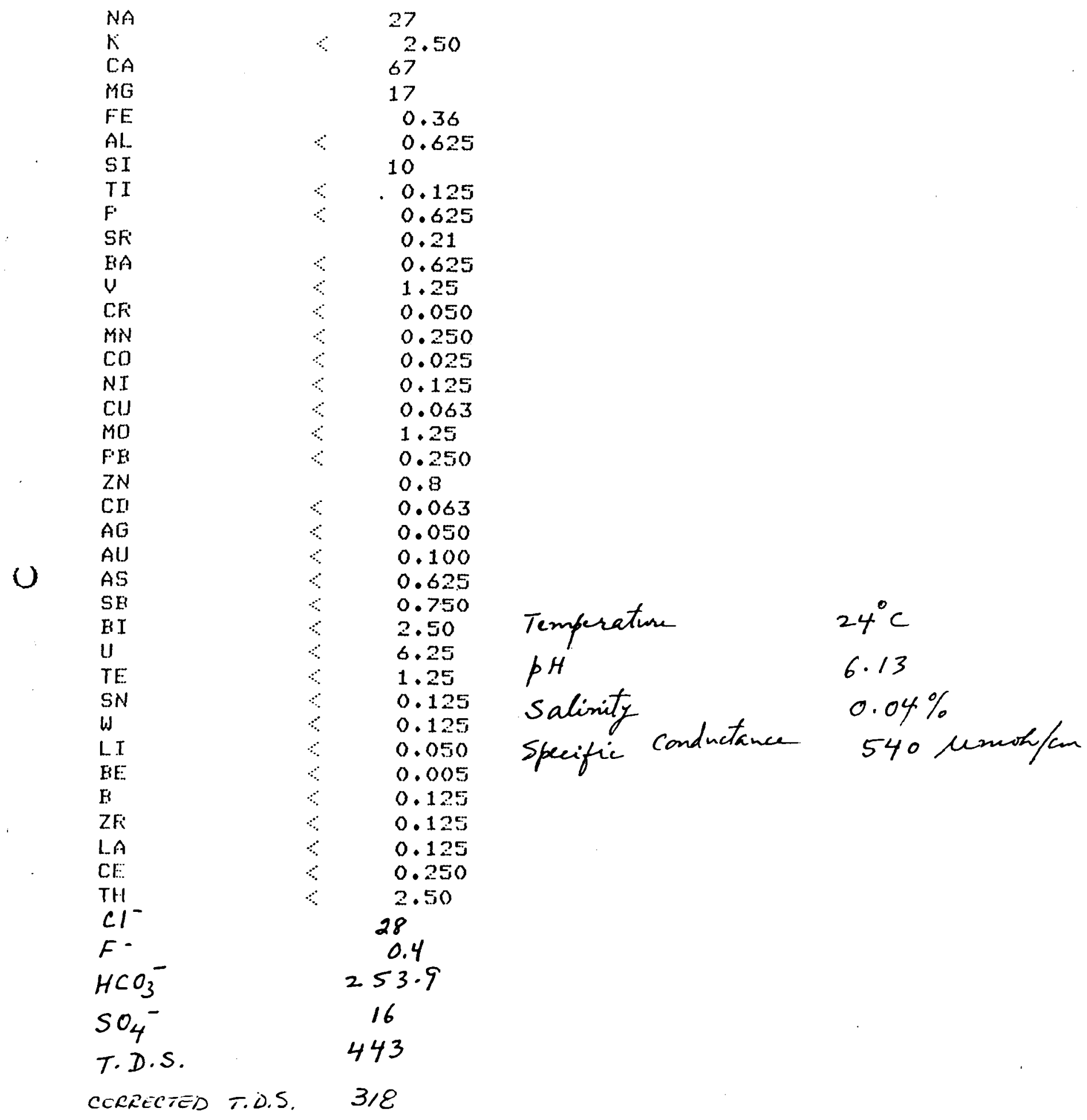


CALISTOGA SET 3

85 G-085-80

ELEMENT

CONCENTFATION (PPM)

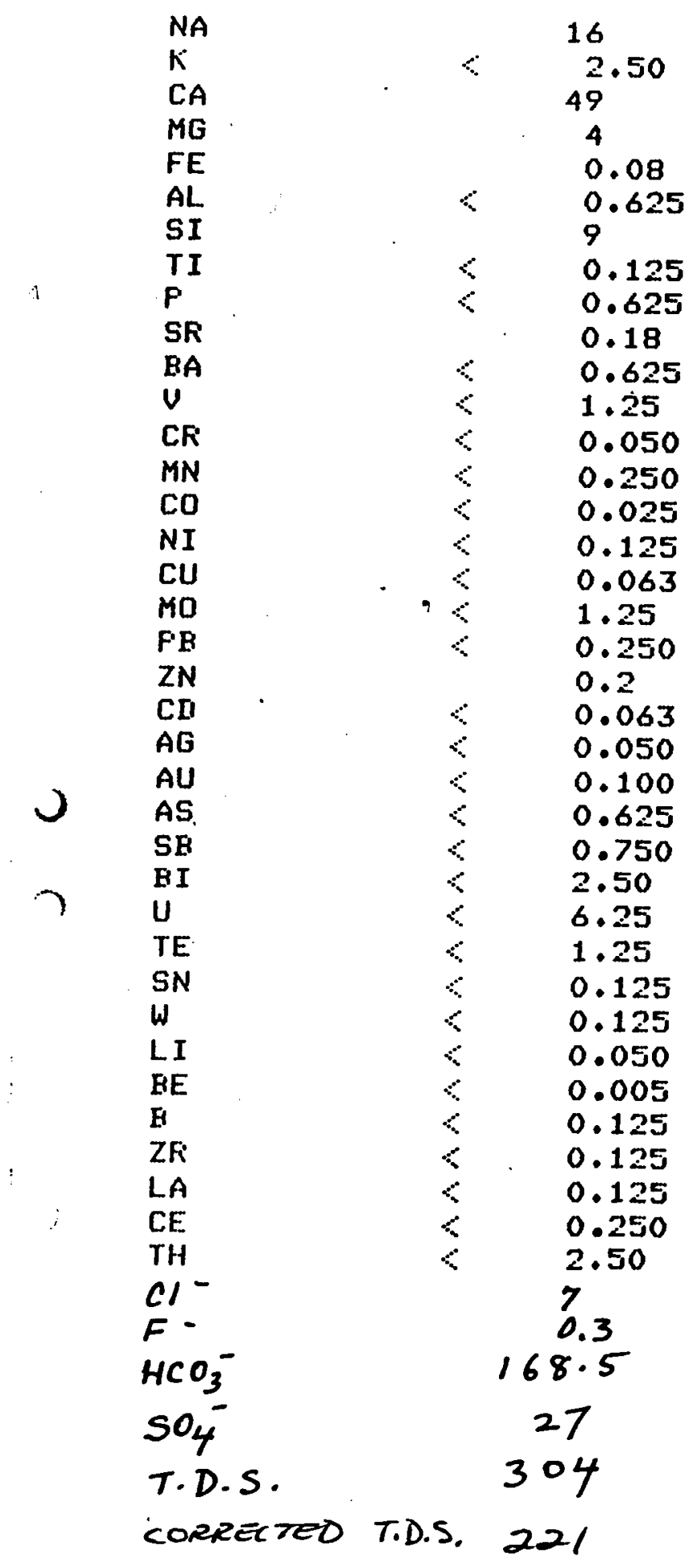


CALISTOGA SET 3

$86 \quad G-086-80$

ELEMENT

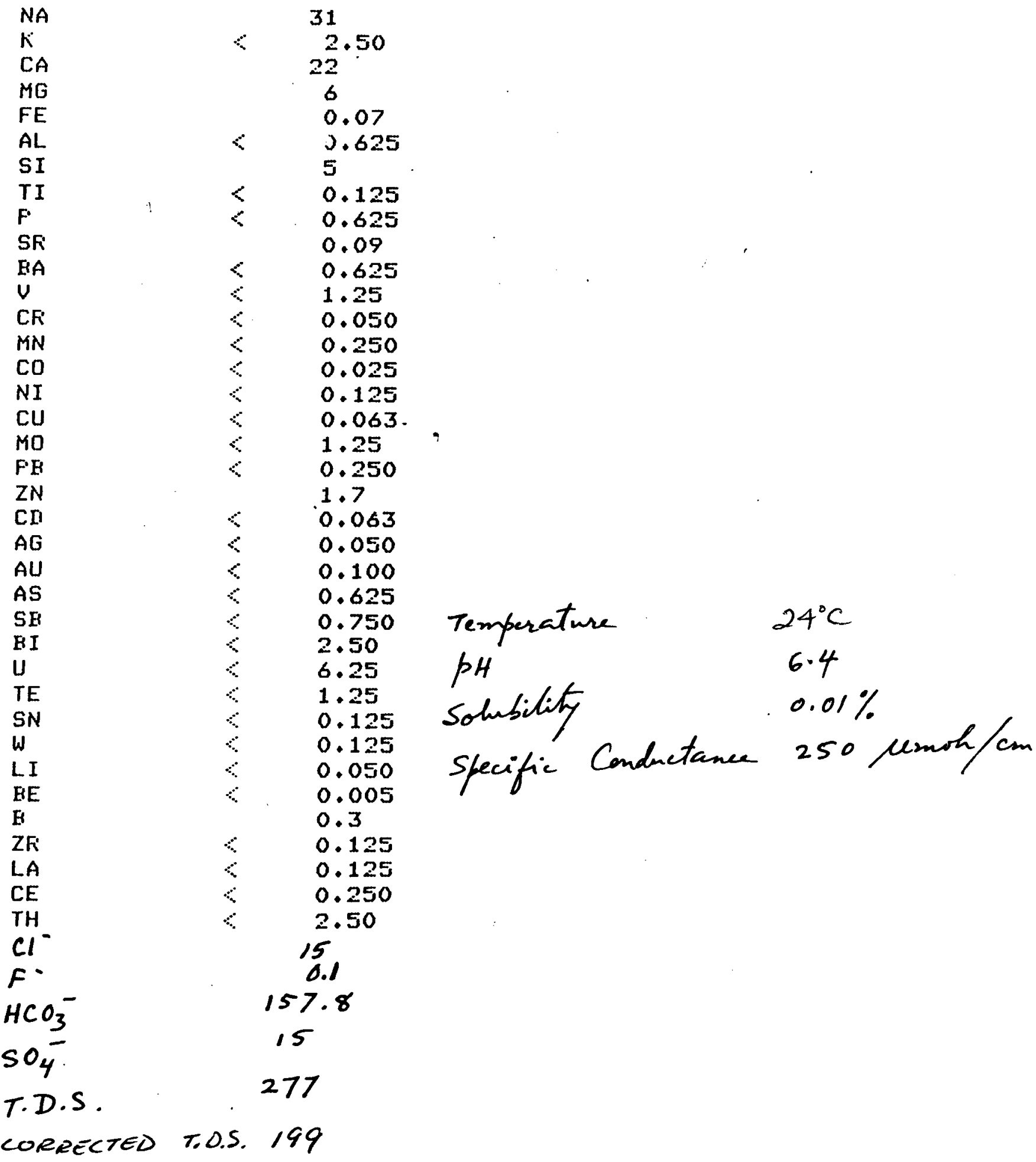


CALISTOGA SET 3

87

G-087-80

ELEMENT

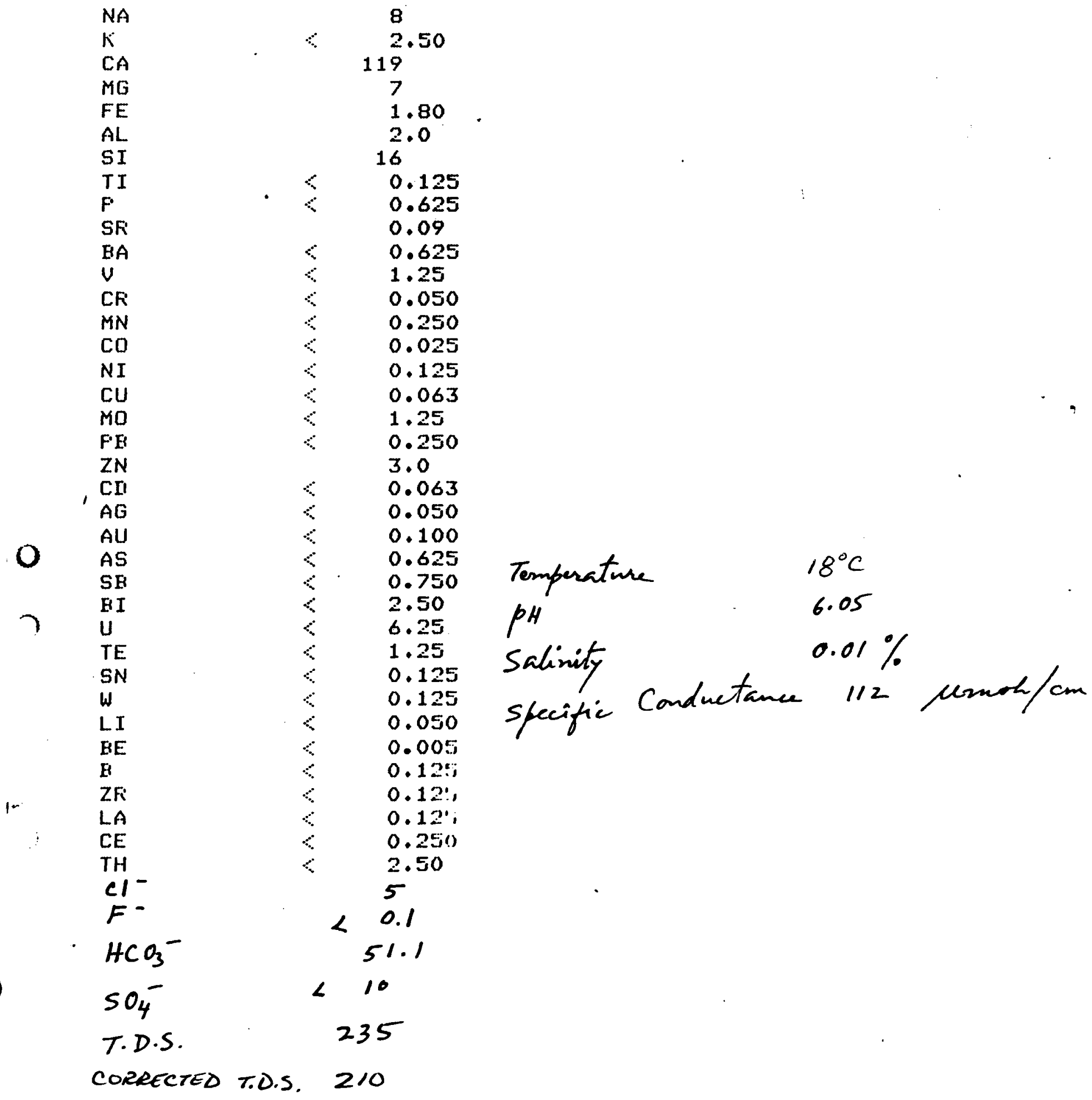


88

$$
G-088-80
$$

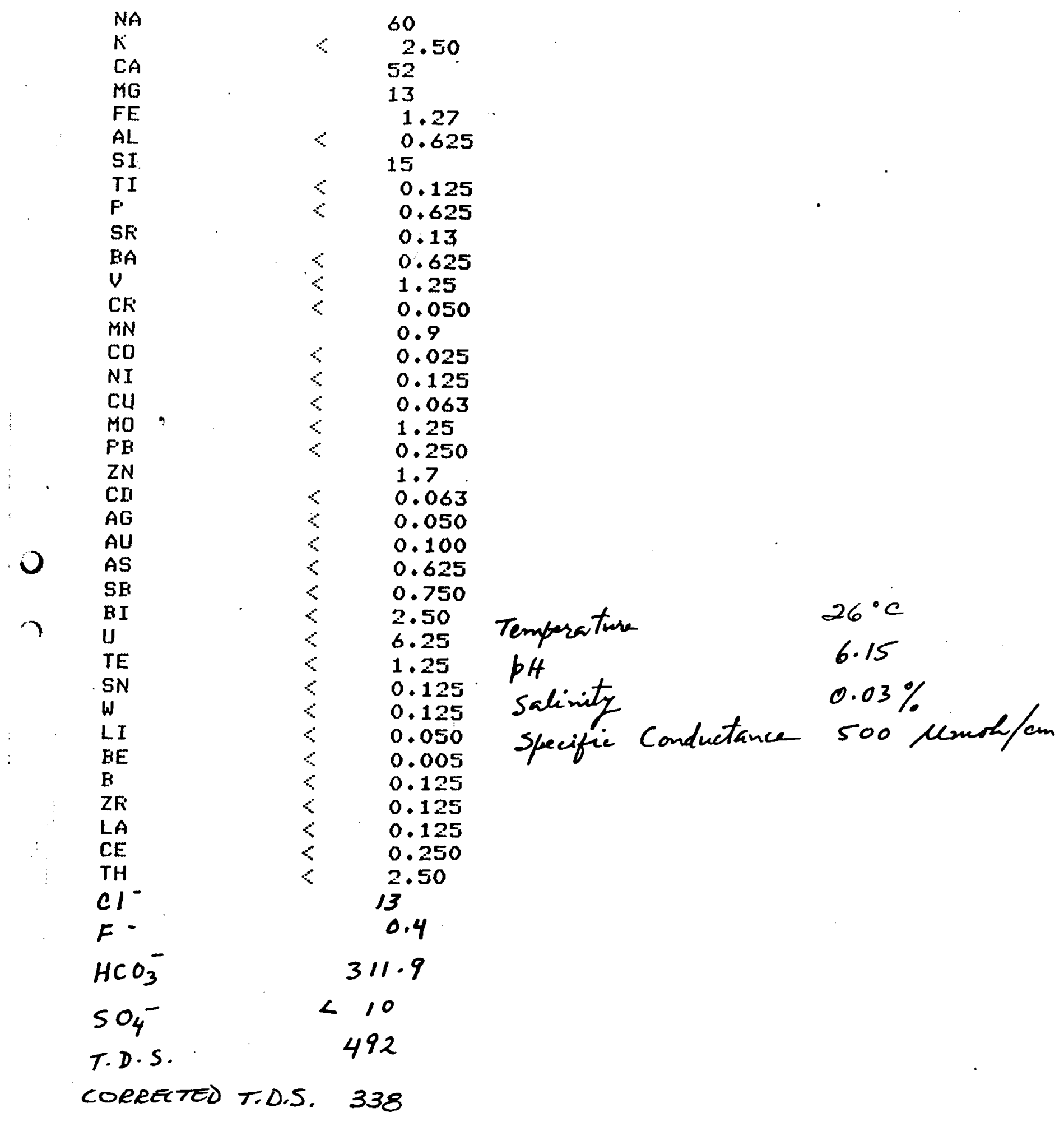


i

CALISTOGA SET 3

$89 \quad$ G-089-80

ELEMENT

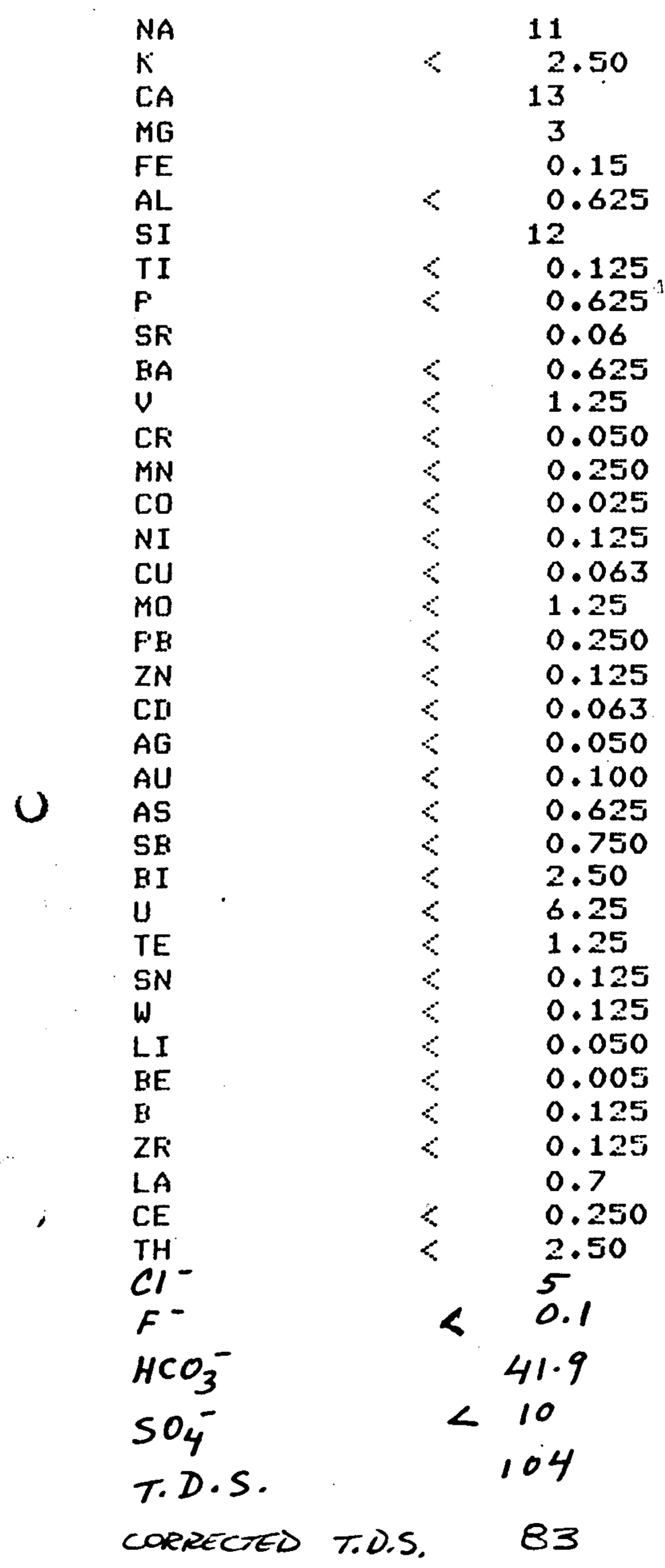

CONCENTFATION (FFM)

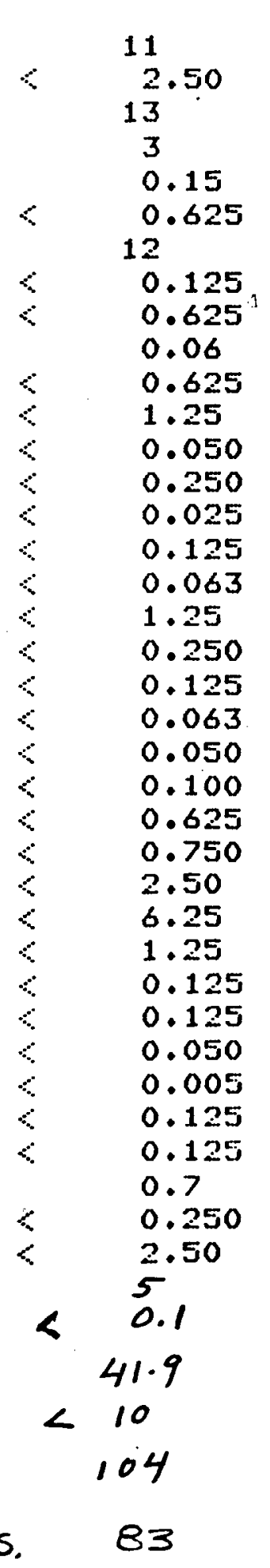


CALISTOGA SET 3

90

G-090-80

ELEMENT

CONCENTFATION (FFM)

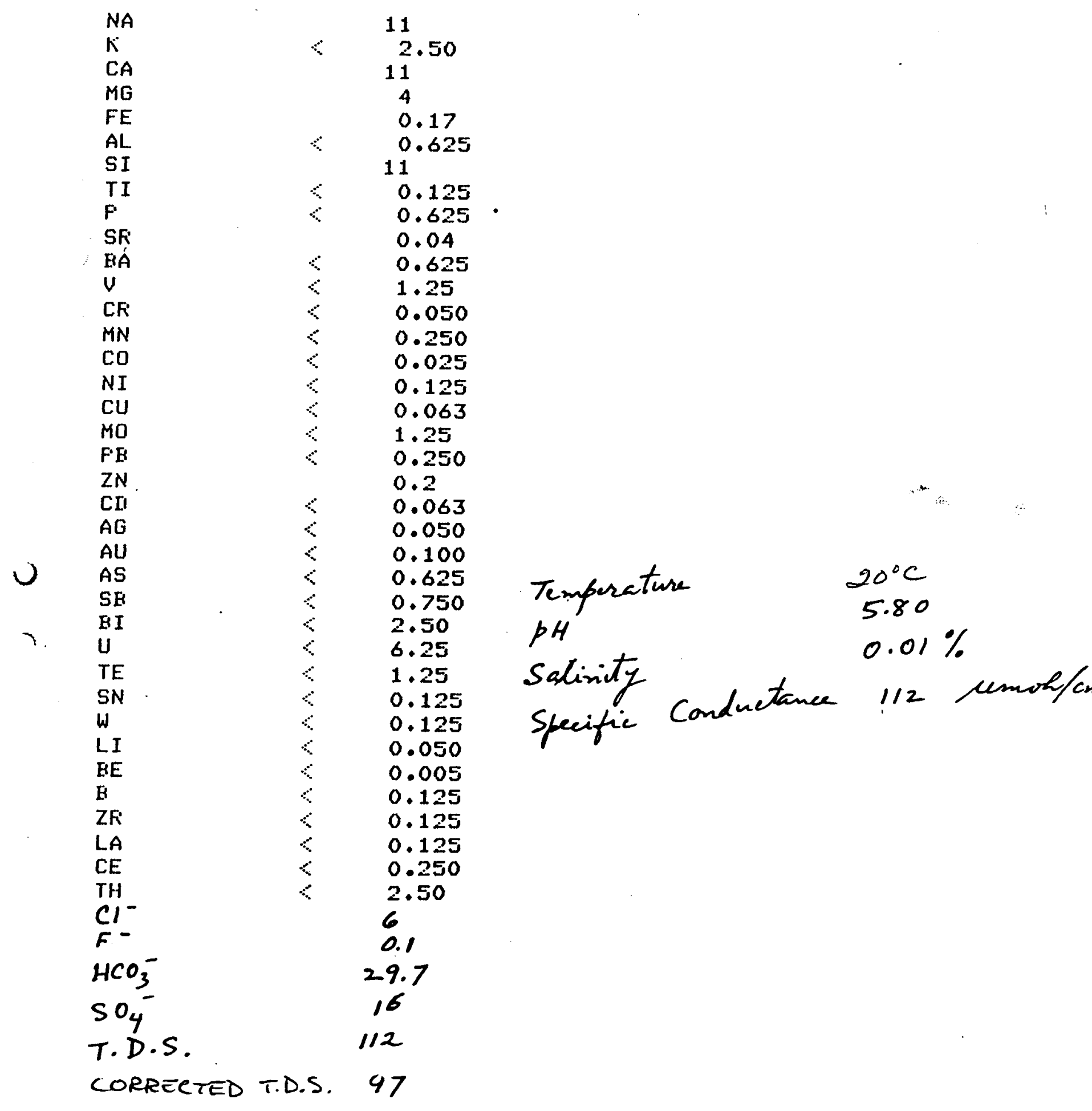


)

CALISTOGA SET 3

91

G-091-80

ELEMENT

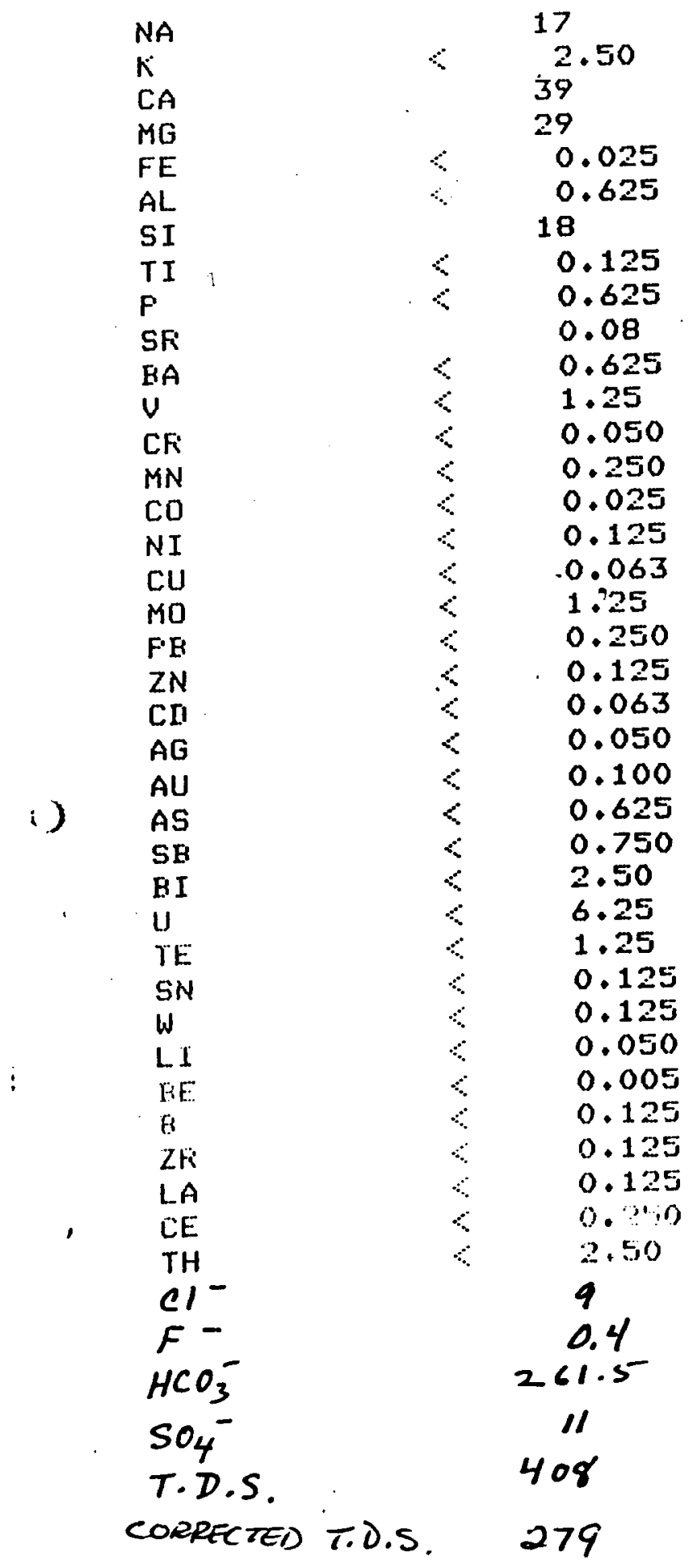

CONCENTRATION (FFM)

i) 
,

)

CALISTOGA SET 3

$92 \quad$ G-092-80

ELEMENT

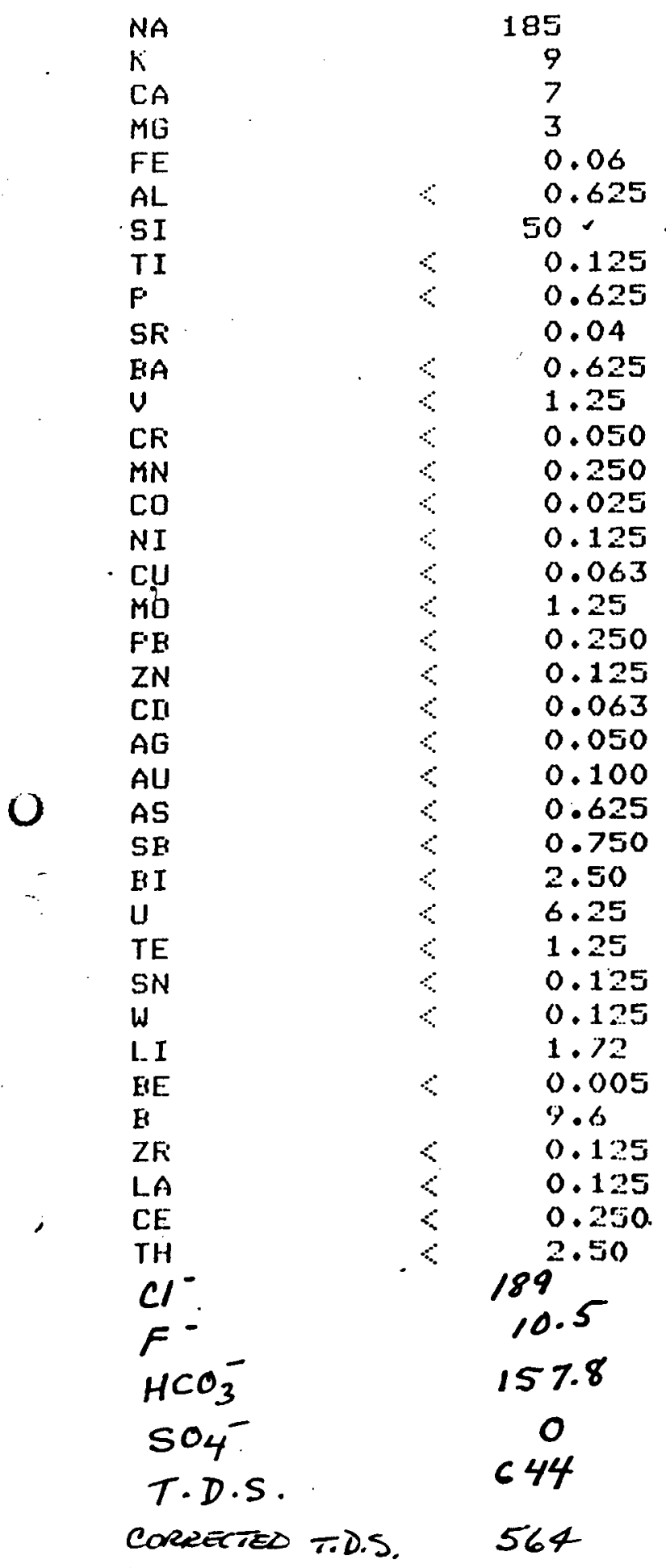

CONCENTFATION (FFM) 
CALISTOGA SET 4

$93 \quad G-093-80$

ELEMENT

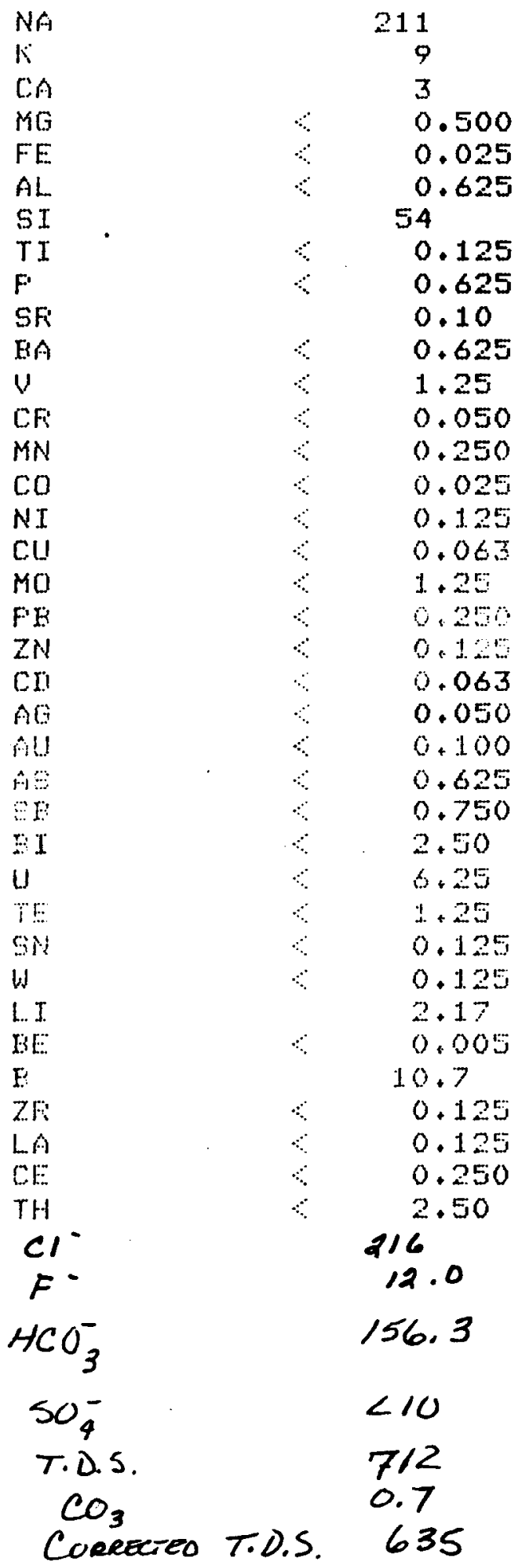

CONCENTFATION (FFM)

Temperpture $93^{\circ} \mathrm{C}$

8.80

$0.08 \%$

Apec. Conductunce $1430 \mu \mathrm{moh} / \mathrm{cm}$ 
CALISTOGA SET A

$94 \quad \quad G-094-80$

ELEMENT

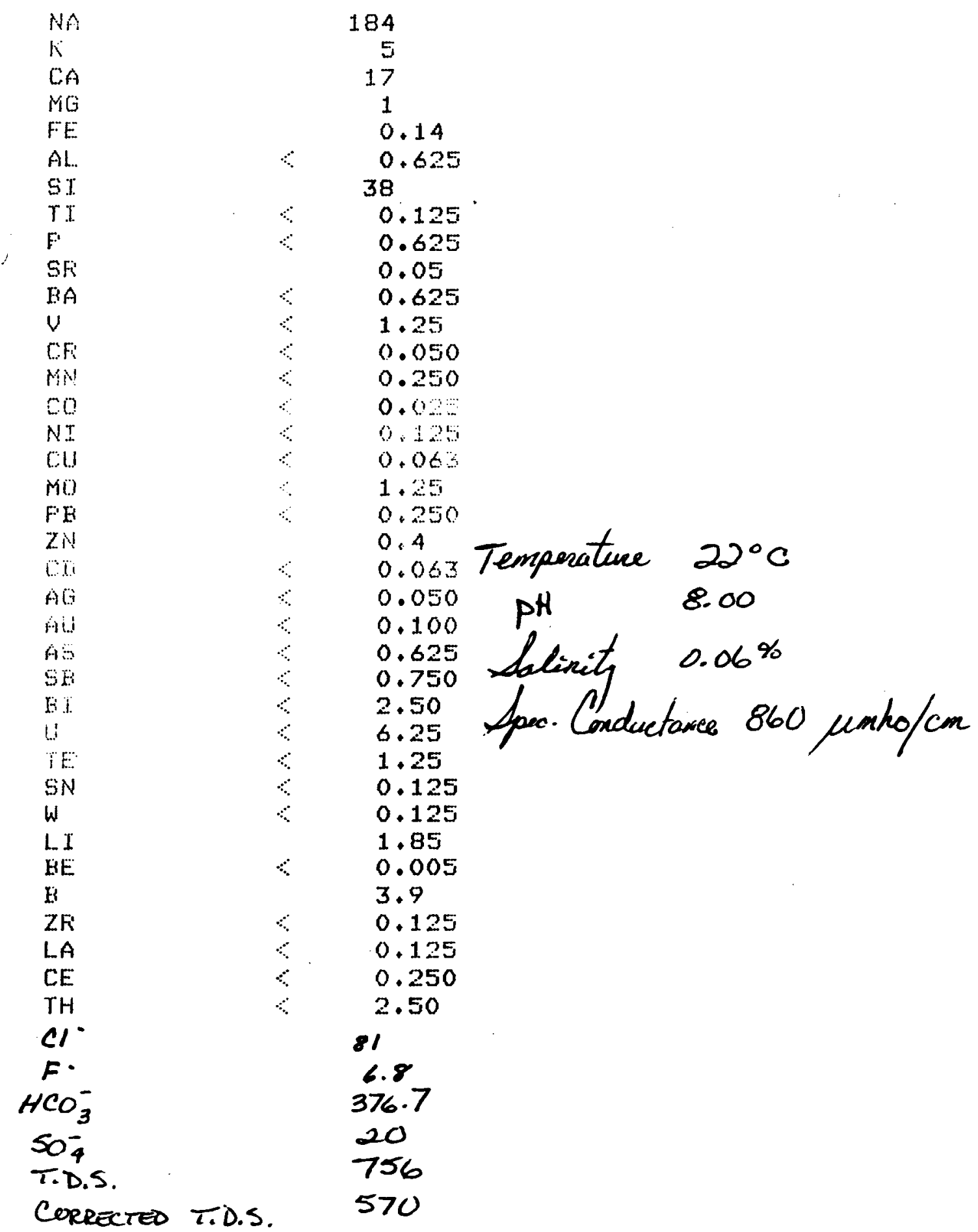


CAL ISTOGA SET 4

$$
95 \quad 6-095-80
$$

ELEMENT

$$
\text { CONCENTFIATION (FFM) }
$$

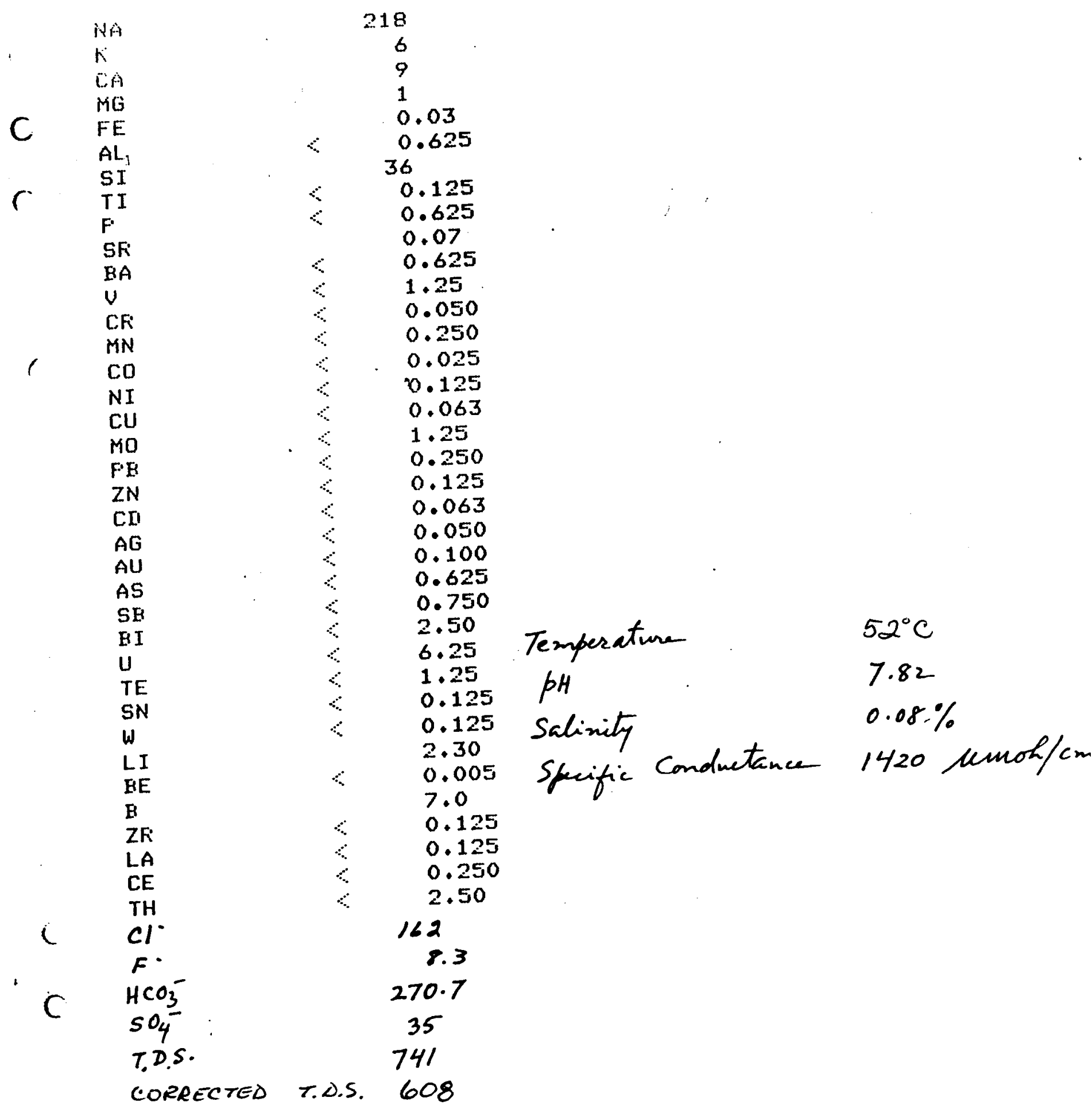




\section{CALISTOGA SET 4}

r $96 \quad$ G-096-80

ELEMENT

NA

K

CA

$M G$

C FE

$A L$

SI

O TI

$P$

SF

BA

U

CF:

MN

CO

$N I$

$\mathrm{CU}$

MO

$F B$

ZN

CII

AG

AU

AS

SE

BI

U

TE

SN

W

LI

BE

$\mathrm{B}$

ZFi

LA

CE

$\mathrm{TH}$

$\mathrm{Cl}^{-}$

$F^{-}$

$\mathrm{HCO}_{3}$

$\mathrm{SO}_{4}^{-}$

T.D.S.

\section{CONCENTFIATION (FFM)}

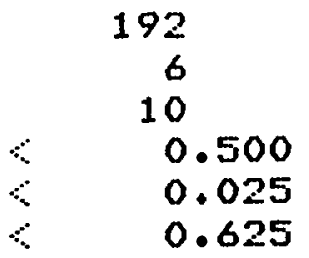

$$
\begin{aligned}
&<\quad 41 \\
&<\quad 0.125 \\
& 0.625 \\
& 0.09
\end{aligned}
$$$$
0 \quad 0.625
$$$$
\therefore \quad 1.25
$$$$
\because \quad 0.050
$$$$
\because \quad 0.250
$$$$
\because \quad 0.025
$$$$
\therefore \quad 0.125
$$$$
\therefore \quad 0.063
$$$$
\therefore \quad 1.25
$$$$
\therefore \quad 0.250
$$$$
0.125
$$$$
\therefore \quad 0.063
$$$$
\therefore \quad 0.050
$$$$
\therefore \quad 0.100
$$$$
<0.625
$$$$
0.750
$$$$
<\quad 2.50
$$$$
\therefore \quad 6.25
$$$$
<1.25
$$$$
0.125
$$

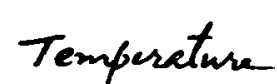

0.125

2.02

$<\quad 0.005$

8.8

0.125

0.125

0.250

2.50

187

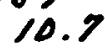

$203 \cdot 6$

19
PH

$85^{\circ} \mathrm{C}$

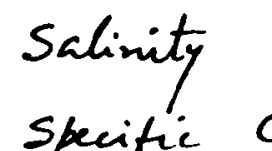

$8 \cdot 05$

$0.08 \%$

CORRECTED T.D.S. 581 


$$
\text { ( } 97 \quad \text { G-097-80 }
$$

\section{ELEMENT}

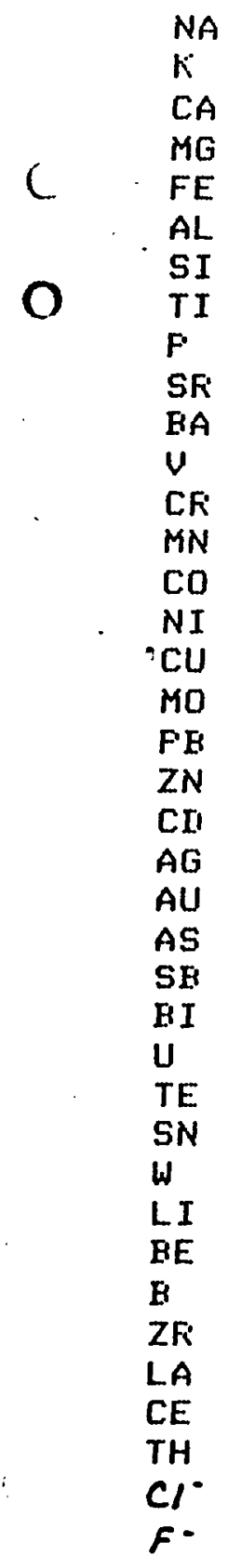

(.) $\mathrm{HCO}_{3}^{-}$

$\mathrm{CO}_{3}^{-}$

$1 \mathrm{SO}_{4}^{-}$

T.D.S .

\section{CONCENTFATION (FFM)}

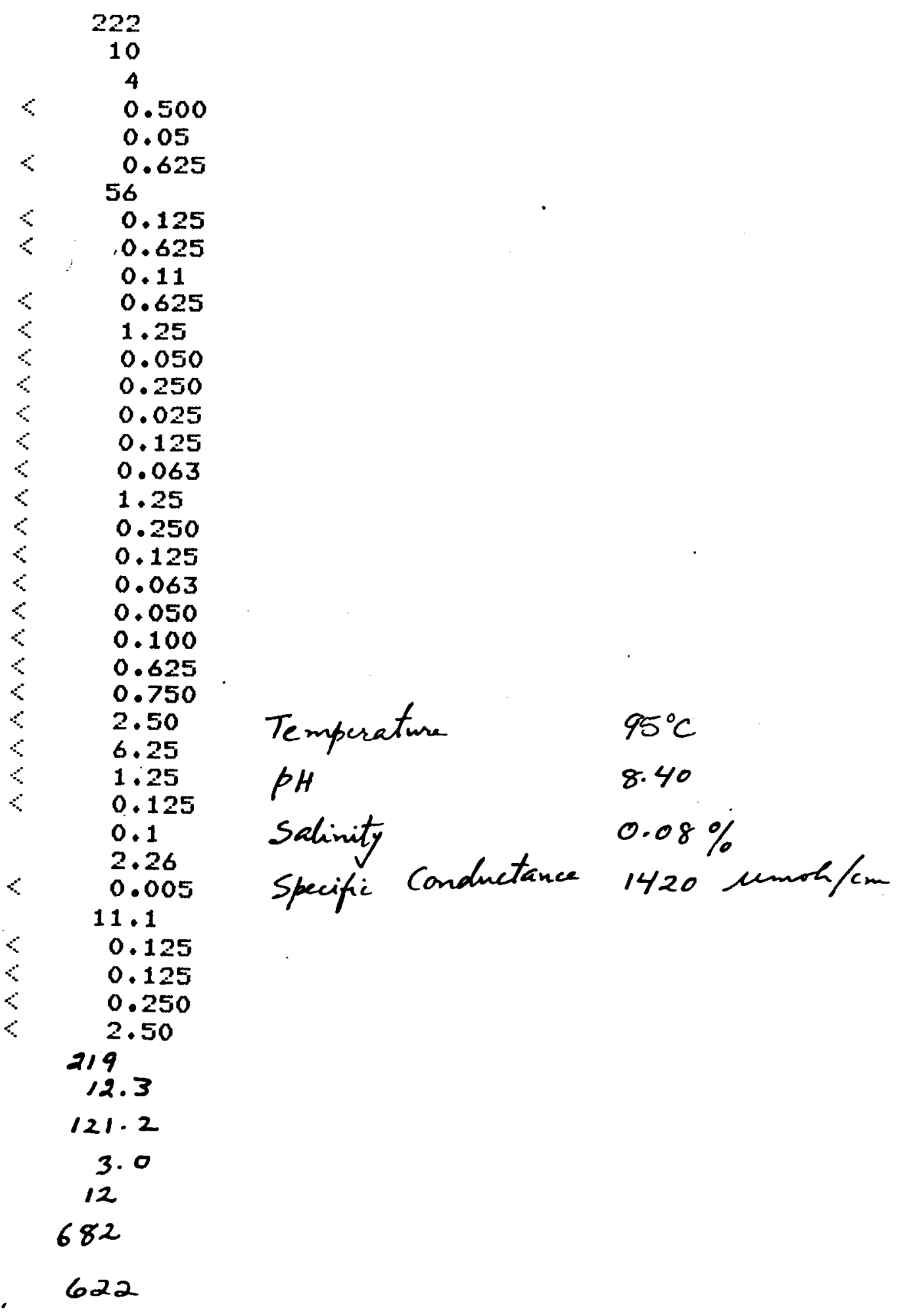


CALISTOGA SET 4

$98 \quad 6-098-80$

ELEMENT

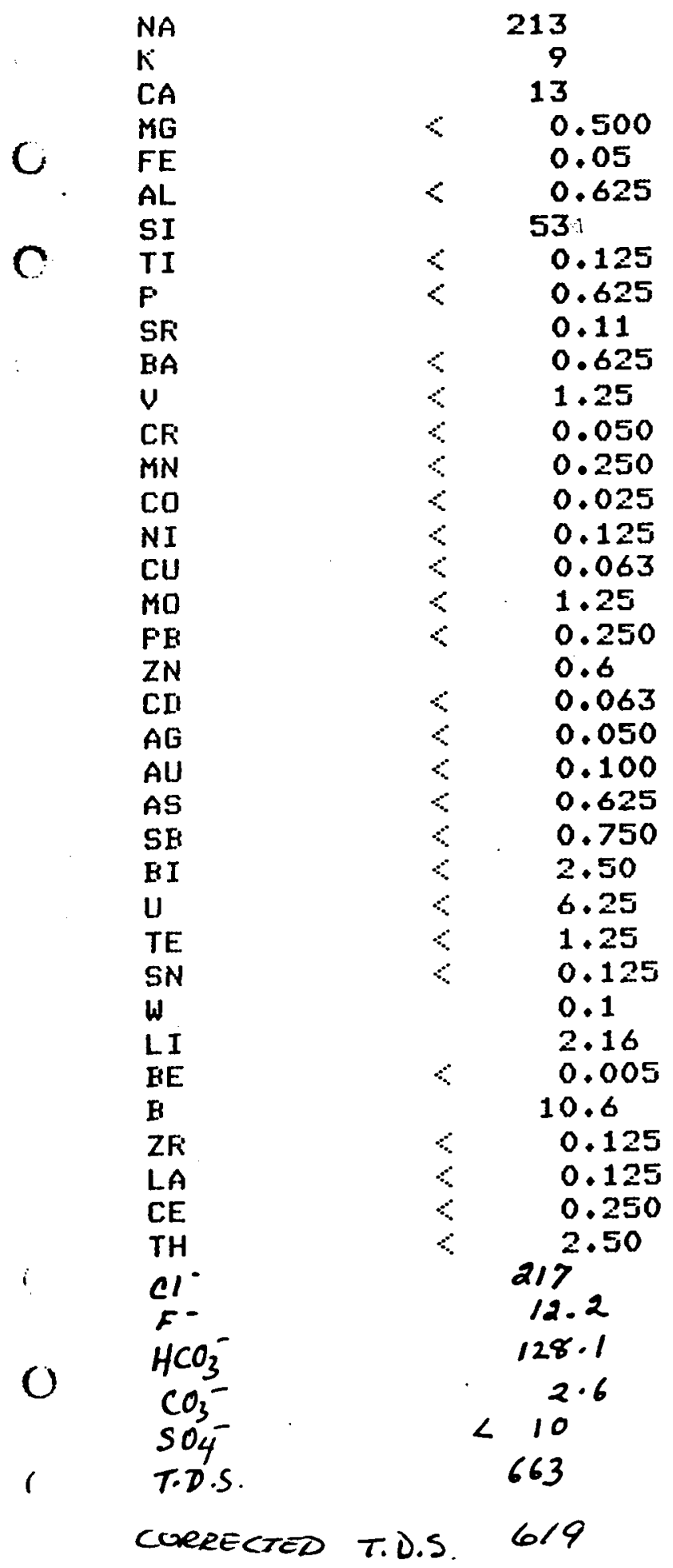

CONCENTRATION (FF)

$\begin{array}{ll}\text { Temperature } & 96^{\circ} \mathrm{F} \\ \text { pH } & 8.48 \\ \text { salinity } & 0.07 \%\end{array}$

Specific Conductance $1410 \mathrm{umoh} / \mathrm{cm}$ 


\section{CALISTOGA SET 4}

99

G-099-80

ELEMENT

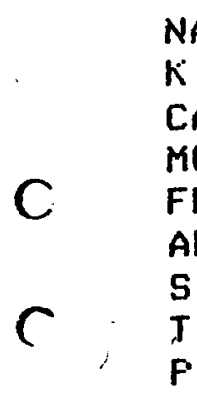

SFi

BA

U

CF

$M N$

CO

NI

CU

$M O$

$F B$

$Z N$

CII

AG

$A U$

AS

SE

HI

U

TE

SN

W

LI

BE

B

ZFi

LA

CE

$\mathrm{TH}$

$\mathrm{Cl}^{-}$

$F$ -

$\mathrm{HCO}_{3}^{-}$

$\mathrm{CO}_{3}^{-}$

$\mathrm{SO}_{4}^{-}$

T.D.S.
CONCENTKATION (FFM)

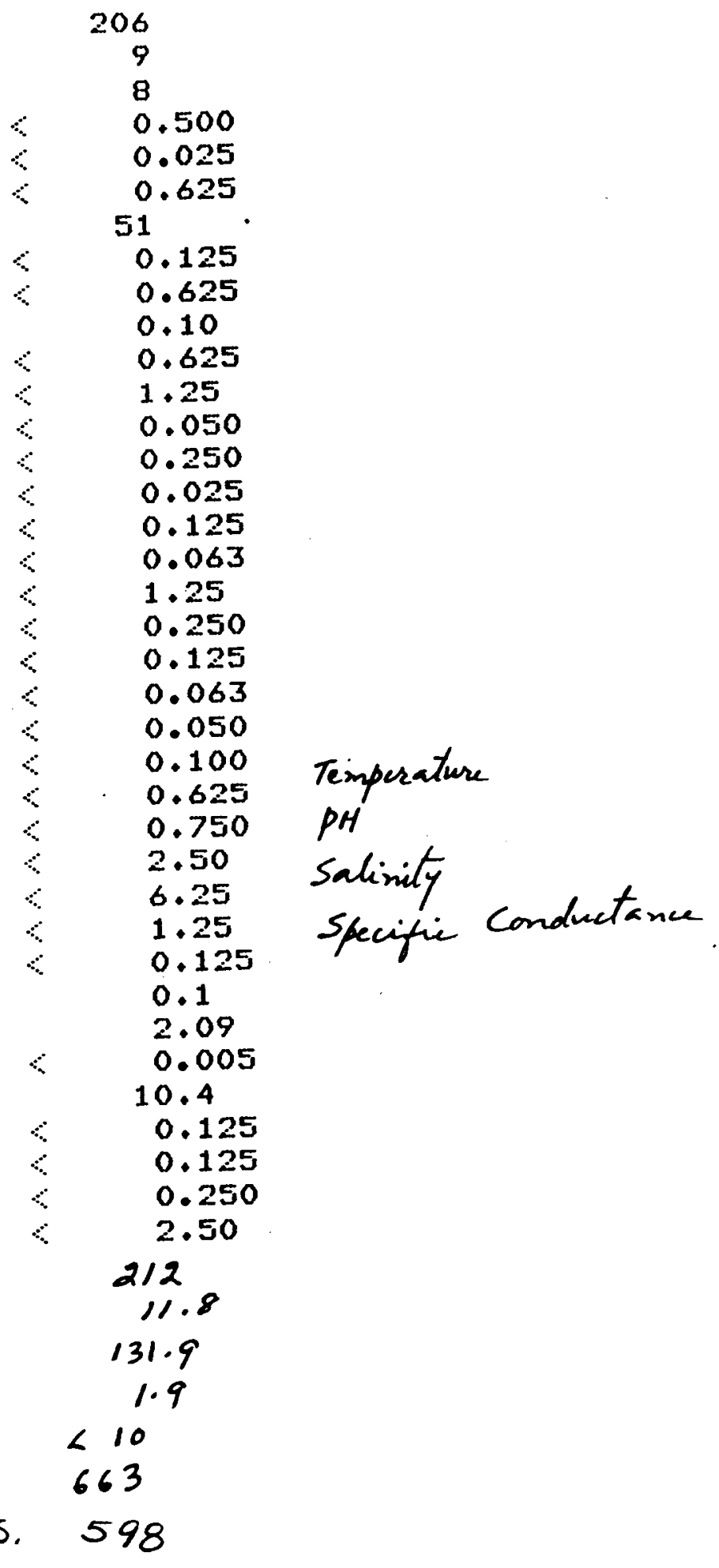

$94^{\circ} \mathrm{C}$

8.59

$0.08 \%$

1350 munot $/ \mathrm{cm}$ 
CALISTOGA SET 4

r. $100 \quad \mathrm{G}-100-80$

ELEMENT

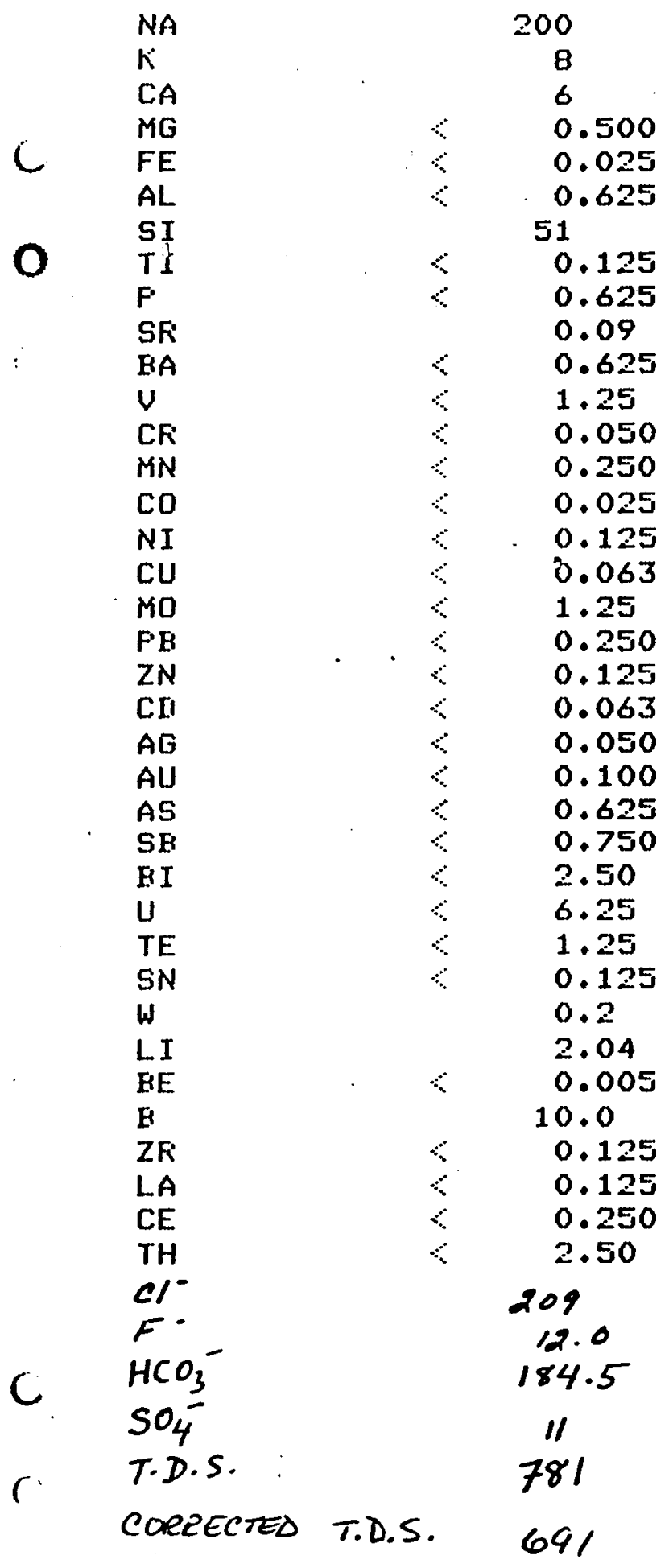

CONCENTFATION (FFM) 
CALISTOGA SET 4

101

$G-101-80$

ELEMENT

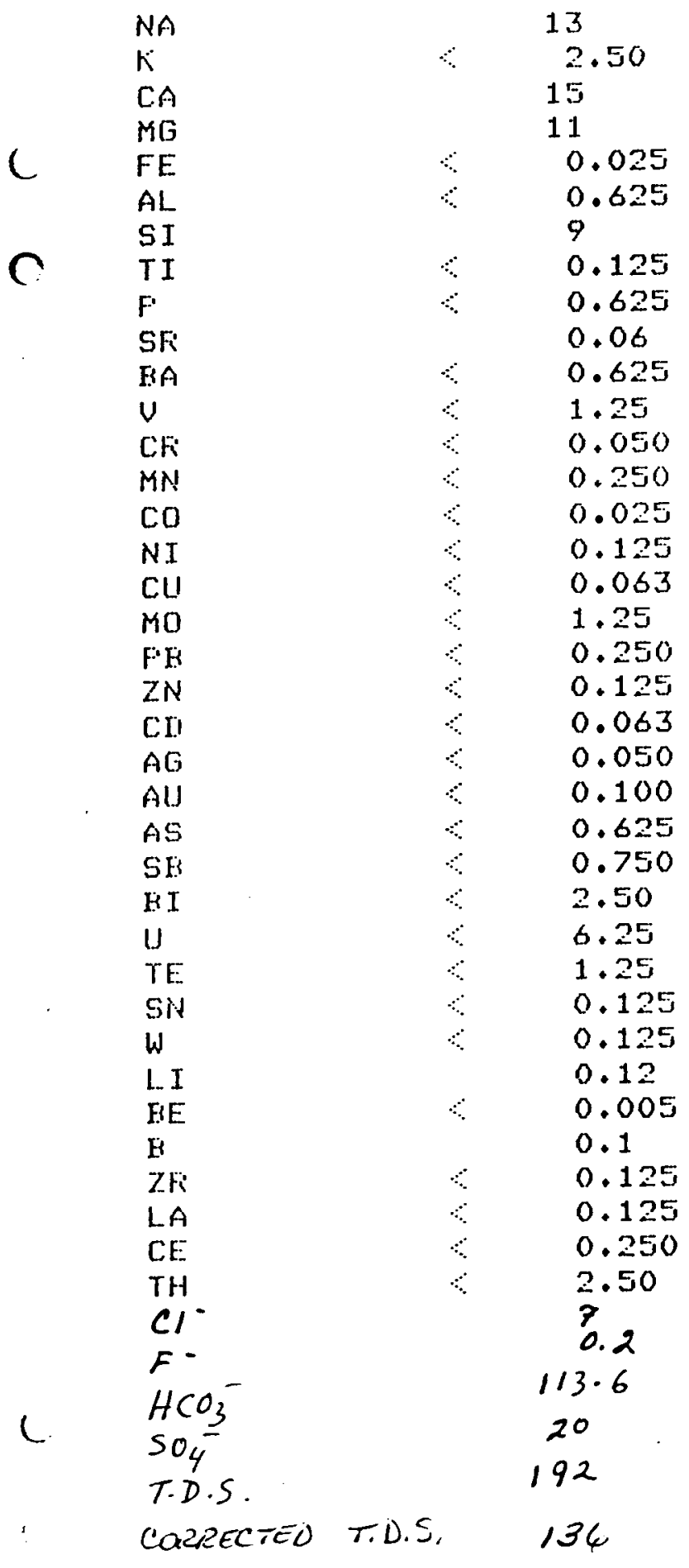

CONCENTRATION (FEM)

Temperature

$25^{\circ} \mathrm{C}$

7.20

$0.01 \%$

salinity

Specific Conductance 250 unity 
CALISTOGA SET 4

$102 \quad 6-102-80$

ELEMENT

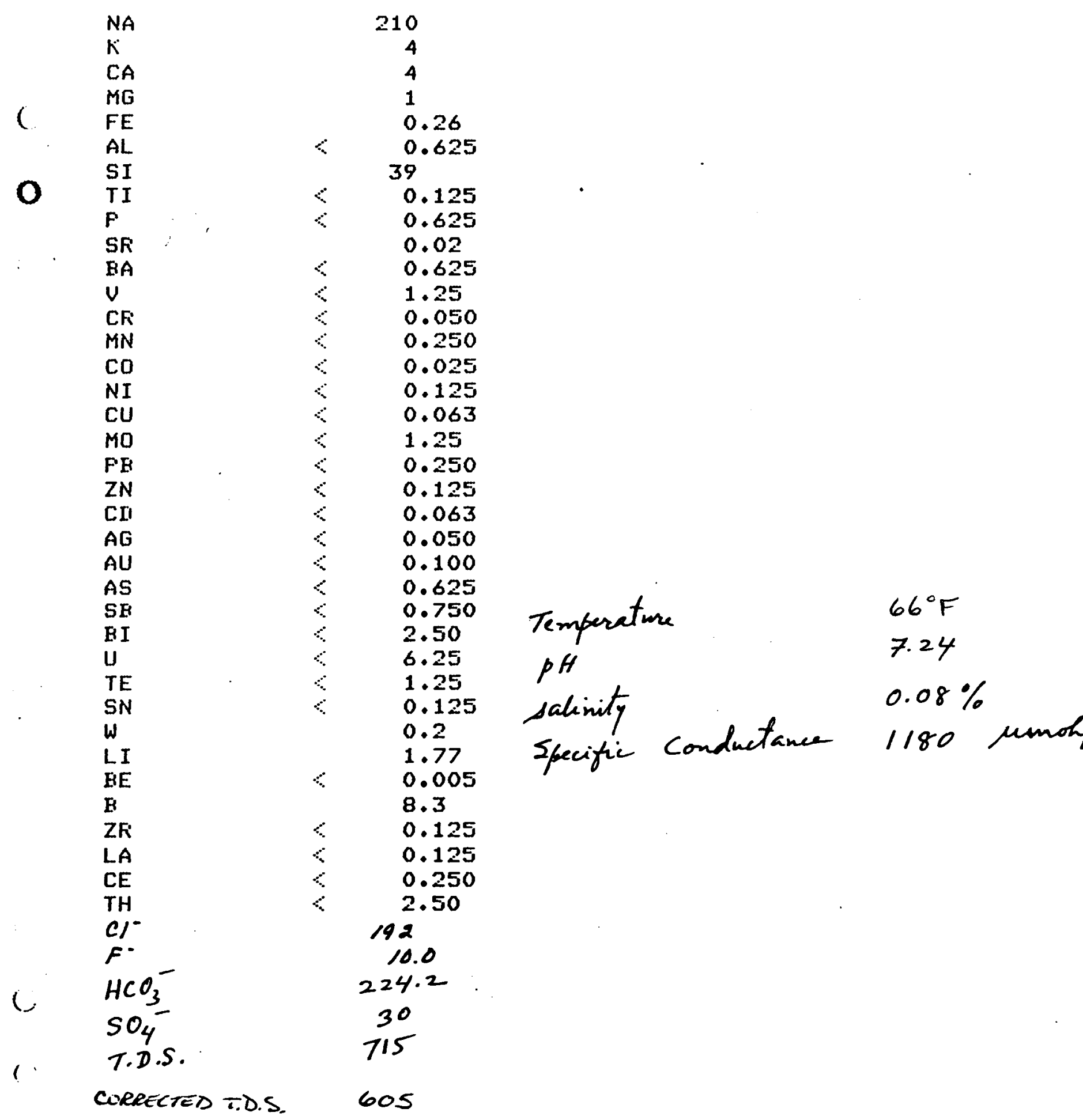


CALISTOGA SET 4

103 G-103-80

$r$

ELEMENT

CONCENTFATION (FFM)

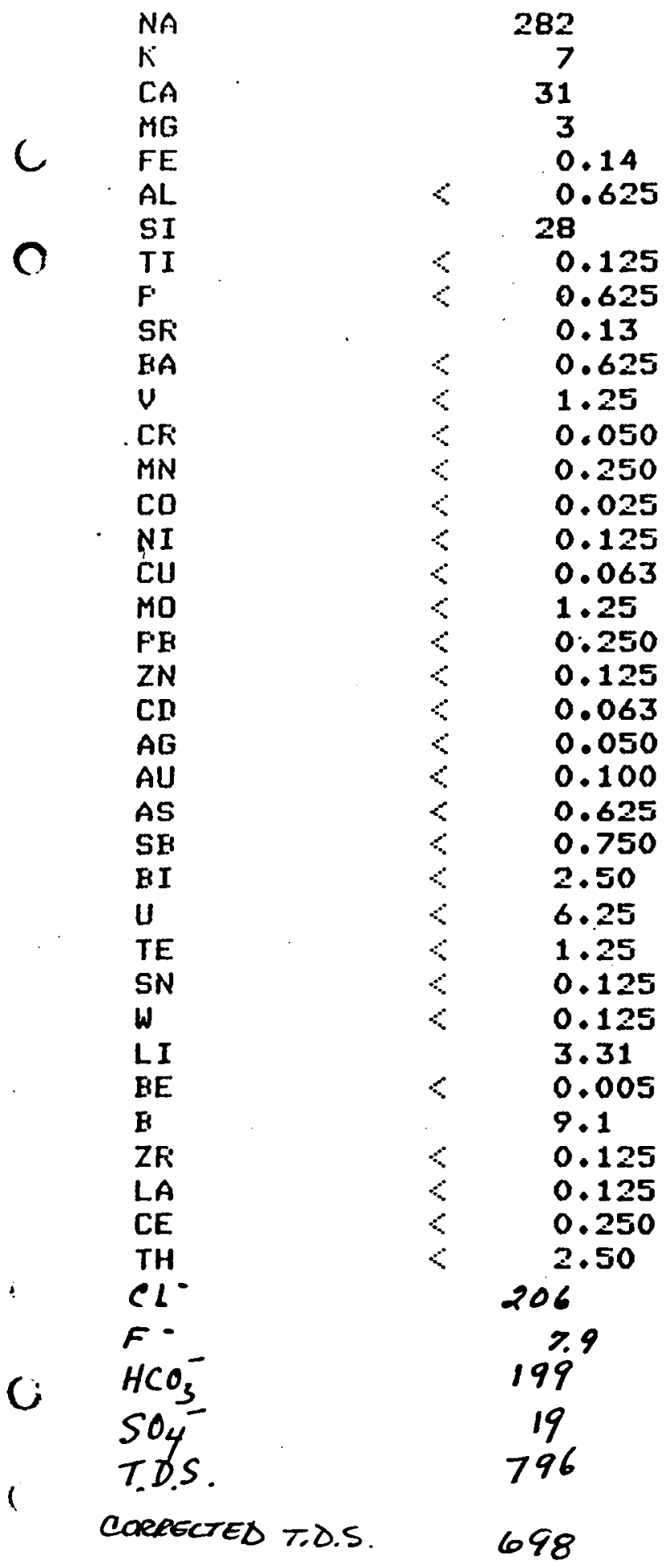

Temperature

it

Salinity

Specific Conductance 1680. umoly 
CALISTOGA SET 4

104 G-104-80

ELEMENT

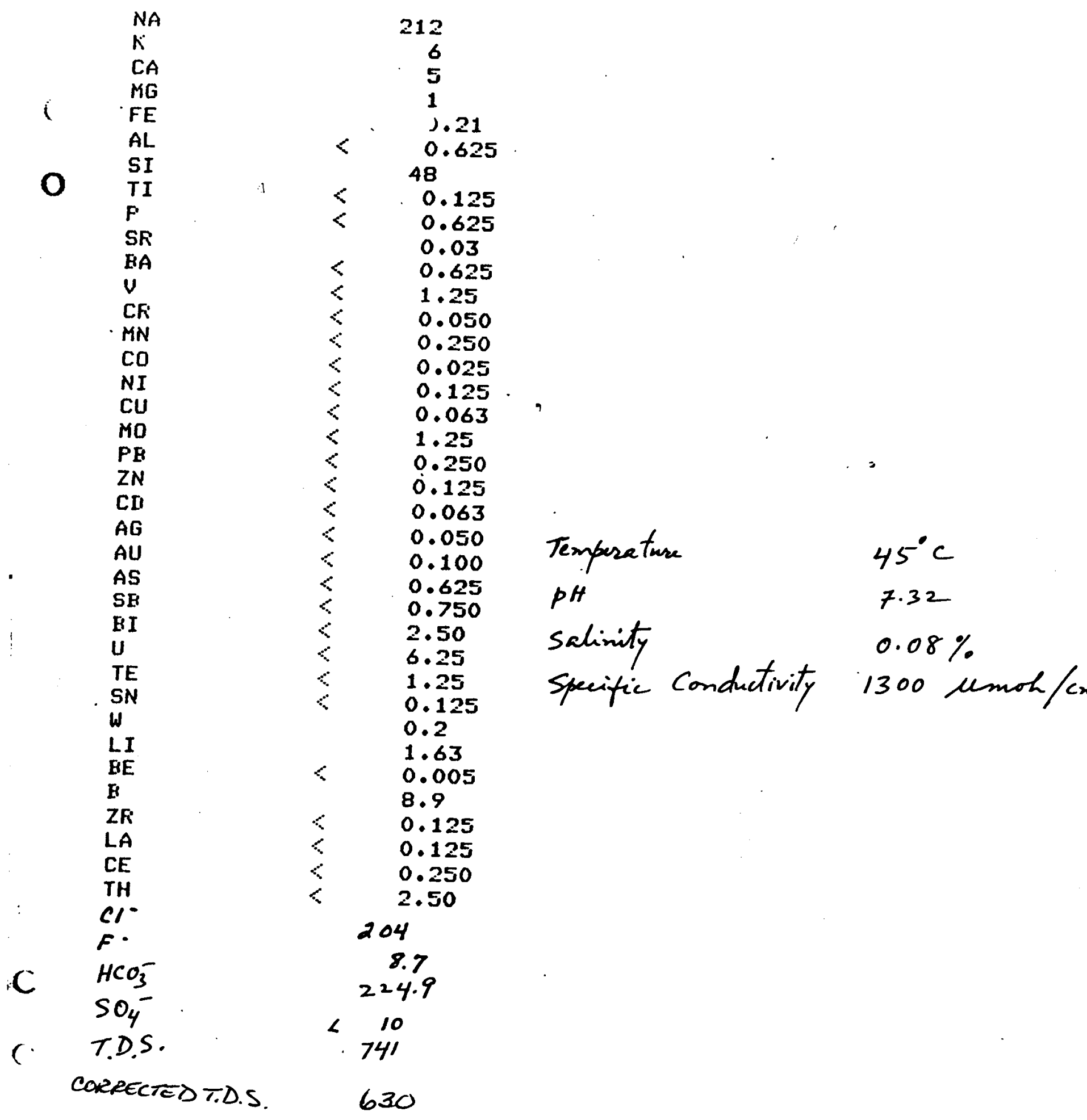


CALISTOGA SET 4

105 G-105-80

ELEMENT

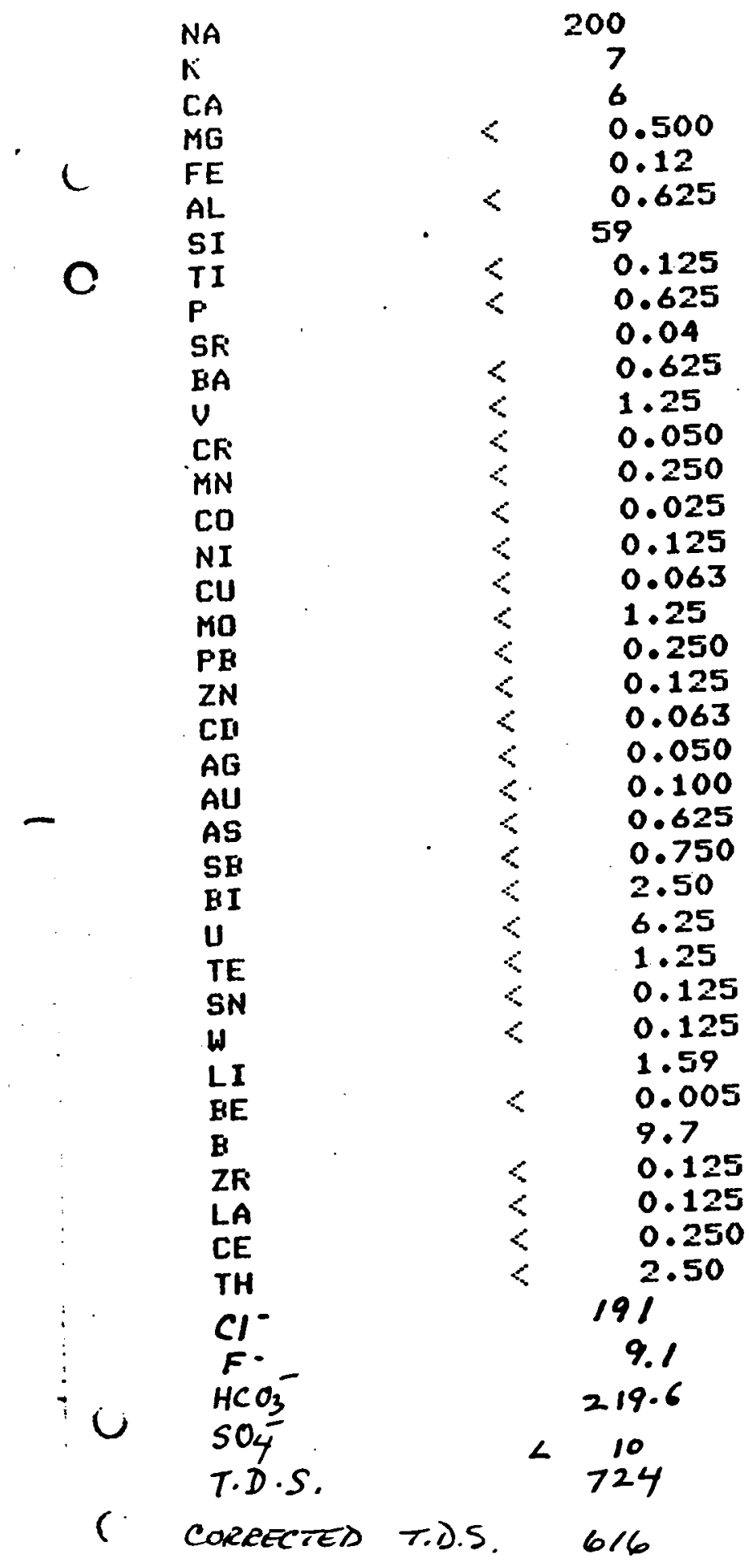


CALISTOGA SET 4

$106 \quad G-106-80$

ELEMENT

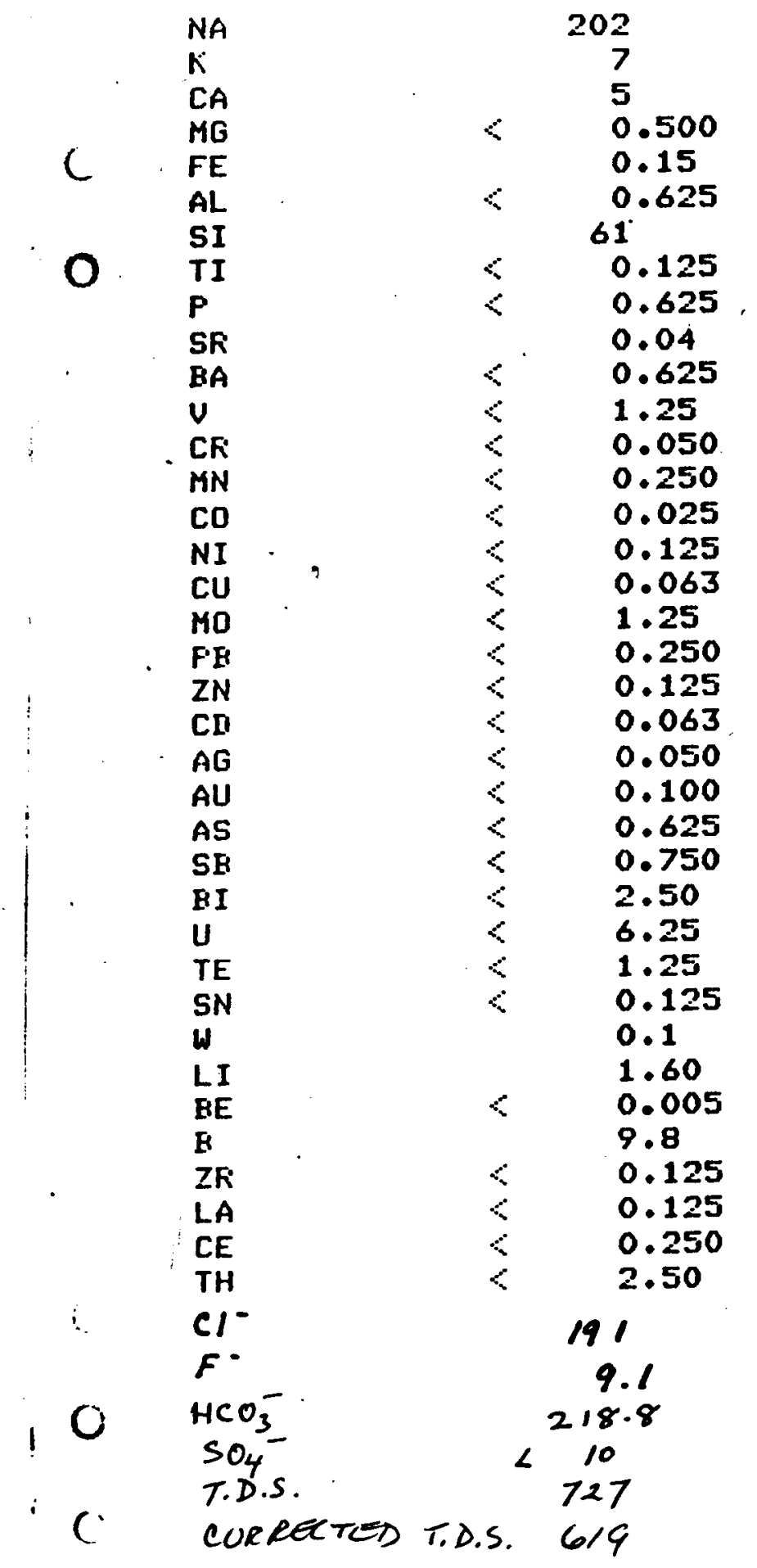

CONCENTRATION (PPM)

$\begin{array}{ll}\text { Temperature } & 130^{\circ} \mathrm{F} \\ \text { pH } & 7.41 \\ \text { salinity } & 0.08 \%\end{array}$

salinity conductance 1350 umolfoc 
CALISTUGA SET 4

107 G-107-80

ELEMENT

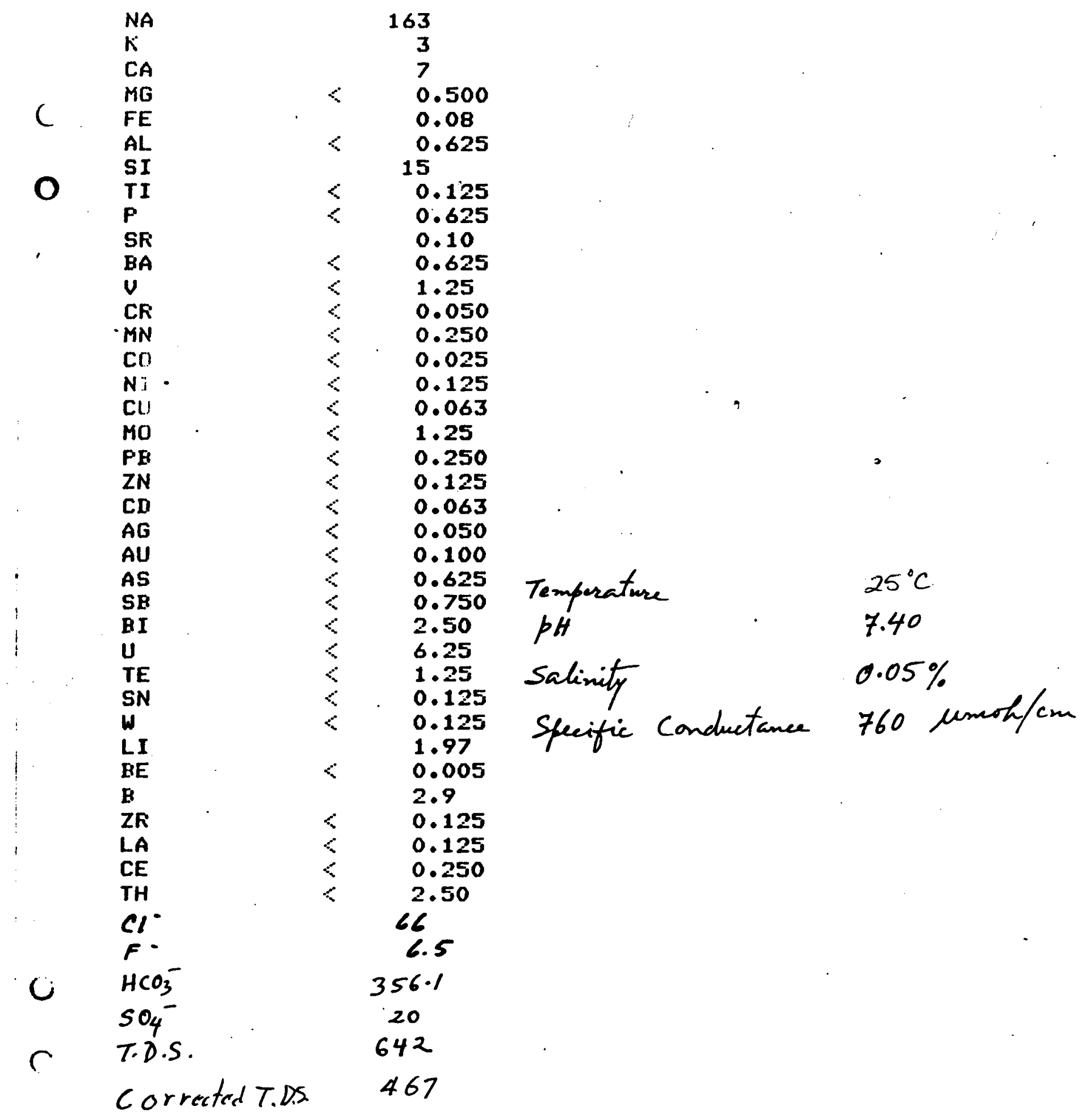


CALISTOGA SET 4

$r$

108

G-108-80

ELEMENT

CONCENTKATION (FPM)

$\begin{array}{cl} & N A \\ & K \\ & C A \\ & M G \\ & \text { FE } \\ & \text { AL } \\ & \text { SI } \\ & \text { TI } \\ & \\ & F\end{array}$

SF

$\checkmark$

MN

CO

NI

MO

$P E$

ZN

CD

AU

AS

SB

BI

U

TE

SN

LI

BE

B

ZR

LA

TH

$i$

$\mathrm{Cl}^{-}$

$F$

$\mathrm{HCO}_{3}$

$\mathrm{SO}_{4}^{-}$

T.D.S.

corrected T.D.S. 396 


\title{
CALISTOGA SET 4
}

109

G-109-80

ELEMENT

\author{
CONCENTFATION (FFM)
}

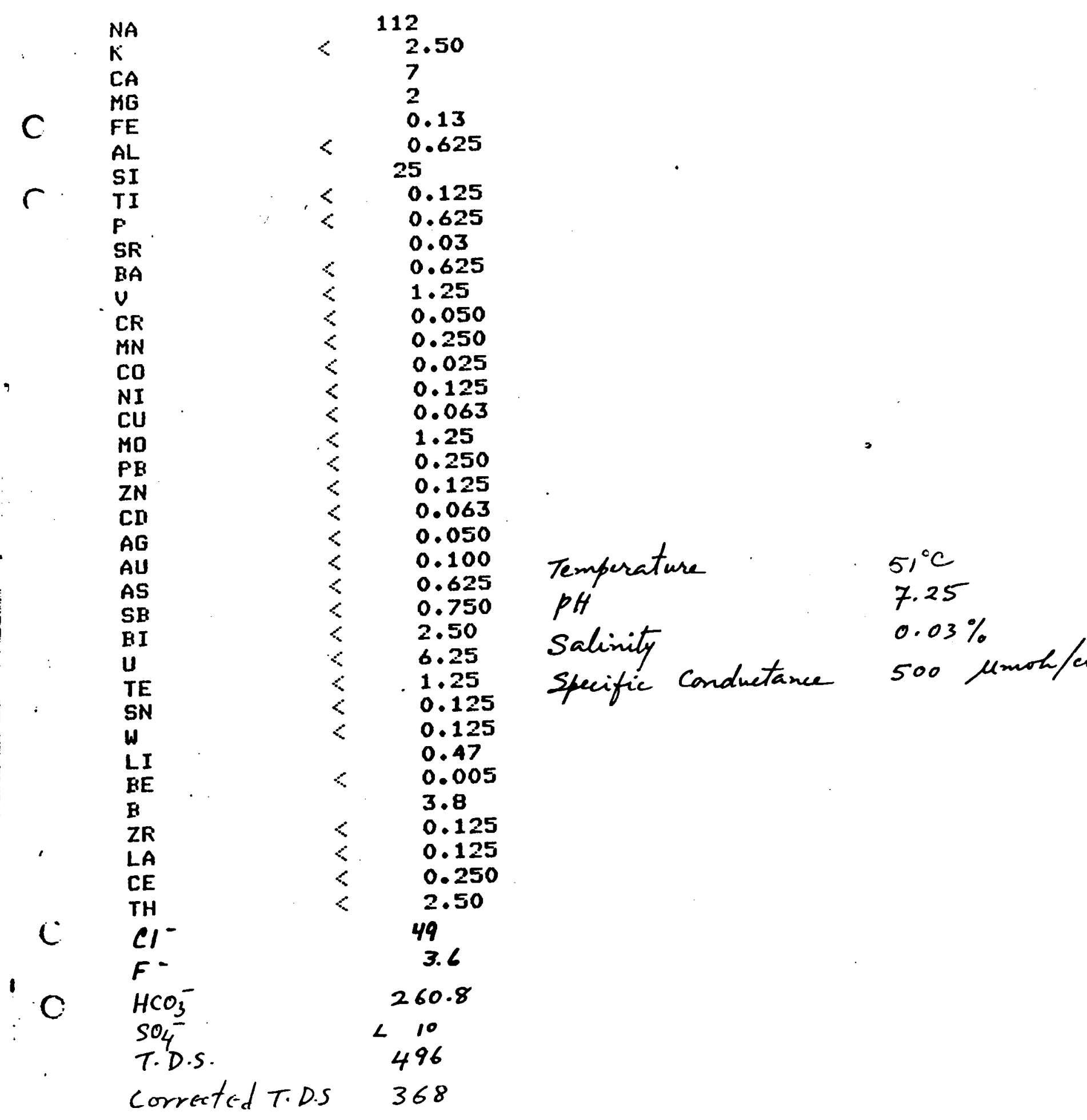


CALISTOGA SET 4

110

G-110-80

ELEMENT

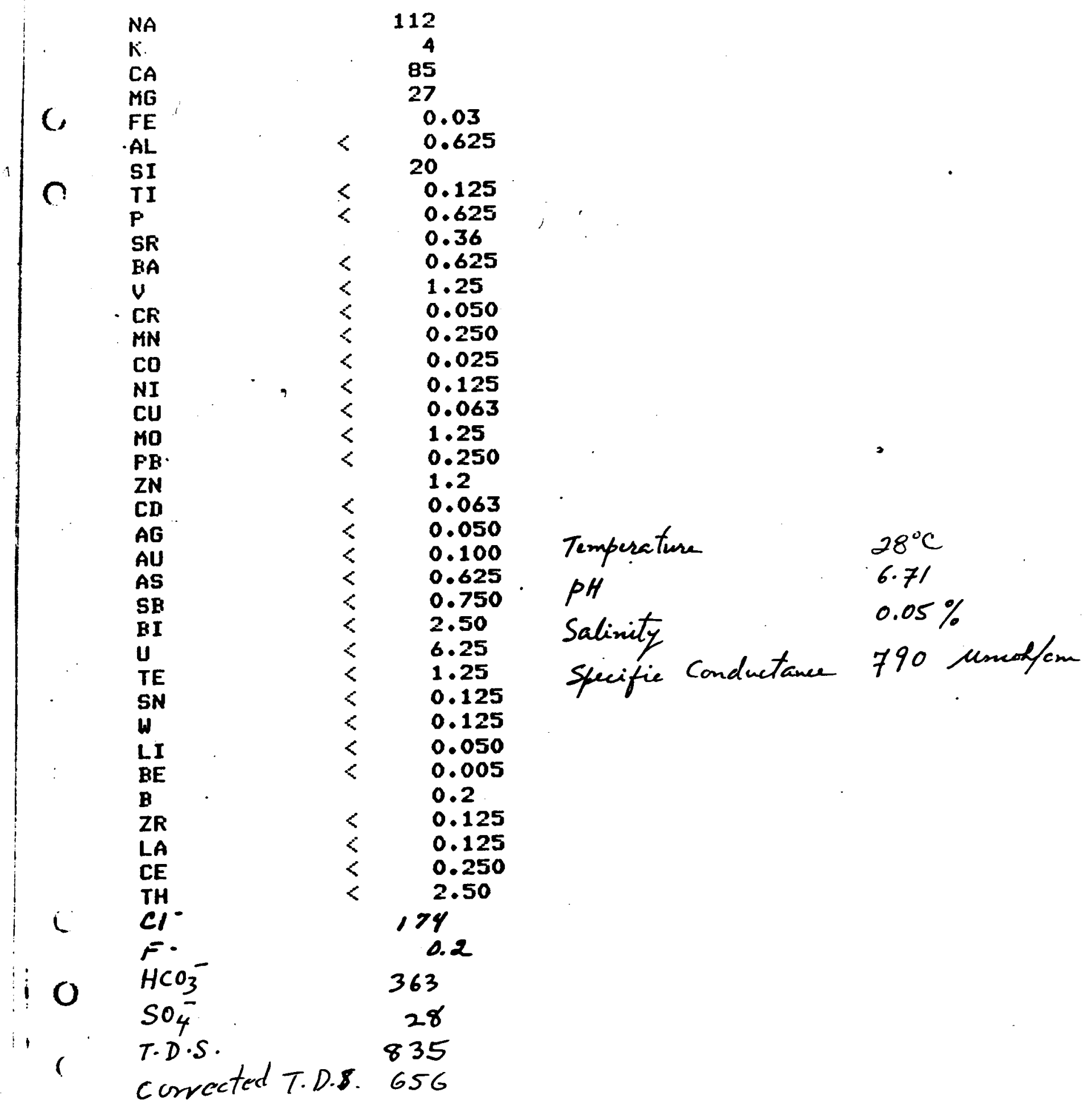


CALISTOGA SET 4

111 G-111-80

ELEMENT

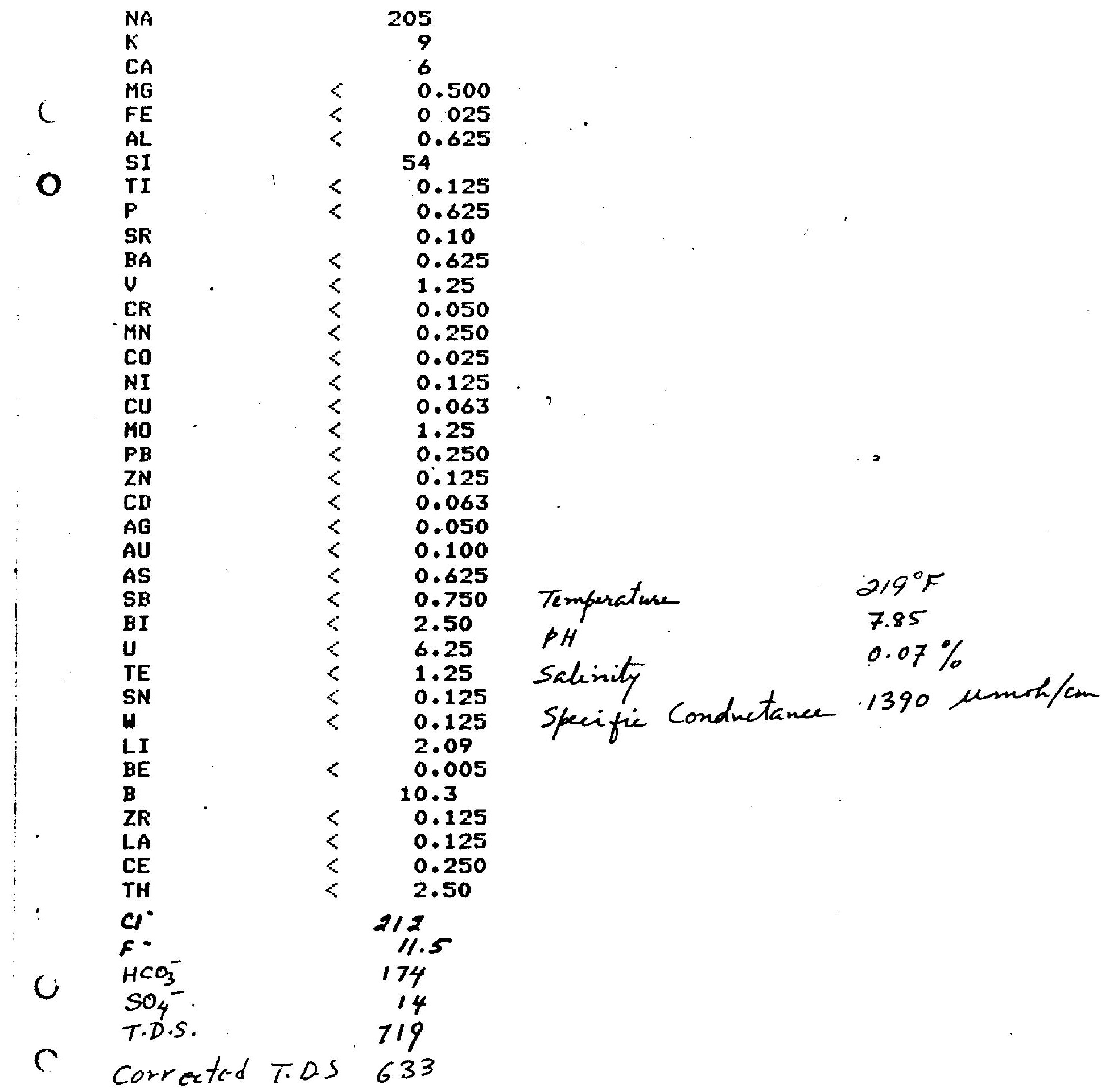


CALISTOGA SET 4

112 G-112-80

ELEMENT

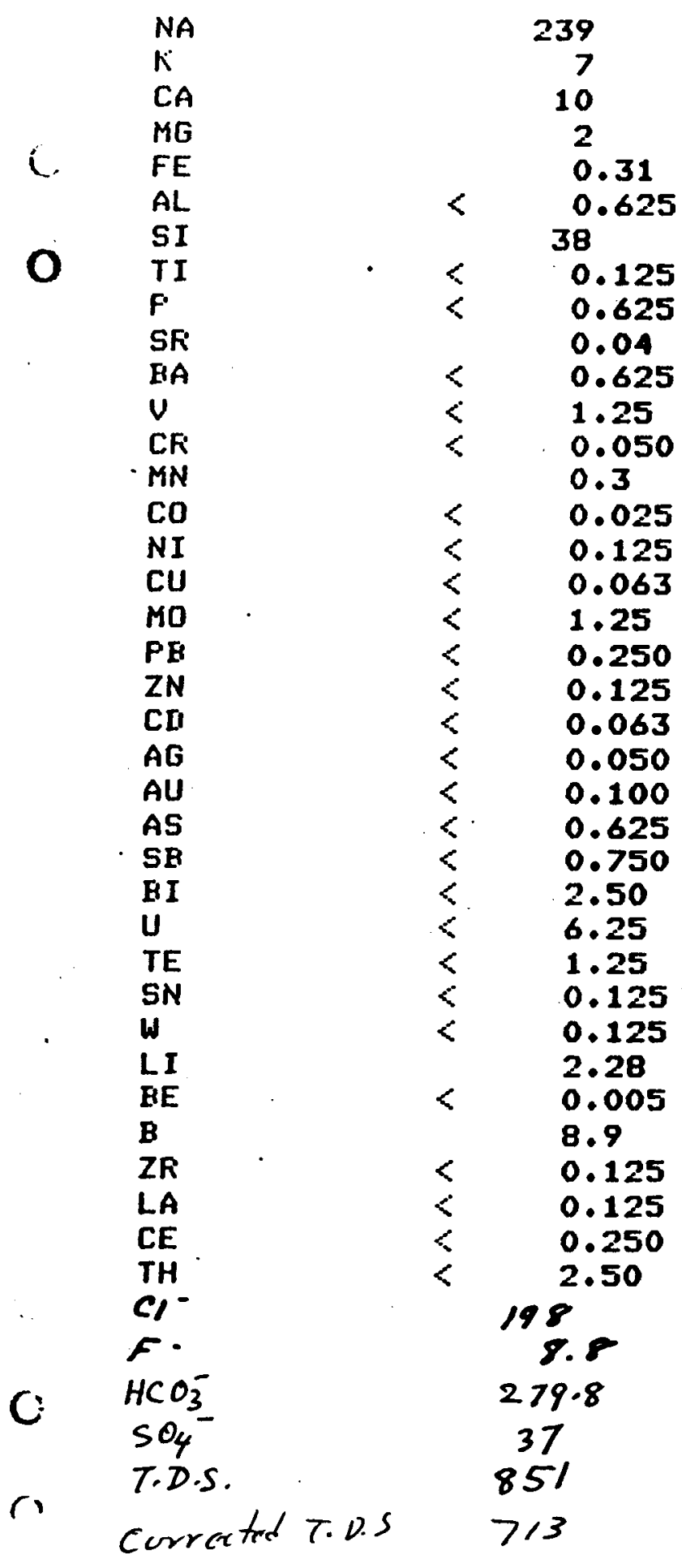

CONCENTRATION (FFM)

1

$$
\begin{aligned}
& 30^{\circ} \mathrm{C} \\
& 6.40 \\
& 0.08
\end{aligned}
$$

salinity.

specifie Conductance 1120 umoh/an 
CALISTOGA SET 4

113 G-113-80

ELEMENT

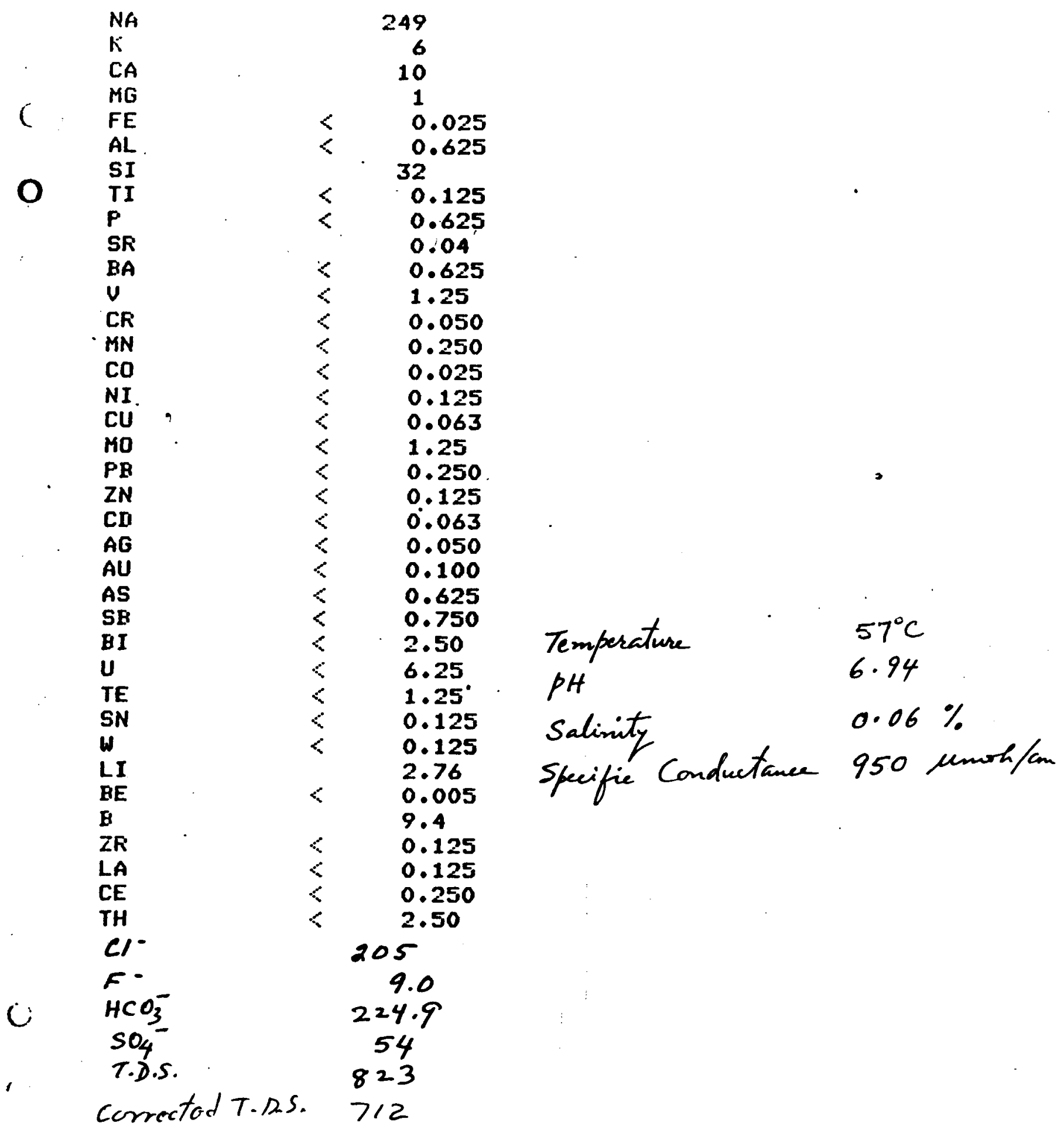




\section{CALISTOGA SET 4}

114

$$
\text { G-114-80 }
$$

ELEMENT

NA

CA

IMG

FE

AL.

$S I$

TI

SF

BA

U

CR

$M N$

CO

$N I$

$\mathrm{CU}$

MO

PB

ZN

CI

( $A G$

(O) AU

AS

$\Longrightarrow$ SE

BI

U

TE

SN

W

LI

BE

B

ZK

LA

CE

TH

$\mathrm{CI}^{\circ}$

$F$ -

$\mathrm{HCO}_{3}^{-}$

$\mathrm{SO}_{4}-$

T.D.S.

CONCENTFATION (FPM)

189

$\begin{array}{ll} & 6 \\ 12 \\ <\quad 0.500 \\ & 1.72 \\ <\quad 0.625\end{array}$

28

$<\quad 0.125$

$<\quad 0.625$

0.07

$<\quad 0.625$

$<\quad 1.25$

$<\quad 0.050$

$<\quad 0.250$

$<\quad 0.025$

$<\quad 0.125$

$\because \quad 0.063$

$\div \quad 1.25$

$<\quad 0.250$

0.4
$<\quad 0.063$

$<\quad 0.050$

$<\quad 0.100$

$<\quad 0.625$

$<\quad 0.750$

Temperature

$41^{\circ} \mathrm{C}$

$<\quad 2.50$

$<\quad 6.25$

$<\quad 0.125$

$<$

0.125

pH

7.15

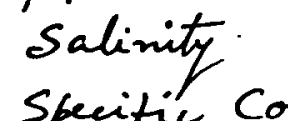

1.99

$\therefore \quad 0.005$

8.0

$<\quad 0.125$

$<\quad 0.125$

$<\quad 0.250$

$<\quad 2.50$

specific Conductance

$0.05 \%$

155

10.0

$25 \% .5$

Corrated T. D.S. 580 
CALISTOGA SET 4

r

$$
115 \text { G-115-80 }
$$

ELEMENT

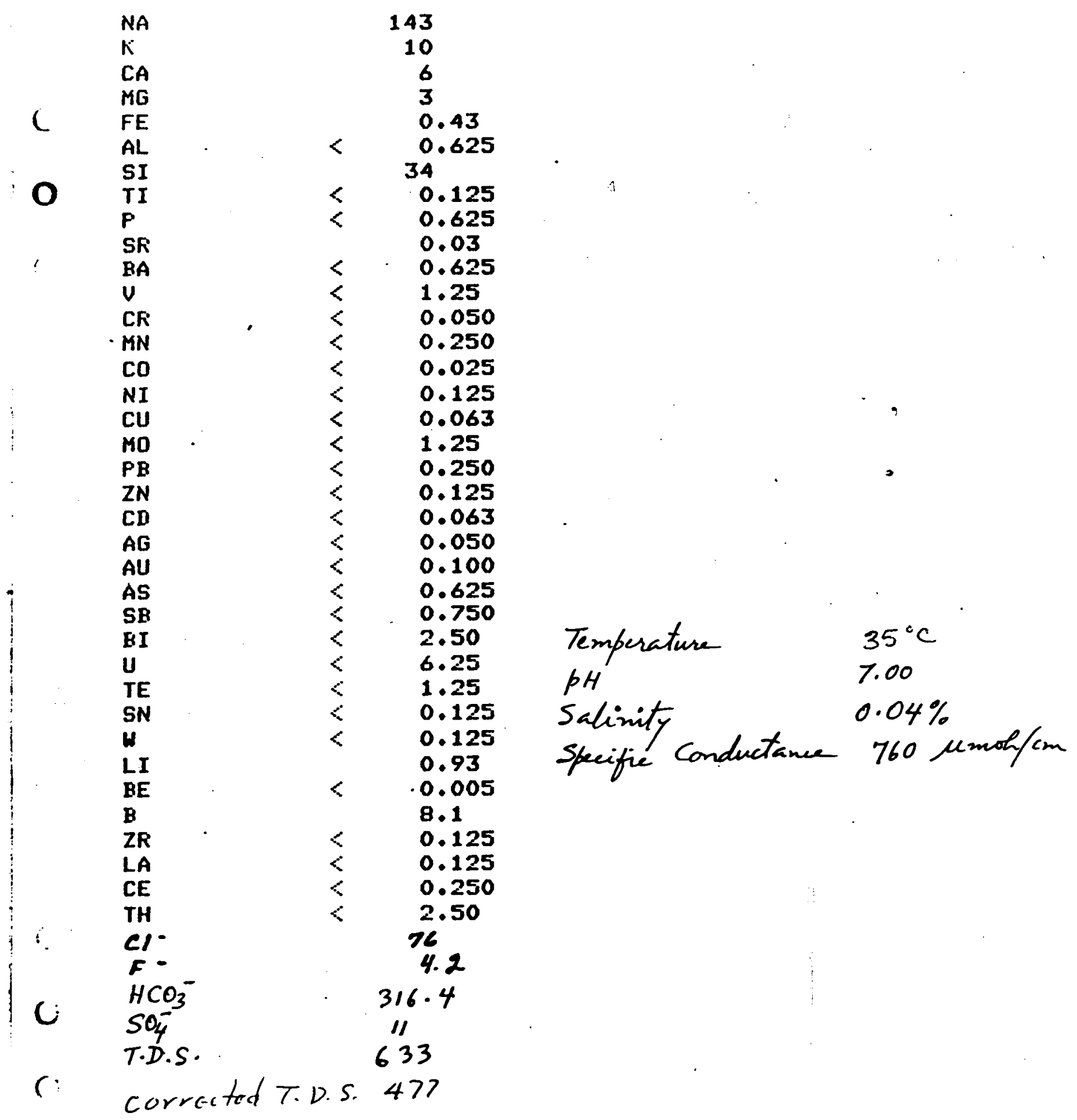




\section{CALISTOGA SET 4}

116 G-116-80

\section{ELEMENT}

$$
\text { CONCENTRATION (FPM) }
$$

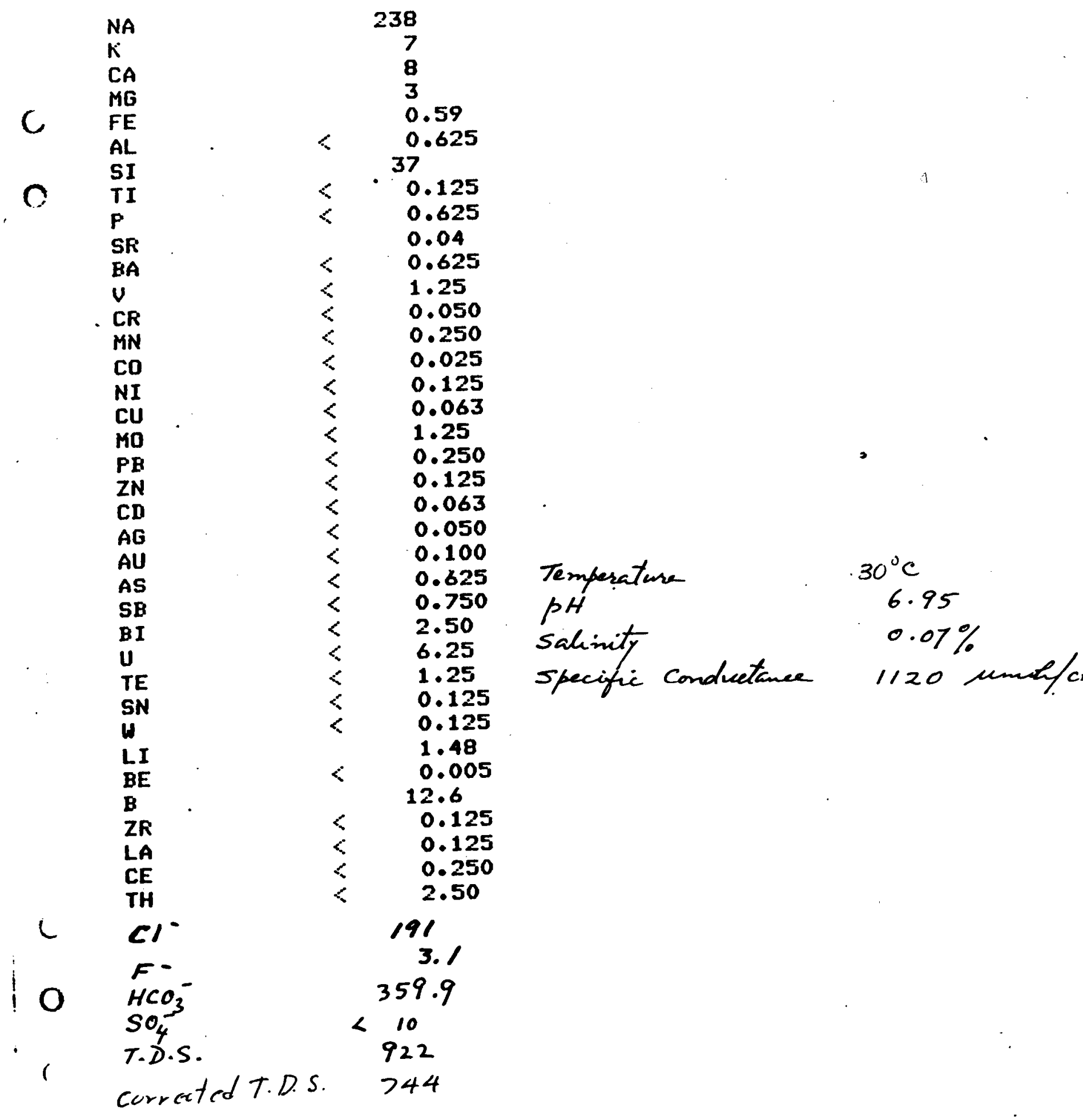


CALISTOGA SET 5

$117 \quad G-117-80$

r

ELEMENT

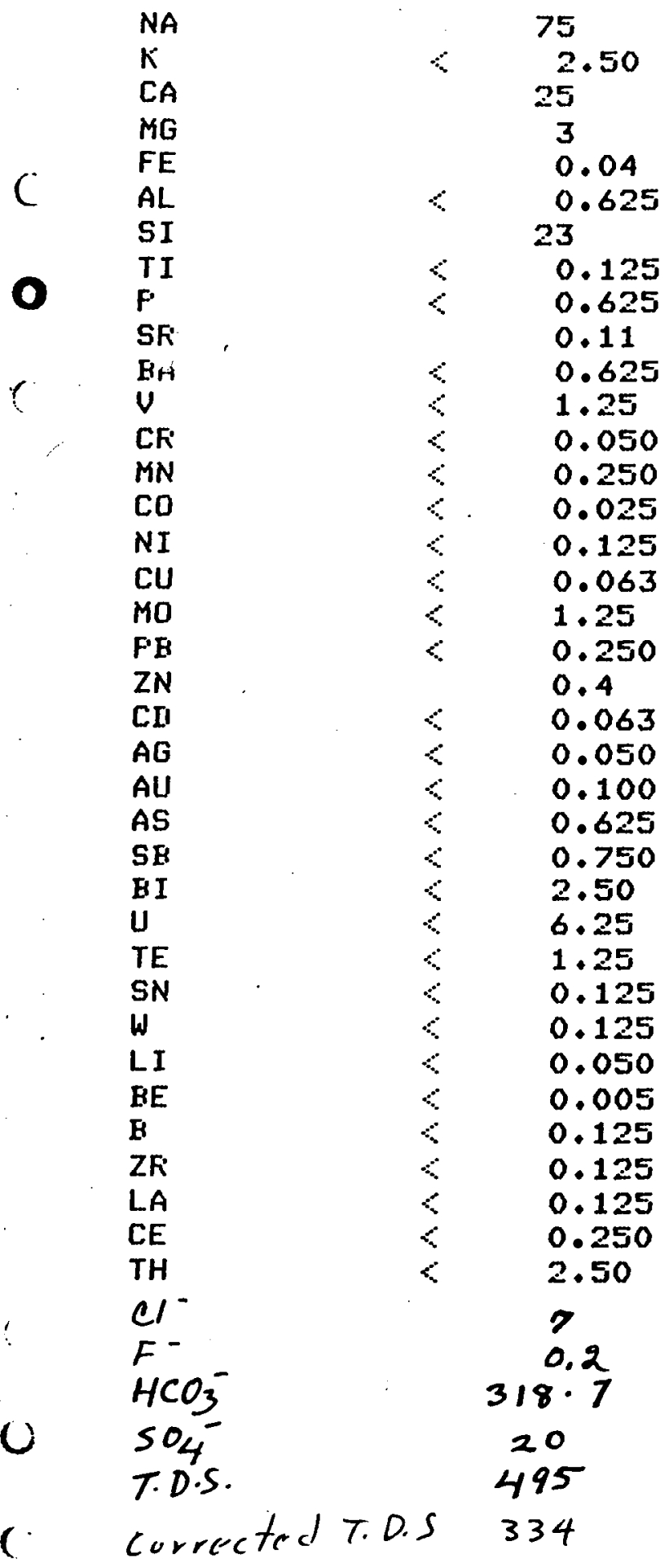

CONCENTFATION (FFMA)

$\begin{array}{ll}\text { Temperatuse } & 24^{\circ} \mathrm{C} \\ \text { PH } & 6.20 \\ \text { salimity } & 0.02 \% \\ \text { Specific conductance } & 450 \% \text { umolem }\end{array}$ 
CALISTOGA SET 5

$118 \quad G-118-80$

$r$

ELEMENT

CONCENTRATION (FF)

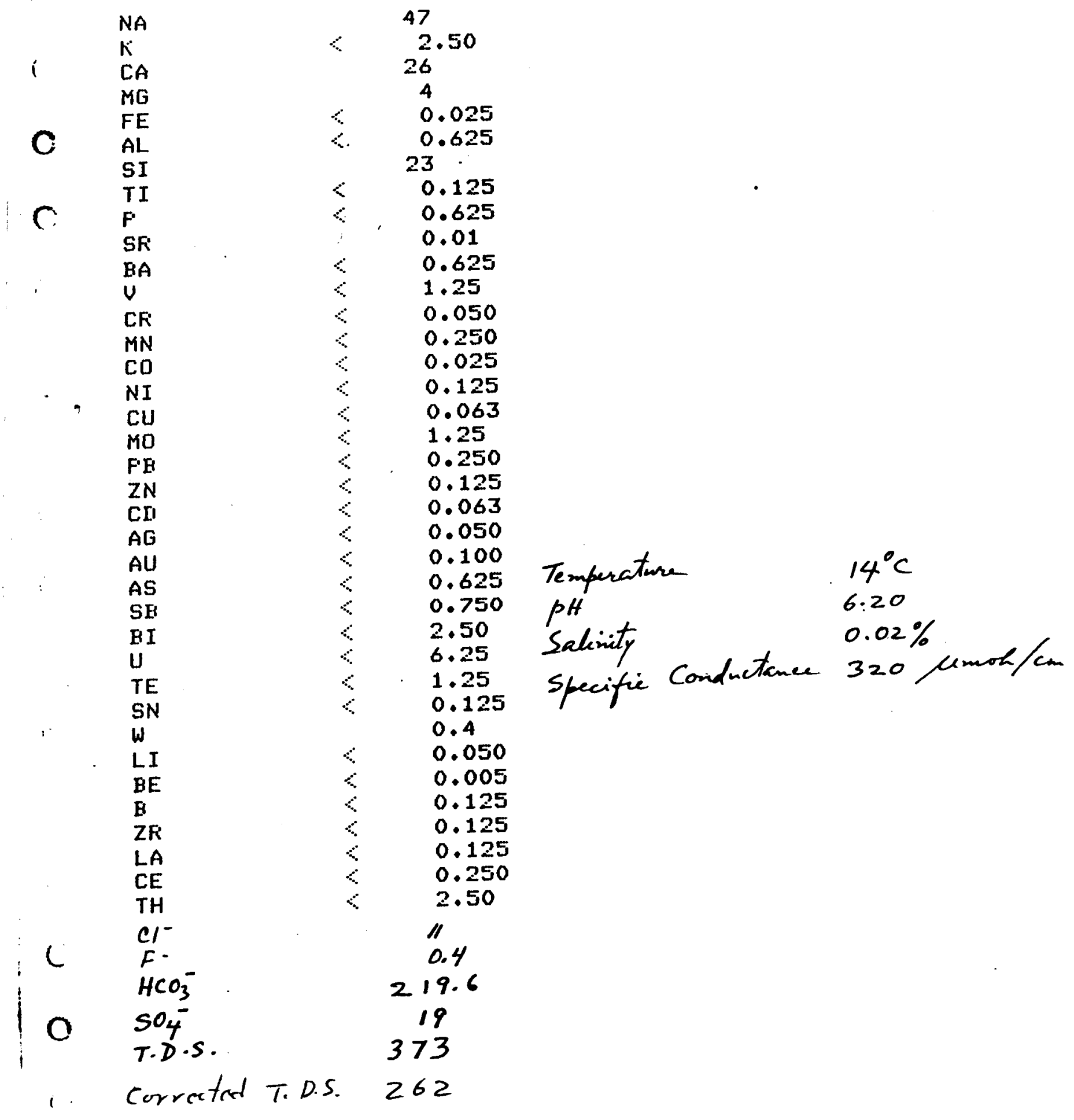




\section{CALISTOGA SET 5}

$$
119 \quad \text { G-119-80 }
$$

r

\section{ELEMENT}

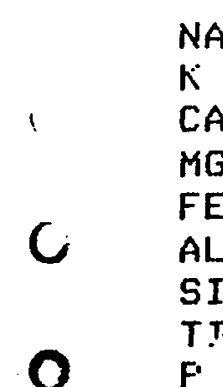

SF

BA

$\checkmark$

CR

$M N$

CO

NI

CU

MO

F'B

ZN

Cn

$A G$

AU

AS

SE

BI

U

TE

SN

W

LI

$\mathrm{BE}$

1 B

$Z F$

LA

CE

TH

$\mathrm{Cl}^{-}$

$\mathrm{F}^{-}$

$\mathrm{HCO}_{3}^{-}$

$\mathrm{SO}_{4}^{-}$

T.D.S.

\section{CONCENTRATION (FFM)}

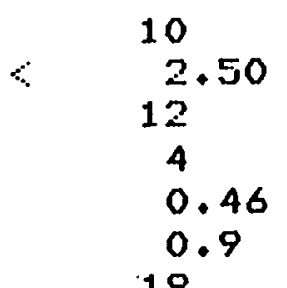

$<\quad 0.125$

0.06

0.625

1.25

0.050

0.250

0.025

0.125

0.063

1.25

0.250

0.125

0.063

0.050

0.100

0.625

0.750

2.50

6.25

1.25

0.125

0.125

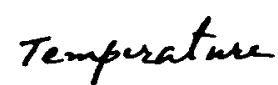

$p H$

Salinity

specifie conductance $20^{\circ} \mathrm{C}$

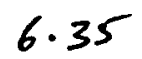

$0.00 \%$
0.050

0.005

0.125

0.125

0.125

0.250

2.50

$<$

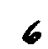

$<0.1$

54.1

$<10$

139

ated T.D.S. 112 
CALISTOGA SET 5

120

$G-120-80$

(

ELEMENT

CONCENTRATION (PPM)

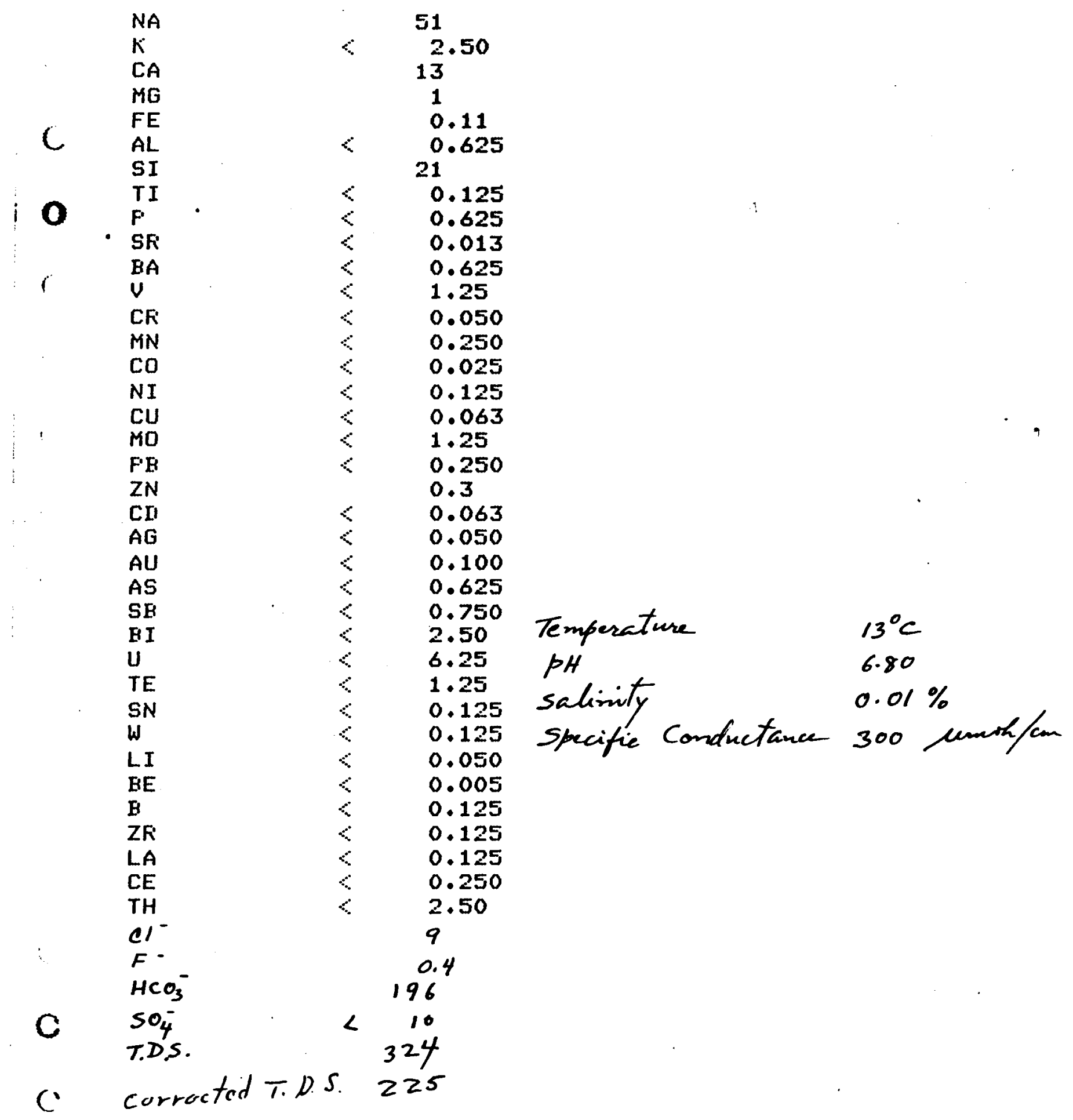


CALISTUGA SET 5

121

G-121-80

ELEMENT

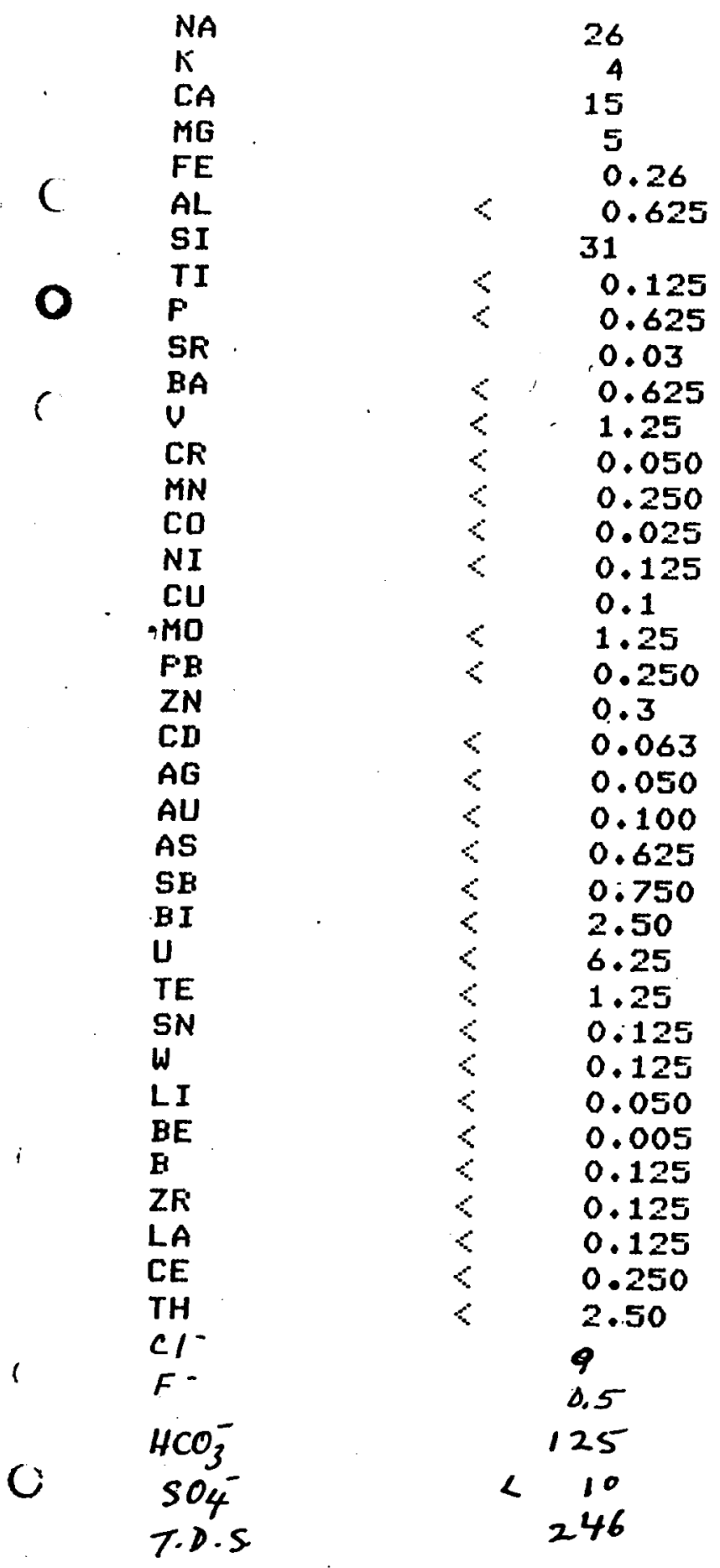

CONCENTFATION (FFM)

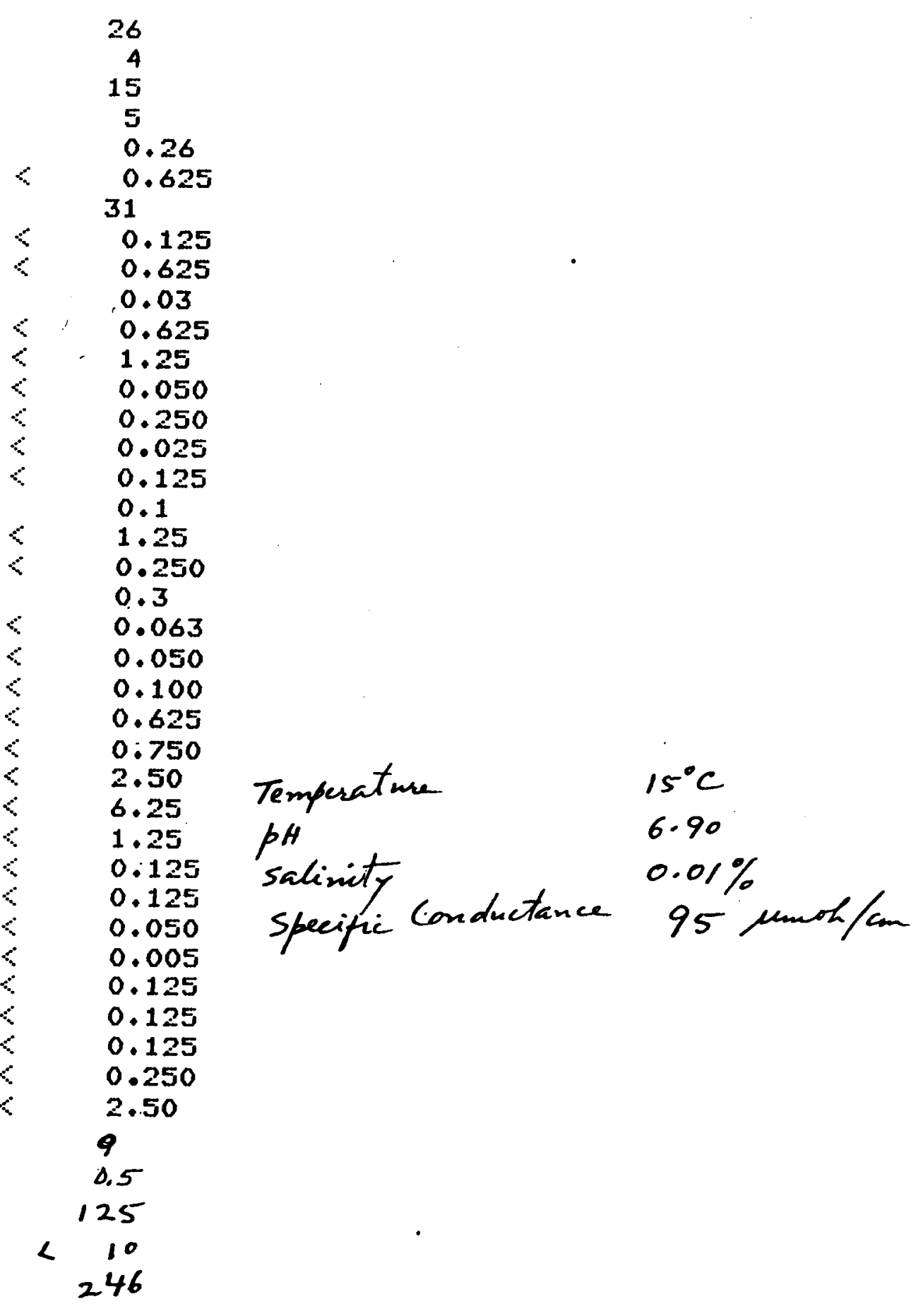

() corrected T.D.S 183 
CALISTUGA SET 5

$122 \quad G-122-80$

C.

ELEMENT

CONCENTRATION (FAFF)

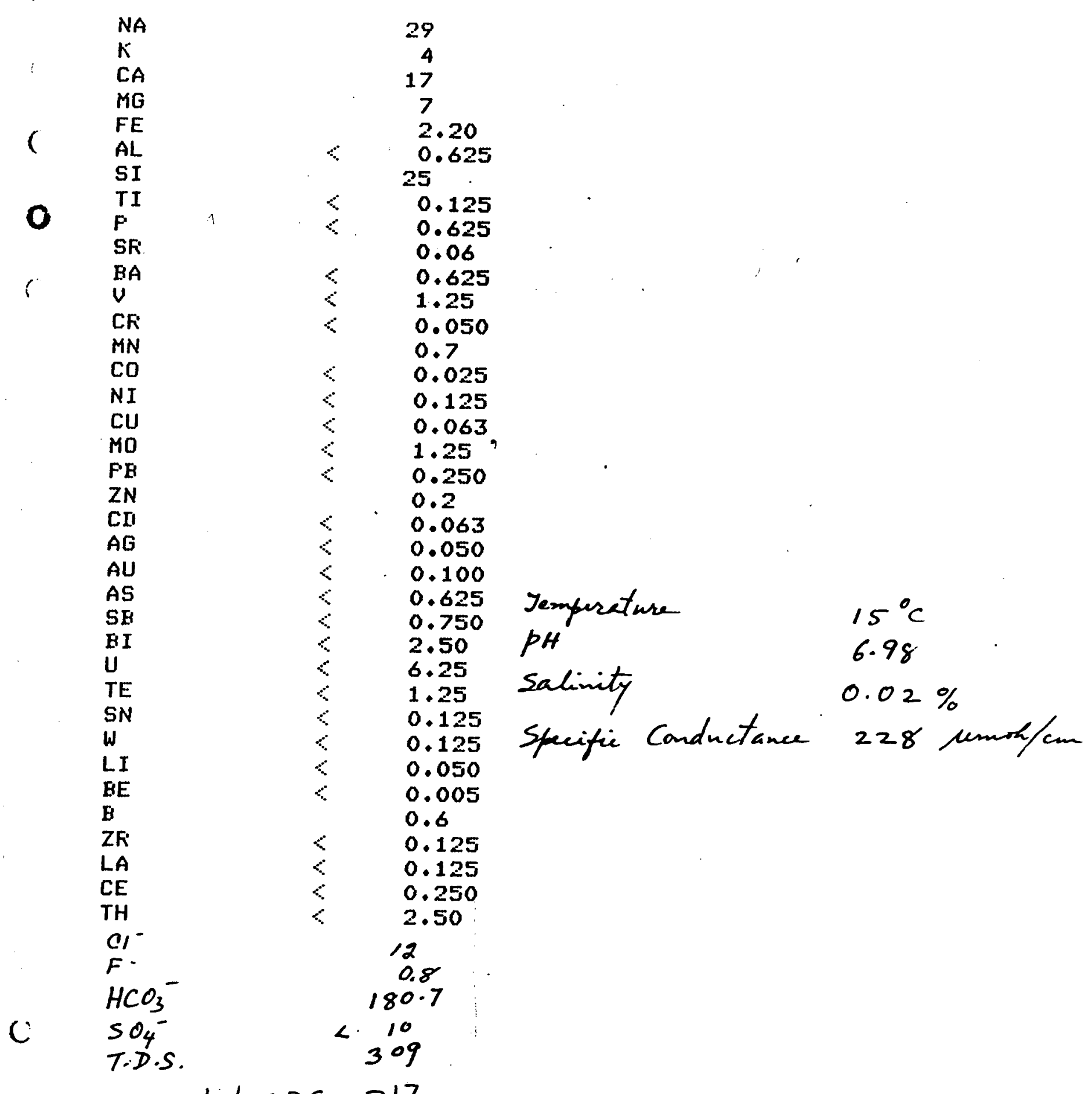

() Correcter T.D.S. 217 
CALISTOGA SET 5

123 G-123-80

ELEMENT

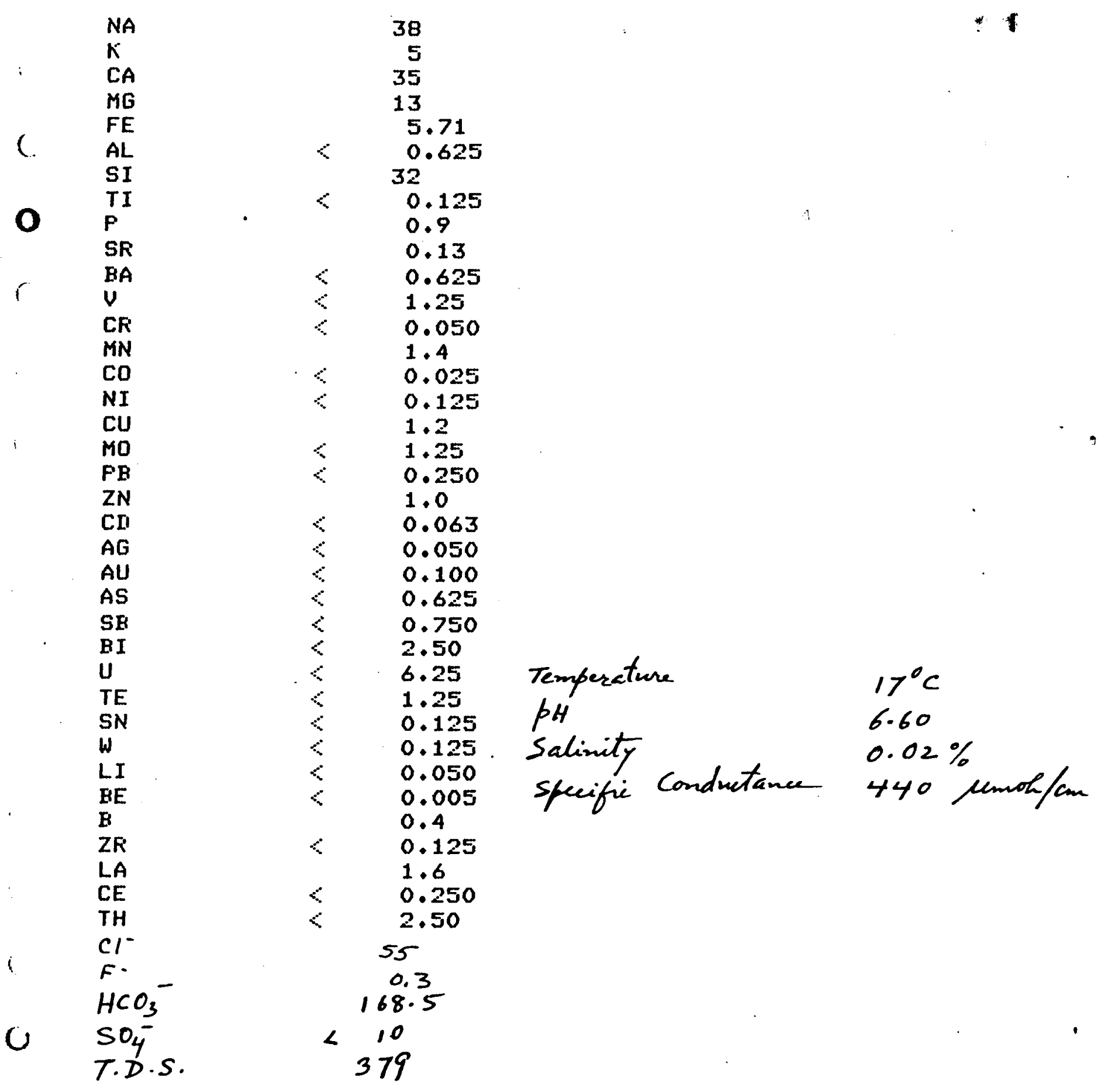

(1) corrected T.D.S. 294 
CALISTOGA SET 5

i

$124 \quad G-124-80$

$r$

ELEMENT

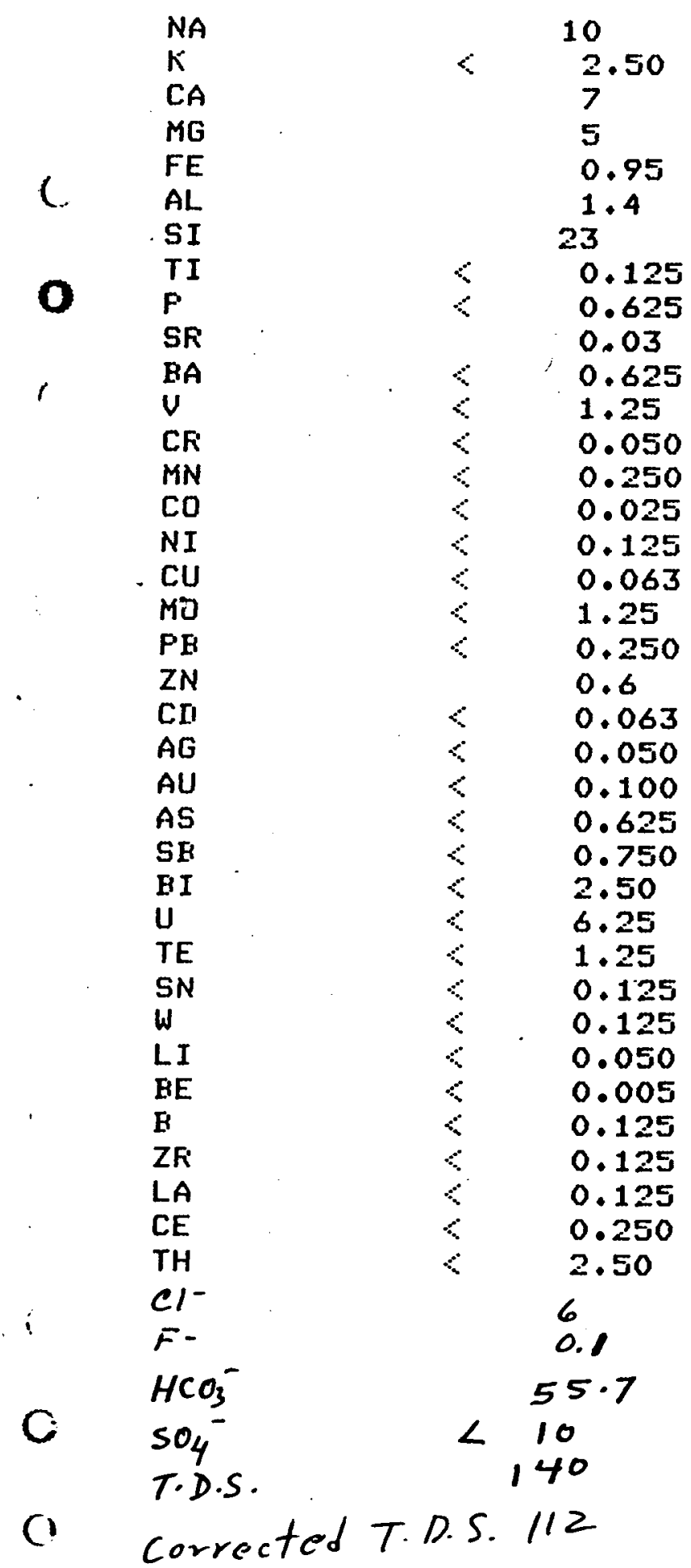

CONCENTRATION (PPM)

$\begin{array}{ll}\text { Temperature } & 17^{\circ} \mathrm{C} \\ & 6.89\end{array}$

ph

salinity

$0.01 \%$

specific Conductance 105 umish/an 
CALISTDGA SET 5

1

$$
125 \quad G-125-80
$$

$r$

ELEMENT

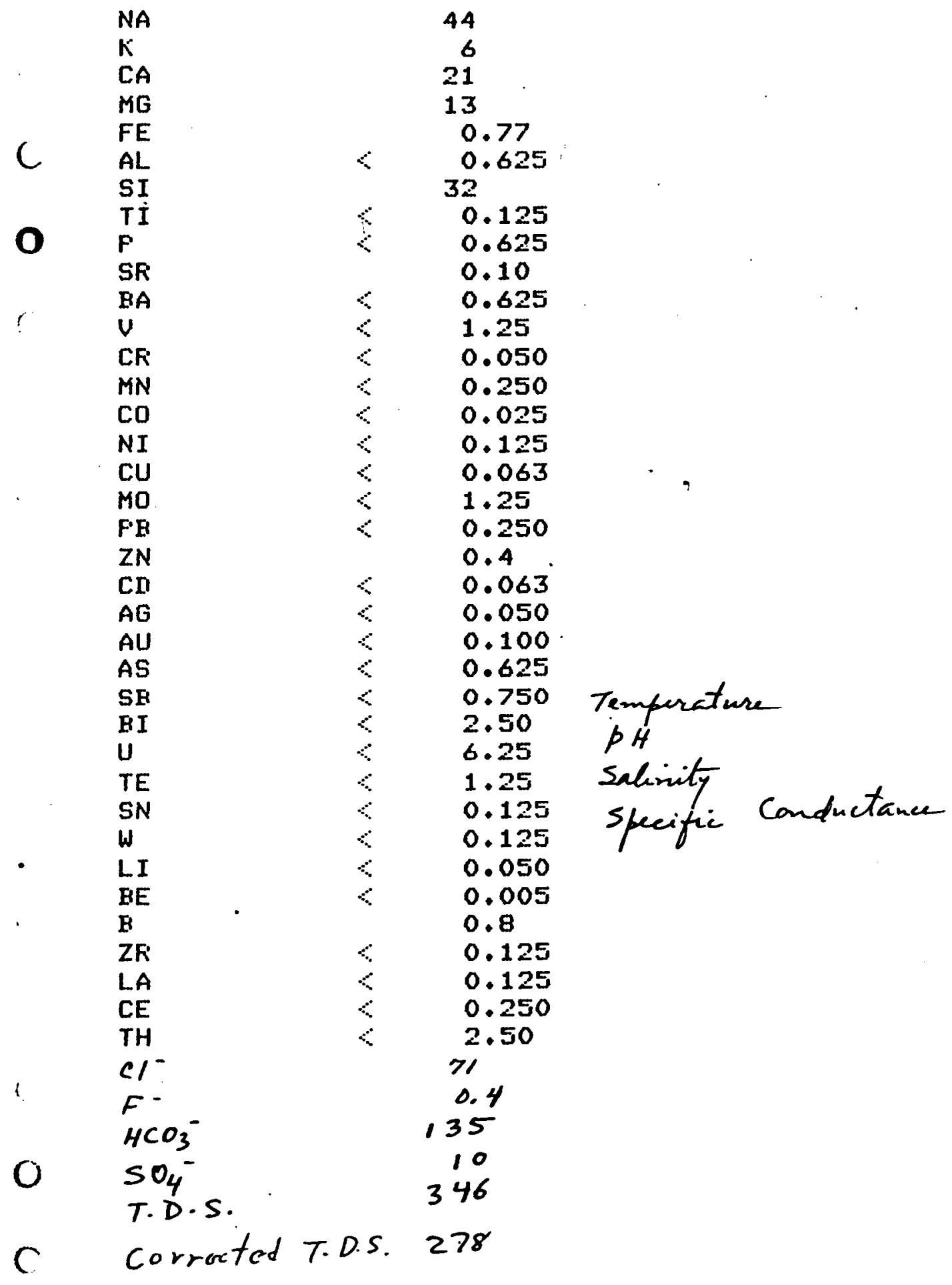

CONCENTRATION (FAM)

$17^{\circ} \mathrm{C}$

6.12

$0.03 \%$

$430 \mathrm{mmoh} / \mathrm{cm}$ 
CALISTOGA SET 5

$126 \quad G-126-80$

ELEMENT

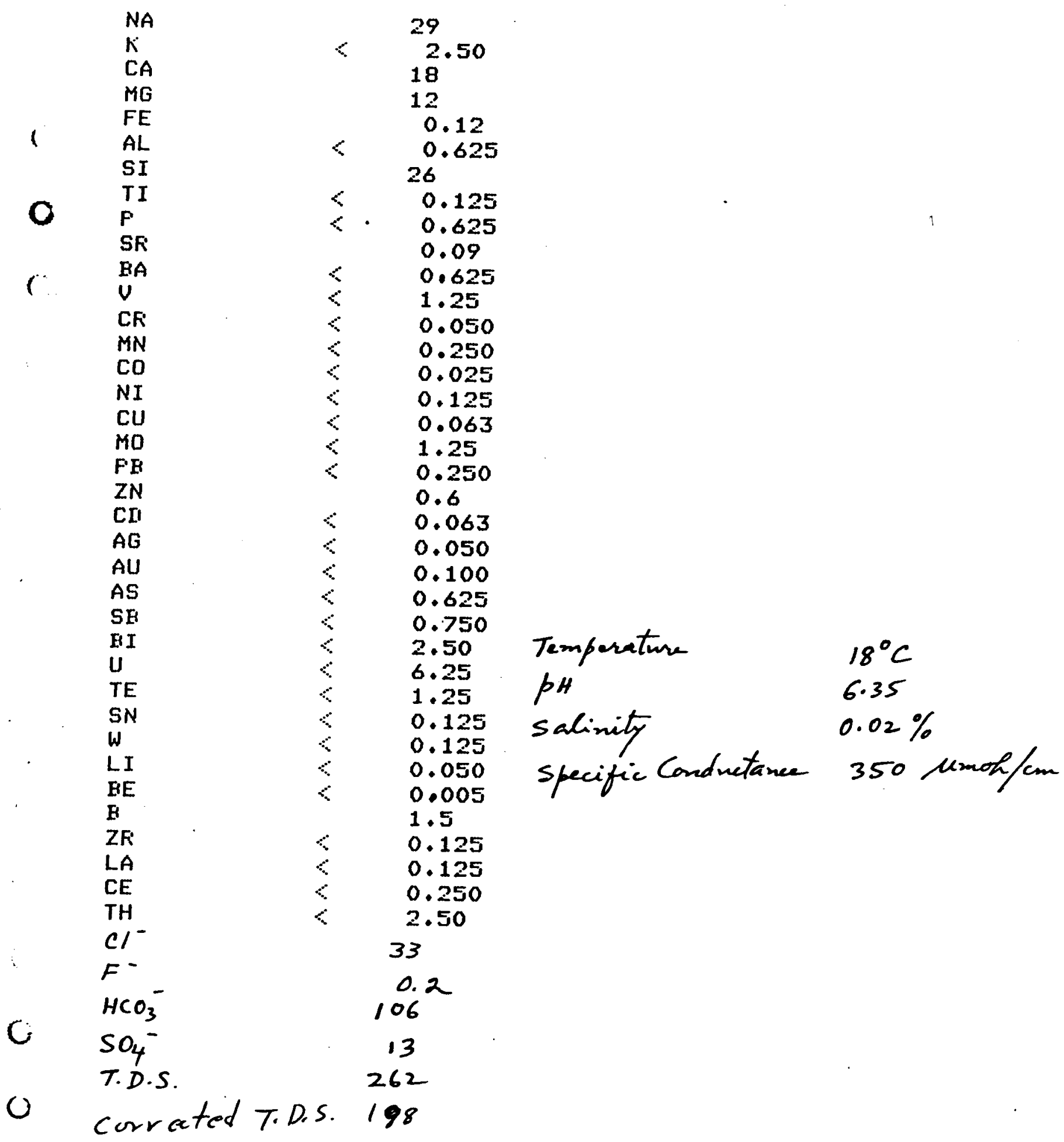


$127 \quad G-127-80$

( ELEMENT

\section{CONCENTRATION (FPM)}

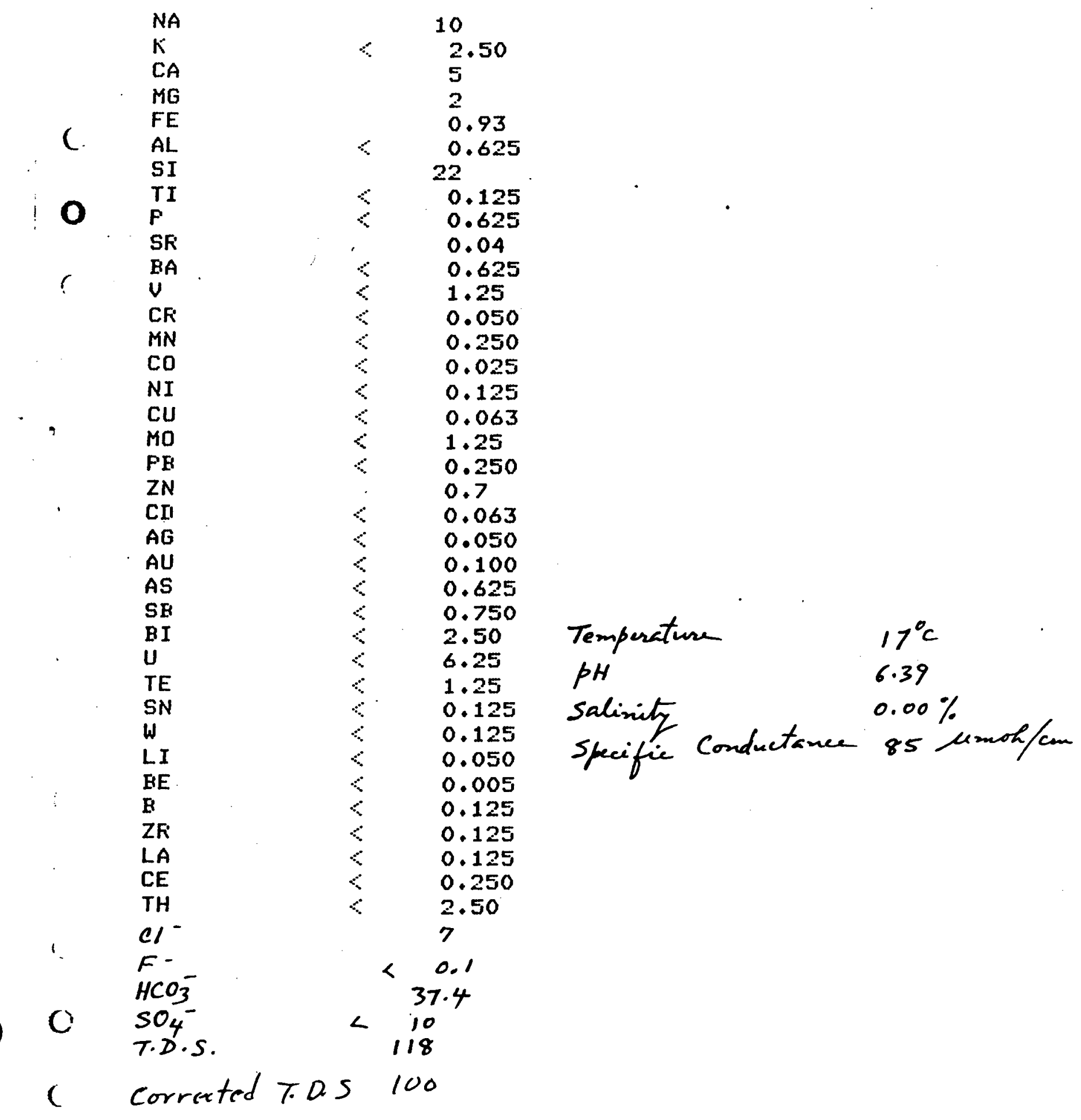




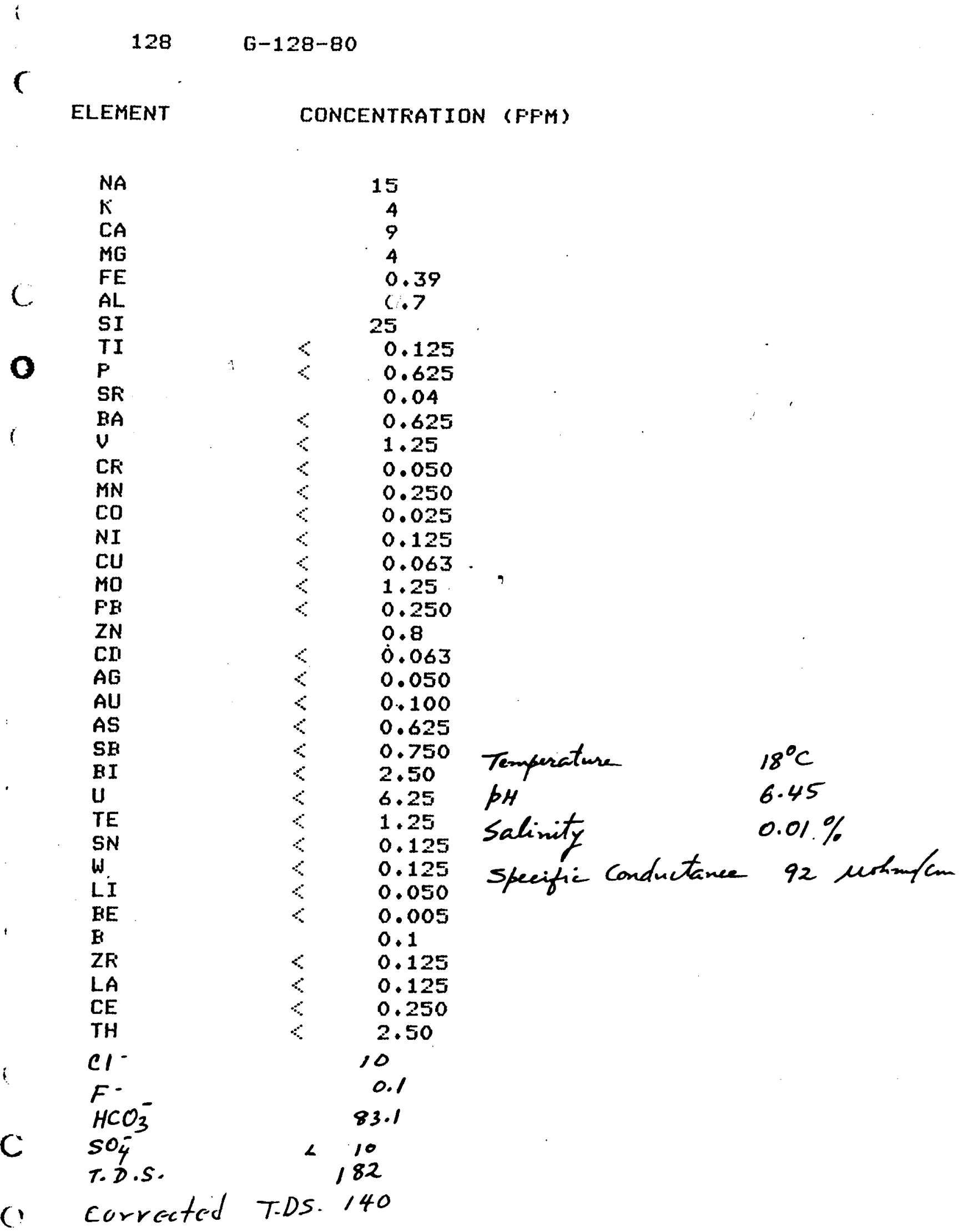


CALISTOGA SET 5

129 G-129-80

c

ELEMENT CONCENTRATION (FFM)

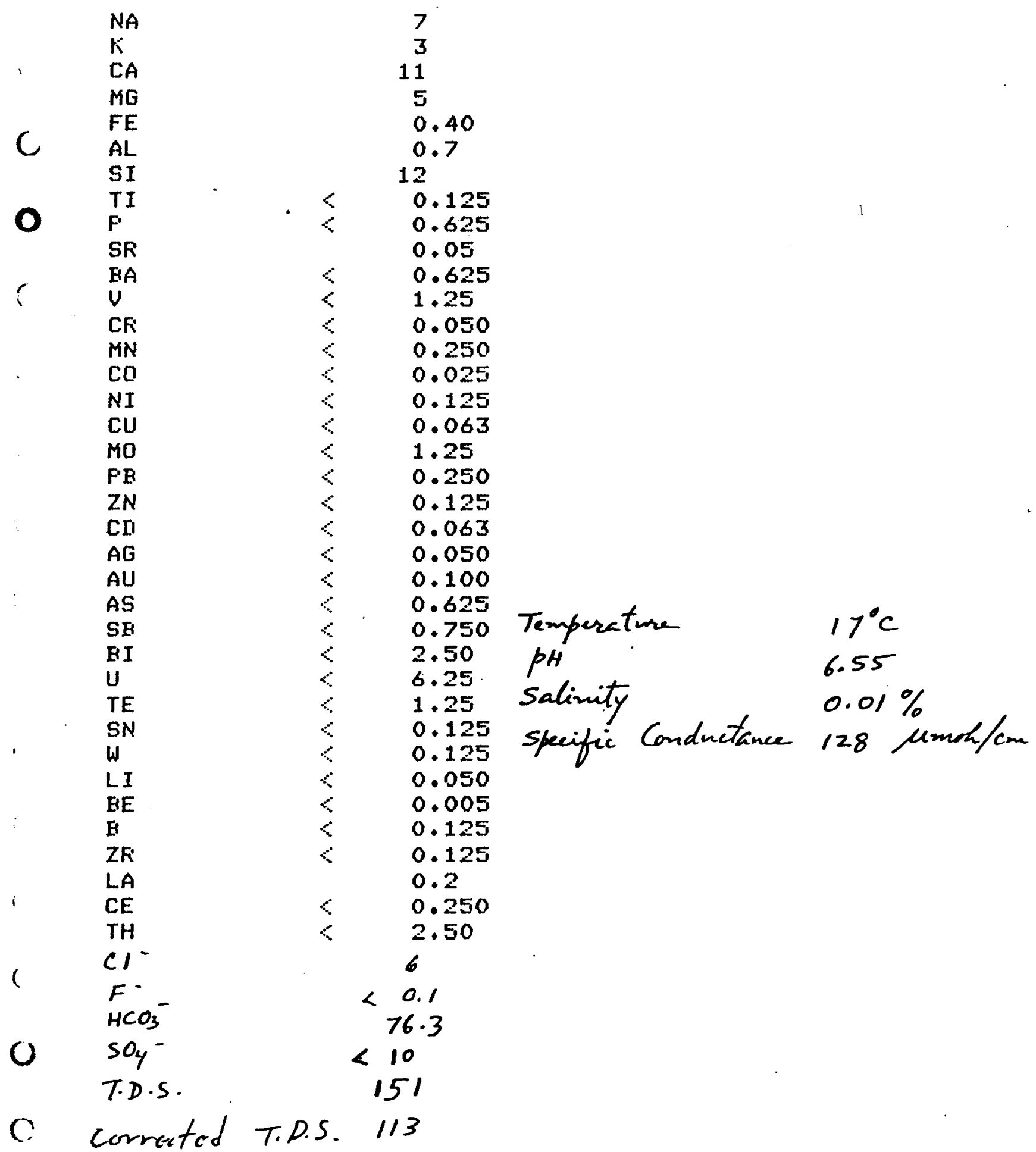


CALISTOGA SET 5

$130 \quad 6-130-80$

ELEMENT CONCENTRATION (FAM)

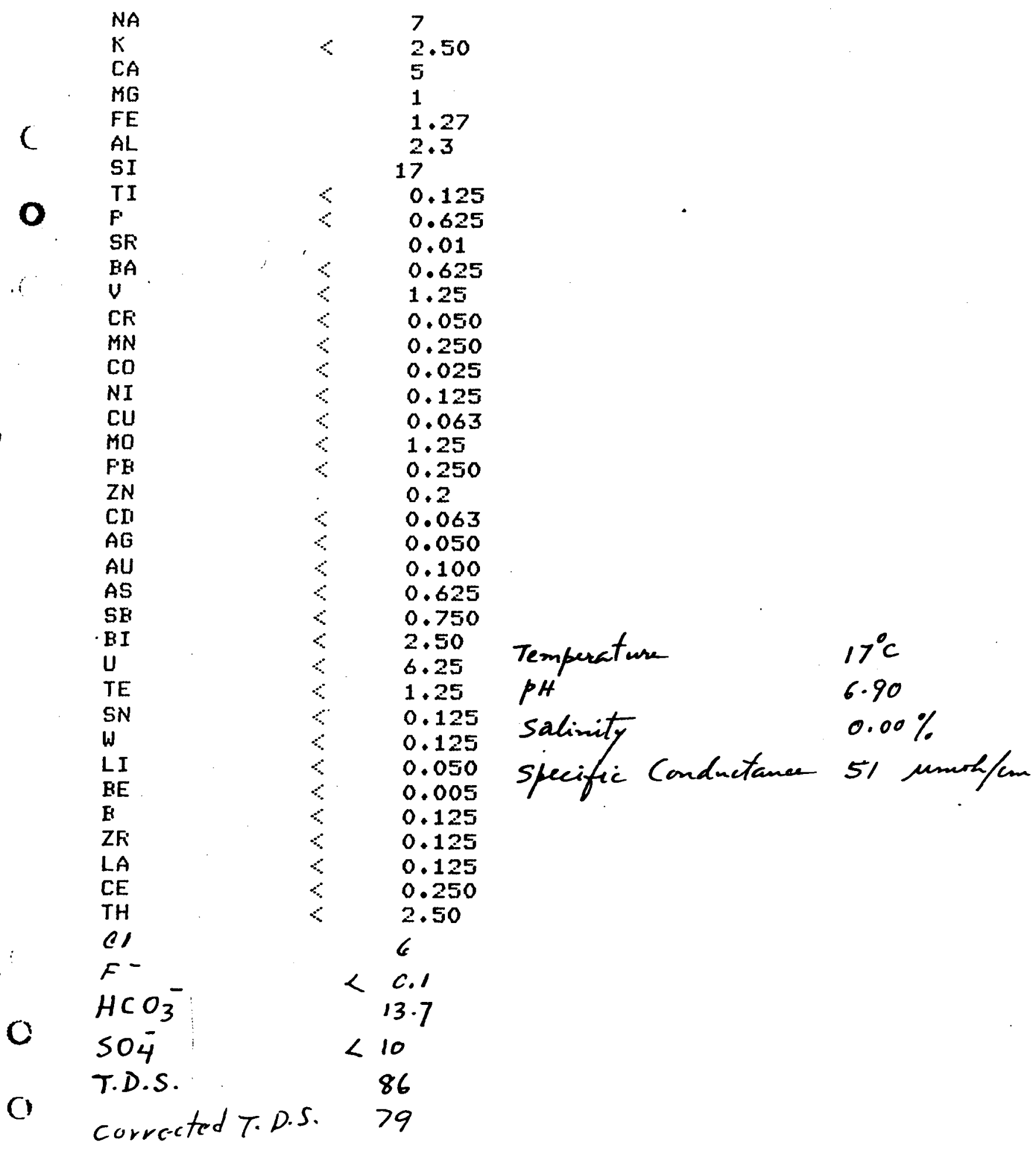


CALISTOGA SET 5

$131 \quad$ G-131-80

ELEMENT

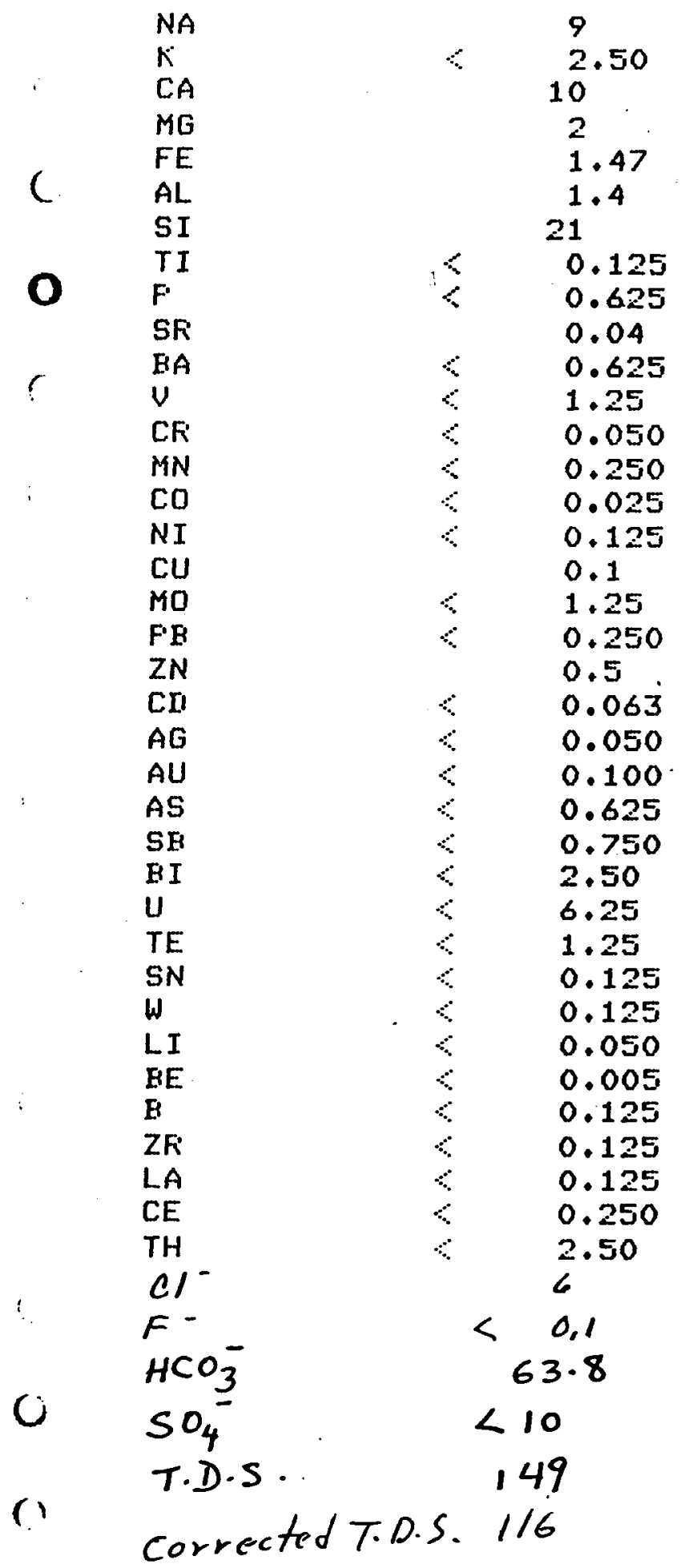

CONCENTRATION (FAM)

$\begin{array}{ll}\text { Temperature } & 18^{\circ} \mathrm{C} \\ \text { PH } & 6.45\end{array}$

salinity

$0.00 \%$

specific conductance $q / \mu m o h / c m$ 
CALISTOGA SET 5

132 G-132-80

C

ELEMENT

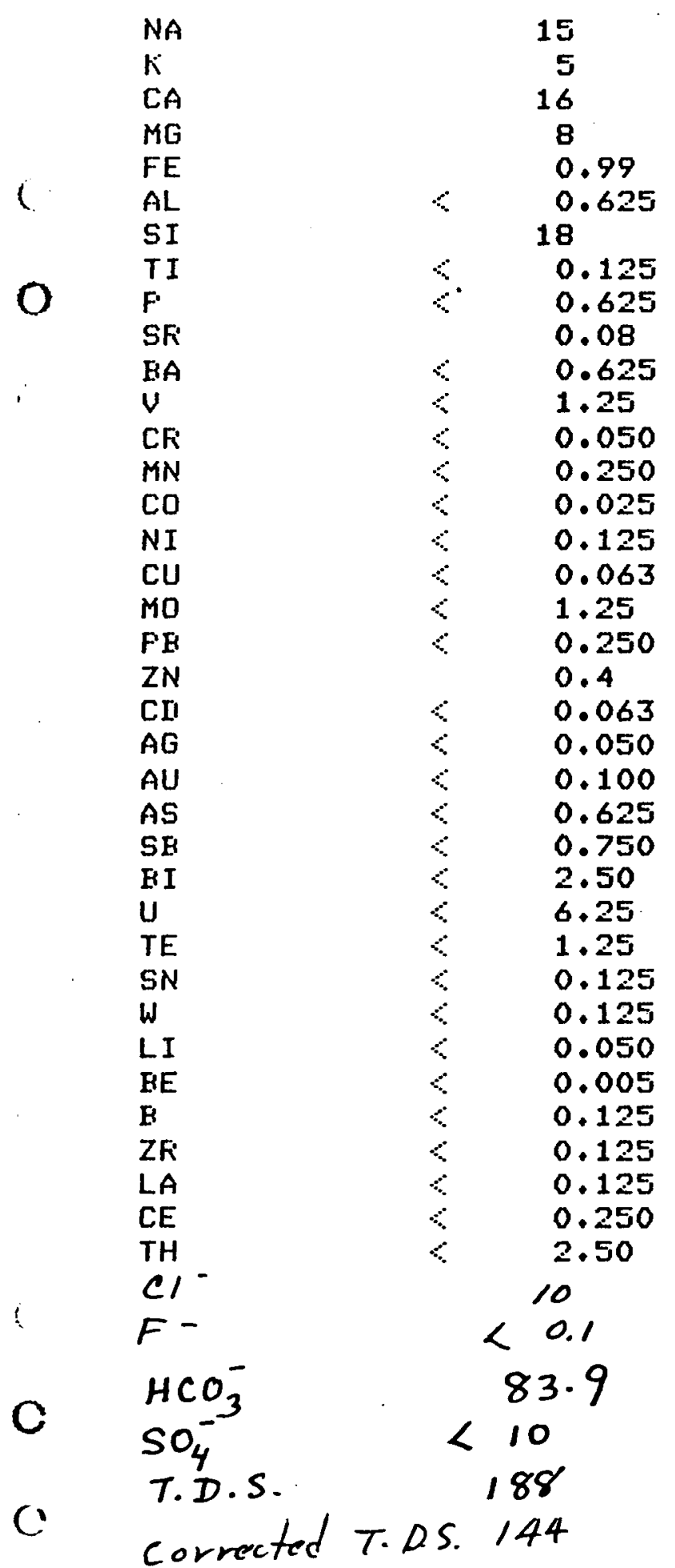

CONCENTRATION (FFM)

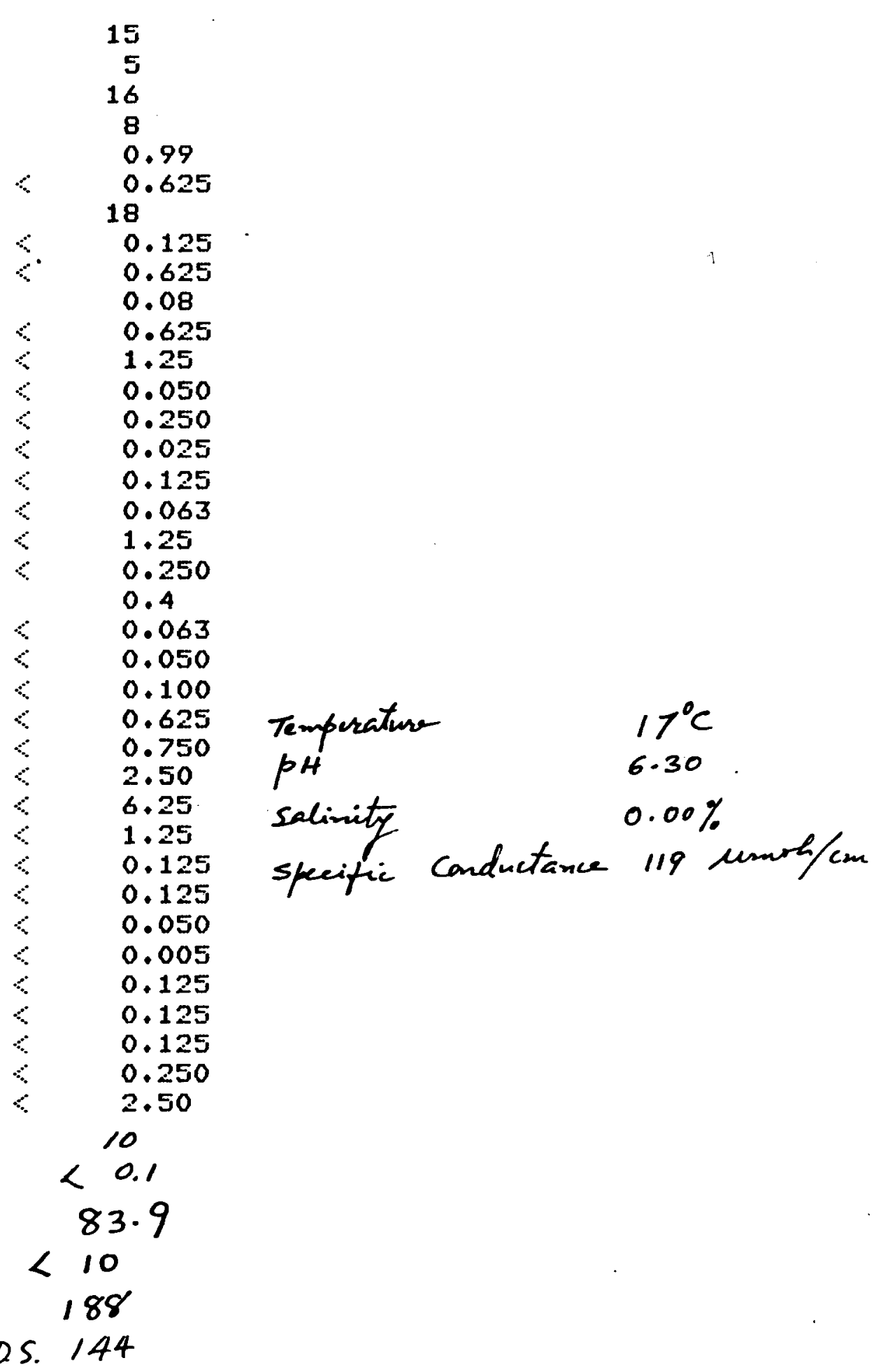


CALISTOGA SET 5

133

G-133-80

r

ELEMENT

$N A$
$K$
$C A$
$M G$
$F E$
$A L$
$S I$
$T I$
$F$

SF

HA

U

CF

MN

$\mathrm{CO}$

$N I$

$\mathrm{CU}$

MO

FB

ZN

CI

$A G$

$A U^{\circ}$

AS

SE

EI

U

TE

SN

W

L.I

BE

B

ZF

LA

CE.

$\mathrm{TH}$

$\mathrm{Cl}^{-}$

$\mathrm{F}^{-}$

$\mathrm{HCO}_{3}^{-}$

$\mathrm{SO}_{4}^{-}$

$\begin{array}{lr}\mathrm{SO}_{4} & 152 \\ \text { T.D.S. } & 129\end{array}$

CONCENTRATION (FFM)

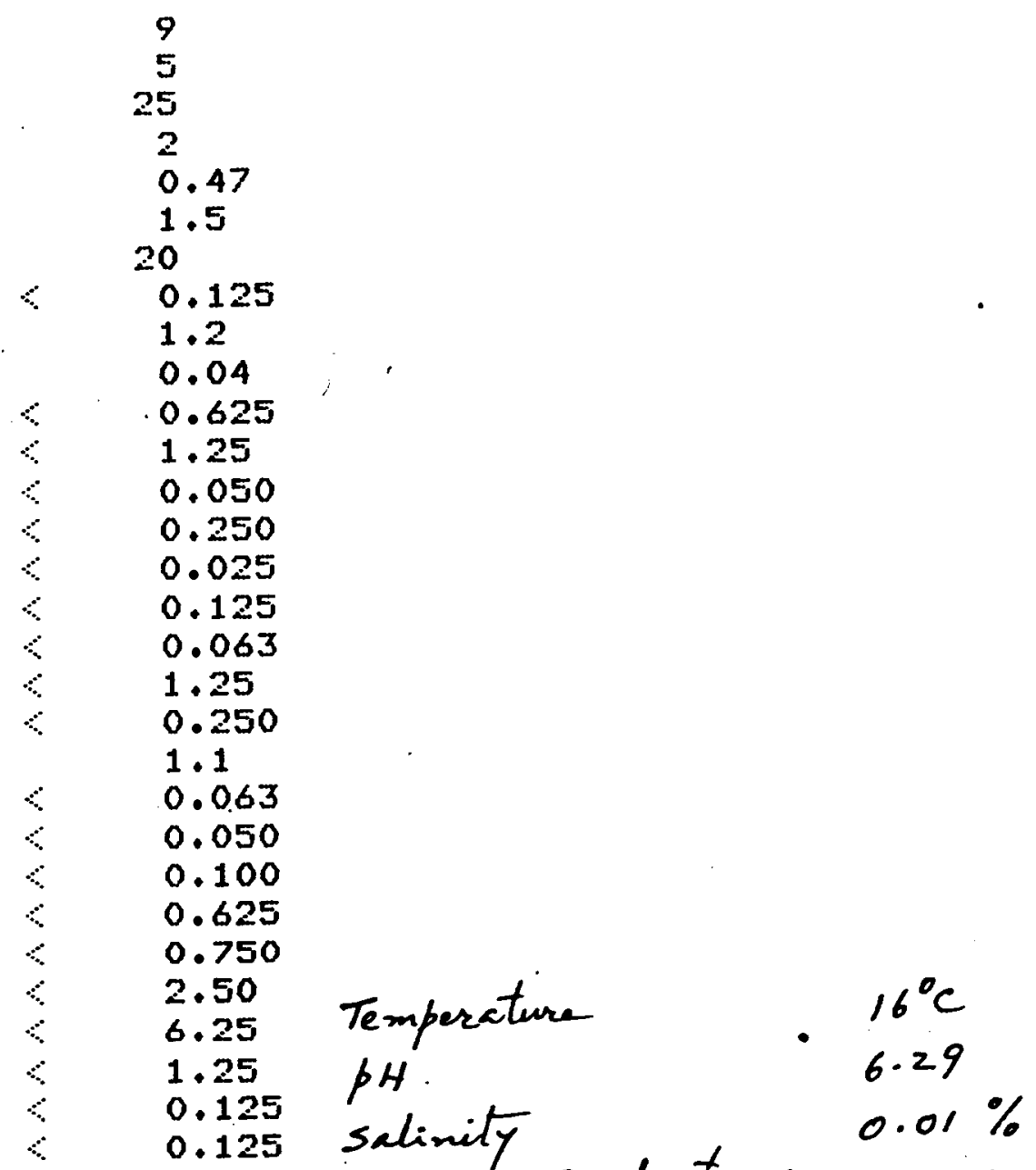

specific Conductance 82 umelf 
CALISTOGA SET S

$$
134 \quad G-134-80
$$

r

ELEMENT

NA

CA

$M G$

FE

AL

SI

TI

F

SR

BA

U

CF

$M N$

CO

$N I$

CU

MO

$F B$

ZN

CII

$A G$

AU

AS

SE

BI

$U$

TE

SN

W

LI

BE

H

ZF

LA

CE

$\mathrm{TH}$

c

$\mathrm{Cl}^{-}$

$\mathrm{HCO}_{3}^{-}$

$\mathrm{SO}_{4}^{-}$

$\begin{array}{ll}\mathrm{SO}_{4} & 199 \\ \text { T.D.S. } & 459 \\ \text { Corrected T.D.S. } & 328\end{array}$

1.0

$\therefore \quad 0.250$
$\therefore \quad 2.50$

13

0.6

257

19

CONCENTFATION (PFM)

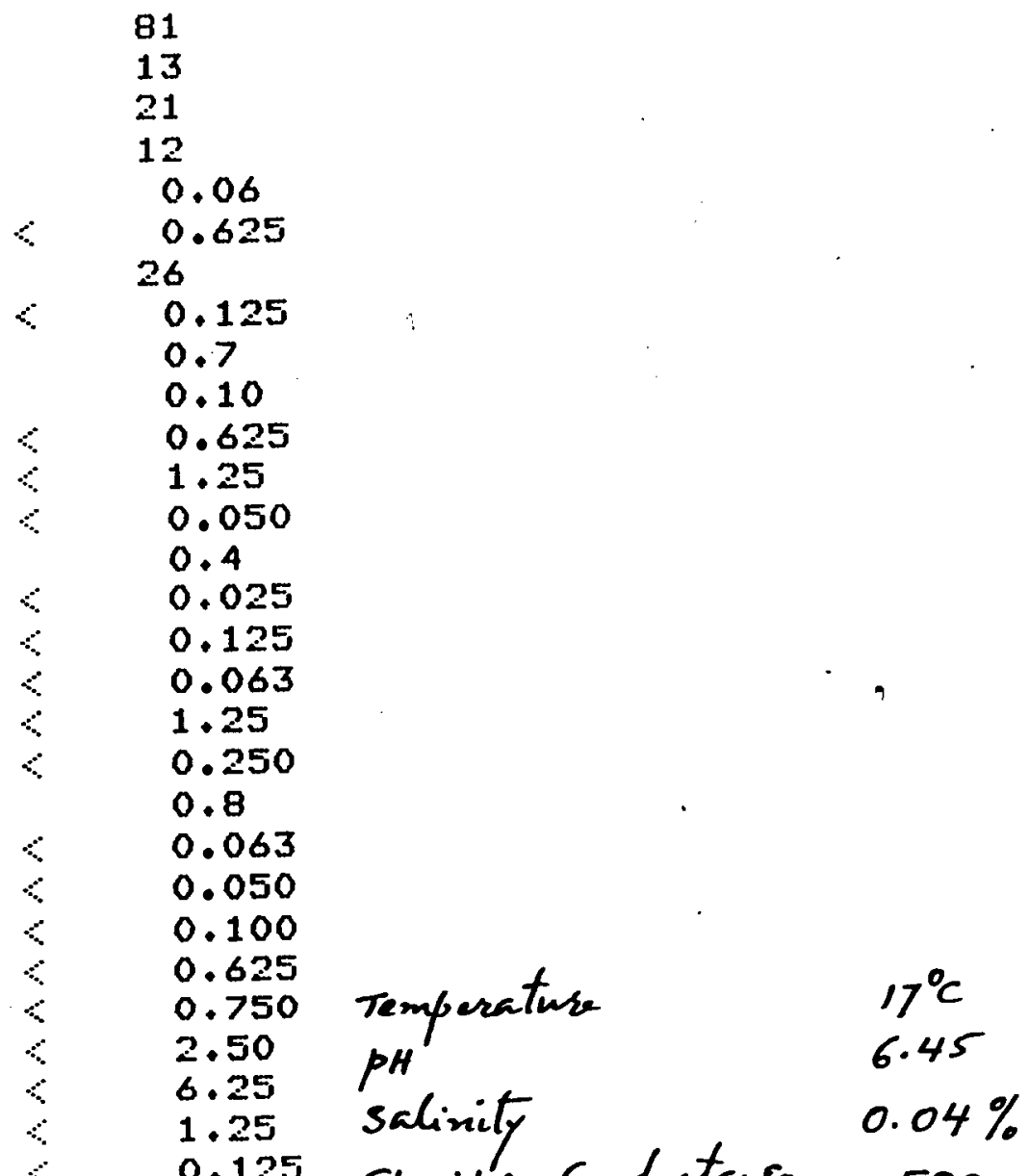

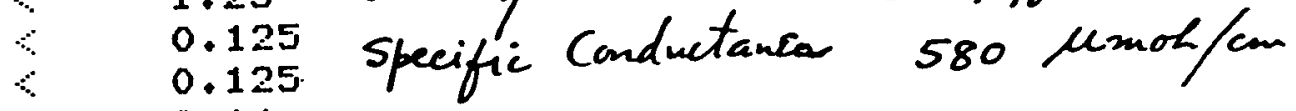

0.14
0.005

$<\quad 0.125$

0.125

$17^{\circ} \mathrm{C}$

6.45

$0.04 \%$ 
CALISTOGA SET 5

$135 \quad G-135-80$

ELEMENT

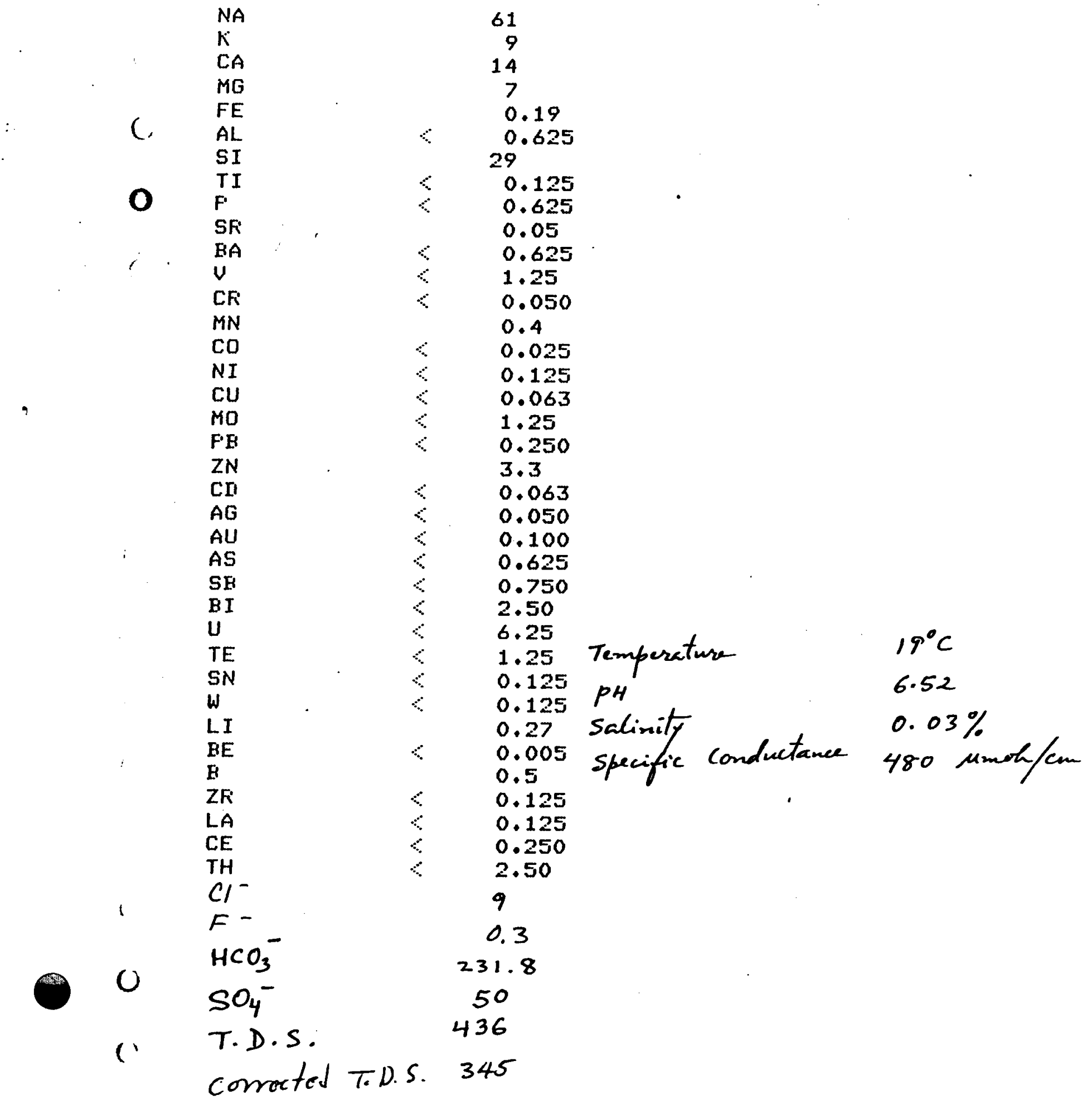


CALISTOGA SET 5

$136 \quad G-136-80$

(

ELEMENT

NA

$M G$

FE

AL

SI

TI

O F

$5 F^{\circ}$

BA

$\checkmark$

CF

MN

CO

$N I$

CU

$M O$

FE

ZN

CI

$A G$

$A U$

AS

SB

BI

U

TE

SN

W

LI

BE

B

ZR

LA

CE

TH

$\therefore \quad \mathrm{Cl}^{\circ}$

$\mathrm{HCO}_{3}^{-}$

$\mathrm{C} \quad \mathrm{SO}_{4}^{-}$

T.D.S.
CONCENTRATION (FEM)

5
13
11

0.20

$\therefore \quad 0.625$

8
$8 \quad 0.125$

$\therefore \quad 0.625$

0.07

$\therefore \quad 0.625$

1.25

$<\quad 0.050$

$\therefore \quad 0.250$

$\therefore \quad 0.025$

$<\quad 0.063$

$\therefore \quad 1.25$

$\begin{array}{ll} & 1.7 \\ -\quad 0.063\end{array}$

$<\quad 0.063$
$<\quad 0.050$

0.100
$0 \quad 0.625$

$\therefore \quad 0.625$

$\begin{array}{ll}0.750 \\ 2 & 2.50\end{array}$

$6 \quad 6.25$

$\therefore \quad 1.25$

$<\quad 0.125 \quad P H$

0.125

$\begin{array}{ll}\text { Salinity } & 0.01 \% \\ \text { specific conductance } 180 \mathrm{mon} / \mathrm{cm}\end{array}$

0.005

specific conductance $180 \mathrm{umoh} / \mathrm{cm}$

0.125

$17^{\circ} \mathrm{C}$

5.80

$0.01 \%$
$180 \mu$ Mnoh/can

0.125

0.125

0.250

2.50

7

0.1

112.1

45

226

C corrected T.D.S. 169 
CALISTOGA SET 5

$137 \quad G-137-80$

r.

ELEMENT

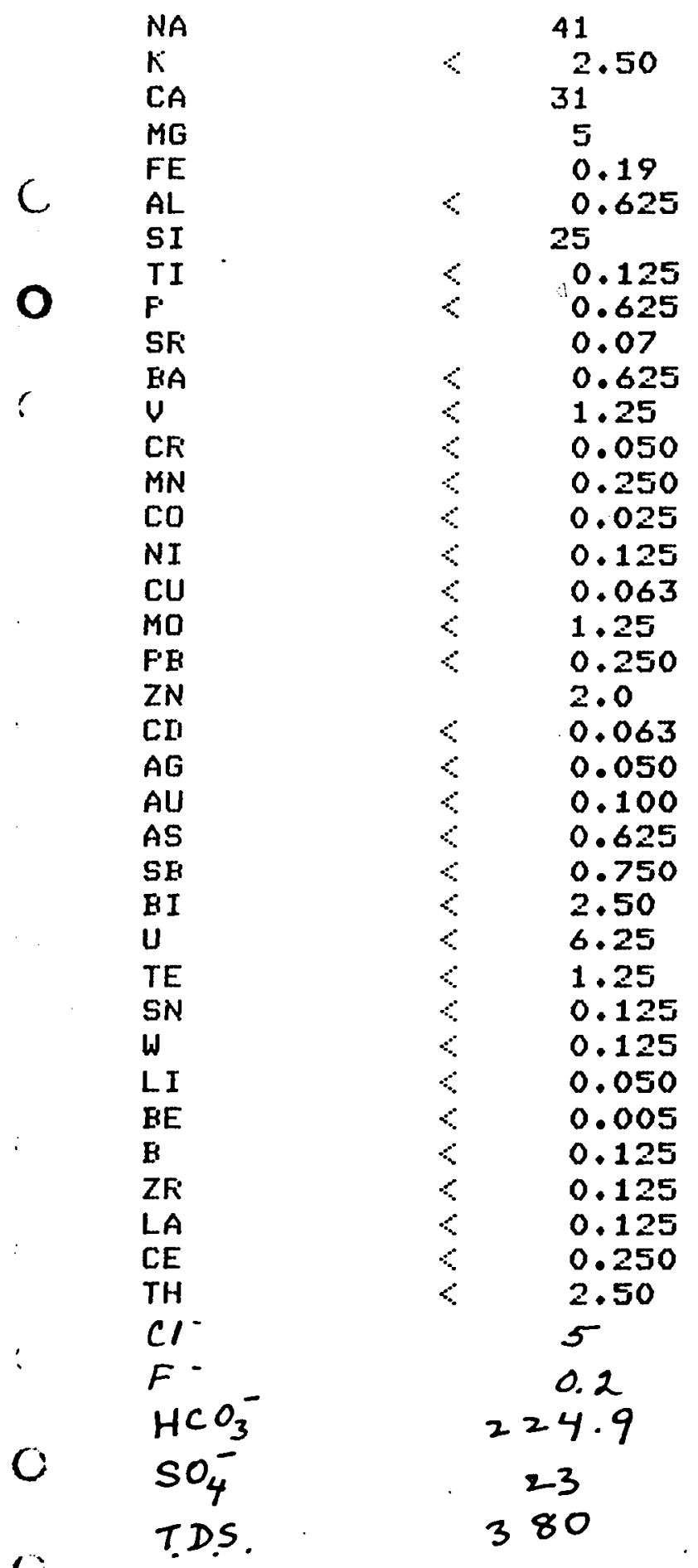

CONCENTRATION (FFM)

Temperature

PH

$\begin{array}{ll}\text { Salimity } & 0.01 \% \\ \text { Specific Conductance } & 282 \mathrm{umoli} / \mathrm{con}\end{array}$ $27^{\circ} \mathrm{C}$

5.85

2.82 unolifom

Corrocted T.D.S. 266 
CALISTOGA SET 5

$138 \quad G-138-80$

ELEMENT CONCENTRATION (FEM)

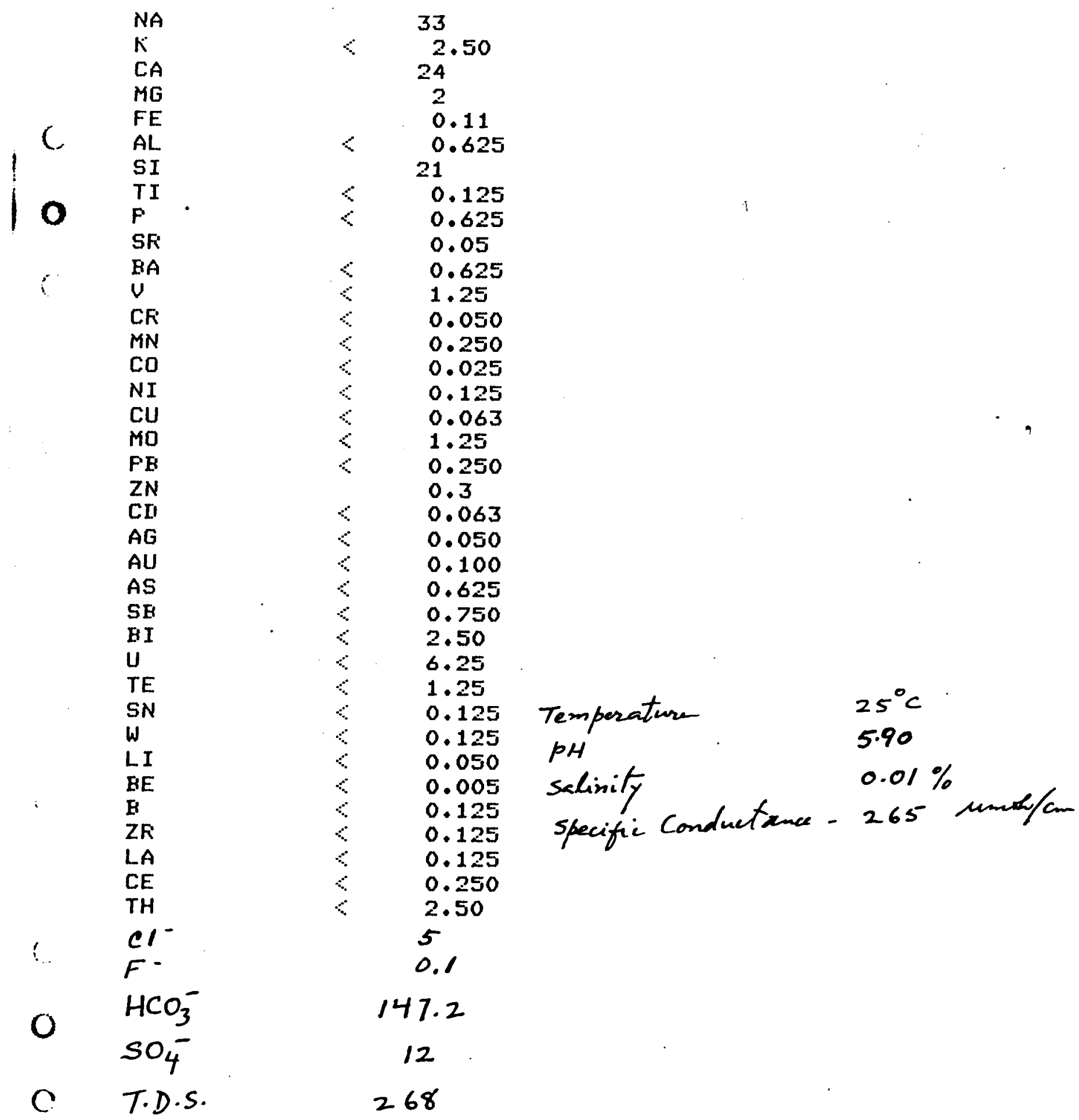

Corrected T.D.S. 193 
CALISTOGA. SET 6.

$139 \quad \mathrm{G}-139-80$

ELEMENT

NA

$K$

CA

FE

AL

SI

$\dot{T}$

SFi

BA<smiles>[TeH]</smiles>

MN

CO

NI

CU

$P B$

ZN

CII

$A G$

$A U$

AS

SB

EI

U

TE

SN

W

BE

E

ZF

LA

CE

TH

$F$

$\mathrm{HCO}_{3}^{-}$

$\mathrm{SO}_{4}$

T.D.S.

corrected T.D.S. 123

$<\begin{aligned} & 15 \\ & 153\end{aligned}$
CONCENTFATION (FFM)

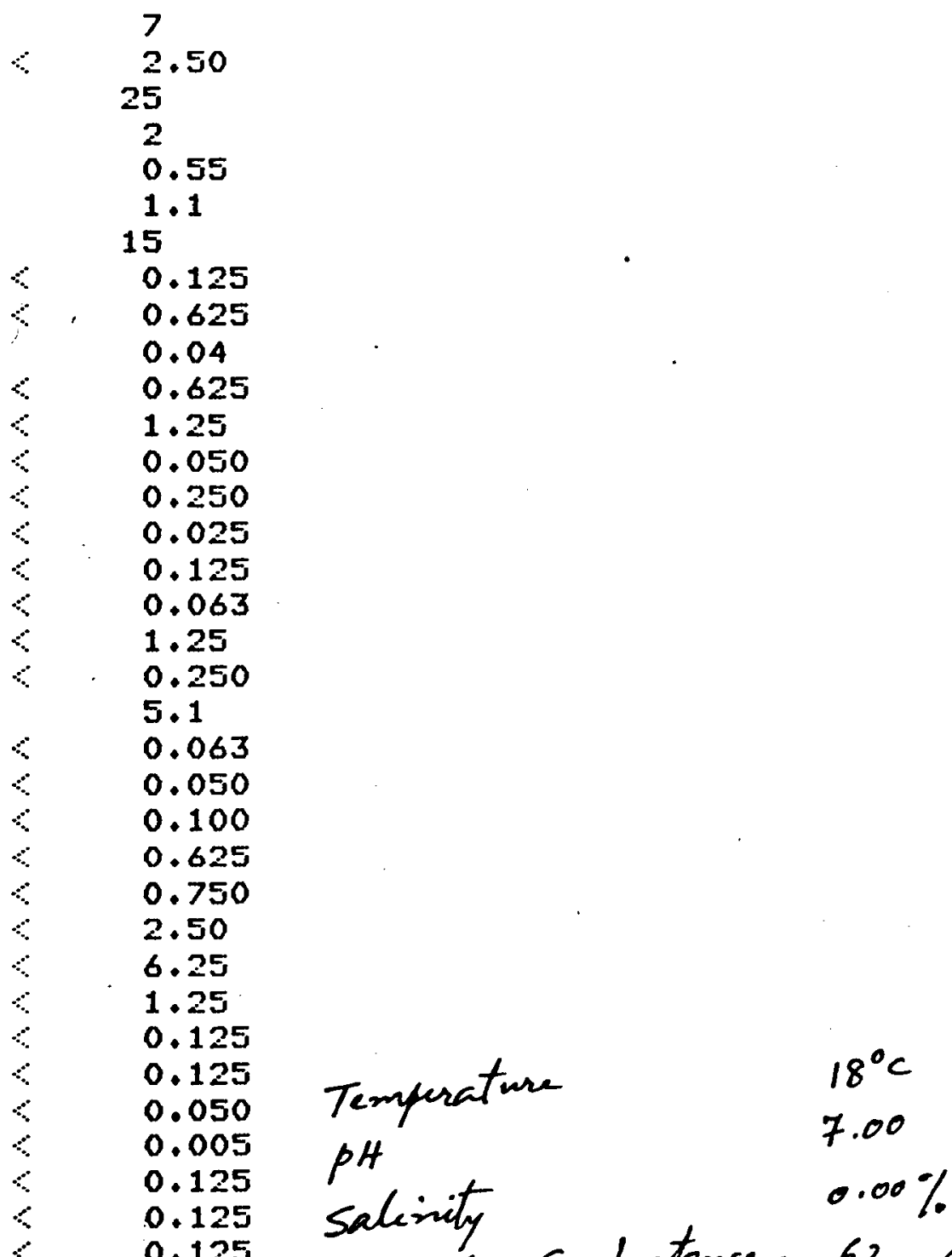

$\therefore \quad \begin{aligned} & 0.125 \\ & 0.250 \\ & 2.50\end{aligned}$ specific Conductance 62 umot/ce

$<\quad 0.1$

60.2 
CALISTOGA SET 6

c

$140 . G-140-80$

ELEMENT

CONCENTRATION (FEM)

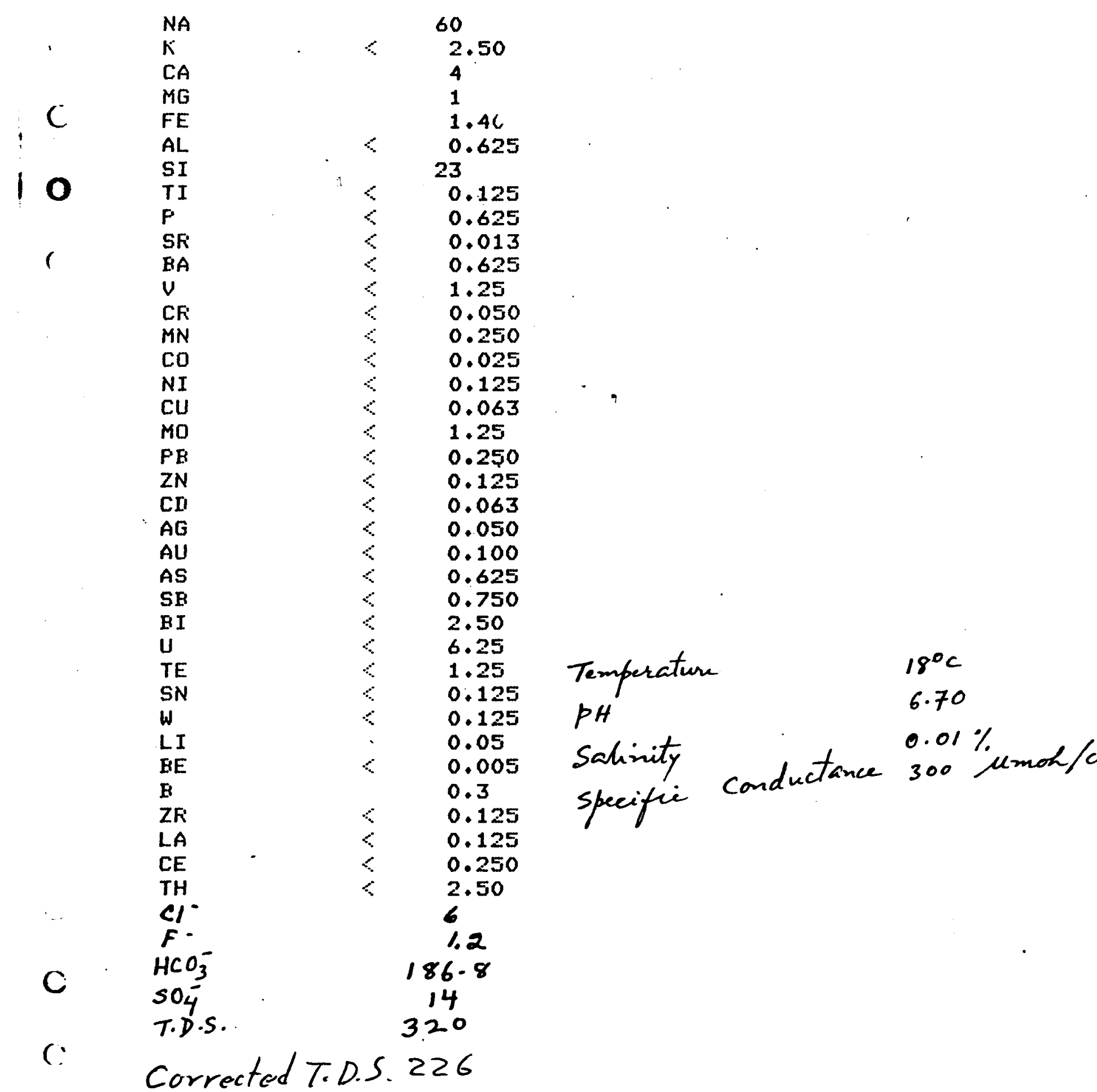


CALISTOGA SET 6

141 G-141-80

ELEMENT

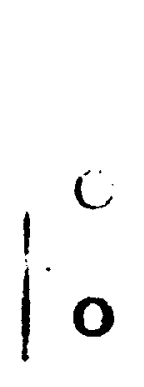

$N A$
$K$
$C A$
$M G$
$F E$
$A L$
$S I$
$T I$

$F$

$$
(
$$

:

EA

V

CF i

$M N$

CO

$N I$

CU

MO

FE

ZN

CI

AG

AU

AS

SE

BI

$U$

TE

SN

W

LI

HE

B

ZR

LA

CE

TH

CI.

$F-$

?

c

$\mathrm{HCO}_{3}^{-}$

$\mathrm{SO}_{4}^{-}$

$C^{\prime}$

CONCENTRATION (PPM)

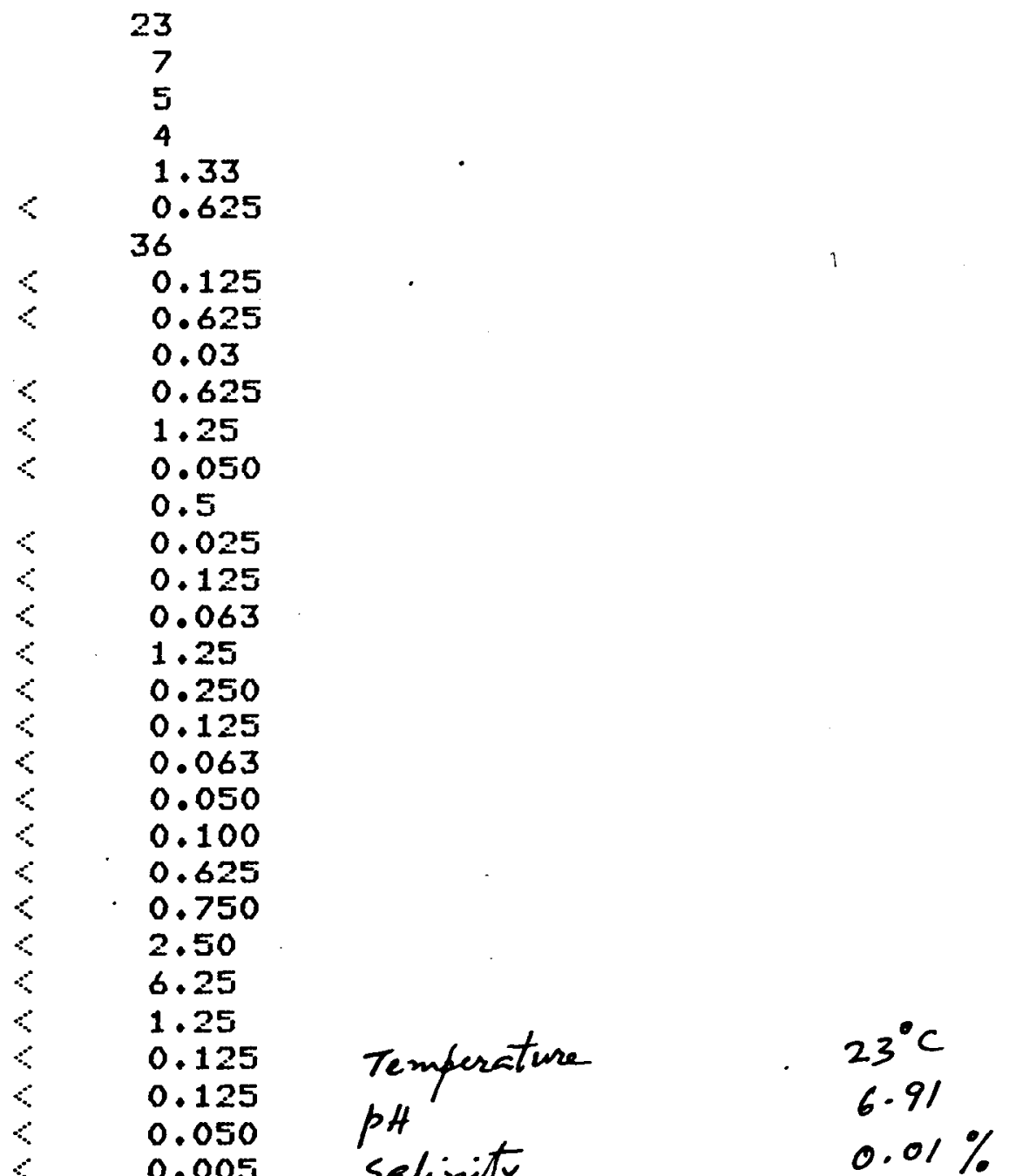

salinity

specific Conductance 118 umoh/an
0.125

80.125

$<\quad 0.125$

$<\quad 2.50$

6.3

127

$<10$

240

Corrected T.D.S. 176 
CAL ISTUGA SET 6

C $142 \quad$ G-142-80

ELEMENT CONCENTRATION (FAM)

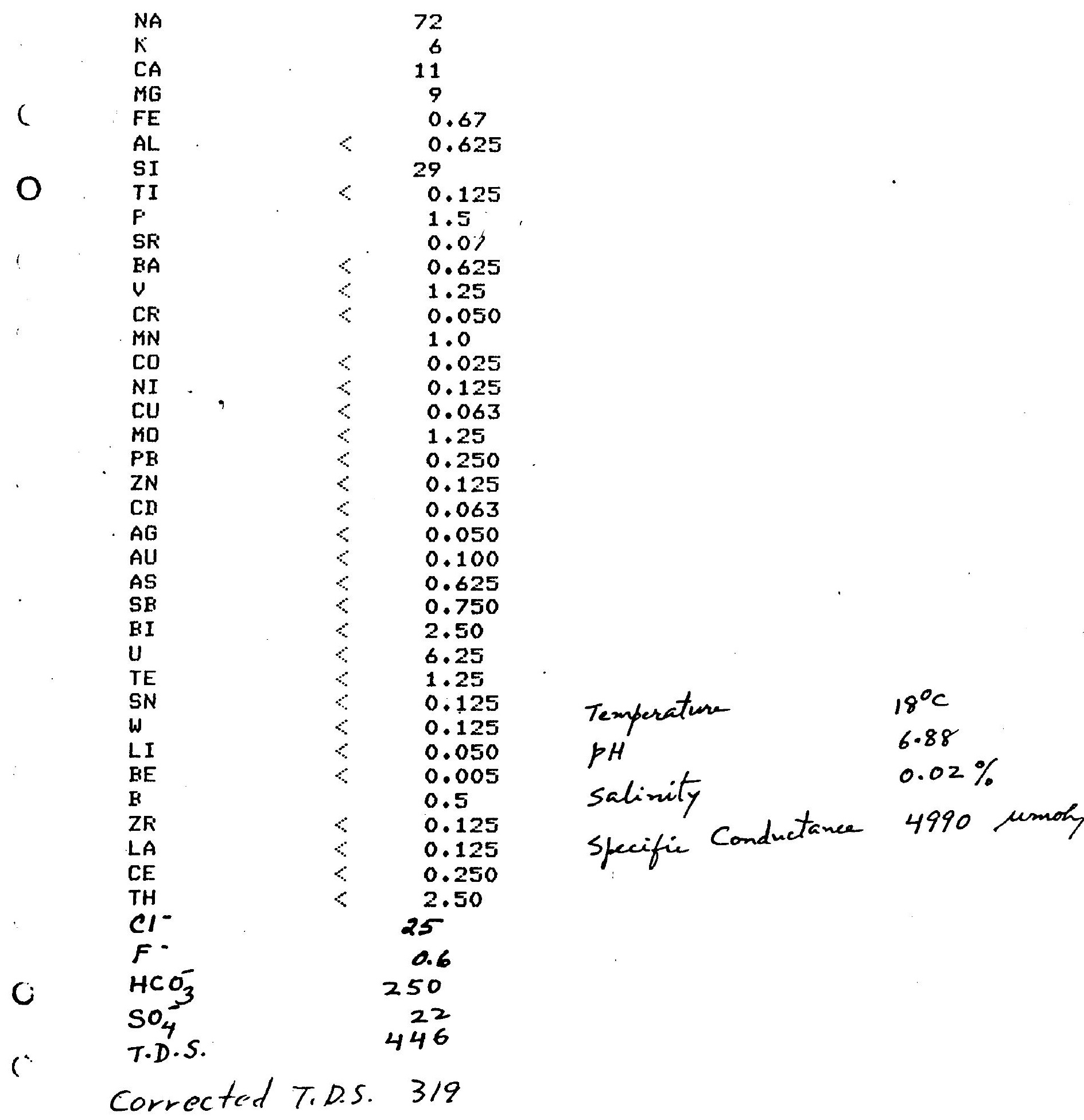




\section{CALISTOGA SET 6}

1

r

$$
143 \quad G-143-80
$$

\section{ELEMENT}

\begin{tabular}{|c|c|}
\hline \multirow{3}{*}{ ? } & $N A$ \\
\hline & $K$ \\
\hline & $C A$ \\
\hline \multirow{3}{*}{ C } & $M G$ \\
\hline & FE \\
\hline & $\begin{array}{l}\text { HL } \\
S I\end{array}$ \\
\hline \multirow[t]{2}{*}{0} & TI \\
\hline & $F_{5 F}$ \\
\hline \multirow[t]{8}{*}{ r } & $\mathrm{BA}$ \\
\hline & $v$ \\
\hline & CF \\
\hline & MN \\
\hline & $\mathrm{CO}$ \\
\hline & NI \\
\hline & $\mathrm{CU}$ \\
\hline & MO \\
\hline & $F \cdot F$ \\
\hline \multirow{10}{*}{, } & $Z N$ \\
\hline & CII \\
\hline & AG \\
\hline & $\begin{array}{l}\text { AU } \\
\text { AS }\end{array}$ \\
\hline & SE \\
\hline & BI \\
\hline & u \\
\hline & TE \\
\hline & SN \\
\hline & $\omega$ \\
\hline & LI \\
\hline & $\mathrm{EE}$ \\
\hline & B \\
\hline & $Z F$ \\
\hline & LA \\
\hline & CE \\
\hline \multirow{2}{*}{8} & TH \\
\hline & $\mathrm{F}^{-}$ \\
\hline$c^{\circ}$ & $\mathrm{HCO}_{3}^{-}$ \\
\hline & $\mathrm{SO}_{4}^{-}$ \\
\hline
\end{tabular}

CONCENTRATION (FFM)

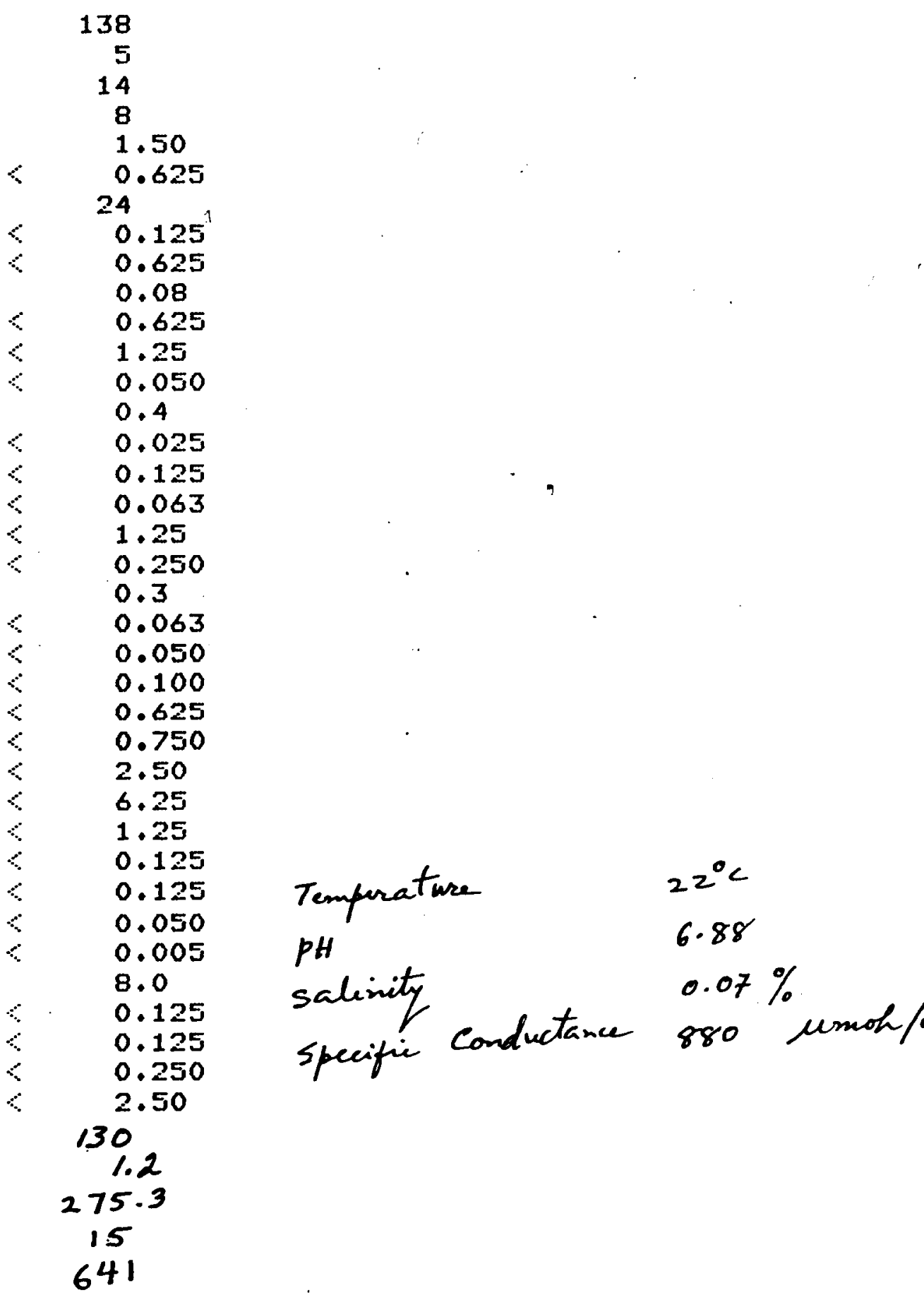

Corrected T. D.S. 501 
CALISTOOA SET O

C

144

$G-144-80$

ELEMENT

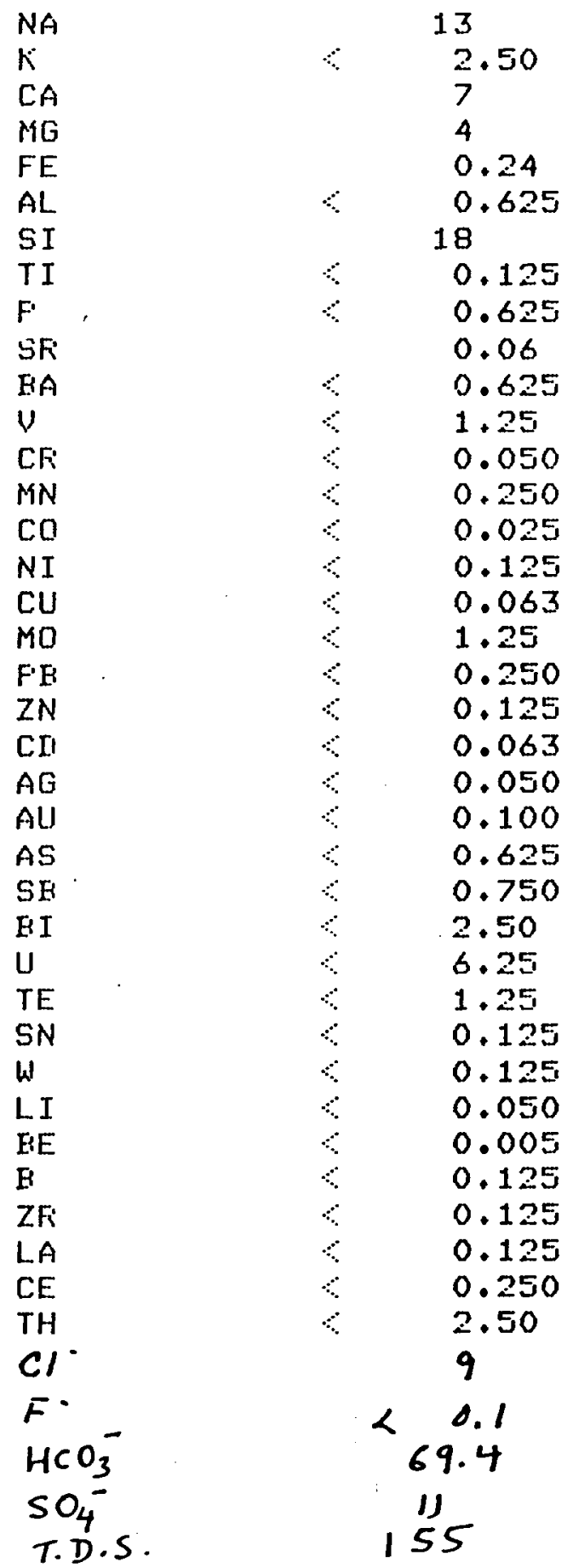

corrected T. D.S. 119 
CALIISTOGA SET 6

r. 145 G-145-80

ELEMENT

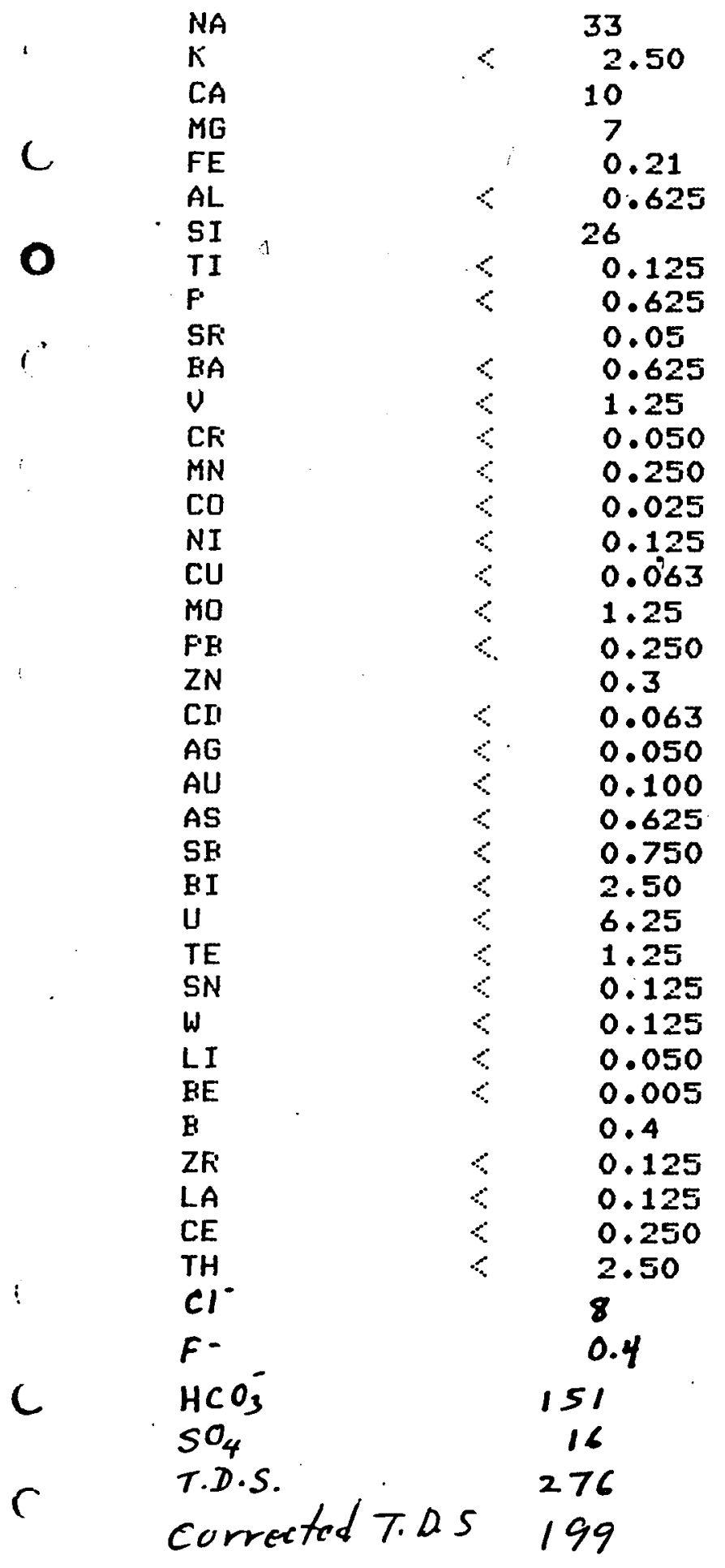

CONCENTRATION (FFM) 
CAL TSTOGA SET 6

( $146 \quad 6-146-80$

ELEMENT CONCENTFIATION (FFM)

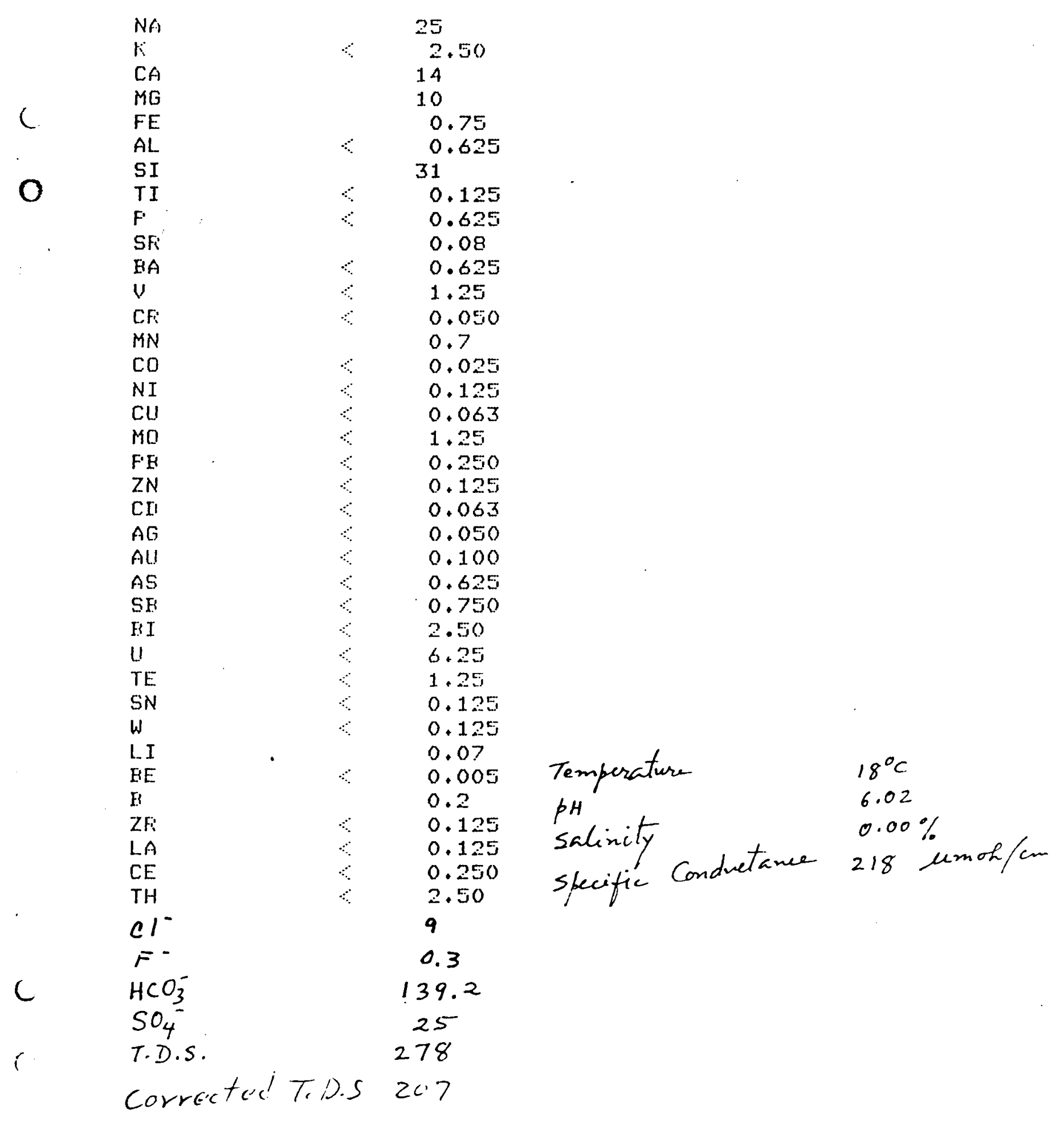


CALISTOGA SET 6

c

147

ELEMENT

NA
$K$
$C A$
$M G$
$F E$

AL

SI

TI

$F$

SF

BA

U

CF

$M N$

CO

NI

$\mathrm{CU}$

MO

FE

ZN

CII

$A G$

AU

AS

SE

BI

U

TE

SN

W

LI

EE

B

ZF

LA

CE

TH

CI.

$F^{-}$

$\mathrm{HCO}_{3}^{-}$

9

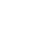

G-147-80

CONCENTRATION (FFM)

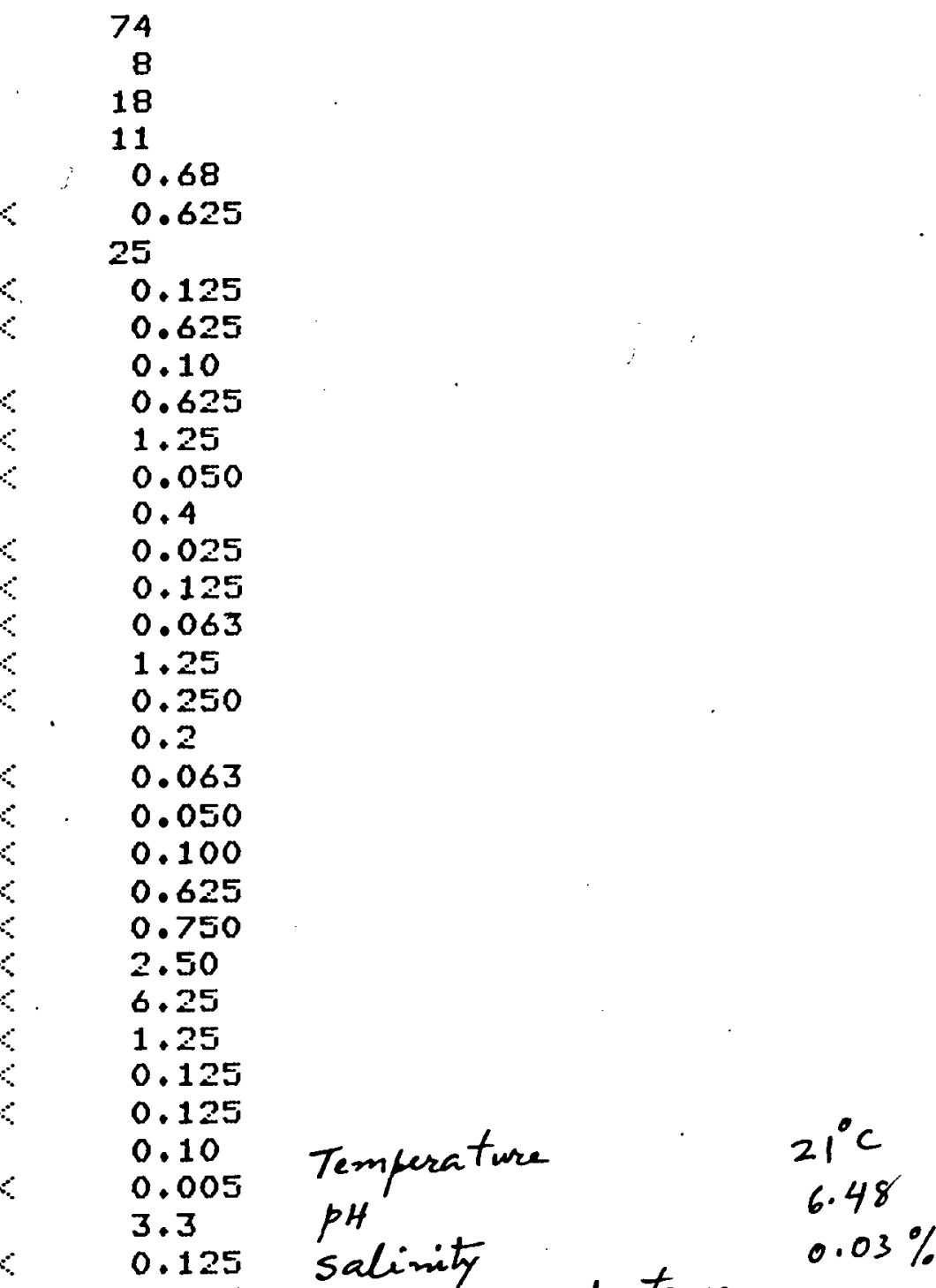

0.125 salimity conductance 550 unot/an
2.50

68

0.3

269.9

$<10$

509

T.D.S.

corrected T-DS. 372 
CALISTTOGA SET 6

$r$

148

ELEMENT

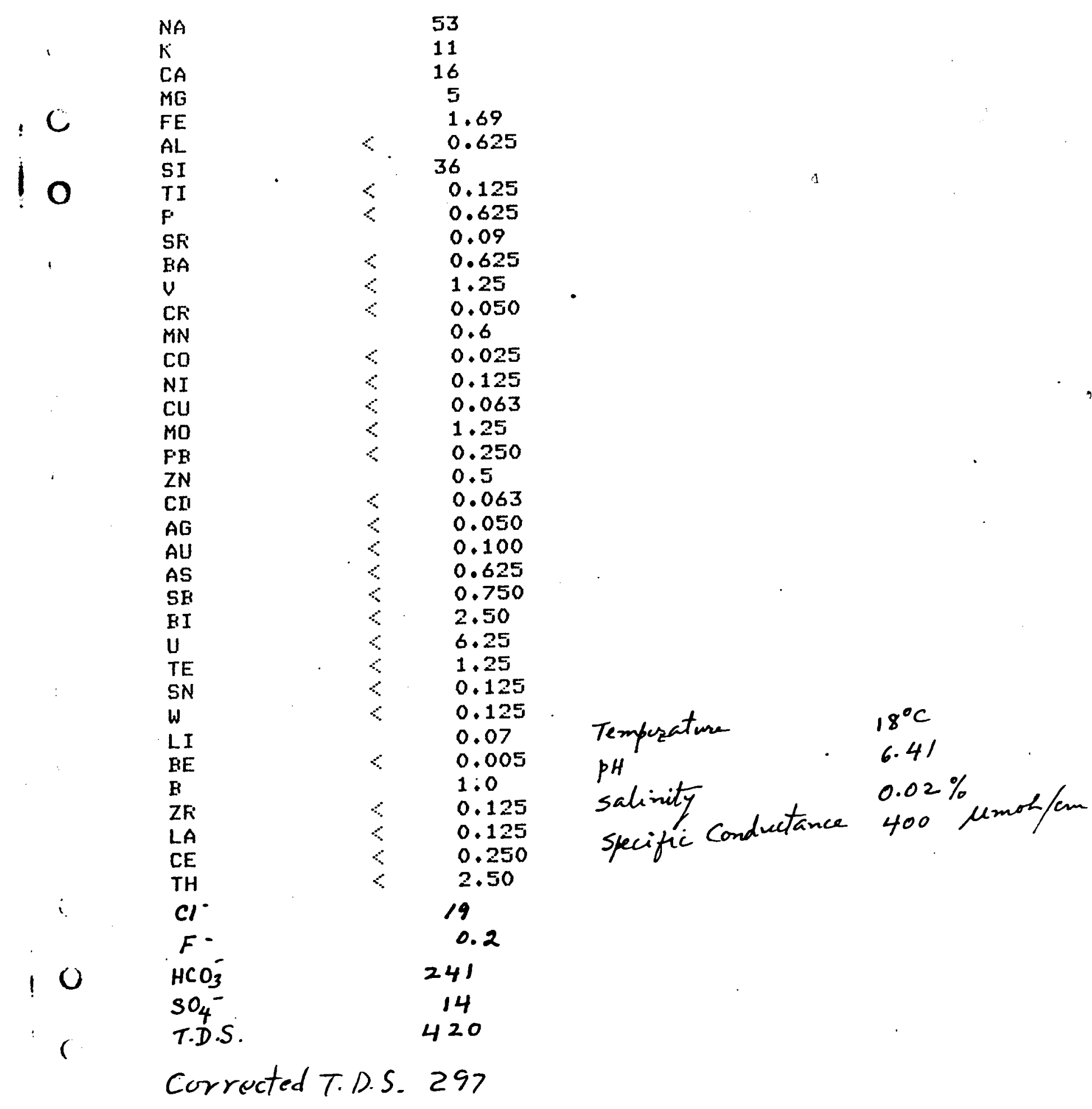


CALISTOGA SET 6

149

G-149-80

ELEMENT

NA
$K$
$C A$
$M G$
$F E$

AL

SI

TI

$F$

SF

BA

$\checkmark$

CFi

MN

CO

NI

$\mathrm{CU}$

MO

FE

ZN

CII

AG

AU

AS

SB

FI

U

TE

SN

W

LI

FE

$\mathrm{B}$

ZFi

LA

CE

$\mathrm{TH}$

CI

$F$ -

c.

$\mathrm{HCO}_{3}^{-}$

$\mathrm{SO}_{4}^{-}$

T.D.S.
CONCENTRATION (FF'M)

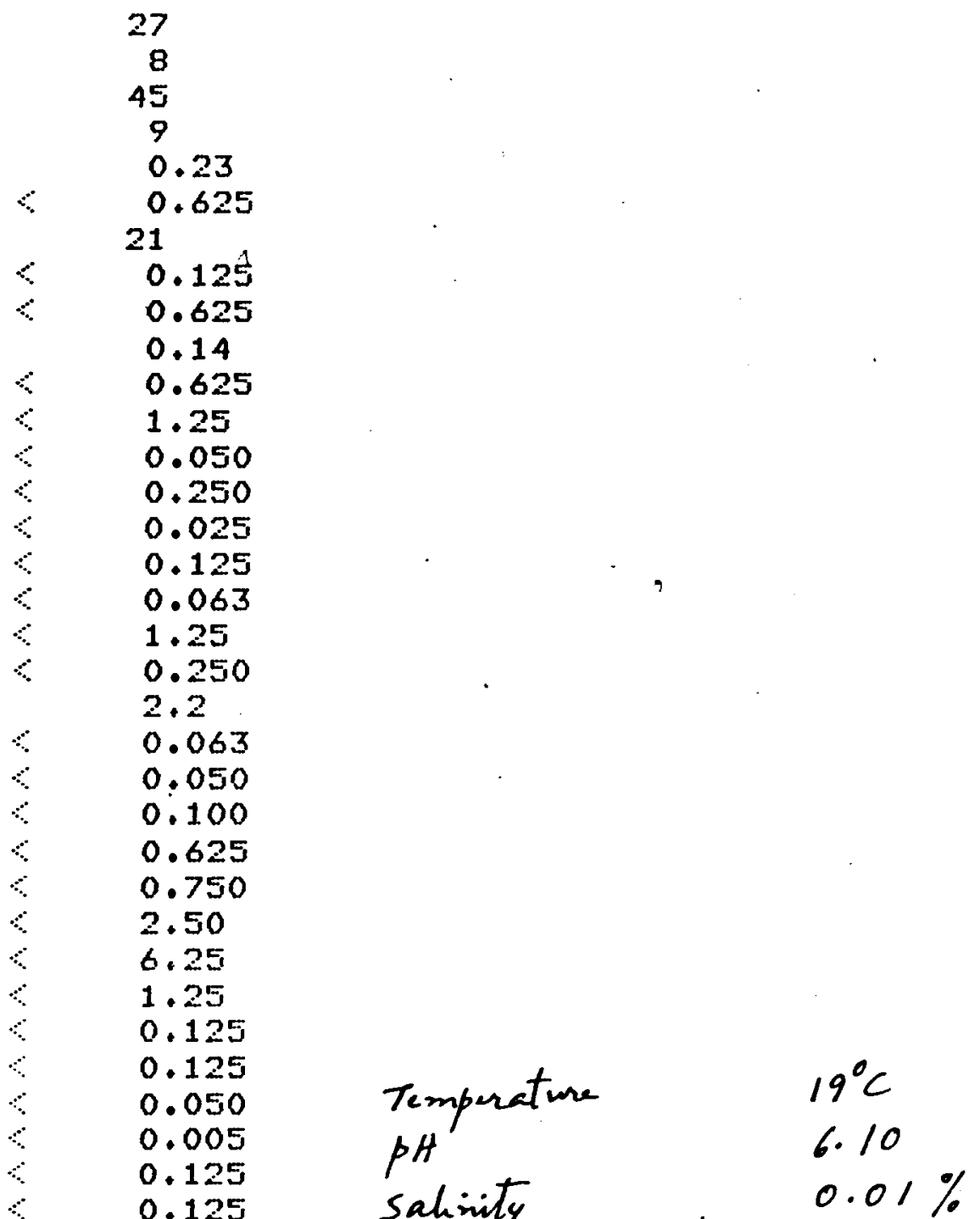

sahinity

specifie Conductance $320 \mu \mathrm{moh} / \mathrm{cm}$

corrected T.D.S 227 
CALISTOGH SET 6

$c$

150

ELEMENT

NA
$K$
$C A$
$M G$
$F E$
$A L$
$S I$
$T I$

$F$.

$S F$

BA

v

CF

MN N

CO

NI

CU

$M O$

$F \cdot E$

ZN

CI

$A G$

ALI

AS

SF

BI

1.

TE

SN

W

LI

BE

$\mathrm{H}$

IF

LA

CE

TH

Cl.

$F$.

$\mathrm{C} \mathrm{HCO}_{3}^{-}$

$\mathrm{SO}_{4}^{-}$

(. T.D.S.
$G-150-80$

CONCENTRATION (FEM)

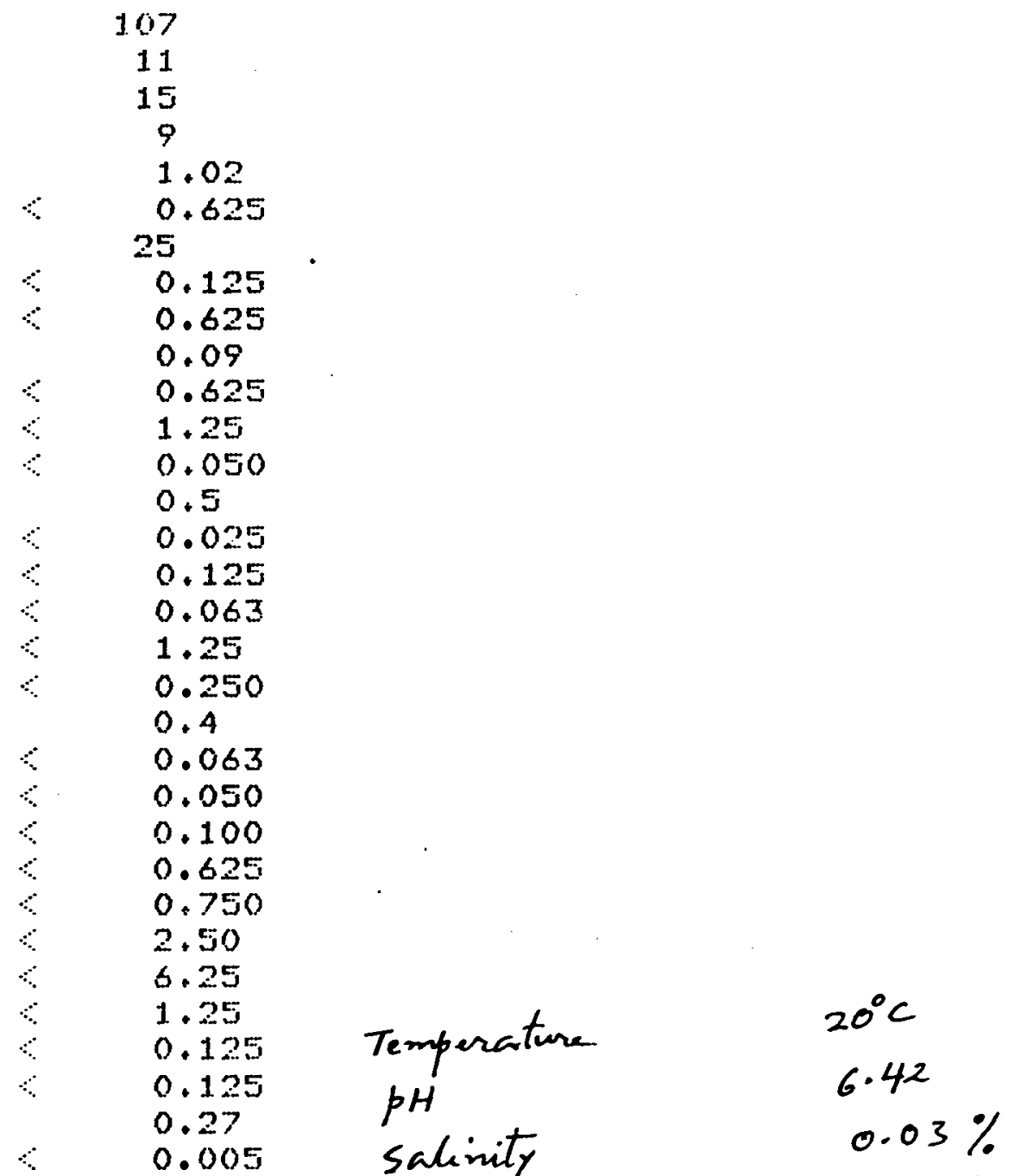

salinity

Specific Conductance $650 \mathrm{und} / \mathrm{cm}$

0.3

264.2
10
577

Corrected T.DS. 443 
CAL ISTOGO SET 6

1

r. $151 \quad 6-151-80$

ELEMENT

CONCENTRATION (FEM)

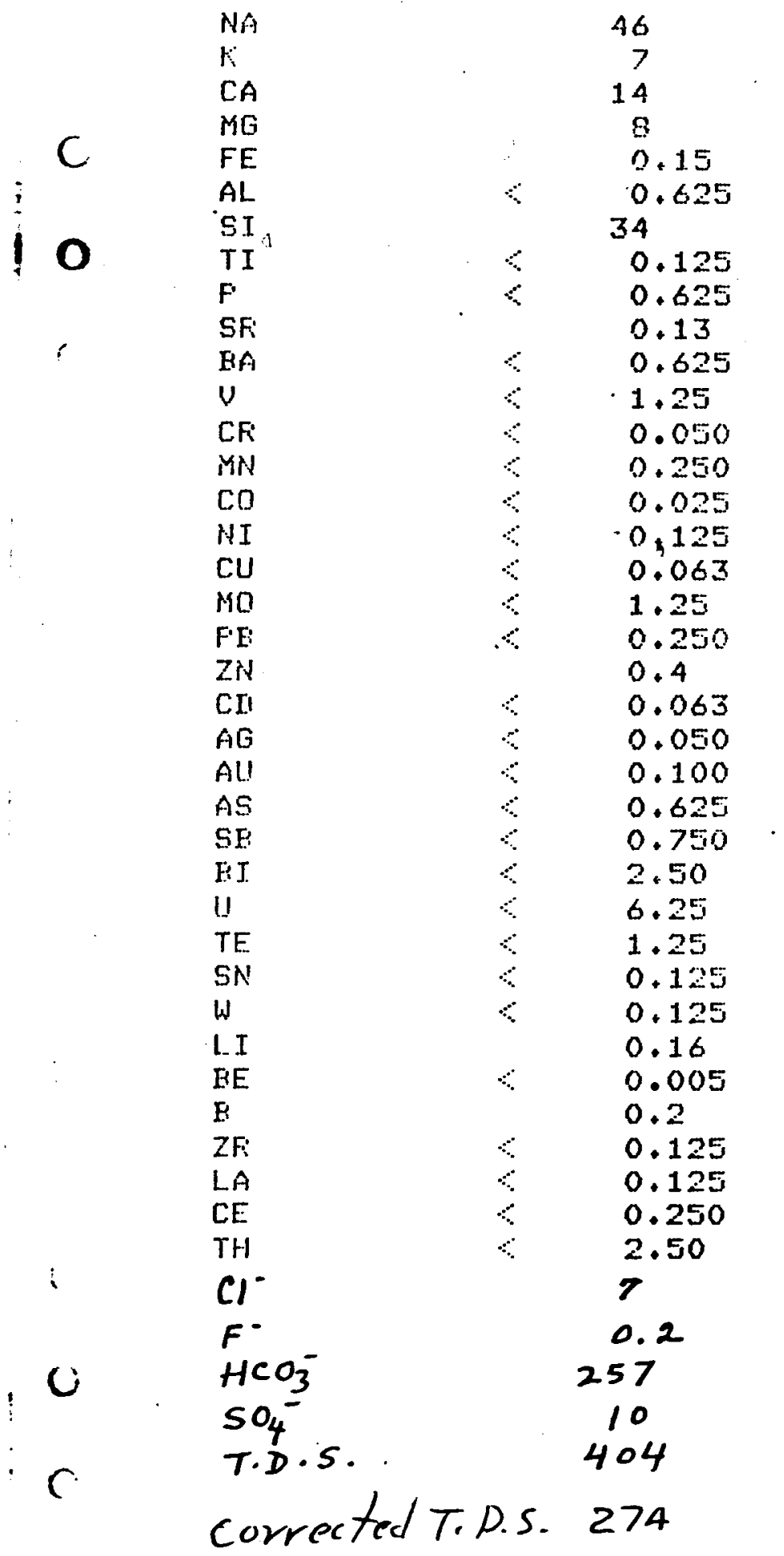

Temperature

pH

salinity

specific Conductance $18^{\circ} \mathrm{C}$
6.32
$0.02 \%$

$400 \mathrm{mmoh} / \mathrm{cm}$ 


\section{C.FLISTOGA SET 6}

(, $152 \quad 6-152-80$

\section{ELEMENT}

\section{CONCENTFATION (FFM)}

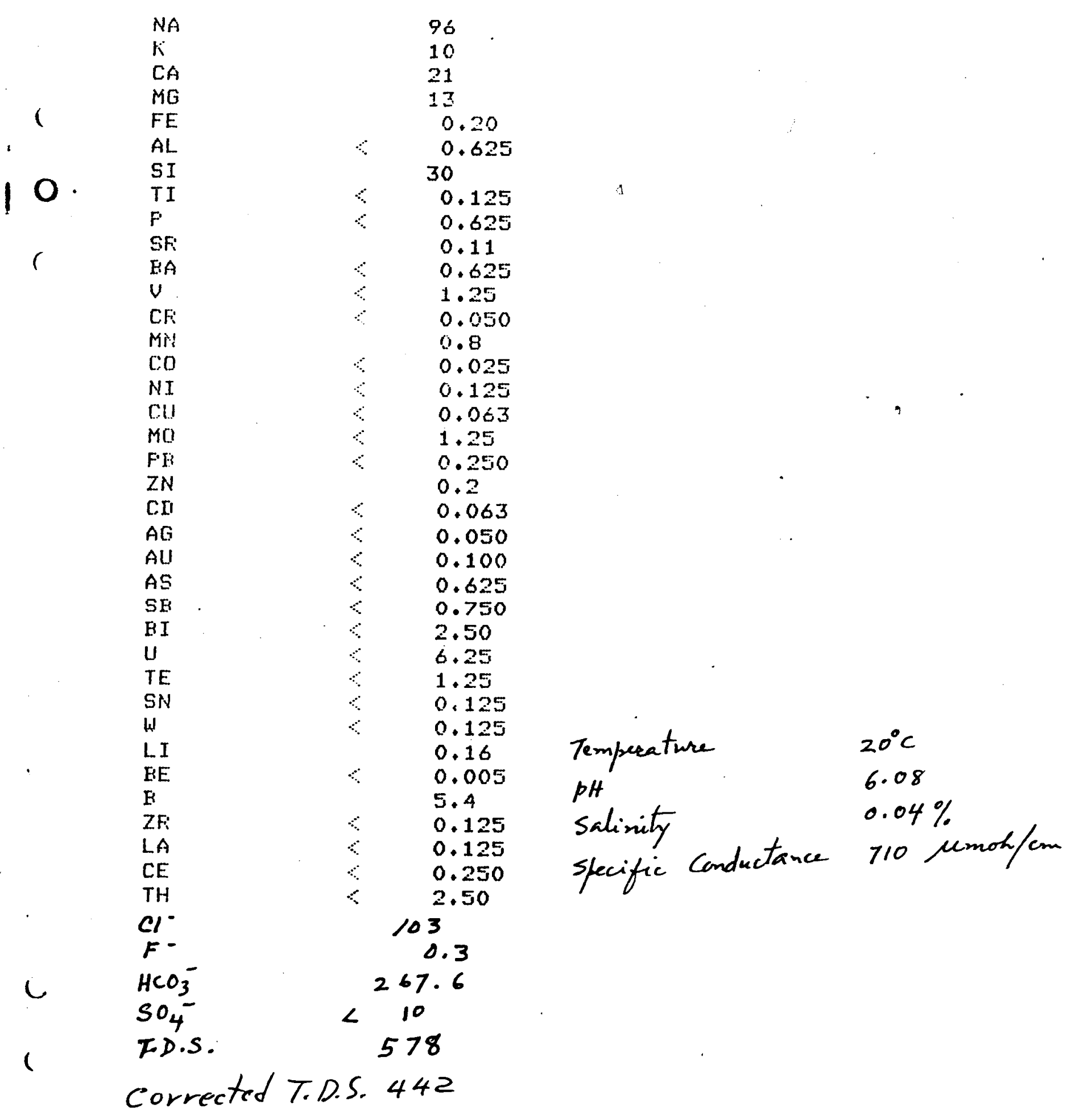


EALISTOGA SET 6

C $153 \cdot G-153-80$

ELEMENT CONCENTRATION (FEM)

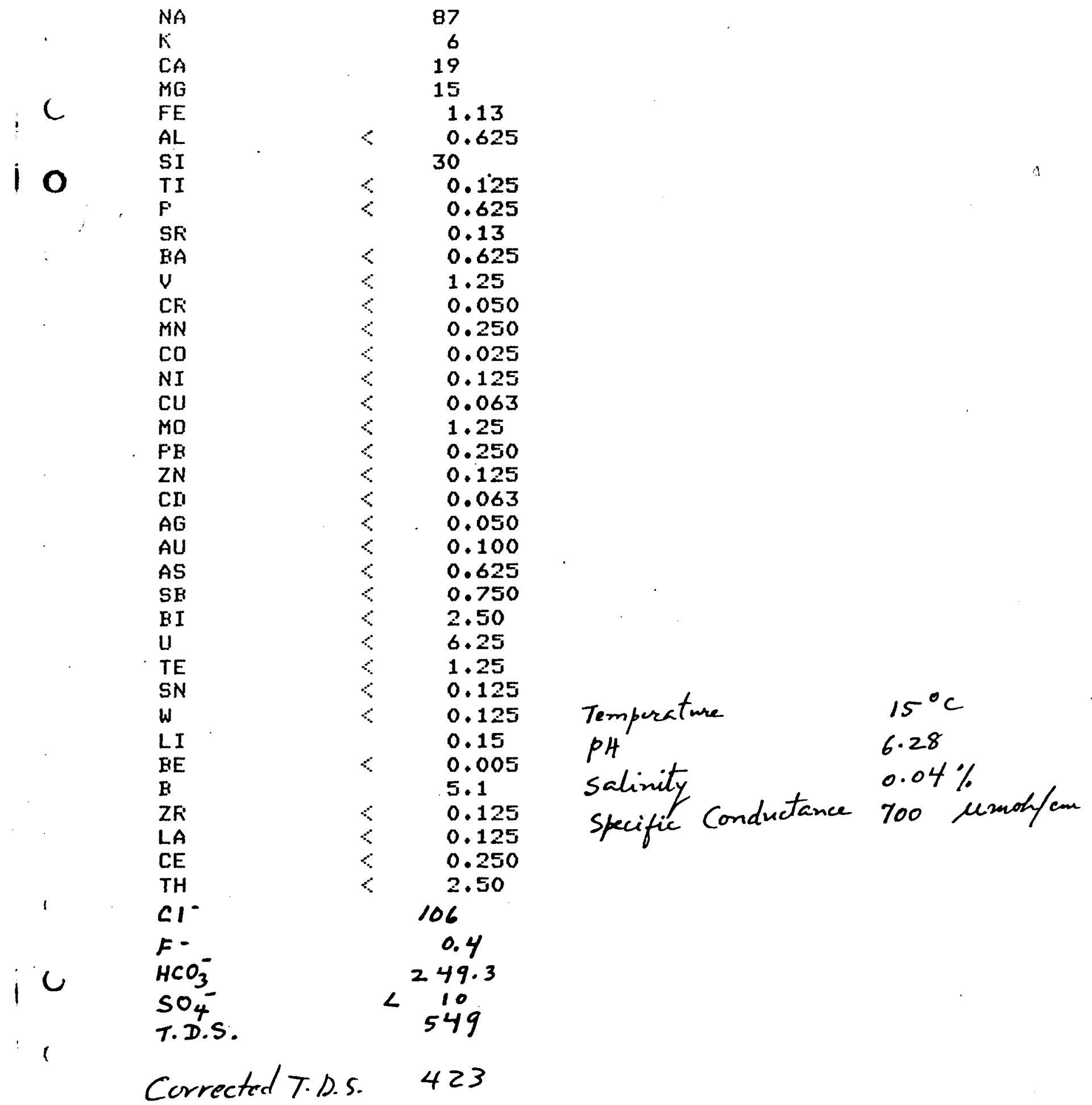


CALISTOGA SET 6

$r$

154

ELEMENT

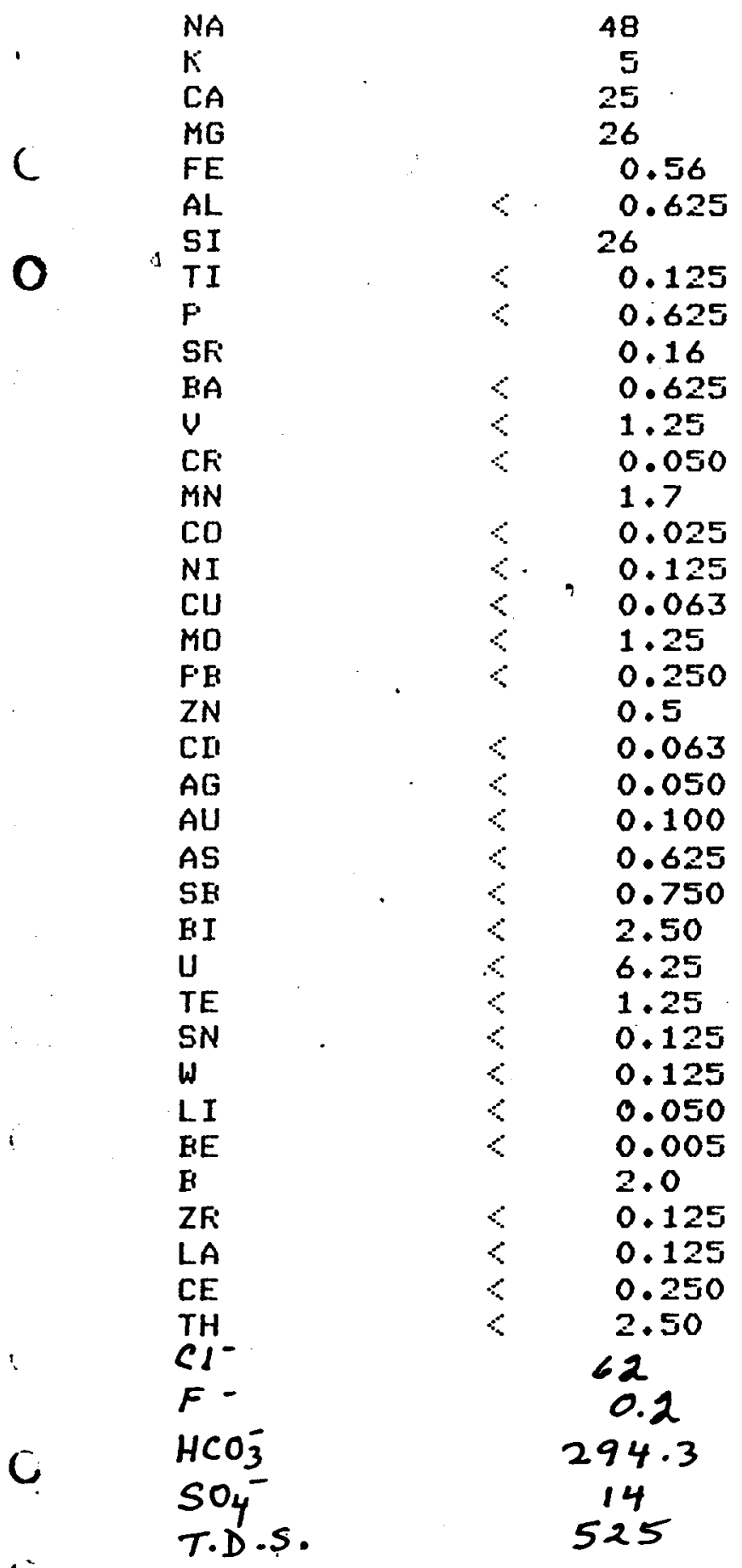

Corrected T.D.S. 376 
CALISTOGA SET 6

$r^{\circ} \quad 155 \quad G-155-80$

ELEMENT

NA

$K$

$C A$

MG

( $F E$

AL

SI

O TI

F

(5) $\mathrm{EA}$

$\checkmark$

CF

$M N$

CO

$N I$

$\mathrm{CU}$

$M O$

FE

$Z N$

CII

$A G$

AU

AS

SR

BI

U

TE

SN

W

LI

EE

B

ZFi

LA

CE

TH

$\mathrm{Cl}^{-}$

$F$ -

$\mathrm{HCO}_{3}^{-}$

$\mathrm{SO}_{4}^{-}$

T.D.S.
CONCENTRATION (FFMM)

36

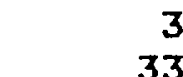

12
$6 \quad 0.025$

$6 \quad 0.625$

19
$<\quad 0.125$

$<0.625$

0.16

0.625

1.25

0.050

0.250

0.025

0.125

0.063

1.25

0.250

0.125

0.063

0.050

0.100

0.625

0.750

2.50

6.25

1.25

0.125

0.125

0.050

0.005

1.7

0.125

0.125

0.250

2.50

37

0.2

241

16

419

Corrected T.D.S. 297

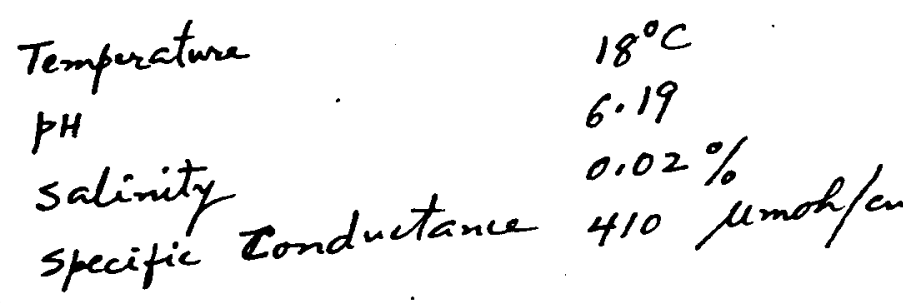




\section{CALISTOGA SET 7}

( $156 \quad G-156-80$

\section{ELEMENT}

C

NA

$K$

CA

MG

FE

AL

SI

TI

F

SF

U

CF

$M N$

CO

NI

CU

MO

FE

ZN

CII

$A G$

AU

AS

SB

BI

U

TE

SN

W

LI

BE

H

ZF

LA

CE

TH

$\mathrm{Cl}^{-}$

0

$F$.

$\mathrm{HCO}_{3}^{-}$

$\mathrm{SO}_{4}^{-}$
T.D.S.
CONCENTRATION (FFM)

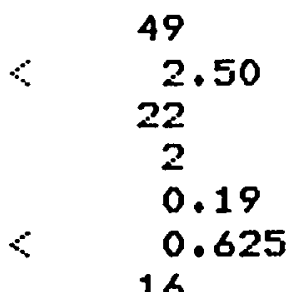

-16
$-\quad 0.125$

$\because \quad 0.625$

$<\quad 0.625$

$\because 1.25$

$\therefore \quad 0.050$

$\therefore \quad 0.250$

$\therefore \quad 0.025$

$\therefore \quad 0.125$

$<\quad 0.063$

1.25

$\therefore \quad 0.250$

0.2

0.063

0.050

0.100

0.625

0.750

2.50

$6+25$

1.25

0.125

0.125

0.050

0.005

0.125

0.125

0.125

0.250

2.50

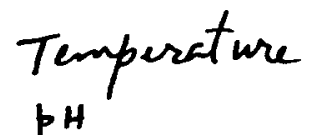

$30^{\circ} \mathrm{C}$

6.30

salinity specific

corrected T.D.S. 236

$216 \cdot 6$

11

346 
CALISTOGA SET 7

C.

157

$G-157-80$
ELEMENT

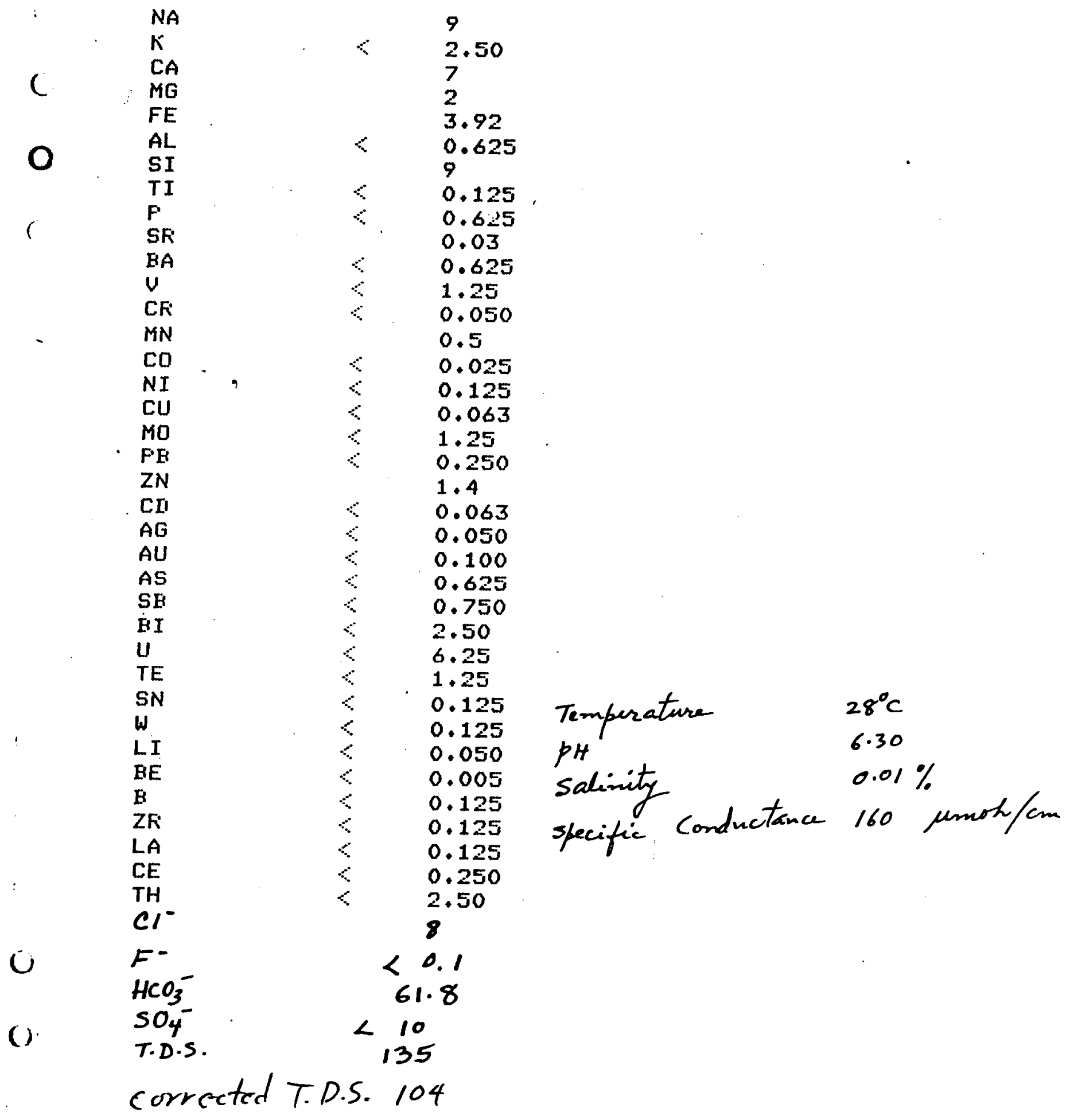




\section{CALISTOGA SET 7}

$158 \quad G-158-80$

\section{ELEMENT CONCENTFATION (FFM)}

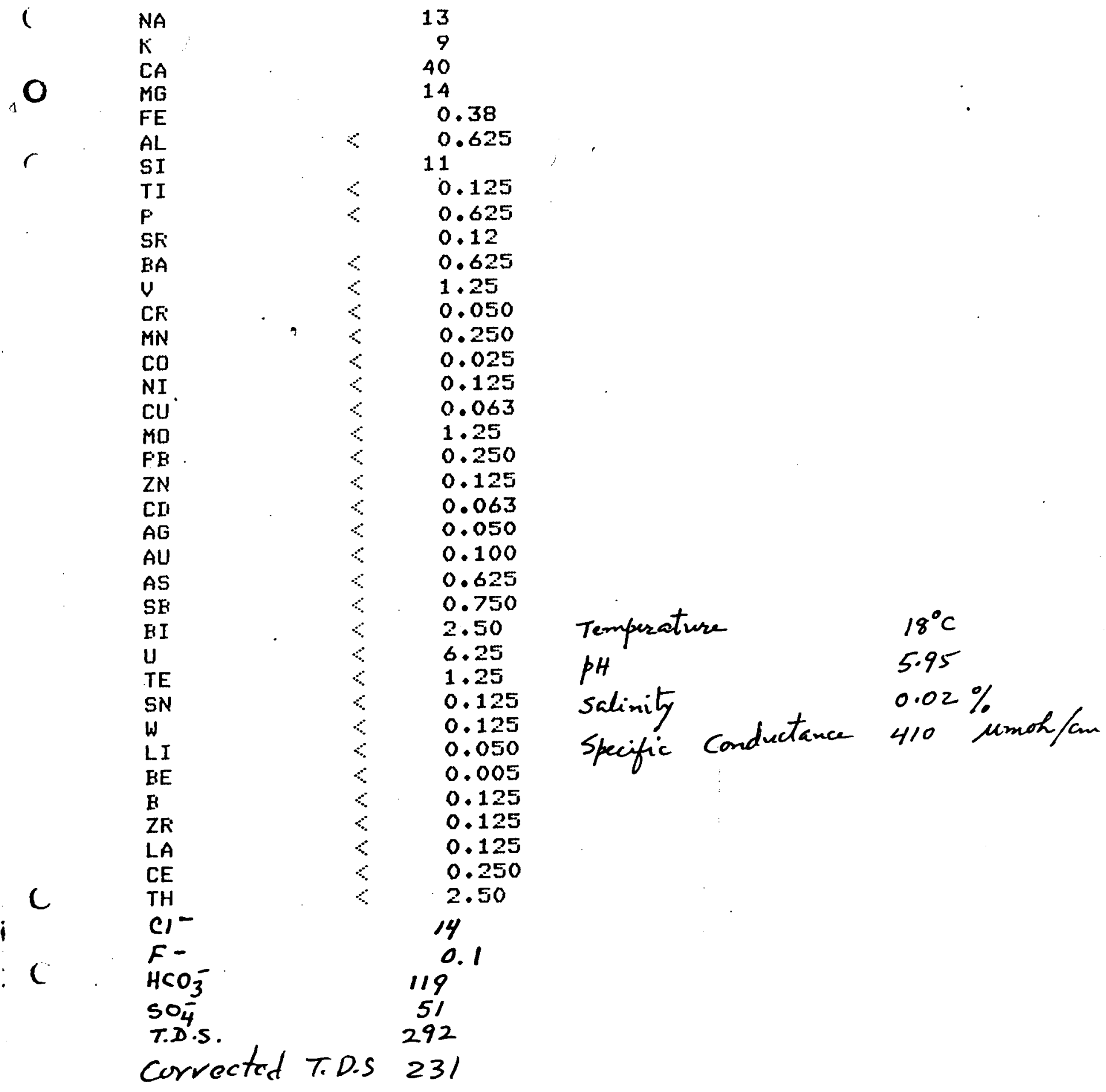


CALISTOGA SET 7

(

159

G-159-80
CONCENTRATION (F'FM)

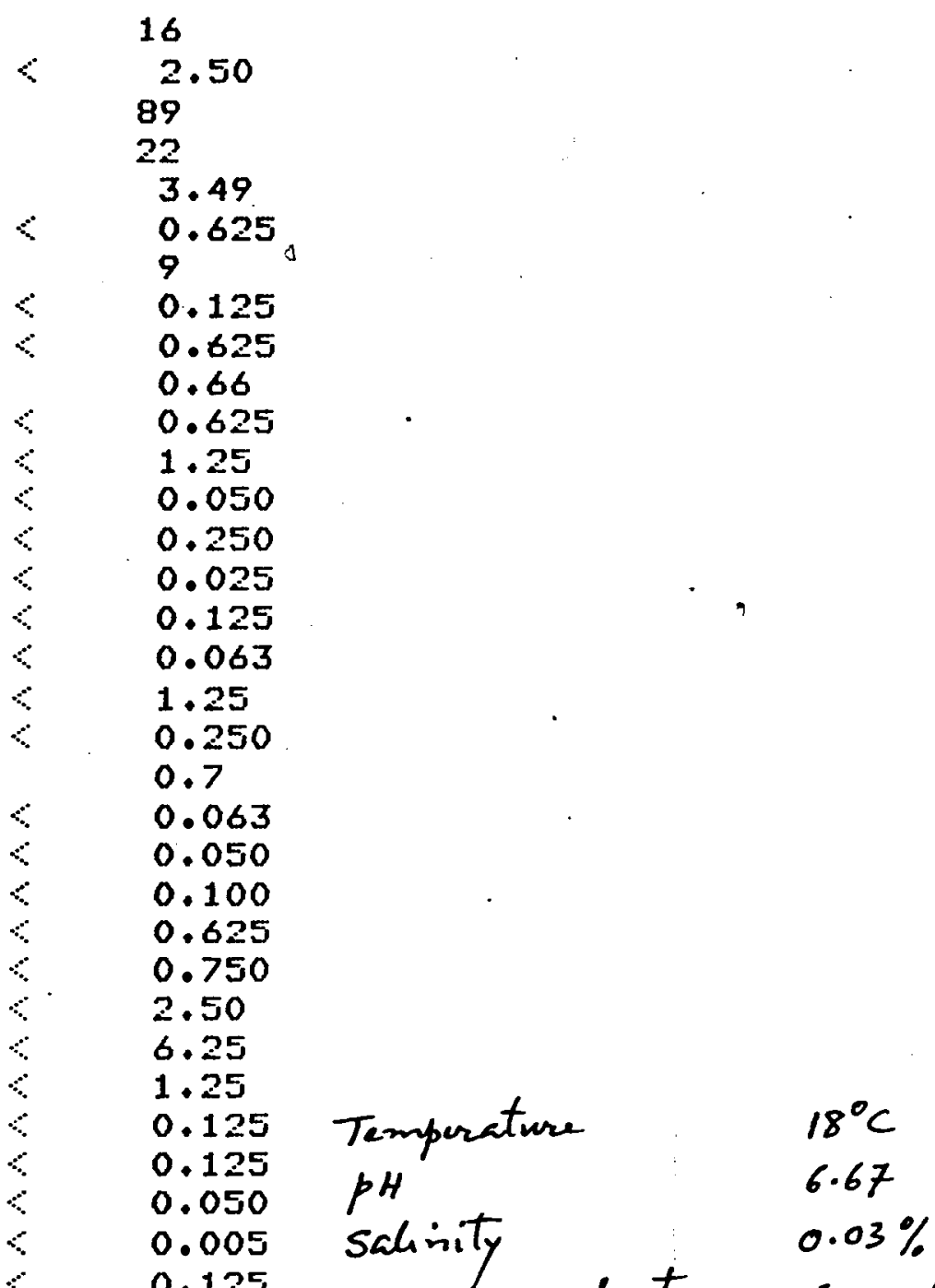

ZFi

LA

CE

TH

$\mathrm{Cl}^{-}$

$\mathrm{Fr}^{-}$

$\mathrm{HCOO}_{3}^{-}$

$\mathrm{SO}_{4}^{-}$

(.) T.D.S.

0.125

0.2

$<\quad 0.125$

0.250

2.50

12

0.3

390.4
52

618

specific Conductance $630 \mu \mathrm{mol} / \mathrm{cm}$

Corrected T. D.S. 420 


\section{CALISTOGA SET 7}

$i$

$1 \quad 160 \quad G-160-80$

\section{ELEMENT}

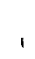

C

$r ; \quad A L$

TI

$F$

SFi

BA

U

CF

$M N$

CO

NI

CU

MO

F'B

ZN

CII

$A G$

$A U$

AS

SH

EI

$U$

TE

SN

W

LI

HE

B

ZF

LA

CE

$\mathrm{TH}$

$\mathrm{Cl}^{-}$

F -

$\mathrm{HCO}_{3}^{-}$

$\mathrm{SO}_{4}^{-}$

T.D.S.
CONCENTFIATION (FFM)

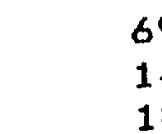

69

14

18

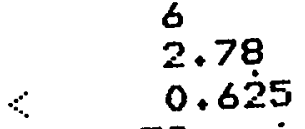

32

$\therefore \quad 0.125$

0.625

0.09

0.625

1.25

0.050

1.0

0.025

0.125

0.063

1.25

0.250

0.2

0.063

0.050

0.100

0.625

0.750

2.50

6.25

1.25

0.125

0.125

0.10

$<$

$\therefore \quad 0.005$

1.5

$\therefore \quad 0.125$
$\therefore \quad 0.125$

Temperature

PH

$20^{\circ} \mathrm{C}$

salinity

specific Conductance

$6 \cdot 72$

$0.02 \%$

0.250

2.50

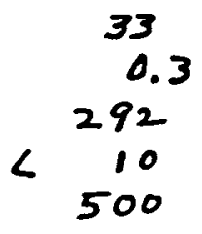

0.3

92

500

Corrected T.D.S. 352 


\author{
CALISTOGA SET 7
}

C

161

G-161-80

ELEMENT

CONCENTRATION (FFM)

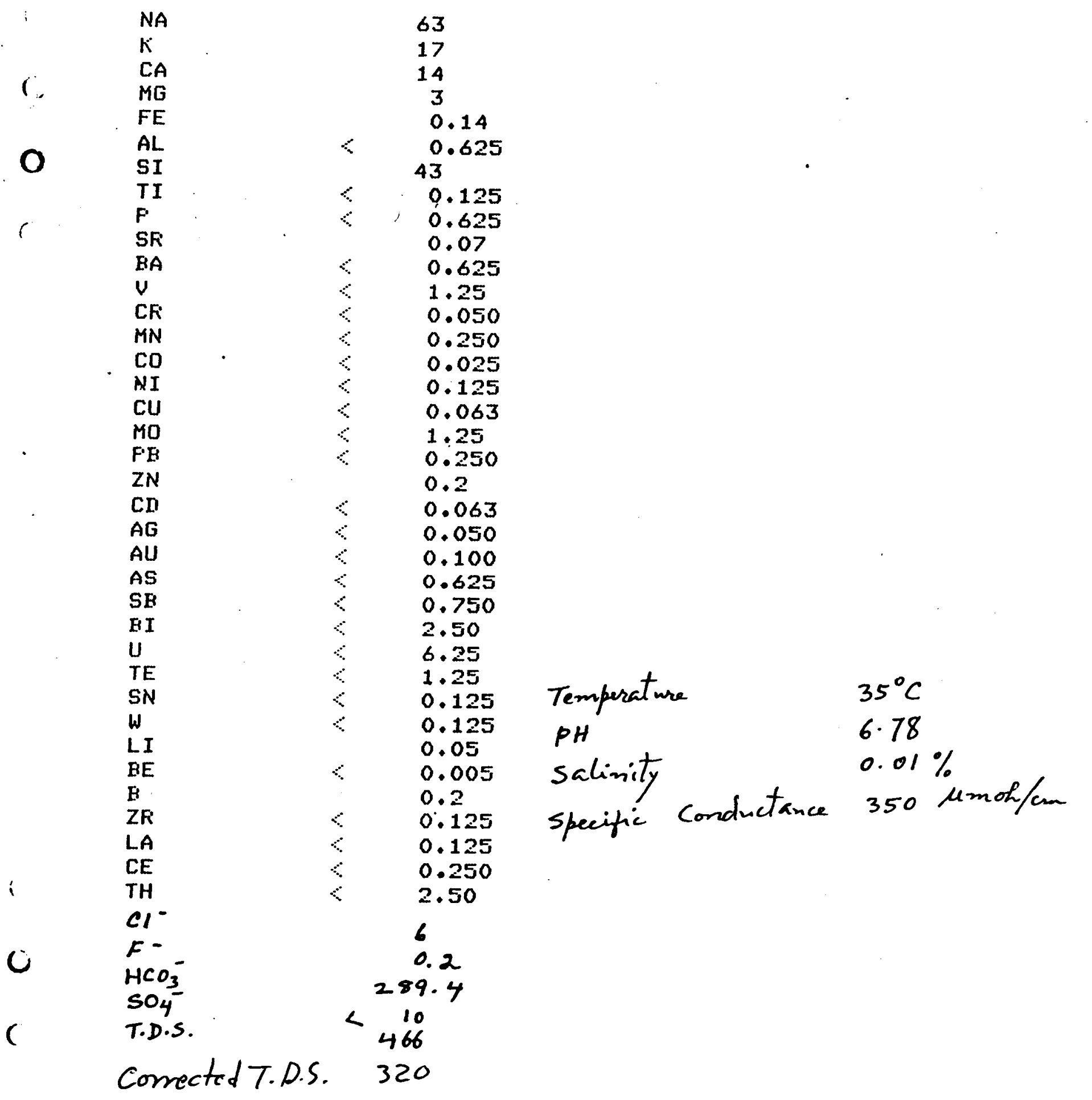


CALISTOGA SET 7

C

162

G-162-80

ELEMENT

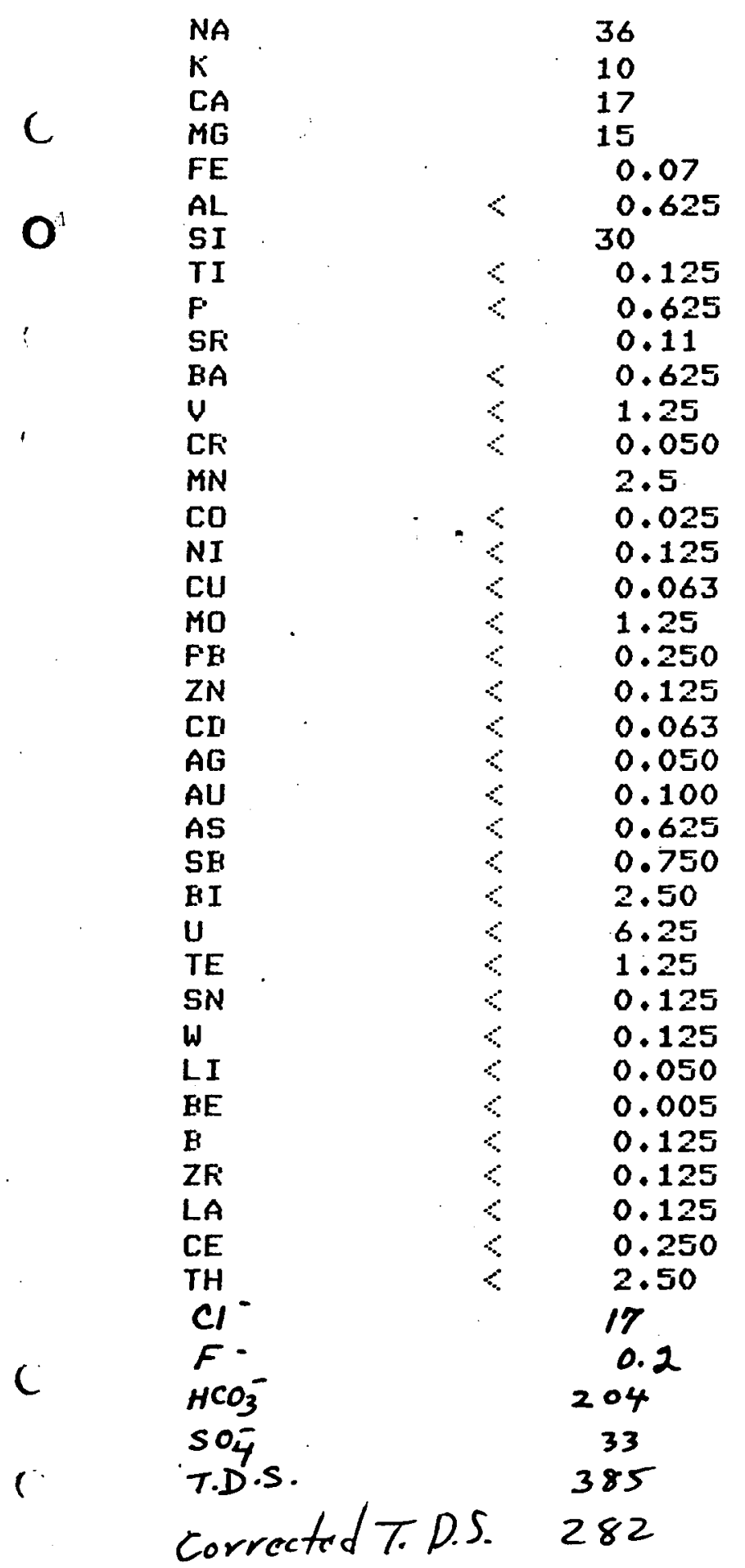

CONCENTFIATION (FFM)

$\begin{array}{ll}\text { Temperature } & 14^{\circ} \mathrm{C} \\ \text { pH } & 6.4 \\ \text { Salinity } & 0.02 \%\end{array}$

specific Conductance 360 umoh/cm 
CALISTOGA SET 7

( 163 G-163-80

ELEMENT

CONCENTFATION (FFFM)

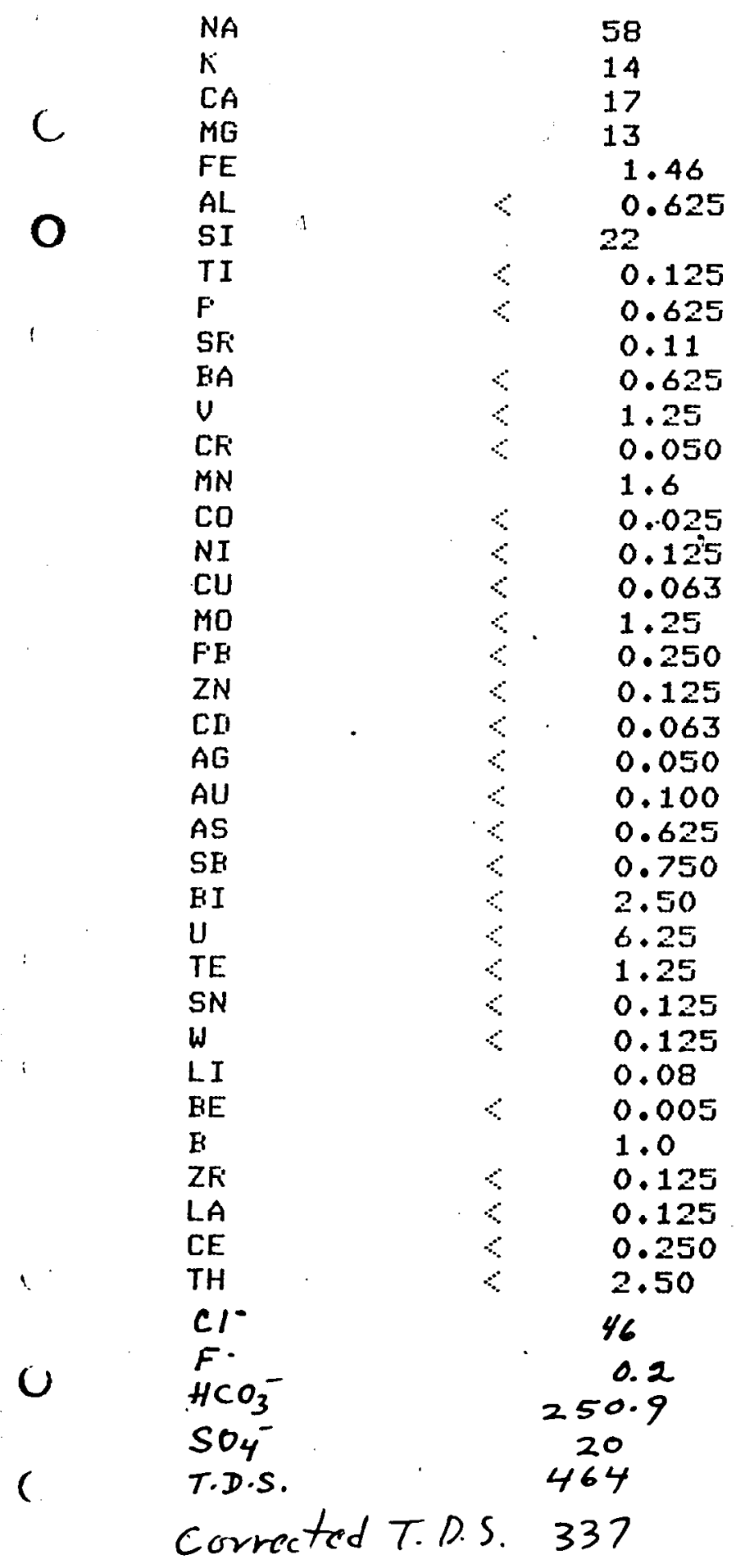


CALISTOGA SET 7

r

164

G-164-80

ELEMENT

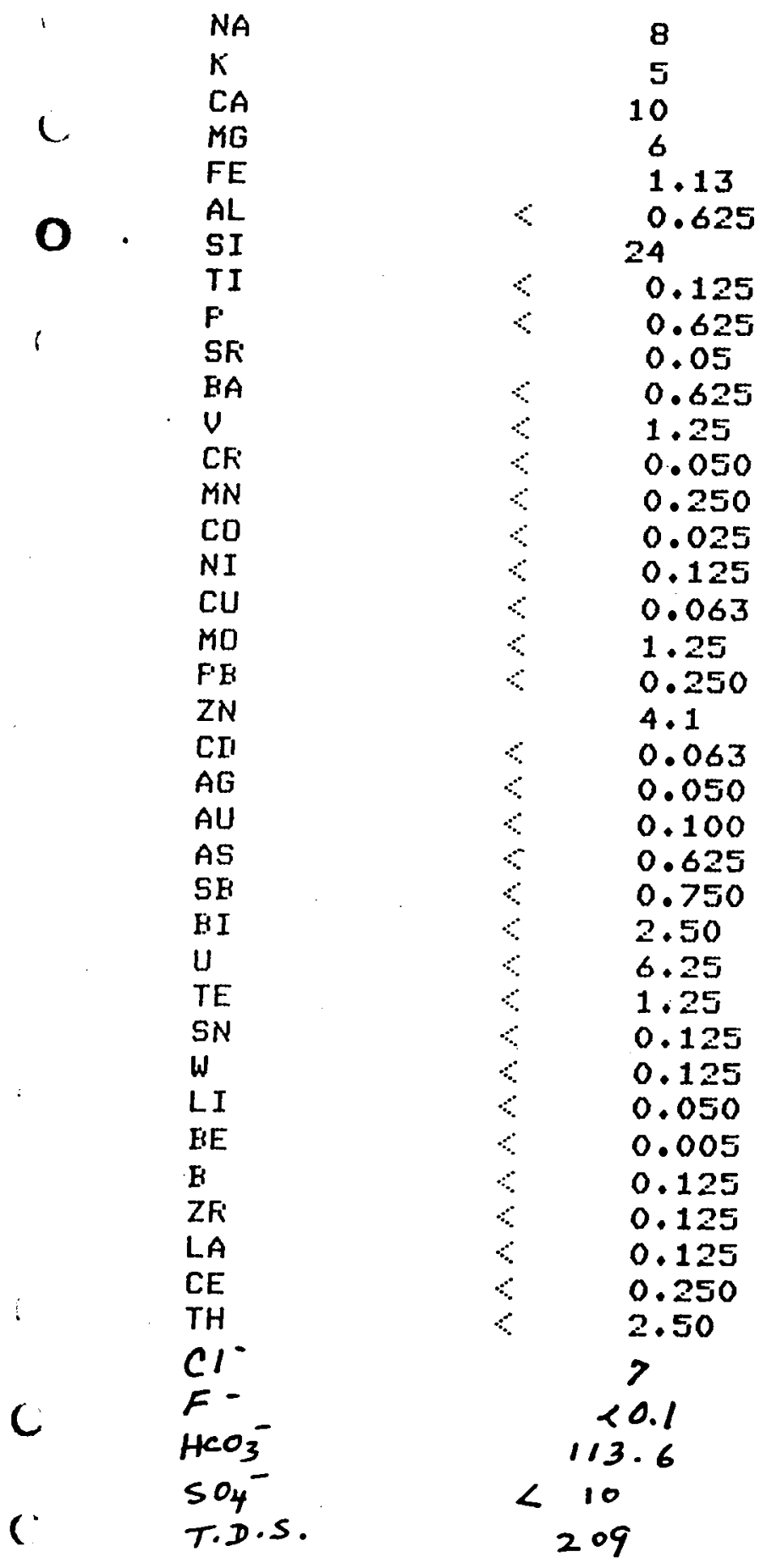

CONCENTRATION (FFMY)

1

$\begin{array}{ll}\text { Temperature } & 200^{\circ} \mathrm{C} \\ \text { pH } & 6.00 \\ \text { Salinity } & 0.00 \%\end{array}$

specific Conductance $155 \mu$ moh/cm

Corected T.D.S. 152 


\section{CALISTOGA SET 7}

r $165 \quad$ G-165-80

ELEMENT

NA

$K$

CA

$M G$

FE

o

AL

SI

TI

$F$

SFi

U

CF

$M N$

CO

$N I$

$\mathrm{CU}$

MO

$F \cdot B$

$Z N$

CII

$A G$

AU

AS

SB

BI

U

TE

SN

W

LI

BE

B

$Z F i$

LA

CE

(.. $\mathrm{TH}$

$\mathrm{Cl}^{-}$

$\boldsymbol{F}^{-}$

$\mathrm{HCO}_{3}^{-}$

$\mathrm{SO}_{4}$

T.D.S.
CONCENTFATION (FFM)

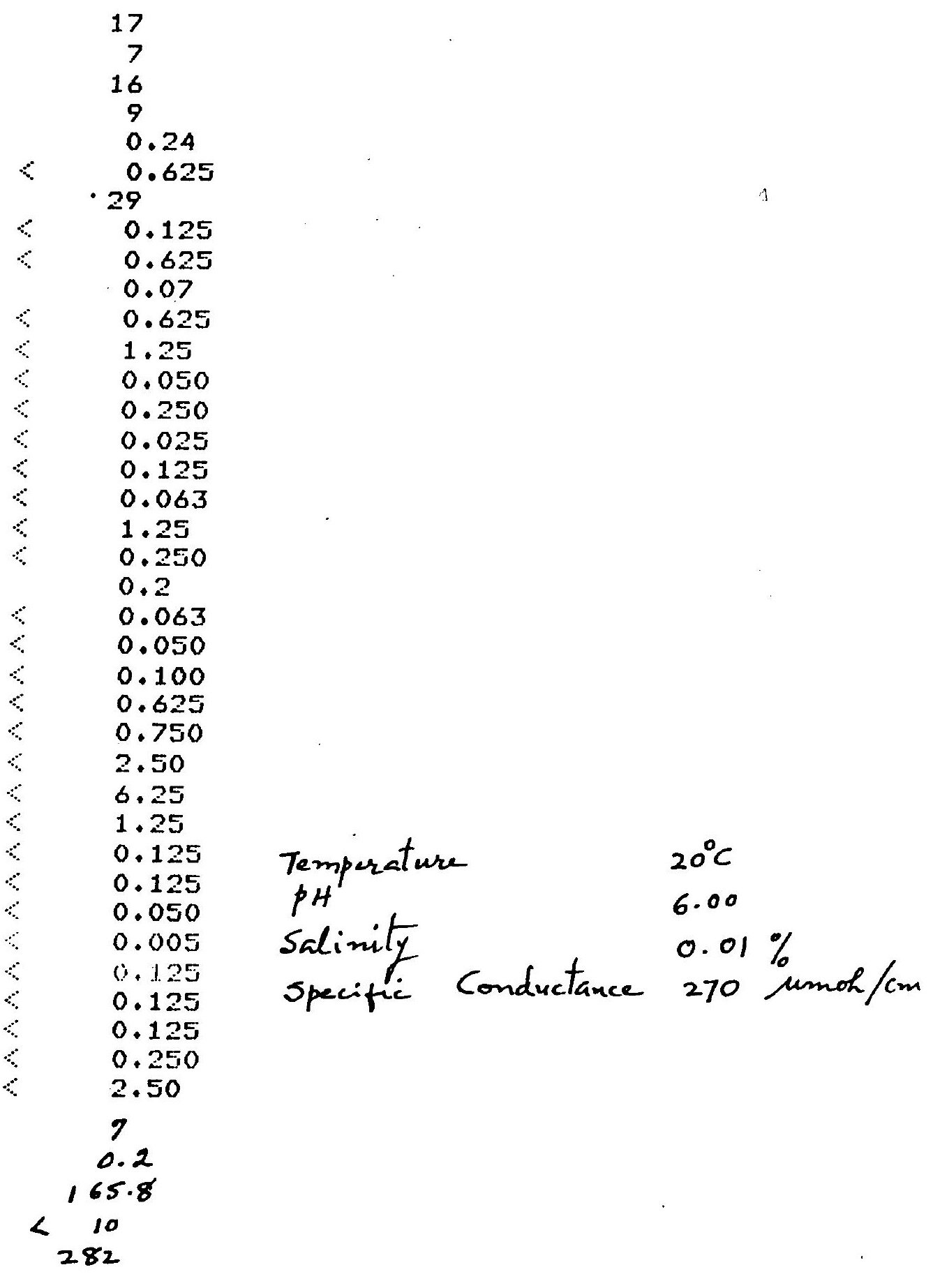

Corrected TD.S. 198 


\section{CALISTOGA SET 7}

$166 \quad$ G-166-80

\section{ELEMENT}

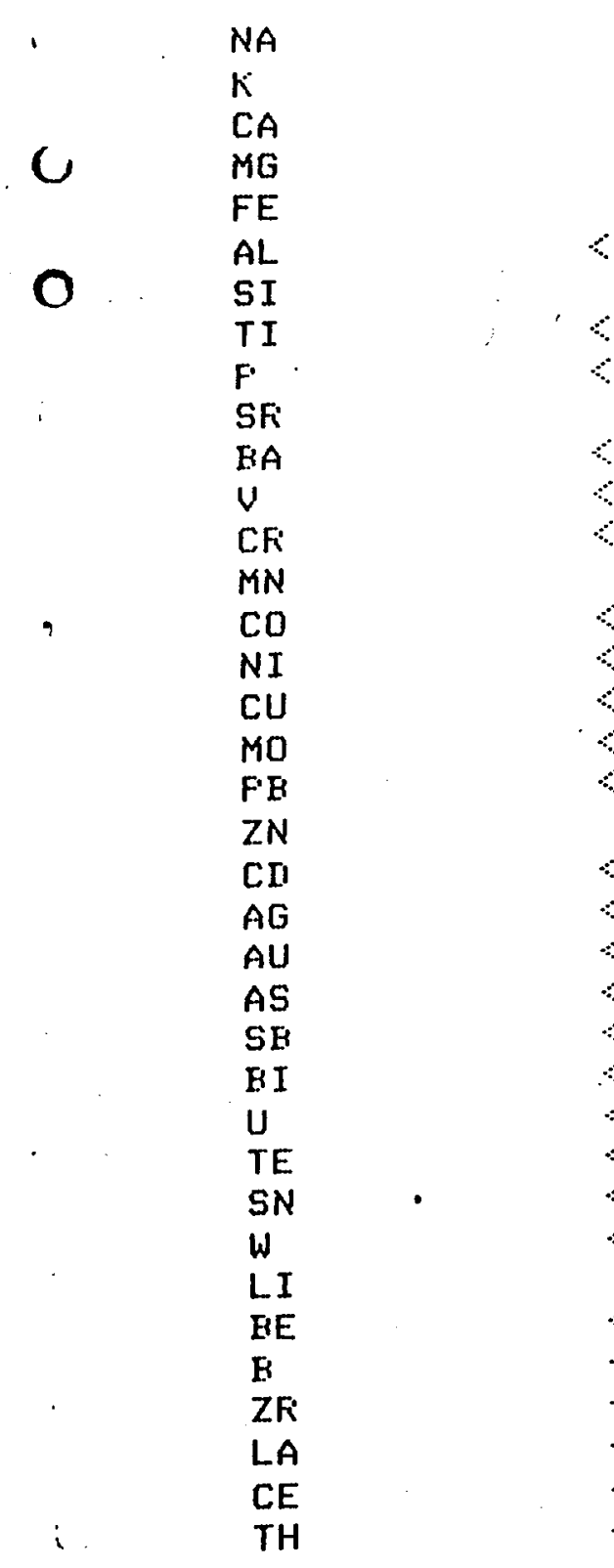

(j)

$\mathrm{Cl}^{-}$

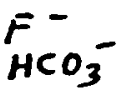

$\mathrm{SO}_{4}=$

T.D.S .

corrected T.D.S.
CONCENTFATION (FFM)

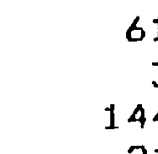

61

3

21

0.10

$6 \quad 0.625$

18

0.125

0.625

0.22

0.625

1.25

0.050

1.2

0.025

0.125

0.063

1.25

0.250

1.1

$0: 063$

0.050

0.100

0.625

0.750

2.50

6.25

1.25

0.125

0.125

0.13

0.005

0.125

0.125

0.125

0.250

2.50

12

0.2

221.1

125

629

$5 / 6$ 
CALISTOGA SET 7

167 G-167-80

ELEMENT

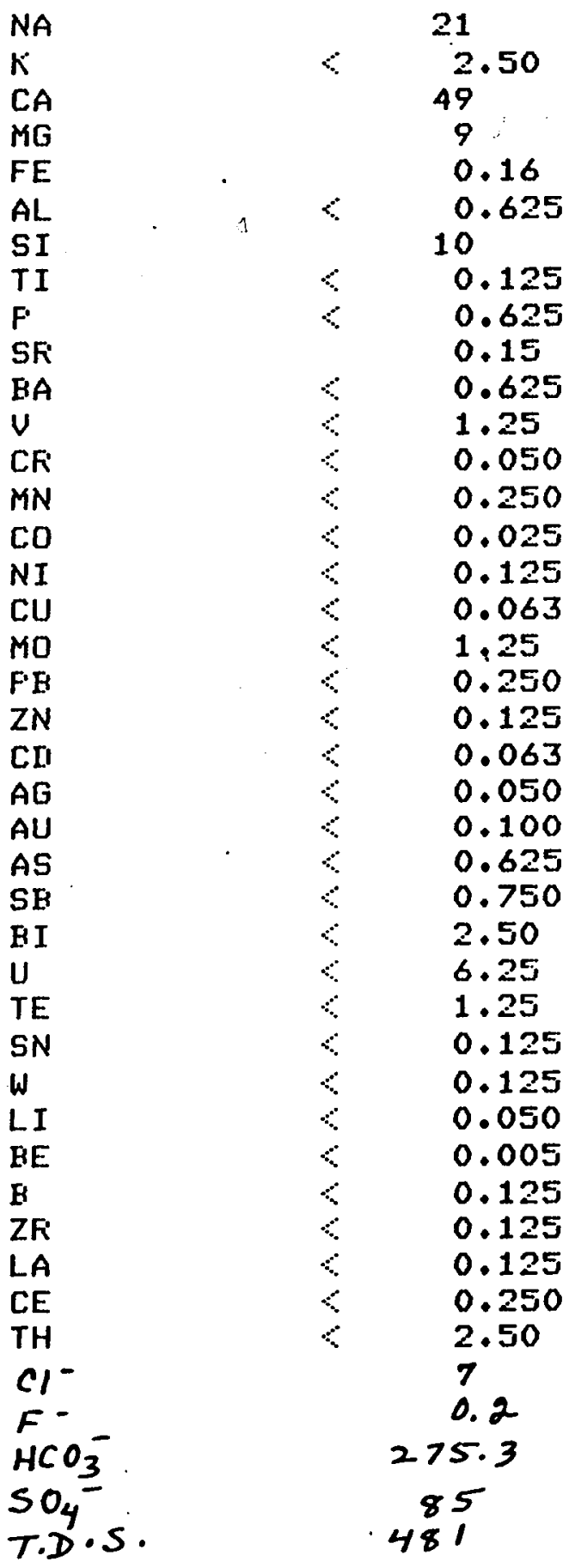

corrected T. D.S. 341 


\section{CALISTOGA SET 7}

$r$

168

G-168-80

ELEMENT

CONCENTRATION (FF'M)

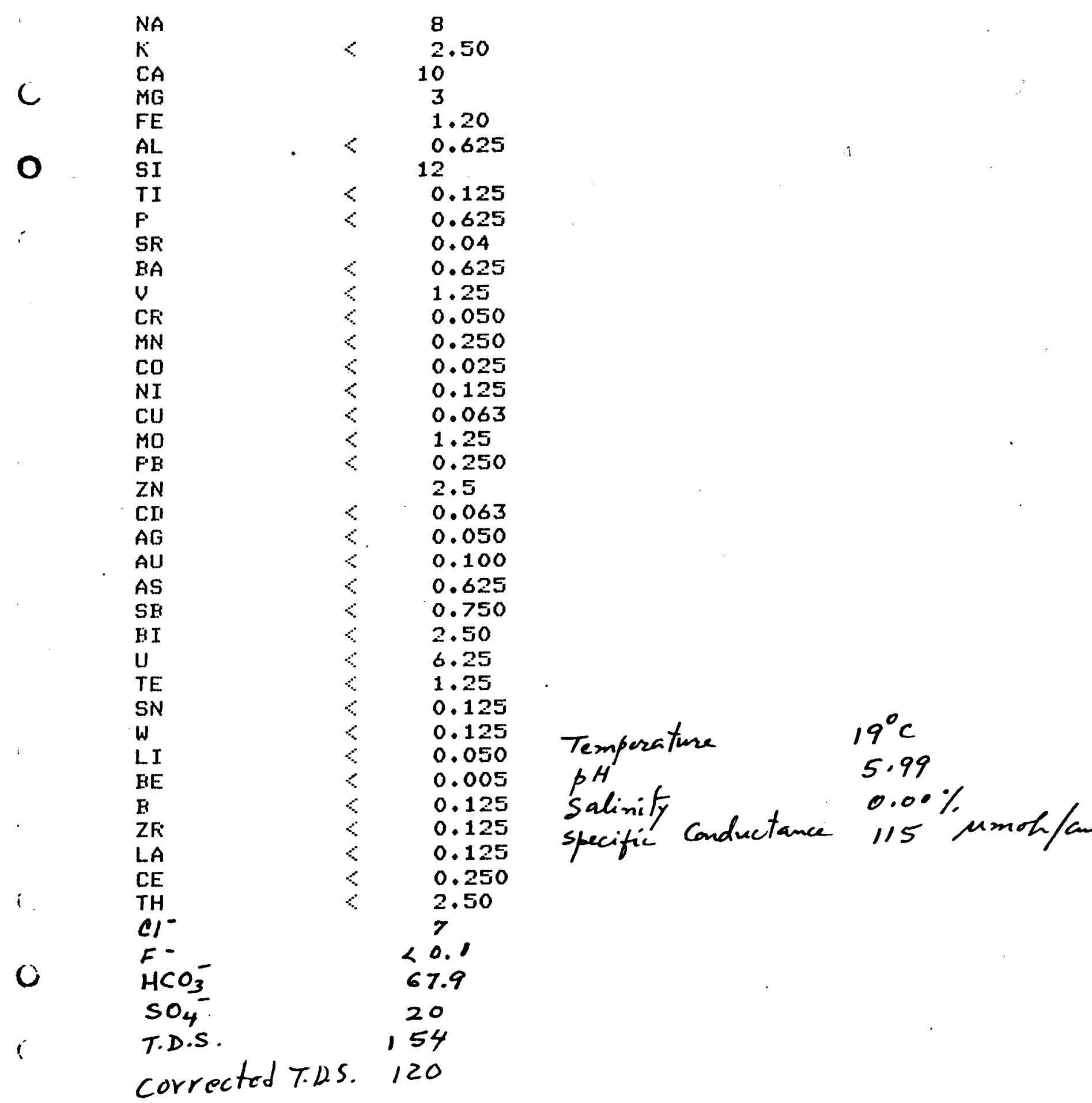


i

\author{
CALISTOGA SET 7
}

C 169 G-169-80

\title{
ELEMENT
}

CONCENTFIATION (F'F'M)

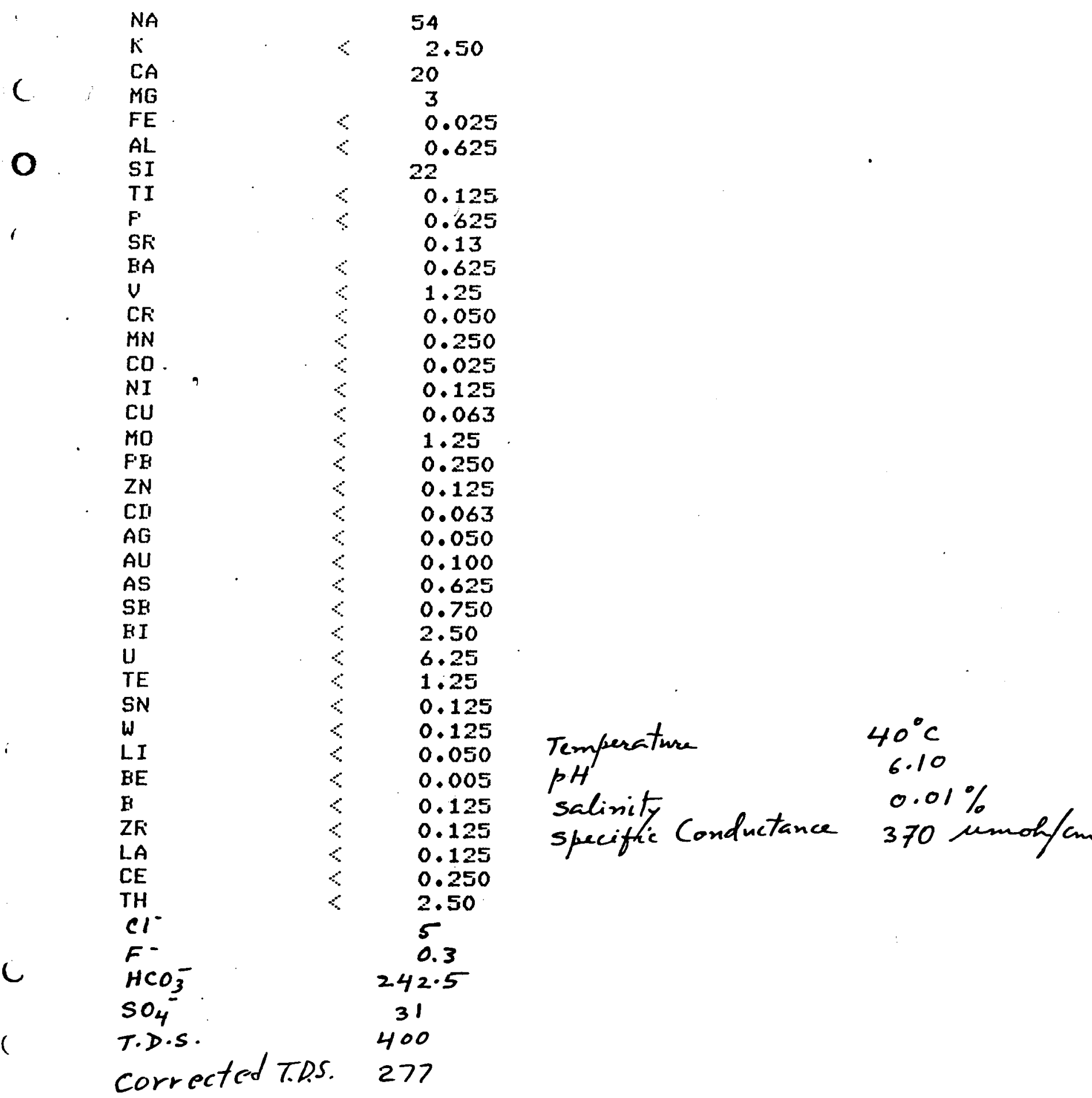




\section{CALISTOGA SET 7}

r $\quad 170 \quad$ G-170-80

ELEMENT

C

$\mathbf{0}$

KA

CA

MG

FE

AL

TI

$\mathrm{F}$

SF

BA

$\checkmark$

CF

$M N$

CO

$N I$

CU

$M O$

$F \cdot B$

$Z N$

CII

$A G$

AU

AS

SB

BI

$U$

TE

SN

W

LI

EE

F

$Z F$

LA

CE

TH

$\mathrm{Cl}^{-}$

F -

$\mathrm{HCO}_{3}^{-}$

$\mathrm{SO}_{4}^{-}$

T.D.S.

corrected T.D.S. 334

49

473

\section{CONCENTRATION (FFM)}

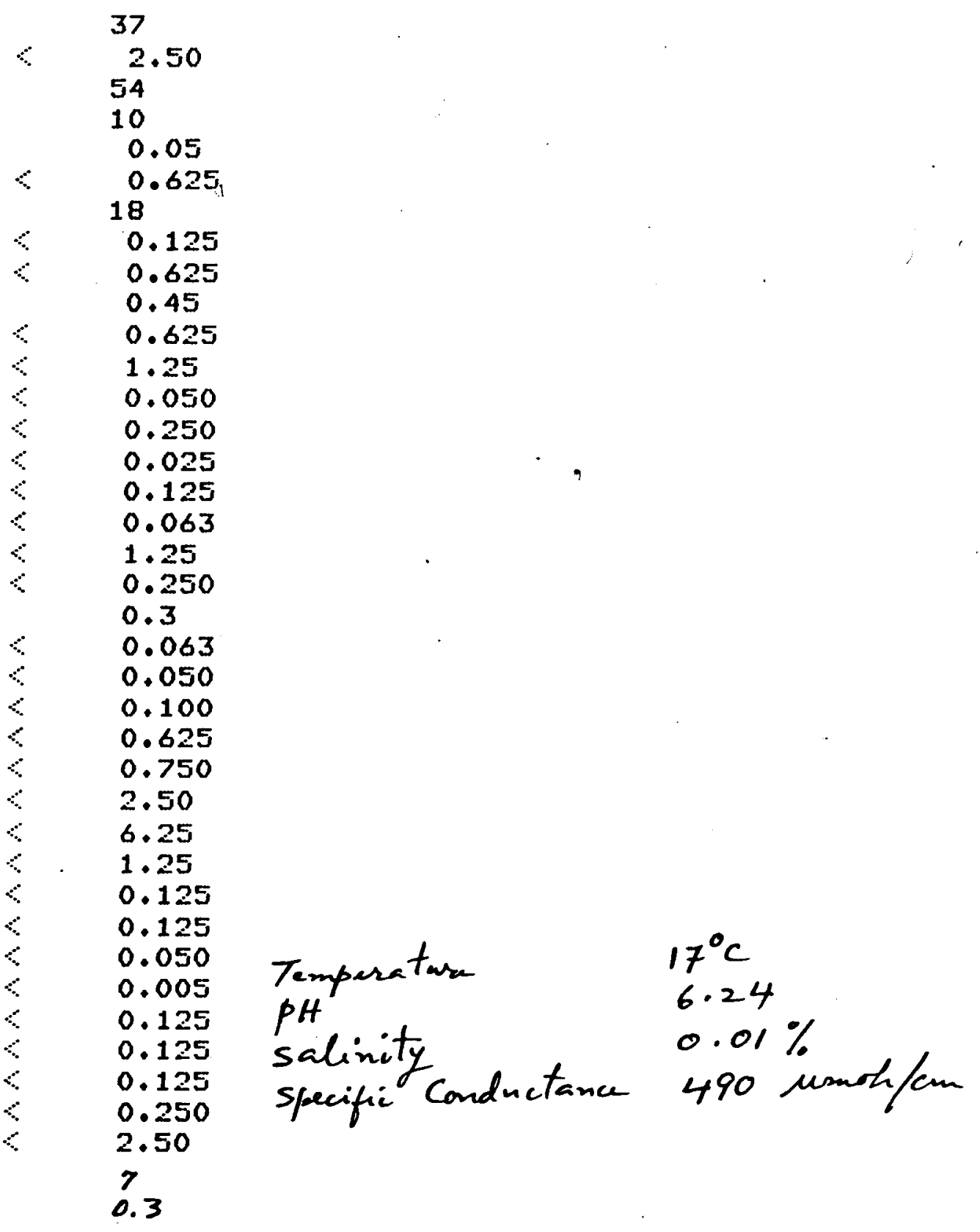

273.7 


\section{CALISTOGA SET 7}

C $\quad 171 \quad G-171-80$

\section{ELEMENT}

c

NA

$K$

$C A$

$M G$

FE

AL

SI

TI

$P$

$S F$

EA

U

CF

$M N$

CO

$N I$

$\mathrm{CU}$

MO .

FB

ZN

CII

$A G$

AU

AS

SE

HI

$U$

TE

SN

W

LI

BE

E

ZFi

LA

CE

TH

$\mathrm{Cl}^{\circ}$

$F^{-}$

$\mathrm{HCO}_{3}^{-}$

$\mathrm{SO}_{4}^{-}$

T.D.S.
CONCENTFATION (FFPM)<smiles>[3H]</smiles>

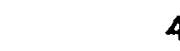

4

1. 1.08

$1 \cdot 3$

23

$<\quad 0.125$

$<\quad 0.625$

0.03

$<\quad 0.625$

$\therefore \quad 1.25$

0.050

0.250

0.025

0.125

0.8

1.25

0.250

5.8

0.063

0.050

0.100

0.625

0.750

2.50

6.25

$1+25$

0.125

0.125

0.050

0.005

0.125

0.125

0.125

0.250

2.50

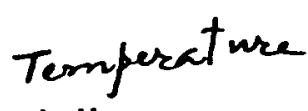

$p H$

salinity

specific Conductance $14^{\circ} \mathrm{C}$

$6 \cdot 20$

$0.00 \%$

$94 \mathrm{umoh} / \mathrm{cm}$

Corrected T.D.S III 


\section{CALISTOGA SET 7}

$r$ 172

G-172-80

ELEMENT

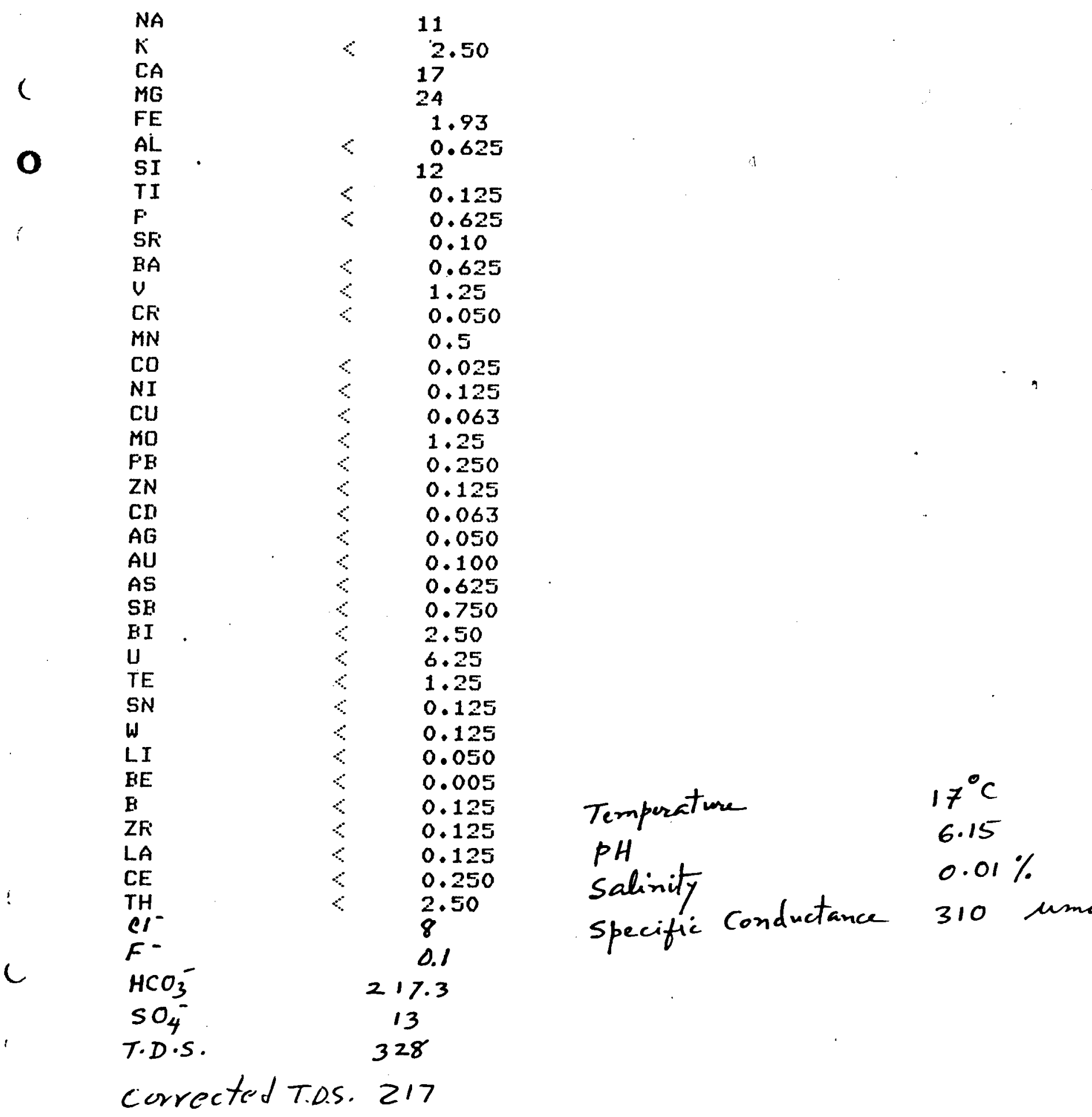


CALISTOGA SET 7

( $173 \quad$ G-173-80

ELEMENT

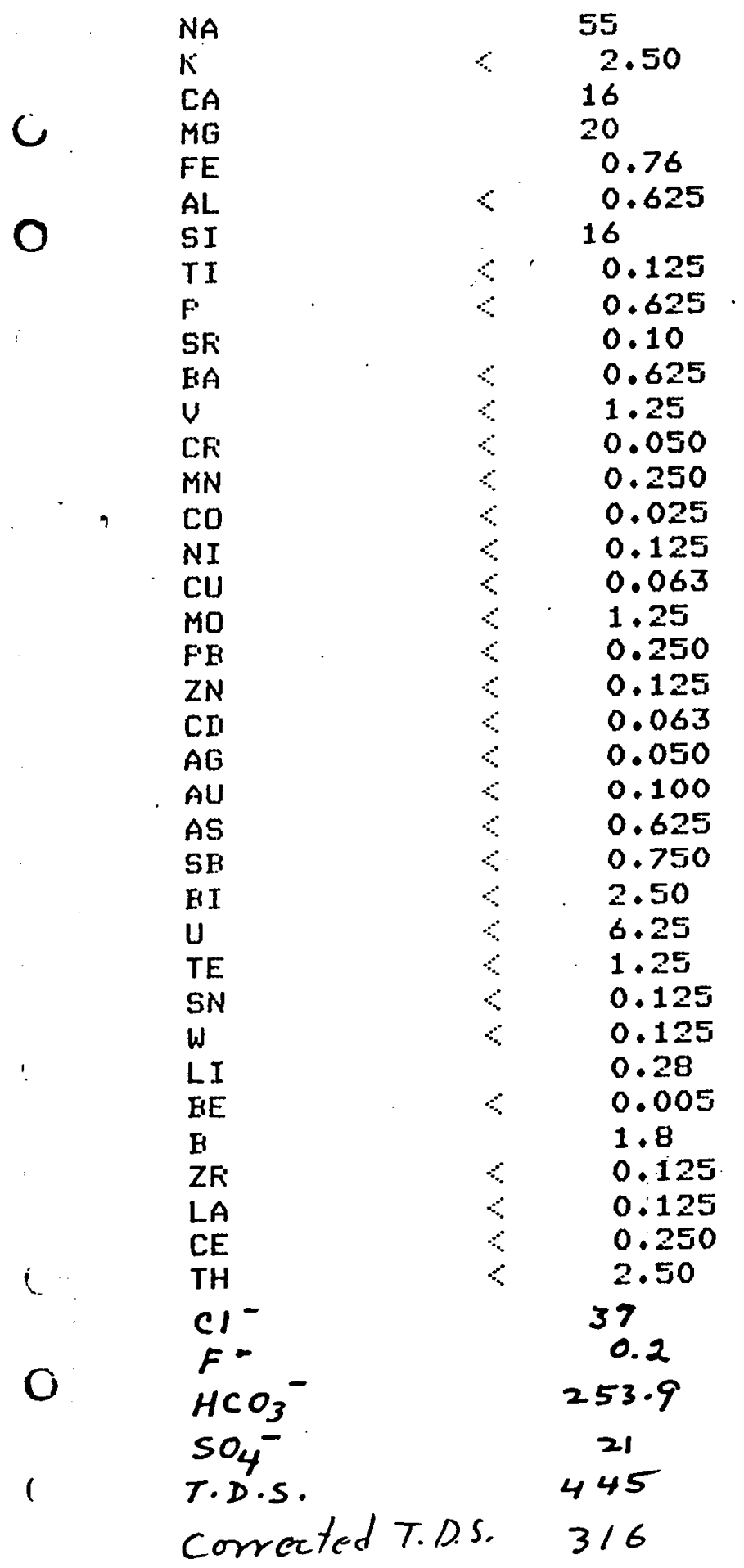

CONCENTRATION (FFMM) 
CALISTOGA SET 7

$r$

174

$G-174-80$

ELEMENT

CONCENTRATION (FF)

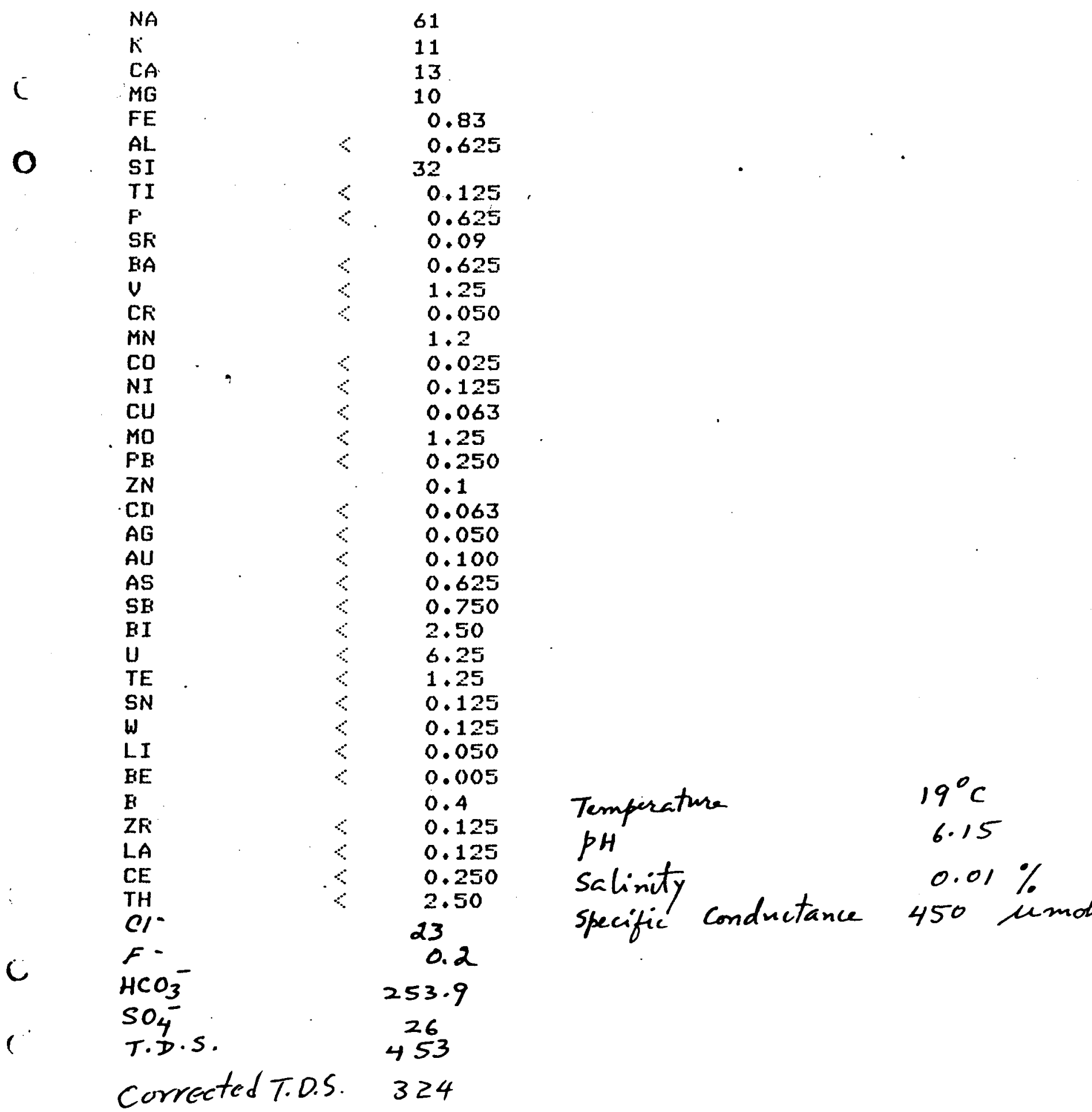




\section{CALISTOGA SET 7}

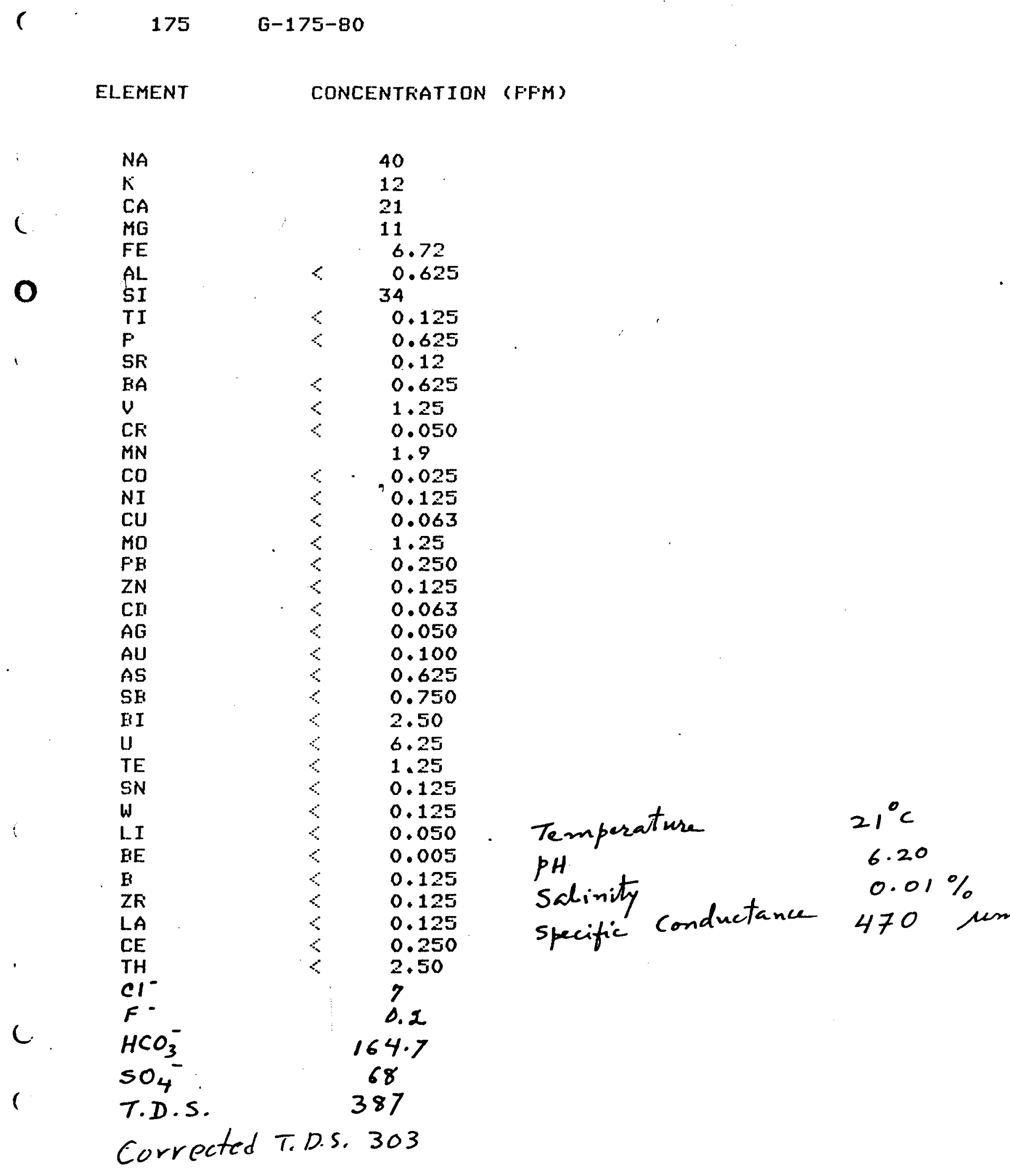


CALISTOGA SET 7

C

176

$6-176-80$

ELEMENT

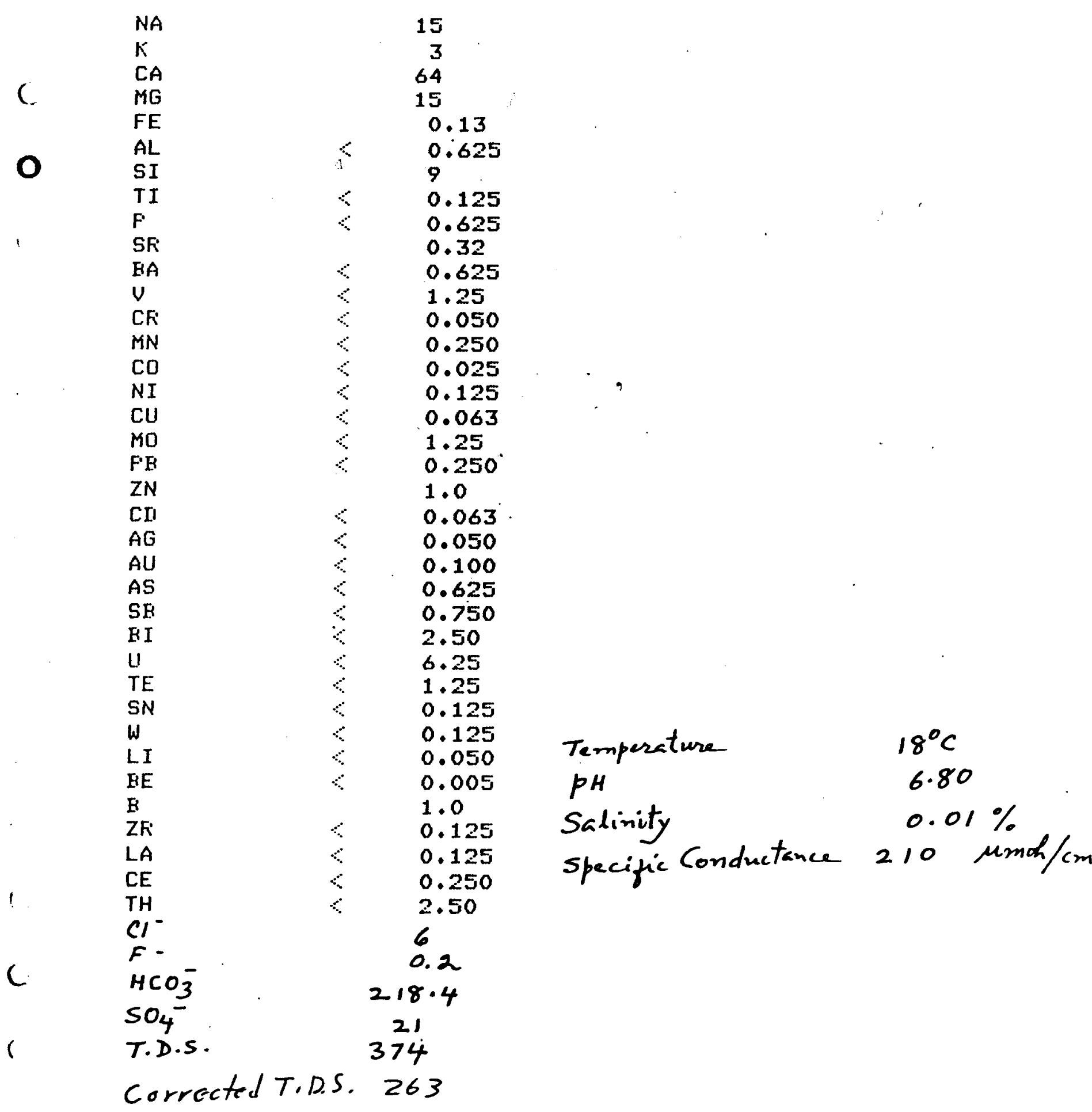


CALISTOGA SET 7

( $177 \quad$ G-177-80

ELEMENT

$\begin{array}{ll} & N A \\ & K \\ & C A \\ & M G\end{array}$

FE

AL

SI

TI

$F$

SFi

BA

U

CF:

$M N$

CO

NI

$\mathrm{CU}$

MO

FB

ZN

CII

$A G$

AU

AS

$S B$

BI

U

TE

SN

W

LI

BE

E

ZF

LA

CE

TH

$\mathrm{Cl}^{-}$

c

$\mathrm{HCO}_{3}^{-}$

$\mathrm{CO}_{2}^{-}$

$\mathrm{SO}_{4}^{-}$

T.D.S.

corrected T. D.S. 183
CONCENTFATION (FFM)

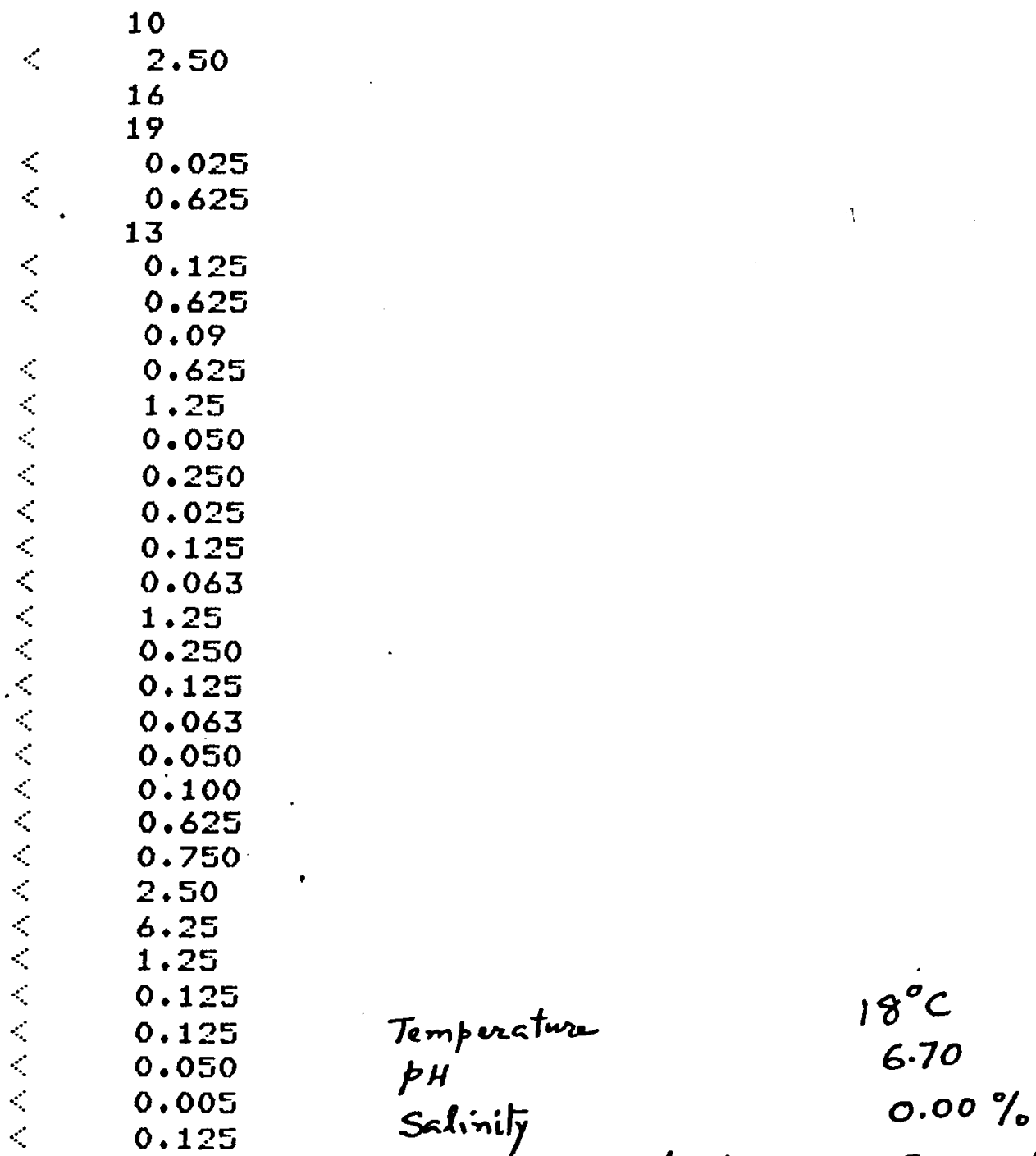

specific Conductance $340 \mu \mathrm{mo}$ 
CALISTOGA SET 8

$178 \quad G-178-80$

ELEMENT

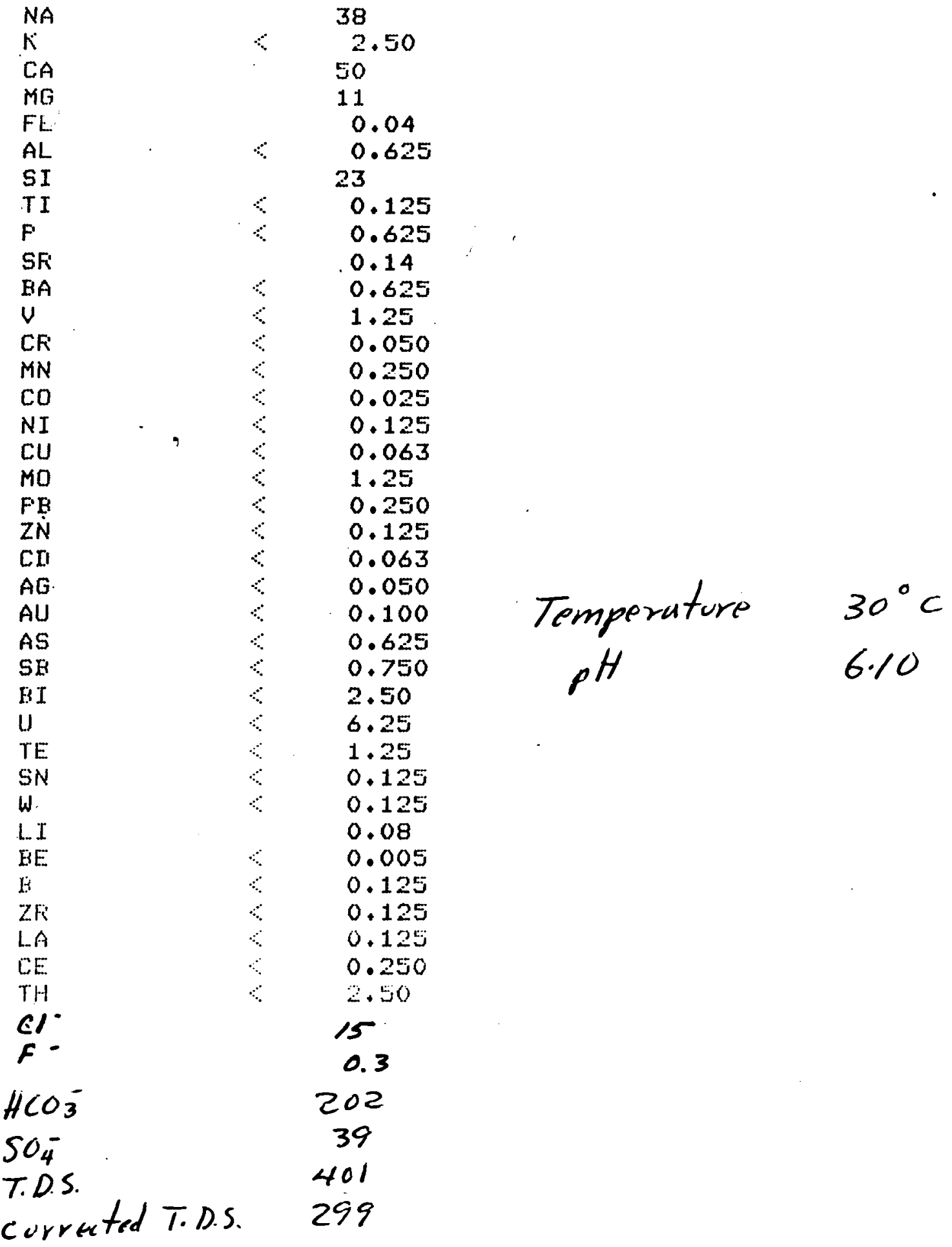


CALISTOGA SET 8

179

$G-179-80$

ELEMENT

CONCENTRATION (FEM)

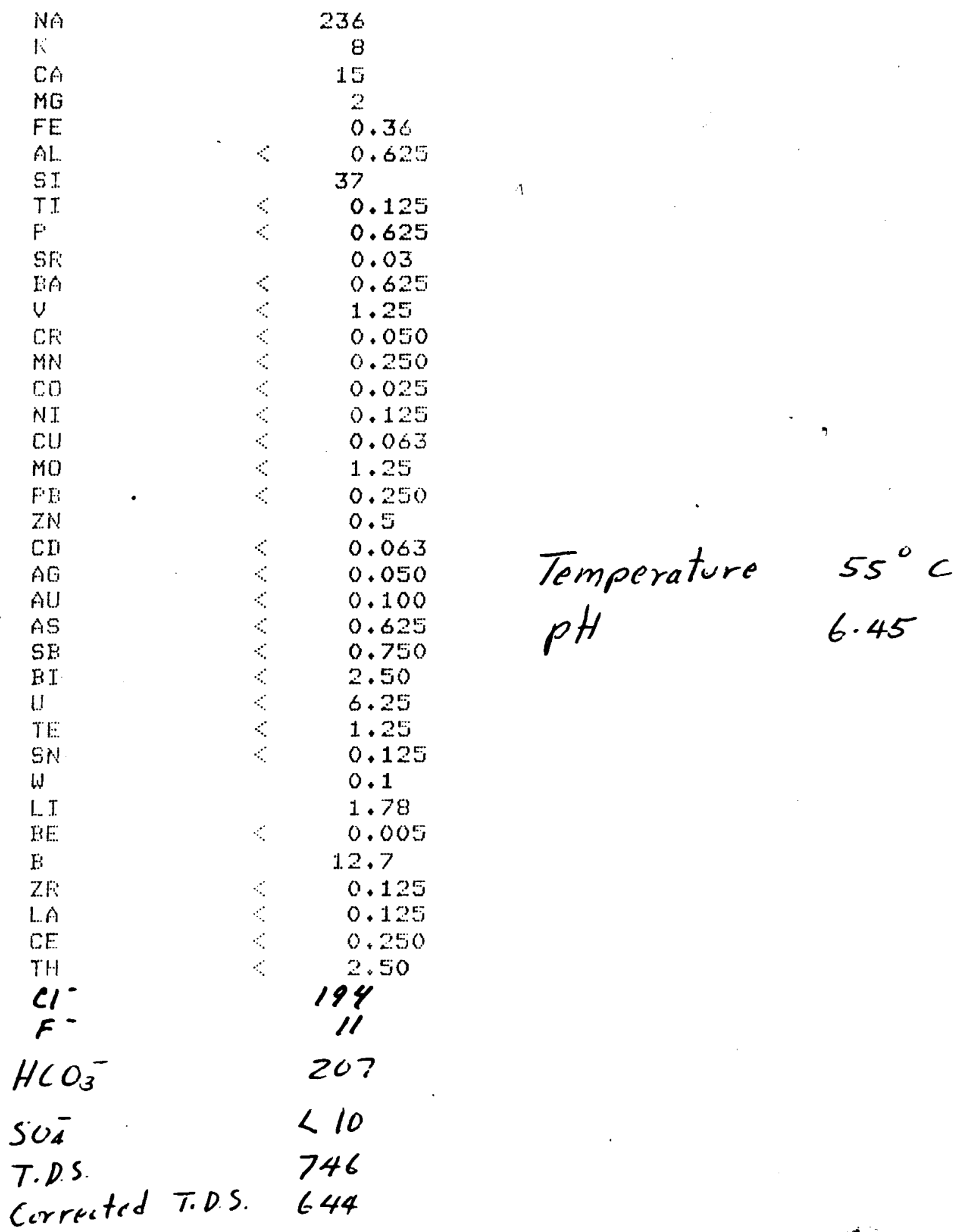


- CALISTOGA SET 8

180

$6-180-80$

ELEMENT

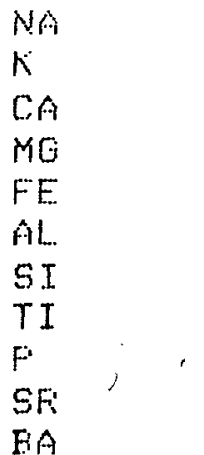

U

CF

MN

Co

NT

cu

MO)

FE

ZN

Cn

$A G$

AU

AS

$5 \mathrm{~B}$

BI

U

$T E$

SN

W

L. I

HE

$\mathrm{B}$

ZFi

L.A

CE.

$\mathrm{Cl}^{\mathrm{TH}}$

$F^{-}$

$\mathrm{HCO}_{3}^{-}$

$\mathrm{SO}_{4}^{-}$

T.D.S.

Correctad T. D.S.
CONCENTFATION (FFM)

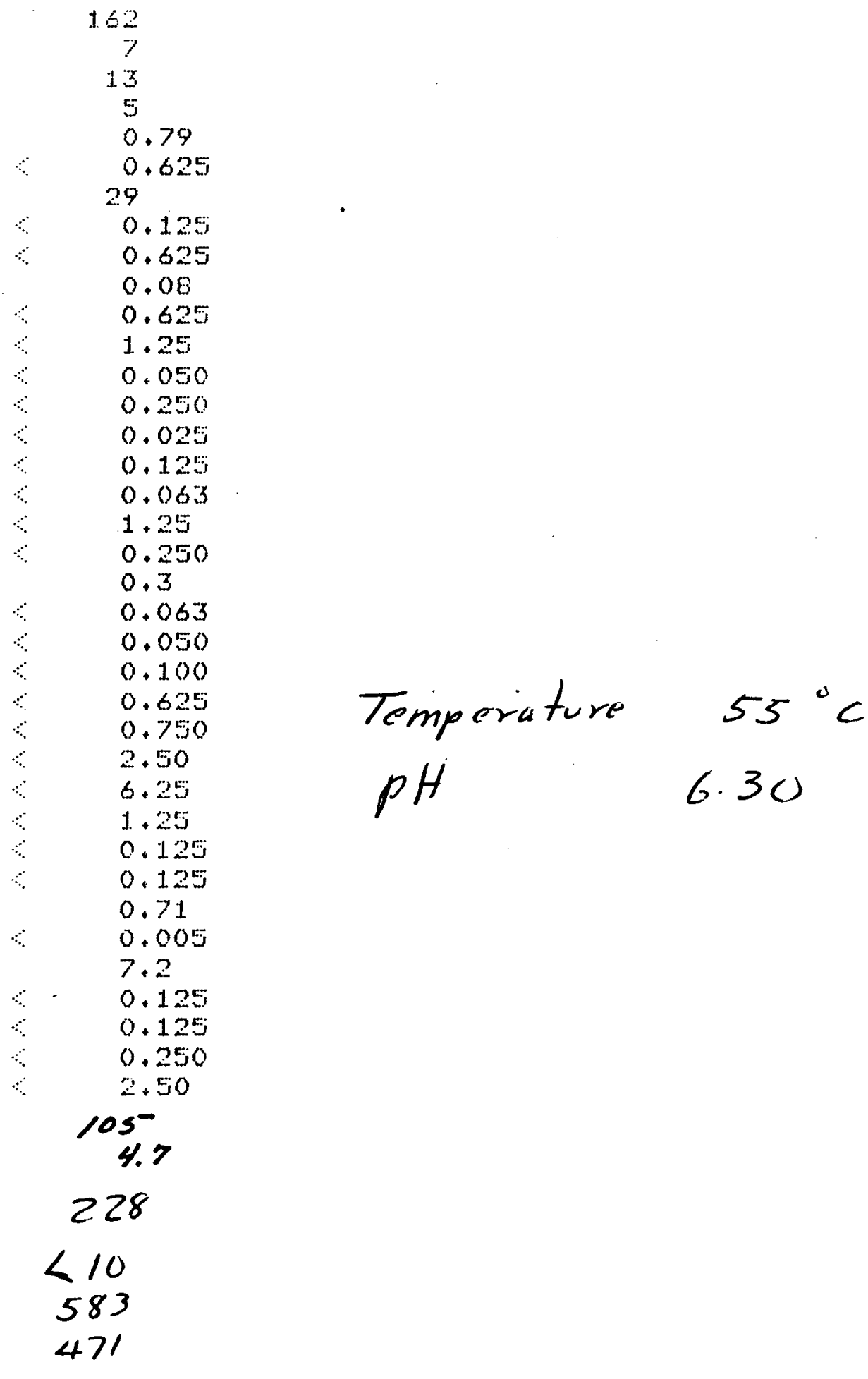


CALISTOGA SET 8

1. $81 \quad G-181-80$

ELEMENT

NA

$\mathrm{CA}$

$M G$

FE

AL.

SI.

TI

$F$

SFi

BA

U

CFi

$M N$

$\mathrm{CO}$

$N I$

$\mathrm{CU}$

MO

FB

ZN

CII

$A G$

AU

AS

SE

BI

U.

TE

SN

W

LI

BE

B

ZFi

LA

CE

$\mathrm{TH}$

$\mathrm{Cl}$

$F$ -

$\mathrm{HCO}_{3}^{-}$

$\mathrm{SO}_{4}^{-}$

T.DS.

Corrected T.D.S.
CONCENTFATION (FFM)

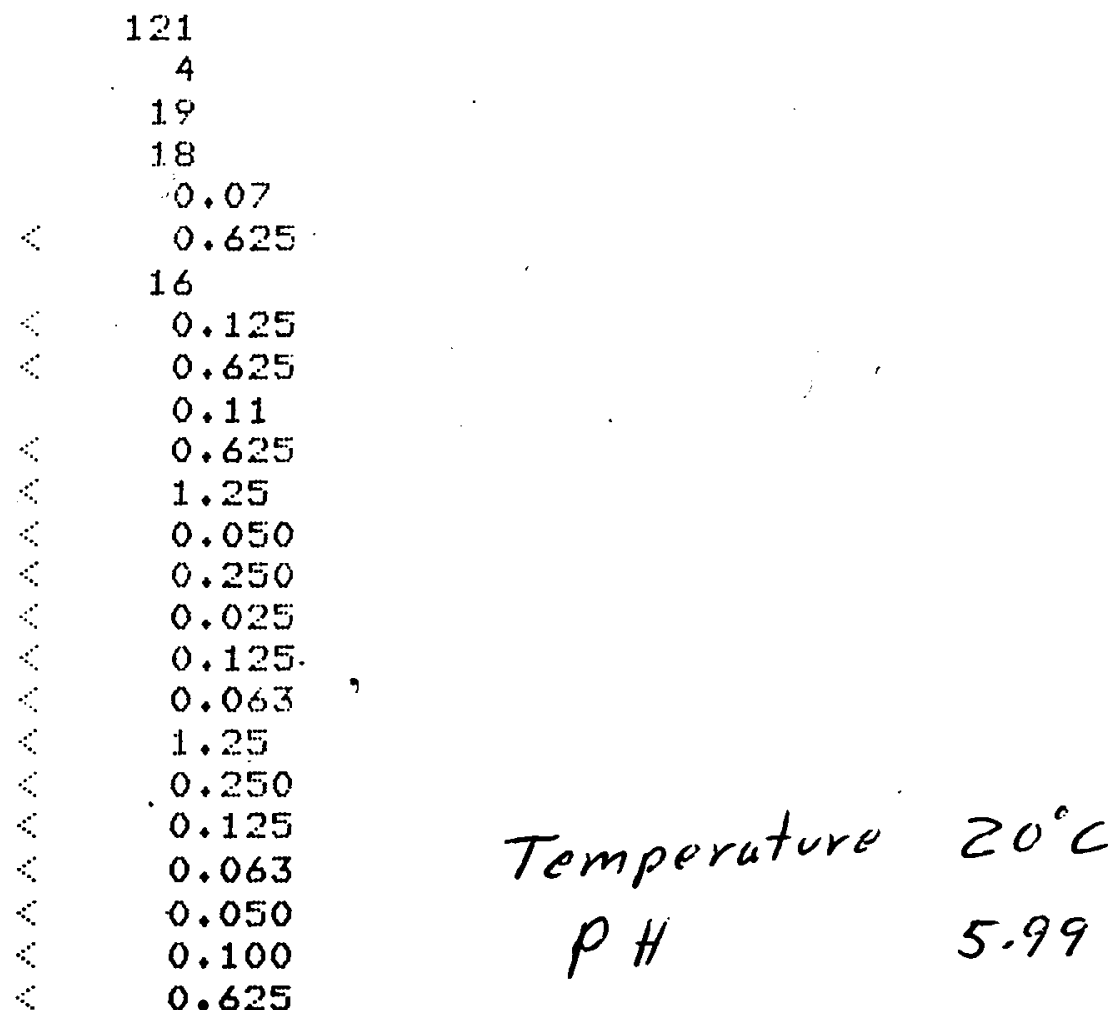

0.625

0.750

2.50

6.25

1.25

0.125

0.125

0.06

0.005

8.3

0.125

0.125

0.250

2.50

107

1.7

225.7

$<10$

541

430 
CALISTOGA SET 8

182 G-182-80

ELEMENT CONCENTRATION (FPM)

NA

$K$

CA

MG

FE

AL.

SI

PI

SF

BA

U

CF

$M N$

CO

$N I$

CU

MO

FB

ZN

CII

$A G$

AU

AS

SE

EI

U

TE

SN

W

LI

BE

B

ZR

LA

CE

TH

c)

F -

77

5

16

4

1.17

$<\quad 0.625$

31

$<\quad 0.125$

$<\quad 0.625$

0.06

$<\quad 0.625$

$<1.25$

$<0.050$

0.4

$6 \quad 0.025$

$<\quad 0.125$

$<\quad 0.063$

$<\quad 1.25$

$<\quad 0.250$

$<\quad 0.125$

$<\quad 0.063$

$<\quad 0.050$

$<\quad 0.100$

Tenperature

$18^{\circ} \mathrm{C}$

$p H$

6.20

1

<. 0.625

$<\quad 0.750$

$<\quad 2.50$

$<\quad 6.25$

$8 \quad 1.25$

$<\quad 0.125$

$\therefore \quad 0.125$

$<\quad 0.050$

$\therefore \quad 0.005$

0.2

$<\quad 0.125$

$<\quad 0.125$

$<\quad 0.250$

$<2.50$

8

0.2

$\infty 0$

$\mathrm{HCO}_{3}^{-}$

$\mathrm{Sq}^{3}$

C

T.DS.

240.2

11

414

Comected T.D.S. 296 


\section{CALISTOGA SET 8}

183 G-183-80

\section{ELEMENT}

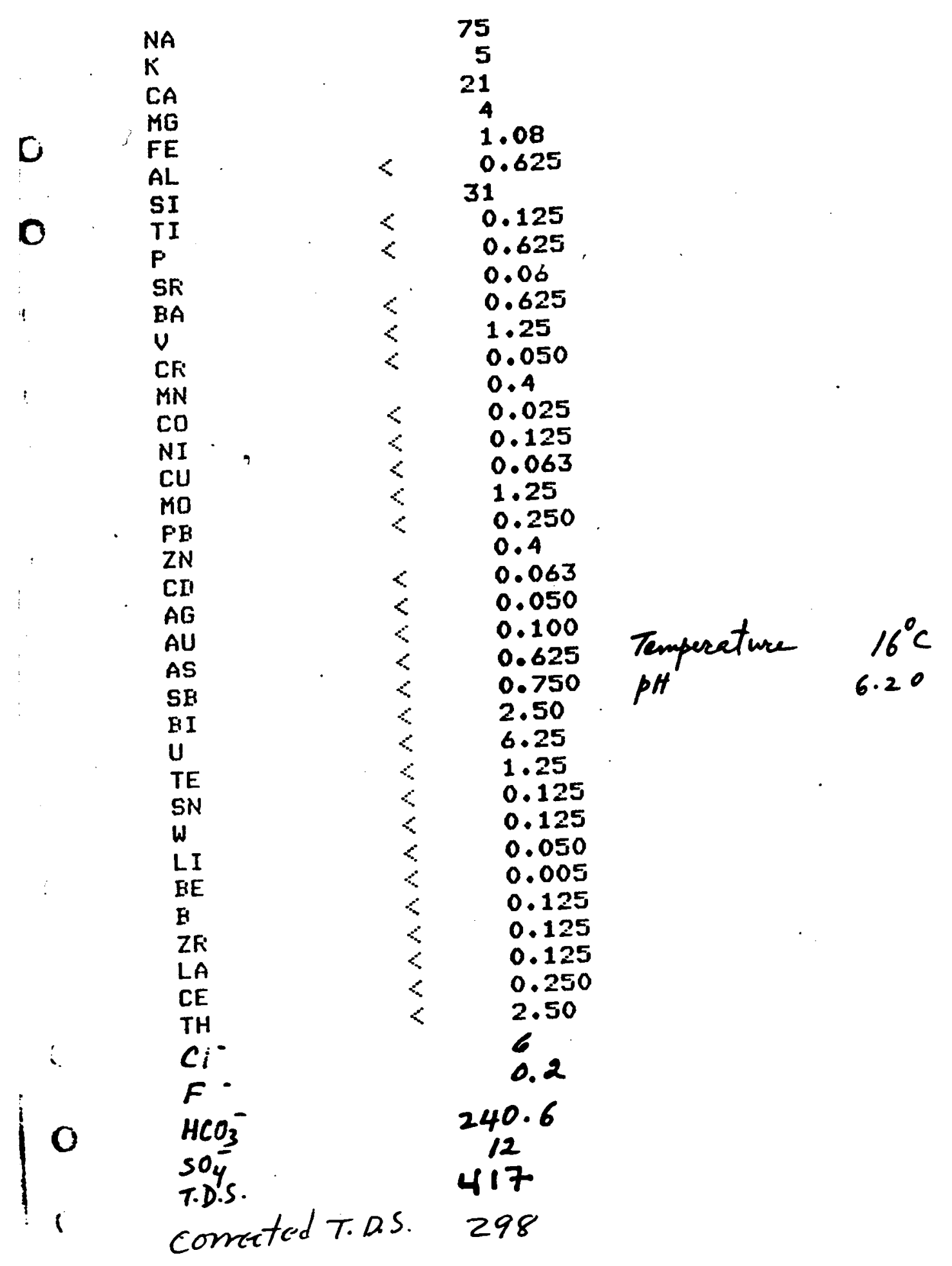

CONCENTRATION (FPM) 


\section{CALISTOGA SET $B$}

184

$6-184-80$

\section{ELEMENT}

NA

$K$

CA

MG

FE

AL

SI

TI

$P$

SR

$B A$

V

CR

$M N$

CO

$N I$

CU

MO

PB

ZN

CD

AG

AU

AS

SB

EI

U

TE

SN

W

L.I

BE

B

ZR

LA

CE

TH

c/

$F$ -

$\mathrm{HCO}_{3}^{-}$

$\mathrm{SO}_{4}^{-}$

T.8.S.
CONCENTRATION (FFM) -

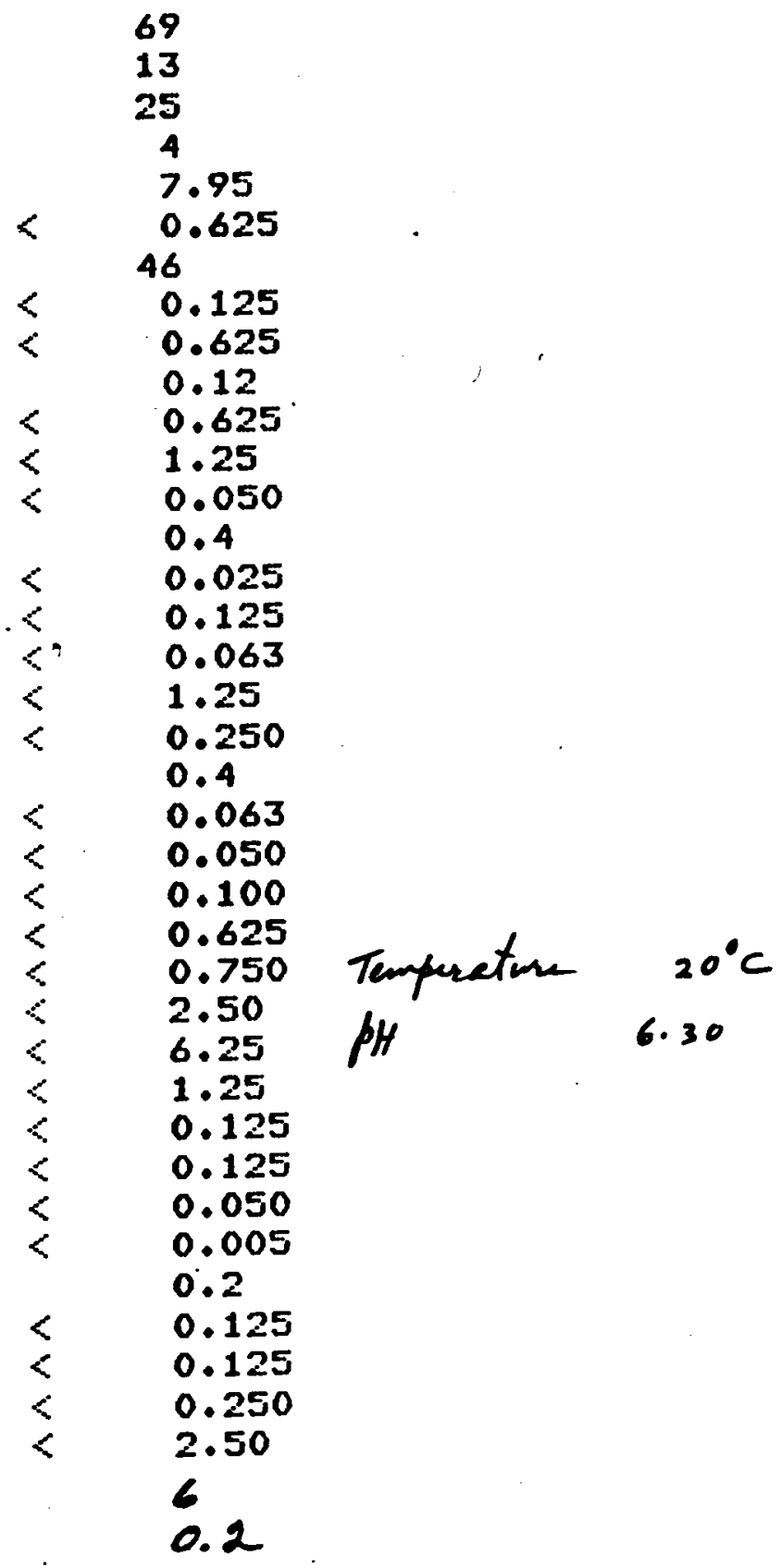

$238 \cdot 3$

$<10$

413

corceted T.D.S. 296 
CALISTOGA SET 8

$$
185 \quad G-185-80
$$

ELEMENT

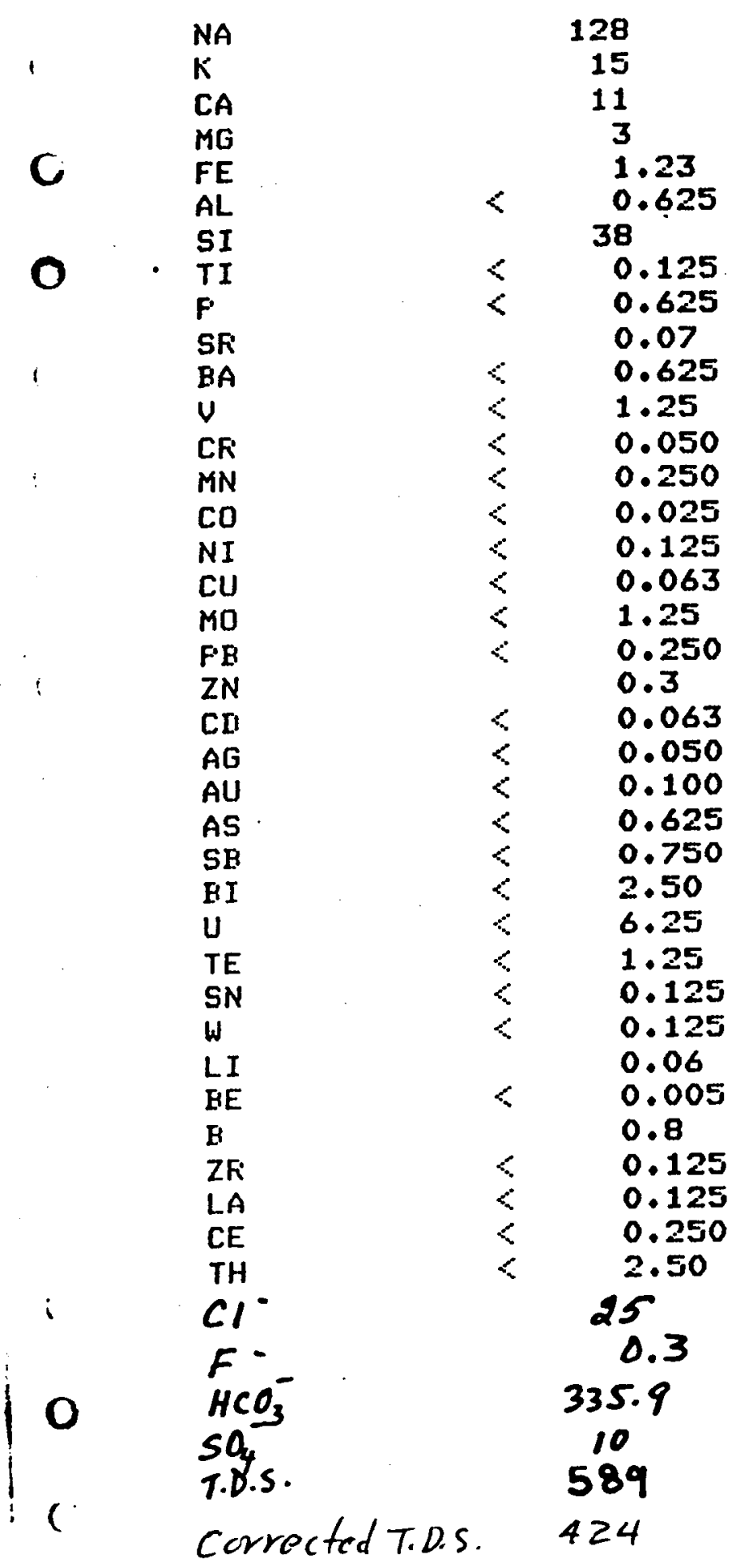

CONCENTRATION (PFM)

1

\begin{tabular}{ll} 
Temperature & $20^{\circ} \mathrm{C}$ \\
\hline $\mathrm{PH}$ & 6.39
\end{tabular}

Salinit

N.2.

specific Conductance N.D. 


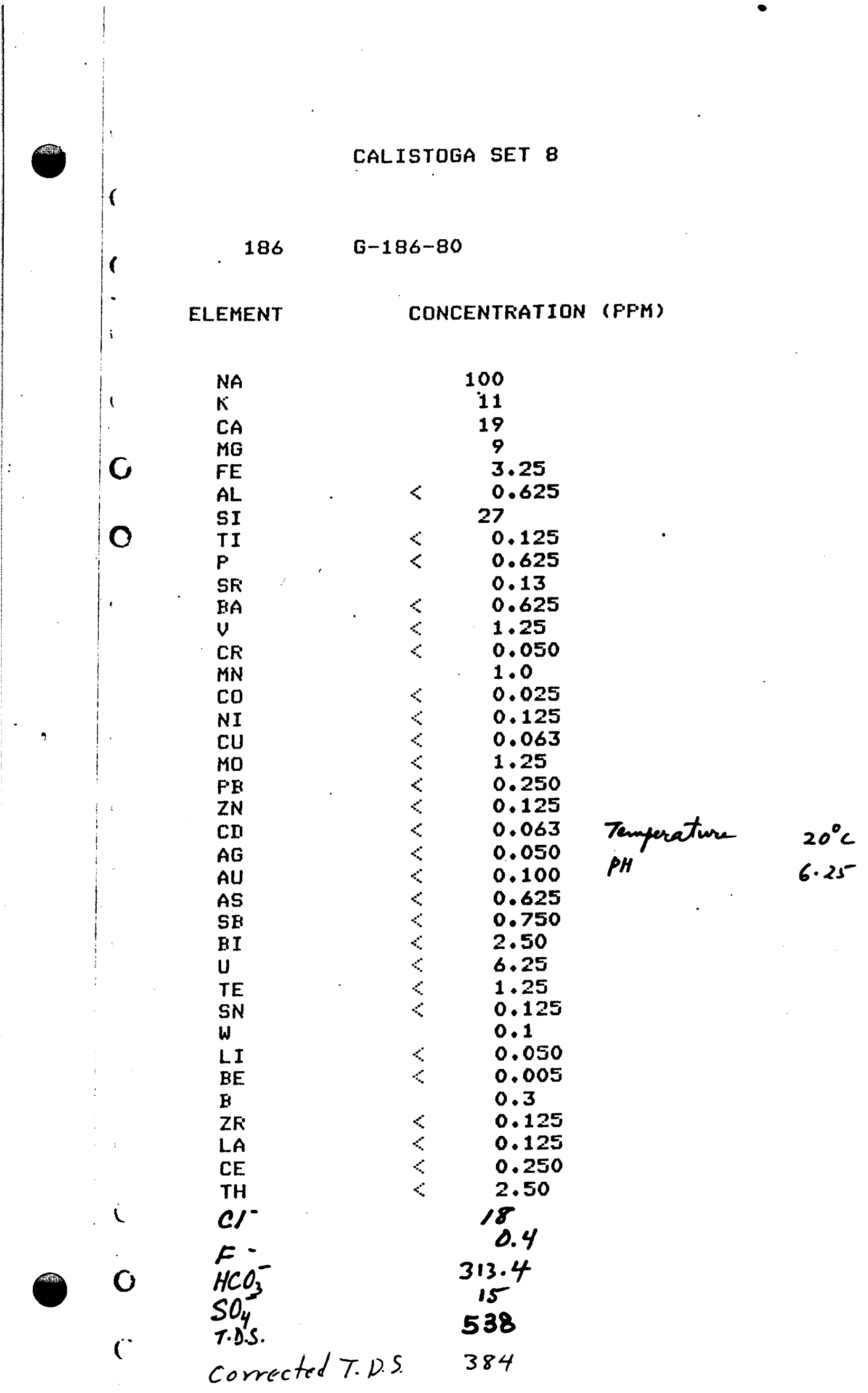




\section{CALISTOGA SET 8}

187 G-187-80

\section{ELEMENT}

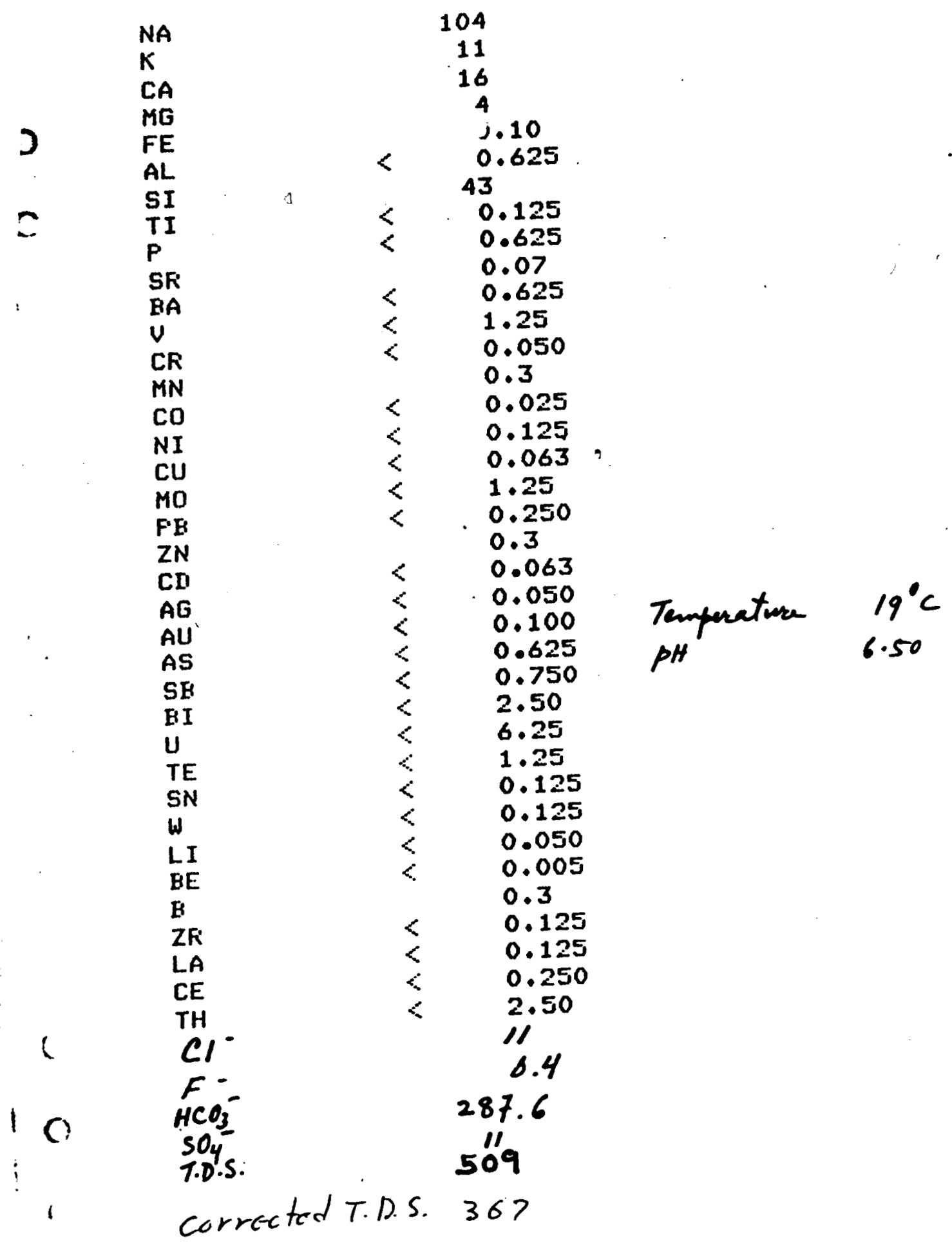

\author{
CONCENTKATION (FF'M)
}


CALISTOGA SET 8

188 G-188-80

ELEMENT

CONCENTRATION (FFM)

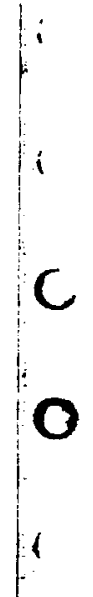

$N A$
$K$
$C A$
$M G$

FE

AL

TI

$P$

SF

BA

CR

MN

CO

NI

CU

ME

ZN

CD

AL

AS

SE

BI

U

TE

SN

LI

BE

$B$

ZF

LA

CE

c/

F.

$\mathrm{HCO}_{3}^{-}$

$\mathrm{SO}_{4}^{-}$

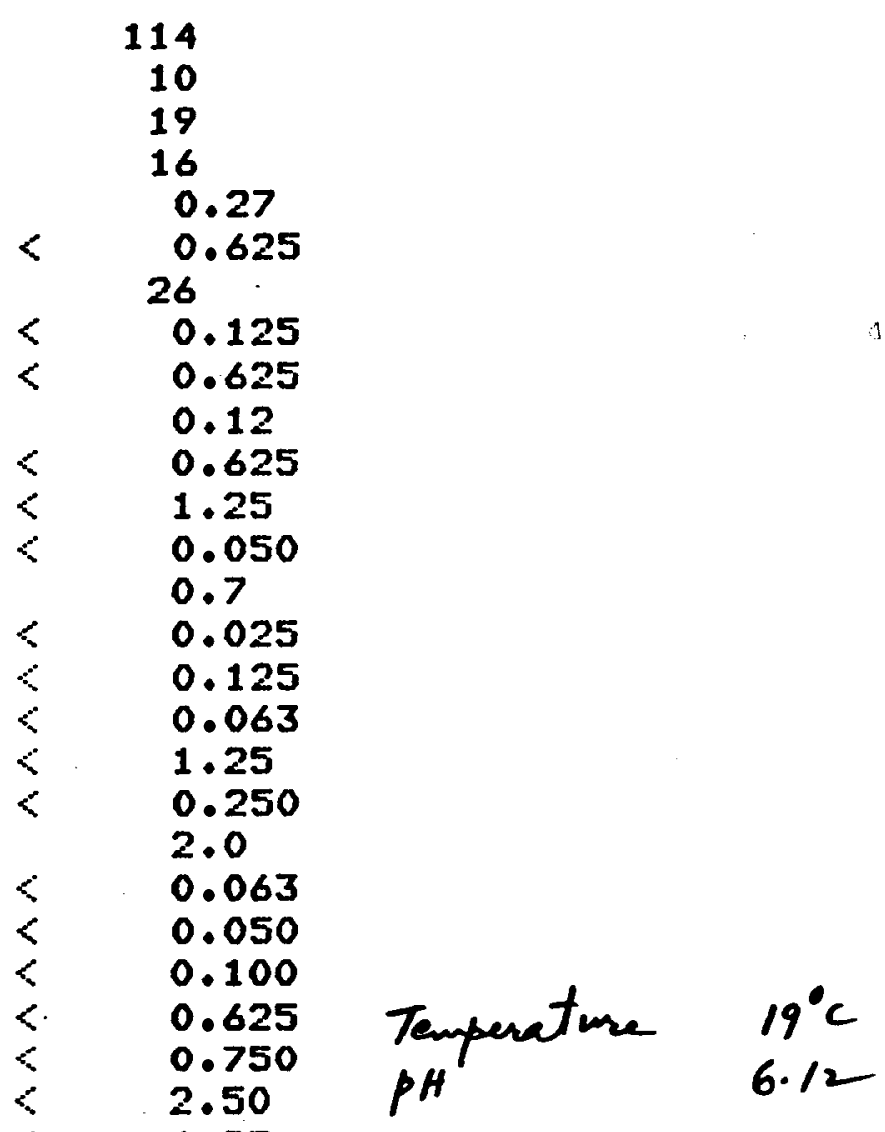

0

$\therefore \quad 6.25$

$<\quad 1.25$

$<\quad 0.125$

$<\quad 0.005$

1.3

$<\quad 0.125$

$\begin{array}{ll}< & 0.250 \\ < & 2.50\end{array}$

36

1

C.

0.3

$366 \cdot 8$

610

Corrected T. D.S. 431 


\section{CALISTOGA SET 8}

(.

$$
189 \text { G-189-80 }
$$

\section{ELEMENT}

CONCENTRATION (FPM)

c.

o

NA

$K$

CA

$M G$

FE

$A L$

SI

TI

F

SF

BA

V

CR

$M N$

CO

$N I$

CU

$\mathrm{MO}$

$P B$

ZN

CII

AG

AU

AS

SE

EI

$U$

TE

SN

W

LI

HE

I

ZR

LA

CE

$\mathrm{TH}$

$\mathrm{Cl}^{-}$

$F^{-}$

$\mathrm{HCO}_{3}^{-}$

$\mathrm{SO}_{4}^{-}$

T.D.S.

3

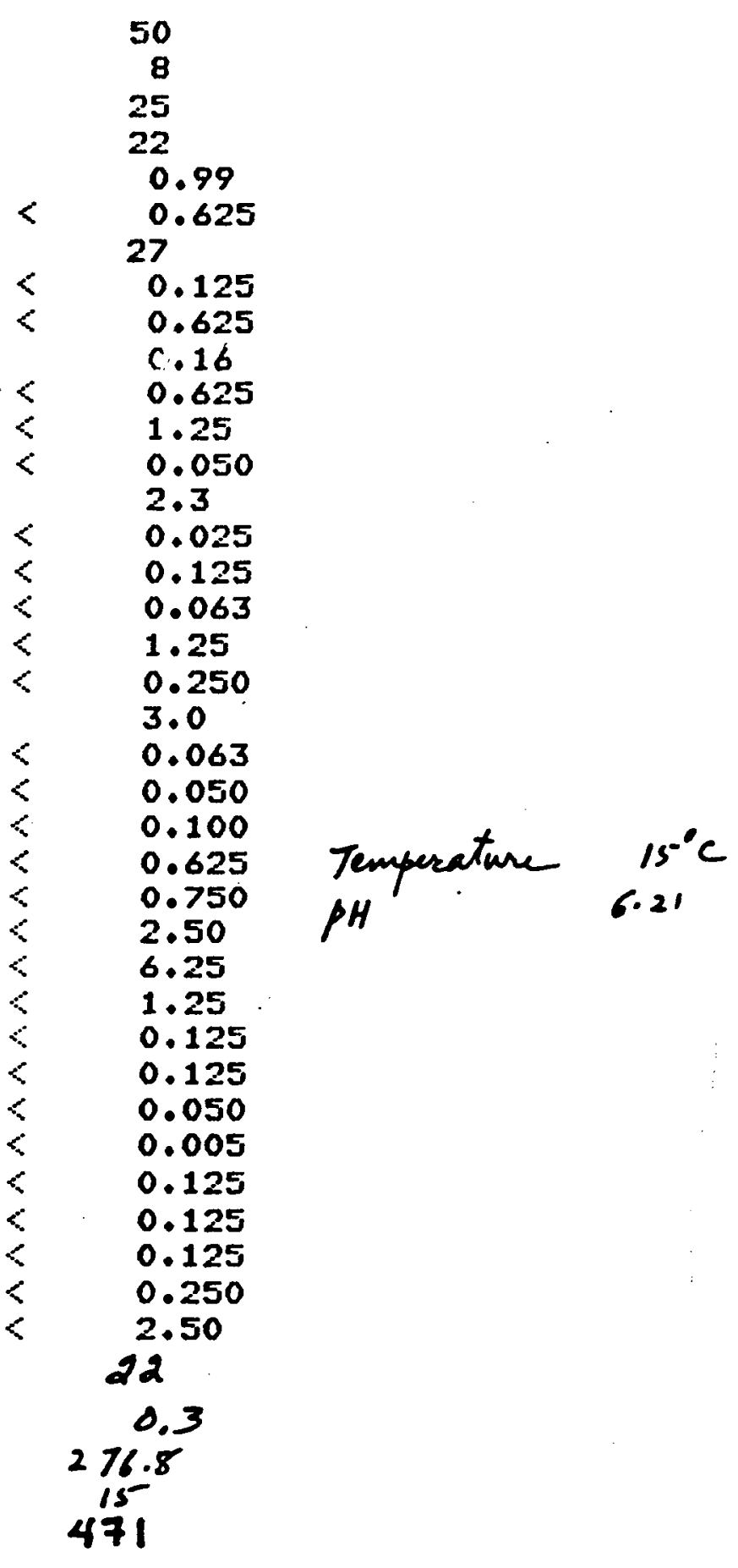

corrected T.D.S. 335 


\section{CAI.ISTOGA SET 8}
190
G-190-80

\section{ELEMENT}

CONCENTRATION (FPM)

NA

$K$

CA

MG

FE

AL

SI

TI

$P$

SF

BA

$\checkmark$

CR

MN

CO

NI

CU

MO

FB

ZN

CII

AG

AU

AS

SB

BI

U

TE

SN

W

LI

BE

E

ZF

LA

CE

TH

c/

$F \cdot$

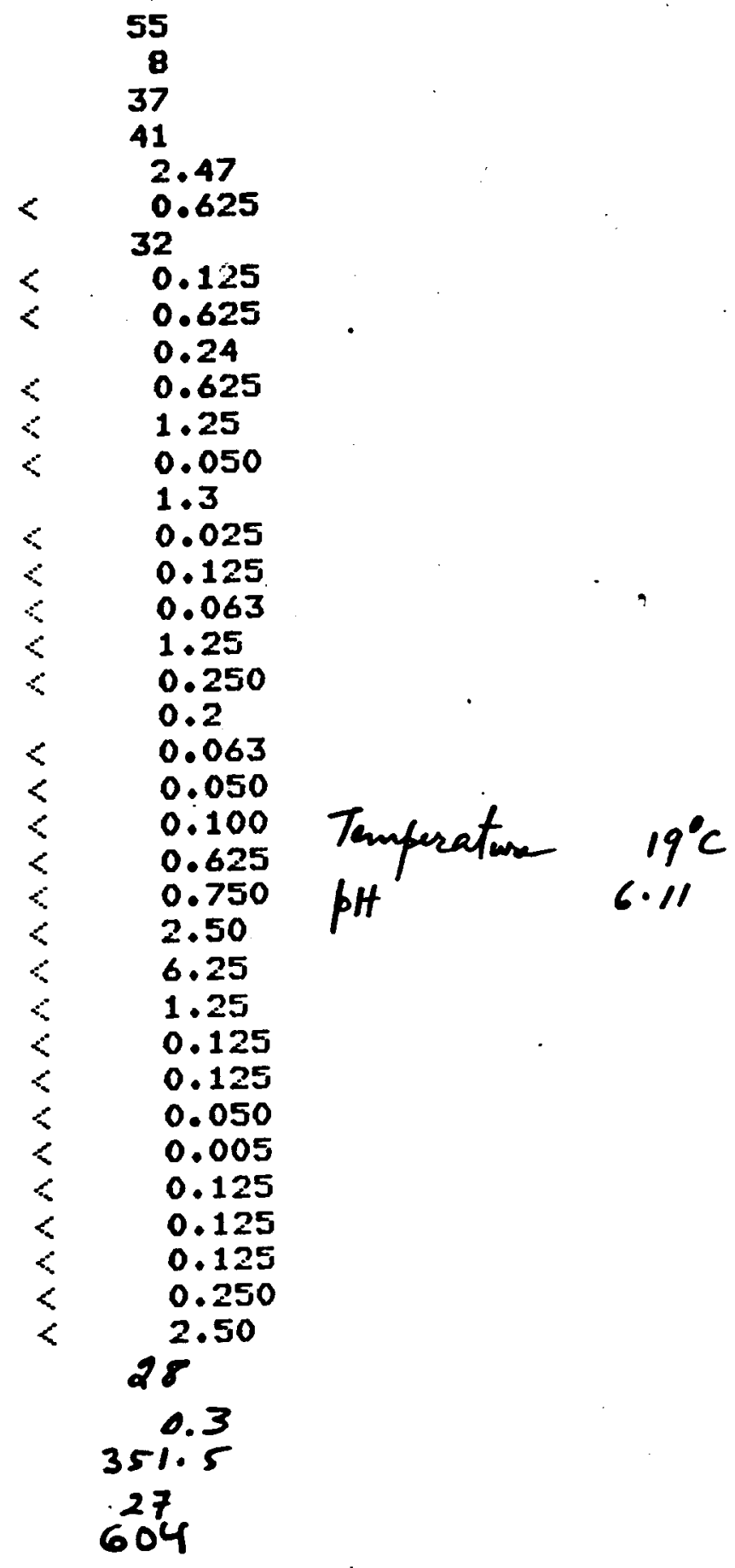

T.D.S.

corrected T. D.S. 43 ' 
CALISTOGA SET $B$

C. 191 G-191-80

ELEMENT

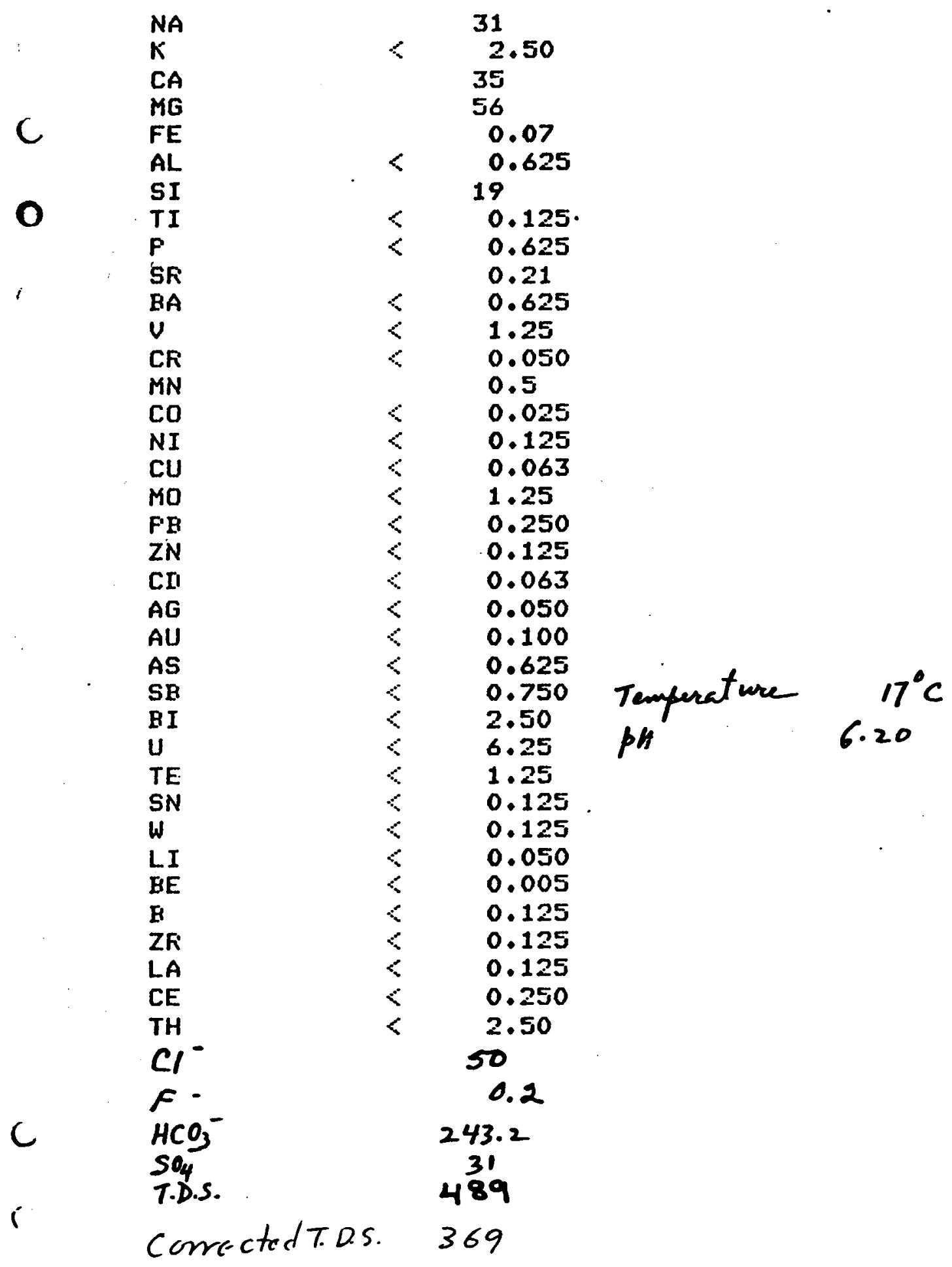




\section{CALISTOGA SET 8}

$r$

(.) $192 \quad$ G-192-80

ELEMENT CONCENTRATION (F.FM)

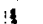

NA

$K$

CA

110

12

MG

C) F5.

AL

SI

TI

F

SF

BA

V

CF

$M N$

CO

NI

CU

MO

PB

ZN

CI

AG

AU

AS

SB

BI

$U$

TE

SN

$W$

LI

BE

H

ZF:

LA

CE

TH

$\mathrm{Cl}^{-}$

17

10

1.18

$<\quad 0.625$

35

$<\quad 0.125$

0.7

0.09

$<\quad 0.625$

$<1.25$

$<\quad 0.050$

0.6

$<\quad 0.025$

$<\quad 0.125$

$<\quad 0.063$

$<\quad 1.25$

$<\quad 0.250$

0.7

$<\quad 0.063$

$\therefore \quad 0.050$

$<\quad 0.100$

$<\quad 0.625$

$<\quad 0.750$

$\therefore \quad 2.750$

6.25

1.25

0.125

0.125

0.050

0.005

0.3

$<\quad 0.125$

$<\quad 0.250$

$<2.50$

$F$ -

$\mathrm{HCO}_{3}^{-}$

T.0.5.

1

0.4

331.7

$-12$

C:

Corrected T. D.S. 389 
CALISTOGA SET 8

$$
193 \text { G-193-80 }
$$

ELEMENT

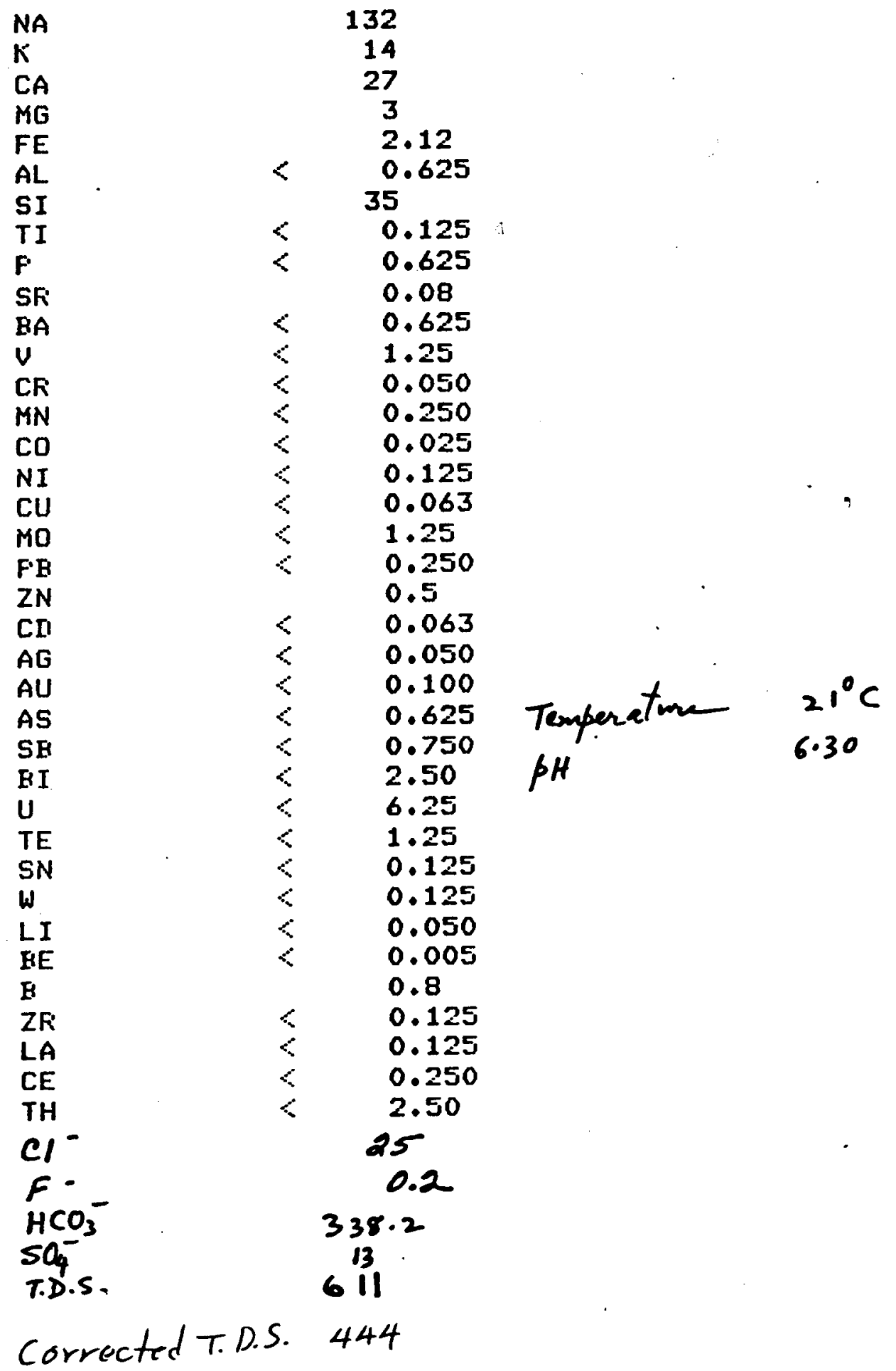


CALISTOGA SET 8

r. $194 \quad$ G-194-80

ELEMENT

CONCENTRATION (FFM)

. NA

$K$

CA

C $\quad$ FE

AL.

O $\quad$ TI

F.

EF

BA

$\checkmark$

CR

MN

CO

$N I$

CU

MO

$P E$

$Z N$

CII

AG

AU

AS

SB

BI

U

TE

SN

W

LI

BE

$B$

ZFi

LA

CE

TH

$\mathrm{CI}^{-}$

25

3

17

7

3.92

0.7

25

$<\quad 0.125$

$<\quad 0.625$

0.07

$<\quad 0.625$

$\therefore \quad 1.25$

$\therefore \quad 0.050$

$<\quad 0.250$

$<\quad 0.025$

$\therefore \quad 0.125$

$<\quad 0.063$

$<\quad 1.25$

$<\quad 0.250$

0.5

$<\quad 0.063$

$\therefore \quad 0.050$

$\div \quad 0.100$

$<\quad 0.625$

$\div \quad 0.750$

$<\quad 2.50$

$<6.25$

$\therefore \quad 1.25$

$<\quad 0.125$

$<\quad 0.125$

$<\quad 0.050$

$<\quad 0.005$

$<0.125$

$<\quad 0.125$

$<0.125$

$\therefore \quad 0.250$

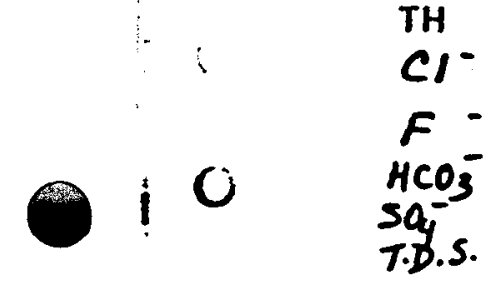

C

T.D.S.

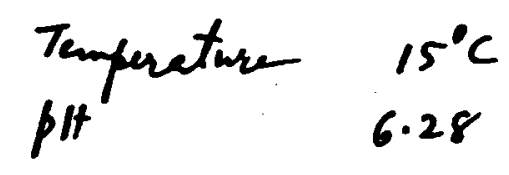

$<2.50$

13.1

75.9

10

201

Cometed T.D.S. 164 


\section{CALISTOGA SET 9}

1

$r$

195

G-195-80

ELEMENT

CONCENTKATION (FFM)

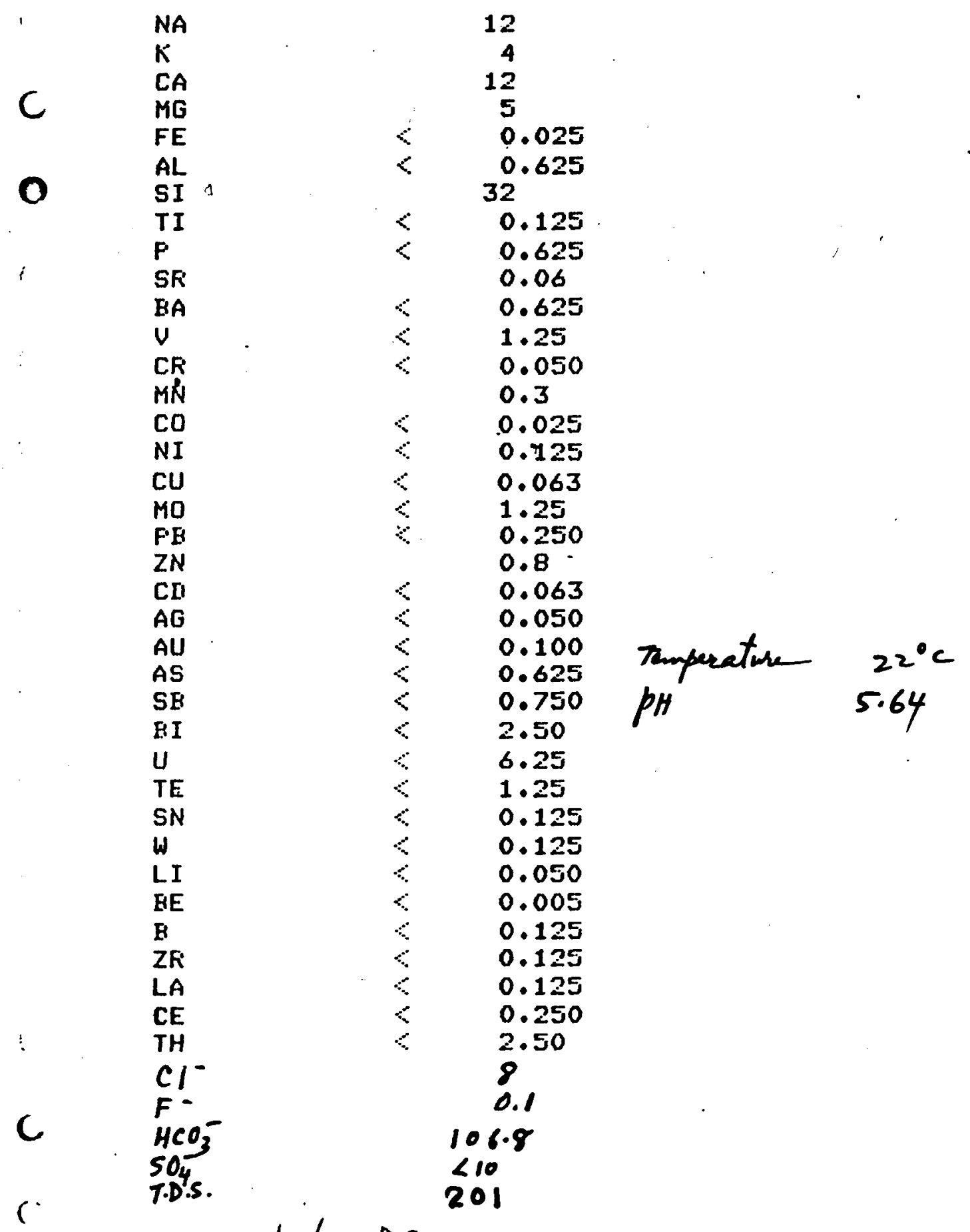

Corrected.T. D.S 148 
CALISTOGA SET 9

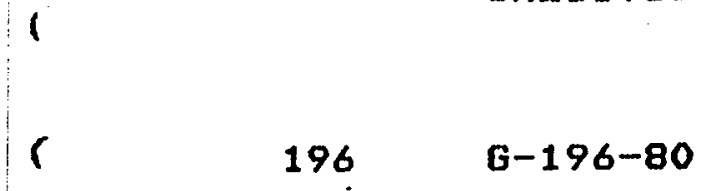

ELEMENT

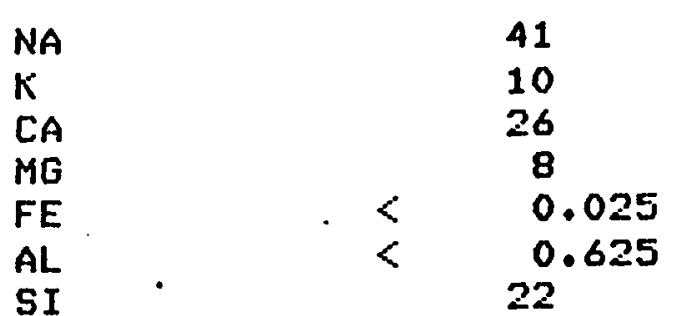

CONCENTRATION (FFM)

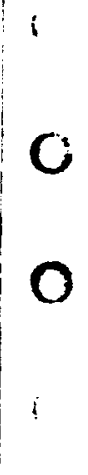

SR

$<\quad 0.125$

$<\quad 0.625$

0.06

$<\quad 0.625$

$\begin{array}{lll}U & < & 1.25 \\ C F & < & 0.050\end{array}$

$M N$

0.4

CO $<\quad 0.025$

$\begin{array}{lll}N I & < & 0.125 \\ \mathrm{CU} & < & 0.063\end{array}$

$\begin{array}{lll}\mathrm{MO} & < & 1.25 \\ \mathrm{PH} & < & 0.250\end{array}$

ZN 1.6

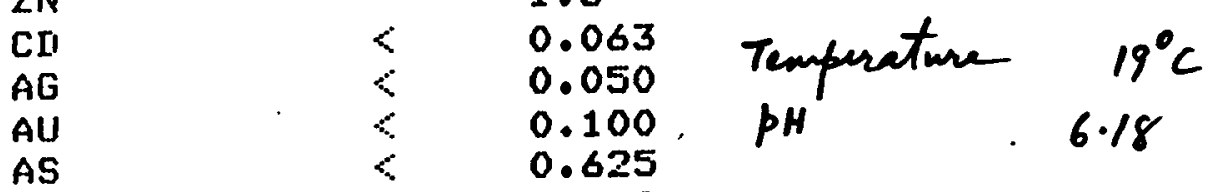

SE

BI

U

TE

SN

W

LI

BE

B

ZR

LA

CE

TH

$\mathrm{CI}^{-}$

$\mathrm{HCO}_{3}^{-}$

$d$

0.750

2.50

6.25

1.25

0.125

0.125

0.050

0.005

0.125
0.125

0.125

$\begin{array}{ll}< & 0.250 \\ 2 & 2.50\end{array}$

$236.4^{0.3}$

$\mathrm{SO}_{4}^{-3}<10$

T.D.S.

corrected T.D.S. 257 
- calistoga SET 9

197

$G-197-80$

ELEMENT

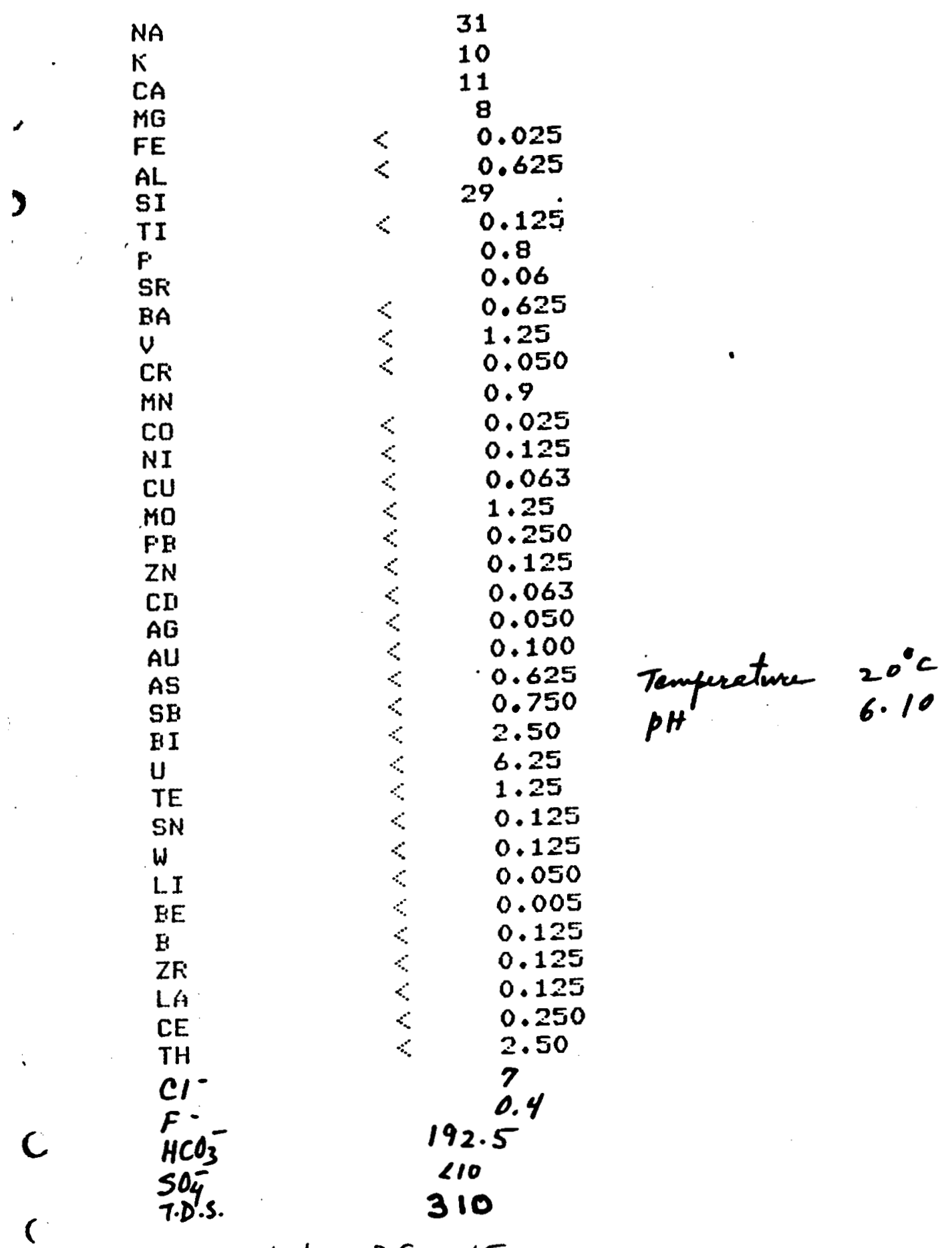

Corrected T.D.S. 215 
CALISTOGA SET 9

198

G-198-80

ELEMENT

CONCENTRATION (FFPY)

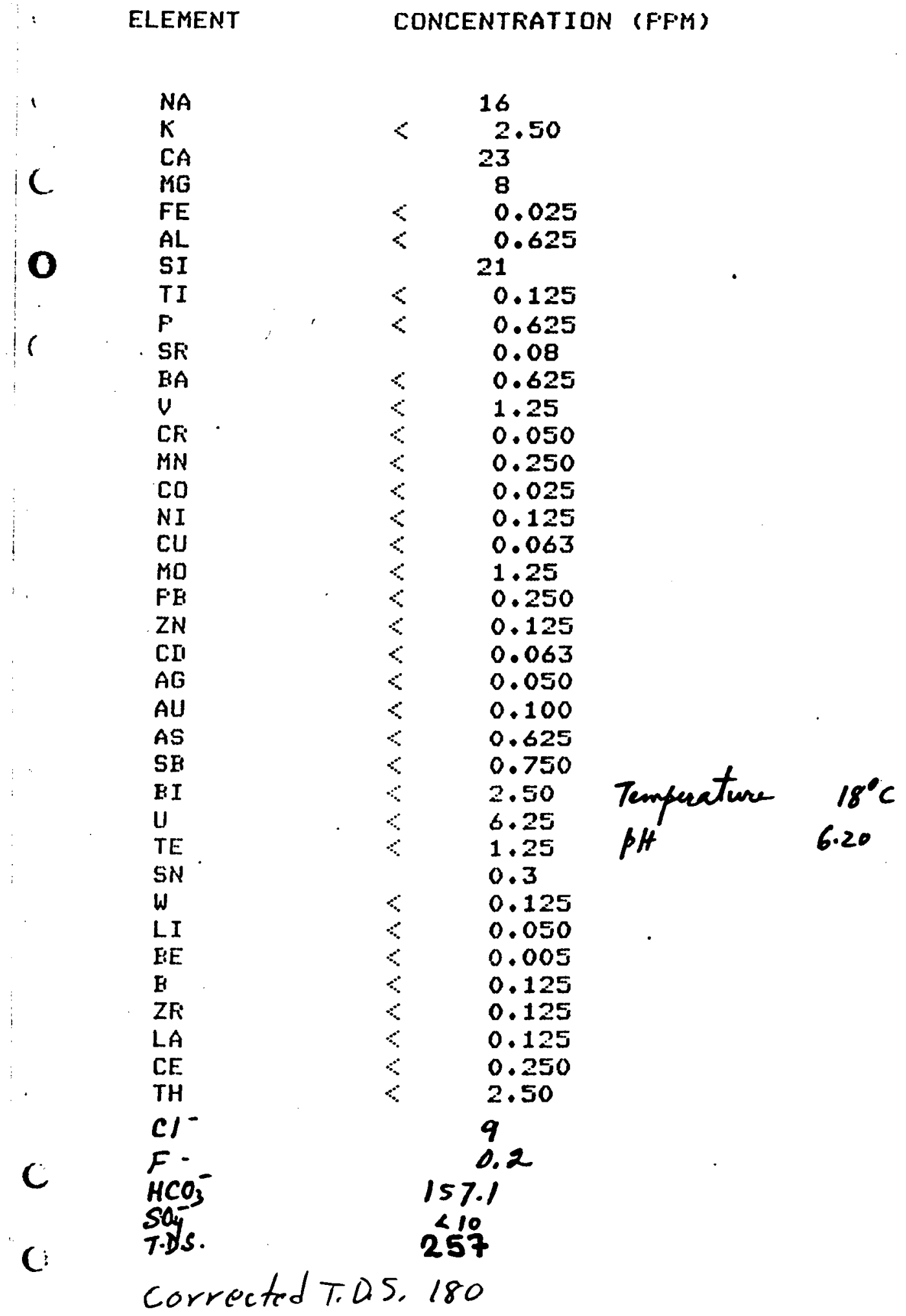




\section{CALISTOGA SET 9}

199

G-199-80

ELEMENT

NA

$K$

CA

MG

FE

AL

0

SI

TI

$F$

SFi

BA

$\checkmark$

CR

$M N$

CO

$N I$

CU

$\mathrm{MO}$

PB

$Z N$

CII

$A G$

AU

AS

SB

FI

$U$

TE

SN

W

LI

BE

B

ZR

LA

CE

TH

$\mathrm{Cl}^{-}$
CONCENTFIATION (F.F'M)

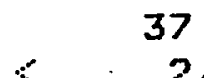

$<\quad 2.50$

28

12

$<\quad 0.025$

$<\quad 0.625$

27

$<\quad 0.125$

$<\quad 0.625$

0.12

$<\quad 0.625$

$<1.25$

$<0.050$

$<\quad 0.250$

$<\quad 0.025$

$<0.125$

0.063

$<1.25$

$\therefore \quad 0.250$

0.1

$\therefore \quad 0.063$

$\therefore \quad 0.050$

$<0.100$

< 0.625

0.125
0.750

2.50

6.25

1.25

0.125

0.050

0.005

0.2

0.125

0.125

0.250

2.50

\section{2}

0.2

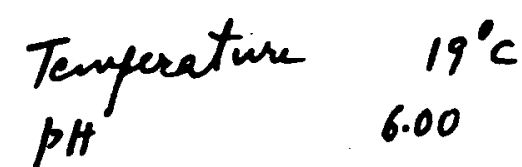

177.7

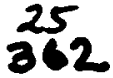

corrected T.DS 274 
CALISTOGA SET 9

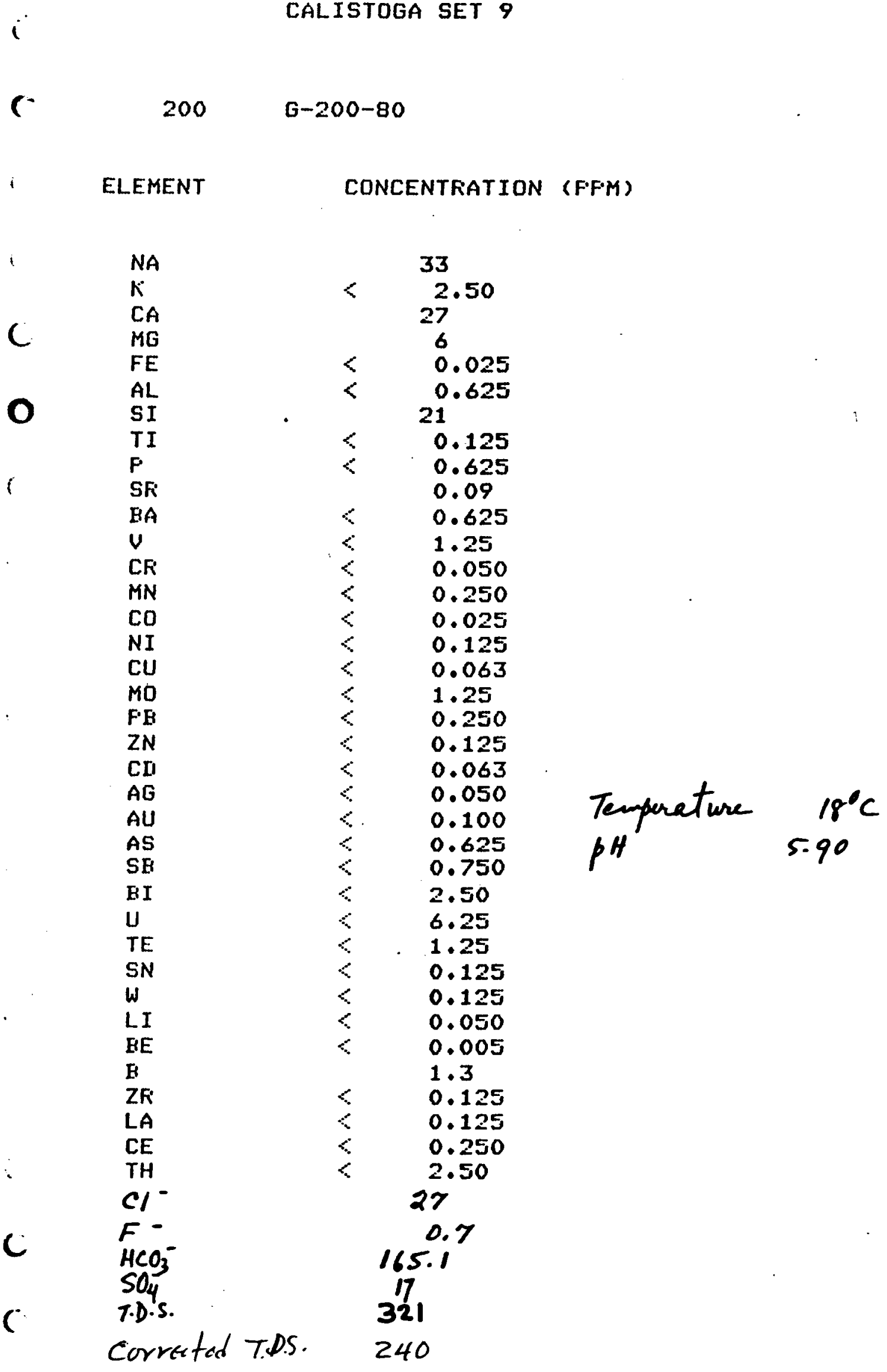


CALISTOGA SET 9

201

G-201-80

\section{ELEMENT}

NA

$K$

CA

MG

FE

AL

SI

TI

$F$

SR

BA

$\checkmark$

CR

$M N$

CO

NI

$\mathrm{CU}$

MO

FB

ZN

Cn

$A G$

AU

AS

SE

BI

U

TE

SN

W

LI

BE

$\mathrm{B}$

ZF

LA

CE

TH

$\mathrm{Cl}^{-}$

F.

C

(: T.DS.

conraced T.DS.
CONCENTFATION (FFPM)
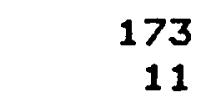

11

13

5
0.025

$<\quad 0.625$

32

$<\quad 0.125$

$<\quad 0.525$

0.05

$<\quad 0.625$

$<\quad 1.25$

$<\quad 0.050$

$<\quad 0.250$

$<\quad 0.025$

$<\quad 0.125$

$<\quad 0.063$

$<\quad 1.25$

$<\quad 0.250$

0.3

$<\quad 0.063$

$8 \quad 0.050$

8.100

0.625

0.750

2.50

6.25

1.25

0.125

0.125

- 1.20

$<\quad 0.005$

10.1

$<\quad 0.125$

$<\quad 0.125$

$<\quad 0.250$

$<\quad 2.50$

191

7.5

229.5

$<10$

691

578
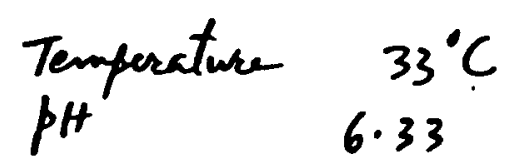

6.33 
CALISTOGA SET ?

$202 \quad$ G-202-80

ELEMENT

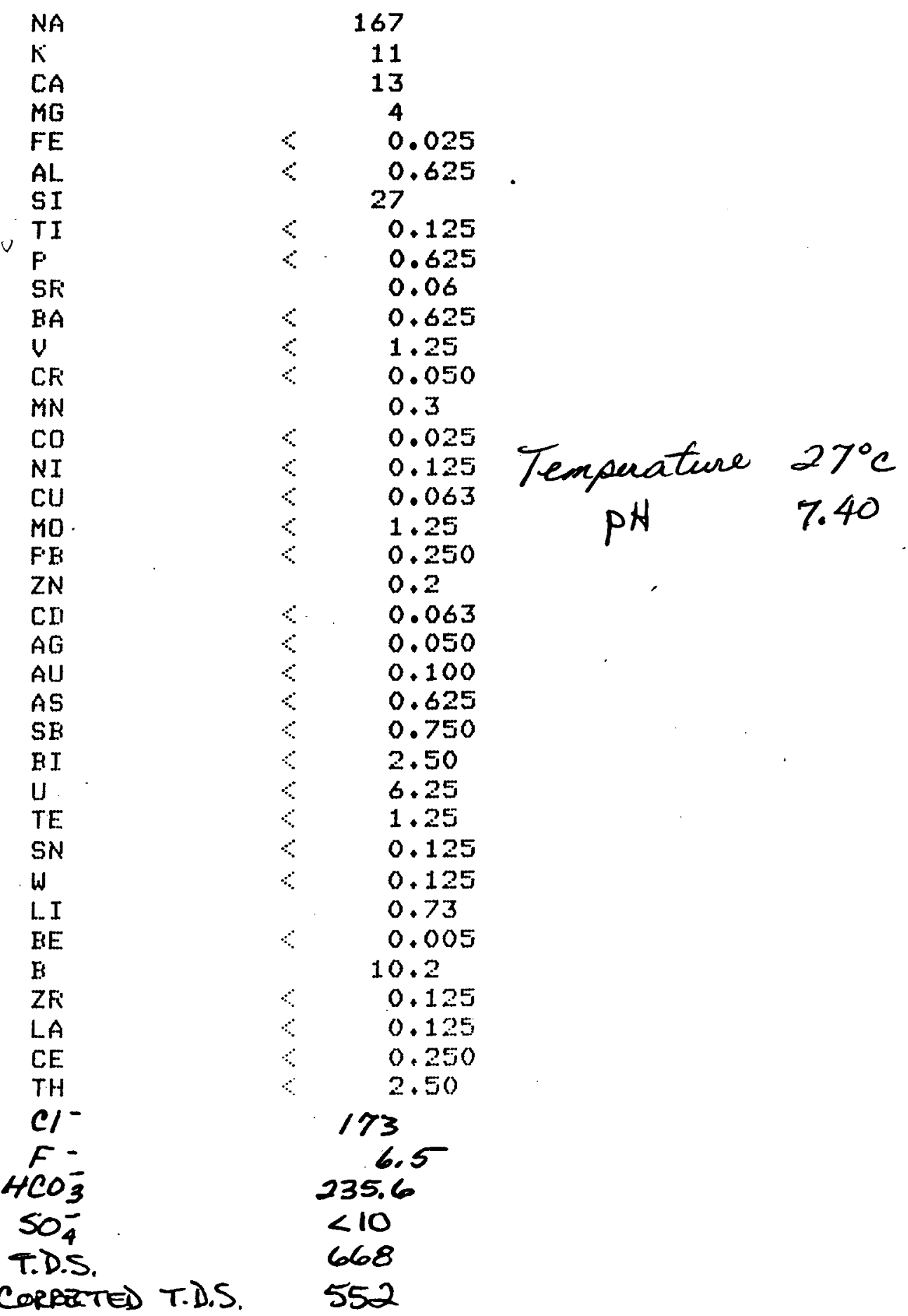


CALISTOGA SET 9

$203 \quad 6-203-80$

ELEMENT

$N A$

$K$

$C A$

$M G$

FE

AL.

ST.

TI.

F

SF

BA

U

CF i

$M N$

$\mathrm{CO}$

Cl.

MO

$F$

ZN

CIT

a 6

Alt

A 5

$\mathrm{er}$

$\mathrm{Br}$

11

TE:

$\mathrm{SN}$

!)

I... $\mathrm{r}$

BEE

H

$7 F$

CE:

TH

Cl

$F-$

$\mathrm{HCO}_{3}^{-}$

$\mathrm{SO}_{4}^{-}$

T. DE.

corrected T.D.S.
CONCENTRATION (FEM)

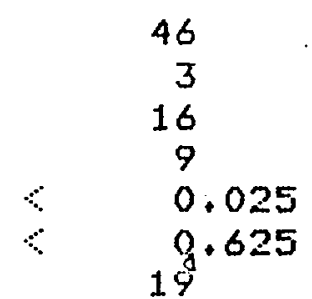

$\begin{array}{ll}\ddots & 0.125 \\ \ddots & 0.625\end{array}$

0.08

0.625

$1+25$

0.000

0.250

0.026

0.126

0.063

1.20
$0+250$

3.1

0.063

Temperature $18^{\circ} \mathrm{C}$

0.100

pH

7.22

0.525
0.750

$2: 50$

6. 23

1. $\div 25$

0.120

0.00

0.005

2.2

0.120

0.125

0.250
2.50

32

0.2

168.1

$<10$

319

236 


\section{CAITSOOA SEY}

$$
204 \quad 6-204 \cdots 80
$$

\section{CONCENTEATION (FFM)}

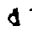

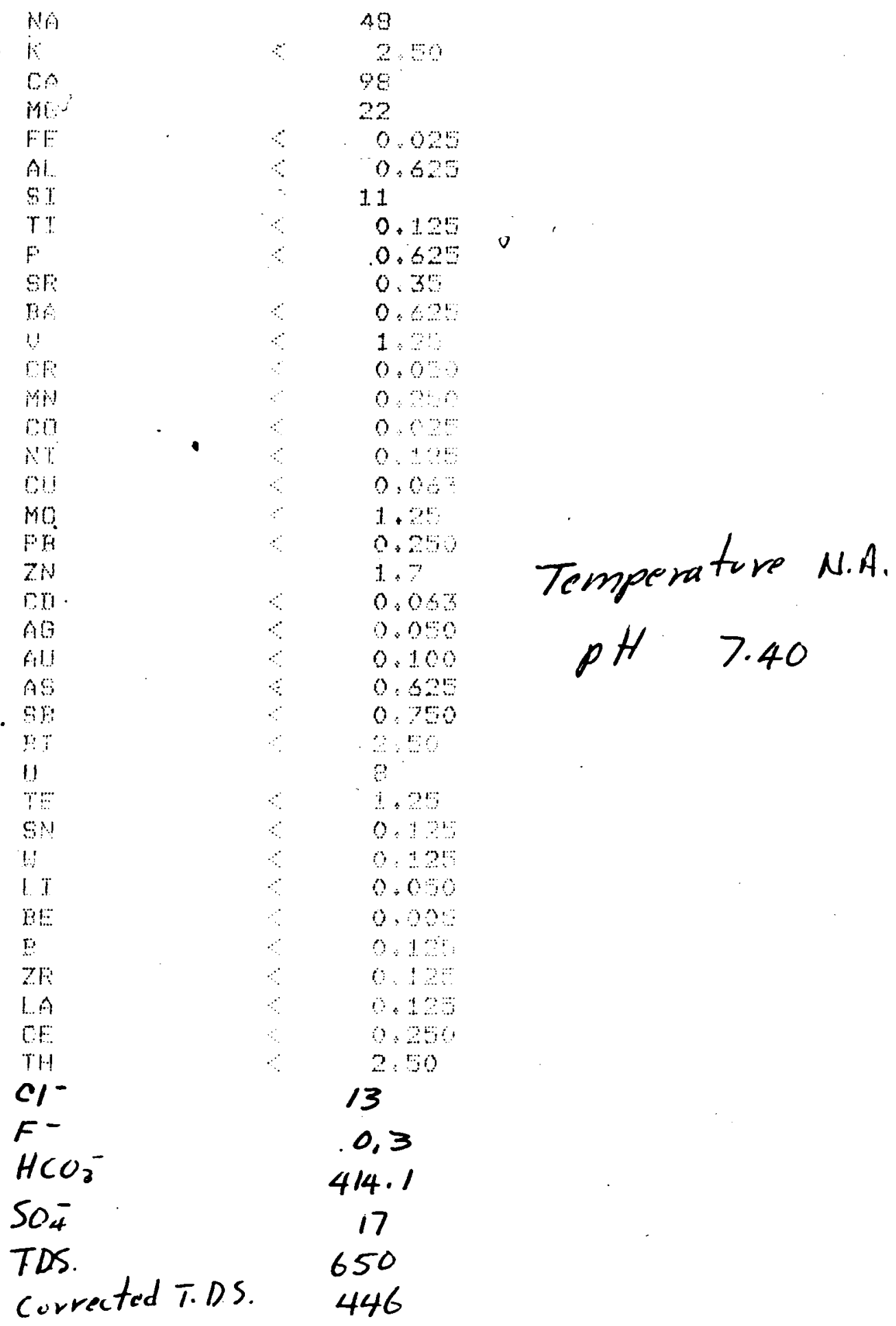


लिए roroक

$205 \quad 0-205-80$

EIEMUT

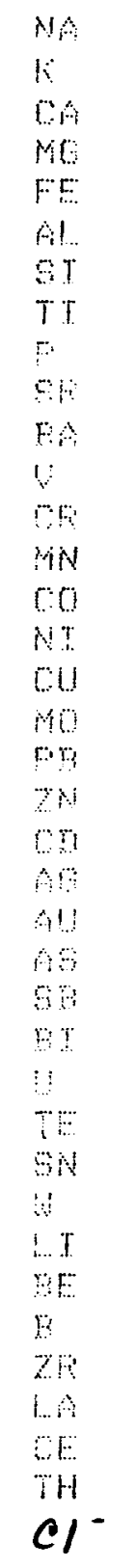

$F$

$\mathrm{HCO}_{3}^{-}$

$\mathrm{SO}_{4}^{-}$

T.0.S.

currected T.D.S.

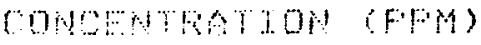

$d$

$\begin{array}{ll}\text { Temperature } & 23^{\circ} \mathrm{C} \\ \text { pH } & 8.00\end{array}$ 
CALISTOBS SET

$206 \quad 6-200-80$
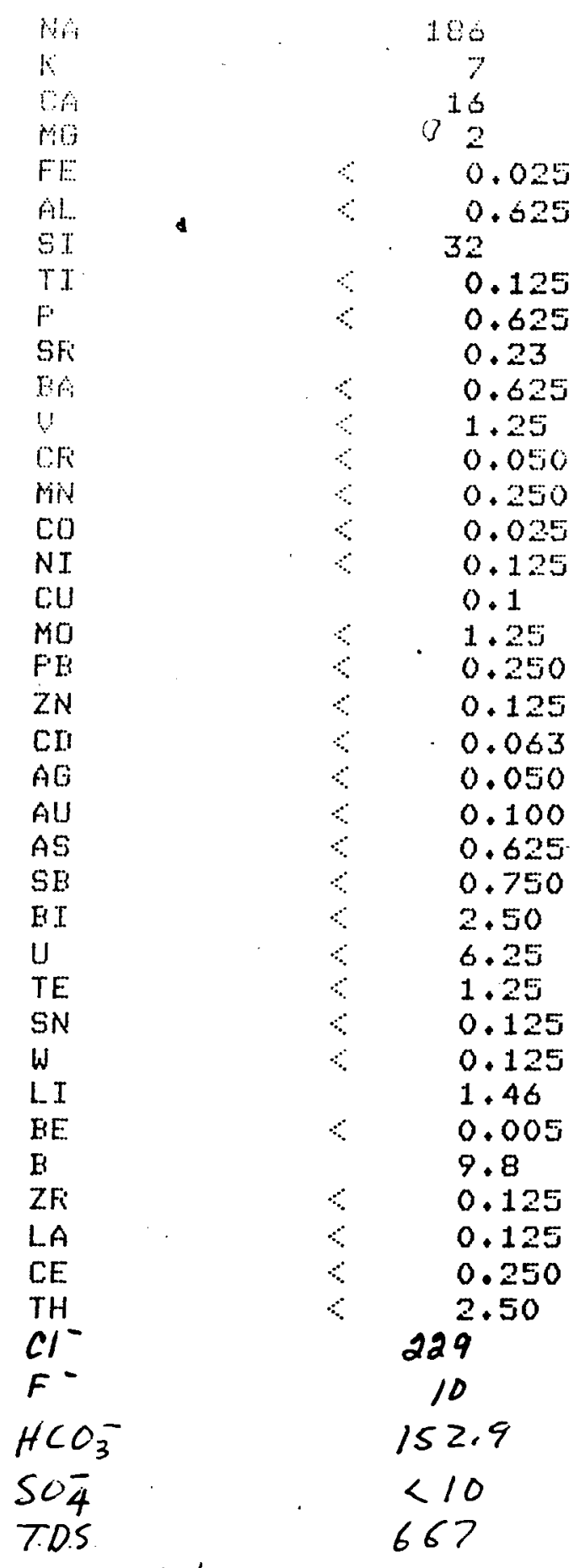

32

$\because \quad 0.125$

$\therefore \quad 0.625$

0.23

$\therefore \quad 0.625$

$\therefore \quad 1.25$

$\because \quad 0.050$

$\because \quad 0.250$

0.025

$0 \quad 0.125^{\circ}$

0.1

$\because \quad 1.20$

$\because \quad 0.250$

$\therefore \quad 0.125$

$\therefore \quad 0.063$

$\because \quad 0.050$

$\because \quad 0.100$

$\because \quad 0.625$

$\because \quad 0.750$

$\therefore \quad 2.50$

6.25

1.25

0.125

0.125

1.46

$\because \quad 0.005$

9.8

$<\quad 0.125$

$4 \quad 0.125$

$\therefore \quad 0.250$

$\because \quad 2.50$
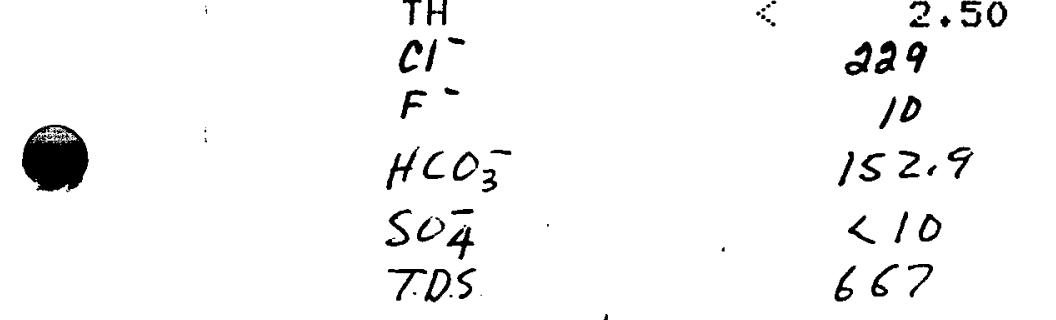

152.9

$<10$

667

CorrectedT.DS. 592 
CALIFORIIA DIVISION of AIIES MO GEOLOSY

TEPERATURE L0S 1

CDH WEL W.1 G. COCCIDEMTA WEL M.

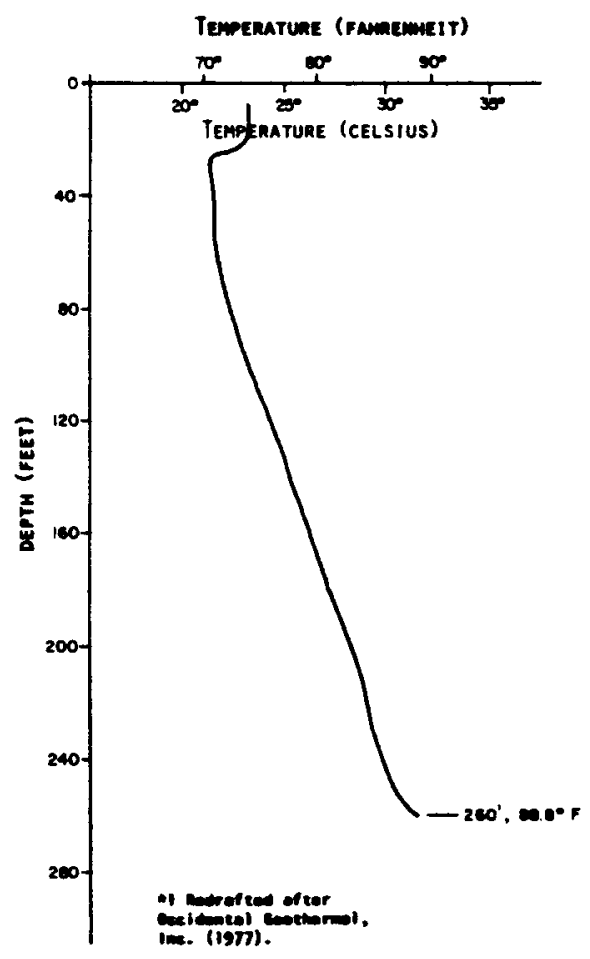

-.

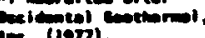
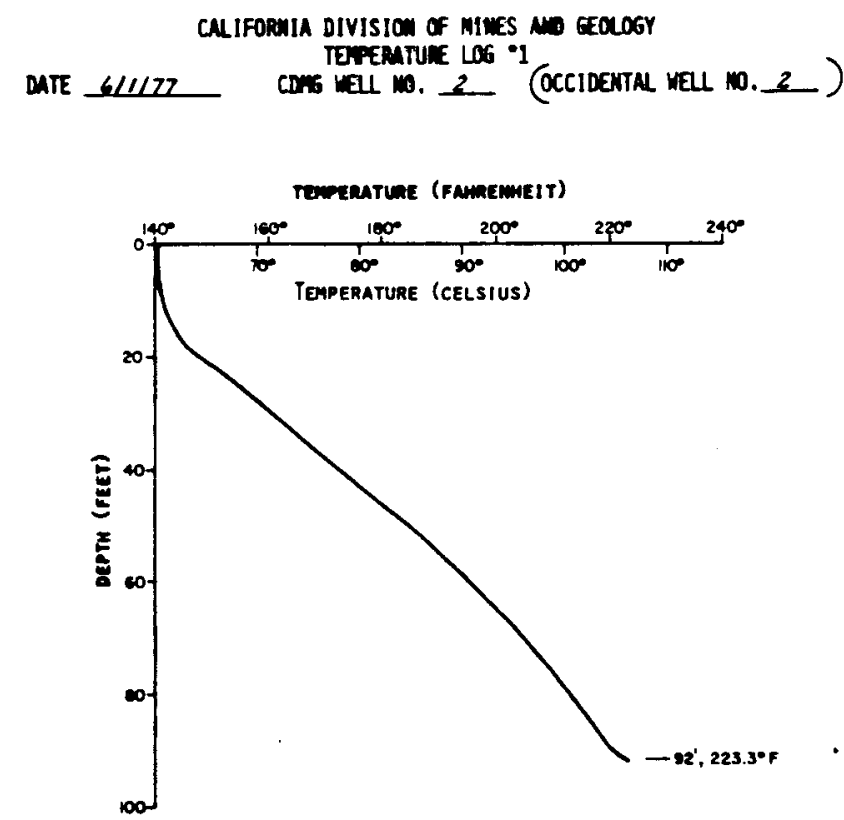

- I Marefen afier

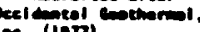

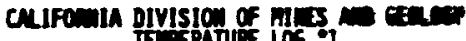

DATE $6 / 6 / 7$

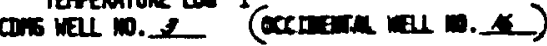

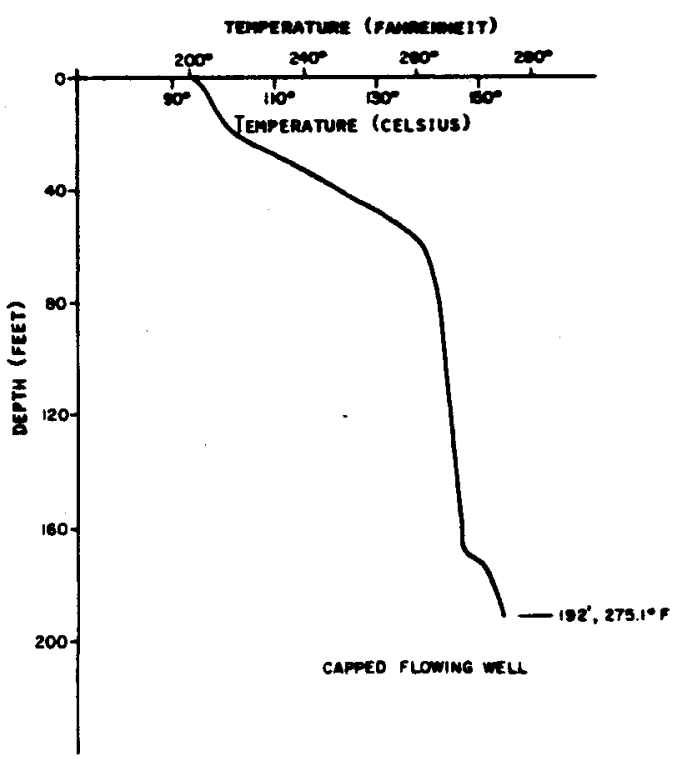

-1 morefes of ter

inc. (ism).

CUIFOANIA DIVISIOH OF MIIES ND GEOLOSY

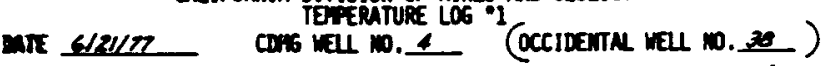

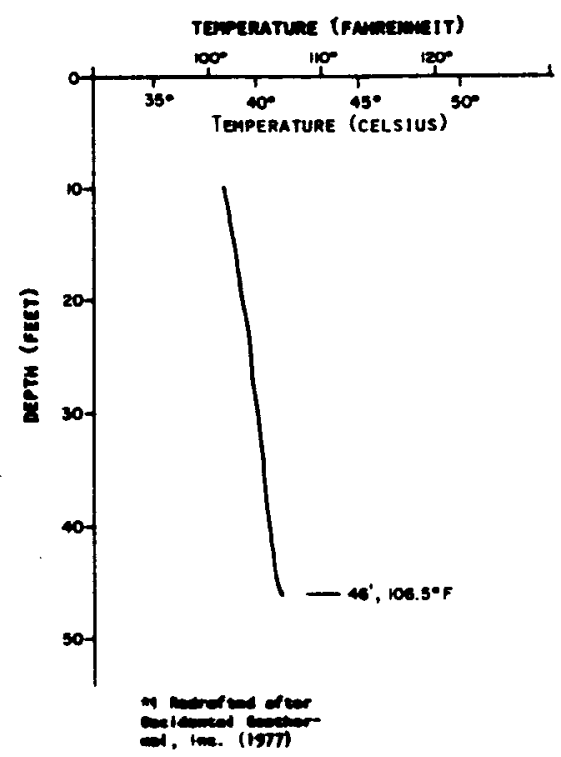




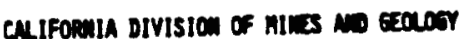
TETERUTURE LOS 1

DATE $6 / 4 / T 7$ cons well m. 10 (occisemin well 1.1 )

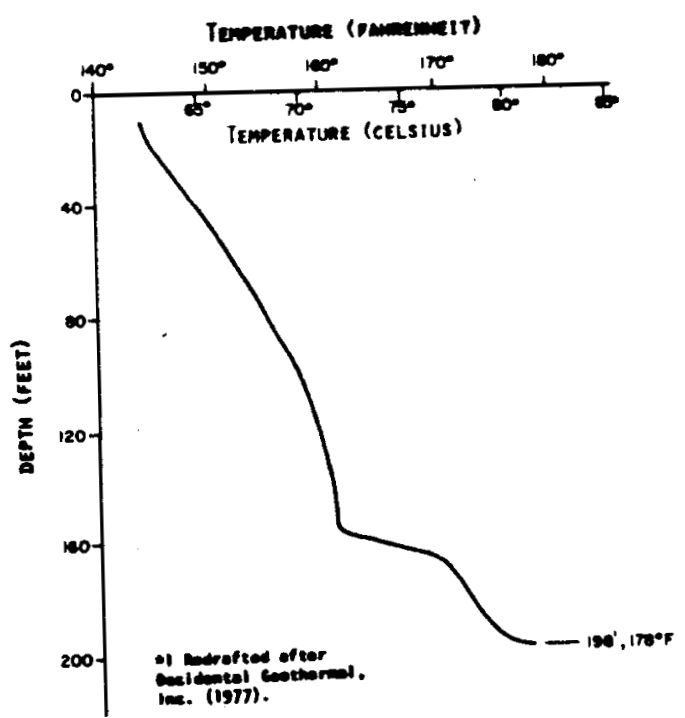

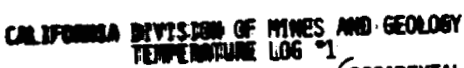

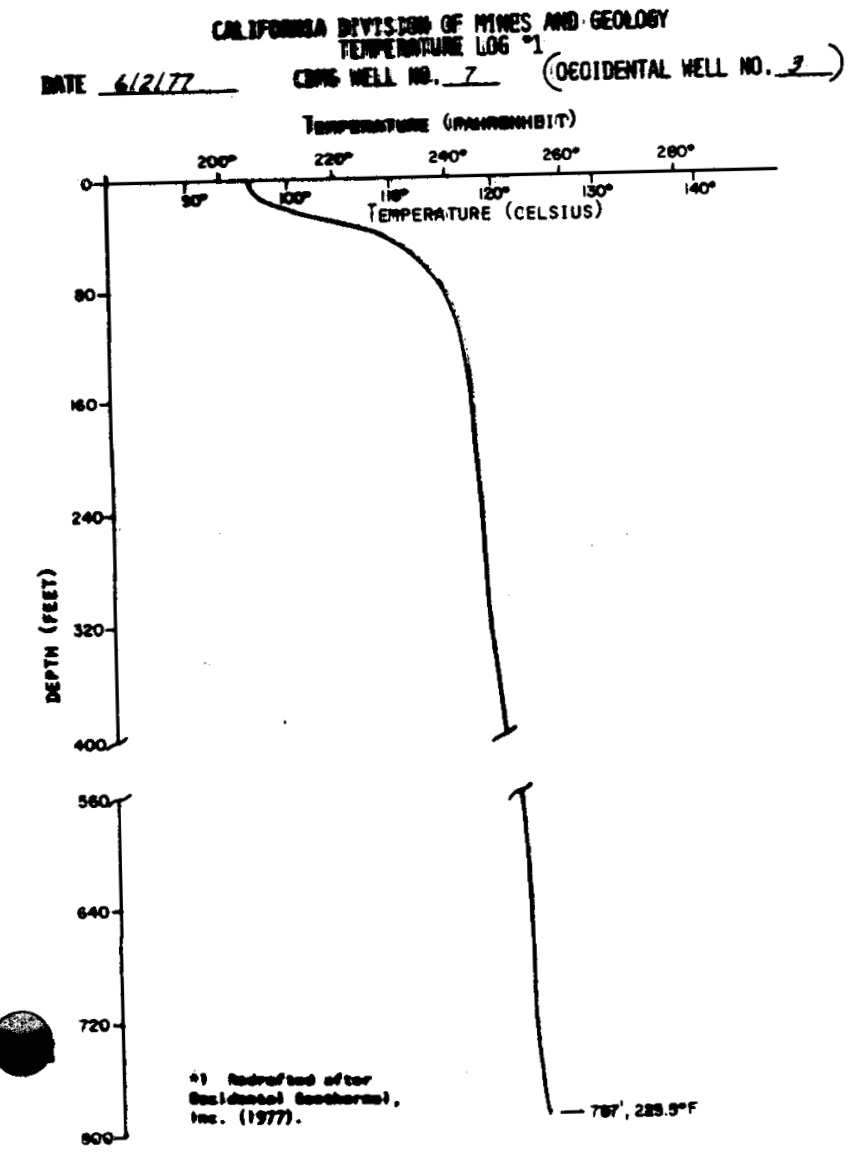

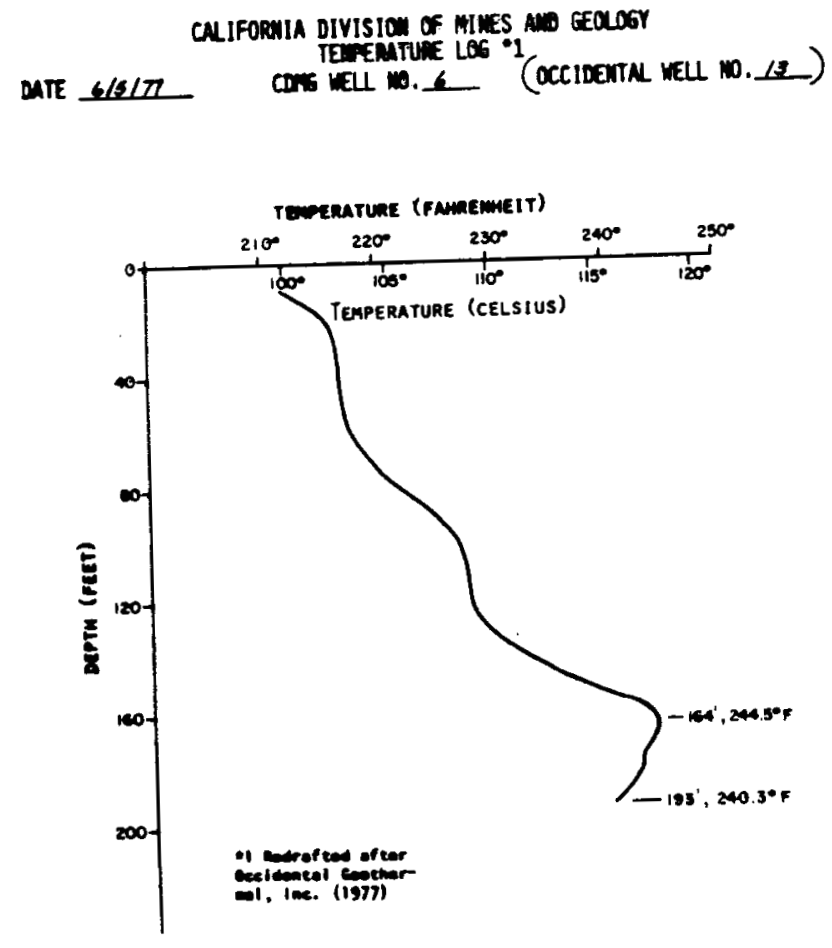

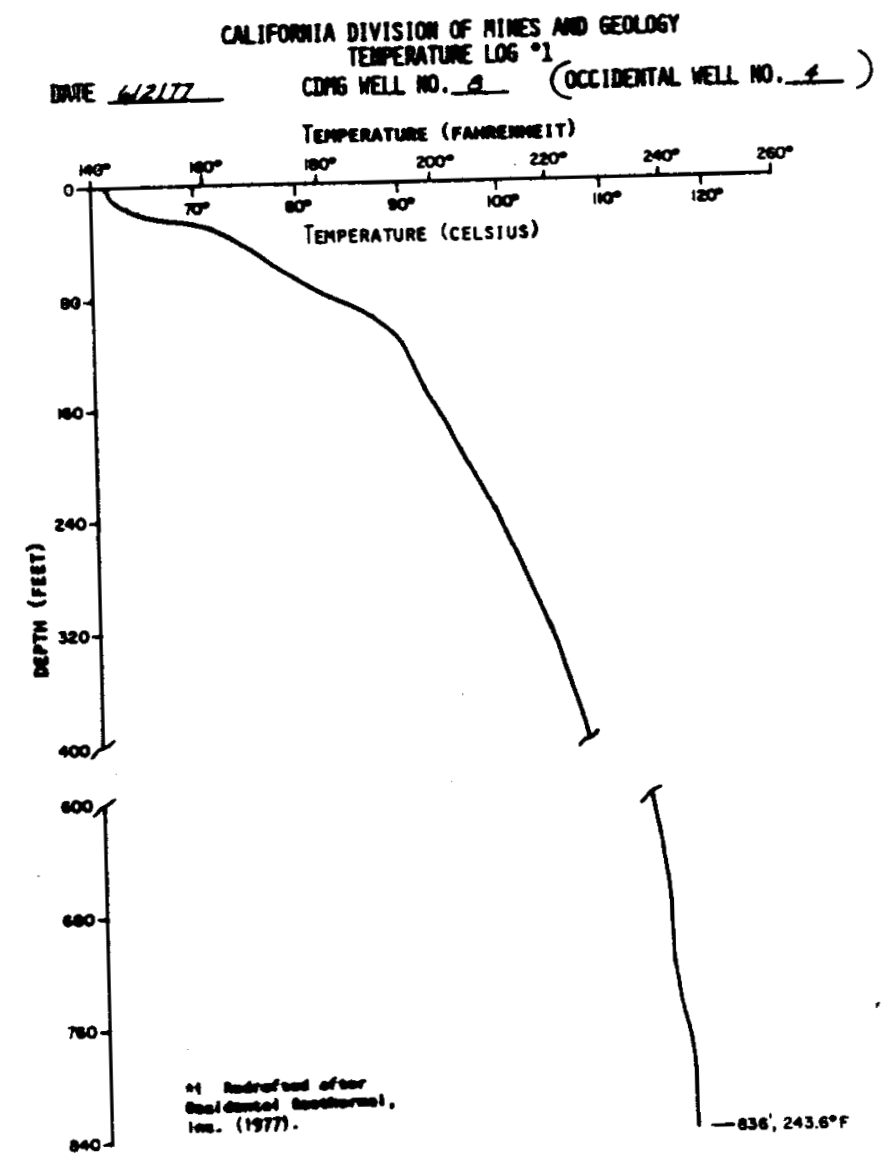




\section{CHIFomil givision of MIrES M ezocosy}

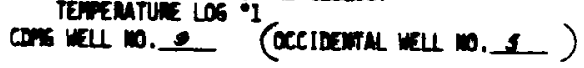

DATE $6 / 3 / 7 \pi$

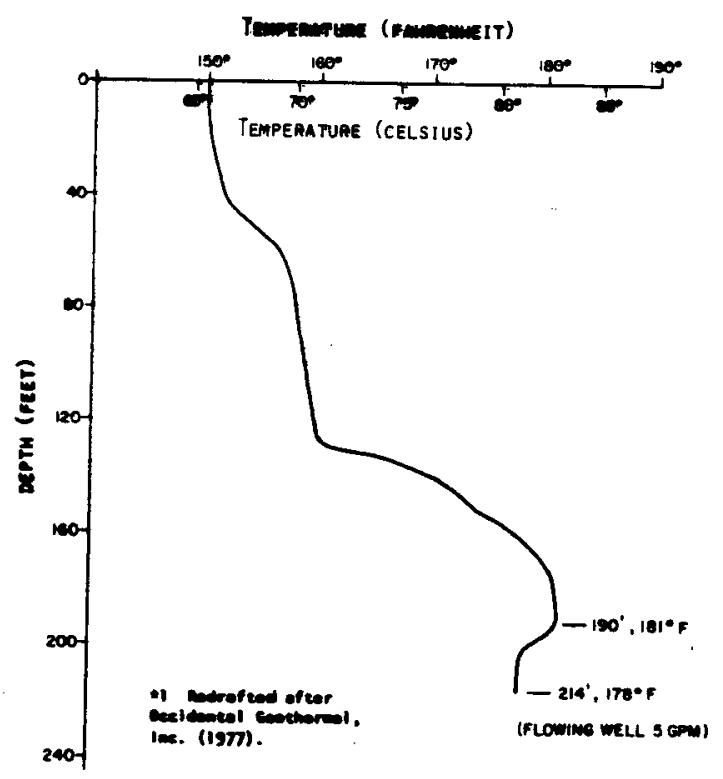

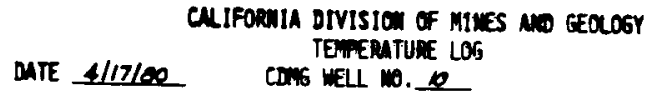

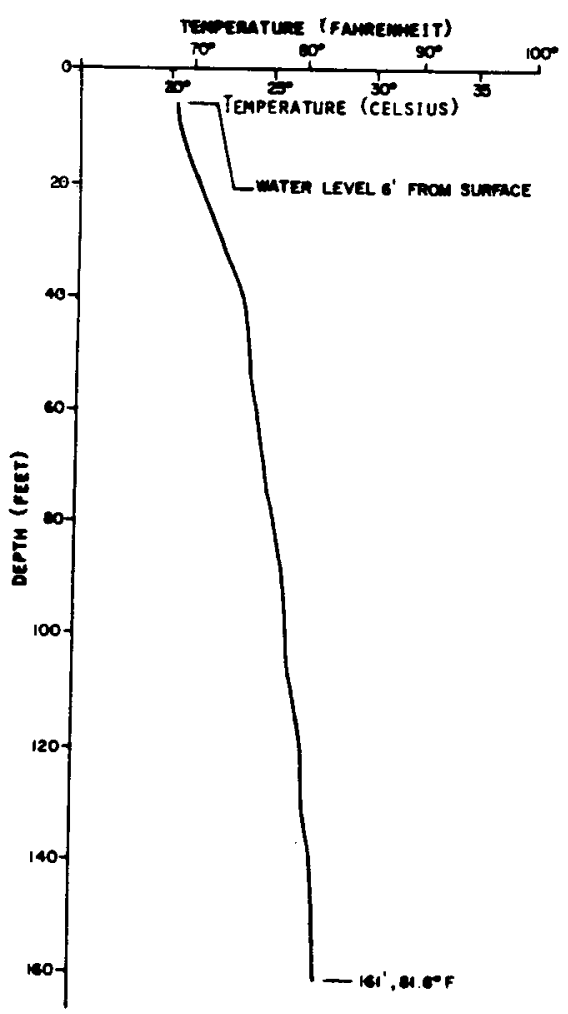

CAIFomin Division of Mines no EeOCor

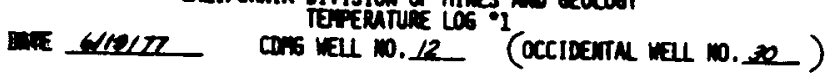

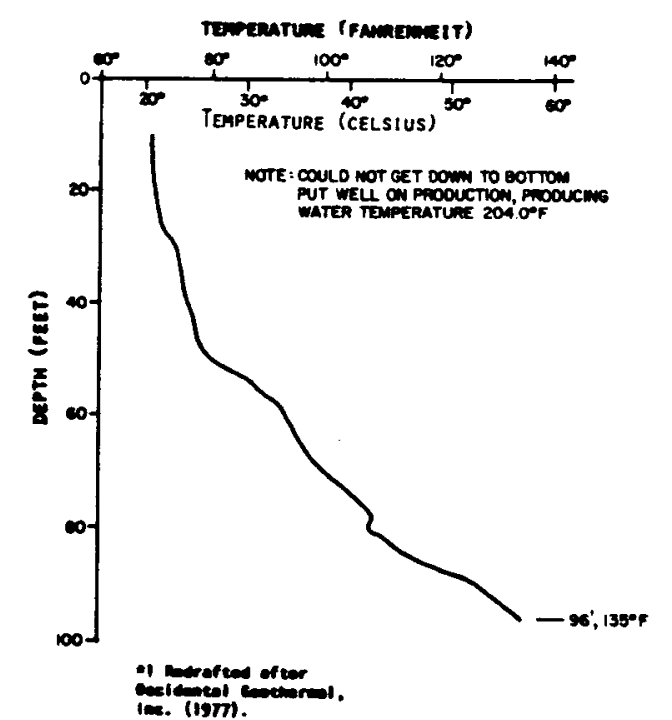

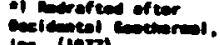

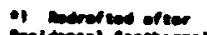

imision

givis ja: OF MUES AND GEOLOGY

ans Well W. HI (OGCIDENTAL WELL W.

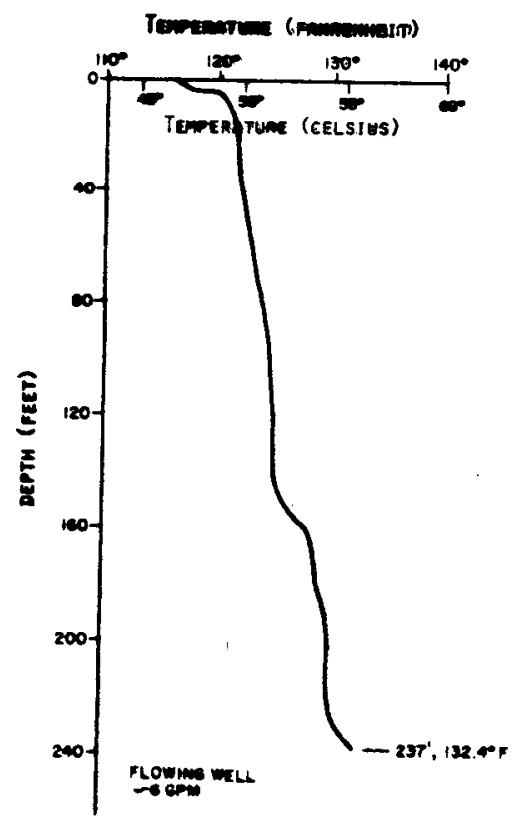




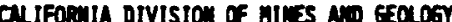

TEMPERATURE LOS '1

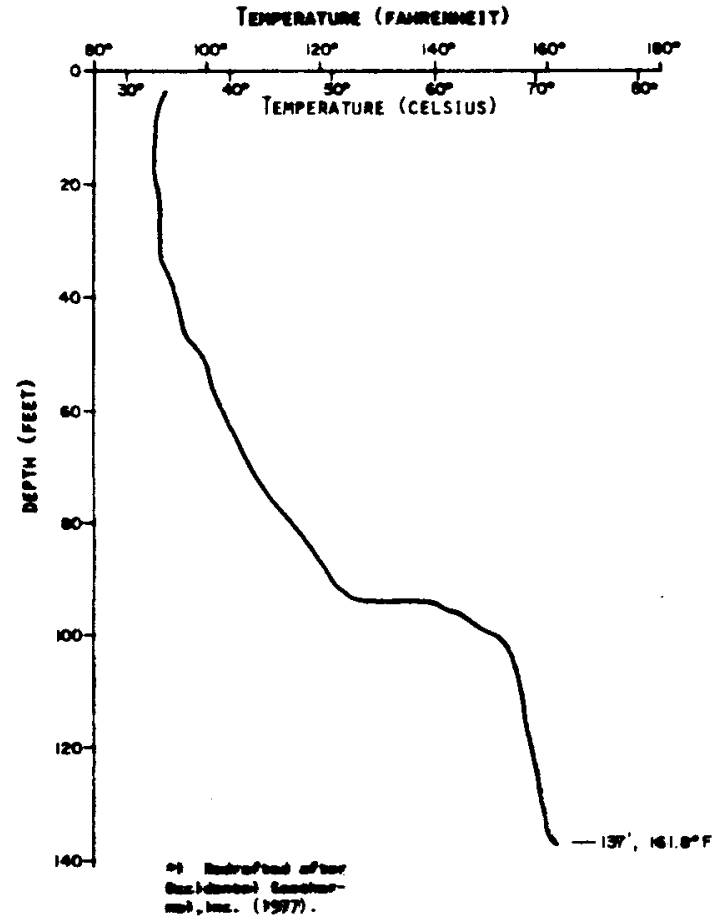

CM UFO BIVTSIDH OF MIMES AAD GEOLOGY TEMTERATURE LOS 1

DaIE

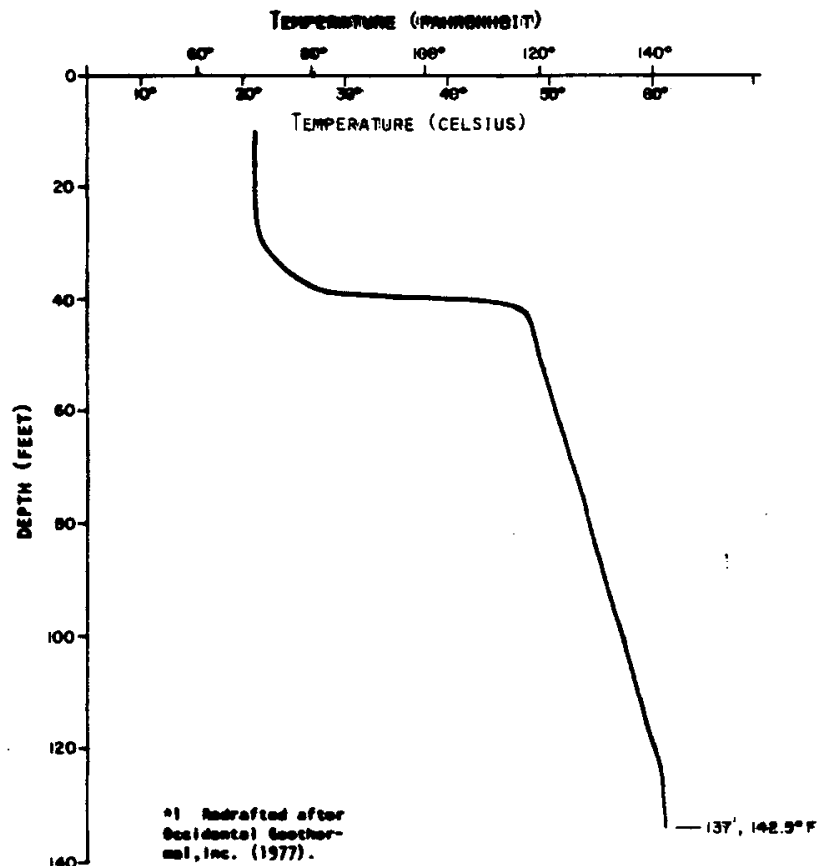

CALIFOPUIA DIVISIOW $\propto$ FIMFS EREMTURE LOS

DATE L/N/80 CDN WEL W. No
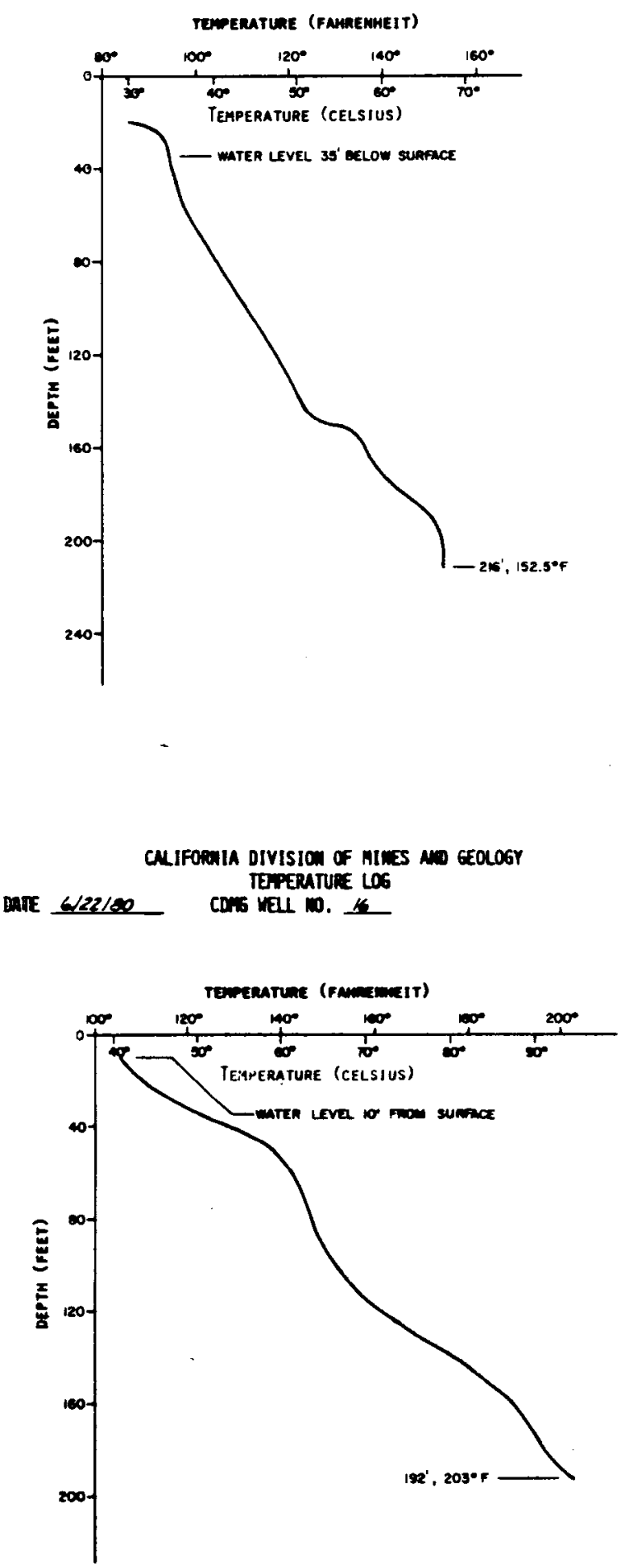

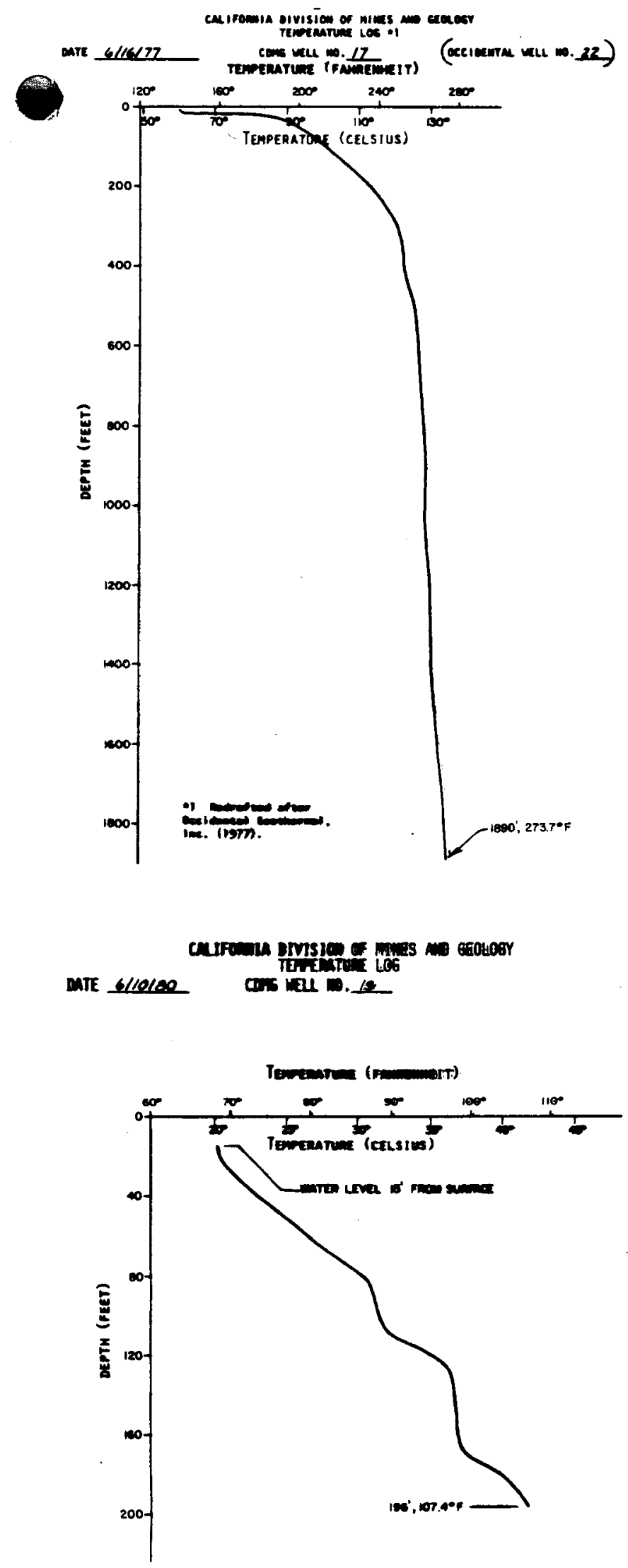

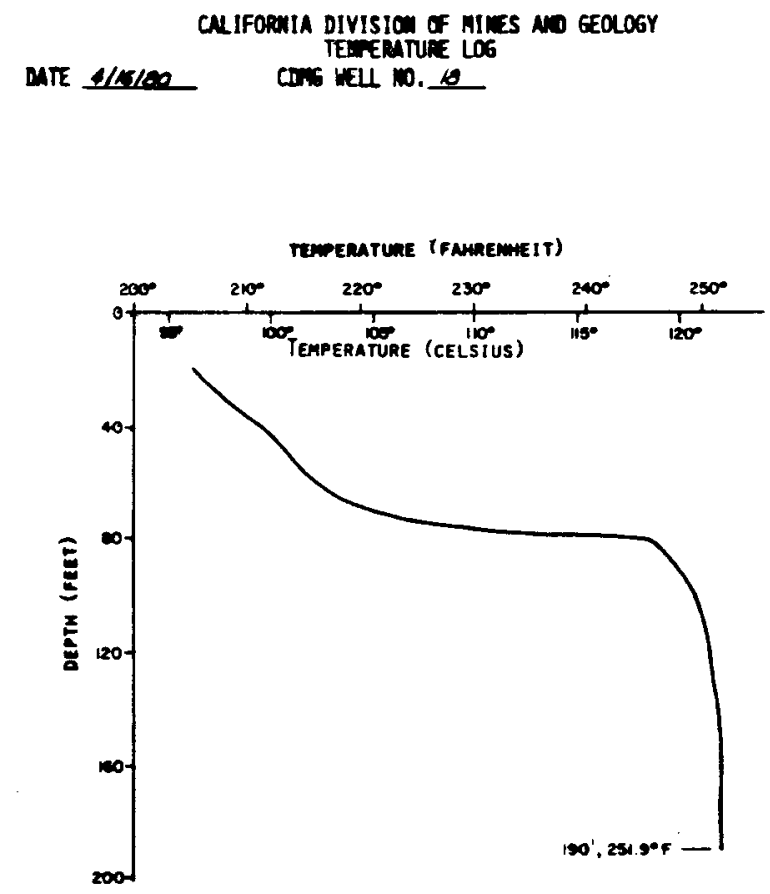

CULIFORIIA DIVISION OF MINES NDO GEOLOGY

TEMPEPATURE LOG *1

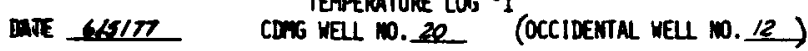

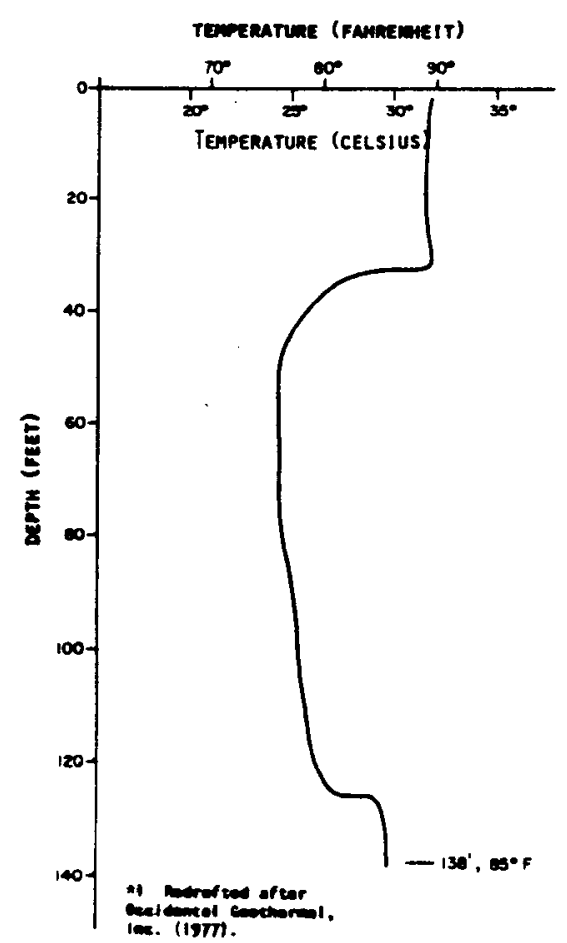




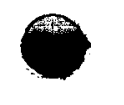

CALIFORMIA DIVISION OF MIIES ANO GEOLOSY

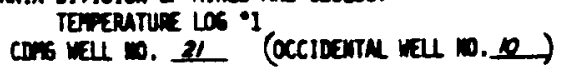

DATE $6 / 5 / 77$

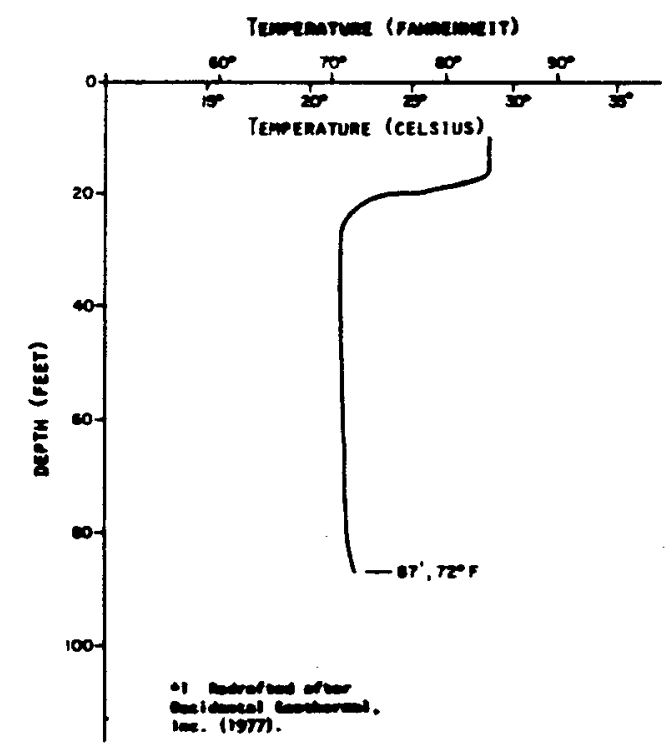

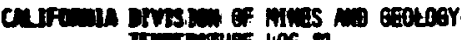
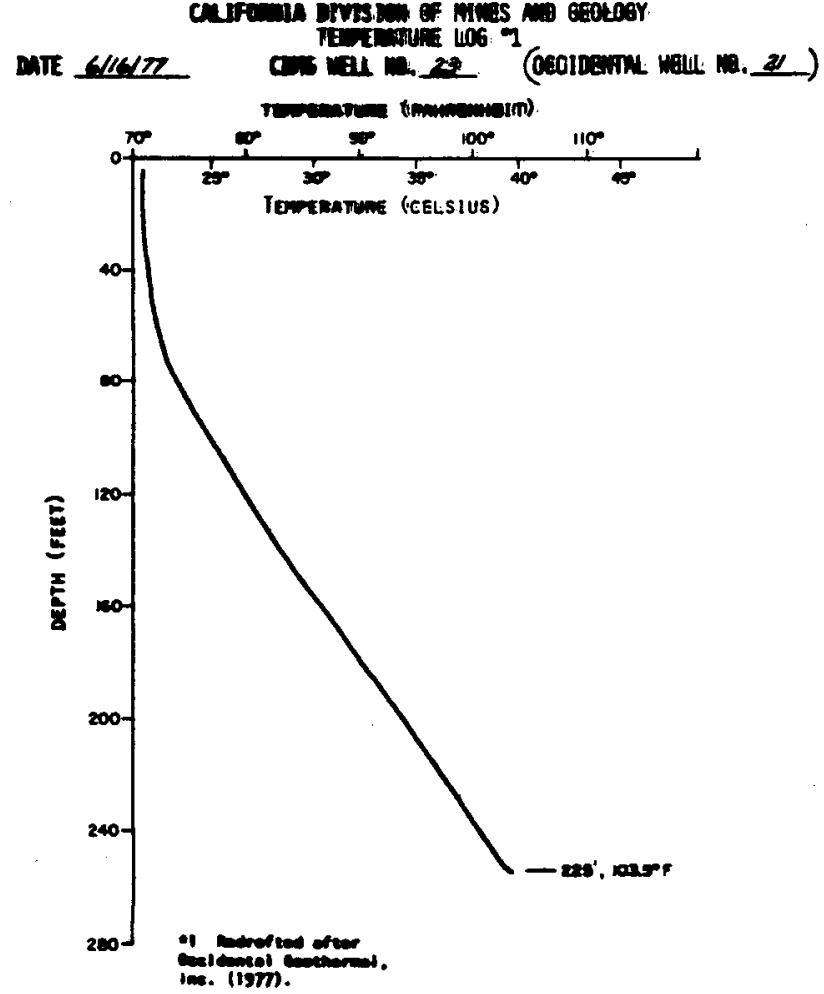

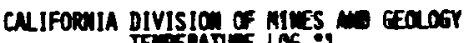

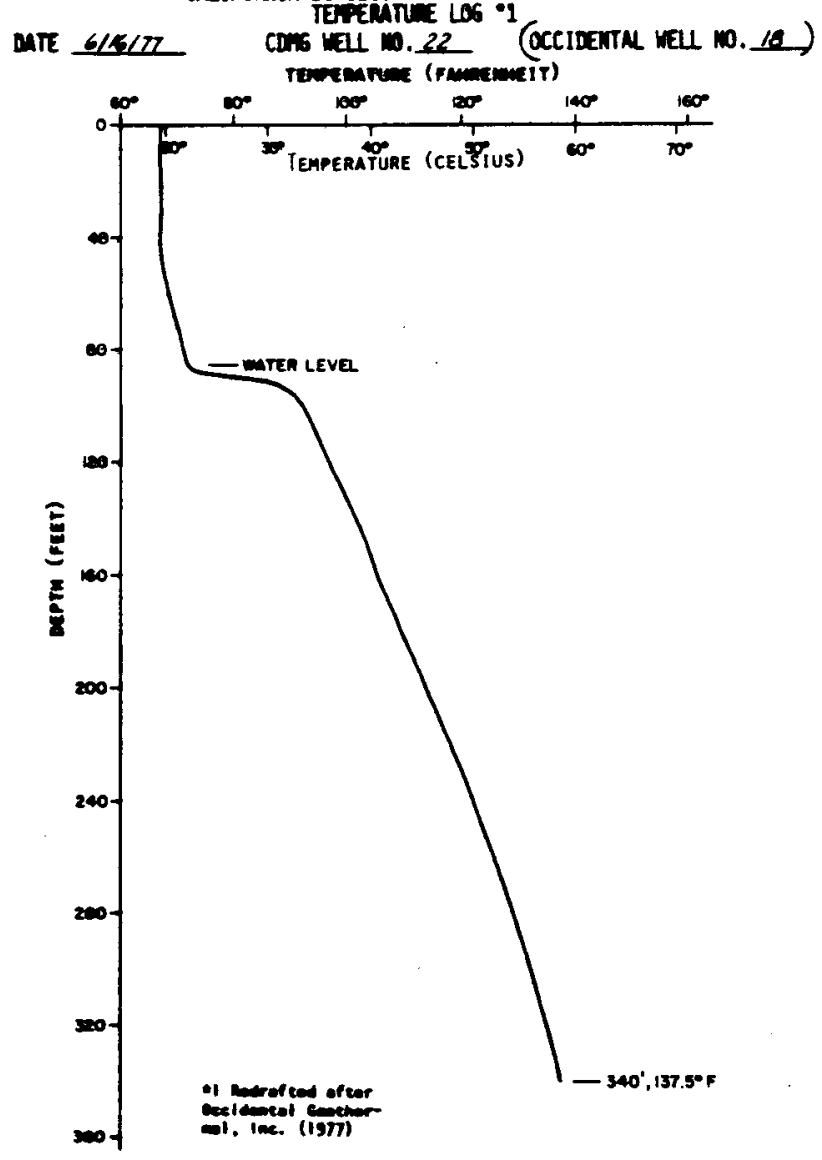

CUIFOCHIA DIVISION OF MIIES NO EEOCOY

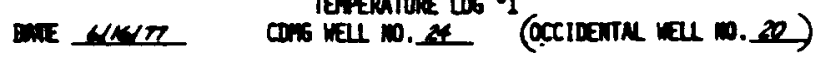

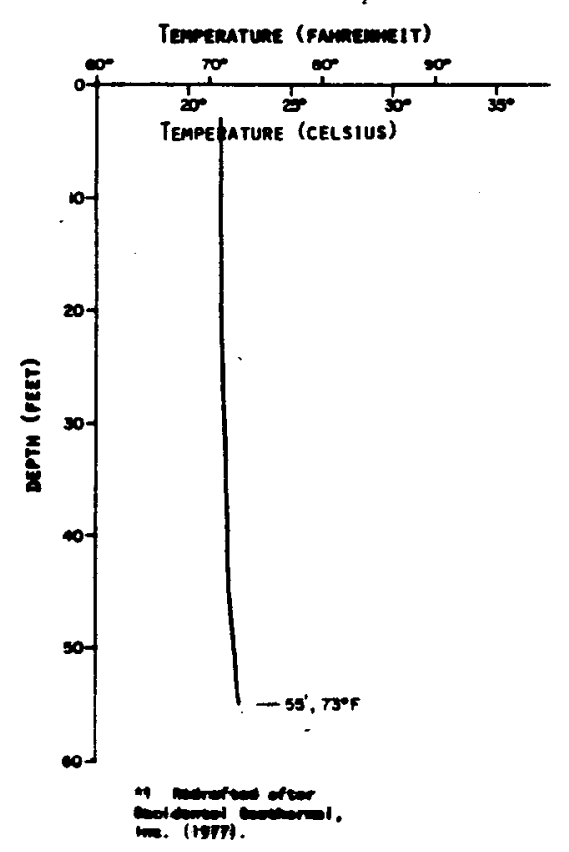




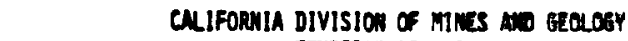
TEMPERATURE LOS

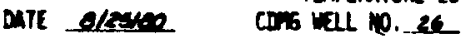

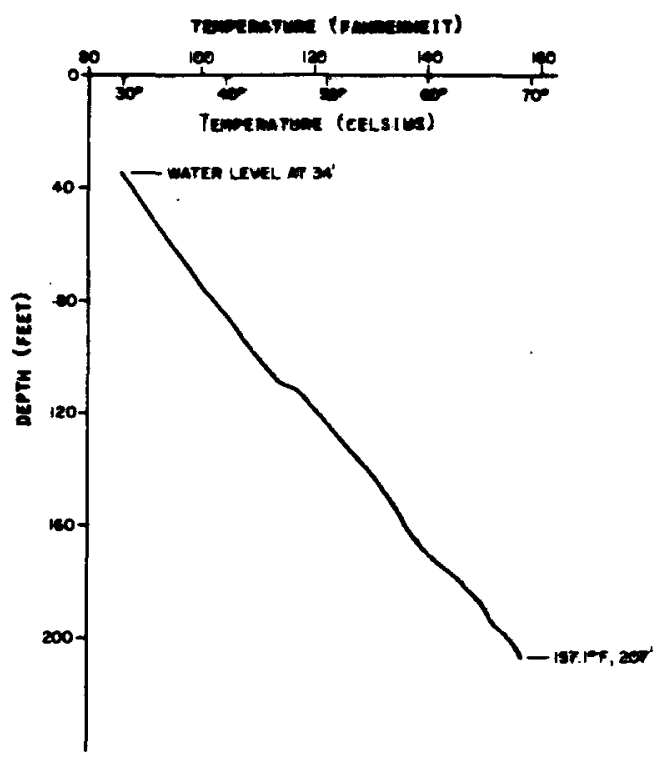

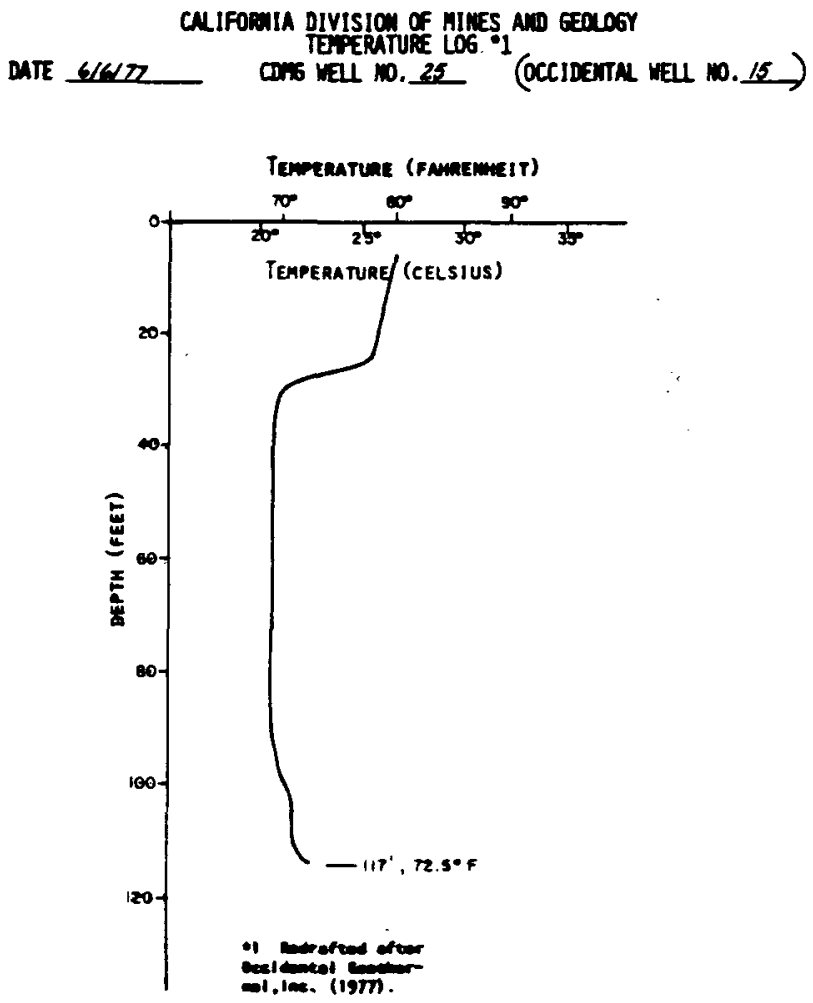

